\title{
O
}

\section{Ciências da Saúde Ensino, Formação e Pesquisa}

Yasmin da Silva Santos

Fernanda Ferreira Evangelista

Fernanda de Oliveira Bottino

Arthur Daniel Rocha Alves

Tiaģo Savig̨non Cardoso Machado

Tainah Silva Galdino de Paula

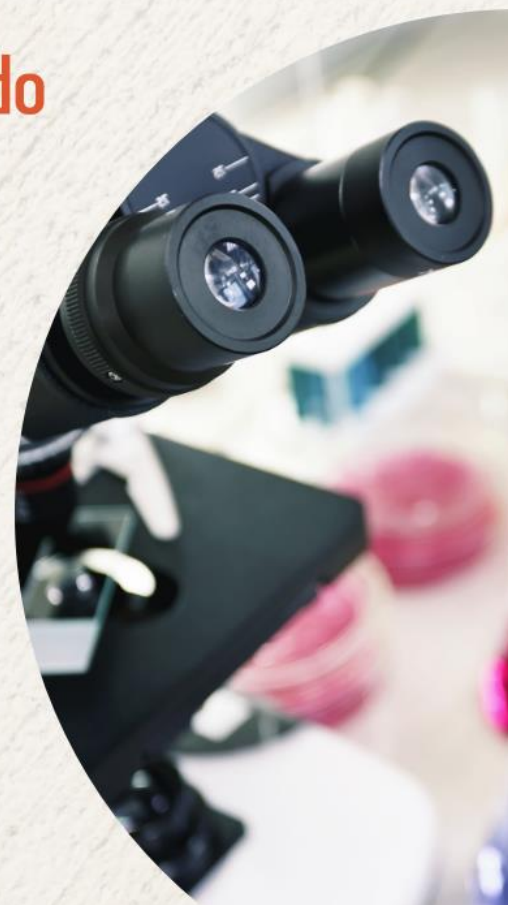

\section{ZAMPLLA}




\section{(A)}

Ciências da Saúde

\section{Ensino, Formação e Pesquisa}

Yasmin da Silva Santos

Fernanda Ferreira Evangelista

Fernanda de Oliveira Bottino

Arthur Daniel Rocha Alves

Tiaģo Saviognon Cardoso Machado

Tainah Silva Galdino de Paula

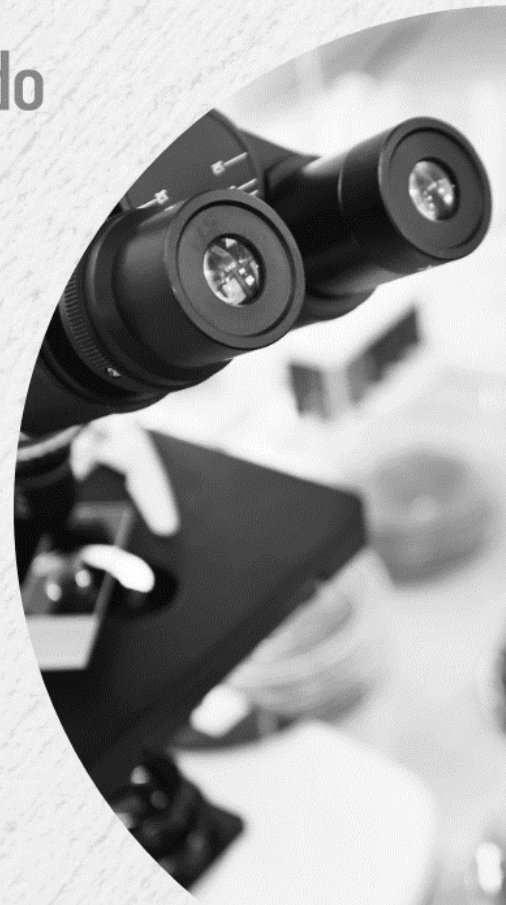

\section{ZAMMPLA}


2021 - Editora Amplla

Copyright @ Editora Amplla

Editor Chefe: Leonardo Pereira Tavares

Design da Capa: Editora Amplla

Projeto Gráfico e Editoração: Higor Costa de Brito

Ciências da saúde: ensino, formação e pesquisa está licenciado sob CC BY 4.0.

\begin{abstract}
cc (i) Esta licença exige que as reutilizações deem crédito aos criadores. Ele permite que os reutilizadores distribuam, remixem, adaptem e construam o material em qualquer meio ou formato, mesmo para fins comerciais.

O conteúdo da obra e seus dados em sua forma, correção e confiabilidade são de responsabilidade exclusiva dos autores, não representando a posição oficial da Editora Amplla. É permitido o download da obra e o compartilhamento desde que sejam atribuídos créditos aos autores. Todos os direitos para esta edição foram cedidos à Editora Amplla.
\end{abstract}

ISBN: 978-65-88332-23-8

Editora Amplla

Campina Grande - PB - Brasil contato@ampllaeditora.com.br www.ampllaeditora.com.br 


\section{Conselho Editorial}

Bergson Rodrigo Siqueira de Melo - Universidade Estadual do Ceará Carla Caroline Alves Carvalho - Universidade Federal de Campina Grande Cícero Batista do Nascimento Filho - Universidade Federal do Ceará Clécio Danilo Dias da Silva - Universidade Federal do Rio Grande do Norte Daniela de Freitas Lima - Universidade Federal de Campina Grande Denise Barguil Nepomuceno - Universidade Federal de Minas Gerais Dylan Ávila Alves - Instituto Federal Goiano Érica Rios de Carvalho - Universidade Católica do Salvador Gilberto de Melo Junior - Universidade Federal de Goiás Higor Costa de Brito - Universidade Federal de Campina Grande Italan Carneiro Bezerra - Instituto Federal da Paraíba Ivo Batista Conde - Universidade Estadual do Ceará João Henriques de Sousa Júnior - Universidade Federal de Santa Catarina Joilson Silva de Sousa - Instituto Federal do Rio Grande do Norte José Cândido Rodrigues Neto - Universidade Estadual da Paraíba Jose Henrique de Lacerda Furtado - Instituto Federal do Rio de Janeiro Josenita Luiz da Silva - Faculdade Frassinetti do Recife Luís Paulo Souza e Souza - Universidade Federal do Amazonas Luiza Catarina Sobreira de Souza - Faculdade de Ciências Humanas do Sertão Central Manoel Mariano Neto da Silva - Universidade Federal de Campina Grande Marcus Vinicius Peralva Santos - Universidade Federal da Bahia Marina Magalhães de Morais - Universidade Federal de Campina Grande Natan Galves Santana - Universidade Paranaense Nathalia Bezerra da Silva Ferreira - Universidade do Estado do Rio Grande do Norte Neide Kazue Sakugawa Shinohara - Universidade Federal Rural de Pernambuco Sabrynna Brito Oliveira - Universidade Federal de Minas Gerais Samuel Miranda Mattos - Universidade Estadual do Ceará Tatiana Paschoalette Rodrigues Bachur - Universidade Estadual do Ceará Telma Regina Stroparo - Universidade Estadual do Centro-Oeste Virginia Tomaz Machado - Faculdade Santa Maria de Cajazeiras Walmir Fernandes Pereira - Miami University of Science and Technology Wanessa Dunga de Assis - Universidade Federal de Campina Grande Wellington Alves Silva - Universidade Estadual de Roraima Yáscara Maia Araújo de Brito - Universidade Federal de Campina Grande Yuciara Barbosa Costa Ferreira - Universidade Federal de Campina Grande 
2021 - Editora Amplla

Copyright @ Editora Amplla

Editor Chefe: Leonardo Pereira Tavares

Design da Capa: Editora Amplla

Projeto Gráfico e Editoração: Higor Costa de Brito

Dados Internacionais de Catalogação na Publicação (CIP)

Sueli Costa CRB-8/5213

Santos, Yasmin da Silva

Ciências da saúde [livro eletrônico] ensino, formação

e pesquisa / Yasmin da Silva Santos... [et al.] - Campina

Grande : Editora Amplla, 2021.

$356 \mathrm{p}$.

Vários autores: Fernanda Ferreira Evangelista; Fernanda

de Oliveira Bottino; Arthur Daniel Rocha Alves; Tiago

Savignon Cardoso Machado; Tainah Silva Galdino de Paula

Formato: $\mathrm{PDF}$

ISBN : $978-65-88332-23-8$

1. Saúde 2. Análise clínicas 3. Microbiologia

4. Genéti 5. Imunologia 6. Farmacologia I. Evangelista, Fernanda Ferreira II. Bottino, Fernanda de Oliveira

III. Alves, Arthur Daniel Rocha IV. Machado, Tiago

Savignon Cardoso V. Paula, Tainah Silva Galdino de

IV. Título

$\mathrm{CDD}-613$

\section{Índices para catálogo sistemático:}
1. Saúde : Pesquisa 613

Editora Amplla

Campina Grande - PB - Brasil contato@ampllaeditora.com.br www.ampllaeditora.com.br 


\section{Prefácio}

Esta obra é fruto da adaptação de alunos, professores e pesquisadores a uma era digital que nos abraçou com afinco, trazendo novas perspectivas na divulgação científica. Os trabalhos contidos neste e-book foram apresentados em formato de resumo no Congresso On-line de Ciências da Saúde de 26 a 29 de outubro de 2020 pelo grupo Ciência em Alvo. A possibilidade de realizar um evento totalmente on-line modificou a maneira de pensar e participar de eventos científicos.

A pandemia do novo Coronavírus fez com que a necessidade de informação alcançasse o máximo de pessoas além de criar uma oportunidade para nos ensinar como a tecnologia favorece a todos os níveis acadêmicos.

A troca de informações entre profissionais da saúde foi, e continuará sendo, fundamental para o enfrentamento dos desafios impostos no atual contexto. Desta forma, este e-book tem o objetivo principal de atualização e promoção de conhecimento a todos os profissionais da saúde, em especial, aos estudantes que estão iniciando na carreira científica.

O conteúdo deste material é atualizado e diversificado com pesquisas quantitativas e qualitativas, atuando em diferentes áreas das ciências da saúde como: análises clínicas, microbiologia, biologia molecular/genética, imunologia, farmacologia, entre outros.

Esta produção foi pensada como uma extensão do que foi realizado no evento científico para continuidade dos trabalhos que foram relevantes para a construção do mesmo e também, estimular a comunidade científica a dar seguimento aos trabalhos e divulgá-los mesmo que em períodos difíceis.

Os organizadores desejam a todos uma ótima leitura e um bom proveito de todo o conteúdo disponível nesta composição. 
Yasmin da Silva Santos

Biomédica, professora de análises clínicas.

Fundadora do Grupo Ciência em Alvo

Mestre em Ciências pelo Instituto Nacional de Infectologia Evandro Chagas (FIOCRUZ)

Especialista em Análises Clínicas e Microbiologia pela Faculdade do Vale

Elvira Dayrell - FAVED,

Doutoranda de Fisiopatologia e Toxicologia (USP)

Fernanda Ferreira Evangelista

Enfermeira pela Universidade Estadual de Maringá (UEM)

Colaboradora do Ambulatório de Toxoplasmose Gestacional no hospital Universitário de Maringá;

Mestre em Ciências da saúde (UEM);

Doutoranda em Ciências da saúde (UEM)

Fernanda de Oliveira Bottino

Médica Veterinária formada pela Universidade Federal Fluminense (UFF)

Professora de Microbiologia dos Cursos Técnicos de Nivel Médio da Escola Politécnica de Saúde Joaquim

Venâncio (EPSJV/ Fiocruz)

Especialista em Patologia Clínica Veterinária pela Faculdade Qualittas

Mestre em Ciências pelo Programa de Biologia Parasitária do Instituto Oswaldo Cruz (IOC/ Fiocruz)

Arthur Daniel Rocha Alves

Biólogo formado pela Universidade Estadual da Zona Oeste (UEZO)

Mestre em Ciência pelo Programa de Biologia Parasitária do Instituto Oswaldo Cruz (IOC/Fiocruz)

Doutorando em Medicina Tropical pelo Instituto Oswaldo Cruz (IOC/Fiocruz)

Técnico em Gestão Hospitalar pela Escola Técnica Estadual Oscar Tenório (Faetec)

Tiago Savignon Cardoso Machado

Biólogo, Professor adjunto da Universidade do Estado do Rio de Janeiro (CAp / UERJ).

Professor de Bioquímica dos cursos Técnicos de Nível Médio da Escola Politécnica de Saúde Joaquim

Venâncio.

Doutor em Ciência pelo programa de Pós Graduação em Fisiopatologia Clínica e Experimental

(FISCLINEX) da UERJ

Tainah Silva Galdino de Paula

Bióloga formada pela Universidade Federal Fluminense (UFF)

Professora de Biologia Molecular dos Cursos Técnicos de Nível Médio da Escola Politécnica de Saúde

Joaquim Venâncio (EPSJV/Fiocruz)

Mestre em Ciências pelo Programa de Ciências Médicas da Universidade do Estado do Rio de Janeiro

(UERJ)

Doutora em Ciências pelo programa de Biologia Parasitária do Instituto Oswaldo Cruz (IOC/Fiocruz)

Pós-Doc pelo programa Brasil sem Miséria (CAPES/Fiocruz) 


\section{Sumário}

CAPÍTULO I - ASPECTOS GERAIS DO SARS-COV-2: UMA REVISÃO DA LITERATURA..........................................

CAPÍTULO II - CRISPR/CAS COMO FERRAMENTA BIOTECNOLÓGICA APLICADA À VIROLOGIA.............................20

CAPÍTULO III - DETECÇ̃̃o DOS VÍRUS EPSTEIN-BARR, CITOMEGALOVÍRUS E HERPESVÍRUS HUMANO 6 E 7 EM

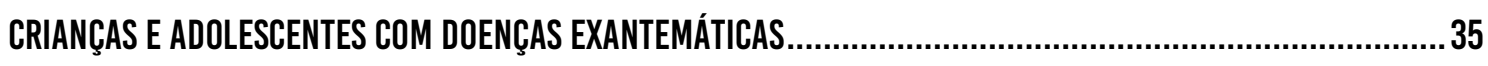

CAPÍTULO IV - UTILIZAÇÃO DA SALIVA E DA URINA COMO ESPÉCIMES DE DIAGNÓSTICO DA DENGUE: ANÁLISE DA

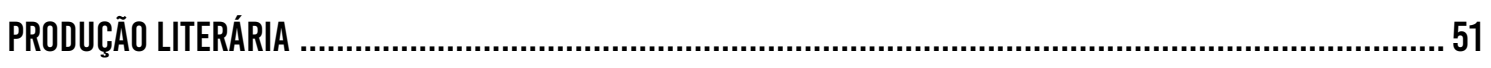

CAPÍTULO V - REVISÃO DA LITERATURA: LEISHMANIOSE TEGUMENTAR AMERICANA - MÉTODOS DIAGNÓSTICOS... 67 CAPÍTULO VI - NÍVEIS DE CITOCINAS TNF- $\alpha$, IFN- $\gamma$, E TGF- $\beta$ E O PERFIL CLÍNICO-EPIDEMIOLÓGICO DE INDIVÍDUOS COM CORIORETINITE POR TOXOPLASMOSE, SUL DO BRASIL .77

CAPÍTULO VII - NEUROCISTICERCOSE: ASPECTOS EPIDEMIOLÓGICOS, CLÍNICOS E LABORATORIAIS - UMA REVISÃO BIBLIOGRÁFICA

CAPÍTULO VIII - APLICAÇÃO DE FERRAMENTAS MOLECULARES PARA O DIAGNÓSTICO DE LEISHMANIOSE TEGUMENTAR AMERICANA.

CAPÍTULO IX - ESTUDO COMPARATIVO DE PROTOCOLOS DE EXTRAÇÃO DE DNA EMPREGADOS NA DETECÇÃO DE TRYPANOSOMA CRUZI EM DOIS AMBIENTES: LABORATÓRIO DE ENSINO E DE PESQUISA .111

CAPítULO X - CORYNEBACTERIUM STRIATUM: PATÓGENO MULTIRRESISTENTE NEGLIGENCIADO PELA DIFÍCIL E INCORRETA IDENTIFICAÇÃO. .128

CAPÍTULO XI - BIOFILME FORMADO POR STAPHYLOCOCCUS AUREUS: CAUSA ALARMANTE DE INFECÇ̃̃ES NOSOCOMIAIS 153

CAPITULO XII - INFECÇ̃̃ES DO TRATO URINÁRIO CAUSADAS POR CORYNEBACTERIUM SPP. .181

CAPÍTULO XIII - IDENTIFICAÇÃO DE BACTÉRIAS NOCIVAS DECORRENTES DO MANUSEIO INCORRETO DO KEFIR.... 194 CAPÍTULO XIV - INFECÇ̃̃O POR TREPONEMA PALLIDUM E DANOS NO DESENVOLVIMENTO EMBRIONÁRIO E FETAL .200

CAPÍTULO XV - PERCEPÇÕES DOCENTES E DISCENTES SOBRE FEEDBACK EM ESTÁGIOS PRÁTICOS NO CURSO DE MEDICINA .212 
CAPÍTULO XVI - O CAFÉ E SUAS PROPRIEDADES FUNCIONAIS: UMA BREVE REVISÃO DE LITERATURA SOBRE O USO DA CAFEINA E SEUS BENEFICIOS

CAPITULLO XVII - CONTROLE DE QUALIDADE EM MEDICAMENTOS CONTENDO O PRINCÍPIO ATIVO MELOXICAM..... 245

CAPÍTULO XVIIII - POTENCIAL ANTIOBESOGÊNICO DO EXTRATO DE FEIJÃO-BRANCO (PHASEOLUS VULGARIS L.)... 253

CAPÍTULO XIX - AVALIAÇÃO DO CONHECIMENTO DOS ALUNOS INGRESSOS DE UMA INSTITUIÇÃO DE ENSINO TÉCNICO PRIVADO DA ÁREA DA SAÚDE SOBRE ISTS NO MUNICÍPIO DE SÃO GONÇALO/RJ 261

CAPÍTULO XX - USO RACIONAL DAS PANCS: UM RESGATE NA REGIÃO NA REGIÃO DE AMERICANA/SP 268

CAPÍTULO XXI - PREVALÊNCIA DOS TRANSTORNOS MENTAIS COMUNS ENTRE OS ESTUDANTES DO CURSO TÉCNICO EM ADMINISTRAÇÃO 280

CAPÍTULO XXII - COMPREENSÃO EXISTENCIAL-FENOMENOLÓGICA DO SUICÍDIO DURANTE A PANDEMIA. 292

CAPITULL XXIII - ASSISTÊNCIA DE ENFERMAGEM NO DIAGNÓSTICO E TRATAMENTO FOTOTERÁPICO DA ICTERÍCIA FISIOLÓGICA EM NEONATOS PRÉ-TERMO .306

CAPÍTULO XXIV - PRÉ-NATAL HUMANIZADO E EDUCAÇÃO EM SAÚDE PARA O PARTO ATIVO: PERCEPÇÃO DOS MÉDICOS E ENFERMEIROS DE UMA UNIDADE BÁSICA DE SAÚDE. 315

CAPÍTULO XXV - AVALIAÇÃO HIGIÊNICO-SANITÁRIA DE ALFACE (LACTUCA SATIVA L.) COMERCIALIZADA IN NATURA EM RESTAURANTES SELF-SERVICE NO MUNICÍPIO DE MARINGÁ-PR .329

CAPÍTULO XXVI - ATUAÇÃO DO ENFERMEIRO FRENTE AO CÂNCER DA MAMA MASCULINA NA ATENÇÃO BÁSICA... 339 


\section{CAPÍTULO I}

\section{ASPECTOS GERAIS DO SARS-COV-2: UMA REVISÃO DA LITERATURA}

Lygia Cristine Soares da Silva ${ }^{1}$ Arthur Daniel Rocha Alves ${ }^{2}$ Fernanda de Oliveira Bottino ${ }^{3}$

\footnotetext{
${ }^{1}$ Estudante do Ensino Médio/Técnico da Escola Politécnica de Saúde Joaquim Venâncio - FIOCRUZ

${ }^{2}$ Doutorando em Medicina Tropical no Laboratório de Desenvolvimento Tecnológico em Virologia do Instituto Oswaldo Cruz - FIOCRUZ

${ }^{3}$ Professora-Pesquisadora do Laboratório de Educação Profissional em Técnicas Laboratoriais em Saúde da Escola Politécnica de Saúde Joaquim Venâncio - FIOCRUZ
}

\section{RESUMO}

O SARS-CoV-2 é o agente etiológico da Covid-19, uma doença infecciosa caracterizada por um quadro de Síndrome Respiratória Aguda Grave (SRAG) e cujo os primeiros casos foram identificados em dezembro de 2019 na cidade Chinesa de Wuhan. Em 2019, o Comitê Internacional de Taxonomia Viral divulgou uma nova classificação para os coronavírus; o SARS-CoV-2 pertences à família Coronaviridae, subfamília Orthocoronavirinae, gênero Betacoronavírus, juntamente com o SARS-CoV e o MERSCoV responsáveis, respectivamente, pelas SRAG e Síndrome Respiratória do Oriente Médio (MERS). Possui um genoma RNA de fita simples polaridade positiva, não segmentado, e um capsídeo de simetria helicoidal, envolto por um envelope lipídico que confere uma morfologia esférica de 80 a 120 nanômetros de diâmetro aos vírions. Dos componentes integrados à partícula viral, destacam-se as glicoproteínas Spike (S) que desempenham a função de se ligar à Enzima Conversora de Angiotensina 2 (ECA2) presente em tecidos humanos, como o pulmão, o coração e o intestino, permitindo a entrada do vírus na célula por endocitose. Até o momento, a única via de transmissão cientificamente comprovada para o SARS-CoV-2 é a respiratória, através de gotículas, aerossóis e contato direto com o indivíduo infectado. Outras formas de transmissão, como: vertical, fecal-oral, zoonótica ou parenteral necessitam de mais estudos a fim de serem comprovadas cientificamente.

Palavras-chave: Covid-19. SARS-CoV-2. Coronavírus. Virologia

\section{INTRODUÇÃO}

Em apenas duas décadas, o mundo sofreu com três grandes epidemias causadas por vírus pertencentes ao gênero Betacoronavírus da família Coronaviridae (PAULES et al., 2020). De novembro de 2002 à julho de 2003 a Síndrome Respiratória Aguda Grave (SRAG ou SARS, do inglês Severe Acute Respiratory Syndrome) atingiu países Asiáticos, 
Europeus e a América do Norte, resultando em 8.439 casos notificados, sendo 812 fatais. A doença emergiu na China, na província de Guangdong e o SARS-CoV foi identificado como o agente etiológico (KUIKEN et al., 2003). Uma década depois, no período de 2012 e 2013, surgiu o MERS-CoV, causador da Síndrome Respiratória do Oriente Médio (MERS, do inglês Middle East Respiratory Syndrome), permanecendo este limitado à Arábia Saudita, com poucos casos descritos em outros países (DE GROOT et al., 2013).

A partir de 12 de dezembro de 2019, foram relatados casos de pneumonia grave e SRAG com etiologia não definida em Wuhan, cidade localizada na província de Hubei, no centro da China. Foram testadas amostras de sete pacientes com sintomas graves da infecção, admitidos na Unidade de Terapia Intensiva do Hospital Wuhan Jin Yin-Tan, para investigação do agente etiológico. Tais amostras foram enviadas para o Instituto de Virologia de Wuhan (WIV) e, através de testes moleculares como a Reação em Cadeia da Polimerase em Tempo Real precedida de Transcrição Reversa (RT-qPCR) e testes sorológicos como o Ensaio de Imunoabsorção Enzimática (ELISA), foi confirmada a infecção viral dos pacientes por um vírus similar ao SARS-CoV e até então desconhecido. O mercado de frutos do mar de Huanan foi considerado o local de origem desta infecção, pois seis destes pacientes tinham vínculo com o mesmo, sendo entregadores ou vendedores (ZHOU et al., 2020).

Inicialmente, esse novo vírus era denominado como 2019-nCoV. Diante da percepção das semelhanças de sua estrutura com o agente etiológico da epidemia da SRAG, o Grupo de Estudos de Coronavírus (CSG, do inglês Coronavírus Study Group) pertencente ao Comitê Internacional de Taxonomia Viral (ICTV) nomeou o vírus atual como SARS-CoV-2 (GORBALENYA et al., 2020). Em 11 de fevereiro de 2020, a Organização Mundial de Saúde (OMS) denominou a patologia causada por esse novo Coronavirus de Covid-19 (do inglês Coronavírus disease ou "Doença do Coronavírus"), sendo o número 19 referente ao ano de ocorrência dos primeiros casos notificados dessa infecção (WHO, 2020; FIOCRUZ, 2020). Em 11 de março de 2020, a OMS decretou a pandemia pelo SARS-CoV-2, causador da Covid-19 (OPAS, 2020). 


\section{REVISÃO BIBLIOGRÁFICA}

\subsection{Classificação da família Coronaviridae}

Em 2019, o ICTV divulgou uma nova classificação para os coronavírus que passaram a pertencer ao domínio Riboviria, reino Orthornavirae, filo Pisuviricota, classe Pisoniviricetes, ordem Nidovirales, subordem Cornidovirineae, família Coronaviridae. Esta família foi dividida em duas novas subfamílias, sendo elas: Letovirinae (gênero Alphaletovirus) e Orthocoronavirinae, sendo esta, dividida em em quatro gêneros: Alphacoronavírus, Betacoronavírus, Deltacoronavírus e Gammacoronavírus (ICTV, 2019). Os gêneros Alphacoronavírus e Betacoronavírus são conhecidos por infectar mamíferos, incluindo o homem; enquanto que os Deltacoronavírus e Gammacoronavírus infectam espécies de aves (ICTV, 2019; PAULES et al., 2020).

As sete principais espécies conhecidas que infectam humanos são: HCoV-229e, HCoV-NL63 (pertencentes ao gênero Alphacoronavírus), HCoV-OC43, HCoV-HKU1 (gênero Betacoronavírus), sendo estas responsáveis principalmente por infecções respiratórias brandas. Além do SARS-CoV-2, SARS-CoV e MERS-CoV, pertencentes ao gênero Betacoronavírus, que, como mencionado anteriormente, são responsáveis pela Covid-19, SRAG e MERS, respectivamente (SHUO et al., 2016; BULUT E KATO, 2020).

\subsection{Estrutura dos coronavírus}

Os coronavírus possuem um genoma RNA de fita simples, não segmentado, com senso positivo (ssRNA+) (FUNG et al, 2019; PAULES et al., 2020). O RNA dos coronavírus são considerados grandes (cerca de $30 \mathrm{~kb}$ ), logo, sua tradução é considerada complexa (DE WILDE et al., 2017).

Estes vírus são envelopados, com morfologia esférica variando de 80 a 120 nanômetros de diâmetro e capsídeo de simetria helicoidal. Em seu envelope (envoltório externo) existem componentes glicoproteicos ou proteicos, que estão integrados na partícula viral em uma membrana lipídica, como: a glicoproteína Spike (S) que forma projeções em trímeros; a glicoproteína da membrana (M), sendo esta a mais abundante; a proteína Hemaglutinina Esterase (HE), encontrada somente em alguns Betacoronavírus; e a proteína do Envelope (E), que é altamente hidrofóbica. No interior deste envelope, há um nucleocapsídeo helicoidal formado pela junção da proteína do

WWW.AMPLLAEDITORA.COM.BR (2)

CONTATO@AMPLLAEDITORA.COM.BR M 
Nucleocapsídeo $(\mathrm{N})$ com o material genético do vírus (ssRNA+), para proteção do genoma (Figura 1A) (CRUZ et al., 2020).

Figura 1 - Estrutura dos coronavírus
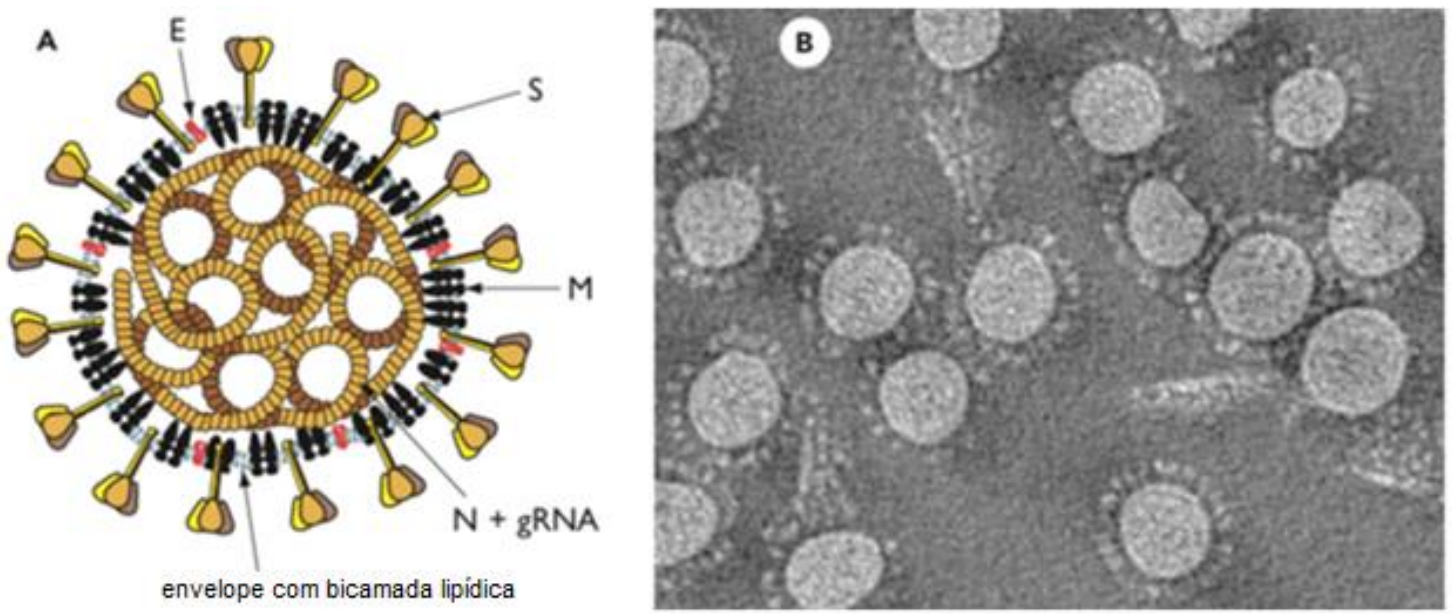

Legenda: A - Esquema demonstrando o nucleocapsídeo heliocoidal e as principais proteínas estrurais: proteína Spike (S), proteína de Membrana (M), proteína do Envelope (E) e proteína do Nucleocapsídeo (N); B - Eletromicrografia de vírions purificados de coronavírus murino evidenciando o formato de 'coroa'. (Fonte: adaptado de MASTERS E PERLMAN., 2013)

O termo coronavírus tem origem na palavra em Latim corona e significa coroa ou auréola, fazendo referência à estrutura da sua superfície, visualizada a partir de microscopia eletrônica, com projeções que fazem o vírus parecer com uma coroa (Figura 1B) (RICHMAN et al., 2016).

\subsection{Ciclo de replicação}

Assim como o SARS-CoV, a glicoproteína Spike (S) do SARS-CoV-2 têm grande afinidade pela Enzima Conversora de Angiotensina 2 (ECA2), uma proteína que está presente em células de tecidos humanos que compõem o pulmão, o coração, o rim, o endotélio e a superfície luminal das células epiteliais intestinais. A interação da glicoproteína $S$ do envelope viral com a ECA2 permite a entrada do vírus na célula, através de endocitose (DE WILDE et al., 2017; ZHANG et al., 2020).

Após a entrada do vírus na célula, tem-se a liberação do material genético no citoplasma da célula e ocorre a produção de poliproteínas. O genoma dos coronavírus é constituído por uma molécula de RNA fita simples de polaridade positiva, com a 
presença de uma "cap" 7-metilguanosina na extremidade 5' e uma cauda poliadenilada (poli-A) na extremidade $3^{\prime}$. A replicase dos coronavírus é codificada por duas fases de leitura aberta (ORFs, do inglês Open Reading Frames) que se sobrepõem (ORF1a e ORF1b), ocupando dois terços do genoma e sendo diretamente traduzidas do RNA genômico. Além disso, o genoma possui um grande número de pequenas ORFs espalhadas entre os genes que codificam as proteínas estruturais ( $S, E, M, N$ e HE). Independente da espécie de coronavírus, a ordem codificante do genoma é: 5'Replicase-S-E-M-N-3' (Figura 2) (FUNG et al, 2019).

Figura 2 - Estrutura do genoma dos coronavírus SARS-CoV e MERS-CoV

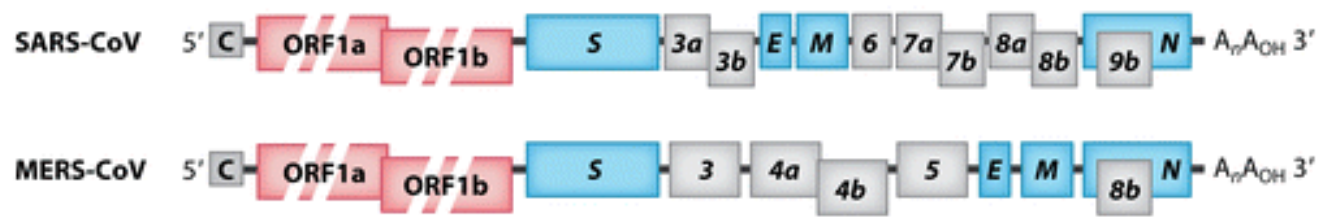

Legenda: Diagrama esquemático demonstrando a estrutura do genoma dos vírus SARS-CoV e MERS-CoV, na seguinte ordem: 5'-Replicase-S-E-M-N-3', com pequenas ORFs espalhadas ao longo dos genes estruturais. As ORFs 1a e 1b são responsáveis pela codificação da replicase e estão representadas de vermelho. Os genes que codificam as proteínas estruturais ( $S, E, M, N$ e HE) estão representados de azul e os genes que codificam as proteínas acessórias de cinza. (Fonte: adaptado de FUNG et al., 2019)

Após a sintese da replicase nas ORFs, o RNA viral positivo serve de molde para um RNA negativo, que por sua vez, é utilizado como base para novos RNAs genômicos. Além desse mecanismo, há outro para a produção de RNAs subgenômicos, responsáveis pela tradução dos genes acessórios e estruturais durante o processo de transcrição e replicação viral (FUNG et al, 2019).

Depois da produção das proteínas estruturais traduzidas a partir da ORF 5' (ORF1a e ORF1b), a partícula viral é sintetizada com todos seus componentes no Complexo de Golgi, transportada pela via secretora dentro de vesículas e excretada para o meio extra celular por exocitose (Figura 3) (FUNG et al, 2019). 


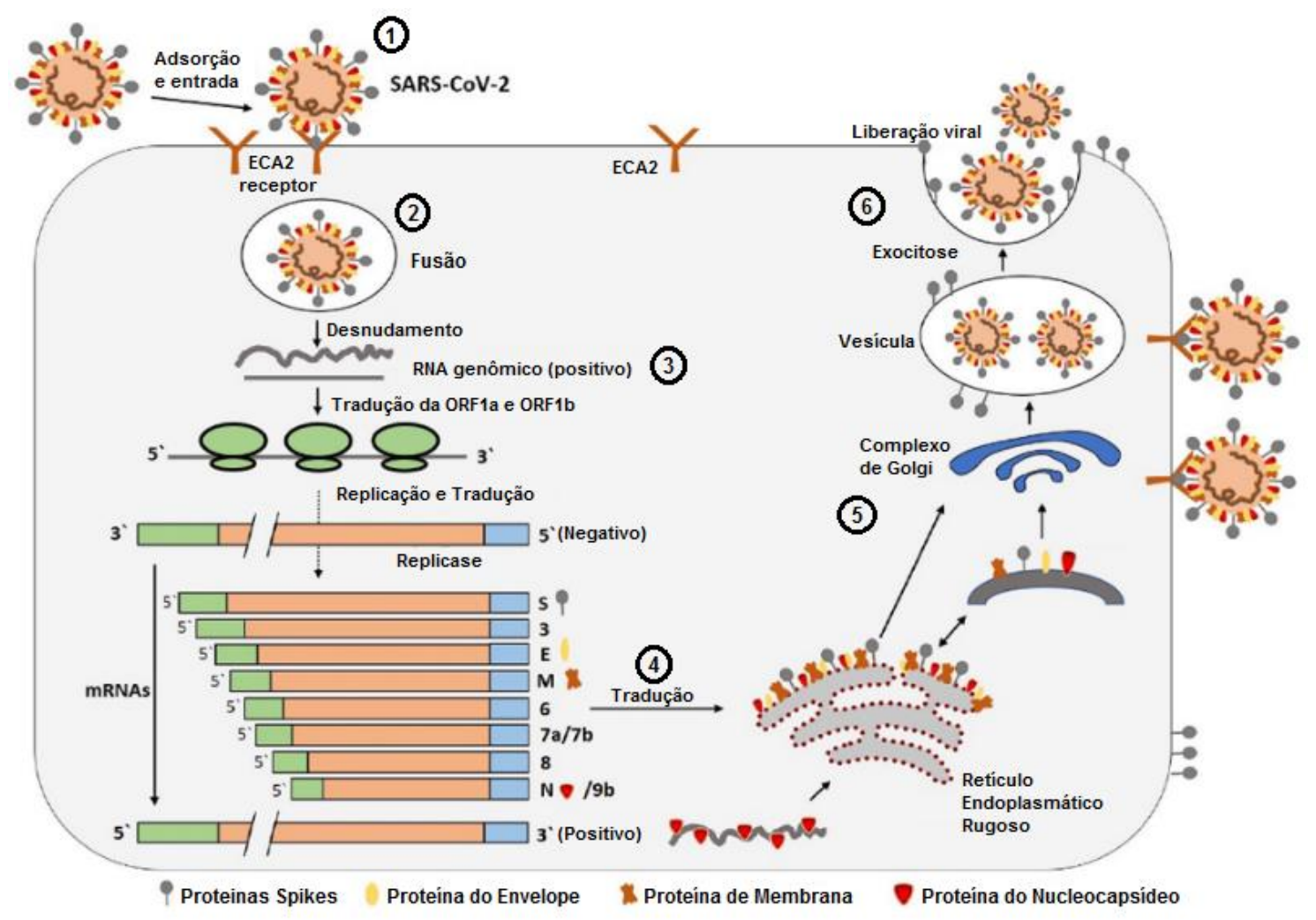

Legenda: (1) adsorção do vírus ao receptor ECA2 e entrada nas células por endocitose, (2) fusão do vírion com a membrana da vesícula e liberação do genoma viral, (3) codificação da replicase a partir das ORFs 1a e 1b, (4) tradução de proteínas estruturais e acessórias, (5) montagem dos vírions no Complexo de Golgi e (6) transporte das novas partículas virais pela via secretora para saída da célula por exocitose. (Fonte: SHEREEN et al., 2020)

\section{4. $\quad$ Formas de Transmissão}

O SARS-CoV-2, causador da Covid-19, tem a transmissão respiratória como única via confirmada, até o momento, de humano para humano, através de gotículas, aerossóis e contato direto com o indivíduo infectado (ROTHAN E BYRAREDDY, 2020). Portadores do vírus que estejam assintomáticos também são uma fonte de transmissão, ainda que esses pacientes possam ter uma carga viral menor em relação aos que desenvolveram a doença. Esse vírus tem alta transmissibilidade e, aliado às viagens globais, constatou-se o seu grande potencial para o desenvolvimento da pandemia (LAI et al, 2020).

Sobre a transmissão vertical, que se caracteriza pela passagem do vírus da mãe para o feto durante o período gestacional, ainda não há comprovação científica. Entretanto, esta forma de transmissão não pode ser descartada. Há relatos de fetos que 
apresentaram sofrimento intra-uterino, resultando em cesárea de emergência e de neonatos que ficaram na Unidade de Terapia Intensiva (UTI) neonatal com falta de ar, apresentando radiografia de tórax com turvação difusa, incluindo um caso fatal. Em ambos os casos relatados, as gestantes testaram positivo para o SARS-CoV-2 (ZAIGHAM E ANDERSSON, 2020).

A transmissão fecal-oral também não foi comprovada cientificamente. Amostras fecais de indivíduos com Covid-19 apresentaram o RNA do SARS-CoV-2 detectável através da Reação em Cadeia pela Polimerase precedida de Transcrição Reversa em tempo real (RT-qPCR). Entretanto, é importante ressaltar que esta técnica detecta apenas o material genético do vírus, não a partícula viral infecciosa (BULUT e KATO, 2020; Ll et al., 2020). Outros estudos mostram que o vírus viável foi cultivado em cultura celular a partir de fezes contaminadas (WANG et al., 2020), porém mais estudos sobre o tema se fazem necessários para confirmar esse tipo de transmissão.

Shi e colaboradores (2020) verificaram um potencial de transmissão e replicação do SARS-CoV-2 através de inoculação do vírus em animais que têm contato próximo com humanos. Segundo os autores, porcos, galinhas e patos não são suscetíveis ao vírus. Cães possuem baixa suscetibilidade. Furões apresentam alta suscetibilidade e replicação viral localizada no trato respiratório superior. Os gatos possuem além da alta suscetibilidade ao vírus, a replicação viral no trato respiratório inferior e a transmissibilidade para outros gatos, o que os torna potenciais transmissores para humanos e alvo de atenção para a vigilância epidemiológica da Covid-19 (SHI et al., 2020).

Sobre a via parenteral, ainda não se sabe se o SARS-CoV-2 pode ser transmitido por transfusão de sangue ou hemoderivados. Essa informação é fundamental para evitar a transmissão do vírus pela doação de sangue por portadores assintomáticos do vírus. Até o momento, foi encontrado apenas o RNA viral no plasma ou soro (CHANG, et al., 2020; CHO et al., 2020). 


\section{CONSIDERAÇÕES FINAIS}

O entendimento dos aspectos gerais do SARS-CoV-2 faz-se necessário, afim de que sejam desenvolvidos métodos mais eficazes de prevenção, tratamento e diagnóstico para a Covid-19. Além disso, a revisão da literatura científica sobre esta temática deve ser feita de forma constante, uma vez que novos estudos a cerca da compreensão desta doença vêm sendo realizados e publicados diariamente.

\section{AGRADECIMENTOS}

Agradecemos à Escola Politécnica de Saúde Joaquim Venâncio (EPSJV/ Fiocruz) pela concessão de bolsa auxílio para que a aluna Lygia Cristine Soares da Silva pudesse realizar este trabalho e ao Congresso Online de Ciências da Saúde (CONCIS) pela oportunidade de expor este trabalho através de apresentação na plataforma, na edição de 2020.

\section{REFERÊNCIAS}

BULUT, C., KATO, Y. Epidemiology of COVID-19. Turkish Journal Of Medical Sciences, v. 50, № 3, p. 563-570, 2020. Disponível em: https://www.ncbi.nlm.nih.gov/pmc/articles/PMC7195982/. Acesso em: 18 mai. 2020.

DE GROOT, R. J., BAKER, S. C., BARIC, S. R. et al. Middle east respiratory syndrome coronavírus (MERS-CoV): announcement of the Coronavírus Study Group. Journal of Virology, v. 87, no 14, p. 7790-7792, 2013. Disponível em: https://www.ncbi.nlm.nih.gov/pmc/articles/PMC3700179/. Acesso em: 04 mai. 2020.

DE WILDE, A. H., SNIJDER, E. J., KIKKERT, M., VAN HEMERT, M. J.. Host factors in coronavírus replication. Current Topics in Microbiology and Immunology, v. 419, p. 1-49, 2017. Disponível em: https://link.springer.com/chapter/10.1007/82_2017_25. Acesso em: 04 mai. 2020.

CHANG, L., YAN, Y., WANG, L. Coronavírus Disease 2019: Coronavíruses and Blood Safety. Transfusion Medicine Review, v. 34, no 2, p. 75-80, 2020. Disponível em: https://www.sciencedirect.com/science/article/pii/S0887796320300146?via\%3 Dihub. Acesso em: 12 jun. 2020. 
CHO, H. J., KOO, J. W. ROH, S. K. et al. COVID-19 transmission and blood transfusion: A case report. Journal of Infection an Public Health, 2020. Disponível em: https://www.sciencedirect.com/science/article/pii/S1876034120304676?via\%3 Dihub. Acesso em: 12 jun. 2020.

CRUZ, M. P., SANTOS, E., CERVANTES, M. A. V. et al. COVID-19, una emergencia de salud pública mundial. Revista Clínica Espanõla, 2020. Disponível em: https://www.sciencedirect.com/science/article/pii/S0014256520300928\#bib02 30. Acesso em: 04 mai. 2020.

FIOCRUZ. Por que a doença causada pelo novo vírus recebeu o nome de Covid-19? Disponível em: https://portal.fiocruz.br/pergunta/por-que-doenca-causadapelo-novo-virus-recebeu-o-nome-de-covid-

19\#: :text=COVID\%20significa\%20COrona\%20VIrus\%20Disease,chin\%C3\%AAs\% 20no\%20final\%20de\%20dezembro. Acesso em: 20 nov. 2020.

FUNG, T. S., LIU, D. X. Human coronavírus: host-pathogen interaction. Annual Review of Microbiology, v. 73, p. 529-557, 2019. Disponível em: https://www.annualreviews.org/doi/full/10.1146/annurev-micro-020518115759. Acesso em: 04 mai. 2020.

GORBALENYA, A. E., BAKER, S. C., BARIC, R. S. et al. The species severe acute respiratory syndrome-related coronavirus: classifying 2019-nCoV and naming it SARS-CoV2. Nature Microbiology, v. 5, p. 536-544, 2020. Disponível em: https://www.nature.com/articles/s41564-020-0695-z. Acesso em: 04 mai. 2020.

ICTV. Virus Taxonomy: 2019, Release. EC 51, Berlin, Germany, July 2019; Email ratification March 2020 (MSL \#35); 2019. Disponível em: https://talk.ictvonline.org/ictv-reports/ictv_9th_report/positive-sense-rnaviruses-2011/w/posrna_viruses/222/coronaviridae. Acesso em: 11 mai. 2020.

KUIKEN, T., FOUCHIER, R. A. M., SCHUTTEN, M. et al. Newly discovered coronavírus as the primary cause of severe acute respiratory syndrome. The Lancet, v. 362, no 9380, p. 263-270, 2003. Disponível em: https://www.ncbi.nlm.nih.gov/pmc/articles/PMC7112434/. Acesso em: 04 mai. 2020.

LI, J., FENG, J., LIU, T. et al. An infant with a mild SARS-CoV-2 infection detected only by anal swabs: a case report. The Brazilian Journal of Infectious Diseases, p. 1-3, 2020. em:https://www.sciencedirect.com/science/article/pii/S141386702030043X?vi a\%3Dihub. Acesso em 10 jun. 2020.

LAI, C., SHIH, T. et al. Severe acute respiratory syndrome coronavírus 2 (SARS-CoV-2) and coronavírus disease-2019 (COVID-19): The epidemic and the challenges. International Journal of Microbiology Agents, v. 55, n , 2020. Disponível em: 
https://www.ncbi.nlm.nih.gov/pmc/articles/PMC7127800/. Acesso em: 18 mai. 2020.

MASTERS, P. S., PERLMAN, S. Coronviridae in KNIPE, D. M. HOWLEY, P. M. Fields Virology. 6a edição, 2013.

OPAS. OMS afirma que COVID-19 é agora caracterizada como pandemia. 2020. Disponível em:

https://www.paho.org/bra/index.php?option=com_content\&view=article\&id=6120:0 ms-afirma-que-covid-19-e-agora-caracterizada-como-pandemia\&ltemid=812. Acesso em: 11 mai. 2020.

PAULES, C. I., MARSTON, H. D., FAUCl, A. S. Coronavirus infections - more than just the common cold. JAMA, v. 233, no 8, p. 707-708, 2020. Disponível em: https://jamanetwork.com/journals/jama/fullarticle/2759815. Acesso em: 04 mai. 2020.

RICHMAN, D. D., WHITLEY, R. J., HAYDEN, F. G. Clinical Virology. 4a edição, 2017. Disponível em: https://books.google.com.br/books?id=G9zIDwAAQBAJ\&printsec=frontcover\& $\mathrm{dq}=\mathrm{CLINICAL}+\mathrm{VIROLOGY \& hl=pt-}$

BR\&sa=X\&ved=0ahUKEwjy88XxyZrpAhU9HbkGHaJ7C3gQ6wEILTAA\#v=onepage $\& q=C L I N I C A L \% 20 V I R O L O G Y \& f=$ false. Acesso em: 04 mai. 2020.

ROTHAN, H. A., BYRAREDDY, S. N. The epidemiology and pathogenesis of coronavirus disease (COVID-19) outbreak. Journal of Autoimmunity, v. 109, 2020. Disponível em:

https://www.sciencedirect.com/science/article/pii/S0896841120300469?via\%3 Dihub. Acesso em: 18 mai. 2020.

SHI, J., WEN, C., ZHONG, G. et al. Susceptibility of ferrets, cats, dogs, and other domesticated animals to SARS-coronavírus 2. Science, v. 368, no 6494, p. 101610-20, $2020 . \quad$ Disponível em: https://www.ncbi.nlm.nih.gov/pmc/articles/PMC7164390/. Acesso em: 11 jun. 2020.

SHUO, S., WONG, G., SHI, W. et al. Epidemiology, genetic recombination, and pathogenesis of coronavíruses. Trends in Microbiology, v. 24, no 6, p. 490-502, 2016. https://www.ncbi.nlm.nih.gov/pmc/articles/PMC7125511/. Acesso em: 20 nov. 2020.

SHEREEN, M. A., KHAN, S., KASMI, A. et al. COVID-19 infection: Origin, transmission, and characteristics of human coronavíruses. Journal of Advanced Research, v. 24, p. 91-98. 2020.

Disponível em: https://www.sciencedirect.com/science/article/pii/S2090123220300540. Acesso em: 11 mai. 2020 
WANG, W., XU, Y., GAO, R. et al. Detection of SARS-CoV-2 in different types of clinical specimens. JAMA, v. 323, no 18, p. 1843-1844, 2020. Disponível em: https://jamanetwork.com/journals/jama/article-abstract/2762997. Acesso em 11 jun. 2020.

WORLD HEALTH ORGANIZATION (WHO). Coronavírus Disease 2019 (Covid-19) Situation Report $\quad 22.2020 .2$ Disponível em: https://apps.who.int/iris/handle/10665/330991. Acesso em: Acesso em: 20 nov. 2020.

ZAIGHAM, M., ANDERSSON, O. Maternal and perinatal outcomes with COVID-19: A systematic review of 108 pregnancies. Acta Obstetricia et Gynecologica Scandinavica, v. 99, p. 1-7, $2020 . \quad$ Disponível em: https://obgyn.onlinelibrary.wiley.com/doi/full/10.1111/aogs.13867. Acesso em: 02 jun. 2020.

ZHANG, H., PENNINGER, J. M., LI, Y. et al. Angiotensin-converting enzyme 2 (ACE2) as a SARS-CoV-2 receptor: molecular mechanisms and potential therapeutic target. Intensive Care Medicine, v. 46, p. 586-590, 2020. Disponível em: https://link.springer.com/article/10.1007/s00134-020-05985-9. Acesso em 04 mai. 2020.

ZHOU, P., YANG, X., WANG, X. et al. A pneumonia outbreak associated with a new coronavírus of probable bat origin. Nature, v. 579, p. 270-273, 2020. Disponível em: https://www.nature.com/articles/s41586-020-2012-7. Acesso em: 04 mai. 2020. 


\title{
CAPITULO II
}

\section{CRISPR/CAS COMO FERRAMENTA BIOTECNOLÓGICA APLICADA À VIROLOGIA}

\author{
Wagner Luis da Costa Nunes Pimentel Coelho ${ }^{1}$ \\ Carlos Gabriel Mathias Alves ${ }^{2}$ \\ Arthur Daniel Rocha Alves ${ }^{3}$ \\ Alexandre dos Santos da Silva ${ }^{4}$

\footnotetext{
${ }^{1}$ Mestrando no Programa de pós-graduação em Medicina Tropical. Instituto Oswaldo Cruz - Fundação Oswaldo Cruz, Rio de Janeiro, RJ.

${ }^{2}$ Graduado em Biomedicina. Centro Universitário IBMR, Rio de Janeiro, RJ. Cruz, Rio de Janeiro, RJ. arthur.alves@ioc.fiocruz.br

${ }^{4}$ Doutor em Medicina Tropical. Instituto Oswaldo Cruz - Fundação Oswaldo Cruz, Rio de Janeiro, RJ.
} \\ ${ }^{3}$ Doutorando no Programa de pós-graduação em Medicina Tropical. Instituto Oswaldo Cruz - Fundação Oswaldo
}

\section{RESUMO}

Introdução: O CRISPR, mecanismo de defesa presente em procariotos, é capaz de incorporar uma sequência de material genético e, posteriormente, junto de proteínas associadas (Cas), clivar DNA/RNA específico de acordo com a sequência incorporada ao locus. A possibilidade de reprogramar este mecanismo em laboratório possibilitou sua utilização na área biotecnológica. Desta forma, o complexo CRISPR/Cas tem sido estudado como alternativa ao desenvolvimento de terapias, métodos diagnósticos e até na produção de transgênicos. Objetivo: Avaliar o potencial de utilização do CRISPR como ferramenta na pesquisa direcionada à virologia. Materiais e métodos: Este estudo de revisão bibliográfica teve como principal fonte de pesquisa a plataforma Pubmed, na qual foram realizadas buscas no período entre março de 2019 e setembro de 2020, utilizando as seguintes palavras-chave: CRISPR, virology, therapy, editing, diagnostic. Resultados: A presente revisão demonstra algumas das possibilidades de utilização do CRISPR no campo de estudo da virologia, como por exemplo, uma forma eficaz em conferir resistência à vírus de RNA em plantas, levar à apoptose células infectadas pelo HPV, e identificar sensível e especificamente os vírus Zika, Dengue e o novo coronavírus (SARS-CoV-2) em diversas amostras biológicas. Devido ao pouco tempo desde a descoberta do CRISPR, sua utilização em humanos ainda deve ser planejada com cautela. Conclusões: O CRISPR, embora ainda seja uma técnica nova, demonstra potencial para se disseminar cada vez mais em laboratórios que trabalham com biologia molecular, e desta forma, ser utilizado para as resoluções nos campos da virologia.

Palavras-chave: Biotecnologia. Crispr. Diagnóstico. Virologia. 


\section{INTRODUÇÃO}

Uma forma de defesa de bactérias contra invasores foi descoberta e denominada como complexo CRISPR/Cas. Em procariotos, ocorre a incorporação ao lócus CRISPR de parte do material genético do organismo que se pretende combater, por exemplo, um bacteriófago. Ao incorporar essa sequência no material genético do procarioto, este torna-se capaz de reconhecer o organismo invasor em um futuro encontro e, portanto, consegue clivar seu material genético (Ishino et al. 1987, Mojica et al. 2005). Tendo em vista essa capacidade de "cortar" o DNA, logo foi sugerida a utilização do CRISPR como ferramenta biotecnológica (Jinek et al. 2012).

O sistema CRISPR (Repetições Palindrômicas Curtas Agrupadas e Regularmente Interespaçadas, ou do inglês, Clustered Regularly Interspaced Short Palindromics Repeats) é composto basicamente por um RNA guia específico para o alvo que se deseja clivar ligado à uma endonuclease, da família Cas (Proteínas Associadas ao CRISPR, ou do inglês, CRISPR Associated Protein), que será direcionada até a sequência específica do genoma de interesse, para realizar um "corte" no material genético, silenciando o DNA invasor (alvo) (Terns \& Terns 2011, Bhaya et al. 2011, Jinek et al. 2012, Wiedenheft et al. 2012).

Devido à possibilidade de programar este sistema para clivar sequências específicas de DNA ou RNA, inúmeras finalidades foram sugeridas para utilização do CRISPR, dentre as quais: tratamento para câncer, terapia para doenças infecciosas, diagnóstico laboratorial, produção de transgênicos, alteração genética de vetores, alteração genética de modelos experimentais animais, estudos genéticos, bioquímicos e moleculares. Tamanha diversidade de estratégias fez com que as pesquisadoras Emmanuelle Charpentier e Jennifer Doudna, que a desenvolveram, fossem laureadas com o Prêmio Nobel de Química de 2020.

Diante das diversas possibilidades proporcionadas por este sistema, tanto no estudo, quanto no diagnóstico e até no tratamento de infecções virais, esta revisão busca explorar a utilização do CRISPR na virologia. 


\section{REVISÃO BIBLIOGRÁFICA}

\subsection{Aspectos históricos}

O lócus CRISPR foi inicialmente identificado em Escherichia coli em 1987 (Ishino et al. 1987), porém somente em 2005 foi descoberta a sua função de imunidade adquirida em procariotos (Mojica et al. 2005). Posteriormente, demostrou-se que a resistência dos procariotos à bacteriófagos e plasmídeos invasores deve-se à atividade de clivagem do DNA provocada pelo CRISPR (Garneau et al. 2010).

Emmanuelle Charpentier e colaboradores (2012) demonstraram a capacidade de programar o complexo CRISPR/Cas, no qual a Cas9 ligada ao RNA guia consegue clivar o DNA específico, destacando o potencial deste para edição gênica (Jinek et al. 2012). No ano seguinte, foi visto que este sistema poderia ser utilizado em células humanas (Cho et al. 2013). Desde então, devido ao seu potencial para edição genética, o complexo CRISPR/Cas tem sido altamente visado e, portanto, discutido sob os aspectos éticos de sua utilização.

\subsection{CRISPR/Cas e seu potencial para edição genômica}

Após o entendimento geral da funcionalidade do CRISPR, logo foi sugerida sua utilização como ferramenta para edição genômica. Para tal, foi explorado o sistema CRISPR/Cas que utilizava a endonuclease Cas9, o sistema CRISPR/Cas9.

A endonuclease Cas9 está associada à um RNA guia formado por tracrRNA (RNA trans-ativador) e crRNA (CRISPR RNA), que formam um pareamento específico com uma região do DNA alvo, permitindo que a Cas9 quebre a fita-dupla de interesse.

Desta forma, foi possível a criação de um sistema específico, que usa um RNA guia (sgRNA), em que o lado 5' determina a sequência do DNA alvo ao qual o sistema se ligará e o lado 3' está ligado à Cas9 (Doudna \& Charpentier 2014). Tendo capacidade sítio-específica, este sistema permite, por exemplo, o silenciamento de um gene de forma planejada a se evitar efeitos de ligações inespecíficas não intencionais (efeitos off-target).

Após a clivagem da fita dupla do DNA em uma célula eucariótica, a célula busca o reparo da fita, que pode ser realizado por dois mecanismos: HDR (recombinação homóloga, ou do inglês, homology-directed repair) e NHEJ (recombinação não 
homóloga, ou do inglês, non-homologous end joining). A NHEJ ocorre naturalmente através da inserção de nucleotídeos aleatórios, enquanto a HDR necessita de uma sequência molde sintética para realizar os reparos de forma a reduzir possíveis erros e mutações indesejadas (Le Cong et al. 2013, Yang et al. 2013).

\subsection{O uso do complexo CRISPR/Cas para o tratamento de infecções virais}

Buscando a utilização do complexo CRISPR/Cas9 como tratamento antiviral, há trabalhos que o relacionam a vias de knockout de genes específicos como CXCR4 (que age em células T CD4). O sgRNA do CRISPR, neste caso, foi projetado para reconhecer somente a sequência alvo, de modo a interferir na proteína CXCR4, que funciona como co-receptor para a infecção pelo HIV (Schumann et al. 2015). Para permitir a inserção do complexo Cas através da membrana celular, foi utilizada a via de eletroporação, uma técnica que utiliza campos elétricos sobre determinadas células, a fim de que tenham sua permeabilidade artificialmente aumentada (Neumann et al. 1982). A metodologia de knockout de CXCR4 utilizando o CRISPR/Cas9 resulta em linfócitos T, geneticamente alteradas, não suscetíveis à infecção pelo HIV, ou seja, resistentes à infecção (Schumann et al. 2015).

O ART (tratamento antirretroviral) é considerado hoje como o melhor tratamento para pacientes com HIV, porém esta terapia somente diminui a carga viral e não elimina o vírus em sua forma latente (Gandhi et al. 2010). Existem trabalhos que utilizam o complexo CRISPR/Cas9 para eliminar o gene do HIV-1 dos linfócitos T.

Kaminski e colaboradores (2016), com o intuito de quantificar a eliminação da proteína Nef (codificada pelo HIV) utilizaram o marcador GFP (proteína fluorescente verde) para substituí-la, o que, por sua vez, forneceu um meio de cultura viável para a quantificação. Neste trabalho foi utilizada a linhagem clonal 2D10 como modelo de latência de células T, a fim de se analisar a capacidade do CRISPR/Cas9 de deleção da sequência que codifica o HIV-1. Concluiu-se então que o tratamento dos linfócitos T previamente inoculados com o CRISPR/Cas9 foi eficiente para eliminação de parte do DNA viral dentro da região LTR 3U, o que representa um nível relevante de supressão, mostrando que o CRISPR/Cas9 pode efetivamente diminuir a expressão do DNA do HIV1 em sua forma latente. Tendo este trabalho em vista, há um grande potencial de 
utilização do CRISPR/Cas9 em modelos ex-vivo, que são preferencialmente utilizados devido às implicações éticas da utilização de algumas terapias in vivo.

Alguns trabalhos relacionam a utilização do complexo CRISPR/Cas9 para tratamento de câncer cervical causado por Papilomavírus Humano (HPV). O HPV-16 e o HPV-18 estão entre os tipos virais mais perigosos, devido a sua capacidade carcinogênica. Para estes vírus é de vital importância a expressão das oncoproteínas E6 e E7. Caso esta expressão não ocorra, isto resultará na apoptose das respectivas células infectadas pelo vírus, bem como a aceleração de seu processo de envelhecimento (DeFilippis et al. 2002). O mecanismo de ação da Cas9 neste trabalho está relacionado à supressão da expressão destas duas proteínas em um sítio específico em células em processo de oncogênese no colo do útero. Este knockout causa o aumento dos níveis celulares de p53, gene responsável pela principal via de apoptose e de pRb (proteína do retinoblastoma), encarregada do processo de aceleração do envelhecimento celular (senescência) e inibe o crescimento tumoral do câncer cervical (Hu et al. 2014, Kennedy et al. 2014).

\subsection{Uso do sistema CRISPR/Cas para o diagnóstico de infecções virais}

Uma das maiores dificuldades para o diagnóstico viral está na diferenciação entre vírus relacionados entre si, ou seja, problemas na especificidade do teste, resultando em alta ocorrência de reatividade cruzada em muitos testes, como é o caso da família Flaviviridae, com os vírus da Dengue (DENV), Zika (ZIKV) e Febre Amarela (YFV) (Priyamvada et al. 2016, Munoz-Jordan 2017).

Buscando um teste diagnóstico com alta sensibilidade e especificidade, ainda capaz de implementar rapidez e sem a necessidade da utilização de equipamentos de alto custo, um grupo de pesquisadores utilizou o complexo CRISPR/Cas13 para o desenvolvimento de um método para diagnóstico viral.

O método desenvolvido por eles combina a amplificação isotérmica através de recombinase polimerase (RPA) com a alta especificidade do sistema CRISPR. Dois testes foram realizados isoladamente, nos quais um deles demonstrou ser capaz de detectar sensível e especificamente o ZIKV, e no outro o DENV. Ambos foram realizados a partir de amostras de pacientes RT-PCR-positivos. Foi demonstrado por essa equipe que 0

WWW.AMPLLAEDITORA.COM.BR (2)

CONTATO@AMPLLAEDITORA.COM.BR M 
teste desenvolvido por eles é capaz de detectar o material genético do ZIKV presente em amostras de urina, sangue total, plasma, soro e saliva. Além de detectar o DENV em sangue total, soro e saliva (Myhrvold et al. 2018).

Nesta técnica, chamada de SHERLOCK (Desbloqueio Enzimático-Específico de Alta Sensibilidade, ou do inglês, Specific High Sensitivity Enzymatic Reporter UnLOCKing), utiliza-se a Cas13, proteína associada ao CRISPR, que após realizar o corte específico do RNA alvo, passa a clivar quaisquer moléculas de RNA não específico próximos a ela. Portanto, é possível marcar essas moléculas com sondas, que serão visualizadas (através de fluorescência) após o corte deste RNA não específico pela proteína Cas13, indicando que anteriormente a Cas13 se ligou e clivou o RNA alvo (Gootenberg et al. 2017).

Embora, ainda hoje, a principal finalidade para a Cas9 não esteja relacionada ao desenvolvimento de diagnóstico, o sistema CRISPR/Cas9 possui elevado potencial para detecção de DNA. Portanto, Zhang e colaboradores (2018) desenvolveram algumas técnicas que associam este sistema à tecnologia PCR (Reação em Cadeia da Polimerase, ou do inglês, Polymerase Chain Reaction) (Wang et al. 2018, Zhang et al. 2018a).

Em um dos últimos trabalhos publicados por esta equipe, eles demonstraram o desenvolvimento do Cas9/sgRNA-typing PCR, versão 3.0 (ctPCR3.0), sendo demonstrada alta confiabilidade, especificidade e sensibilidade em detectar e identificar diversos genótipos do Papilomavírus Humano (HPV). Para isso, foi desenhado um par de RNA guia para os genes L1 (proteína estrutural do HPV) de 10 subtipos virais.

Inicialmente, para demonstrar a sensibilidade e especificidade da técnica, foi realizado um experimento para detectar os genes do HPV em plasmídeos clonados. Esse trabalho demonstrou que a técnica teve sucesso não apenas em detectar os genes, como também em distingui-los. Além deste e de outros testes, através do ctPCR3.0, o trabalho demonstrou a detecção e identificação dos genes L1 de diferentes subtipos do HPV em 20 de 26 amostras (6 amostras verdadeiramente negativas) de células obtidas a partir do muco cervical, indicando o grande potencial desta tecnologia. O ctPCR3.0 detecta e identifica o DNA alvo a partir do corte neste DNA provocado pelo Cas9/sgRNA, que é observado a partir de uma PCR em tempo real (qPCR) (Zhang et al. 2018b).

Outro trabalho que demonstra a utilização do CRISPR para detecção e distinção entre genótipos do HPV, também criou uma nova técnica para diagnóstico utilizando o sistema CRISPR/Cas (Chen et al. 2018). Esta técnica, nomeada como DETECTR (DNA

WWW.AMPLLAEDITORA.COM.BR (2)

CONTATO@AMPLLAEDITORA.COM.BR M 
Endonuclease Targeted CRISPR Trans Reporter), utiliza como proteína associada ao CRISPR, a Cas12. Esta proteína age de forma semelhante à Cas13, com a diferença de ser direcionada para o DNA alvo. A Cas12 se liga à fita dupla de DNA alvo e então, a partir disso, passa a clivar indiscriminadamente qualquer fita simples de DNA nas proximidades. Portanto, para utilização da Cas12 em diagnóstico, os pesquisadores acoplam sondas às fitas simples de DNA que serão utilizadas no teste. A partir do reconhecimento e clivagem da fita dupla de DNA alvo pela Cas12, esta passa a clivar as fitas simples, liberando as sondas acopladas, que poderão ser visualizadas a partir de fluorescência.

Como resultados obtidos neste trabalho, o DETECTR demonstrou ser capaz de detectar e identificar HPV-16 em 25/25 amostras de DNA extraído, a partir de swab retal, além de também detectar 23/25 HPV-18 das mesmas amostras (que continham uma mistura heterogênea dos genótipos do HPV), mostrando alta correlação entre os resultados obtidos a partir de PCR e do DETECTR nas mesmas amostras (Chen et al. 2018).

Recentemente, um estudo demonstrou a utilização do CRISPR em conjunto com biossensores no desenvolvimento de uma nova técnica para diagnóstico molecular, permitindo a detecção de DNA e RNA patogênicos. Este trabalho demonstrou a eficiência da técnica ao detectar e identificar uma bactéria chamada Orientia tsutsugamushi e o vírus Huaiyangshan banyangvirus, que são transmitidos por artrópodes e apresentam sinais clínicos semelhantes, como febre, dor de cabeça e mialgia e, além disso, ambas são endêmicas no leste da Ásia, o que dificulta o diagnóstico clínico (Kim et al. 2018). Os biossensores permitem a identificação de determinados alvos a partir de reações biológicas, por exemplo, de material genético ou anticorpos em uma dada amostra, possibilitando sua utilização como método diagnóstico (Wang 2000). A detecção desta reação pode ser visualizada através de fluorescência, medindo-se a diferença do índice de refração entre uma amostra positiva e um controle negativo (Wang 2000, Koo et al. 2018). Koo e colaboradores (2018) desenvolveram esta metodologia utilizando o CRISPR e biosensor, que é capaz de amplificar, através de reação isotermal, e detectar ácido nucleico com alta sensibilidade e especificidade. 
Para isso, utilizaram a dCas9, uma proteína Cas9 que perdeu sua função de endonuclease, através de mutações. Portanto, essa proteína é capaz de se ligar especificamente ao DNA alvo, no entanto, sem provocar clivagem desse material (Guilinger et al. 2014). Após a ligação entre a dCas9 e o DNA alvo, ocorre uma alteração do índice de refração, que aumenta a sensibilidade em comparação com o teste realizado somente com o biosensor. Para a amplificação do ácido nucleico, é realizada uma reação isotermal através da RPA. Ao buscar o DNA, o oligonucleotídeo iniciador se liga ao DNA para permitir a sua extensão. Por outro lado, quando o alvo é um RNA, é adicionada uma transcriptase reversa à reação de amplificação (RT-RPA), possibilitando a transcrição do DNA complementar (cDNA) a partir do RNA. A dCas9 se liga ao produto amplificado e aumenta o peso molecular na superfície do sensor, sendo medido através da alteração do índice de refração. Como resultados, este trabalho demonstrou que o biosensor mediado por CRISPR é capaz de distinguir os dois patógenos testados em amostras de soro, indicando o potencial diagnóstico desta técnica (Koo et al. 2018).

Com a pandemia do novo coronavírus (SARS-CoV-2), agente causador da COVID19, estratégias de detecção viral foram desenvolvidas com a associação da enzima Cas12. Esses métodos de detecção foram considerados ultrasensíveis por terem um limite de detecção de 10 cópias/ $\mu \mathrm{L}$, rápidos por demorarem cerca de 30 minutos para execução do ensaio, de baixo custo (cerca de 1 a 2 dólares americanos por teste) e portáteis, melhorando a detecção do vírus em campo (Broughton et al. 2020, Lucia et al., 2020).

\subsection{Produção de transgênicos utilizando o complexo CRISPR/Cas}

Um dos maiores problemas relacionados à indústria agrícola global, são os vírus capazes de infectar plantas. Percebendo o potencial do CRISPR para edição gênica, logo surgiram alguns trabalhos buscando utilizar esta ferramenta para produção de transgênicos (Makarova et al. 2018, Eş et al. 2019, Zhan et al. 2019).

Em um trabalho recente, um grupo de pesquisadores reprogramou o sistema CRISPR/Cas9 da bactéria Francisella novicida (FnCas9) com o objetivo de conferir imunidade molecular contra vírus de RNA às plantas (Zhang et al. 2018c). Para verificar a eficiência desta metodologia, foram realizados testes de inibição para o vírus do 
mosaico do tabaco (TMV) e para o vírus do mosaico do pepino (CMV), ambos vírus de RNA fita simples polaridade positiva. Para a realização desta pesquisa, foi construído um vetor pCR01, derivado do plasmídeo pCambia1300, contendo a FnCas9 e o sgRNA desenhado. Posteriormente, foi realizado um experimento no qual se injetou, nas folhas de plantas Nicotiana benthamiana, bactérias contendo o vetor experimental e o vetor controle junto de clones CMV. Os clones CMV foram injetados na parte superior da folha, enquanto que os vetores foram injetados em áreas separadas na parte inferior da folha. Alguns dias após a injeção foram colhidos fragmentos da parte inferior das folhas. Através de RT-qPCR, foi verificado que o sgRNA-FnCas9 foi capaz de inibir o acúmulo do vírus nas regiões injetadas. Para verificar resistência nas folhas de tabaco, foram injetados nas folhas de $N$. benthamiana o vetor experimental e o vetor controle e, um dia depois foi inoculado o CMV. Após duas semanas, as plantas nas quais foram inoculadas o vetor controle apresentaram sintomas típicos da infecção. No entanto, em plantas inoculadas com o vetor experimental não foi observado nenhum sintoma grave relacionado à infecção por CMV.

Além deste experimento, também foi incluído no trabalho um ensaio utilizando TMV-GFP (TMV contendo uma proteína fluorescente, que é expressa quando ocorre a infecção pelo vírus). Para isso, foram desenhados três sgRNA específicos para o TMV, que foram inseridos no pCR01. Uma semana após a inoculação dos vetores, foi observada fluorescência nas plantas controle. Por outro lado, nas plantas previamente inoculadas com o vetor experimental, a fluorescência observada foi significativamente mais fraca.

Os pesquisadores buscaram demonstrar a habilidade do sgRNA-FnCas9 em inibir a infeç̧ão por CMV em plantas transgênicas estáveis. Com este objetivo, o pCR01 específico para CMV foi inserido na planta Arabidopsis. Duas semanas após a inoculação do CMV em plantas controle e plantas que receberam o pCR01, foram observados os sintomas. Nas plantas controle foram observados sintomas severos da infecção, como deformidade da folha e crescimento tardio. Por outro lado, a maior parte das plantas que receberam o pCR01 demonstrou sintomas leves relacionados à infecção. Além disso, foi realizada a quantificação do acúmulo de vírus através de ELISA (Ensaio de Imunoabsorção Enzimática, ou do inglês, Enzyme-Linked Immunosorbent Assay) e de RT-qPCR. Para verificar a ocorrência de herança de resistência, estas plantas foram

WWW.AMPLLAEDITORA.COM.BR (2) 
observadas e testadas até a sexta geração. Com isso, todas as plantas testadas demonstraram resistência ao CMV, sugerindo que o sgRNA-FnCas9 é capaz de gerar plantas resistentes à vírus de RNA (Zhang et al. 2018c).

Outra possível utilização do CRISPR para produção de transgênicos é a produção de novas linhagens de modelos experimentais animais sensíveis à infecções virais para o estudo e avaliação de tratamentos e vacinas. Uma das utilizações mais emblemáticas do CRISPR ocorreu com a pandemia do SARS-CoV-2. No inicio da pandemia, não havia uma grande diversidade de modelos experimentais para esse vírus, principalmente, pois, para que a infecção pelo SARS-CoV-2 ocorra, é necessário que as células do hospedeiro possuam receptores ACE2 parecidos com receptores ACE2 humanos ( $\mathrm{HACE} 2$ ) e grande parte dos modelos experimentais conhecidos não possui receptores ACE2 que são reconhecidos pelo vírus.

Desta forma, foi gerado um modelo experimental de camundongos expressando o hACE2 pela utilização da tecnologia de CRISPR/Cas9. Em comparação com o camundongo selvagem C57BL/6, os camundongos que possuiam o hACE2 apresentaram altas cargas virais no pulmão, traqueia e cérebro, mostrando que essa linhagem pode ser utilizada como modelo experimental para se estudar a infecção causada pelo SARSCoV-2 e também para o tratamento ou avaliação de vacinas (Sun et al., 2020).

\subsection{Possíveis problemas relacionados ao CRISPR e}

\section{perspectivas futuras}

O CRISPR tem se mostrado uma ferramenta muito eficiente para diversos ramos da ciência. Porém, embora ele esteja baseado em um sistema capaz de se ligar especificamente ao alvo de interesse, proporcionando inúmeras possibilidades no campo da terapia, diagnóstico, edição genômica, dentre outros, os pesquisadores ainda acabam por esbarrar em alguns obstáculos.

Buscando explorar alguns dos problemas existentes na utilização do CRISPR, principalmente em relação ao seu uso terapêutico, houve, recentemente, a publicação de um artigo de revisão, no qual são discutidos a forma de entrega do CRISPR ao alvo de interesse, assim como os possíveis efeitos off-target que ocorrem neste sistema. Neste trabalho, fala-se sobre a utilização de vetores virais e não virais para a distribuição do 
CRISPR no alvo e sobre como cada vetor deve ser planejado, levando em consideração as barreiras que podem ser encontradas (Lee \& Kim 2019).

Em relação aos problemas relacionados ao uso de vetores virais, destacam-se: o sistema imune e o tropismo do vetor por uma determinada célula. Por outro lado, um problema para um tipo de vetor não viral é o dano celular causado por eletroporação, restringindo sua aplicação no âmbito terapêutico (Cvetković et al. 2017).

Além dos problemas relacionados aos vetores, também já foi observada ação da resposta imune contra o RNA guia, a Cas9 e a Cas12, o que pode levar à redução da eficiência do CRISPR, dano tecidual por inflamação e até mesmo formação de memória imunológica (Mingozzi et al. 2007, Machitani et al. 2017).

A importância dos efeitos off-target no uso desta ferramenta também deve ser levada em consideração, pois, embora o funcionamento do CRISPR tenha como princípio se ligar à uma sequência de pares de base especificamente, ainda podem ocorrer ligações inespecíficas. Essas ligações inespecíficas podem levar à ocorrência de mutações indel não desejadas, na qual há inserção ou deleção de um nucleotídeo, alterando a proteína a ser produzida por determinado gene, e ao rearranjo cromossômico, uma alteração estrutural do cromossomo, e que pode levar à doenças genéticas e ao desenvolvimento de câncer (Lee \& Kim 2019).

\section{CONSIDERAÇÕES FINAIS}

Diversos aspectos sobre o CRISPR ainda devem ser estudados para que esta ferramenta possa ser utilizada em todo seu potencial, evitando desta forma, possíveis problemas aos seres humanos. Ainda assim, desde seu descobrimento, houve inúmeros avanços com a utilização desta técnica. Dentre os avanços, muitos estão relacionados ao campo de estudo da virologia, área de pesquisa que se mostra extremamente necessária por diversos motivos, como: dificuldades no tratamento de infecções virais; necessidade de desenvolvimento de vacinas; prejuízos agrícolas causados por vírus; fácil ocorrência de mutações no material genético viral; capacidade oncogênica de alguns vírus; necessidade de métodos diagnósticos cada vez mais específicos e sensíveis; além da facilidade de transmissão destes microrganismos através de insetos vetores, principalmente em regiões tropicais, como é o caso do Brasil. 
Deste modo, o complexo CRISPR/Cas pode ser capaz de agregar à pesquisas no campo da virologia, proporcionando novas possibilidades para desenvolvimento de terapias e métodos diagnósticos, além de possibilitar alterações genéticas em insetos vetores e plantas que são parasitadas por vírus.

\section{REFERÊNCIAS}

Bhaya D, Davison M, Barrangou R 2011. CRISPR-Cas Systems in Bacteria and Archaea: Versatile Small RNAs for Adaptive Defense and Regulation. Annu. Rev. Genet. 45: 273-297.

Broughton, James P. et al. CRISPR-Cas12-based detection of SARS-CoV-2. Nature Biotechnology, [S. I.], 2020. DOI: 10.1038/s41587-020-0513-4.

Chen JS, Ma E, Harrington LB, Costa M Da, Tian X, Palefsky JM, Doudna JA 2018. CRISPRCas12a target binding unleashes indiscriminate single-stranded DNase activity. Science (80-. ). 360: 436-439.

Cho SW, Kim S, Kim JM, Kim JS 2013. Targeted genome engineering in human cells with the Cas9 RNA-guided endonuclease. Nat. Biotechnol. 31: 230-232.

Cong Le, Ran FA, Cox D, Lin S, Barretto R, Habib N, Hsu PD, Wu X, Jiang W, Marraffini LA, Zhang F 2013. Multiplex Genome Engineering Using CRISPR/Cas Systems. Science (80-. ).: 819-824.

Cvetković DM, Živanović MN, Milutinović MG, Djukić TR, Radović MD, Cvetković AM, Filipović ND, Zdravković ND 2017. Real-time monitoring of cytotoxic effects of electroporation on breast and colon cancer cell lines. Bioelectrochemistry.

DeFilippis RA, Goodwin EC, Wu L, DiMaio D 2002. Endogenous Human Papillomavirus E6 and E7 Proteins Differentially Regulate Proliferation, Senescence, and Apoptosis in HeLa Cervical Carcinoma Cells. J. Virol.

Doudna JA, Charpentier E 2014. The new frontier of genome engineering with CRISPRCas9. 346.

Eş I, Gavahian M, Marti-Quijal FJ, Lorenzo JM, Mousavi Khaneghah A, Tsatsanis C, Kampranis SC, Barba FJ 2019. The application of the CRISPR-Cas9 genome editing machinery in food and agricultural science: Current status, future perspectives, and associated challenges. Biotechnol. Adv.

Gandhi RT, Zheng L, Bosch RJ, Chan ES, Margolis DM, Read S, Kallungal B, Palmer S, Medvik K, Lederman MM, Alatrakchi N, Jacobson JM, Wiegand A, Kearney M, Coffin JM, Mellors JW, Eron JJ 2010. The effect of raltegravir intensification on low-level residual viremia in HIV-infected patients on antiretroviral therapy: A randomized controlled trial. PLoS Med. 
Garneau JE, Dupuis M-È, Villion M, Romero DA, Barrangou R, Boyaval P, Fremaux C, Horvath P, Magadán AH, Moineau S 2010. The CRISPR/Cas bacterial immune system cleaves bacteriophage and plasmid DNA. Nature 468: 67-71.

Gootenberg JS, Abudayyeh OO, Lee JW, Essletzbichler P, Dy AJ, Joung J, Verdine V, Donghia N, Daringer NM, Freije CA, Myhrvold C, Bhattacharyya RP, Livny J, Regev A, Koonin E V., Hung DT, Sabeti PC, Collins JJ, Zhang F 2017. Nucleic acid detection with CRISPR-Cas13a/C2c2. Science (80-. ).

Guilinger JP, Thompson DB, Liu DR 2014. Fusion of catalytically inactive Cas9 to Fokl nuclease improves the specificity of genome modification. Nat. Biotechnol.

Hu Z, Yu L, Zhu D, Ding W, Wang X, Zhang C, Wang L, Jiang X, Shen H, He D, Li K, Xi L, Ma D, Wang H 2014. Disruption of HPV16-E7 by CRISPR/Cas System Induces Apoptosis and Growth Inhibition in HPV16 Positive Human Cervical Cancer Cells. Biomed Res. Int.

Ishino Y, Shinagawa H, Makino K, Amemura M, Nakatura A 1987. Nucleotide sequence of the iap gene, responsible for alkaline phosphatase isoenzyme conversion in Escherichia coli, and identification of the gene product. J. Bacteriol.

Jinek M, Chylinski K, Fonfara I, Hauer M, Doudna JA, Charpentier E 2012. A Programmable Dual-RNA - Guided. Science (80-. ). 337: 816-822.

Kaminski R, Chen Y, Fischer T, Tedaldi E, Napoli A, Zhang Y, Karn J, Hu W, Khalili K 2016. Elimination of HIV-1 Genomes from Human T-lymphoid Cells by CRISPR/Cas 9 Gene Editing. Sci. Rep.

Kennedy EM, Kornepati AVR, Goldstein M, Bogerd HP, Poling BC, Whisnant AW, Kastan MB, Cullen BR 2014. Inactivation of the Human Papillomavirus E6 or E7 Gene in Cervical Carcinoma Cells by Using a Bacterial CRISPR/Cas RNA-Guided Endonuclease. J. Virol.

Kim MC, Chong YP, Lee SO, Choi SH, Kim YS, Woo JH, Kim SH 2018. Differentiation of Severe Fever with Thrombocytopenia Syndrome from Scrub Typhus. Clin. Infect. Dis.

Koo B, Kim D eun, Kweon J, Jin CE, Kim SH, Kim Y, Shin Y 2018. CRISPR/dCas9-mediated biosensor for detection of tick-borne diseases. Sensors Actuators, B Chem.

Lee M, Kim H 2019. Therapeutic application of the CRISPR system: current issues and new prospects. Hum. Genet.

Lucia, Curti; Federico, Pereyra-Bonnet; Alejandra, Gimenez Carla. An ultrasensitive, rapid, and portable coronavirus SARS-CoV-2 sequence detection method based on CRISPR-Cas12. [S. I.], n. 11, 2020. DOI: 10.1101/2020.02.29.971127.

Machitani M, Sakurai F, Wakabayashi K, Nakatani K, Takayama K, Tachibana M, Mizuguchi H 2017. Inhibition of CRISPR/Cas9-Mediated Genome Engineering by 
a Type I Interferon-Induced Reduction in Guide RNA Expression. Biol. Pharm. Bull. Pharm. Bull.

Makarova SS, Khromov A V., Spechenkova NA, Taliansky ME, Kalinina NO 2018. Application of the CRISPR/Cas System for Generation of Pathogen-Resistant Plants. Biochem.

Mingozzi F, Maus M V., Hui DJ, Sabatino DE, Murphy SL, Rasko JEJ, Ragni M V., Manno CS, Sommer J, Jiang H, Pierce GF, Ertl HCJ, High KA 2007. CD18+ T-cell responses to adeno-associated virus capsid in humans. Nat. Med.

Mojica FJM, Díez-Villaseñor C, García-Martínez J, Soria E 2005. Intervening sequences of regularly spaced prokaryotic repeats derive from foreign genetic elements. $J$. Mol. Evol. 60: 174-182.

Munoz-Jordan JL 2017. Diagnosis of Zika Virus Infections: Challenges and Opportunities. J. Infect. Dis.

Myhrvold C, Freije CA, Gootenberg JS, Abudayyeh OO, Metsky HC, Durbin AF, Kellner MJ, Tan AL, Paul LM, Parham LA, Garcia KF, Barnes KG, Chak B, Mondini A, Nogueira ML, Isern S, Michael SF, Lorenzana I, Yozwiak NL, Maclnnis BL, Bosch I, Gehrke L, Zhang F, Sabeti PC 2018. Field-deployable viral diagnostics using CRISPR-Cas13. Science (80-. ). 360: 444-448.

Neumann E, Schaefer-Ridder M, Wang Y, Hofschneider PH 1982. Gene transfer into mouse lyoma cells by electroporation in high electric fields. EMBO J.

Priyamvada L, Quicke KM, Hudson WH, Onlamoon N, Sewatanon J, Edupuganti S, Pattanapanyasat K, Chokephaibulkit K, Mulligan MJ, Wilson PC, Ahmed R, Suthar MS, Wrammert J 2016. Human antibody responses after dengue virus infection are highly cross-reactive to Zika virus. Proc. Natl. Acad. Sci. U. S. A. 113: 78527857.

Schumann K, Lin S, Boyer E, Simeonov DR, Subramaniam M, Gate RE, Haliburton GE, Ye CJ, Bluestone JA, Doudna JA, Marson A 2015. Generation of knock-in primary human T cells using Cas9 ribonucleoproteins. Proc. Natl. Acad. Sci.

Terns MP, Terns RM 2011. CRISPR-based adaptive immune systems. Curr. Opin. Microbiol. 14: 321-327.

Wang J 2000. From DNA biosensor to gene chips. Nucleic Acids Res.

Wang Q, Zhang B, Xu X, Long F, Wang J 2018. CRISPR-typing PCR (ctPCR), a new Cas9based DNA detection method. Sci. Rep.

Wiedenheft B, Sternberg SH, Doudna JA 2012. RNA-guided genetic silencing systems in bacteria and archaea. Nature 482: 331-338.

Yang L, Guell M, Esvelt KM, DiCarlo JE, Mali P, Norville JE, Aach J, Church GM 2013. RNAGuided Human Genome Engineering via Cas9. Science (80-. ). 339: 823-826. 
Zhan X, Zhang F, Zhong Z, Chen R, Wang Y, Chang L, Bock R, Nie B, Zhang J 2019. Generation of virus-resistant potato plants by RNA genome targeting. Plant Biotechnol. J.

Zhang B, Wang Q, Xu X, Xia Q, Long F, Li W, Shui Y, Xia X, Wang J 2018a. Detection of target DNA with a novel Cas9/sgRNAs-associated reverse PCR (CARP) technique. Anal. Bioanal. Chem.

Zhang B, Xia Q, Wang Q, Xia X, Wang J 2018b. Detecting and typing target DNA with a novel CRISPR-typing PCR (ctPCR) technique. Anal. Biochem.

Zhang T, Zheng Q, Yi X, An H, Zhao Y, Ma S, Zhou G 2018c. Establishing RNA virus resistance in plants by harnessing CRISPR immune system. Plant Biotechnol. J. 


\title{
CAPÍTULO III
}

\section{DETECÇÃO DOS VÍRUS EPSTEIN-BARR, CITOMEGALOVÍRUS E HERPESVÍRUS HUMANO 6 E 7 EM CRIANÇAS E ADOLESCENTES COM DOENÇAS EXANTEMÁTICAS}

\author{
Rafaela Moraes Pereira de Sousa ${ }^{1}$ \\ Jéssica Vasques Raposo ${ }^{2}$ \\ Arthur Daniel Rocha Alves ${ }^{3}$ \\ Claudete Aparecida Araújo Cardoso ${ }^{4}$ \\ Luciane Almeida Amado Leon ${ }^{5}$ \\ Vanessa Salete de Paula ${ }^{6}$

\footnotetext{
${ }^{1}$ Graduanda do curso de Biomedicina. Universidade Federal Fluminense - UFF e Laboratório de Virologia Molecular, Instituto Oswaldo Cruz - FIOCRUZ

${ }^{2}$ Doutoranda em Biologia Parasitária. Laboratório de Virologia Molecular , Instituto Oswaldo Cruz - FIOCRUZ

${ }^{3}$ Doutorando em Medicina Tropical. Laboratório de Desenvolvimento Tecnológico em Virologia, Instituto Oswaldo Cruz - FIOCRUZ

${ }^{4}$ Médica infectologista pediátrica. Departamento Materno-Infantil da Faculdade de Medicina. Universidade Federal Fluminense - UFF

${ }^{5}$ Pesquisadora em Saúde Pública. Laboratório de Desenvolvimento Tecnológico em Virologia, Instituto Oswaldo Cruz - FIOCRUZ

${ }^{6}$ Pesquisadora em Saúde Pública. Laboratório de Virologia Molecular , Instituto Oswaldo Cruz - FIOCRUZ
}

\section{RESUMO}

A prevalência dos Herpesvírus nos casos pediátricos de doenças exantemáticas ainda não é clara no Brasil, e faz-se necessária sua elucidação num contexto em que diversas doenças virais apresentam a mesma sintomatologia (sarampo, rubéola e arboviroses), dificultando o diagnóstico e escolha da abordagem adequada para o tratamento. Neste estudo foi avaliada a infecção pelos vírus Epstein-Barr, Citomegalovírus e Herpesvírus Humano 6 e 7 em crianças e adolescentes com doenças exantemáticas atendidos em dois hospitais públicos de Niterói, Rio de Janeiro, no período de dezembro de 2018 a dezembro de 2019. Amostras de soro de 54 participantes foram analisadas por qPCR multiplex para os Betaherpesvírus e monoplex para o vírus Epstein-Barr. A detecção do DNA viral encontrado foi de $6(11,1 \%)$ para HHV-6; 3 (5,5\%) para HCMV e $2(3,7 \%)$ para o EBV, nenhuma amostra foi positiva para o HHV-7. Entre os participantes infectados, $63,6 \%$ pertenciam ao sexo masculino e a média da faixa etária foi de 2 anos $( \pm 2,3)$. Em $11(20,4 \%)$ dos casos sem etiologia definida foi detectado o DNA viral para um dos Herpesvírus. Os resultados ressaltam a importância do diagnóstico diferencial para doenças exantemáticas sem etiologia definida em crianças e adolescentes.

Palavras-chave: Doenças exantemáticas. Betaherpesvírus. Vírus Epstein-Barr. qPCR. 


\section{INTRODUÇÃO}

Doenças exantemáticas (DE) são caracterizadas pelo surgimento de erupções cutâneas localizadas ou disseminadas, associadas ou não a enantemas, febre, mal-estar, prurido e demais sinais e sintomas sistêmicos (DRAGO et al. 2017). Os vírus Epstein-Barr, Citomegalovírus, Herpesvírus Humano 6, Herpesvírus Humano 7, Chikungunya, Dengue, Parvovírus Humano B19, Rubéola, Sarampo, Varicela e Zika são os principais agentes etiológicos de doenças exantemáticas virais. As DE constituem um grave problema de saúde pública, pois costumam ser a principal causa de procura por atendimento médico em hospitais e clínicas pediátricas (SUGA et al. 1997; MENDELSON et al. 2006; MAGALHÃES et al. 2011).

$\mathrm{O}$ vírus Epstein-Barr (EBV) pertence à subfamília Gammaherpesvirinae e infecta cerca de $90 \%$ dos adultos em todo o mundo. No Brasil, foi encontrada uma soroprevalência de $71 \%$ em crianças e adolescentes de famílias de baixa renda e menor escolaridade (FIGUEIRA-SILVA et al. 2004), fatores socioeconômicos têm influência sobre a aquisição do vírus (BALFOUR et al. 2013). A infecção primária por EBV é usualmente assintomática, mas pode também manifestar-se como mononucleose infecciosa. Após replicação lítica em células epiteliais, o EBV infecta linfócitos B onde um conjunto distinto de genes e transcritos associados à latência são expressos (STANFIELD et al. 2017). A infecção por EBV tem início na mucosa oral. A replicação em células epiteliais é tipicamente lítica, contudo, infecções latentes de células epiteliais podem resultar em carcinoma nasofaríngeo ou câncer. Após a replicação no epitélio, o vírus infecta os linfócitos $B$, onde fatores de crescimento transitório levam à maturação da célula infectada (HENLE et al. 1966; POPE et al. 2009). Grande parte das infecções em crianças são benignas e ocorrem de maneira subclínica, porém quando sintomática, apresenta sinais e sintomas semelhantes a outras doenças do trato respiratório superior, como faringite e amigdalite (NOWALK et al. 2016). A mononucleose infecciosa foi inicialmente descrita em 1889 por Pfeiffer como "febre glandular" e em seguida denominada de "doença do beijo". Trata-se de uma doença de baixa mortalidade e letalidade, de manifestações agudas e geralmente benignas, apresentando um grande espectro clínico, porém, pode resultar em casos graves quando acomete indivíduos 
imunocomprometidos ocasionando potencialmente elevada morbidade (DUNMIRE et al. 2015).

O Citomegalovírus Humano (HCMV), o Herpesvírus Humano 6 (HHV-6) e o Herpesvírus Humano 7 (HHV-7) pertencem à subfamília Betaherpesvirinae. Os vírus classificados dentro desta subfamília têm como principais características um número restrito de hospedeiros, são citomegálicos, apresentam crescimento lento e infecções latentes nas glândulas secretórias, nos rins e outros tecidos (REZAEI et al. 2016). São vírus de fácil transmissão entre crianças no período pré-escolar (creches) e escolar por via oral (secreções salivares) e a transmissão por transplantes de órgãos já foi observada (LE et al. 2013; MOCARSKI 2004; POTENA et al. 2007). As infeç̧ões causadas pelo HCMV demonstram alta prevalência no mundo todo, em crianças de 1 a 5 anos, pode ser baixa $(20,7 \%)$, mas em adultos de países em desenvolvimento se aproxima de 100\% (DIOVERTI et al. 2016). No Brasil foi encontrada uma soroprevalência para o HCMV de 96,4\% em estudo com doadores de sangue (SOUZA et al. 2010). O HCMV é transmitido amplamente através da saliva, sangue, secreções genitais, urina e leite materno (TRAVAN et al. 2016). Após a primo-infecção, geralmente assintomática ou como uma síndrome semelhante à mononucleose infecciosa, o HCMV pode estabelecer latência celular em monócitos e linfócitos, permanecendo no hospedeiro durante sua vida, com possibilidade de ser reativado (IIDA et al. 2016). No entanto, são nos indivíduos imunodeprimidos que este vírus causa doença clínica significativa e, ocasionalmente, pode levar à morte se não tratada (DRAGO et al. 2014; SUN et al. 2015; SAI TIN et al. 2015; ADAMSON-SMALL et al. 2016). Embora exista tratamento com o fármaco ganciclovir, o tratamento não representa uma cura para a infecção latente do HCMV (DRAGO et al. 2015).

O HHV-6 e HHV-7 pertencem ao gênero Roseolovirus, são linfotrópicos (embora possam infectar outros tipos celulares), altamente prevalentes e associados a doenças exantemáticas (TANAKA et al. 1994; TOMOIU et al. 2006). Reativações são intrinsecamente relacionadas ao estado imunológico do indivíduo, sendo comuns em pacientes imunodeprimidos. A infecção pelo HHV-6 usualmente ocorre de maneira assintomática na infância, e pode resultar em quadros de febre alta, diarreia, prurido e exantema súbito (ES). Estudos mostram que $95 \%$ dos adultos possuem sorologia positiva para HHV-6 (FREITAS et al. 1997; DE BOLLE 2005). Aos dois anos de idade, oito em cada

WWW.AMPLLAEDITORA.COM.BR $(2)$

CONTATO@AMPLLAEDITORA.COM.BR 
dez crianças já entraram em contato com o vírus, com pico de incidência entre 9 e 21 meses de idade (CLARK et al., 2002). Embora de uma forma mais rara, essa infecção também pode causar convulsões febris e encefalite (ABLASHI et al. 2014 ONGRÁDI et al. 2017). No ES, ocorre febre alta nos primeiros 3 a 4 dias. Metade das crianças cursa com temperatura acima de $40^{\circ} \mathrm{C}$, que é uma das principais causas de convulsão febril. Após o declínio da febre, as erupções cutâneas aparecem, iniciando-se no tronco ou região cervical e disseminando-se para as extremidades.

O HHV-7 foi isolado pela primeira vez em 1990 de linfócitos TCD4+ por Frenkel e colaboradores. É um vírus ubíquo com tropismo mais seletivo por células TCD4+, sendo este o seu receptor. O HHV-7 pode ser observado em pele, glândulas salivares e outros tecidos, assim como outros Betaherpesvírus (AGUT et al. 2017). O HHV-7 é transmitido pela saliva, e alguns estudos apontam o aleitamento materno como uma potencial via de transmissão (FUJISAKI et al. 1998). A prevalência deste vírus é bem alta, acima de $90 \%$ na população adulta (BENITO et al. 2003). A infecção primária por HHV-7 pode ser assintomática, assim como para o HHV-6, mas já foi relatada sua associação a doenças exantemáticas febris no Brasil (OLIVEIRA et al. 2003; FREITAS et al. 2004) e em casos mais raros de encefalites e convulsões (embora menos documentadas). A infecção em crianças ocorre gradualmente até quinto ou sexto ano de vida. No Reino Unido a maioria dos casos de infecção por HHV-7 avaliada ocorreram aos 3 anos de idade (WARD et al. 2005), e no Brasil casos mais precoces (<1 ano) já foram relatados (OLIVEIRA et al. 2003).

As infecções causadas por Herpesvírus são muitas vezes assintomáticas, benignas e autolimitadas, sendo a capacidade de permanecer em latência no hospedeiro uma característica intrínseca a todos os integrantes da família Herpesviridae. Em consonância com a latência viral, é esperada maior gravidade e reativações das infecções herpéticas em pacientes imunossuprimidos, em faixas etárias específicas como infância e senilidade, assim como durante a gravidez. Nos casos graves e não tratados, as infecções por Herpesvírus podem levar o paciente ao óbito. O número elevado de agentes etiológicos é um desafio para o diagnóstico exato, e consequentemente para escolha adequada do tratamento do paciente com doença exantemática. No contexto brasileiro em que diversos vírus emergentes como o vírus Dengue, Chikungunya e Zika e a crescente elevação no número de casos de Sarampo demandam a devida atenção dos órgãos públicos de saúde, as infecções herpéticas são

WWW.AMPLLAEDITORA.COM.BR (2)

CONTATO@AMPLLAEDITORA.COM.BR 
subestimadas e pouco diagnosticadas, afetando diretamente a saúde do paciente. Apesar da maioria dessas doenças serem benignas e autolimitadas, algumas representam um risco importante para certos grupos etários e situações clínicas específicas, uma vez que podem evoluir com curso clínico mais grave. Por isso, é de grande importância averiguar o diagnóstico etiológico que pode estar implicado nas doenças exantemáticas virais, a fim de garantir um tratamento adequado e estabelecer as medidas necessárias para o controle da doença.

\section{METODOLOGIA}

\subsection{Desenho do estudo}

Trata-se de estudo de corte transversal, aprovado pelo Comitê de Ética em Pesquisa da Fundação Oswaldo Cruz (Fiocruz) e da Universidade Federal Fluminense (UFF), com CAAE 80635017.4.3001.5243 e número de aprovação 3.020.225. Foram incluídos no estudo 54 crianças e adolescentes, com idades entre 0 a 18 anos, atendidos no Hospital Getúlio Vargas Filho (HGVF) e Hospital Universitário Antônio Pedro da Universidade Federal Fluminense (HUAP-UFF), ambos na cidade de Niterói-RJ, no período de dezembro de 2018 a dezembro de 2019. A amostra foi obtida por conveniência, sendo incluídos soros de participantes que apresentaram doenças exantemáticas sem etiologia definida. Responsáveis e pacientes que concordaram em participar do estudo foram entrevistados pessoalmente por profissionais treinados, assinaram os termos de consentimento e assentimento livre e esclarecido, respectivamente, e preencheram seus dados em um questionário epidemiológico para posterior coleta de sangue. Amostras com volume inferior a $200 \mathrm{uL}$ foram excluídas. Os Herpesvírus HCMV, EBV, HHV-6 e HHV-7 foram testados por meio da técnica de PCR em tempo real, e os resultados foram disponibilizados em formulários impressos e encaminhados para o arquivo do paciente nos hospitais correspondentes.

\subsection{Amostras de soro}

As amostras foram coletadas e processadas na unidade de origem (HUAP-UFF ou HGVF). Os participantes eram encaminhados para coleta de sangue, realizada por profissionais do próprio hospital. Após a coleta, a amostra de sangue era encaminhada 
ao laboratório de análises clínicas da unidade, onde foi centrifugada a 2500xg por 15 minutos a temperatura ambiente para a obtenção do soro. As amostras de soro obtidas foram armazenadas a uma temperatura de $-20^{\circ} \mathrm{C}$ até o transporte para unidade destinatária. As amostras biológicas foram acondicionadas, rotuladas, etiquetadas e transportadas para o Laboratório de Virologia Molecular no Instituto Oswaldo Cruz de acordo com as recomendações da Agência Nacional de Vigilância Sanitária para substâncias biológicas de categoria B (UN 3373).

\subsection{Extração de ácidos nucléicos}

O DNA viral foi extraído utilizando o kit comercial High Pure Viral Nucleic Acid Kit (Roche, New Jersey, EUA) para as amostras de soro, de acordo com o protocolo do fabricante. As amostras extraídas foram armazenadas a $-70^{\circ} \mathrm{C}$ até o processamento.

\section{4. $\quad$ PCR em tempo real (qPCR) multiplex e monoplex}

O EBV foi detectado e quantificado através de PCR em tempo real (qPCR) e os Betaherpesvírus (HCMV, HHV-6 e HHV-7) através de qPCR multiplex (RAPOSO et al. 2019). Para amplificação do HCMV, HHV-6 e HHV-7 foram utilizadas sondas e oligonucleotídeos específicos para a região UL54 (referente a síntese de DNA, com 130bp), região U56 (referente ao capsídeo viral, com 150 bp) e para região U37 (referente ao tegumento do vírus, com 312 bp), respectivamente. A detecção e quantificação do EBV foi realizada por qPCR monoplex (FELLNER et al. 2014), utilizando oligonucleotídeos e sonda para a região alvo EBNA-1, referente ao antígeno nuclear EB (100 bp). Iniciadores (oligonucleotídeos) e sondas TaqMan são apresentados na tabela 1.

Tabela 1. Sequências de oligonucleotídeos e sondas utilizadas para qPCR.

\begin{tabular}{|c|c|c|c|c|}
\hline & HCMV UL54 (5'-3') & HHV-6 U56 (5'-3') & HHV-7 U37 (5'-3') & EBV EBNA-1 $\left(5^{\prime}-3^{\prime}\right)$ \\
\hline Sonda & \begin{tabular}{l}
\multicolumn{1}{c}{ FAM- } \\
CCGTATTGGTGCGCGATC \\
TGTTCAA
\end{tabular} & $\begin{array}{l}\text { VIC- } \\
\text { TTAGATGGTGGTGAGCTGG } \\
\text { GATCGGT }\end{array}$ & \begin{tabular}{l}
\multicolumn{1}{c}{ NED- } \\
CTCGCAGATTGCTTGTTG \\
GCCATG
\end{tabular} & \begin{tabular}{l}
\multicolumn{1}{c}{ FAM- } \\
TGCAGCTTTGACGAT \\
GG
\end{tabular} \\
\hline $\begin{array}{l}\text { Oligonucleotí } \\
\text { deos (Senso) }\end{array}$ & $\begin{array}{l}\text { GGCCGTTACTGTCTGCAG } \\
\text { GA }\end{array}$ & $\begin{array}{l}\text { AAAGACCTAAATTGCCGCTA } \\
\text { СCT }\end{array}$ & $\begin{array}{l}\text { CGGAAGTCACTGGAGTAA } \\
\text { TGACAA }\end{array}$ & $\begin{array}{l}\text { CCGCTCCTACCTGCAA } \\
\text { TATCA } 3\end{array}$ \\
\hline $\begin{array}{l}\text { Oligonucleotí } \\
\text { deos } \\
\text { (Anti-senso) }\end{array}$ & $\begin{array}{l}\text { GGCCTCGTAGTGAAAATT } \\
\text { AATGGT }\end{array}$ & $\begin{array}{l}\text { GCAAGCTCATGAACATCGTC } \\
\text { A }\end{array}$ & $\begin{array}{l}\text { CCAATCCTTCCGAAACCG } \\
\text { AT }\end{array}$ & $\begin{array}{l}\text { GGAAACCAGGGAGG } \\
\text { CAAATC }\end{array}$ \\
\hline
\end{tabular}

Fonte: Autoria própria. 


\section{5. $\quad$ qPCR multiplex para Betaherpesvírus}

O kit AgPath-ID PCR (Life Technologies, Carlsbad, EUA) foi utilizado para realização da qPCR. Foi preparado um mix com volume final de $25 \mu \mathrm{L}$, contendo $12,5 \mu \mathrm{L}$ de PCR Buffer 1x, 0,4 $\mu \mathrm{L}$ de oligonucleotídeos senso ( $3 \mu \mathrm{M})$ e 0,4 $\mu \mathrm{L}$ de oligonucleotídeos anti-senso (3 $\mu \mathrm{M})$ (HCMV/HHV-6/HHV-7) simultaneamente, além de 0,4 $\mu \mathrm{L}$ de sonda específica $(0,4 \mu \mathrm{M})$ para cada um dos Betaherpesvírus e $1 \mu \mathrm{L}$ da enzima 25x, por amostra testada. O volume de DNA incluído na reação foi de $5 \mu \mathrm{L}$, $1 \mathrm{uL}$ da curva sintética padrão $\left(10^{1}-10^{8}\right.$ cópias $\left./ \mu \mathrm{L}\right)$ para cada vírus e controles negativos também foram utilizados para quantificação absoluta das cargas virais (Raposo et al., 2019)

\section{6. $\quad$ qPCR monoplex para EBV}

A reação foi preparada utilizando o kit AgPath-ID PCR (Life Technologies, Carlsbad, EUA), o mix com volume final de $25 \mu \mathrm{L}$, continha $12,5 \mu \mathrm{L}$ de PCR Buffer $1 \mathrm{x}, 2,5$ $\mu \mathrm{L}$ de oligonucleotídeos senso $(1 \mu \mathrm{M}), 2,5 \mu \mathrm{L}$ de oligonucleotídeos anti-senso $(1 \mu \mathrm{M}), 2$ $\mu \mathrm{L}$ de sonda específica $(0,4 \mu \mathrm{M})$ e $1 \mu \mathrm{L}$ da enzima $1 x$ para qPCR por amostra. O volume de DNA incluído na reação foi de $5 \mu \mathrm{L}, 1 \mu \mathrm{L}$ da curva sintética padrão $\left(10^{1}-10^{8}\right.$ cópias $\left./ \mu \mathrm{L}\right)$ EBV-curva

(5’TTCGTGGAAACCAGGGAGGCAAATCCGTATCCATCGTCAAAGCTGCAATGCGTTGATATTG CAGGTAGGAGCGGCTGATA 3') e controles negativos também foram utilizados.

\section{RESULTADOS E DISCUSSÃO}

Foram incluídos neste estudo 54 participantes, com idade média de 1,95 $\pm 2,3$ anos, sendo $34(63,6 \%)$ do sexo masculino. Onze $(20,37 \%)$ amostras foram positivas para um dos Herpesvírus avaliados. O HHV-6 foi o vírus mais prevalente, sendo detectado em $6(11,11 \%)$ das 54 amostras, seguido pelo HCMV que foi detectado em 5,5\% (3/11) e o EBV detectado em 3,7\% (2/11) das amostras. O HHV-7 não foi detectado em nenhuma das amostras. A distribuição da detecção dos herpesvírus, assim como a média da carga viral de cada vírus, está descrita na tabela 2. Os exantemas foram observados em todos os pacientes incluídos no estudo, o local de início e a progressão das lesões foram avaliadas nos pacientes positivos e descritos na tabela 3. No momento da entrevista foram relatados os sinais e sintomas dos pacientes. Os sinais e sintomas mais

WWW.AMPLLAEDITORA.COM.BR (2)

CONTATO@AMPLLAEDITORA.COM.BR M 
prevalentes entre os pacientes infectados foram febre $(81,8 \%)$, prurido $(36,4 \%)$, diarreia $(27,3 \%)$, cefaleia, náuseas, vômito e mialgia $(18,2 \%)$ e linfadenomegalia $(9,1 \%)$.

Tabela 2. Prevalência e carga viral média para EBV, HCMV, HHV-6 e HHV-7 nos casos de doenças exantemáticas.

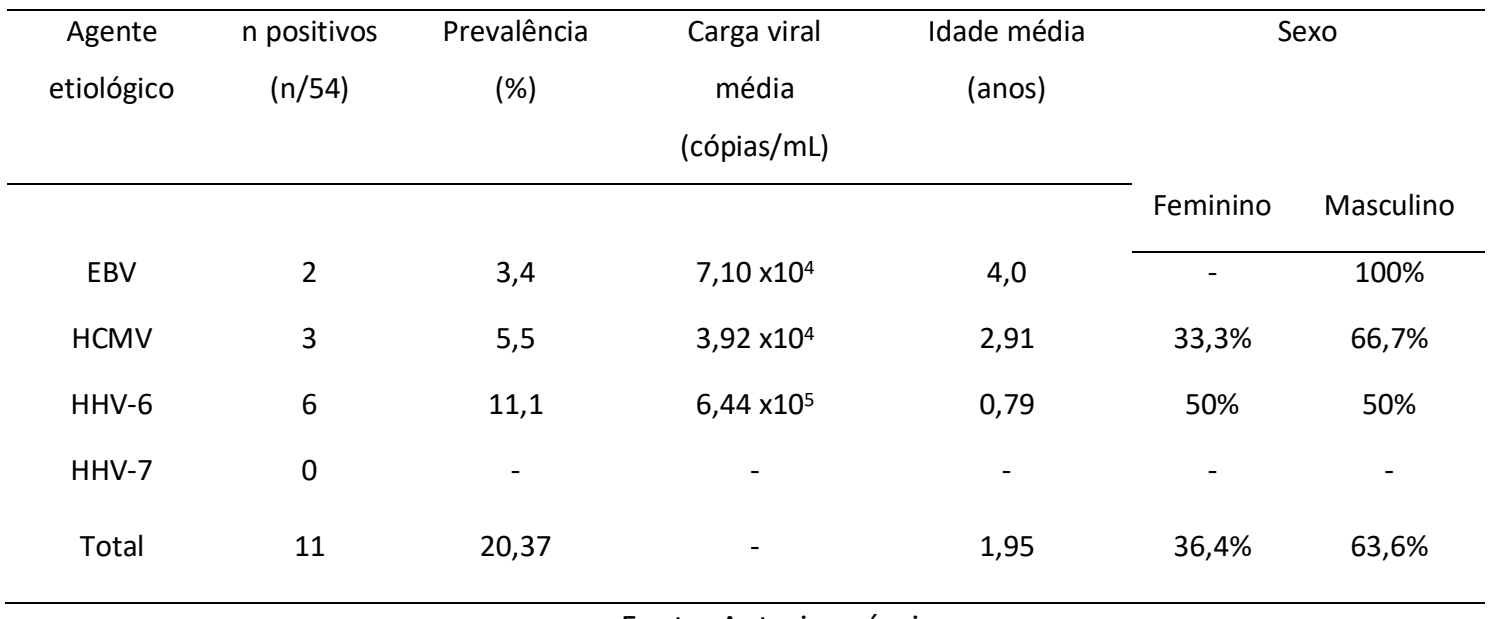

Fonte: Autoria própria.

Tabela 3. Características dos exantemas nos pacientes positivos para EBV, HCMV e HHV-6.

\begin{tabular}{|c|c|c|c|}
\hline $\begin{array}{c}\text { Agente } \\
\text { etiológico }\end{array}$ & $\begin{array}{c}\text { Dias com exantema } \\
\text { (média) }\end{array}$ & Início do exantema & Progressão do exantema \\
\hline \multirow[t]{2}{*}{$\operatorname{EBV}(n=2)$} & $>2$ dias & $\mathbf{5 0 \%}$ Difuso pelo corpo & $\mathbf{5 0 \%}$ Difuso pelo corpo \\
\hline & & $\mathbf{5 0 \%}$ Membros inferiores & $50 \%$ Tronco \\
\hline \multirow[t]{2}{*}{$\operatorname{HCMV}(n=3)$} & $>1$ dia & 33,3\% Cabeça/Pescoço & $100 \%$ Difuso pelo corpo \\
\hline & & $66,7 \%$ Tronco & \\
\hline \multirow[t]{2}{*}{ HHV-6 $(n=6)$} & $>2$ dias & 66,7\% Cabeça/Pescoço & $100 \%$ Difuso pelo corpo \\
\hline & & $33,3 \%$ Tronco & \\
\hline
\end{tabular}

Fonte: Autoria própria.

Este trabalho pesquisou simultaneamente todos os betaherpesvírus e o vírus Epstein-Barr em casos pediátricos de doenças exantemáticas, não foi encontrado na literatura outro artigo que avaliasse todos os mesmos Herpesvírus para DE em uma população infantil e infanto-juvenil. Dos 11 pacientes positivos para um dos Herpesvírus, 3 receberam diagnóstico clínico no momento da coleta. Um dos pacientes foi diagnosticado como infecção por HHV-6, e o diagnóstico molecular confirmou a presença do HHV-6 na amostra de soro. Contudo, dois pacientes foram diagnosticados por vínculo epidemiológico e apresentação clínica com infecção por vírus Chikungunya 
e Sarampo, respectivamente, mas o diagnóstico molecular detectou a presença dos vírus Epstein-Barr e HHV-6. Evidenciando a importância do diagnóstico diferencial e laboratorial em pacientes com doença exantemática. A detecção qualitativa dos Herpesvírus em soro é considerada suficiente para diagnosticar a infecção (GÄRTNER et al. 2010; AGUT et al. 2015), no entanto, uma carga viral elevada tem sido relacionada a maior gravidade da infecção nos casos pediátricos de ES (ASANO et al. 1991). No nosso estudo, as cargas virais médias observadas para o EBV e HCMV foram maiores que 70.000 e 30.000 cópias $/ \mathrm{mL}$, respectivamente, e para o HHV-6 maior que 600.000 cópias/mL.

Este é o primeiro trabalho que retrata as cargas virais de herpesvírus em pacientes com doenças exantemáticas. As cargas virais foram consideradas altas em comparação as amostras de tecidos de doadores que detectaram cargas entre $10^{2}-10^{3}$ cópias/ug para HHV-6 e EBV (SECCHIERO et al. 1995; CUI et al. 2020), e em soro de recém nascidos, $10^{3}-10^{4}$ cópias/ $\mu \mathrm{L}$ de HCMV (SCHÄFER et al. 1996).

Os pacientes positivos para EBV não apresentaram sintomas associados ao exantema, exceto um paciente com linfadenomegalia. O exantema iniciou-se disseminado ou nos membros inferiores, progrediu espalhando-se por todo o corpo. A mononucleose infecciosa por EBV com surgimento de exantemas e febre, embora seja mais comum em adolescentes e jovens adultos, pode ser vista também em crianças (MUZUMDAR et al. 2019). Pacientes positivos para HCMV apresentaram febre (100\%), cefaleia, prurido e náuseas (66,6\%); vômitos, mialgia e diarreia (33,3\%). Os exantemas surgiram nas regiões do tronco e da cabeça, progredindo de maneira disseminada pelo corpo.

O Herpesvírus Humano 6 obteve a maior frequência de detecção entre os três Herpesvírus avaliados, contudo, não foi possível fazer a comparação com outros trabalhos no Brasil e no mundo, pois a maioria dos trabalhos que analisam doenças exantemáticas fez apenas a detecção sorológica. Em 2008, Vianna e colaboradores encontraram uma soroprevalência de 43,5\% para HHV-6 de um total de 223 amostras, na cidade de Niterói-RJ, com febre $(93,8 \%)$ e exantema disseminado $(90,7 \%)$ na maioria dos casos. O perfil de sintomas associados a infecção por HHV-6 encontrado no atual estudo conteve febre (100\%), prurido e diarreia (33,3\%); mialgia e vômitos (16,6\%) corroborando com os achados de Vianna e colaboradores. A maioria dos exantemas

WWW.AMPLLAEDITORA.COM.BR (2)

CONTATO@AMPLLAEDITORA.COM.BR 
$(66,7 \%)$ nas infecções por HHV-6 teve início na cabeça ou pescoço e progrediu para todo o corpo de maneira difusa, confirmando a descrição encontrada na literatura. Em nosso estudo o HHV-7 não foi detectado, contudo Magalhães e col. em 2011, por meio da técnica de Nested PCR, o detectou em 6,4\% (9/141) de casos de DE em crianças (<4 anos). As diferenças encontradas na prevalência do HHV-6 e na ausência de detecção do HHV-7 pode ter relação com número amostral maior utilizado nos estudos de 2008 e 2011, outro ponto relevante foi a triagem das amostras analisadas, pois ambos estudos excluíram amostras previamente positivas para sarampo, rubéola, dengue e parvovírus B19 no diagnóstico sorológico, diferente do nosso estudo que incluiu todos os pacientes exantemáticos, sem diagnóstico etiológico prévio. A idade média encontrada para HHV$6(0,79), \operatorname{HCMV}(2,91)$ e $\operatorname{EBV}(4,0)$ refletem os dados relatados na literatura, a infeç̧ão por HHV-6 foi observada na maioria dos casos entre 6 meses e 3 anos em um estudo na França (AGUT et al. 2017), o HCMV pode acometer crianças logo em seus primeiros anos de vida (1 a 5 anos), devido a sua capacidade de transmissão por diferentes fluídos e alta prevalência na população adulta, podendo ocorrer também a infecção congênita durante a gravidez ou parto (DIOVERTI et al. 2016), na China foi relatada idade mediana de 6 anos, com picos entre 4 e 6 anos para o EBV (GAO et al. 2011). É comum para o EBV a ocorrência da infecção em uma faixa etária juvenil, por contato com secreções salivares durante o beijo, porém o compartilhamento de objetos e alimentos entre crianças pode ser uma via de transmissão, embora ainda não confirmada (DUNMIRE et al. 2018).

\section{CONCLUSÕES}

A deteç̧ão do EBV, HCMV, HHV-6 e 7 foi possível por meio da qPCR, demonstrando a importância do diagnóstico molecular na identificação do agente etiológico em casos de $\mathrm{DE}$ em pacientes pediátricos com etiologia não definida. A prevalência encontrada para os Herpesvírus ressalta a importância do diagnóstico diferencial destas infecções diante das doenças exantemáticas, não apenas para fins epidemiológicos, mas também para o manejo adequado do paciente. 


\section{AGRADECIMENTOS}

Gostaria de agradecer ao apoio financeiro realizado pelo CNPq e pela CAPES. As instituições participantes desta pesquisa, a Fundação Oswaldo Cruz, a Universidade Federal Fluminense e as equipes do Hospital Getúlio Vargas Filho e Hospital Universitário Antônio Pedro. Aos autores e colaboradores, pela orientação durante o desenvolvimento do estudo.

\section{REFERÊNCIAS}

Ablashi, Dharam, Henri Agut, Roberto Alvarez-Lafuente, Duncan A. Clark, Stephen Dewhurst, Dario DiLuca, Louis Flamand, et al. 2014. "Classification of HHV-6A and HHV-6B as Distinct Viruses". Archives of Virology 159 (5): 863-70. https://doi.org/10.1007/s00705-013-1902-5. Acesso em: Novembro de 2020.

Adamson-Small, Laura A, e Blanca Haydé Ruiz-Ordaz. 2016. "Hepatic Inflammation Resulting from Localized, Subcutaneous Expression of Parvovirus VP1u Capsid Protein: Importance and Implication". Virulence 7 (2): 70-71. https://doi.org/10.1080/21505594.2016.1141163. Acesso em: Novembro de 2020.

Agut, H., P. Bonnafous, e A. Gautheret-Dejean. 2017. “Update on Infections with Human Herpesviruses 6A, 6B, and 7". Médecine et Maladies Infectieuses 47 (2): 83-91. https://doi.org/10.1016/j.medmal.2016.09.004. Acesso em: Novembro de 2020.

Agut, Henri, Pascale Bonnafous, e Agnès Gautheret-Dejean. 2015. "Laboratory and Clinical Aspects of Human Herpesvirus 6 Infections". Clinical Microbiology Reviews 28 (2): 313-35. https://doi.org/10.1128/CMR.00122-14. Acesso em: Novembro de 2020.

Asano, Yoshizo, Toshihiko Nakashima, Tetsushi Yoshikawa, Sadao Suga, e Takehiko Yazaki. 1991. "Severity of Human Herpesvirus-6 Viremia and Clinical Findings in Infants with Exanthem Subitum". The Journal of Pediatrics 118 (6): 891-95. https://doi.org/10.1016/S0022-3476(05)82200-0. Acesso em: Novembro de 2020.

Balfour, Henry H., Frangiscos Sifakis, Joseph A. Sliman, Jennifer A. Knight, David O. Schmeling, e William Thomas. 2013. “Age-Specific Prevalence of Epstein-Barr Virus Infection Among Individuals Aged 6-19 Years in the United States and Factors Affecting Its Acquisition". The Journal of Infectious Diseases 208 (8): 1286-93. https://doi.org/10.1093/infdis/jit321. Acesso em: Novembro de 2020.

Benito, Natividad, Asunción Moreno, Tomás Pumarola, e M. ${ }^{a}$ Ángeles Marcos. 2003. "Virus del herpes humano tipo 6 y tipo 7 en receptores de trasplantes". 
Enfermedades Infecciosas y Microbiología Clínica 21 (8): 424-32. https://doi.org/10.1016/S0213-005X(03)72980-2. Acesso em: Novembro de 2020.

Clark, Duncan A. 2002. "Human Herpesvirus 6 and Human Herpesvirus 7: Emerging Pathogens in Transplant Patients". International Journal of Hematology 76 Suppl 2 (agosto): 246-52. https://doi.org/10.1007/BF03165124. Acesso em: Novembro de 2020.

Cui, Aili, Shulei Wang, Qiang Zhang, Huiling Wang, Zhen Zhu, Aqian Li, Qinqin Song, et al. 2020. "Development of a Multiplex One-Step Real-Time RT-PCR Assay for the Simultaneous Detection of Eight Viruses Associated with Febrile Rash Illnesses". Biosafety and Health 2 (2): 89-94. https://doi.org/10.1016/j.bsheal.2020.04.003. Acesso em: Novembro de 2020.

De Bolle, Leen, Lieve Naesens, e Erik De Clercq. 2005. “Update on Human Herpesvirus 6 Biology, Clinical Features, and Therapy". Clinical Microbiology Reviews 18 (1): 217-45. https://doi.org/10.1128/CMR.18.1.217-245.2005. Acesso em: Novembro de 2020.

Dioverti, M. Veronica, e Raymund R. Razonable. 2016. "Cytomegalovirus". Microbiology Spectrum 4 (4). https://doi.org/10.1128/microbiolspec.DMIH2-0022-2015. Acesso em: Novembro de 2020.

Drago, Francesco, Giulia Ciccarese, Francesco Broccolo, Emanuele Cozzani, e Aurora Parodi. 2015. "Pityriasis Rosea in Children: Clinical Features and Laboratory Investigations". Dermatology $231 \quad$ (1): https://doi.org/10.1159/000381285. Acesso em: Novembro de 2020.

Drago, Francesco, Giulia Ciccarese, Giulia Gasparini, Ludovica Cogorno, Sanja Javor, Antonio Toniolo, e Francesco Broccolo. 2017. "Contemporary Infectious Exanthems: An Update". Future Microbiology 12: 171-93. https://doi.org/10.2217/fmb-2016-0147. Acesso em: Novembro de 2020.

Drago, Francesco, Giulia Ciccarese, e Alfredo Rebora. 2014. "Exanthems Associated with Parvovirus B19 Infection in Adults". Journal of the American Academy of Dermatology 71 (6): 1256. https://doi.org/10.1016/j.jaad.2014.07.063. Acesso em: Novembro de 2020.

Dunmire, Samantha K., Kristin A. Hogquist, e Henry H. Balfour. 2015. "Infectious Mononucleosis". Current topics in microbiology and immunology 390: 211-40. https://doi.org/10.1007/978-3-319-22822-8_9. Acesso em: Novembro de 2020.

Dunmire, Samantha K., Priya S. Verghese, e Henry H. Balfour. 2018. "Primary EpsteinBarr Virus Infection". Journal of Clinical Virology 102 (maio): 84-92. https://doi.org/10.1016/j.jcv.2018.03.001. Acesso em: Novembro de 2020. 
Fellner, María Dolores, Karina Durand, Marcelo Rodriguez, Lucía Irazu, Virginia Alonio, e María Alejandra Picconi. 2014. “Duplex Realtime PCR Method for Epstein-Barr Virus and Human DNA Quantification: Its Application for Post-Transplant Lymphoproliferative Disorders Detection". The Brazilian Journal of Infectious Diseases 18 (3): 271-80. https://doi.org/10.1016/j.bjid.2013.07.011. Acesso em: Novembro de 2020.

Figueira-Silva, Cecília M., e Fausto E.L. Pereira. 2004. "Prevalence of Epstein-Barr Virus Antibodies in Healthy Children and Adolescents in Vitória, State of Espírito Santo, Brazil". Revista Da Sociedade Brasileira de Medicina Tropical 37 (5): 409-12. https://doi.org/10.1590/S0037-86822004000500008. Acesso em: Novembro de 2020.

Freitas, R. B. de, e A. C. Linhares. 1997. "Prevalence of Human Herpesvirus 6 Antibody in the Population of Belém, Pará, Northern Brazil". Transactions of the Royal Society of Tropical Medicine and Hygiene 91 (5): 538-40. https://doi.org/10.1016/s00359203(97)90016-x. Acesso em: Novembro de 2020.

Freitas, Ronaldo B., Maria R. Freitas, Consuelo S. Oliveira, e Alexandre C. Linhares. 2004. "Human Herpesvirus-7 as a Cause of Exanthematous Ilnesses in Belém, Pará, Brazil". Revista Do Instituto de Medicina Tropical de São Paulo 46 (3): 139-43. https://doi.org/10.1590/S0036-46652004000300004. Acesso em: Novembro de 2020.

Fujisaki, H., K. Tanaka-Taya, H. Tanabe, T. Hara, H. Miyoshi, S. Okada, e K. Yamanishi. 1998. "Detection of Human Herpesvirus 7 (HHV-7) DNA in Breast Milk by Polymerase Chain Reaction and Prevalence of HHV-7 Antibody in Breast-Fed and Bottle-Fed Children". Journal of Medical Virology 56 (3): 275-79. https://doi.org/10.1002/(sici)1096-9071(199811)56:3<275::aid-jmv17>3.0.co;2d. Acesso em: Novembro de 2020.

Gao, Li-Wei, Zheng-De Xie, Ya-Yi Liu, Yan Wang, e Kun-Ling Shen. 2011. "Epidemiologic and Clinical Characteristics of Infectious Mononucleosis Associated with EpsteinBarr Virus Infection in Children in Beijing, China". World Journal of Pediatrics 7 (1): 45-49. https://doi.org/10.1007/s12519-011-0244-1. Acesso em: Novembro de 2020.

Gärtner, Barbara, e Jutta K. Preiksaitis. 2010. "EBV Viral Load Detection in Clinical Virology". Journal of Clinical Virology 48 (2): 82-90. https://doi.org/10.1016/j.jcv.2010.03.016. Acesso em: Novembro de 2020.

Henle, G., e W. Henle. 1966. "Immunofluorescence in Cells Derived from Burkitt's Lymphoma". Journal of Bacteriology 91 (3): 1248-56. https://doi.org/10.1128/JB.91.3.1248-1256.1966. Acesso em: Novembro de 2020. 
lida, Tomoya, Shuji Satoh, Suguru Nakagaki, Haruo Shimizu, e Hiroyuki Kaneto. 2016. "Autoimmune Hemolytic Anemia Triggered by Infection with Human Parvovirus B19 after Total Abdominal Colectomy for Ulcerative Colitis". Internal Medicine 55 (março): 677-81. https://doi.org/10.2169/internalmedicine.55.5657. Acesso em: Novembro de 2020.

Lee, Deborah, Jeong Nan Kang, Sung Hwan Hwang, Young Suk Lee, Hyojin Kim, Jong Keun Seo, e Ho Suk Sung. 2014. "Acute Generalized Exanthematous Pustulosis Induced by Parvovirus B19 Infection". Annals of Dermatology 26 (3): 399-400. https://doi.org/10.5021/ad.2014.26.3.399. Acesso em: Novembro de 2020.

Magalhães, Ivna de Melo, Rebeca Vasquez Novo Martins, Renata Oliveira Vianna, Solange Artimos Oliveira, e Silvia Maria Baeta Cavalcanti. 2011. "Diagnosis of Human Herpesvirus 6B Primary Infection by Polymerase Chain Reaction in Young Children with Exanthematic Disease". Revista Da Sociedade Brasileira de Medicina Tropical 44 (3): 306-8. https://doi.org/10.1590/S003786822011005000021. Acesso em: Novembro de 2020.

McKeown, Emily, Janet E. Pope, e Suzanne Leaf. 2009. "Epstein-Barr Virus (EBV) Prevalence and the Risk of Reactivation in Patients with Inflammatory Arthritis Using Anti-TNF Agents and in Those Who Are Biologic Naive". The Open Rheumatology Journal 3 (julho): $30-34$. https://doi.org/10.2174/1874312900903010030. Acesso em: Novembro de 2020.

Mendelson, Ella, Yair Aboudy, Zahava Smetana, Michal Tepperberg, e Zahava Grossman. 2006. "Laboratory Assessment and Diagnosis of Congenital Viral Infections: Rubella, Cytomegalovirus (CMV), Varicella-Zoster Virus (VZV), Herpes Simplex Virus (HSV), Parvovirus B19 and Human Immunodeficiency Virus (HIV)". Reproductive Toxicology (Elmsford, N.Y.) $21 \quad$ (4): 350-82. https://doi.org/10.1016/j.reprotox.2006.02.001. Acesso em: Novembro de 2020.

Mocarski, Edward S. 2004. "Immune Escape and Exploitation Strategies of Cytomegaloviruses: Impact on and Imitation of the Major Histocompatibility System". Cellular Microbiology 6 (8): 707-17. https://doi.org/10.1111/j.14625822.2004.00425.x. Acesso em: Novembro de 2020.

Muzumdar, Sonal, Marti Jill Rothe, e Jane M. Grant-Kels. 2019. "The Rash with Maculopapules and Fever in Children". Clinics in Dermatology 37 (2): 119-28. https://doi.org/10.1016/j.clindermatol.2018.12.005. Acesso em: Novembro de 2020.

Nowalk, Andrew, e Michael Green. 2016. "Epstein-Barr Virus". Microbiology Spectrum 4 (3). https://doi.org/10.1128/microbiolspec.DMIH2-0011-2015. Acesso em: Novembro de 2020. 
Oliveira, S. A., D. J. Turner, W. Knowles, J. P. Nascimento, D. W. G. Brown, e K. N. Ward. 2003. "Primary human herpesvirus- 6 and -7 infections, often coinciding, misdiagnosed as measles in children from a tropical region of Brazil." Epidemiology and Infection 131 (2): 873-79.

Ongrádi, Joseph, Dharam V. Ablashi, Tetsushi Yoshikawa, Balázs Stercz, e Masao Ogata. 2017. "Roseolovirus-Associated Encephalitis in Immunocompetent and Immunocompromised Individuals". Journal of Neurovirology 23 (1): 1-19. https://doi.org/10.1007/s13365-016-0473-0. Acesso em: Novembro de 2020.

Potena, Luciano, e Hannah A Valantine. 2007. "Cytomegalovirus-Associated Allograft Rejection in Heart Transplant Patients": Current Opinion in Infectious Diseases 20 (4): 425-31. https://doi.org/10.1097/QCO.0b013e328259c33b. Acesso em: Novembro de 2020.

Raposo, Jéssica Vasques, Arthur Daniel Rocha Alves, Alexandre dos Santos da Silva, Damião Carlos dos Santos, Juliana Gil Melgaço, Otacílio C. Moreira, Marcelo Alves Pinto, e Vanessa Salete de Paula. 2019. "Multiplex QPCR Facilitates Identification of Betaherpesviruses in Patients with Acute Liver Failure of Unknown Etiology". BMC Infectious Diseases 19 (1): 773. https://doi.org/10.1186/s12879-019-43094. Acesso em: Novembro de 2020.

Rezaei, Farhad, Behrang Sarshari, Nastaran Ghavami, Parisa Meysami, Azadeh Shadab, Hamid Salimi, e Talat Mokhtari-Azad. 2016. "Prevalence and Genotypic Characterization of Human Parvovirus B19 in Children with Measles- and Rubella-like Illness in Iran". Journal of Medical Virology 88 (6): 947-53. https://doi.org/10.1002/jmv.24425. Acesso em: Novembro de 2020.

Sai Tin, S., e V. Wiwanitkit. 2015. "Acute Parvovirus B19 Infection in Adults". Actas Dermo-Sifiliograficas 106 (4): 343. https://doi.org/10.1016/j.ad.2014.09.005. Acesso em: Novembro de 2020.

Schäfer, P., e R. Laufs. 1996. "Experience with Quantitative PCR for the Management of HCMV Disease". Intervirology 39 (3): 204-12. https://doi.org/10.1159/000150496. Acesso em: Novembro de 2020.

Secchiero, P, D Zella, R W Crowley, R C Gallo, e P Lusso. 1995. “Quantitative PCR for Human Herpesviruses 6 and 7." Journal of Clinical Microbiology 33 (8): 2124-30. https://doi.org/10.1128/JCM.33.8.2124-2130.1995. Acesso em: Novembro de 2020.

Sekiguchi, Yasunobu, Asami Shimada, Hidenori Imai, Mutsumi Wakabayashi, Keiji Sugimoto, Noriko Nakamura, Tomohiro Sawada, Norio Komatsu, e Masaaki Noguchi. 2014. "A Case of Recurrent Autoimmune Hemolytic Anemia during Remission Associated with Acute Pure Red Cell Aplasia and Hemophagocytic Syndrome Due to Human Parvovirus B19 Infection Successfully Treated by 
Steroid Pulse Therapy with a Review of the Literature". International Journal of Clinical and Experimental Pathology 7 (5): 2624-35.

Souza, Marli Adelina, Ana Maria Passos, Arício Treitinger, e Celso Spada. 2010. "Seroprevalence of Cytomegalovirus Antibodies in Blood Donors in Southern, Brazil". Revista Da Sociedade Brasileira De Medicina Tropical 43 (4): 359-61. https://doi.org/10.1590/s0037-86822010000400004. Acesso em: Novembro de 2020.

Stanfield, Brent A., e Micah A. Luftig. 2017. "Recent Advances in Understanding EpsteinBarr Virus". F1000Research 6: 386. https://doi.org/10.12688/f1000research.10591.1. Acesso em: Novembro de 2020.

Suga, S., T. Yoshikawa, T. Nagai, e Y. Asano. 1997. "Clinical Features and Virological Findings in Children With Primary Human Herpesvirus 7 Infection". PEDIATRICS 99 (3): e4-e4. https://doi.org/10.1542/peds.99.3.e4. Acesso em: Novembro de 2020.

Sun, Jia-peng, Xin-tian Lu, Wei-hong Zhao, e Ying Hua. 2015. "[Autoimmune lymphoproliferative syndrome: a case report and literature review]". Beijing $D a$ Xue Xue Bao. Yi Xue Ban = Journal of Peking University. Health Sciences 47 (6): 1022-27.

Tanaka, K., T. Kondo, S. Torigoe, S. Okada, T. Mukai, e K. Yamanishi. 1994. "Human Herpesvirus 7: Another Causal Agent for Roseola (Exanthem Subitum)". The Journal of Pediatrics 125 (1): 1-5. https://doi.org/10.1016/s00223476(94)70113-x. Acesso em: Novembro de 2020.

Travan, Laura, Samuele Naviglio, Gabriele Cont, Pierpaolo Brovedani, Riccardo Davanzo, e Sergio Demarini. 2016. "Isolated Hypoplasia of Abdominal Wall Muscles Associated with Fetal Ascites". Congenital Anomalies 56 (4): 184-86. https://doi.org/10.1111/cga.12156. Acesso em: Novembro de 2020.

Tomoiu, Andru, e Louis Flamand. 2006. "Biological and Clinical Advances in Human Herpesvirus-6 and -7 Research". Future Virology 1 (5): 623-35. https://doi.org/10.2217/17460794.1.5.623. Acesso em: Novembro de 2020.

Ward, K.N. 2005. "The Natural History and Laboratory Diagnosis of Human Herpesviruses- 6 and -7 Infections in the Immunocompetent". Journal of Clinical Virology 32 (3): 183-93. https://doi.org/10.1016/j.jcv.2004.11.008. Acesso em: Novembro de 2020. 


\section{CAPÍTULO IV}

\section{UTILIZAÇÃO DA SALINA E DA URINA COMO ESPÉCIMES DE DIAGNÓSTICO DA DENGUE: ANÁLISE DA PRODUÇÃO LITERÁRIA}

Ana Carolina de Jesus Souza ${ }^{1}$

Natalia Moysés ${ }^{2}$

Gabriela Cardoso Caldas ${ }^{3}$

\footnotetext{
' Centro de Ciências da Saúde - Universidade Católica de Petrópolis, Rio de Janeiro, RJ.

${ }^{2}$ Centro de Ciências da Saúde - Universidade Católica de Petrópolis, Rio de Janeiro, RJ.

${ }^{3}$ Laboratório de Morfologia e Morfogênese Viral/Laboratório de Patologia - Instituto Oswaldo Cruz - FIOCRUZ, Rio de Janeiro, RJ.
}

\section{RESUMO}

Introdução: As amostras de urina e saliva possuem diversas características vantajosas, sendo coletadas de maneira rápida, indolor e não invasiva. Além disso, vêm se mostrado espécimes promissores no diagnóstico da dengue (DEN). Contudo, existe uma defasagem de estudos que revisem os resultados primários existentes sobre uso destes espécimes na investigação desta doença. Objetivo: $O$ objetivo deste trabalho foi sistematizar os dados brutos existentes sobre o uso desses fluidos no diagnóstico da DEN. Material e métodos: A busca pelos trabalhos foi realizada no período de junho de 2019 a março de 2020. Foram consultadas as bases de dados PubMed, Lilacs e Scielo, e utilizados os descritores "dengue", "urine" e "saliva". Após a triagem, realizada a partir de critérios de inclusão e exclusão pré-estabelecidos, 30 artigos foram separados para leitura íntegra. Resultados: Trabalhos de DEN e urina foram publicados entre os anos de 2007 e 2019, enquanto trabalhos de DEN e saliva apresentaram período de publicação entre 1998 e 2017. A idade dos participantes foi de 6 meses até 55-61 anos em ambas as buscas. Em relação à quantidade de participantes incluídos, estudos de DEN e urina abrangeram entre 1 a 293 participantes, enquanto estudos de DEN e saliva contaram com a participação de até 7.048 indivíduos. Este fato pode estar relacionado à maior facilidade da coleta de saliva em relação à de urina. A maioria dos estudos analisou os fluidos em questão juntamente com o soro/plasma. Os anticorpos foram as moléculas de preferência no diagnóstico e, deste modo, a metodologia escolhida pela maioria dos trabalhos foi a sorologia. Porém, a metodologia de preferência nos trabalhos de DEN e urina foi a combinação entre sorologia e a RTqPCR, pois a excreção do RNA viral nesta amostra é mais prolongada. Em relação aos sorotipos detectados, notou-se o predomínio de DENV-1, DENV-2 e DENV-3, em comparação com o DENV-4, somente detectado junto aos outros três sorotipos. Conclusão: Conclui-se, portanto, que diversos métodos de diagnóstico na DEN podem utilizar de maneira satisfatória a saliva e a urina e, embora a urina apresente excreção de RNA viral mais prolongada que a saliva, a utilização desta mostra-se mais consolidada no diagnóstico até então. 
Palavras-chave: Análise de literatura. Dengue. Saliva. Urina

\section{INTRODUÇÃO}

A ocorrência de surtos de arboviroses com espectro clínico semelhante, como a dengue (DEN), febre do zika, febre do chikungunya e febre amarela nos últimos anos, somada ao contexto atual da pandemia do novo coronavírus (SARS-CoV-2), suscitou diversos questionamentos a respeito da rapidez e confiabilidade dos testes de diagnóstico para a verificação dos casos suspeitos (BALMASEDA et al., 2003; MUSSO et al., 2015; 2016; AZZI et al., 2020).

Frequentemente, no curso da investigação de uma infecção, uma amostra de sangue é coletada para a análise de parâmetros sanguíneos, bem como para a detecção de antígenos do patógeno ou de anticorpos específicos. As desvantagens da coleta de sangue incluem o caráter minimamente invasivo, a necessidade de um venipunturista treinado e da separação do soro antes do teste diagnóstico, além da dificuldade e risco adicional da punção venosa em crianças, idosos, pacientes hemodialisados e indivíduos que residem em áreas de difícil acesso. Neste contexto, o diagnóstico a partir da coleta de espécimes não invasivos, como a saliva e a urina, pode representar uma alternativa valiosa na investigação de infecções virais. Apesar do uso dessas amostras no diagnóstico de arboviroses ser relatado na literatura, essas não são comumente utilizadas no diagnóstico de rotina (NIEDRIG et al., 2018).

Em relação ao diagnóstico da infecção por DENV, os espécimes clínicos normalmente utilizados são o sangue total, plasma, soro e, em alguns casos, o líquido cefalorraquidiano e o leite materno (GUZMAN \& HARRIS, 2015; MULLER et al., 2017). Porém, mais recentemente, diversos trabalhos vêm descrevendo o progresso do uso da saliva e urina como amostras não invasivas para o diagnóstico de DEN (NIEDRIG et al., 2018).

Apesar do aumento do interesse pelo uso dessas amostras, encontra-se uma lacuna na literatura no que diz respeito à compilação dos resultados dos estudos primários existentes no tema. A análise dos trabalhos correlatos existentes e a realização de revisões sistemáticas atuais sobre o uso destas amostras no diagnóstico tornam-se então de crucial importância para evidenciar quais perguntas ainda precisam

WWW.AMPLLAEDITORA.COM.BR (2) 
ser respondidas e auxiliar na criação de novos protocolos de diagnóstico, que sejam mais rápidos, baratos e menos invasivos para o paciente.

Neste trabalho, buscou-se realizar o levantamento dos estudos publicados nas três principais bases de dados de ciências médicas a respeito do uso da saliva e da urina no diagnóstico da DEN.

\section{MATERIAIS E MÉTODOS}

A análise de literatura foi realizada seguindo a recomendação PRISMA (Liberati et al., 2009) e, a elaboração da pergunta da mesma foi elaborada diante do acrônimo PICOT onde P (população) são indivíduos com DEN, I (intervenção) é o diagnóstico através de fluidos alternativos, C (comparador) é o diagnóstico padrão (sangue), $\mathrm{O}$ (outcome/desfecho) é o diagnóstico da DEN e T (tipo de estudo) são estudos epidemiológicos observacionais.

A busca pelos trabalhos foi realizada no período de junho de 2019 a março de 2020, através das bases de dados PubMed, Lilacs e Scielo. Foram utilizados como descritores os termos "dengue", "saliva", "urina" e "urine". Não foi obtido resultado com o uso do termo "urina", em português, na base de dados PubMed, portanto fez-se necessária a inserção do termo somente em inglês nesta base de dados.

O critério de inclusão consistiu em trabalhos referentes à pesquisa em humanos que investigavam amostras de urina ou saliva no diagnóstico da DEN. Os critérios de exclusão foram: trabalhos de revisão, artigos cuja população era formada de pacientes com coinfecção (DEN e algum outro agente infeccioso), ou com infeç̧ão/doença de etiologia distinta, trabalhos que não utilizavam saliva e/ou urina como espécimes diagnósticos e, por último, artigos com modelos experimentais. Não foram inseridos nesta pesquisa artigos em chinês $(\mathrm{N}=1)$ e artigos de difícil acesso $(\mathrm{N}=2)$.

Após a exclusão inicial de artigos que não se enquadravam nos critérios de inclusão, a partir da leitura dos títulos e resumos disponibilizados, foi feito o upload de todos os artigos elegíveis restantes em Formato Portátil de Documento (PDF) para leitura completa. As seguintes informações foram extraídas dos artigos selecionados: país das amostras citadas no trabalho, ano de publicação, ano ou intervalo de tempo em que o estudo fora realizado, população estudada, $\mathrm{N}$ amostral e idade dos participantes, 
molécula e método de pesquisa, sorotipo e o tipo de infecção (primária ou secundária). Todas as informações, bem como o título e autores dos trabalhos, foram inseridas na base de dados Microsoft Excel. Após a montagem do banco de dados, foram confeccionados os gráficos, tabelas e feitas as inferências.

\section{RESULTADOS}

Foram encontrados 329 artigos mediante os descritores anteriormente citadas, sendo 12 encontrados na base de dados Scielo, 18 no Lilacs, e 299 no PubMed, dos quais foram excluídos os duplicados ( $\mathrm{N}=21)$, sobrando 308 artigos para análise. Após observar estes estudos, foram selecionados apenas aqueles que se tratavam de pesquisa do DENV em amostras de saliva e urina em humanos, totalizando 30 artigos. Os demais não se encaixaram nos critérios de inclusão ( $N=299)$. Portanto, foram selecionados para a realização deste trabalho, 30 artigos.

\subsection{Dengue e urina}

Após a busca com os termos "dengue", "urina" e "urine", foram encontrados 166 artigos, sendo $87.3 \%$ na base de dados PubMed, 5.4\% no Scielo e 7.2\% no Lilacs. Do total, 14 trabalhos estavam duplicados e as cópias foram excluídas da análise, totalizando 152 artigos. Deste resultado, 135 trabalhos foram excluídos, principalmente terem como foco outra infecção que não a DEN. Somente 17 trabalhos se enquadravam no critério de inclusão e foram separados para posterior leitura na íntegra. A totalidade de artigos, bem como os critérios de exclusão está explicitada no gráfico abaixo (Gráfico 1). 
Gráfico 1 - Totalidade dos artigos encontrados utilizando os termos "dengue", "urina" e "urine", duplicados, selecionados e excluídos.

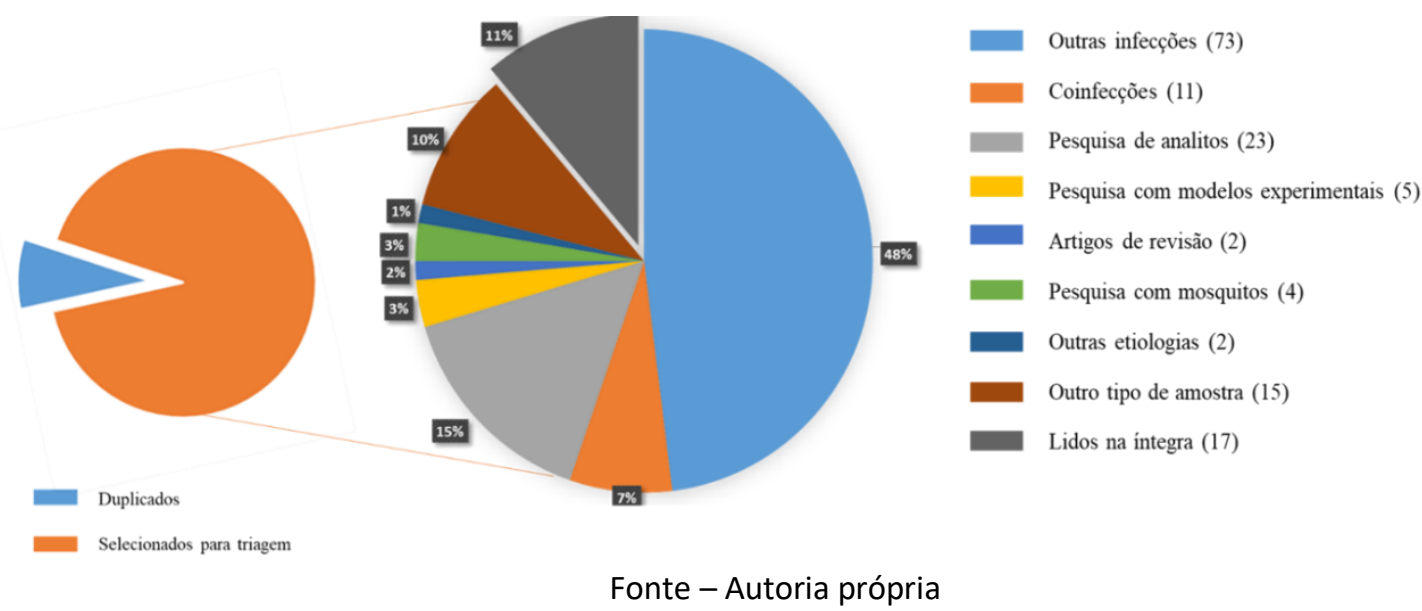

Em relação ao período de publicação, observou-se uma produção entre os anos de 2007 a 2019, com ausência de publicações no tema nos anos 2008, 2009, 2013 e 2017. O gráfico 2 mostra o volume de publicações distribuída do período entre 2007 e 2019.

Gráfico 2 - Volume de publicações no tema distribuído no período entre os anos de 2007 e 2019

(“dengue" AND “urine").

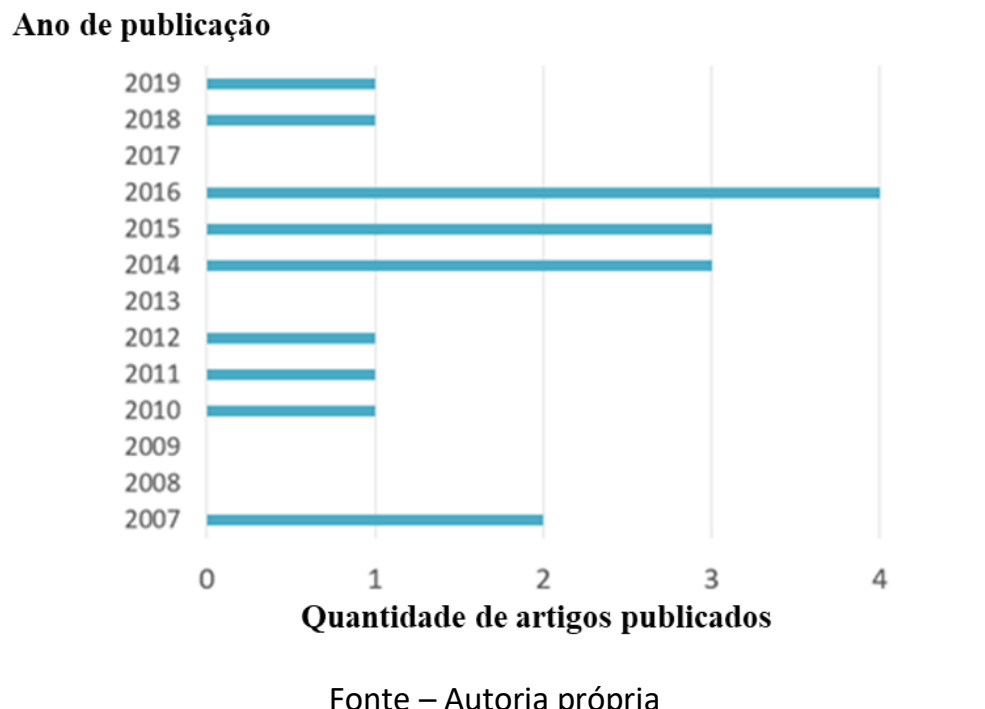

O número de indivíduos incluídos nos trabalhos variou de 1 a 293 pacientes, com idades entre 6 meses a 61 anos. Os pacientes pertencentes aos estudos provinham da Europa (1), América Central (1), América do Sul (3) e, principalmente Ásia ( $N=12$ ). Dois 
trabalhos utilizaram amostras provenientes de indivíduos brasileiros, mais especificamente do estado de São Paulo. A tabela 1 detalha o país de origem dos indivíduos incluídos nos trabalhos selecionados.

Tabela 1 - Origem dos indivíduos incluídos nos estudos selecionados ("dengue" AND "urine").

\begin{tabular}{|c|c|}
\hline Estudo & País das Amostras \\
\hline 1 & Cuba \\
\hline 2 & Tailândia e China \\
\hline 3 & Brasil \\
\hline 4 & Indonésia, Malásia, Tailândia, Gabão, Índia, Sri Lanka e Singapura \\
\hline 5 & Camboja \\
\hline 6 & Brasil \\
\hline 7 & Singapura \\
\hline 8 & Malásia \\
\hline 9 & Venezuela \\
\hline 10 & Indonésia \\
\hline 11 & China \\
\hline 12 & Índia \\
\hline 13 & Singapura \\
\hline 14 & Bélgica \\
\hline 15 & Japão \\
\hline 16 & Tailândia \\
\hline 17 & Japão \\
\hline
\end{tabular}

Fonte - Autoria própria

A maioria dos trabalhos utilizou a urina como espécime diagnóstico associada a análises com soro ou plasma ( $\mathrm{N}=12)$. Desses, quatro artigos também incluíram a saliva como amostra de análise. Quatro trabalhos realizaram o diagnóstico da DEN somente em amostras de urina e saliva e apenas um trabalho utilizou a urina individualmente para o diagnóstico. Os alvos mais pesquisados foram anticorpos IgM, IgG, IgA e IgE, porém também se observou a pesquisa da proteína NS1 e do RNA viral. Dois trabalhos basearam-se somente na pesquisa da proteína NS1 e um trabalho optou apenas pela detecção do RNA viral. A metodologia diagnóstica mais utilizada pelos grupos foi a combinação entre o método sorológico (ELISA) com o molecular (RTPCR) ( $N=9$ ). Em quatro trabalhos optou-se apenas pela utilização de testes sorológicos (principalmente ELISA). Um trabalho utilizou biossensor como método de diagnóstico. A tabela 2 mostra as informações pareadas referentes à amostra utilizada, molécula pesquisada e metodologia escolhida. 
Tabela 2 - Informações pareadas referentes à amostra utilizada, molécula pesquisada e método diagnóstico escolhido ("dengue" AND "urine”).

\begin{tabular}{c|c|c|c|} 
Artigo & Amostras & Alvo & Método de Pesquisa \\
\hline 1 & Soro, saliva e urina & Anticorpo IgG, IgM e IgA e IgE & ELISA \\
\hline 2 & Plasma, saliva e urina & Anticorpo IgG e IgM; RNA & ELISA e RT-PCR \\
\hline 3 & Saliva e urina & Anticorpo IgG e IgM; RNA & ELISA e RT-PCR \\
\hline 4 & Saliva e urina & RNA e NS1 & ELISA e RT-PCR \\
\hline 5 & Saliva e urina & Anticorpo IgG, IgM e IgA; NS1; RNA & ELISA, RT-PCR e Kit antígeno NS1 \\
\hline 6 & Soro, saliva e urina & Anticorpo IgG e IgM; NS1; RNA & ELISA, RT-PCR e Kit antígeno NS1 \\
\hline 7 & Saliva e urina & Anticorpo IgG, IgM e IgA; NS1 & ELISA e Kit antígeno NS1 \\
\hline 8 & Soro, saliva e urina & RNA & Genosensor à base de acrílico \\
\hline 9 & Plasma e urina & Anticorpo IgG, IgM e IgA; NS1 & ELISA \\
\hline 10 & Plasma e urina & RNA & RTqPCR e RT-PCR pan-flavivirus \\
\hline 11 & Soro e urina & Anticorpo IgA & ELISA \\
\hline 12 & Soro e urina & Anticorpo IgM; NS1; RNA & ELISA, RT-PCR e Kit de antígeno NS1 \\
\hline 13 & Urina & NS1 & PCR \\
\hline 14 & Soro e urina & Anticorpo IgG e IgM; RNA & RT-PCR e kit antígeno NS1 \\
\hline 15 & Soro e urina & Anticorpo IgG e IgM; RNA; NS1 & ELISA e RT-PCR \\
\hline 16 & Soro e urina & NS1 & ELISA \\
\hline 17 & Soro e urina & Anticorpo IgG e IgM; RNA & ELISA e RT-PCR \\
\hline
\end{tabular}

Fonte - Autoria própria

Todos os sorotipos tiveram detecção descrita, porém os sorotipos 1, 2 e 3 foram detectados sozinhos em 2 trabalhos cada. A detecção do DENV-4 somente foi citada em conjunto aos demais sorotipos $(\mathrm{N}=6)$. A maioria dos trabalhos não informou se o diagnóstico foi realizado em amostras provenientes de uma infecção primária ou secundária por um sorotipo heterólogo $(\mathrm{N}=10)$. A tabela 3 traz as informações referentes aos sorotipos detectados e o tipo de infecção.

Tabela 3 - Sorotipos detectados e tipo de infecção ("dengue" and "urine"). NI: Não informado.

\begin{tabular}{c|c|c|} 
Artigo & Sorotipo & Tipo de Infecção \\
\hline 1 & DENV-3 & Infecção primária e secundária \\
\hline 2 & DENV-1 & - \\
\hline 3 & DENV-2 e DENV-3 & Infecção primária \\
\hline 4 & DENV-1, DENV-2, DENV-3 e DENV-4 & - \\
\hline 5 & DENV-1, DENV-2, DENV-3 e DENV-4 & - \\
\hline 6 & DENV-1, DENV-2, DENV-3 & Infecção primária e secundária \\
\hline 7 & DENV-1 & Infecção primária e secundária \\
\hline 8 & DENV-2 & - \\
\hline 9 & NI & - \\
\hline 10 & DENV-3 & - \\
\hline 11 & DENV-1, DENV-2, DENV-3 e DENV-4 & Infecção primária e secundária \\
\hline 12 & DENV-2 & Infecção secundária \\
\hline 13 & NI & - \\
\hline 14 & DENV-1, DENV-2, DENV-3 & - \\
\hline 15 & DENV-1, DENV-2, DENV-3 e DENV-4 & - \\
\hline 16 & DENV-1, DENV-2, DENV-3 e DENV-4 & Infecção secundária \\
\hline 17 & DENV-1, DENV-2, DENV-3 e DENV-4 & - \\
\hline
\end{tabular}

Fonte - Autoria própria 


\subsection{Dengue e saliva}

Após a busca com os termos "dengue" e "saliva", foram encontrados 163 artigos, sendo $94.4 \%$ na base de dados PubMed, 1,8\% no Scielo e 3,6\% no Lilacs. Do total, 16 trabalhos estavam duplicados e as cópias foram excluídas da análise, totalizando 147 artigos. Deste resultado, 134 trabalhos foram excluídos, principalmente utilizarem a saliva do vetor como amostra de pesquisa. Ao final da triagem, 13 trabalhos foram separados para posterior leitura na íntegra. A totalidade de artigos, bem como os critérios de exclusão está explicitada no gráfico abaixo (gráfico 3).

Gráfico 3 - Totalidade dos artigos encontrados utilizando os termos "dengue" e "saliva", duplicados, selecionados e excluídos.

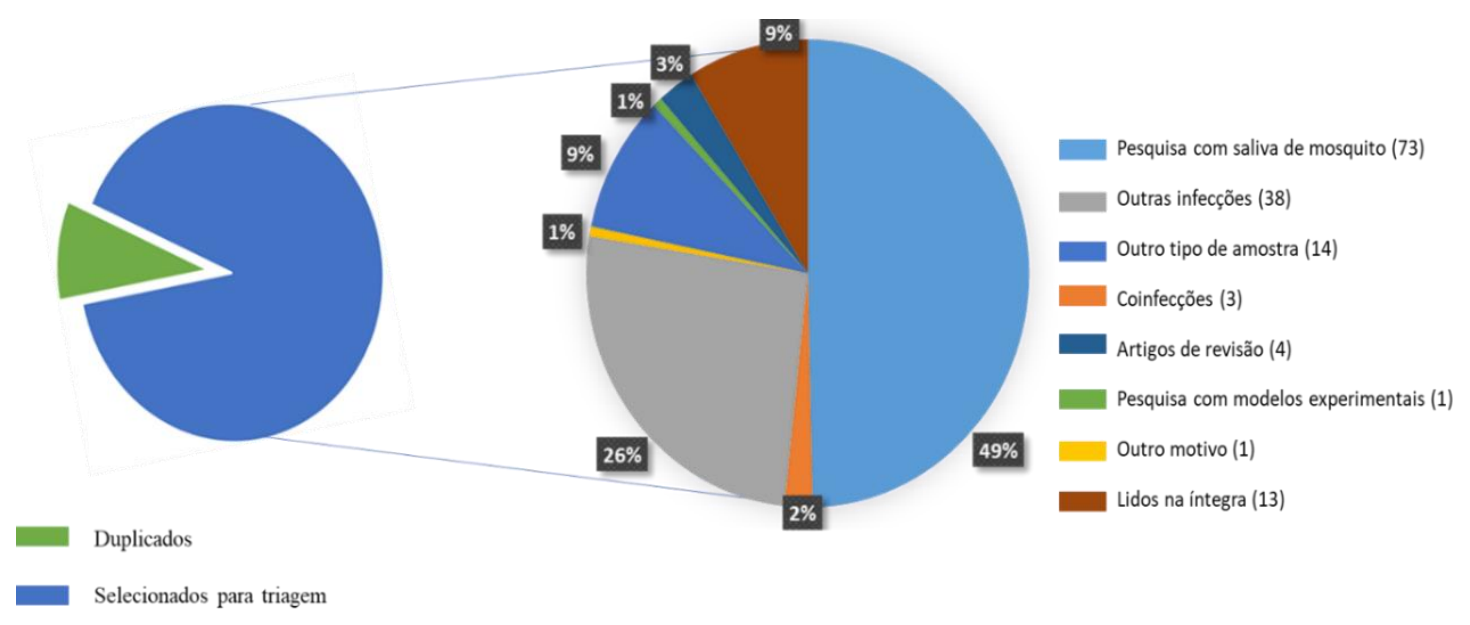

Fonte - Autoria própria

Em relação ao período de publicação, observou-se uma produção entre os anos de 1998 a 2017, com ausência de publicações no tema nos anos 2001/2002, 20042006, 2009/2010 e 2016. O gráfico 4 mostra o volume de publicações distribuída do período entre 1998 e 2017. 
Gráfico 4 - Volume de publicações no tema distribuído no período entre os anos de 1998 e 2017

("dengue" AND "saliva").

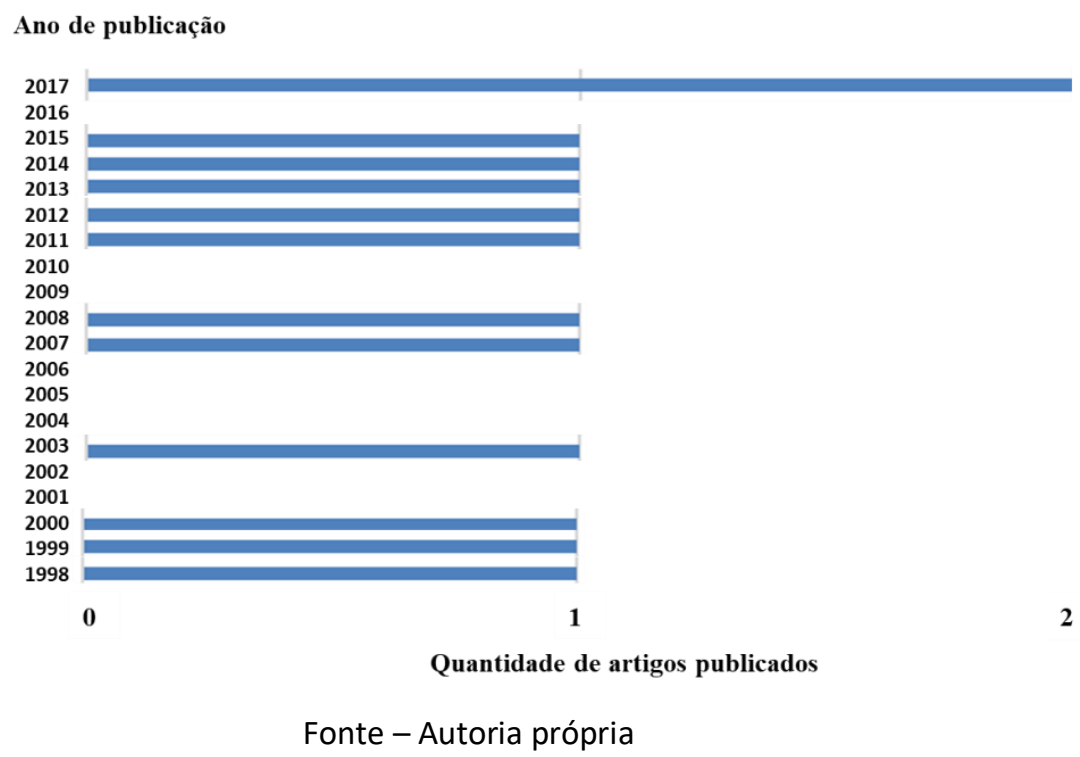

O número de indivíduos incluídos nos trabalhos variou de 1 a 7.048 pacientes, com idades entre 6 meses a 55 anos. Os pacientes pertencentes aos estudos provinham da América do Norte $(\mathrm{N}=2)$, América do Sul $(\mathrm{N}=2)$, América Central $(\mathrm{N}=3)$ e, o maior número pertencia ao continente asiático $(\mathrm{N}=6)$. Apenas um trabalho utilizou amostras provenientes de indivíduos brasileiros. A tabela 5 detalha o país de origem dos indivíduos incluídos nos trabalhos selecionados.

Tabela 5 - Origem dos indivíduos incluídos nos estudos selecionados ("dengue" AND "saliva").

\begin{tabular}{c|c|} 
Estudo & País das Amostras \\
\hline 1 & Nicarágua \\
\hline 2 & México \\
\hline 3 & Malásia \\
\hline 4 & EUA \\
\hline 5 & Índia \\
\hline 6 & Vietnã \\
\hline 7 & Singapura \\
\hline 8 & Nicarágua \\
\hline 9 & Tailândia \\
\hline 10 & Venezuela \\
\hline 11 & Brasil \\
\hline 12 & Índia \\
\hline 13 & Nicarágua \\
\hline
\end{tabular}

Dez trabalhos utilizaram a saliva como amostra para o diagnóstico associada a análises com soro, plasma ou sangue total. Os outros três trabalhos restantes utilizaram 
somente a saliva como amostra de análise. Onze trabalhos pesquisaram anticorpos nas amostras, com predomínio da pesquisa por IgM e IgG, esta última pesquisada sozinha em três trabalhos. Dois trabalhos investigaram a presença de NS1 nas amostras e apenas um voltou-se para a pesquisa do RNA viral. Por conta da predominância da pesquisa por anticorpos, a metodologia mais utilizada foi a sorológica, representada em sua maioria pelo ELISA. Apenas dois estudos utilizaram a metodologia de RT-PCR para as análises. A tabela 6 mostra as informações pareadas referentes à amostra utilizada, molécula pesquisada e metodologia escolhida.

Tabela 6 - Informações pareadas referentes à amostra utilizada, molécula pesquisada e método diagnóstico escolhido ("dengue" AND "saliva").

\begin{tabular}{c|c|c|c|} 
Artigo & Amostras & Alvo & Método de pesquisa \\
\hline 1 & Saliva & Anticorpo IgG & ELISA \\
\hline 2 & Saliva & Anticorpo IgG & ELISA \\
\hline 3 & Saliva e sangue & NS1 & Kit antígeno NS1 \\
\hline 4 & Saliva e sangue & Anticorpo IgG & ELISA \\
\hline 5 & Saliva & Anticorpo IgG e IgM & ELISA e RT-PCR \\
\hline 6 & Saliva e plasma & Anticorpo IgG e IgM; NS1 & ELISA \\
\hline 7 & Saliva e soro & Anticorpo IgG, IgM e IgA & ELISA \\
\hline 8 & Saliva e soro & Anticorpo IgM e IgA & ELISA \\
\hline 9 & Saliva e soro & Anticorpo IgG e IgM & RT-PCR \\
\hline 10 & Saliva e soro & RNA & ELISA \\
\hline 11 & Saliva e soro & Anticorpo IgG e IgM & ELISA \\
\hline 12 & Saliva e soro & Anticorpo IgG e IgM & ELISA \\
\hline 13 & Saliva e soro & Anticorpo IgG, IgM e IgA &
\end{tabular}

Apenas dois trabalhos relataram os sorotipos detectados, um com detecção de DENV-1, DENV-2 e DENV-3 e outro apenas com detecção de DENV-1. Dois trabalhos analisaram amostras provenientes de infecções recentes, mas a maioria $(\mathrm{N}=6)$ utilizou amostras provenientes de uma infecção primária e secundária por um sorotipo heterólogo. Cinco trabalhos não indicaram o tipo de infecção. A tabela 7 traz as informações referentes aos sorotipos detectados e o tipo de infecção. 
Tabela 7 - Sorotipos detectados e tipo de infecção ("dengue" AND "saliva"). NI: Não informado.

\begin{tabular}{c|c|c|} 
Artigo & Sorotipo & Tipo de Infecção \\
\hline 1 & $\mathrm{NI}$ & Infecção recente \\
\hline 2 & $\mathrm{NI}$ & Infecção recente \\
\hline 3 & $\mathrm{NI}$ & $\mathrm{NI}$ \\
\hline 4 & $\mathrm{NI}$ & Infecção primária e secundária \\
\hline 5 & $\mathrm{NI}$ & $\mathrm{NI}$ \\
\hline 6 & $\mathrm{NI}$ & $\mathrm{NI}$ \\
\hline 7 & $\mathrm{NENV}-1, \mathrm{DENV}-2$ e DENV-3 & Infecção primária e secundária \\
\hline 8 & $\mathrm{NI}$ & Infecção primária e secundária \\
\hline 9 & $\mathrm{NENV}-1$ & Infecção primária e secundária \\
\hline 10 & $\mathrm{NI}$ & $\mathrm{NI}$ \\
\hline 11 & $\mathrm{NI}$ & NI \\
\hline 12 & $\mathrm{NI}$ & Infecção primária e secundária \\
\hline 13 & Fonte - Autoria própria
\end{tabular}

\section{DISCUSSÃO}

A saliva e a urina mostram-se fluidos promissores no diagnóstico da DEN. A literatura descreve que os anticorpos IgA, IgG e $\lg M$ encontrados na saliva, são semelhantes aos valores encontrados no soro (VÁZQUEZ. et al., 2007; KORAKA et al., 2001; TALARMIN et al., 1998) e, neste fluido, se é possível quantificar também o RNA viral e o antígeno NS1. A urina é um fluido que apresenta concentrações mais baixas de anticorpos, porém, mensuráveis sendo mais facilmente detectado o antígeno NS1 e, o RNA-DENV que segundo a literatura, é detectável por um tempo mais prolongado do que no soro (KORHONEN et al., 2014). Há a necessidade de mais estudos utilizando estes fluidos no diagnóstico da DEN, visto que há trabalhos que comprovam sua eficiência, entretanto, são escassos os mesmos que fazem uma comparação quantitativa detalhada dos fluidos alternativos e o fluido de diagnóstico padrão, com um número significante de pacientes, fazendo-se necessário mais pesquisas sobre estes espécimes.

Notou-se também a ausência de trabalhos que sistematizam a utilização da saliva e da urina no diagnóstico da DEN, já que, apesar de terem sido encontradas 6 revisões na busca total realizada neste trabalho, somente dois abordam especificamente este tema (COLONETTI et al., 2018; NIEDRIG et al., 2018). Por conta disso, torna-se de crucial importância que a pesquisa realizada neste trabalho sirva como base para a elaboração de um robusto artigo de revisão sistemática sobre o assunto. 
Após a triagem dos resultados da busca com os mediadores "dengue" e "urine", a maioria dos artigos foi excluída por ter como foco outra infecção que não a DEN. Esses trabalhos tratavam quase que em sua totalidade da associação do ZIKV com a amostra de urina e essa informação pode ser entendida por conta da forte associação desse arbovírus com fluidos, como o sêmen, secreção vaginal e a própria urina (LAMB et al., 2016; KURSCHEID et al., 2019). Em comparação, após o mesmo processo utilizando as palavras chave "dengue" e "saliva", a exclusão da maioria dos trabalhos encontrados se deu pelo fato dos mesmos utilizarem a saliva do vetor, o mosquito Ae. aegypti, como base das análises. De fato, diversos estudos já demostraram a importância de proteínas presentes na saliva do vetor para o sucesso da infecção e da imunopatogênese, sendo investigadas também para atuar em formulações vacinais (PINGEN et al., 2017; MANNING et al., 2018).

Quando analisados os períodos de publicação, notou-se que trabalhos de DEN e urina foram publicados entre os anos de 2007 e 2019, com média de 1 artigo por ano. Observou-se um aumento na publicação no tema entre os anos de 2014 a 2016, com média de 3 artigos por ano. Este dado pode estar relacionado à epidemia de ZIKV ocorrida no mesmo período, que aumentou o interesse dos pesquisadores pela utilização de secreções, como o sêmen, como amostras de diagnóstico (GORNET et al., 2016). Já em relação aos trabalhos de DEN e saliva, observou-se um período de publicação um pouco mais longo, entre 1998 e 2017. O volume de publicações mostrou tendência contínua, com média de 1 trabalho por ano. Este fato pode estar relacionado a já conhecida associação entre diversas infecções virais e a saliva, como no caso do vírus da hepatite $C$, vírus da síndrome da imunodeficiência humana e vírus Epstein-Barr (HERMIDA et al., 2002; CORSTJENS et al., 2016).

Em relação à localidade das amostras, pode-se observar que o continente asiático concentrou o maior número de trabalhos. Além disso, não foram encontrados trabalhos que utilizaram amostras de indivíduos africanos ou foram publicados no continente africano. Esta informação pode estar associada ao fato que o perfil mundial de produção científica é historicamente enraizado e pouco se alterou no decorrer das décadas, embora o aumento de redes de colaboração tenha tido grande impacto no desempenho de países emergentes, como os BRICS (Brasil, Rússia, Índia, China e África do Sul). Apesar de apresentarem alto volume de publicação científica ao longo das 
décadas, foram encontradas poucas produções com amostras oriundas da América do Norte e da Europa. Este fato pode estar relacionado ao clima destas regiões, que não é favorável à disseminação do vetor, embora a dinâmica da DEN venha mudando nos últimos anos por conta dos efeitos do aquecimento global e da própria globalização (WHO, 2014; WILSON \& CHEN, 2015).

A idade dos participantes não apresentou diferenças relevantes, mantendo-se entre 6 meses até 55-61 anos. Porém, quando analisada a quantidade de participantes incluídos, notou-se uma grande diferença entre as buscas: em comparação com os estudos de DEN e urina, cuja quantidade de participantes variou entre 1 a 293, estudos de DEN e saliva contaram com a participação de até 7.048 indivíduos. Este fato pode estar relacionado a facilidade maior da coleta de saliva em relação à de urina, já que não necessita da higienização prévia do local e nem de um banheiro próximo (AQUINO et al., 2020). Além disso, o recrutamento dos pacientes é também facilitado, uma vez que costuma ocorrer na espera do atendimento para a coleta de sangue, quando o mesmo já está em jejum (uma das únicas exigências para a coleta de saliva).

Após a seleção dos estudos relacionados à DEN e saliva, notou-se que a grande maioria dos trabalhos analisou este espécime em conjunto ao plasma/soro ou sangue total e três trabalhos utilizaram somente a saliva como amostra para o diagnóstico. Já nos trabalhos relacionados à DEN e urina, notou-se que, além do soro e plasma e da própria urina, a saliva também foi utilizada como amostra. Apenas um trabalho utilizou somente a urina como amostra (VASANWALA et al., 2014). Infere-se, portanto, que a maioria dos trabalhos que optam pela utilização de fluidos alternativos como amostras de urina para o diagnóstico da DEN o fazem em conjunto com a saliva.

Como resultado de ambas as buscas, percebeu-se que os anticorpos foram as moléculas de preferência no diagnóstico, com a presença também da pesquisa por NS1 e RNA viral. De fato, a pesquisa de anticorpos por ensaios imunoenzimáticos é a mais utilizada na rotina, sendo vantajosa no diagnóstico quando não se sabe precisar o início da infecção, fato que é comum no manejo de pacientes infectados pelo DENV, além de ser menos custosa (MARTINS et al., 2014; SEKARAN \& SOE, 2017). Portanto, já se esperava que a metodologia escolhida pela maioria dos trabalhos de DEN e saliva fosse a sorologia, representada na maioria dos casos pelo ELISA. Porém, nos trabalhos de DEN e urina, percebeu-se também a deteç̧ão do RNA viral associada à pesquisa de 
anticorpos. Isso está relacionado ao fato da excreção do RNA viral neste espécime ocorrer de forma mais prolongada que na maioria dos fluidos (BARZON et al., 2013; MA et al., 2014; GOURINAT et al., 2015). Portanto, nesses casos a metodologia de preferência dos trabalhos foi a combinação entre sorologia e a RTqPCR.

Em relação aos sorotipos detectados, notou-se o predomínio de DENV-1, DENV2 e DENV-3. De fato, esses sorotipos são historicamente mais detectados nas pesquisas, por conta das características epidemiológicas e da maior associação a quadros mais graves (BALMASEDA et al., 2006; HERINGER et al., 2017), em comparação com o sorotipo 4, que só foi detectado em conjunto aos outros três sorotipos.

\section{CONSIDERAÇÕES FINAIS}

Conclui-se, portanto, que diversos métodos de diagnóstico na DEN podem utilizar de maneira satisfatória a saliva e a urina e, embora a urina apresente excreção de RNA viral mais prolongada que a saliva, a utilização desta mostra-se mais consolidada no diagnóstico até então.

\section{REFERÊNCIAS}

AQUINO, J. M. et al. A saliva como sendo um meio de diagnósticos: uma revisão de literatura. Revista Eletrônica Acervo Saúde, n. 41, p. e2506-e2506, 2020

AZZI, L. et al. Saliva is a reliable tool to detect SARS-CoV-2. Journal of Infection. Apr 14:S0163-4453(20)30213-9. 2020

BALMASEDA, A. et al. Diagnosis of dengue virus infection by detection of specific immunoglobulin $\mathrm{M}$ (IgM) and IgA antibodies in serum and saliva. Clinical and Diagnosis Laboratory Immunology, v. 10, n. 2, p.317-322, 2003

BALMASEDA, A. et al. Serotype-specific differences in clinical manifestations of dengue. American Journal of Tropical Medicine and Hygiene, v. 74, n. 3, p.449-456, 2006

BARZON, L. et al. Excretion of West Nile virus in urine during acute infection. Journal of Infectious Disease, n. 208, p. 1086-1092, 2013

COLONETTI, T., et al. Accuracy of immunoglobulin $\mathrm{M}$ and immunoglobulin $\mathrm{A}$ of saliva in early diagnosis of dengue: Systematic Review and Meta-analysis. An. Acad. Bras. Ciênc., Rio de Janeiro, v. 90, n. 3, p. 3147-3154, Sept. 2018

CORSTJENS, P. L.; ABRAMS W. R.; MALAMUD, D. Saliva and viral infections. Periodontol 2000. v. 70, n. 1, p. 93-110, 2016 
GORNET, M. E.; BRACERO, N. J.; SEGARS, J. H. Zika Virus in Semen: What We Know and What We Need to Know. Seminars in Reproductive Medicine, v. 34, n. 5, p. 285292, 2016

GOURINAT, A. C. et al. Detection of Zika virus in urine. Emerging Infectious Diseases. $n$. 21, p. 84-86, 2015

GUZMAN, M. G. \& HARRIS, E. Dengue. The Lancet, v. 385, n. 9966, p. 453-465, 2015

HERINGER, M. et al. Dengue type 4 in Rio de Janeiro, Brazil: case characterization following its introduction in an endemic region. BMC infectious diseases, v. 17, n. $1,410,2017$

HERMIDA, M. et al. Detection of HCV RNA in saliva of patients with hepatitis $C$ virus infection by using a highly sensitive test. Journal of Virological Methods, v. 101, n. $1-2$, p. 29- 35, 2002

KORAKA, P. et al. Kinetics of dengue virus-specific serum immunoglobulin classes and subclasses correlate with clinical outcome of infection. Journal of Clinical Microbiology, v. 39, n. 4332, p. 8- 26, 2001

KORHONEN, E. et al. Approach to non-invasive sampling in dengue diagnostics: Exploring virus and NS1 antigen detection in saliva and urine of travelers with dengue. Journal of Clinical Virology, v. 61, n. 3, p. 353-358, 2014

KURSCHEIDT, F. A. et al. Persistence and clinical relevance of Zika virus in the male genital tract. Nature Reviews Urology, v. 16, n. 4, p. 211-230, 2019

LAMB, L.E., et al. Rapid Detection of Zika Virus in Urine Samples and Infected Mosquitos by Reverse Transcription-Loop-Mediated Isothermal Amplification. Scientific Reports, n. 8, p. 3803, 2018.

LIBERATI, A., et al. The PRISMA statement for reporting systematic reviews and metaanalyses of studies that evaluate health care interventions: explanation and elaboration. PLoS medicine, v. 6, n. 7, p. e1000100.

MANNING, J. E. et al. Mosquito Saliva: The Hope for a Universal Arbovirus Vaccine?. Journal of Infectious Disease. v. 218, n. 1, p. 7-15, 2018

$M A, X$. et al. First confirmation of imported dengue virus serotype 2 complete genome in urine from a Chinese traveler returning from India. Virology Journal, n. 11, p. 56,2014

MARTINS, A. C. et al. Seroprevalence and seroconversion of dengue and implications for clinical diagnosis in amazonian children. Interdisciplinary Perspectives on Infectious Diseases, v. 2014 p. 703875, 2014

MUSSO, D. et al. Detection of Zika virus in saliva. Journal of Clinical Virology, n. 68, p. 53-55, 2015 
MULLER, D. A., et al., Clinical and Laboratory Diagnosis of Dengue Virus Infection. The Journal of infectious diseases, n. 215 (suppl_2), p. S89-S95, 2017

NIEDRIG, M. et al. Find the right sample: A study on the versatility of saliva and urine samples for the diagnosis of emerging viruses. BMC infectious diseases v. $18, \mathrm{n}$. 1, p. 707, 2018

PINGEN, M. et al. Mosquito Biting Modulates Skin Response to Virus Infection. Trends in Parasitology, v. 33, n. 8, p. 645-657, 2017

SEKARAN, S. D. \& SOE, H. J. Issues in contemporary and potential future molecular diagnostics for dengue. Expert Review of Molecular Diagnostics, v. 17, n. 3, p. 217-223, 2017.

TALARMIN, A. et al. Immunoglobulin Aspecific capture enzyme-linked immunosorbent assay for diagnosis of dengue fever. Journal of Clinical Microbiology, n. 36, p. 1189-92, 1998

VASANWALA, F. F. et al. Predictive value of proteinuria in adult dengue severity. PLoS neglected tropical diseases, v. 8, n. 2, p. e2712, 2014.

Vázquez, S., et al. Kinetics of antibodies in sera, saliva, and urine samples from adult patients with primary or secondary dengue 3 virus infections. International Journal of Infectious Diseases, v. 11, n. 3, p.256-262, 2007

WHO. Global Alert and Response. 2014. Disponível em: http://www.who.int/csr/disease/dengue/en/. Acesso em 01/06/2020

Wilson, M.E \& Chen L.H. Dengue: update on epidemiology. Curr Infect Dis Rep, v. 17, n. 1, p. 457,2015 


\section{CAPÍTULO V}

\section{REVISÃO DA LITERATURA: LEISHMANIOSE TEGUMENTAR AMERICANA - MÉTODOS DIAGNÓSTICOS}

Elizabeth Cristina Araujo Ferreira da Silva ${ }^{1}$

${ }^{1}$ Mestranda em Pesquisa Clínica em Doenças Infecciosas do Instituto Nacional de Infectologia Evandro Chagas (INI) FIOCRUZ.

\section{RESUMO}

Leishmanioses são antropozoonoses causadas por protozoários do gênero Leishmania com distribuição mundial em 98 países. A doença humana acomete a pele e/ou as mucosas das vias aero-digestivas superiores. As lesões mucosas geralmente aparecem depois de meses ou mesmo vários anos após a cura espontânea ou terapêutica da lesão cutânea primária, ou ainda podem se manifestar simultaneamente. A transmissão é através da picada da fêmea de insetos flebotomíneos. O gênero Leishmania compreende protozoários parasitas, com um ciclo de vida digenético (heteroxênico), vivendo alternadamente em hospedeiros vertebrados e insetos vetores, estes últimos sendo responsáveis pela transmissão dos parasitos de um mamífero a outro. Nas Américas existem dois tipos da doença: Leishmaniose Tegumentar Americana (LTA), que afeta pele e mucosas, e Leishmaniose Visceral Americana, que afeta principalmente baço e fígado. A epidemiologia das leishmanioses é complexa, e pode ser alterada pela ocorrência de mudanças em qualquer posição no ciclo: vetor-reservatório-homem. 0 desmatamento e a urbanização são exemplos característicos das alterações que são seguidas por mudanças principalmente em reservatórios e na população de insetos vetores. No Brasil, já foram identificadas seis espécies do subgênero Viannia e duas do subgênero Leishmania. As principais são: L. (V.) braziliensis, L. (V.) guyanensis e L. (L.) amazonensis e, mais recentemente, L. (V.) lainsoni, L. (V.) naiffi, L. (V.) lindenbergi, L. (V.) shawi e $L$. (L.) infantum (forma visceral), encontradas em estados das regiões Norte e Nordeste. No Rio de Janeiro, a maioria dos primeiros casos descritos foi proveniente de outras regiões endêmicas do país, sugerindo uma doença importada. Por possuir uma ampla variedade de espécies com manifestações distintas, faz com que o diagnóstico seja complexo. Dos métodos utilizados para o diagnóstico temos a Intradermorreação de Montenegro, a cultura, que se apresenta como o padrão de referência, exame parasitológico direto, testes sorológicos como teste de aglutinação direta (DAT), imunofluorescência indireta (IFA) e o teste imunoenzimático (enzyme linked immunosorbent assay, ELISA), exame histopatológico como imunocitoqúimica e imunohistoquímica e o diagnóstico molecular. O tratamento para essa doença é hepatotóxico, por isso um diagnóstico preciso é importante. O objetivo deste trabalho é elucidar cada um dos métodos utilizados para o diagnóstico e esclarecer alguns aspectos de cada um deles. 
Palavras-chave: Leishmaniose Tegumentar Americana. Métodos Diagnósticos. Revisão da Literatura.

\section{INTRODUÇÃO}

As leishmanioses são doenças infecciosas parasitárias causadas por protozoários flagelados pertencentes ao gênero Leishmania (MINISTÉRIO DA SAÚDE, 2017; WORLD HEALTH ORGANIZATION, 2010). A Organização Mundial da Saúde (OMS) estima que existam 700.000 a um milhão de casos novos ao ano (WORLD HEALTH ORGANIZATION, 2020).

São transmitidos pelas fêmeas de insetos dos gêneros Phlebotumus ou Lutzomia (MINISTÉRIO DA SAÚDE, 2017; WORLD HEALTH ORGANIZATION, 2010). Os insetos do gênero Phlebotomus spp. são comumente encontrados na Europa, norte da África, Oriente Médio e Ásia, já Lutzomia spp. são encontrados do sul dos Estados Unidos até o norte da Argentina. (CATAÑO; PINZÓN, 2019; REITHINGER et al., 2007). São pequenos insetos de aproximadamente 2-3 milímetros de comprimento. Há cerca de 500 flebotomineos conhecidos, mas apenas 30 destes são incriminados na transmissão da doença (BATES, 2007; SRIVASTAVA et al., 2016).

A taxonomia é complexa, abrangendo mais de 20 espécies agrupadas em dois subgêneros, Leishmania (Leishmania) e Leishmania (Viannia). (BAÑULS, 2002; FRAGA et al., 2010; Lainson e Shaw, 1987; ODIWUOR et al., 2011). Originam doenças negligenciadas que causam importante morbidade em áreas endêmicas, principalmente nas áreas tropicais e subtropicais (CANTACESSI et al., 2015; SALES et al., 2019) e afetando predominantemente populações pobres (WORLD HEALTH ORGANIZATION, 2020). As manifestações clínicas da doença em seres humanos dependem de interações complexas entre as características de virulência da Leishmania spp. e as respostas imunológicas do hospedeiro. As leishmanioses podem se manifestar de diversas formas, desde lesões cutâneas até quadros com envolvimento do fígado e de outras vísceras. (SINGH; DEY; SIVAKUMAR, 2005; SRIVASTAVA et al., 2016).

A diversidade clínica e epidemiológica da leishmaniose leva à complexidade da taxonomia (FRAGA et al., 2010, ODIWUOR et al., 2011; ROUGERON et al., 2009; TIBAYRENC et al., 1993). As Leishmanias têm um ciclo de vida dimórfico, onde existem 
formas promastigotas extracelulares, que se multiplicam no trato alimentar do vetor, e formas amastigotas intracelulares que se multiplicam nas células mononucleares do hospedeiro. $\mathrm{O}$ acúmulo gradual de mutações por divisão celular mitótica e/ou por recombinação sexual produzem misturas de genomas (INBAR et al., 2019; ROUGERON; DE MEEUS; BANULS, 2015). A ampla diversidade genética dos parasitos do gênero Leishmania, sobretudo L. (V.) braziliensis, espécie de maior prevalência no Brasil, é conhecida (CUPOLILLO et al., 2003; ISHIKAWA et al., 2002; PACHECO et al., 1990). Esses organismos mostram plasticidade inter e intraespécies quanto ao número e tamanho dos cromossomos (cariótipo molecular), e também no genoma mitocondrial, variando, principalmente, no tamanho e organização dos maxicírculos. Diferentes padrões epidemiológicos poderiam influenciar os níveis de variabilidade: amostras de L. (V.) braziliensis da Amazônia demonstraram elevada heterogeneidade genética, o que foi relacionado ao grande número de vetores e animais que atuam nos ciclos de transmissão ali, ao contrário da Costa Atlântica do Brasil, onde as amostras indicaram baixo nível de heterogeneidade (CUPOLILLO et al., 2003). No Rio de Janeiro, L. (V.) braziliensis parece ser bastante homogênea (BAPTISTA et al., 2009).

O diagnóstico da LTA se baseia na apresentação clínica, no isolamento parasitário por cultura, exames moleculares, sorologia e na visualização dos protozoários através de exame direto ou de avaliação histopatológica, (CAVALCANTI et al., 2013; PEDRAL-SAMPAIO et al., 2016; TSUKAYAMA et al., 2013).

O diagnóstico diferencial clínico e laboratorial para doenças como esporotricose, tuberculose, paracoccidioidomicose entre outras, deve ser considerado (MINISTÉRIO DA SAÚDE, 2017).

\section{REVISÃO BIBLIOGRÁFICA - MÉTODOS DIAGNÓSTICOS}

\subsection{Teste intradérmico de Montenegro}

O teste intradérmico de Montenegro representa o principal exame complementar para o diagnóstico da Leishmaniose Tegumentar Americana, entretanto, o antígeno para realização da IDRM não está disponível no Brasil há alguns anos, sem previsão de fornecimento pelo Ministério da Saúde. Trata-se de uma reação de hipersensibilidade tardia ocasionada após a inoculação de antígenos extraídos de

WWW.AMPLLAEDITORA.COM.BR (2)

CONTATO@AMPLLAEDITORA.COM.BR M 
culturas de leishmania spp. na derme do paciente. (CERUTTI et al., 2017; JOSÉ et al., 2001).

A resposta imune celular se manifesta por um endurecimento cutâneo resultante da aplicação intradérmica do antígeno de Leishmania, que pode ser medido em milímetros (ABBAS; LICHTMAN; PILLAI, 2012; GUEDES et al.,2017). É utilizado como método complementar ao diagnóstico por apresentar alta sensibilidade e especificidade (ANTONIO et al., 2014; GUEDES et al., 2017), que variam de 86 a 100\%, porém a especificidade diminui pelo fato de ocorrerem reações cruzadas do coquetel de antígeno utilizado. (ANDRADE et al., 2005; CERUTTI et al., 2017). E é de fácil execução e de baixo custo, pelo fato de não requerer equipamentos sofisticados. (ANTONIO et al., 2014; GUEDES et al., 2017).

\subsection{Cultura}

A cultura é um método de confirmação da presença do parasito, pois permite a visualização das formas promastigotas através do microscópio ótico. O fragmento de tecido é inoculado em meio de cultura bifásico NNN (McNeal, Novy e Nicolle), acrescido de meio líquido Schneider e incubado entre $26^{\circ} \mathrm{C}$ e $28^{\circ} \mathrm{C}$, temperatura ideal para $\mathrm{O}$ crescimento do parasito. A partir do quinto dia podem ser observadas as formas promastigotas. Serão realizados exames semanais até 1 mês para liberação do resultado negativo (MINISTÉRIO DA SAÚDE, 2017).

Permite a identificação das espécies, porém, como dito anteriormente é uma técnica que demanda tempo de crescimento. É um método específico pois permite a visualização do parasito, porém sua sensibilidade está em torno de 50\%. Casos crônicos, como aqueles com baixa carga parasitária na lesão, diminuem a sensibilidade deste método. (ANDRADE et al., 2005).

\subsection{Exame parasitológico direto}

O exame direto, através da escarificação da lesão que consiste na disposição do material coletado em lâmina, coloração, e visualização em microscópio ótico representa um método simples e acessível mesmo em condições de escassez de recursos laboratoriais em áreas endemicas (MELLO; MADEIRA, 2015). O 'imprint' de um fragmento de lesão cutânea coletado através de procedimento de biópsia também 
constitui método simples com sensibilidade superior à do exame histopatológico (SOUSA et al., 2014), embora necessite de anestesia local e constitua um procedimento exclusivo do profissional médico (MELLO; MADEIRA, 2015).

É o exame de primeira escolha para o diagnóstico de leishmaniose no Brasil. A coleta do material pode ser feita pelo raspado da lesão, aspirado por agulha fina (PAF) ou pelo lavado da cavidade nasal e oral. (MINISTÉRIO DA SAÚDE, 2017).

Apresenta melhores resultados logo nas primeiras semanas da doença pelo fato da contagem do parasito ser maior, porém sua sensibilidade diminui após a evolução das lesões. (CERUTTI et al., 2017; HOSSEINZADEH; OMIDIFAR; LOHRASB, 2012).

\subsection{Testes sorológicos}

Os testes sorológicos são considerados como método de rotina para o diagnóstico da leishmaniose visceral (LV), entretanto esses métodos são pouco utilizados para o diagnóstico da LTA devido à limitada manifestação sistêmica (ROCHA et al., 2006; SARKARI et al., 2014). Entre os testes sorológicos mais frequentemente utilizados para o diagnóstico da LTA estão o teste de aglutinação direta (DAT), imunofluorescência indireta (IFA) e o teste imunoenzimático (enzyme linked immunosorbent assay, ELISA) (PORFIRIO-PASSOS et al., 2012; SZARGIKI et al., 2009; SARKARI et al., 2014).

A sensibilidade e a especificidade desse teste variam dependendo do teste utilizado. Os testes de Western blot, ELISA (Enzyme-Linked Immunosorbent Assay) e imunoflorescência indireta (IFI) são mais citados nos trabalhos, com o ELISA e o IFI atingindo cerca de $90 \%$ de sensibilidade e o Western blot atingindo $100 \%$, porém este apresenta maior complexidade e custo. A utilização dos teste3s em paralelo pode aumentar a sensibilidade. (CERUTTI et al., 2017; SZARGIKI et al., 2009).

\subsection{Exame histopatológico}

As técnicas de imunocitoqúimica e imuno-histoquímica ampliam a sensibilidade do teste. É uma boa opção para o diagnóstico de lesões recentes e crônicas. (CERUTTI et al., 2017; DUARTE; ROCHAEL, 2006).

O exame histopatológico pode demonstrar os parasitos nos tecidos em $44 \%$ a 53\% dos casos (QUINTELLA et al., 2009; SOUSA et al., 2014), sendo fundamental para o 
diagnóstico diferencial com outras enfermidades. A imunohistoquímica é mais sensível que a histopatologia convencional na visualização dos parasitos (QUINTELLA et al., 2009).

Para a obtenção das biópsias é utilizado o "punch", no qual fragmentos de 3 a 5 $\mathrm{mm}$ são retirados facilmente. O local deve ser limpo e o fragmento deve ser manipulado sem que as estruturas sejam danificadas. Deve ser conservado em álcool. (MINISTÉRIO DA SAÚDE, 2017), facilitando a visualização do parasito, aumentando a especificidade do teste. (CERUTTI et al., 2017; VIANA et al., 2013).

\subsection{Diagnóstico molecular}

De todos os métodos apresentados, a Reação em Cadeia da Polimerase (PCR) é considerado o método de maior sensibilidade e especificidade, porém é de uso limitado, por ser caro e de execução complexa. (BOGGILD et al., 2008; CERUTTI et al., 2017).

Os minicírculos do DNA do cinetoplasto (kDNA) foram os primeiros alvos moleculares a serem estudados em parasitos do gênero Leishmania pela técnica de PCR (PACHECO et al., 1990). Pela análise das regiões variáveis dessas moléculas, foram desenvolvidos iniciadores, utilizados na PCR, que identificam as espécies responsáveis pela LTA, em nível de subgêneros ou complexos. Por estar presente em múltiplas cópias e por ser composto por regiões conservadas e variáveis nos minicírculos, o kDNA é excelente para o diagnóstico da LTA (MARCUSSI et al., 2008).

A PCR permite o estudo de variabilidade genética entre as espécies de Leishmania através da amplificação do fragmento de DNA, com ajuda de técnicas auxiliares (MARCUSSI et al., 2008).

\section{CONSIDERAÇÕES FINAIS}

A Leishmaniose é uma doença negligenciada que afeta principalmente pessoas mais necessitadas. O diagnóstico preciso é indispensável pois o tratamento dessa doença é hepatotóxico, e é imprescindível que haja um bom prognóstico. As escolhas do melhor teste podem ser definidas de acordo com a forma de apresentação da doença, a disponibilidade do teste no local onde este paciente está sendo atendido, o tempo de doença e a imunidade do indivíduo. 


\section{REFERÊNCIAS}

ABBAS, A.; LICHTMAN, A.; PILLAI, S. Imunologia Celular e Molecular. $7^{\text {a }}$ ed. Rio de Janeiro, 2012.

ANDRADE BB et al. Métodos Diagnósticos da leishmaniose tegumentar: Fatos, falácias e perspectivas. Gaz. Méd., v. 75, n. 1, p. 75-82, jan 2005.

ANTONIO L DE F. et al. Montenegro skin test and age of skin lesion as predictors of treatment failure in cutaneous leishmaniasis. Revista do Instituto de Medicina Tropical de São Paulo, v. 56, n. 5, p. 375-380, set. 2014.

BAÑULS AL, HIDE M, TIBAYRENC M. Evolutionary genetics and molecular diagnosis of Leishmania species. Transactions of the Royal Society of Tropical Medicine and Hygiene. v. 96, p. S9-S13, abr. 2002.

BAPTISTA C. et al. Leishmania (Viannia) braziliensis genotypes identified in lesions of patients with atypical or typical manifestations of tegumentary leishmaniasis: evaluation by two molecular markers. Exp Parasitol, 121 (4): 317-22, 2009.

BATES PA. Transmission of Leishmania metacyclic promastigotes by phlebotomine sand flies. International Journal for Parasitology. v. 37, n. 10, p. 1097-1106, ago. 2007.

BOGGILD AK et al. Optmization of Microculture and Evaluation of Microcultore for the Isolation of Leishmania Parasites from Cutaneous Laseions in Per. Am. J. Trop. Med. Hyg, v.79, n. 6, p. 847-852, 2008.

CANTACESSI, C. et al. The past, present, and future of Leishmania genomics and transcriptomics. Trends in Parasitology, v. 31, n. 3, p. 100-108, mar. 2015.

CATAÑO JC, PINZÓN MA. Disseminated Cutaneous Leishmaniasis in a Patient Infected by Leishmania panamensis. Am J Trop Med Hyg. 100(3):489-490, Mar 2019.

CAVALCANTI, M P, et al. Quantitative real time PCR assays for the detection of Leishmania (Viannia) braziliensis in animals and humans. Molecular and Cellular Probes, v. 27, n. 3-4, p. 122-128, jun. 2013.

CERUTTI PHP, LOPES CG, LOPES-FILHO FG, GUEDES VR. Métodos diagnósticos da leishmaniose tegumentar Americana: Uma revisão da literatura. Revista de Patologia do Tocantins, V. 4, n 4, dez 2017.

CUPOLILLO, E. et al. Genetic Polymorphism and Molecular Epidemiology of Leishmania (Viannia) braziliensis from Different Hosts and Geographic Areas in Brazil. JOURNAL OF CLINICAL MICROBIOLOGY, v. 41, n. 7, jul. 2003.

DUARTE ML, ROCHAEL MC. Perfil histopatológico e imuno-histoquímico da leishmaniose tegumentar Americana com ênfase nos dentrócitos dérmicos FXIIla+. Na. Bras. Dermatol., v.81, n. 6, p. 541-548, maio 2006. 
FRAGA, J. et al. Phylogeny of Leishmania species based on the heat-shock protein 70 gene. Infection, Genetics and Evolution, v. 10, n. 2, p. 238-245, mar. 2010.

GUEDES, D. C. et al. New strategy to improve quality control of Montenegro skin test at the production level. Revista da Sociedade Brasileira de Medicina Tropical, v. 50, n. 6, p. 788-794, dez. 2017.

HOSSEINZADEH M; OMIDIFAR N; LOHRASB MH. Use of fine needle aspiration cytology in the diagnosis of cutaneous leishmaniasis: A comparison with the conventional scraping method. Trop. Doct., v. 42, n. 2, p. 112-113, abr. 2012.

INBAR E, SHAIK J, IANTORNO SA, ROMANO A, NZELU CO, OWENS K, et al. Whole genome sequencing of experimental hybrids supports meiosis-like sexual recombination in Leishmania. Plos Genetics. 15(5): e1008042, 2019.

ISHIKAWA, E. A. Y. et al. Genetic variation in populations of Leishmania species in Brazil. Transactions of the Royal Society of Tropical Medicine and Hygiene, v. 96, p. S111-S121, abr. 2002.

JOSÉ FF et al. Avaliação do poder sensibilizante da reação de Montenegro. Revista da Sociedade Brasileira de Medicina Tropical, v. 34, n. 6, p. 537-542, nov 2001.

LAINSON R, SHAW JJ. Evolution, classification and geographical distribution. In: Peters $W$, KillickKendrick R, editors. The leishmaniases in biology and medicine. London: Academic Press. p. 12-120, 1987.

MARCUSSI et al. Leishmania (Viannia) braziliensis: New primers for identification using polymerase chain reaction. Experimental Parasitology. v 120, p. 300-305, 2008.

MELLO C. X.; MADEIRA M. F. Skin scraping is the most accessible technique for the parasitological diagnosis of American tegumentary leishmaniasis Am. J. Trop. Med. Hyg., v. 92, n. 5, p. 1082, 2015.

MINISTÉRIO DA SAÚDE. Manual de vigilância da leishmaniose tegumentar. Brasília-DF: 2017.

ODIWUOR, S. et al. Leishmania AFLP: Paving the way towards improved molecular assays and markers of diversity. Infection, Genetics and Evolution, v. 11, n. 5, p. 960967, jul. 2011.

PACHECO, R.S.; GRIMALDI Jr, G.; MOMEN, H.; MOREL, C.M. Population heterogeneity among clones of New World Leishmania species. Parasitology, v. 100, p. 393-8, 1990.

PEDRAL-SAMPAIO, G. et al. Detection of IgG Anti-Leishmania Antigen by Flow Cytometry as a Diagnostic Test for Cutaneous Leishmaniasis. Plos One. 885-941, 2016.

PORFIRIO-PASSOS, G. et al. MÉTODOS PARA DIAGNÓSTICO DA LEISHMANIOSE TEGUMENTAR AMERICANA - Revisão. ENCICLOPÉDIA BIOSFERA, v. 8, n. 15, p. 1233, 2012. 
QUINTELLA, L. P., et al. Immunoperoxidase technique using an anti-Leishmania (I.) chagasi hyperimmune serum in the diagnosis of culture-confirmed American tegumentary leishmaniasis. Rev. Inst. Med. Trop.Sao Paulo, v. 51, n. 2, p. 83-6, 2009.

REITHINGER, R. et al. Cutaneous leishmaniasis. The Lancet Infectious Diseases, v. 7, n. 9, p. 581-596, set. 2007.

ROUGERON V, DE MEEUS T, HIDE M, WALECKX E, BERMUDEZ H, AREVALO J, LLANOSCUENTAS A, DUJARDIN JC, DE DONCKER S, LE RAY D, AYALA FJ, BAÑULS AL. Extreme inbreedingin Leishmania braziliensis. Proc.Natl.Acad.Sci.U.S.A. 106, 10224-10229, 2009.

ROUGERON V, DE MEEUS T, BANULS AL. A primer for Leishmania population genetic studies. Trends in parasitology. 31(2):52-9, 2015.

SALES, K. G. DA S. et al. Home sweet home: sand flies find a refuge in remote indigenous villages in north-eastern Brazil, where leishmaniasis is endemic. Parasites \& Vectors, v. 12, n. 1, p. 118, dez. 2019.

SARKARI B. et al. Performance of an ELISA and Indirect Immunofluorescence Assay in Serological Diagnosis of Zoonotic Cutaneous Leishmaniasis in Iran. Interdisciplinary Perspectives on Infectious Diseases, 2014.

SZARGIKI R et al. Comparison of Serological and Parasitological Methods for Cutaneous Leishmaniasis Diagnosis in the State of Paraná, Brazil. The Brazilian Journal of Infection Diseases, v. 13, n. 1, p.47-52, fev. 2009.

SINGH S, DEY A, SIVAKUMAR R. Applications of molecular methods for Leishmania control. Expert Review of Molecular Diagnostics. v. 5, n. 2, p. 251-265, mar. 2005.

SOUSA, A. Q., et al. Short report: Press imprint smear: a rapid, simple, and cheap method for the diagnosis of cutaneous leishmaniasis caused by Leishmania (Viannia) braziliensis. Am. J. Trop. Med. Hyg. v. 91, n. 5, p. 905-7, 2014.

SRIVASTAVA S, SHANKAR P, MISHRA J, SINGH S. Possibilities and challenges for developing a successful vaccine for leishmaniasis. Parasites \& Vectors. v. 9, 12 mai. 2016.

TIBAYRENC M, BEN AS, GUERRINI F, BAÑULS AL. Leishmania and the clonal theory of parasitic protozoa. Arch.Inst.PasteurTunis.70,375-382, 1993.

TSUKAYAMA, P. et al. A FRET-Based Real-Time PCR Assay to Identify the Main Causal Agents of New World Tegumentary Leishmaniasis. PLoS Neglected Tropical Diseases, v. 7, n. 1, p. e1956, 3 jan. 2013. 
VIANA AG et al. Histopatological and immunohistochemical aspects of American cutaneous leishmaniasis before and after different treatments. Anais Brasileiros de Dermatologia, v. 88, n. 1, p. 32-40, jun 2013.

WORLD HEALTH ORGANIZATION. Status de endemicidade da leishmaniose cutânea no mundo. https://www.who.int/leishmaniasis/burden/GHO_CL_2018.pdf?ua=1 Acesso em 29/11/2020. 


\title{
CAPÍTULO VI
}

\section{NÍVEIS DE CITOCINAS TNF- $\alpha$, IFN- $\gamma$, E TGF- $\beta$ E 0 PERFIL CLINICO- EPIDEMIOLÓGICO DE INDIVIDUUOS COM CORIORETINITE POR TOXOPLASMOSE, SUL DO BRASIL}

\author{
Fernanda Ferreira Evangelista ${ }^{1}$ \\ Cristiane Maria Colli ${ }^{2}$ \\ Ariella Andrade Marchioro ${ }^{1}$ \\ Érika Cristina Ferreira ${ }^{1}$ \\ Ana Lúcia Falavigna-Guilherme ${ }^{1}$ \\ 1 Programa de pós-graduação - Ciências da Saúde, Universidade Estadual de Maringá (UEM), Brasil. \\ ${ }^{2}$ Departamento de Análises clínicas e biomedicina, UEM, Brasil.
}

\section{RESUMO}

As infecções pós-natais por Toxoplasma gondii podem ser responsáveis por lesões retinianas, incluindo a América do Sul, onde há desfechos mais frequentes e graves devido à diversidade genética do parasita. Objetivo: Descrever os níveis das citocinas TNF- $\alpha$, IFN- $\gamma$ e TGF- $\beta$ e o perfil clínico-epidemiológico de indivíduos com coriorretinite por toxoplasmose no Sul do Brasil. Métodos: Foram avaliados doze pacientes com coriorretinite, atendidos em serviços de oftalmologia da cidade de Maringá, Paraná, submetidos a fundoscopia e análise sorológica para anti-T. gondii IgM e IgG, usando Elisa MEIA e dosagem de TNF- $\alpha$, IFN- $\gamma$ e TGF- $\beta$ usando ELISA. O grupo controle foi composto por indivíduos saudáveis descritos por Conde et al 2013. Foram registrados dados clínico-epidemiológicos. Resultados: Os pacientes avaliados tinham idade média de 29 anos, predomínio de acometimento unilateral, e três indivíduos com IgM anti-T.gondii reativo, sendo duas crianças, com transmissão congênita e um, do sexo feminino, 20 anos, com infarto nodular. Os demais apresentavam apenas a presença do anticorpo IgG anti-T.gondii. Os níveis médios de TNF- $\alpha$ e IFN- $\gamma$ foram menores quando comparados aos controles. O TGF- $\beta$, por outro lado, estava em níveis mais elevados, destacando-se em um indivíduo adulto com IgM reativa e em outro paciente com imunodeficiência. Todos eles tinham pelo menos um fator de risco. Conclusão: Indivíduos com coriorretinite por toxoplasmose, geralmente unilateral e na idade adulta, com visão turva, apresentaram diminuição dos níveis de citocinas inflamatórias e aumento das citocinas antiinflamatórias. Estudos como esses são relevantes para auxiliar no entendimento da evolução da coriorretinite toxoplasmática na América do Sul.

Palavras-chave: Toxoplasma gondii. Coriorretinite. Citocina. TGF- $\beta$. TNF- $\alpha$. IFN- $\gamma$. 


\section{INTRODUÇÃO}

A toxoplasmose, causada pelo protozoário Toxoplasma gondii, é geralmente assintomática em indivíduos imunocompetentes, mas casos graves podem ocorrer em fetos por transmissão vertical de mulheres grávidas na fase aguda e em indivíduos imunossuprimidos (Frenkel, Dubey, \& Miller, 1970) . Porém, infecções pós-natais também podem ser responsáveis por casos de lesões retinianas, com sintomas clínicos no início, meses ou anos após a infecção, principalmente na população que vive na América do Sul. (Grigg et al., 2015; Silveira et al., 2015). Este fato, até então desconhecido, costumava ser atribuído a infecções congênitas (Wilson et al., 2011). No entanto, os resultados mais frequentes e graves da coriorretinite na América do Sul são atribuídos à diversidade genética de $T$. gondii (Grigg et al., 2015; Silveira et al., 2015), com polimorfismos únicos que não podem ser agrupados em nenhum dos 12 haplogrupos descritos (Higa et al., 2014). No Brasil, os genótipos circulantes geralmente variam de moderada a alta virulência (Peyron et al., 2006). Com o objetivo de contribuir para o entendimento da toxoplasmose ocular em indivíduos residentes no Sul do Brasil, este estudo descreveu os níveis das citocinas TNF$\alpha$, IFN- $\gamma$ e TGF- $\beta$ e o perfil clínico-epidemiológico de indivíduos com coriorretinite por toxoplasmose.

\section{MÉTODOS}

Entre janeiro e dezembro de 2015, dez pacientes com queixas clínicas de visão turva e história de toxoplasmose, e duas crianças cujas mães tiveram soroconversão dessa zoonose durante a gravidez, foram atendidas em serviços de oftalmologia na cidade de Maringá, Paraná. Este estudo foi aprovado pelo Comitê de Ética em Envolvimento de Seres Humanos (COPEP) do Centro Universitário Ingá (UNINGÁ), sob o no 301.312.

O exame oftalmológico consistiu na avaliação do fundo do olho por meio de mapeamento retiniano, utilizando oftalmoscópio indireto Eyetec e lente Volk de 20 dioptrias, realizado por oftalmologista especializado. O exame foi realizado sob midríase, utilizando colírio tropicamida $1 \%$ e fenilefrina $10 \%$ (Aleixo et al., 2009). Foco de coriorretinite em atividade, caracterizado por lesões brancas na coróide e retina, com ou sem exsudação vítrea, foram considerados características da toxoplasmose. 0 
sangue dos pacientes foi coletado para avaliação sorológica anti-T. gondii lgM e lgG, pelo método Elisa MEIA (Abbot Diagnostics AxSYM ${ }^{\oplus}$ ) e para dosagem de citocinas de TNF- $\alpha$, IFN- $\gamma$ e TGF- $\beta$. Essas citocinas foram analisadas por meio do kit ELISA (Human / Mouse ELISA Ready-Set Go, Bioscience, EUA), seguindo as recomendações do fabricante. As sensibilidades de deteç̧ão do kit foram as seguintes: TNF- $\alpha: 4$ pg / mL, IFN- 4 pg / mL e TGF- $\beta$ : 8 pg / mL. No momento da coleta, os pacientes não estavam em tratamento quimioterápico.

Para a comparação entre os níveis de citocinas no soro de pacientes e indivíduos saudáveis, usamos como grupo controle os dados publicados por Conde et al., 2013, que mediram as mesmas citocinas no soro de indivíduos saudáveis usando o mesmo kit usado neste estudo. A análise estatística foi realizada por meio da média aritmética e desvio padrão das citocinas investigadas por meio do teste paramétrico $T$, com auxílio do software Statistica Single User. Os valores considerados outliers foram desconsiderados para a análise estatística. Dados clínico-epidemiológicos, como lateralidade da infecção, queixa clínica, sexo, idade, hábitos alimentares como consumo de frescal (leite in natura, queijo fresco), carnes mal cozidas, hortaliças ou frutas in natura, fonte de água, local de residência, contato com gatos e manejo do solo.

\section{RESULTADOS}

Dos pacientes investigados, cinco eram do sexo masculino e sete do feminino, com média de idade de 29 anos, variando de 9 meses a 64 anos (Tabela 1). Houve apenas um caso com infecção bilateral (Tabela 1). Em três pacientes, foi detectada a presença de IgM anti-T.gondii. Os pacientes eram duas crianças, uma com 9 meses e a outra criança com um ano, correspondendo a casos de transmissão congênita. $O$ terceiro caso de IgM positivo foi uma mulher de 20 anos com infarto nodular. Os demais pacientes (9/12) apresentavam apenas anticorpo IgG anti-T.gondii reativo. 
Tabela 1: Dados clínico-laboratoriais de indivíduos com coriorretinite, Sul do Brasil.

\begin{tabular}{|c|c|c|c|c|c|c|c|c|c|c|}
\hline Caso & Idade & Sexo & $\operatorname{Ig} M$ & IgG & $\begin{array}{l}\text { TNF- } \alpha \\
\mathrm{pg} / \mathrm{mL}\end{array}$ & $\begin{array}{l}\text { INF- } \nu \\
\mathrm{pg} / \mathrm{mL}\end{array}$ & $\begin{array}{l}\text { TGF- } \beta \\
\mathrm{pg} / \mathrm{mL}\end{array}$ & Queixa principal & $\begin{array}{l}\text { Coriorretinite } \\
\text { recoreente }\end{array}$ & $\begin{array}{l}\text { Lateralidade } \\
\text { da infecção }\end{array}$ \\
\hline 1 & $9 \mathrm{~m}$ & $\mathrm{~F}$ & $\mathrm{R}$ & $\mathrm{R}$ & 6,26 & 23,01 & 2,85 & Visão embaçada & Não & Unilateral \\
\hline 2 & $1 a$ & $\mathrm{~F}$ & $\mathrm{R}$ & $\mathrm{R}$ & 13,67 & 24,63 & 60,51 & Visão embaçada & Sim & Bilateral \\
\hline 3 & $20 a$ & $\mathrm{~F}$ & $\mathrm{R}$ & $\mathrm{R}$ & 6,81 & 0,62 & $\begin{array}{c}17470 \# \\
88\end{array}$ & $\begin{array}{c}\operatorname{lnNd**} \\
\text { e Visão embaçada }\end{array}$ & Não & Unilateral \\
\hline 4 & $6 a$ & $\mathrm{~F}$ & NR & $\mathrm{R}$ & 6,58 & 6,01 & 16,52 & Visão embaçada & Sim & Unilateral \\
\hline 5 & $20 a$ & $F$ & NR & $\mathrm{R}$ & 6,89 & 9,57 & 106,78 & Visão embaçada & Sim & Unilateral \\
\hline $6^{*}$ & $24 a$ & $\mathrm{~F}$ & NR & $\mathrm{R}$ & 7,02 & 11,3 & $\begin{array}{c}22669 \# \\
74\end{array}$ & Visão embaçada & Sim & Unilateral \\
\hline 7 & $24 a$ & $\mathrm{~F}$ & NR & $\mathrm{R}$ & 6,55 & 23,74 & 94,25 & Visão embaçada & Sim & Unilateral \\
\hline 8 & $30 a$ & $M$ & NR & $R$ & 5,71 & 25,52 & 72,36 & Visão embaçada & Sim & Unilateral \\
\hline 9 & $38 a$ & $M$ & NR & $\mathrm{R}$ & 5,89 & 23,38 & 88,89 & Visão embaçada & Sim & Unilateral \\
\hline 10 & $55 a$ & $M$ & $N R$ & $R$ & 6,78 & 24,88 & 36,92 & Visão embaçada & Sim & Unilateral \\
\hline 11 & $63 a$ & $M$ & NR & $\mathrm{R}$ & 6,02 & 21,34 & 49,8 & Visão embaçada & Sim & Unilateral \\
\hline 12 & $64 a$ & $M$ & NR & $\mathrm{R}$ & 6,25 & 21,04 & 9,34 & Visão embaçada & Sim & Unilateral \\
\hline
\end{tabular}

m: meses de idade; a: anos / *: Paciente com histórico de imunodeficiência / R: Reativo / NR: Não Reativo / ** InNd: Infarto nodular/ \#: O valor não pode ser calculado com precisão por extrapolação linear da curva padrão.

A Tabela 1 mostra os níveis de TNF- $\alpha$, IFN- $\gamma$ e TGF- $\beta$ em cada um dos pacientes investigados. Os níveis médios de citocinas e o desvio padrão encontrados em pacientes com toxoplasmose ocular e em 97 controles, descritos por Conde et al 2013, são apresentados na tabela 2. Os níveis médios de TNF- $\alpha$, IFN- $\gamma$ e TGF- $\beta$ no o soro dos pacientes foi significativamente menor quando comparado ao grupo controle $(p<0,01$, Tabela 2). Os níveis de TGF- $\beta$ estavam especialmente aumentados em uma paciente adulta do sexo feminino, com anti-T. gondii IgM positivo, e em outra paciente adulta do sexo feminino, com histórico de imunodeficiência (Tabela 1).

Todos os indivíduos eram residentes em áreas urbanas, utilizavam água da Estação de Tratamento de Água (ETA) e apresentavam pelo menos um fator de risco para a infecção, principalmente hábito de ingestão de vegetais crus consumidos, ingestão de carne mal cozida e frescal. Nove $(9 / 12,75 \%)$ desses pacientes tinham dois ou mais fatores de risco. 
Tabela 2. Níveis de citocinas ( $\mathrm{pg} / \mathrm{mL}$ ) TNF- $\alpha$, IFN- $\gamma$ e TGF- $\beta$ no soro de indivíduos com toxoplasmose ocular recorrente, carnes mal cozidas e frescal do sul do Brasil.

\begin{tabular}{|c|c|c|c|c|c|c|c|}
\hline \multirow{3}{*}{ Citocina } & \multirow{2}{*}{\multicolumn{3}{|c|}{$\begin{array}{c}\text { Controle* }^{*} \\
(n=97)\end{array}$}} & \multirow{2}{*}{\multicolumn{3}{|c|}{$\begin{array}{l}\text { Casos } \\
(n=12)\end{array}$}} & \multirow{3}{*}{$P$} \\
\hline & & & & & & & \\
\hline & Média & \pm & SD & Média & \pm & SD & \\
\hline TNF- $\alpha$ & 21,4 & \pm & 15,8 & 7,0 & \pm & 2,1 & $0,0022 * *$ \\
\hline INF- $\nu$ & 136,8 & \pm & 84,4 & 17,9 & \pm & 8,6 & $0,0001 * *$ \\
\hline TGF- $\beta$ & 422,4 & \pm & 210,5 & $53,8 * * *$ & \pm & 37,0 & $0,0001 * *$ \\
\hline
\end{tabular}

\section{DISCUSSÃO}

Os indivíduos deste estudo eram em sua maioria adultos com episódios crônicos de reativação da coriorretinite por toxoplasmose, sendo a queixa principal embaçamento unilateral da visão. Níveis séricos diminuídos de citocinas inflamatórias, IFN- $\gamma$ e TNF- $\alpha$ e antiinflamatórios, citocina TGF- $\beta$ em comparação com indivíduos saudáveis foram observados entre os pacientes investigados. Além disso, De-la-Torre et al., 2013 observaram níveis reduzidos de IFN- $\gamma$ no humor aquoso de pacientes com toxoplasmose ocular na América do Sul, enquanto em pacientes europeus essa citocina estava elevada. Meira et al., 2014, no Brasil, também observaram diminuição dos níveis de IFN- $\gamma$ no soro de pacientes com toxoplasmose ocular, mas aumento dos níveis de TNF- $\alpha$. Tais achados são consistentes com a hipótese de que cepas sul-americanas podem causar toxoplasmose ocular mais grave devido à inibição do efeito protetor do IFN- $\gamma$. Deve-se lembrar que as cepas de $T$. gondii observadas na América do Sul são consideradas mais agressivas (Silveira et al., 2015), e as citocinas IFN- $\gamma$ e TNF- $\alpha$ são essenciais para a resposta imune do hospedeiro, no que se refere ao controle da latência de infecção crônica e diminuição da carga parasitária (Goldszmid et al., 2012). A resposta imune Th1 produz IFN- $\gamma$, TNF- $\alpha$ e outras citocinas, que têm a função de ativar macrófagos (Costa-Silva et al., 2012) e controlar a replicação de taquizoítos, tanto na fase aguda quanto na crônica da infecção (Leng et al., 2009). Já o TGF- $\beta$, com ação antiinflamatória, é capaz de promover a redução da resposta Th1, o que pode aumentar a patogênese do $T$. gondii. 
No entanto, neste estudo, os níveis de todas as citocinas investigadas foram diminuídos quando comparados aos controles. Os níveis de uma citocina podem ser alterados de acordo com o patógeno que pode estimular as vias imunológicas Th1, Th2 ou Th17. A variabilidade genética do hospedeiro também é um componente altamente relevante para a resposta imune individual e contribui para a suscetibilidade, evolução e patogênese de várias doenças infecciosas.

Uma possível falha em nosso estudo foi a comparação dos dados das citocinas com o grupo controle publicado anteriormente (Conde et al., 2013). Entretanto, acreditamos que esse fato não influenciou, uma vez que os indivíduos controle geralmente são pessoas saudáveis, sem processos inflamatórios, doenças autoimunes ou imunodeficiências.

Os pacientes apresentavam pelo menos um fator de risco para infecção e não foi possível estabelecer a provável causa da infecção. No entanto, o consumo de vegetais crus, carnes cruas / mal cozidas, bem como leite cru e fresco são consumidos com frequência. Além disso, Higa et al., 2010, também verificaram a prevalência desse consumo entre gestantes com suspeita de infecção aguda por toxoplasmose na mesma região. A maioria dos pacientes deste estudo não tem confirmação se a infecção foi congênita, com início dos sintomas de reativação na idade adulta.

\section{CONCLUSÃO}

Pacientes com coriorretinite por toxoplasmose, principalmente adultos, costumavam consumir vegetais crus, carnes cruas / mal cozidas e / ou frescal. A dosagem sorológica de algumas citocinas evidenciou baixos níveis de citocinas, IFN- $\gamma$, TNF- $\alpha$ e TGF- $\beta$. Estudos como esses são relevantes para auxiliar no entendimento da evolução da doença. Porém, conhecer o genótipo de T. gondii envolvido, identificar polimorfismos em genes de citocinas, que possam interferir na sua ação e / ou produção, associados a um maior número de amostras analisadas são fatores necessários para um melhor entendimento da coriorretinite causada pelo T. gondii. 


\section{AGRADECIMENTOS}

Agradecemos aos pacientes que aceitaram participar da pesquisa e aos profissionais que colaboraram. Agradecemos também ao programa Ciências da Saúde e a Coordenação de Aperfeiçoamento de Pessoal de Nível Superior (CAPES) pela concessão de bolsas de estudos.

\section{REFERÊNCIAS}

Aleixo, A. L. Q. D. C., Benchimol, E. I., Neves, E. D. S., Silva, C. S. P., Coura, L. C., \& Amendoeira, M. R. R. (2009). Frequência de lesões sugestivas de toxoplasmose ocular em uma população rural do Estado do Rio de Janeiro. Revista Da Sociedade Brasileira de Medicina Tropical, 42(2), 165-169. https://doi.org/10.1590/S0037-86822009000200014

Conde, S. R. S., Feitosa, R. N. M., Freitas, F. B., Hermes, R. B., Demachki, S., Araújo, M. T. F., ... Vallinoto, A. C. R. (2013). Association of cytokine gene polymorphisms and serum concentrations with the outcome of chronic hepatitis B. Cytokine, 61(3), 940-944. https://doi.org/10.1016/j.cyto.2013.01.004

Costa-Silva, T. A., Borges, M. M., Galhardo, C. S., \& Pereira-Chioccola, V. L. (2012). Immunization with excreted/secreted proteins in AS/n mice activating cellular and humoral response against Toxoplasma gondii infection. Acta Tropica, 124(3), 203-209. https://doi.org/10.1016/j.actatropica.2012.08.013

de-la-Torre, A., Sauer, A., Pfaff, A. W., Bourcier, T., Brunet, J., Speeg-Schatz, C., ... Candolfi, E. (2013). Severe South American Ocular Toxoplasmosis Is Associated with Decreased Ifn- $\gamma / \mathrm{II}-17 \mathrm{a}$ and Increased II-6/II-13 Intraocular Levels. PLoS Neglected Tropical Diseases, 7(11). https://doi.org/10.1371/journal.pntd.0002541

Frenkel, J. K., Dubey, J. P., \& Miller, N. L. (1970). Toxoplasma gondii in Cats: Fecal Stages Identified as Coccidian Oocysts. Science, 168(3929), 353-353. https://doi.org/10.1126/science.168.3929.353-a

Goldszmid, R. S., Caspar, P., Rivollier, A., White, S., Dzutsev, A., Hieny, S., ... Sher, A. (2012). NK Cell-Derived Interferon- $\nu$ Orchestrates Cellular Dynamics and the Differentiation of Monocytes into Dendritic Cells at the Site of Infection. Immunity, 36(6), 1047-1059. https://doi.org/10.1016/j.immuni.2012.03.026

Grigg, M. E., Dubey, J. P., \& Nussenblatt, R. B. (2015). Ocular toxoplasmosis: Lessons from Brazil. American Journal of Ophthalmology, 159(6), 999-1001. https://doi.org/10.1016/j.ajo.2015.04.005

Higa, L. T., Araújo, S. M., Tsuneto, L., Castilho-Pelloso, M., Garcia, J. L., Santana, R. G., \& Falavigna-Guilherme, A. L. (2010). A prospective study of Toxoplasma-positive 
pregnant women in southern Brazil: A health alert. Transactions of the Royal Society of Tropical Medicine and Hygiene, 104(6), 400-405. https://doi.org/10.1016/j.trstmh.2010.01.006

Higa, L. T., Garcia, J. L., Su, C., Rossinid, R. C., \& Falavigna-Guilhermee, A. L. (2014). Toxoplasma gondii genotypes isolated from pregnant women with follow-up of infected children in southern Brazil. Transactions of the Royal Society of Tropical Medicine and Hygiene, 108(4), 244-246. https://doi.org/10.1093/trstmh/tru014

Leng, J., Butcher, B. A., Egan, C. E., Abi Abdallah, D. S., \& Denkers, E. Y. (2009). Toxoplasma gondii Prevents Chromatin Remodeling Initiated by TLR-Triggered Macrophage Activation. The Journal of Immunology, 182(1), 489-497. https://doi.org/10.4049/jimmunol.182.1.489

Meira, C. S., Pereira-Chioccola, V. L., Vidal, J. E., de Mattos, C. C. B., Motoie, G., CostaSilva, T. A., ... Previato, M. (2014). Cerebral and ocular toxoplasmosis related with IFN- $y$, TNF- $\alpha$, and IL-10 levels. Frontiers in Microbiology, 5(OCT). https://doi.org/10.3389/fmicb.2014.00492

Peyron, F., Lobry, J. R., Musset, K., Ferrandiz, J., Gomez-Marin, J. E., Petersen, E., ... Cesbron-Delauw, M. F. (2006). Serotyping of Toxoplasma gondii in chronically infected pregnant women: predominance of type II in Europe and types I and III in Colombia (South America). Microbes and Infection, 8(9-10), 2333-2340. https://doi.org/10.1016/j.micinf.2006.03.023

Silveira, C., Muccioli, C., Holland, G. N., Jones, J. L., Yu, F., De Paulo, A., \& Belfort, R. (2015). Ocular involvement following an epidemic of toxoplasma gondii infection in santa isabel do ivaí, Brazil. American Journal of Ophthalmology, 159(6), 10131021.e3. https://doi.org/10.1016/j.ajo.2015.02.017

Wilson, C., Nizet, V., Maldonado, Y., Remington, J., Krupp, M. A., \& Klein, J. (2011). Infectious Diseases of the Fetus and Newborn. Infectious Diseases of the Fetus and Newborn Infant. Elsevier. https://doi.org/10.1016/C2009-0-50442-4 


\section{CAPÍTULO VII}

\section{NEUROCISTICERCOSE: ASPECTOS EPIDEMIOLÓGICOS, CLINICOS E LABORATORIAIS - UMA REVISÃO BIBLIOGRÁFICA}

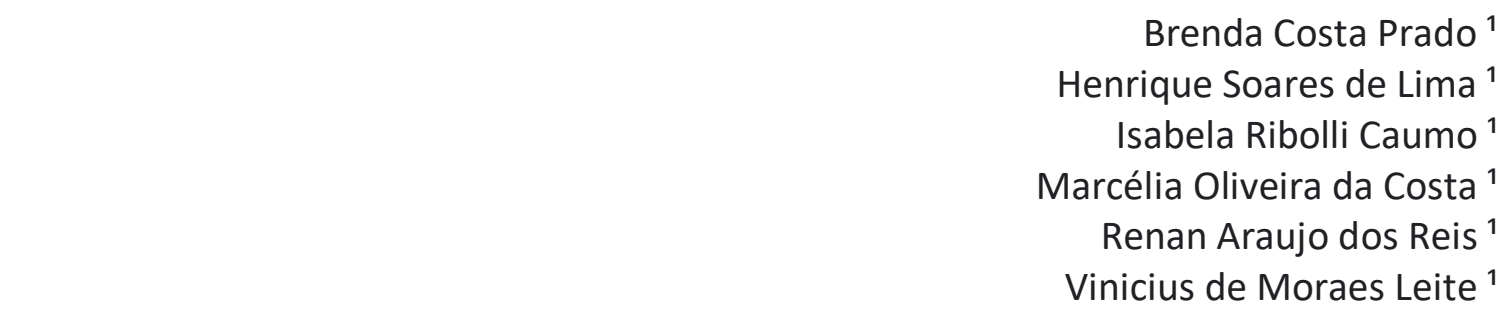

${ }^{1}$ Graduando(a) do curso de Medicina. Universidade Federal de Mato Grosso - UFMT

\section{RESUMO}

Esta revisão bibliográfica acerca da Neurocisticercose (NCC), uma infecção do Sistema Nervoso Central (SNC) causada pelo alojamento da larva da Taenia solium, objetiva abordar a doença dos pontos de vista epidemiológico, clínico e laboratorial, usando artigos das plataformas PubMed e SciELO, em um recorte temporal das duas últimas décadas. Essa doença, intimamente ligada a precárias condições sanitárias, intensificouse recentemente devido ao aumento dos fluxos migratórios e ao êxodo rural. A infecção ocorre por meio da ingestão de alimentos contaminados com os ovos da T. solium. A doença apresenta formas distintas e as manifestações, nos casos sintomáticos, dependem de fatores diversos, como quantidade e localização dos cistos e resposta imunológica individual do hospedeiro. Pode, ainda, desencadear doenças secundárias.

Palavras-chave: Neurocisticercose. Taenia solium. Sistema Nervoso Central.

\section{INTRODUÇÃO}

A NCC é caracterizada por uma infecção do SNC causada pela larva da Taenia solium. Trata-se de uma doença negligenciada, diretamente relacionada a condições sociossanitárias precárias, sendo prevalente em países subdesenvolvidos e em desenvolvimento (AGAPEJEV, 2011).

O diagnóstico da patologia em questão é realizado por meio da TC e da RM da cabeça. Vale ressaltar que além do diagnóstico por imagem, há também a análise laboratorial do líquido cefalorraquidiano (LCR) (LANGE, 2019).

Existem quadros clínicos assintomáticos e sintomáticos. Dentre estes, a convulsão é o sinal clínico mais característico da doença. No mais, o paciente também

WWW.AMPLLAEDITORA.COM.BR (2)

CONTATO@AMPLLAEDITORA.COM.BR M 
pode apresentar cefaleia, náuseas, aumento da pressão intracraniana e até acometimento do aparelho locomotor (DEL BRUTTO, 2013; SYMEONIDOU et al., 2013).

Diante do exposto, este artigo objetiva caracterizar os aspectos clínicos, epidemiológicos e laboratoriais da NCC, discorrendo sobre a fisiopatologia da doença e seu panorama no Brasil e no mundo, além de identificar critérios de avaliação e diagnóstico com base em achados nas duas últimas décadas.

Foi realizada uma revisão de literatura, nos idiomas português, inglês e espanhol, de produções científicas indexadas nas bases de dados eletrônicas SciELO e PubMed. Os descritores utilizados foram "Neurocysticercosis", "Clinical aspects", "Epidemiological aspects" e "cyst formation". O período considerado foi de 2000 a 2020. A seleção dos artigos deu-se, inicialmente, por meio da leitura e julgamento de títulos e resumos das produções. As obras relevantes ao estudo foram lidas integralmente, restando 25 artigos norteadores.

\section{REVISÃO BIBLIOGRÁFICA}

\subsection{Epidemiologia}

A zoonose conhecida por NCC caracteriza a infecção do SNC pela forma larval da Taenia solium (MORALES et al., 2000). Essa doença está atrelada às condições sociossanitárias precárias populacionais, sendo, dessa forma, considerada endêmica em países subdesenvolvidos e em desenvolvimento, como América Latina, África Subsaariana, Índia e sudoeste da Ásia (CHAGAS et al., 2003). Cabe, ainda, destacar que, devido aos fluxos migratórios globais, tem aumentado a incidência de casos em regiões desenvolvidas, tais quais Estados Unidos e Europa (GARCIA et al., 2003).

Nesse sentido, em razão das crises socioeconômicas mundiais ocorridas nos últimos anos, houve intensificação das migrações de populações, oriundas de regiões historicamente endêmicas, as quais, na maioria das vezes, portadoras da Taenia solium, acabam por levar a verminose para países em que não há grande incidência (SYMEONIDOU et al., 2018). Ilustrativamente, temos o aumento da infecção por NCC em crianças norte-americanas devido ao contato contínuo com babás contaminadas provenientes do México (OLIVEIRA et al., 2018). 
Além disso, conforme estudos realizados por Chagas MGL et al., a intensificação do êxodo rural promoveu o aumento do número de casos em áreas urbanas. Isto é favorecido pela baixa cobertura sanitária nas cidades. Outro fator também apontado pelo referido autor é que o perfil do portador de NCC avaliado em sua pesquisa não condiz com o perfil comum dos portadores dessa doença. A identificação de um estudante universitário e um profissional liberal reproduz esse fato controverso (CHAGAS et al., 2003).

A NCC acomete ambos os sexos em qualquer faixa etária, mas apresenta ligeiro predomínio em homens. No entanto, quando afeta mulheres, o curso da doença costuma ser mais agressivo em decorrência da resposta imunológica mais acentuada nesse grupo devido a questões hormonais. Outrossim, quanto maior a idade do paciente, menor a resposta imunológica, pois ocorre diminuição da quantidade de leucócitos presentes no líquido cefalorraquidiano (LCR), o que pode implicar maior quantidade de vermes encapsulados (cistos) (AGAPEJEV et al., 2007; FLEURY et al., 2004).

A perpetuação da NCC deve-se ao saneamento básico ineficiente bem como aos hábitos inadequados de higiene pessoal, que se relacionam diretamente com a contaminação dos recursos hídricos e, consequentemente, com o surgimento de novos casos (AGAPEJEV, 2003; WINKLER et al., 2009). Roman et al. estimam que a taxa de mortalidade, em escala mundial, devido à NCC seja de 50.000 pessoas por ano (ROMAN et al., 2000).

\subsection{Aspectos clínicos}

\subsubsection{Ciclo de vida da Taenia solium}

Após a ingestão, os ovos são eclodidos no estômago pela ação do suco gástrico, liberando a larva, que migra para o intestino, onde conclui seu processo de desenvolvimento, com cerca de 3 metros de comprimento. Aproximadamente dois meses depois, o verme adulto passa a liberar proglótides gravídicas contendo milhares de ovos, o que caracteriza a teníase (WINKLER et al., 2009).

Insta salientar que a larva, ao atingir a corrente sanguínea, pode alcançar qualquer tecido do corpo humano, tendo, contudo, maior afinidade pelos tecidos do 
SNC, onde desencadeia a NCC (AGAPEJEV, 2003). A figura 1 ilustra o complexo teníasecisticercose.

Figura 1 - Ciclo da Taenia solium

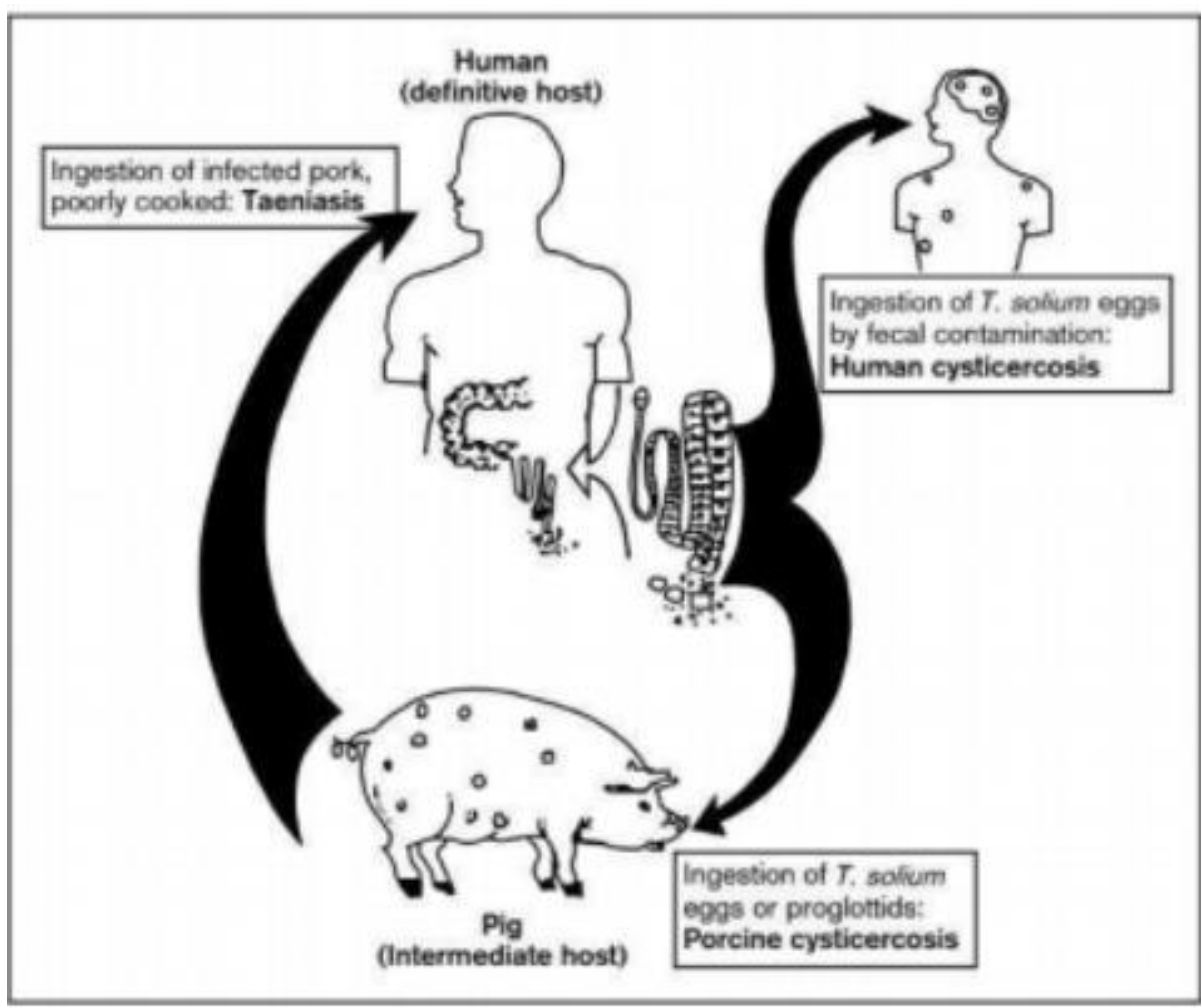

Fonte: (GARCIA et al., 2003).

\subsubsection{Manifestações clínicas}

Em razão de ser considerada um grave problema de saúde pública mundial, a NCC foi incluída na agenda da Assembleia Mundial de Saúde de 2003 (GARCIA et al., 2003). Prova disso é o fato de a NCC ser a maior causa de epilepsia tardia, de acordo com Silva AV et al (SILVA et al., 2006).Além das convulsões características da epilepsia, outros sintomas comuns são a cefaleia e os distúrbios psiquiátricos (WINKLER et al., 2009).

A sintomatologia da NCC depende de múltiplos fatores, tais como o número de cistos, sua localização no SNC e fase evolutiva e a resposta imunológica do hospedeiro. Estes, quando associados, irão determinar o quadro clínico do paciente (CHAGAS et al., 2003).

Um estudo, realizado por Morales NMO et al., identificou que crianças diagnosticadas com NCC, ainda que seja incomum, apresentaram déficit de atenção. 
Entretanto, quando ocorre em crianças, o período de incubação pode variar de poucos meses a até 30 anos. Nesse grupo de pacientes, os sintomas mais frequentes são as crises epiléticas, hipertensão intracraniana, encefalite e distúrbios psiquiátricos e cognitivos (MORALES et al., 2000).Dentre os sinais psíquicos, temos depressão, nervosismo, ansiedade e irritabilidade (AGAPEJEV, 2011).

Conforme a pesquisa de Rodrigues $\mathrm{CL}$ et al., o prejuízo cognitivo da NCC pode, ocasionalmente, variar do prejuízo em um único domínio até a demência, a qual ocorre apenas em pacientes com a doença ativa. Esse dano é mais notável durante a fase ativa vesicular e menos predominante no estágio calcificado. Verificou-se, contudo, que pode haver remissão dos sintomas cognitivos desde que os pacientes com lesões ativas sejam tratados com farmacologia regular (anti-helmínticos), deixando de se enquadrar no diagnóstico de demência (RODRIGUES, 2012).

A depender da localização do cisto, a NCC pode ser classificada como intra ou extraparenquimal. A forma intraparenquimal é considerada a manifestação benigna da doença, que mediante o elevado número de cistos, porém, pode caracterizar a NCC massiva (Figura 2). Esta provoca convulsões descontroladas e deficiência cognitiva. Quando o cisto invade o sulco lateral (fissura de Sylvian), ele se desenvolve a um cisto gigante (Figura 3), causando hemiparesia. Já a forma extraparenquimal, caracterizada pela fixação dos cistos nas cisternas basais (Figura 4 - A e B), ou seja, na região ventricular, culmina em NCC racemosa, que pode desencadear doenças secundárias como meningite neurocisticercótica e hidrocefalia (ODASHIMA e TAKAYANAGUI , 2006). 
Figura 2 - NCC massiva

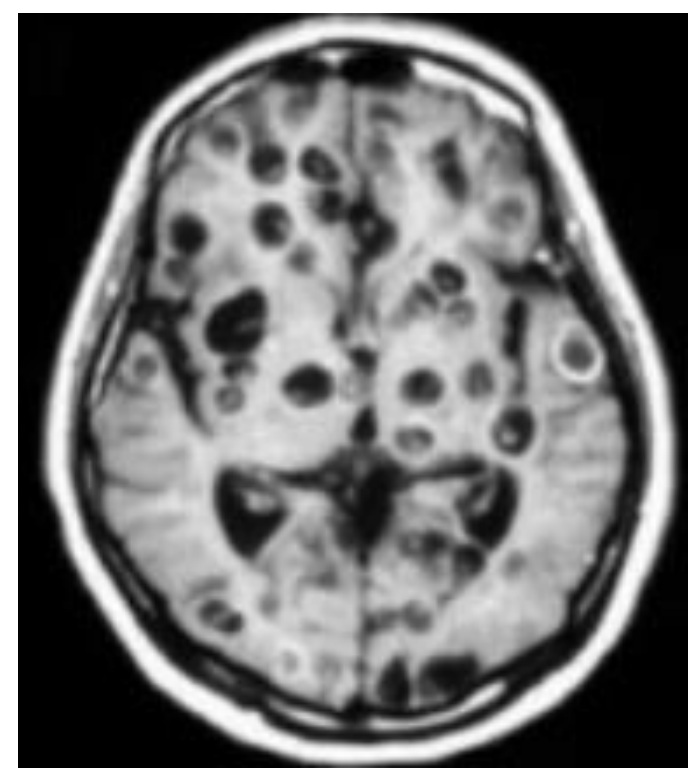

Fonte: (ODASHIMA e TAKAYANAGUI , 2006).

Figura 3 - Cisto gigante

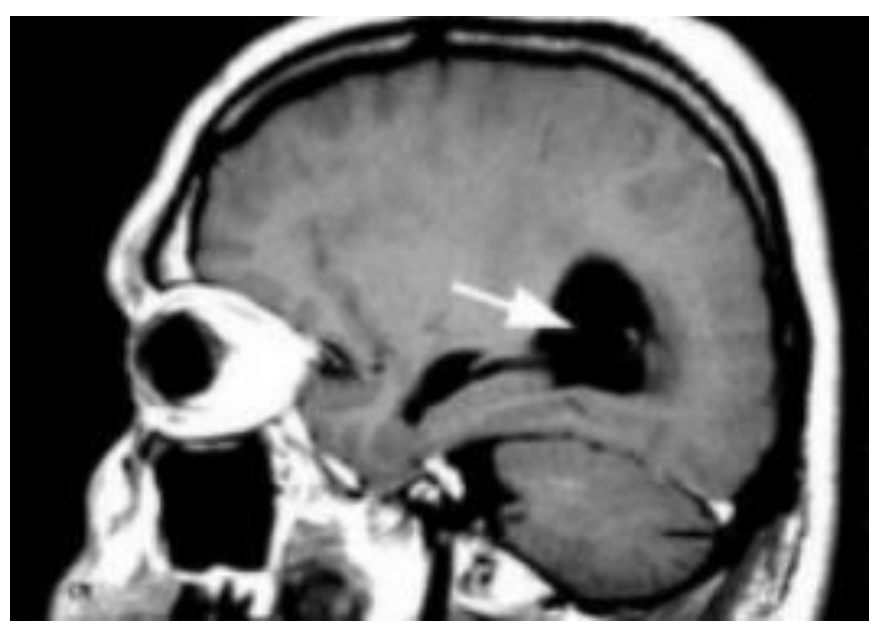

Fonte: (ODASHIMA e TAKAYANAGUI , 2006). 
Figura 4 - Cistos extraparenquimais

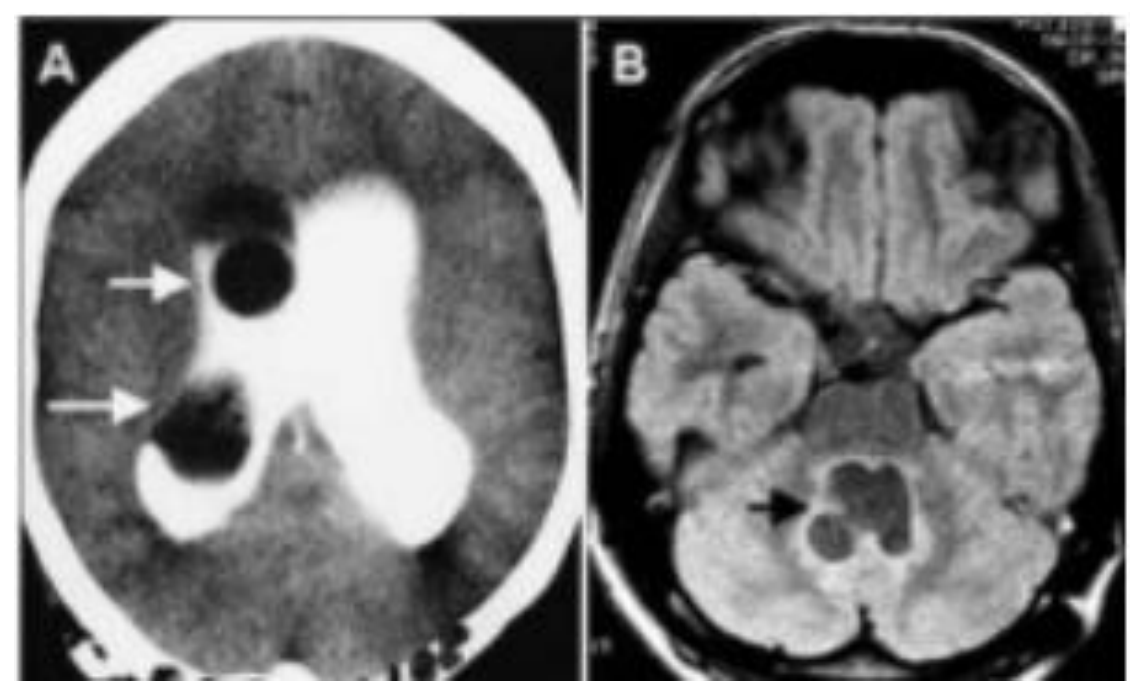

Fonte: (ODASHIMA e TAKAYANAGUI , 2006).

\subsubsection{NCC espinal}

Há também, além dos tipos supracitados e mais frequentes da doença, a NCC espinal (Figura 5), em que os indivíduos acometidos apresentam dor radicular, parestesia, distúrbios do esfíncter, disfunção sexual, dormência progressiva e fraqueza nas extremidades inferiores e, consequentemente, dificuldades para locomoção. Esse tipo, porém, é raro, englobando de 1 a 5,8\% dos casos registrados da doença (NOGUERA et al., 2015).

A baixa incidência relaciona-se ao baixo fluxo sanguíneo na região da medula espinal, ou seja, a ocorrência de lesões é diretamente proporcional ao fluxo de sangue, o que inclusive explica o fato de lesões em regiões cerebrais promovidas pelo curso da NCC serem muito mais frequentes, visto que a corrente sanguínea no cérebro é cerca de 100 vezes maior (GUEDES-CORREA et al., 2006; LACOANGELI et al., 2013). 


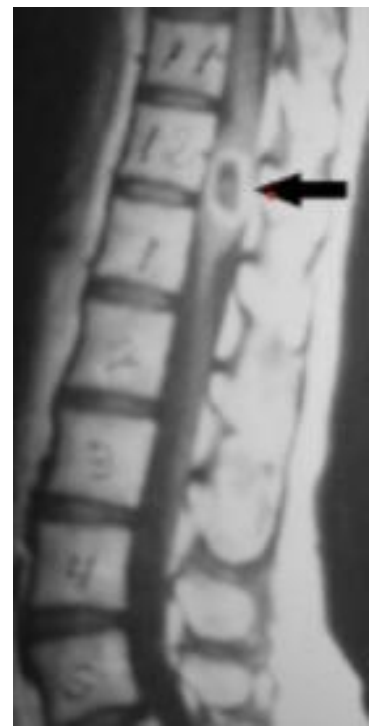

Fonte: (GUEDES-CORREA et al., 2006).

\subsubsection{Fases da NCC}

A NCC, apesar de apresentar um diagnóstico clínico relativamente difícil devido a seu polimorfismo, possui características progressivas de acordo com o estágio em que o cisto se encontra. Estes estágios são denominados: fase vesicular, fase coloidal, fase nódulo-granular e fase calcificada (AGAPEJEV, 2017; LANGE et al., 2017; WHITE JR, 2000).

Após a instalação do cisto no parênquima cerebral, espaço subaracnóideo ou nas cavidades ventriculares, o hospedeiro ainda passa um longo tempo sem apresentar sintomas aparentes. Isso se deve ao fato de que o cisto emprega várias funções modulatórias que permitem que ele permaneça sem ser afetado pelo sistema imunológico do hospedeiro. Esse primeiro estágio, no qual o cisto pode ser referido como "cisto viável", é denominado estágio vesicular (AGAPEJEV, 2017; LANGE et al., 2017; WHITE JR, 2000).

$\mathrm{Na}$ fase vesicular, a resposta inflamatória é nula para quase todos os casos. Nos poucos em que ocorrem manifestações clínicas, o hospedeiro apresenta sintomas como convulsões, aumento da pressão intracraniana, hidrocefalia e meningite (AGAPEJEV, 2017; LANGE et al., 2017; WHITE JR, 2000).

Especificamente, as crises convulsivas da fase vesicular são explicadas pela relação direta das transmissões sinápticas com a mudança significativa nas 
concentrações de neurotransmissores. Essas manifestações acompanham o aumento de glutamato, aspartato e ácido gama-aminobutírico (GABA) no LCR de pacientes com cistos viáveis (BERTOLUCI e CAMARGO, 2015).

Com o decorrer do tempo, o cisto perde sua capacidade de modular a resposta imunológica do hospedeiro e sua parede passa a ser atacada por células inflamatórias do indivíduo; este momento é denominado estágio coloidal. Nesse, o hospedeiro passa a apresentar convulsões e a resposta inflamatória muda ligeiramente, passando a ser muito mais aguda (AGAPEJEV, 2017; LANGE et al., 2017; WHITE JR, 2000).

Decorrido este período, a resposta imune do indivíduo passa a ser extremamente intensa, fazendo com que o cisto seja circundado por colágeno, ocasionando uma gliose perilesional; este período é denominado estágio nódulo-granular. Juntos, o estágio coloidal e o estágio nódulo-granular, formam o chamado período transicional (AGAPEJEV, 2017; LANGE et al., 2017; WHITE JR, 2000).

Finalmente, o cisto é todo revestido em decorrência do processo de fibrose, posteriormente é calcificado e então morre. Neste momento o hospedeiro permanece apresentando convulsões frequentes e, além de gliose perilesional, também passa a apresentar edema na região encefálica; este último estágio é conhecido como fase calcificada (AGAPEJEV, 2017; LANGE et al., 2017; WHITE JR, 2000).

Segundo Christensen NM et al., em uma pesquisa envolvendo porcos, a presença de cistos no tecido nervoso do hospedeiro estimula a resposta imunológica e, assim, promove a deposição de colágeno do tipo I em torno do cisticerco, que pode estar relacionada ao desenvolvimento de crises convulsivas. Desse modo, é possível inferir que a quantidade de colágeno é diretamente proporcional ao grau de degeneração do cisto (CHRISTENSEM, 2016).

\subsubsection{Casos assintomáticos}

Além dos casos sintomáticos clássicos da NCC, há também os casos assintomáticos, nos quais o indivíduo é portador do parasita, mas não manifesta nenhum sintoma. Nestes, só é sabido da condição do portador após seu óbito, decorrente de fatores diversos não relacionados à doença. Conforme Lino-Junior RS et al., em pesquisa, realizada no hospital escola da Universidade Federal do Triângulo Mineiro (UFTM), acerca de protocolos de 2218 autópsias entre os anos de 1970 e 2003, 
detectou-se a NCC em 2,4\% deles. Insta salientar, no entanto, que o referido percentual pode ser subestimado, visto que nem todos os óbitos são submetidos a exames necroscópicos. Cabe, ainda, destacar que, em pacientes assintomáticos, o cisticerco vivo pode causar supressão ativa da resposta imunológica (LINO-JUNIOR et al., 2007;LINO JUNIOR, 2002;SINGH et al., 2003).

\subsection{Aspectos laboratoriais}

A princípio, a detecção da tênia ocorria por meio de exames microscópicos com o intuito de identificar os ovos do parasita. Todavia, a semelhança com outros ovos parasitários torna o método pouco eficaz no âmbito da NCC (LANGE, 2019).

É pertinente destacar o exame ELISA, que, pelas alterações do LCR com a presença de pleocitose mononuclear, somado com eosinófilos e anticorpos, constata o estágio degenerativo do cisto. Contudo, diante de cistos isolados e diferenciação entre T. saginata de T. solium, o recurso mostra-se falho (ODASHMA e TAKAYANAGUI , 2006; SYMEONIDOU, 2018).

Além disso, a utilização de soro pela técnica de imunoeletrotransferência ligada a enzima EITB demonstra uma efetividade eminente quando o paciente apresenta mais de dois cistos extraneurais viáveis. Entretanto, o resultado negativo no teste não elimina a possibilidade de NCC, haja vista que na fase de calcificação não ocorre identificação do cisto (OLIVEIRA et al., 2018).

Atualmente, os métodos mais utilizados são a RM e a TC, que detectam o escólex invaginado. Sendo assim, o primeiro é mais efetivo quando o cisto não se encontra em estágio de calcificação, tendo em vista a membrana fina do cisto e a densidade do LCR. Em contrapartida, a TC evidencia a calcificação com maior precisão (CHAGAS et al., 2003; ODASHMA e TAKAYANAGUI , 2006).

\section{CONSIDERAÇÕES FINAIS}

Conclui-se, portanto, que, apesar da NCC apresentar diferentes quadros clínicos que variam conforme a região de alojamento do cisto, atualmente o diagnóstico da doença pode ser ligeiramente associado a sintomas comuns entre os mais variados casos. A partir dos estudos realizados em populações com grande taxa de indivíduos acometidos pela NCC, foi possível identificar, como aspecto clínico da doença, sintomas

WWW.AMPLLAEDITORA.COM.BR (2) 
frequentes à maior parte destes indivíduos. Dentre as manifestações estão a epilepsia de início tardio e o aumento da pressão intracraniana, além de doenças secundárias à NCC, como hidrocefalia e meningite.

Por outro lado, embora os avanços acerca do que se sabe a respeito da doença helmíntica que mais acomete o SNC no mundo tenham sido significativos, infelizmente não são suficientes para erradicar a NCC em regiões endêmicas. Este fator decorre do baixo investimento em mecanismos intervencionistas relacionados à saúde pública e ao saneamento básico, haja vista que os exames laboratoriais necessários para identificação da doença possuem custo elevado, e mesmo que essas aplicações fossem viabilizadas, ainda não seriam suficientes para sanar a problemática em questão, posto que é imprescindível a implementação de estruturas sociossanitárias dignas a todos os indivíduos vulneráveis.

\section{REFÊRENCIAS}

AGAPEJEV,Svetlana. Publisher.Neurocysticercosis: The Enigmatic Disease. Central Nervous System Agents Medicinal Chemistry.,v.11,n. 4,p.261-284,2011.

LANGE,Anja de.MAHANTY,Siddhartha.RAIMONDO,Joseph V.Model systems for investigating disease processes in neurocisticercosis. Parasitology.,v. 146,p.553562,2019 .

DEL BRUTTO,Oscar H. Neurocysticercosis: new thoughts on controversial issues. Curr Opin Neurol.,v.26,n.3,p.289-294,2013.

SYMEONIDOU,I.et.al.Human taeniasis/cysticercosis: a potentially emerging parasitic disease in Europe.Annals of Gastroenterology.,v. 31,n. 4,p.406-412,2018.

MORALES,Nivea Mo.et.al. Clinical aspects of neurocisticercosis in children. Pediatr Neurol., v. 22, n. 4, p. 287-291,2000.

CHAGAS, Maria das Graças Loureiro das; D' OLIVEIRA JUNIOR, Argemiro; TAVARESNETO, José. Manifestações clínicas da neurocisticercose na região do semi-árido do nordeste brasileiro. Arq. Neuro-Psiquiatr., São Paulo , v. 61, n. 2B, p. 398$402,2003$.

GARCIA, Hector H, GONZALEZ, Armando E, GILMAN, Robert H. Diagnosis, treatment and control of Taenia solium cysticercosis. Curr Opin Neurol ,.v.16, n. 5 ,p. 411$419,2003$.

OLIVEIRA,Ricardo S.et al.Pediatric neurocysticercosis. Child's System,.v.34,p. 19571965, 2018. 
FLEURY,Agnes.et al . Symptomatic human neurocysticercosis. Age, sex and exposure factors relating with disease heterogeneity. J Neurol,.v. 251,p.830-837, 2004.

AGAPEJEV, Svetlana.et al. Aspectos clínicos e evolutivos da hidrocefalia na neurocisticercose. Arq. Neuro-Psiquiatr., São Paulo , v. 65, n. 3a, p. 674680, 2007.

WINKLER,Andrea S. et al. Epilepsy and neurocysticercosis in sub-Saharan África. Springer-Verlag,.v. 121, p.3-12,2009.

AGAPEJEV, Svetlana. Aspectos clínico-epidemiológicos da neurocisticercose no Brasil: análise crítica. Arq. Neuro-Psiquiatr., São Paulo, v. 61, n. 3B, p. 822-828, 2003.

ROMAN, G.et al. A proposal to declare neurocysticercosis an international reportable disease. Bull World Health Organ.,v.78, n.3, p.399-406,2000.

SILVA, Alexandre Valotta da.et al . Neurocysticercosis and microscopic hippocampal dysplasia in a patient with refractory mesial temporal lobe epilepsy. Arq. NeuroPsiquiatr., São Paulo, v. 64, n. 2a, p. 309-313, 2006.

RODRIGUES, Cleonísio L. The spectrum of cognitive impairment in neurocysticercosis: differences according to disease phase (Abstract). Arq. Neuro-Psiquiatr., São Paulo, v. 70, n. 5, p. 387,2012.

TAKAYANAGUI,Osvaldo M,ODASHIMA,Newton S. Clinical aspects of neurocysticercosis. Parasitology International,.v.55,p. 111-115,2006.

NOGUERA, Elda M.S. SIC Pineda R, SOLIS, Fernando E. Intramedullary espinhal cord neurocysticercosis presenting as Brown-Séquard syndrome. BMC Neurology .,v.15,2015.

LACOANGELI, M.et al. Isolated cysticercosis of the cauda equina. Journal of Neurociences in Rural Pratic,v. 4,p. 117-119,2013.

GUEDES-CORREA, José Fernando et al. Cisticercose espinhal intramedular simulando tumor de cone medular: relato de caso. Arq. Neuro-Psiquiatr. , São Paulo, v. 64, n. 1, pág. 149-152,2006.

CAMARGO, José A, BERTOLUCI,Paulo Henrique F. Qualification of Amino Acid Neurotransmitters in Cerebrospinal Fluid of Patients with Neurocysticercosis. The Open Neurology Journal,.v.9, p.15-20.2015.

WHITE JR,AC. Neurocysticercosis: updates on epidemiology, pathogenesis, diagnosis and management. Annual Review of Medicine,.v.51,p.187-206,2000.

CHRISTENSEM,Nina M.et al. The association between seizures and deposition of collagen in the brain in porcine Taenia solium neurocysticercosis. Veterinary Parasitology,.v.228, p.180-182, 2016. 
LINO-JUNIOR, Ruy de Souza. et al .Anatomopathological aspects of neurocysticercosis in autopsied patients. Arq. Neuro-Psiquiatr., São Paulo , v. 65, n. 1, p. 87-91, 2007.

LINO JUNIOR, Ruy de Souza.et al . Características evolutivas do Cysticercus cellulosae no encéfalo e no coração humanos. Rev. Soc. Bras. Med. Trop., Uberaba, v. 35, n. 6, p. 617-622, Dec. 2002.

SINGH,Aloukick K.et al. Immune responses to viable and degenerative metacestodes of Taenia solium in naturally infected swine. International Journal for Parasitology,.v.43,p.1101-1107,2003. 


\title{
CAPÍTULO VIII
}

\section{APLICAÇÃO DE FERRAMENTAS MOLECULARES PARA 0 DIAGNÓSTICO DE LEISHMANIOSE TEGUMENTAR AMERICANA}

\begin{abstract}
Giulia Ribeiro Fernandes ${ }^{1}$ Ricardo Lucas de Abreu da Cruz $^{2}$ Aline Fagundes da Silva ${ }^{3}$ Yasmin da Silva Santos ${ }^{4}$

\footnotetext{
${ }^{1}$ Graduanda do curso de Biomedicina. Universidade Castelo Branco - UCB

${ }^{2}$ Graduando do curso de Biomedicina. Universidade Estácio de Sá- UNESA

${ }^{3}$ Doutora Aline Fagundes da Silva. LaPClinVigiLeish/INI-FIOCRUZ
}

${ }^{4}$ Mestre em Ciências Yasmin da Silva Santos. LaPClinVigiLeish/INI-FIOCRUZ

\section{RESUMO}

As Leishmanioses são doenças causadas por protozoários do gênero Leishmania, caracterizadas por serem infecciosas e não contagiosas acometendo animais e seres humanos. Sua distribuição é global e, no Brasil, o Nordeste tem a maior prevalência de casos. As técnicas utilizadas para o diagnóstico são fundamentadas em exames clínicos, testes parasitológicos, moleculares e imunológicos. Com a busca de metodologias mais sensíveis, o uso da biologia molecular tem sido promissor no diagnóstico da Leishmaniose tegumentar Americana. Os Protocolos de PCR (Reação em cadeia da polimerase) baseados nos diferentes alvos moleculares disponíveis constituem atualmente a principal abordagem, permitindo a detecção da Leismania e sua caracterização em pesquisa. Existe uma ampla diversidade de primers que atendem a pesquisa e ao diagnóstico comportando metodologias simplificadas de biologia molecular a metodologias específicas para a pesquisa científica. Sendo assim este trabalho propõe a descrição dos principais alvos moleculares utilizados no diagnóstico das Leishmanioses e pesquisa científica, abordando suas principais vantagens. Para elaboração do presente estudo foram utilizadas as plataformas SciELO, PubMed, Google Acadêmico, MEDLINE e Lilacs como base de dados científicos. Foram selecionados artigos e dissertações redigidos nos idiomas inglês, português e espanhol publicados nos períodos de 2010 a 2020. A partir desta revisão, é possível constatar que a biologia molecular auxilia no desenvolvimento de novas metodologias para pesquisa e diagnóstico, com tempo de execução reduzido e possibilidade de execução de várias amostras por vez além de, possibilitar a caracterização sem a dependência de outra técnica.
\end{abstract}

Palavras-chave: Leishmaniose Tegumentar Americana. Diagnóstico. PCR. Alvos Moleculares. 


\section{INTRODUÇÃO}

As Leishmanioses são doenças infecto-parasitárias classificadas como antropozoonoses causada pelo protozoário do gênero Leishmania que acometem o homem, animais silvestres e domésticos, sendo o cão um dos principais reservatórios (BRASIL, 2017; LAINSON, 1985).

O parasito Leishmania divide se em dois subgêneros principais: Leishmania (L) e Viannia (V), e o parasita apresenta duas formas evolutivas: a forma promastigota, sendo essa flagelada e extracelular, e a forma amastigota sendo intracelular e sem movimento, vivendo alternadamente entre os hospedeiros vertebrados e insetos vetores, conhecidos como flebotomíneos sendo estes responsáveis pela sua transmissão (BRASIL, 2017; COURA, 2013; GONTIJO \& CARVALHO, 2003; REY, 2008).

As fêmeas dos flebotomíneos se infectam ao picar um hospedeiro infectado com a forma amastigota. As amastigotas se diferenciam em promastigotas no tubo digestivo do flebotomíneo, que se multiplicam migrando para as glândulas salivares do inseto. Ao realizarem um novo repasto sanguíneo em hospedeiros vertebrados, são injetadas as formas promastigotas junto com a saliva, que são fagocitadas pelos macrófagos e assim retomam a sua forma amastigota, onde se multiplicam a ponto de romper a célula hospedeira, sendo fagocitadas novamente por macrófagos. Então o inseto vetor realizará um novo repasto sanguíneo nesse indivíduo infectado, completando assim o ciclo evolutivo e favorecendo a sua propagação (BASANO \& CAMARGO, 2004; GONTIJO \& CARVALHO, 2003; REY, 2008).

Existem duas principais apresentações clínicas: a Leishmaniose Tegumentar (LT) nas Américas é conhecida como Leishmaniose Tegumentar Americana (LTA), e a Leishmaniose Visceral (LV) (Figura 2), com diferentes formas clínicas que se diferem de acordo com a espécie envolvida (BRASIL, 2017). Ainda assim a LTA pode apresentar diferentes padrões, sendo estas cutâneas localizadas, cutânea difusa, cutânea disseminada e mucocutânea (BRASIL, 2017; MORAES, 2015).

A Leishmaniose é descrita em 88 países e são amplamente distribuída em todas as regiões brasileiras com predominância nas regiões norte e nordeste. Em 2019 foram confirmados 18.962 casos de LTA e LV de acordo com os dados disponíveis no DATASUS. 
A Leishmaniose apresenta caráter ocupacional, sendo prevalente em homens com transmissão domiciliar e/ou peridomiciliar (BRASIL, 2017; DATASUS, 2019; OMS, 2014).

No Brasil o tratamento é realizado utilizando o antimoniato pentavalente (Sb5+) disponível sob a formulação de $\mathrm{N}$-metilglucamina e administrado em miligramas por quilograma de acordo com o peso corporal do paciente por dia (mg Sb5/Kg/dia). Por produzir efeitos adversos bem significantes devido a sua composição química em alguns casos onde não se obtém uma boa resposta ou seu uso seja impossibilitado deve ser recorrido um esquema terapêutico com um fármaco alternativo geralmente utilizados a anfontericina e a pentamidina porém ambos os fármacos apresentam reações adversas frequentes tais como complicações renais, alterações cardíacas, nefrotoxidade, hipoglicemia e diabetes mellitus (AGUIAR \& RODRIGUES, 2017; BRASIL, 2017, GONTIJO \& CARVALHO, 2003; SAMPAIO, 2013 FIOCRUZ, 1997).

As técnicas utilizadas para o diagnóstico são fundamentadas em exames clínicos, testes parasitológicos, moleculares e imunológicos. O exame clínico é baseado nos aspectos da lesão e nos sintomas apresentados pelo paciente, geralmente uma lesão característica da patologia apresenta borda bem definida com aspecto granuloso sendo confrontado com os aspectos epidemiológicos e o diagnóstico diferencial da lesão (SCHUBACH et al., 2001; SKRABA et al., 2014).

O isolamento em cultura é feito com o material da biópsia inoculado em meio de cultura NNN bifásico, utilizando Schneider suplementado com soro fetal bovino e, antibióticos (penicilina e estreptomicina), acompanhadas diariamente. Na cultura é possível observar formas infectantes ao vertebrado, a promastigota, sendo este método o padrão de referência diagnóstica, contudo o tempo de execução pode chegar até quatro semanas, além da possibilidade de contaminação por fungos (BRASIL, 2017; GONTIJO \& CARVALHO, 2003).

$\mathrm{Na}$ pesquisa direta das formas amastigotas utilizam-se os procedimentos de escarificação da borda da lesão, ou impressão do fragmento de biópsia em lâmina nos casos de LTA e, então observado em um microscópio óptico (BRASIL, 2017). No exame histopatológico o material da biópsia é armazenado em formol e posteriormente corado com hematoxilina-eosina, para análise baseada na presença do parasito no tecido. Existem também testes sorológicos tais como, o ELISA e imunofluorescência indireta (IFI) que avaliam a reação de anticorpos presentes no soro do paciente com antígeno de 
Leishmania visualizados por espectrofotometria (BRASIL, 2017; MINISTÉRIO DA SAÚDE, 2000).

Os ensaios baseados em PCR (Reação em cadeia da polimerase) constituem atualmente a principal abordagem no diagnóstico molecular permitindo a detecção da Leismania e sua caracterização em pesquisa. A técnica se baseia na amplificação de determinada sequência de DNA através da enzima Taq DNA polimerase que sintetiza seletivamente milhões de cópias. Para que a reação de PCR ocorra além do DNA das amostras a serem analisadas são acrescentados os dNTP's (desoxirribonucleotídeos fosfatados) junto com o par de iniciadores e a enzima Taq DNA polimerase. Ainda são adicionados o cloreto de magnésio $(\mathrm{MgCl} 2)$ e o cloreto de potássio $(\mathrm{KCl})$ que permitem as condições necessárias para o funcionamento da enzima taq-polimerase. Esse mix de reagentes é diluído em um tubo com a água ultrapura, e em seguida é colocado no termociclador que regula as temperaturas adequadas para cada etapa da PCR (MULLIS, 1990; NOVAIS \& PIRES-ALVES, 2004; SANTOS et al., 2014).

A PCR é dividida em três etapas: na primeira etapa a sequência de DNA é desnaturada por um aquecimento de aproximadamente 95 C, em seguida a temperatura diminui e se inicia a etapa de anelamento dos primers que se ligam as regiões específicas e por último ocorre a adição das bases nitrogenadas através da enzima Taq-polimerase, e esse processo ocorre na temperatura de $72 \circ \mathrm{C}$. O ciclo inteiro se repede com o resultado da primeira reação gerando novas cópias do DNA (SANTOS et al., 2014). No caso da cPCR (PCR Convencional), os resultados da amplificação são revelados por eletroforese em gel e posteriormente visualizados por um equipamento que emite luz ultravioleta (NOVAIS \& PIRES-ALVES, 2004; SANTOS et al., 2014).

Com o avanço da tecnologia foram desenvolvidas diferentes variações baseadas nos ensaios de PCR. A PCR em tempo real (qPCR) surgiu como uma metodologia inovadora permitindo a visualização direta dos resultados durante a amplificação de forma mais rápida e mais sensível em relação a PCR convencional, podendo até detectar DNA em amostras com baixa carga parasitária (CABRAL, 2007; BRASIL, 2017; GONTIJO \& MELO, 2004).

As etapas da reação são baseadas no mesmo princípio do método convencional o que difere é justamente a obtenção dos resultados, que são revelados através do termociclador acoplado com um sistema que permite a deteç̧ão e quantificação da

WWW.AMPLLAEDITORA.COM.BR (2)

CONTATO@AMPLLAEDITORA.COM.BR M 
fluorescência proveniente da amostra, após a extração do DNA, gerando curvas de amplificação. Além de um computador com um software especifico para análise final, dispensando assim o uso da eletroforese (AGNE et al., 2009; ARYA et al., 2005; NOVAIS \& PIRES-ALVES, 2004).

A qPCR garante menor risco de contaminação em comparação com outras técnicas como o isolamento em cultura, na qual a sensibilidade acaba sendo afetada pela frequente contaminação por bactérias e fungos, tanto pela manipulação, como da própria microbiota proveniente da pele nas amostras de biópsia (MORAIS, 2015; SANTOS, 2019).

Além da pequena quantidade necessária de material biológico, outro ponto importante da PCR é a diferenciação dos agentes infecciosos, que pode ser feita pela análise de polimorfismo dos alvos através da técnica do polimorfismo de comprimento de fragmento (RFLP) (BHATTARAl et al., 2009). Os alvos são importantes pelas suas sensibilidade e especificidade, características do ensaio que são intrínsecas a escolha dos iniciadores, que podem resultar em falso positivo ou falso negativo (DENIAU et al., 2003).

O Laboratório de Pesquisa Clínica e Vigilância em Leishmaniose (LaPClinVigiLeish) utiliza na sua rotina diagnóstica o mecanismo da PCR baseado na amplificação de uma região conservada dos maxi e mini círculos do cinetoplasto do parasito (KDNA) de 120 pares de base (PB), conhecida como KDNA PCR (FAGUNDES, 2010) sendo capaz de evidenciar a presença do parasito na amostra de pacientes sem o amparo do cultivo in vitro (BASANO \& CAMARGO, 2004; BRASIL, 2017; MINISTÉRIO DA SAÚDE, 2000).

A GP63 é uma glicoproteína encontrada na membrana das duas formas evolutivas de diferentes espécies de Leishmania, e estão ligadas principalmente no grau de virulência do parasito e no reconhecimento dos receptores de macrófagos. Além de conferir proteção ao parasito contra enzimas citolíticas, este alvo molecular e suas subpopulações (MSP) proporcionam a identificação da Leishmania sendo capaz de discriminar as espécies do subgênero Viannia (SANTOS 2019; SILVA, 2010).

Outro alvo molecular disponível é a subunidade do rNA ribossomal (SSU-rNA) que possui múltiplas cópias com uma alta conservação, presente em todas as espécies, o que confere maior sensibilidade na deteç̧ão da Leishmania descartando assim casos de falsos negativos. Como SSU-rNA possui regiões muito conservadas, ocorre uma 
dificuldade frente a relações de filogenias principalmente as espécies do subgênero L. (Vianna), sendo estas necessária à realização de sequenciamento como complemento (SILVA, 2010; WINTER, 2010). A região dos espaçadores internos transcritos (ITS1 e ITS2) é um alvo mais comum na identificação de espécies do Velho mundo como Europa e Ásia. Com o auxílio de enzima de restrição é possível diferenciar algumas espécies que circulam nas Américas, não sendo possível a diferenciação completa do subgênero Viannia (SANTOS, 2019).

Muitos estudos mostram a eficácia da utilização de proteínas de choque térmico como alvo molecular na caracterização específica de Leishmania. A HSP70 possui em torno de 10 a 15 cópias podendo variar de uma espécie para outra. Graça e colaboradores (2012) ainda descreveram quatro primers iniciadores ao longo do gene HSP70, com sensibilidades variantes. Esta proteína está intimamente ligada a síntese de proteínas, no controle de diferenciação entre as formas evolutivas, e desempenha um papel fundamental na proteção do parasito contra fatores tóxicos, prevenindo sua apoptose (GRAÇA et al., 2012; MONTALVO et al., 2017; SANTOS, 2019).

Com a ampla diversidade das técnicas e alvos moleculares disponíveis na biologia molecular este trabalho propõe a descrição dos principais alvos moleculares utilizados no diagnóstico das Leishmanioses e pesquisa científica, abordando suas principais vantagens e finalidades aos seus propósitos.

\section{METODOLOGIA}

O estudo consiste em busca bibliográfica, não fazendo uso de amostras de humanos ou animais, portanto, não foi necessário o aval de um Comitê de ética em pesquisa (CEP). A elaboração desta revisão visou buscar na literatura ferramentas moleculares usadas no diagnóstico de leishmaniose tegumentar empregando as plataformas SciELO, PubMed, Google Acadêmico, MEDLINE e Lilacs como base de dados científicos. Na busca pelos materiais disponíveis na literatura através das plataformas utilizadas foram empregados os descritores Leishmaniose Tegumentar Americana, diagnóstico molecular e alvos moleculares juntamente com o operador AND. Foram previamente selecionados artigos, dissertações e teses redigidos nos idiomas inglês, português e espanhol publicados nos períodos de 2010 a 2020 a partir da análise dos

WWW.AMPLLAEDITORA.COM.BR (2) 
títulos e concordância com os descritores empregados. Em seguida foi realizada a leitura completa dos textos e então selecionados aqueles em que a abordagem realmente se relacionou ao diagnóstico molecular da LTA e os diferentes tipos de alvos moleculares utilizados, sendo esse o principal critério de inclusão.

A estratégia de exclusão levou em consideração o período de publicação (2010 a 2020) e aqueles estudos que de certa forma não atendiam a temática. Ao final da análise de dados foram utilizados 8 artigos em língua portuguesa e 10 em língua estrangeira (inglês e espanhol). Entre os materiais selecionados para a composição utilizou-se também 4 dissertações em português. As informações para a composição da revisão foram obtidas primeiramente por uma pré-leitura seguida de uma leitura seletiva com o intuito de analisar as informações fundamentais onde foram incluídas em um apontamento contendo os dados importantes para a elaboração da revisão.

\section{RESULTADOS}

Com o avanço das tecnologias nas metodologias moleculares muitas pesquisas têm utilizado como foco o desenvolvimento de ferramentas mais sensíveis objetivando a rapidez no diagnóstico das leishmanioses. De acordo com os estudos disponíveis na literatura os ensaios de PCR convencional e PCR em tempo real geralmente associada com enzimas de restrição são as principais abordagens diagnósticas para as leishmanioses dentro do campo da biologia molecular (GOES, 2019; SANTOS, 2019).

Tanto a sensibilidade quanto especificidade da reação de PCR variam de acordo com o alvo molecular utilizado e a espécie envolvida. Dentre os alvos mais utilizados na identificação de Leishmania através da PCR, o DNA presente nos minicírculos do cinetoplasto do parasito, conhecido como kDNA, se destaca por estar presente em maior parte, possuindo em sua composição 500 a 2.500 pares de bases com aproximadamente 10.000 a 20.000 cópias permitindo uma maior sensibilidade, porém quando se trata de caracterização este alvo não

é bem aplicável (CABRAL, 2007; GONTIJO \& MELO, 2004; NUNES et al., 2007).

Procurando avaliar o desempenho da PCR na identificação e na caracterização de Leishmania, os protocolos de cPCR-kDNA utilizados nos em três dos estudos analisados, demostraram alta sensibilidade de deteç̧ão do DNA de Leishmania com o 
alvo kDNA sendo capaz de caracterizar as espécies L. (L.) infantum chagasi e L. (V) braziliensis. Esse alvo mostrou algumas limitações em caracterização espécie-específica não sendo possível caracterizar todas as espécies (COSTA, 2014; MARTINS, et al., 2010; SATOW, et al., 2013).

Muitos estudos vêm propondo a utilização do protocolo HSP70PCR tanto na detecção de Leishmania como a sua caracterização. GRAÇA, et al., (2012) desenhou quatro primers iniciadores no gene $\operatorname{HSP70}(A, B, C$ e D), ao qual a região $C$ de 234 pares de base apresentou maior desempenho em relação aos demais. Utilizando o alvo HSP70c junto a PCR convencional seguido de enzimas de restrição (HSP70c PCR RFLP) foi possível caracterizar espécies de Leishmania dos subgêneros Viannia e Leishmania. Seguindo essa mesmo raciocínio MONTALVO, et al., (2016); MONTALVO, et al., (2017) e SANTOS, (2019), utilizaram os protocolos de cPCR-HSP70 mostrando ainda um ótimo desempenho em caracterização espécie-específica, identificando as espécies $L$. panamensis, L. braziliensis, L. infantum e L. guyanensis.

Dos alvos disponíveis a região IGS rRNA parece possuir um bom potencial para ser utilizado com alvo molecular e consiste em um dos alvos mais analisados destacando-se o SSU-Rrna para caraterização e o ITS muito evidenciado pelo seu poder discriminatório principalmente nas espécies do complexo L. mexicana, L. guyanensis e L. braziliensis (GOES, 2019). Dois estudos utilizaram os ensaios baseados em cPCR-ITS que mostraram alta sensibilidade para identificação dos gêneros sendo capaz de discriminar o complexo donovani e complexo brasiliensis, mas assim com o kDNA, esse alvo apresento limitações em caracterização espécie-específica (MOUTTAKI, et al., 2014; SILVA, et al., 2017).

Além da eficácia em detectar DNA de Leishmania, a PCR tem sido largamente utilizada na caracterização por meio de ensaios utilizando alvos específicos para a espécie ou por meio da análise de RFLP (Polimorfismo do comprimento do fragmento de restrição). A técnica de RFLP utiliza enzimas de restrição que digerem o produto amplificado por PCR onde é possível analisar e distinguir as diferentes espécies existentes de Leishmania bem como as suas variações genéticas (GOES, et al., 2019; MONTALVO et al., 2012; SANTOS, et al., 2019).

Os estudos conduzidos por SANTOS, et al., (2019) e BONI, et al., (2017) evidenciaram a eficácia dos protocolos qPCR-kDNA/HSP70 seguido de RLFP em 
confirmar o gênero Viannia e caracterizar a espécie L. brasiliensis. O ensaio com qPCRkDNA/HSP70 apresentou em ambos os estudos alta sendibilidade de detecção do DNA de Leishmania. SANTOS, et al., (2019) ainda permitiu a quantificação de DNA de diferentes profundidades da lesão.

\section{CONSIDERAÇÕES FINAIS}

O presente trabalho comprovou a utilidade dos métodos moleculares no diagnóstico de leishmaniose Tegumentar Americana, consistindo em uma metodologia mais sensível e com maior rapidez em sua execução. Foi possível observar que os ensaios de PCR também foram muito eficazes em diferentes tipos de amostra, permitindo uma coleta menos agressiva, e como menos risco de contaminação com os ensaios de qPCR por exemplo, onde os resultados podem ser analisados diretamente do equipamento permitindo ainda sua quantificação. Como evidenciado na maioria dos artigos analisados, a associação da PCR com a técnica RFLP compreendeu em uma metodologia precisa para caracterização mostrando concordância com a eletroforese de izoenzimas, técnica considerada padrão ouro na caracterização, resultando em uma boa alternativa diante das limitações dos métodos convencionais.

Diante dos diferentes alvos moleculares, o kDNA demostrou maior percentual de sensibilidade para o gênero leishmania, mas em relação a caracterização este alvo apresentou algumas limitações não sendo possível a diferenciação de todas as espécies. Já os alvos ITS e HSP70 mostraram um grande desempenho em caracterização espécieespecífica. Os alvos G6pd e SSU rRNA obtiveram um maior êxito na quantificação de carga parasitária.

As desvantagens das técnicas que envolvem a biologia molecular são o custo elevado para sua implantação e por serem técnicas com alta sensibilidade demanda de um treinamento específico, por isso tem sido mais utilizada para pesquisas e estudos epidemiológicos do que em rotina laboratorial, além de uma estrutura física própria para sua execução. Ainda assim as ferramentas moleculares proporcionam grande vantagem tanto no diagnóstico como para caracterização espécie-específica podendo ser bastante útil principalmente na avaliação de padrões epidemiológicos importantes para o controle da leishmaniose. 


\section{REFERÊNCIAS}

AGNE, M. et al. Principles and applications of polymerase chain reaction in medical diagnostic fields: A REVIEW. Brazilian Journal of Microbiology, v. 40, p. 1-11, 2009.

AGUIAR, P.F; RODRIGUES, R.K. Leishmaniose Visceral No Brasil: Artigo de Revisão. Revista Unimontes Científica. Montes Claros, v. 19, n.1, p. 194-204, 2017.

ARYA, M. et al. Basic principles of real-time quantitative PCR. Expert Rev. Mol.Diagn, p. 209-219, 2005.

BASANO, S.A; CAMARGO, L.M.A. Leishmaniose tegumentar: histórico, epidemiologia e perspectivas de controle. Revista Brasileira de Epidemiologia, vol. 7., n. 3, p. 330333, 2004.

BHATTARAI, N.R.; AUWERA, G.V.; KHANAL, B.; DONCKER, S.; RIJAL, S.; DAS, M.L.; URANW, S.; OSTYN, B.; PRAET, N.; SPEYBRECK, N.; PICADO, A.; DAVIES, C.; BOELAERT, M.; DUJARDIN, J.C. PCR and direct agglutination as Leishmania infection markers among healthy Nepalese subjescts living in áreas endemic for Kala-Azar. Tropical medicine and international health, v.14, n. 4, p. 404- 411, 2009.

BONI, S.M.; OYAFUSO, L.K.; SOLER, R.C.; LINDOSO, J.A.L. Efficiency of noninvasive sampling methods (swab) together with Polymerase Chain Reaction (PCR) for diagnosing American Tegumentary Leishmaniasis. Revista do instituto de medicina tropical, São Paulo, v. 59, e. 38, p. 1-7, 2017.

BRASIL, 2017. Manual de Vigilância da Leishmaniose Tegumentar Americana, 2 ed.; Ministério da Saúde, Brasília (DF).

CABRAL. Alberto Wagner Delmondes. Estudo comparativo entre o diagnóstico por técnicas sorológicas e da PCR para a detecção de Leishmania spp. 2007. 56p. Dissertação de Mestrado - Instituto de Biociências, UNESP, São Paulo, 2007.

COSTA, Loredana Nilkenes Gomes. Aplicação da técnica de PCR para o diagnóstico e monitoramento da leishmaniose tegumentar e visceral na região de CampinasSP e de Teresina-PI. 2014. 92p. Dissertação de Mestrado - Faculdade de Ciências Médicas, Universidade Estadual de Campinas, São Paulo, 2014.

COURA JR. Dinâmica das Doenças Infecciosas e Parasitárias. 2aa. Ed. Rio de Janeiro, Guanabara Koogan; 2013 - 56 Leishmaniose tegumentar americana (p.746- 760).

DATASUS.

Dados

disponíveis

em

http://tabnet.datasus.gov.br/cgi/deftohtm.exe?sinannet/cnv/ltabr.def>.

Acessado em outubro de 2020. 
DENIAU, M.; CANAVATE, C.; FARUT-GAMBARELLI, F.; MARTY, P. The biological diagnosis of leishmaniasis in HIV-infected patients. Annals of Tropical Medicine \& Parssitology, v.97, n. 1, p. 115-133, 2003.

FAGUNDES, A. SCHUBACH, A.O.; DE PAULA, C.C.; BOGIO, A.; ANTONIO, L.F.; SCHIAVONI, P.B.; MONTEIRO, V.S.; MADEIRA, M.F.; QUINTELLA, L.P.; VALETEROSALINO, C.M.; VASCONCELLOS, E.C.F.; AZEREDO-COUTINHO, R.B.G.; PACHECO, R.S.; MARZOCHI, M.C.A.; MARZOCHI, K.B.F. Evaluation of polymerase chain reaction in the routine diagnosis for tegumentary leishmaniasis in a referral centre. Memórias do Instituto Oswaldo Cruz, Rio de Janeiro, v.105, n.1, p. 109-12, 2010

FIOCRUZ, 1997. As leishmanioses - Projeto Saúde e Meio Ambiente - CAPES - FAPERJ. Laboratório de Imunomodulação - Depto. De Protoozologia/IOC - FIOCRUZ.

GOES, Tayná Correia. Análise in silico e aplicabilidade da região IGS rRNA de Leishmania spp. para identificação de espécies que causam a Leishmaniose Tegumentar Americana. 2019. 66p. Dissertação de Mestrado - Instituto Aggeu Magalhães, Fundação Oswaldo Cruz (FIOCRUZ), Recife, 2019.

GONTIJO, B; CARVALHO, M.L.R. Leishmaniose tegumentar americana. Revista da Sociedade Brasileira de Medicina Tropical, Minas Gerais, v. 36, n.1, p. 71-80, 2003.

GONTIJO, C.M.F.; MELO, M.N. Leishmaniose Visceral no Brasil: quadro atual, desafios e perspectivas. Revista Brasileira de Epidemiologia, v. 7, n. 3, p. 338-349, 2004.

GRAÇA, G.C; VOLPINI, A.C; ROMERO, G.A.S; NETO, M.P.O; HUEB, M; BOITÉ, M.C; CUPOLILLO, E. Development and validation of PCR-based assays for diagnosis of American cutaneous leishmaniasis and identification of the parasite species. Memórias do Instituto Oswaldo Cruz, Rio de Janeiro, v. 107, n. 5, p. 664-674, 2012.

LAINSON, R. Our present knowledge of the ecology and control of leishmaniasis in the Amazon region of Brazil. Revista da Sociedade Brasileira de Medicina Tropical, Belém, v.18, n. 1, p. 47- 56, 1985.

MARTINS, L; ALEXANDRINO, A; GUIMARÃES, G. Detecção de DNA de Leishmania braziliensis em pacientes de Leishmaniose Tegumentar Americana. Revista Saúde Pública, Pernambuco, v. 44, n. 3, 2010.

MINISTÉRIO DA SAÚDE (FUNASA) 2000. Manual de controle da Leishmaniose Tegumentar Americana. Brasília: Centro Nacional de Epidemiologia, FUNASA, MS.

MONTALVO, A.M; FRAGA, J; MONTANO, I.; MONZOTE, L.; VAN DER AUWERA, G., MARÍN, M.; MUSKUS, C. Identificación molecular con base em El gen HSP70 de aislamientos clínicos de Leishmania spp. Em Colombia. Biomédica, Colombia, v. 36, p. 37-44, 2016. 
MONTALVO. A.M; FRAGA, J; TIRADO, D; BLANDÓN, G; ALBA, A; AUWERA, G.V; DARÍO, I; MUSKUS, C. Detection and identification of Leishmania spp.: application of two hsp70-based PCR-RFLP protocols to clinical samples from the New World, Springer-Verlag Berlin Heidelberg, Germany, 2017

MORAIS, Rayana Carla Silva. Aplicabilidade da técnica de PCR em tempo real para caracterização de espécies de Leishmania. 2015. 62p. Dissertação de Mestrado - Centro de Pesquisas Aggeu Magalhães, Fundação Oswaldo Cruz (FIOCRUZ), Recife, 2015.

MOUTTAKI, T.; YUSTE, M.M.; ESPINOSA, G.M.; CHIHEB, S.; FELLAH, H.; SANCHEZ, J.M.; RIYAD, M. Molecular diagnosis of cutaneous leishmaniasis and identification of the causative Leishmania species in Morocco by using three PCR-based assays. Parasites \& Vectors, v. 7, n. 420, p.1-9, 2014.

MULLIS, K.B. Target amplification for DNA analysis by the polymerase chain reaction. Annales de Biologie Clinique, v. 48, n. 8, p. 579-582, 1990.

NOVAIS, C. M.; PIRES-ALVES, M. PCR em tempo real. Revista Biotecnologia Ciências e Desenvolvimento, v. 33, p. 10-13, 2004.

ORGANIZAÇÃO MUNDIAL DA SAÚDE. Leishmaniasis. Disponível em: https://www.who.int/news-room/fact-sheets/detail/leishmaniasis.; 2014

REY, L. Bases da Parasitologia Médica. 3ed. Rio de Janeiro: Guanabara Koogan, 2008. 50.62p.

SAMPAIO. Gilmara de Souza. Estudo comparativo entre o antimoniato-nmetilglucamina (glucantime) e o isotionato de pentamidina (pentacarinat) em lesões cutâneas da leishmaniose tegumentar. 2013. 92p. Dissertação de Mestrado - Centro de Pesquisas Gonçalo Moniz, Fundação Oswaldo Cruz, Salvador, 2013.

SANTOS, E. A. et al. INFLUÊNCIA DA TEMPERATURA AMBIENTE NA ANÁLISE DO TERMOCICLADOR. IN: XXIV Congresso Brasileiro de Engenharia Biomédica, p. 1522-1525, 2014.

SANTOS, L.S.; JÚNIOR, A.C.M.S.; SILVA, V.M.; BERGMANN, J.O.; SILVA, E.F.; SEGATO, L.F.; ARABI, A.Y.M.; PAULA, N.A.; SAMPAIO, R.N.R.; LIMA, B.D.; GOMES, C.M. Accuracy of qPCR for quantifying Leishmania kDNA in different skin layers of patients with American tegumentary leishmaniasis. Elsevier, v.25, p. 242-247, 2019.

SANTOS, Yasmin da Silva. Detecção e caracterização de leishmania em espécimes clínicos por amplificação do gene hsp70 e análise dos perfis de restrição enzimática dos produtos amplificados. 2019. 73p. Dissertação de Mestrado - 
Instituto Nacional de Infectologia Evandro Chagas, Fundação Oswaldo Cruz (FIOCRUZ), Rio de Janeiro, 2019.

SATOW, M.M.; YAMASHIRO-KANASHIRO, E.H.; ROCHA, M.C.; OYAFUSO, L.K.; SOLER, R.C.; COTRIM, P.C. \& LINDOSO, J.A.L. - Applicability of kDNA-PCR for routine diagnosis of American tegumentary leishmaniasis in a tertiary reference hospital. Revista do Instituto de Medicina Tropical de São Paulo, São Paulo, v. 55, n. 6, p. 393-9, 2013.

SCHUBACH, A.; CUZZI-MAYA, T.; OLIVEIRA, A.V., PEREZ, M.A.; PACHECO, R.S.; MOMEN, H.; COUTINHO, S.G.; MARZOCCHI, M.C.A.; MARZOCCHI, K.B.F.; COSTA, S.C. Leishmanial antigens in the diagnosis of active lesions and ancient scars of American tegumentary leishmaniasis patients. Memórias do Instituto Oswaldo Cruz, v. 96, p. 987-996, 2001.

SILVA, M.A.L; MEDEIROS, R.A; FILHO, S.B; MELO, F.L; MEDEIROS, Z. Alvos Moleculares Utilizados Em PCR Para Diagnóstico Da Leishmaniose Visceral Humana. Revista Eletrônica De Farmácia, lowa City, v .7, n. 3, p.1-15, 2010.

SILVA, Fernanda Cristina Assis. Diagnóstico molecular da leishmaniose tegumentar americana em pacientes atendidos no centro de referência em hanseníase e dermatologia sanitária da universidade federal de uberlândia, credesh-ufu. 2017. 82p. Dissertação de Mestrado - Programa de Pós-Graduação em Imunologia e Parasitologia Aplicadas, Universidade Federal de Uberlândia, Minas Gerais, 2017.

WINTER. L.M.F. Descrição e utilização de alvos moleculares para identificação de Leishmania por PCR. Bepa, v. 7, n. 73, p. 21-27, 2010.

NUNES, C. M., DIAS, A.K.K., GOTTARDI, F.P.P.; HENRIQUE B.; DE AZEVEDO, M.A.A., DE LIMA, V.M.F., GARCIA, J.F. Avaliação da reação em cadeia pela polimerase para diagnóstico da leishmaniose visceral em sangue de cães. Revista Brasileira de Parasitologia Veterinária, v. 16, n. 1, p. 5-9, 2007. 


\title{
CAPÍTULO IY
}

\section{ESTUDO COMPARATIVO DE PROTOCOLOS DE EXTRAÇÃO DE DNA EMPREGADOS NA DETECÇÃO DE TRYPANOSOMA CRUZI EM DOIS AMBIENTES: LABORATÓRIO DE ENSINO E DE PESQUISA}

\author{
Thais Cordeiro da Silva ${ }^{1}$ \\ Dário Eluan Kalume ${ }^{2}$ \\ Fernanda de Oliveira Bottino ${ }^{3}$ \\ Tainah Silva Galdino ${ }^{4}$
}

\footnotetext{
${ }^{1}$ Técnica em Análises Clínicas pela Escola Politécnica de Saúde Joaquim Venâncio - Fiocruz

2 Pesquisador do Laboratório Interdisciplinar de Pesquisas Médicas (LIPMED) do Instituto Oswaldo Cruz - Fiocruz

${ }^{3}$ Professora-Pesquisadora do Laboratório de Educação Profissional em Técnicas Laboratoriais em Saúde (LATEC) da Escola Politécnica de Saúde Joaquim Venâncio - Fiocruz

4 Professora-Pesquisadora do Laboratório de Educação Profissional em Técnicas Laboratoriais em Saúde (LATEC) da Escola Politécnica de Saúde Joaquim Venâncio - Fiocruz
}

\section{RESUMO}

Segundo a OMS a doença de Chagas é considerada uma enfermidade negligenciada geralmente veiculada a pobreza. Seu agente etiológico é o Trypanosoma cruzi e sua detecção em indivíduos acometidos pode ser por meio de métodos parasitológicos, sorológicos e moleculares. Esse trabalho objetivou avaliar diferentes metodologias de extração de DNA, usando o T. cruzi como modelo biológico na fase epimastigota em dois ambientes distintos: laboratório de ensino de uma Escola Federal de Ensino Médio Integrado ao Técnico e laboratório de pesquisa. Foram cultivadas células no estágio epimastigota de cepas de CL-Brener em uma estufa B.O.D. a $28^{\circ} \mathrm{C}$ usando o meio de cultura BHI (Brain Heart Infusion) suplementado com $10 \%$ de soro fetal bovino. Os protocolos de extração foram baseados nas metodologias in house, DNAzol ${ }^{\circledR}$ (Thermo Fisher Scientific) e Trizol ${ }^{\circ}$. O DNA extraído foi quantificado através do espectrofotômetro NanoDrop e visualizado em gel de agarose. A viabilidade das moléculas extraídas foi averiguada a partir da amplificação dos DNA extraídos pela técnica de PCR com os iniciadores da cisteíno-peptidase. Os produtos foram analisados por meio de gel de agarose $1,5 \%$ e de poliacrilamida $10,5 \%$. Os resultados obtidos mostram que apesar do laboratório de ensino não conter as especificações destinadas à realização de técnicas de Biologia Molecular, mostrou-se apto à realização de tais procedimentos voltados para a capacitação profissional, bem como para o estímulo à pesquisa.

Palavras-chave: Trypanosoma cruzi. Extração de DNA. Doença de Chagas. 


\section{INTRODUÇÃO}

No ano de 1909, em Lassance, Carlos Chagas descreveu o protozoário flagelado pertencente à família Trypanosomatidae, de ordem Kinoplastidae, de gênero Trypanosoma denominado Trypanosoma cruzi, conhecido como o agente etiológico da doença de Chagas Além disso, foi descrito o inseto vetor hematófago (triatomíneo) da família Reduviidae, o qual possui quatro espécies relevantes no ciclo de transmissão: Triatoma infestans, Rhodnius prolixus, Panstrongylus megistus e Triatoma dimidiata (Chagas, 1909; González, 2010).

Segundo a Organização Mundial da Saúde (OMS), o mal de Chagas acomete cerca de 6 a 7 milhões de pessoas no mundo e é considerada uma enfermidade negligenciada geralmente veiculada a pobreza (WHO, 2015). No entanto, há um crescimento de casos em países não endêmicos devido ao deslocamento de indivíduos infectados por meio das migrações internacionais (Requena-Mendez et al., 2015; Dias, 2016).

O ciclo biológico do T. cruzi é caracterizado como complexo, do tipo heteróxeno, com uma fase de multiplicação intracelular no hospedeiro vertebrado mamífero e extracelular no inseto vetor, tendo como principal característica as modificações morfológicas em diferentes estágios: amastigotas, epimastigotas, tripomastigotas sanguíneas e tripomastigotas metacíclicas (Nagajyothi et al., 2012).

Geralmente, a infecção é associada à via vetorial, no entanto, como mecanismos de transmissão, citam-se: transfusões sanguíneas, via transplacentária, transplante de órgãos e, em especial, a transmissão oral. Esta última mostrou-se de grande relevância médica após a Organização Pan-Americana de Saúde (OPAS) ter declarado a interrupção da transmissão através da via vetorial na região amazônica (Yoshida, 2009; Toso et al., 2011).

A detecção de $T$. cruzi em indivíduos acometidos pela doença de Chagas pode ser realizada por meio de métodos parasitológicos (identificação direta por microscopia ou indireta por xenodiagnóstico e hemocultura); métodos sorológicos (identificação dos anticorpos IgG anti-T.cruzi ou antígenos); e metodologias moleculares (detecção do DNA do patógeno) (Barreto-de-Albuquerque, 2015).

Devido à infecção do T. cruzi possuir distintos níveis de parasitemia (fase aguda e crônica), as metodologias de diagnóstico devem ser coerentes quanto ao nível de 
sensibilidade da infecção presente no hospedeiro. A utilização de metodologias moleculares, tais como a PCR (Reação da Polimerase em Cadeia) e o sequenciamento de DNA (Ácido Desoxirribonucleico) são empregadas na detecção deste parasita, visto que permitem a identificação do DNA em ambas as fases da infecção chagásica (Avila et al, 1993; Moser et al, 1989).

Diante disso, este estudo teve como objetivo avaliar diferentes metodologias de extração de DNA, usando o T. cruzi como modelo biológico na fase epimastigota em dois ambientes distintos: laboratório de ensino de uma Escola Federal de Ensino Médio Integrado ao Técnico e laboratório de pesquisa. Foi desenvolvida uma análise comparativa entre as práticas de extração de DNA (DNAzol ${ }^{\circ}$, Trizol ${ }^{\circ}$ e um método in house baseado no artigo de Rotureau e colaboradores (2005)) a fim de verificarmos a qualidade das técnicas desenvolvidas nestes dois ambientes distintos (Rotureau et al., 2005). Para isto, a metodologia de escolha foi à extração de DNA, uma vez que a pureza deste implica no sucesso das demais práticas na área da Biologia Molecular.

\section{MATERIAL E MÉTODOS}

\subsection{Cultivo de células}

Foram cultivadas células no estágio epimastigota de cepas CL-Brener, proveniente da coleção de Protozoários do Instituto Oswaldo Cruz (COLPROT). As células foram crescidas em uma estufa B.O.D. a $28^{\circ} \mathrm{C}$ usando meio de cultura BHI (Brain Heart Infusion) suplementado com $10 \%$ de soro fetal bovino (Cultilab, Campinas, SP, Brasil).

O crescimento das células de $T$. cruzi foi analisado por meio de contagem na câmara de Neubauer e acompanhado por análise microscópica (microscopia óptica). No meio da fase logarítmica de cultivo, $10^{7}$ células foram obtidas por centrifugação da cultura a 800 g durante 15 minutos, lavadas três vezes com PBS 1X (tampão fosfatosalino).

\subsection{Extração de DNA - Método in house}

A metodologia utilizada foi baseada no artigo de Rotureau e colaboradores (2005) em triplicata experimental, na qual teve início a partir da obtenção de massa celular de T. cruzi, sendo a mesma de aproximadamente $10^{7}$ células/ $\mathrm{mL}$ (Rotureau et 
al., 2005). Foi adicionado $200 \mu \mathrm{L}$ de solução tampão de lise celular com incubação de 30 minutos a $65^{\circ} \mathrm{C}$ sob agitação de $1000 \mathrm{rpm}$.

Posteriormente foi adicionado 2 volumes $(400 \mu \mathrm{L})$ de etanol absoluto (100\%) (SigmaAldrich ${ }^{\circledR}$, EUA) à amostra. Após homogeneização, foi centrifugada durante 15 minutos, a $4^{\circ} \mathrm{C}$ e $14000 \mathrm{rpm}$, com descarte do sobrenadante. O pellet foi seco a $65^{\circ} \mathrm{C}$ por 15 minutos e foi adicionado $200 \mu \mathrm{L}$ de tampão de ressuspensão.

\subsection{Extração de DNA - Método DNAzol ${ }^{\circledR}$ (Thermo Fisher Scientific)}

Essa metodologia foi realizada em triplicata experimental. Após a obtenção da massa celular de $T$. cruzi (cerca de $10^{7}$ células $/ \mathrm{mL}$ ) foi iniciado o processo de lise celular no qual consistiu na adição de $1 \mathrm{~mL}$ da solução de $\mathrm{DNAzo}^{\circledR}$ seguida de homogeneização por meio da inversão do tubo.

Posteriormente, o DNA foi precipitado em $500 \mu \mathrm{L}$ de etanol absoluto (100\%) (SigmaAldrich ${ }^{\circledR}$, EUA) para cada $1 \mathrm{~mL}$ de DNAzol ${ }^{\circledR}$. Após a inversão do tubo, cerca de 10 vezes, as amostras foram incubadas por 3 minutos em temperatura ambiente (T.A: $25^{\circ} \mathrm{C}$ ). A partir disso, pôde-se observar a formação de uma "nuvem" na qual constituiu o DNA precipitado.

Foi realizada a lavagem do DNA duas vezes consecutivas, de forma homogênea, por inversão do tubo cerca de 10 vezes, utilizando $1 \mathrm{~mL}$ de etanol a 75\% (v/v). Após uma incubação de 5 minutos em agitação (1000 rpm) a T.A, o etanol a 75\% foi removido cuidadosamente. Por fim, foi feito o processo de solubilização do DNA, por meio da ressuspensão do DNA entre 100 - 300 $\mu \mathrm{L}$ de $\mathrm{NaOH} 8 \mathrm{mM}$, de acordo com pellet formado, para então armazenamento a $-20^{\circ} \mathrm{C}$.

\subsection{Extração de DNA - Método Trizo/ $\mathbb{R}$}

Todas as amostras foram feitas em triplicata experimental. Após obtenção da massa celular de $T$. cruzi (cerca de $10^{7}$ células $/ \mathrm{mL}$ ) foram realizadas duas lavagens com PBS $1 X$ antes da adição de $1 \mathrm{~mL}$ do reagente Trizol $^{\circledR}$ (Thermo Fisher Scientific). Na etapa de lise celular, foi adicionado $200 \mu \mathrm{L}$ de clorofórmio (Sigma-Aldrich ${ }^{\circledR}$, EUA) com incubação de 3 minutos e posterior centrifugação por 15 minutos a $4^{\circ} \mathrm{C}$ e $12000 \mathrm{~g}$. 
Centrifugada a amostra, observaram-se três fases da solução: a primeira, aquosa (incolor), contendo o RNA; a interfase branca e leitosa contendo principalmente DNA e a fase inferior rósea contendo proteínas. A fase aquosa (fase superior) foi transferida para outro tubo limpo para posterior extração de RNA. À fase orgânica (rosa), referente à fase do nosso interesse, foram adicionados $300 \mu \mathrm{L}$ de etanol absoluto (100\%) (SigmaAldrich $\left.^{\circledR}, E U A\right)$, com posterior homogeneização por inversão do tubo. As amostras foram incubadas durante 3 minutos em T.A e centrifugadas durante 5 minutos a $4^{\circ} \mathrm{C}$ e $2000 \mathrm{~g}$. O sobrenadante foi descartado após a centrifugação. Posteriormente, foi realizada a fase de lavagem do DNA (pellet), na qual foi feita com $1 \mathrm{~mL}$ de solução de citrato de sódio e etanol (0,1 m de citrato de sódio em $10 \%$ de etanol, $\mathrm{pH} 8,5)$, com posterior incubação de 30 minutos a T.A. Passado o período de incubação, as amostras foram centrifugadas durante 5 minutos a $4^{\circ} \mathrm{C}$ com velocidade de $2000 \mathrm{~g}$ com subsequente remoção do sobrenadante. Uma nova etapa de lavagem do DNA com solução de citrato de sódio e etanol $(0,1 \mathrm{~m}$ de citrato de sódio em $10 \%$ de etanol, $\mathrm{pH} 8,5)$ foi realizada conforme supracitado.

Logo depois, foi adicionado 1,5 mL de etanol 75\%, homogeneizado por inversão e incubação durante 15 minutos a T.A, seguido de centrifugação por 5 minutos a $4^{\circ} \mathrm{C}$ sob velocidade de $2000 \mathrm{~g}$. O sobrenadante foi descartado e o pellet foi ressuspendido com volume variando de $300-600 \mu \mathrm{L}$ de $\mathrm{NaOH} 8 \mathrm{mM}$ (até que todo o material tenha sido homogeneizado), homogeneizado e centrifugado por 10 minutos a $4^{\circ} \mathrm{C}$ de velocidade de 12000 g. Finalmente, o sobrenadante foi armazenado a $-20^{\circ} \mathrm{C}$.

\subsection{Adaptações dos protocolos de Extração de DNA}

Algumas alterações foram necessárias para a realização do procedimento metodológico no laboratório de ensino, a fim de substituir equipamentos inexistentes no mesmo. Sendo assim, durante a extração de DNA na metodologia in house a incubação foi realizada sem agitação em Banho-Maria e a centrifugação foi feita à temperatura ambiente.

Já nas extrações realizadas pelo método de DNAzol ${ }^{\circledR}$ (Thermo Fisher Scientific), durante o procedimento da etapa de lavagem do DNA, não houve agitação uma vez que a instituição não possui agitador.

Nas extrações realizadas pelo método de Trizol $^{\circledR}$, a centrifugação refrigerada não

WWW.AMPLLAEDITORA.COM.BR (2)

CONTATO@AMPLLAEDITORA.COM.BR M 
pôde ser realizada uma vez que instituição não possui centrífuga que permite tal prática. Nesse caso, as amostras foram centrifugadas em T.A. Além disso, a prática de extração de Trizol deve ser executada no interior de uma capela de exaustão e, nesse caso, houve uma modificação no protocolo, uma vez que a capela disponível para uso na instituição não possui luz ultravioleta (UV) e funciona como armazenamento de reagentes de técnicas histológicas, fato de grande relevância quanto à uma possível contaminação.

\subsection{Quantificação por Nanodrop $®$}

A quantificação das amostras de DNA extraídas foi realizada em um espectrofotômetro NanoDrop ${ }^{\circledR}$. Inicialmente foi feita toda higienização do instrumento, adicionando $1,5 \mu \mathrm{L}$ de $\mathrm{H}_{2} \mathrm{O}$. O tampão de ressuspensão de cada metodologia foi usado como branco: in house foi adicionado $1,5 \mu \mathrm{L}$ de $\mathrm{H}_{2} \mathrm{O}$; Trizol $^{\bullet}$ e DNAzol ${ }^{\circ}$ foram adicionados $1,5 \mu \mathrm{L}$ de $\mathrm{NaOH} 8 \mathrm{mM}$. Após esse procedimento foi realizado leitura de cada amostra de DNA $(1,5 \mu \mathrm{L})$, sendo que, aquelas que apresentaram partículas em meio ao sobrenadante, foram centrifugadas previamente.

\section{7. $\quad$ Eletroforese das amostras de DNA}

O tampão de preparo do gel e de corrida foi o TBE (Tris Borato EDTA) 0,5X. Os géis foram corados com GelRed ${ }^{\oplus} 3 X$ e posteriormente visualizados sob luz UV, e assim, fotografados.

\subsection{Reação em Cadeia da Polimerase (PCR)}

Para a realização da PCR, foi adicionado $1 \mu \mathrm{L}$ de $\operatorname{dNTP}(10 \mathrm{mM}), 2 \mu \mathrm{L}$ de $\mathrm{Mg}^{+2}$ (50mM), $5 \mu \mathrm{L}$ de Buffer (10X), 37,8 $\mu \mathrm{L}$ de $\mathrm{H}_{2} \mathrm{O}$ e $0,2 \mu \mathrm{L}$ de Taq recombinant (Invitrogen ${ }^{\circledR}$ ). Os iniciadores uasados (primers) foram desenhados para a região do gene da cisteínopeptidase $-1 \mu \mathrm{L}$ de cada iniciador $(10 \mathrm{mM})$ no preparo do mix da reação. As sequências dos iniciadores desenhadas foram as seguintes: Forward: 5'GTGCGACAAAACGGACTCTG3' e Reverse: 5'CGACGCATAAGGGTAGCTGT3'. Ao final do preparo do mix da reação de PCR, foi acrescentado $2 \mu \mathrm{L}$ de DNA. A amplificação foi feita obedendo ao perfil térmico de $96^{\circ} \mathrm{C}$ por $10 \mathrm{~min}$, seguidos por 35 ciclos das seguintes condições: $96^{\circ} \mathrm{C}$ por $30 \mathrm{seg}, 58^{\circ} \mathrm{C}$ durante 45 seg e $72^{\circ} \mathrm{C}$ durante 45 seg., finalizando com uma extensão térmica de $72^{\circ} \mathrm{C}$ durante $10 \mathrm{~min}$.

WWW.AMPLLAEDITORA.COM.BR (2) 


\subsection{Gel de agarose}

Os produtos amplicados (amplicons) foram analisados em gel de agarose a 1,5\% usando tampão TBE 0,5X. Após a corrida, os géis foram mantidos durante 10 minutos na solução de GelRed ${ }^{\oplus}$. Posteriormente foram colocados sobre um transiluminador de luz UV para a visualização e fotografia dos fragmentos.

\subsection{Gel de poliacrilamida}

Os amplicons foram aplicados em gel de poliacrilamida 10,5\%, contendo $3,5 \mathrm{~mL}$ de bis - acrilamida 30\%, $1 \mathrm{~mL}$ de TBE $10 \mathrm{X}, 1,5 \mathrm{~mL}$ de Glicerol 100\%, 3,6 mL de $\mathrm{H}_{2} \mathrm{O}, 400$ $\mu \mathrm{L}$ de APS 1,6\% (Persulfato de Amônia) e 3,5 $\mu \mathrm{L}$ de TEMED. Para visualização foram

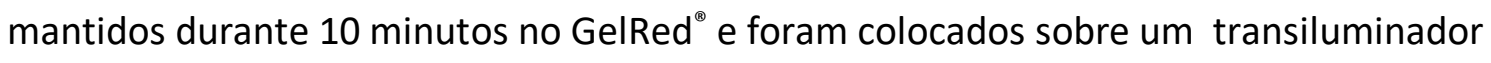
de luz UV para a visualização e fotografia dos fragmentos.

\section{RESULTADOS E DISCUSSÃO}

\subsection{Quantificação por Nanodrop $®$ do DNA extraído}

Após a extração de DNA em ambos ambientes por meio das metodologias selecionadas, foi realizada a quantificação e análise do material através do grau de pureza pelo uso do espectrofotômetro NanoDrop ${ }^{\circledR}$. A relação de absorbância A260/A280 foi utilizada com intuito de verificar se no DNA extraído houve contaminação por proteínas ou reagentes químicos. O valor referencial de um DNA puro apresenta valores de DO260/DO280 (densidade óptica) de 1,8 a 2,0. Onde razões inferiores a 1,8 indicam possível contaminação por proteínas e razões maiores que 2,0 indicam possível contaminação por fenóis (Nicklas \& Buel, 2003) (Tabela 1). 
Tabela 1 - Quantificação por NanoDrop ${ }^{\circledR}$ do DNA extraído pelas diferentes metodologias nos ambientes distintos

\begin{tabular}{|c|c|c|l|c|l|c|}
\hline \multirow{3}{*}{ Metodologias } & \multicolumn{3}{|c|}{ Laboratório de Ensino } & \multicolumn{3}{c|}{ Laboratório de Pesquisa } \\
\cline { 2 - 7 } & Amostra & $\mathrm{ng} / \mu \mathrm{L}$ & $260 / 280$ & Amostra & $\mathrm{ng} / \mu \mathrm{L}$ & $260 / 280$ \\
\hline \multirow{3}{*}{ Trizol $^{\infty}$} & 1 & 98,3 & 1,58 & 1 & 73,7 & 1,86 \\
\cline { 2 - 7 } & 2 & 74,0 & 1,54 & 2 & 124,4 & 1,94 \\
\cline { 2 - 7 } & 3 & 96,7 & 1,32 & 3 & 1087,8 & 1,88 \\
\hline \multirow{3}{*}{ DNAzol } & 1 & 351,5 & 1,97 & 1 & 554,2 & 1,80 \\
\cline { 2 - 7 } & 2 & 308,6 & 1,98 & 2 & 1410,5 & 1,94 \\
\hline \multirow{3}{*}{ In house } & 3 & 399,4 & 2,00 & 3 & 1316,3 & 1,84 \\
\cline { 2 - 7 } & 2 & 462,9 & 1,02 & 1 & 425,4 & 1,99 \\
\cline { 2 - 7 } & 3 & 315,2 & 1,94 & 2 & 364,0 & 1,60 \\
\hline
\end{tabular}

Fonte: Elaborado pelo autor.

O protocolo de extração de DNA pelo Trizol ${ }^{\oplus}$ feito no laboratório de ensino, nas triplicatas, apresentou a razão A260/280 menor do que o valor de referência. Possivelmente essa alteração foi decorrente de contaminação durante a manipulação dos tubos, visto que o ambiente não dispõe de local propício destinado exclusivamente para a execução de tal técnica. No entanto, as amostras extraídas no laboratório de pesquisa apresentaram razão A260/280 dentro do limite imposto pelo valor referencial. O método de extração pelo $\mathrm{DNAzo}^{\circledR}$ nos dois locais apresentaram triplicatas dentro do limite imposto pelo valor referencial, o que indica que mesmo que haja diferenças entre os ambientes, o DNA se mostra puro.

O método de extração de DNA in house realizado no laboratório de pesquisa, em duas das triplicatas, apresentou a razão A260/280 menor do que o valor de referência e em comparação à extração feita no laboratório de ensino. Possivelmente, essa alteração foi decorrente de contaminação de proteínas durante a manipulação dos tubos. No entanto, apesar do ambiente não ser o ambiente específico para práticas relacionadas à Biologia molecular, a razão das triplicatas de amostras extraídas no laboratório de ensino apresentaram razão A260/280 dentro do limite imposto ao valor de referencial.

\subsection{Análise Qualitativa do DNA extraído por eletroforese}

Um gel de agarose foi realizado com o intuito de estabelecer uma padronização da técnica de eletroforese, bem como identificar o nível de detecção visual através da variação de 0,4 a $3 \mu \mathrm{g}$ de concentração de DNA (Figura 1). 
Figura 1 - Análise de Extração de DNA de T.cruzi na metodologia in house em gel de agarose Lowmelting $1 \%$

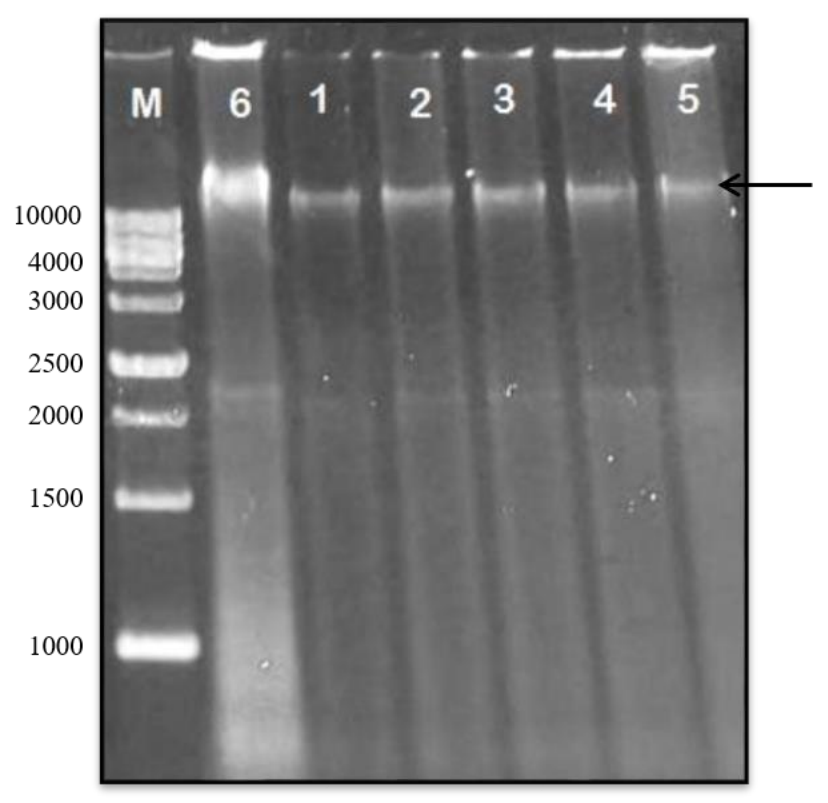

Legenda: Análise por eletroforese em gel de agarose 1\% (p/v) da extração de DNA de Trypanosoma cruzi, cepa CL Brener, os quais foram extraídos com a metodologia in house. Poço M - marcador de peso molecular de 1000 pares de bases (1 kb - DNA Ladder Sinapse Inc). Poço 1 DNA correspondente a 439, 26 ng; Poço 2 a 649,33 ng; Poço 3 a 859, 41 ng; Poço 4 a 1088,58 ng; Poço 5 a 1623,33 ng; Poço 6 correspondente a 2998,40 ng. A seta indica a região das bandas correspondentes ao DNA genômico.

A análise do gel, indicou que, apesar das concentrações $0,46 \mu \mathrm{g}, 0,64 \mu \mathrm{g}, 0,85$ $\mu \mathrm{g}, 1,0 \mu \mathrm{g}, 1,6 \mu \mathrm{g}$ terem intensidades visuais próximas, a concentração de $1 \mu \mathrm{g}$ foi escolhida em virtude das metodologias usadas nesse trabalho fornecerem diferentes graus de concentração de DNA.

Após a padronização da técnica, foi realizado um novo gel contendo as extrações de DNA referente às três metodologias selecionadas, com a mesma concentração $(1 \mu \mathrm{g})$ a fim de comparar a qualidade dos fragmentos extraídos (Figura 2). 
Figura 2 - Análise de Extração de DNA de T.cruzi nas metodologias DNAzol ${ }^{\circ}$, Trizol ${ }^{\circ}$ e in house em gel de agarose $1 \%$

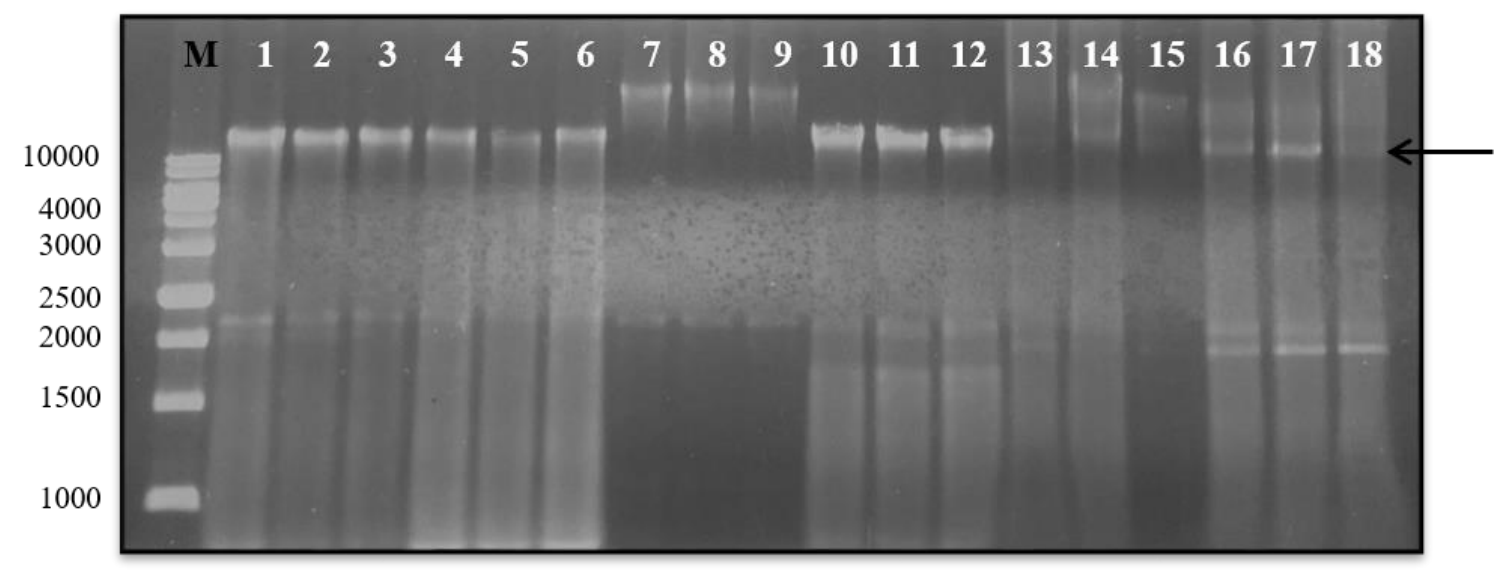

Legenda: Análise por eletroforese em gel de agarose 1\% (p/v) da extração de DNA de Trypanosoma cruzi, cepa CL Brener, os quais foram extraídos pelos métodos $\mathrm{DNAzOl}^{\circ}$, Trizol ${ }^{\circ}$ e in house. O poço $\mathrm{M}$ corresponde ao marcador de peso molecular de 1000 pares de bases (1 kb - DNA Ladder Sinapse Inc). Poço 1-3 Extração de DNA in house laboratório de pesquisa; Poço 4-6 Extração de DNA in house no laboratório de ensino; Poço 7-9 Extração de DNA por DNAzol no laboratório de ensino; Poço 10-12 Extração de DNA por DNAzol ${ }^{\circ}$ no laboratório de pesquisa; Poço 13-15 Extração de DNA por Trizol ${ }^{\circ}$ no laboratório de pesquisa; Poço 16-18 Extração de DNA por Trizol ${ }^{\circledR}$ no laboratório de ensino. A seta indica a região das bandas correspondentes ao DNA genômico.

Feita a análise do gel, observamos que as amostras extraídas pelo protocolo in house, tanto no laboratório de ensino, como no de pesquisa, se mostraram íntegras na detecção visual, no entanto, os fragmentos de DNA derivados do método de extração pelo DNAzol ${ }^{\oplus}$ realizados no primeiro ambiente não foram detectados em gel de agarose. Possivelmente, a concentração não foi suficiente para a detecção por dessa metodologia.

O protocolo de extração de DNA por Trizol $^{\circledR}$ demonstrou que as triplicatas extraídas, em ambos os locais de estudo, apresentaram qualidade inferior. Esse resultado era esperado uma vez que no laboratório de ensino as amostras foram manipuladas em ambiente inadequado, ou seja, com o uso de capela de exaustão sem lâmpada UV e contendo resíduos de materiais de outras práticas.

\subsection{Análise Qualitativa da PCR por eletroforese}

Em seguida, a amplificação dos fragmentos de DNA genômico foi realizada pela técnica da PCR para averiguarmos a viabilidade dessas moléculas extraídas por meio de todas as metodologias $\left(\operatorname{Trizol}^{\circledR}\right.$, DNAzol $^{\circledR}$ e in house). A síntese foi feita com o iniciador 
(primer) da cisteíno-peptidase, uma enzima que possui um papel importante no fator de virulência dos tripanossomatídeos relacionada à interação com as células de mamíferos na relação parasito-hospedeiro (Mottram et al., 1998). O produto obtido foi um fragmento de $115 \mathrm{pb}$. A Figura 3 representa o conjunto de DNA extraído pela metodologia in house e amplificado com os iniciadores da cisteíno-peptidase.

Figura 3 - Análise de Produto de PCR Extração in house em gel de agarose 1,5\%

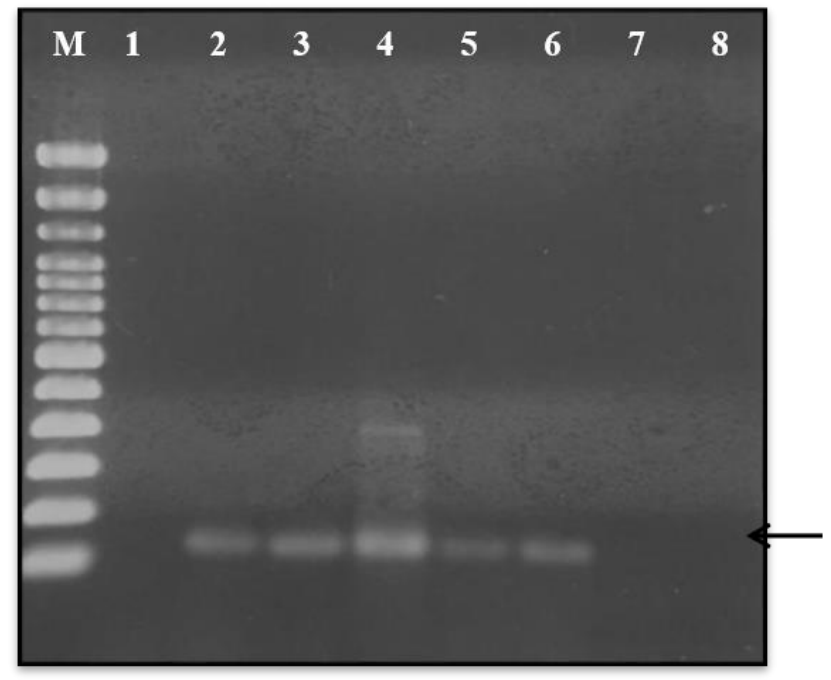

Legenda: Análise de Produto de PCR do gene cisteíno-peptidase por eletroforese em gel de agarose 1,5\% (p/v). As amostras de DNA de Trypanosoma cruzi, da cepa CL Brener, foram obtidas de acordo com o protocolo da metodologia in house. Poço M - marcador de peso molecular de 100 pb (Thermo Fisher Scientific); Poço 1-3 amostras de DNAextraídos no laboratório de Pesquisa; Poço 4-6 amostras de DNA extraídos no Laboratório de Ensino; Poço 7: Controle positivo (não apareceu); Poço 8: Controle negativo. A seta indica a posição da banda esperada de 115 pb.

Devido a diferença entre as técnicas, realizamos géis de poliacrilamida com o intuito de verificarmos se os produtos amplificados teriam o mesmo comportamento, ou seja, se as amostras não detectadas no gel de agarose permaneceriam não visualizadas no gel de poliacrialamida, uma vez que o mesmo é mais sensível à detecção dos fragmentos de DNA quando comparado ao gel de agarose (Figura 4). 
Figura 4 - Análise de Produto de PCR Extração in house em Gel de poliacrilamida 10,5\%

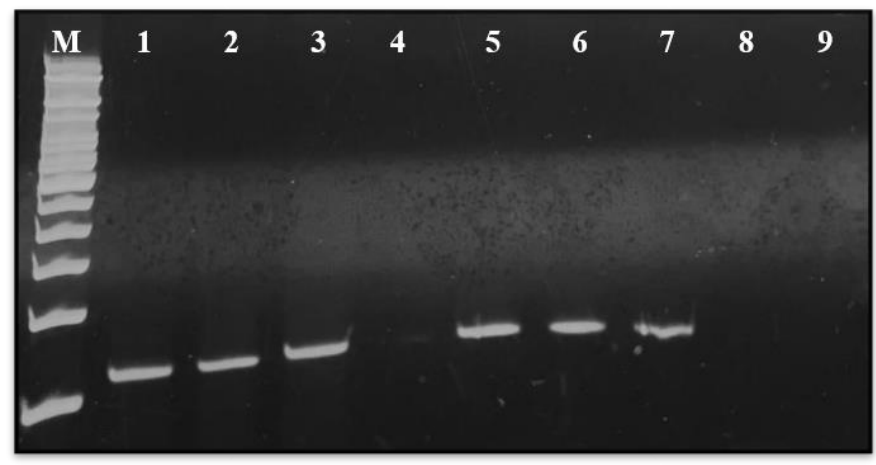

Legenda: Análise de Produto de PCR do gene cisteíno-peptidase por eletroforese em gel de poliacrilamida 10,5\% (p/v). DNA de Trypanosoma cruzi, cepa CL Brener, foram extraídos com a metodologia in house. Poço M- marcador de peso molecular de 100pb (Thermo Fisher Scientific); Poço 1-3 DNA extraídos no laboratório de pesquisa; Poço 4- Branco Poço 5-7 DNA extraídos no laboratório de ensino; Poço 8: Controle positivo (não detectado); Poço 9: Controle negativo. A banda esperada possui $115 \mathrm{pb}$.

Em vista disso, foi possível observar que o fragmento de uma das triplicatas que foi extraída no laboratório de pesquisa não apareceu no gel de agarose, porém pôde ser visualizada no gel de poliacrilamida. Além disso, o rastro presente em uma das amostras extraídas no laboratório de ensino no gel de agarose, não apareceu no gel de poliacrilamida, eliminando a ideia de uma possível contaminação ou excesso de DNA (Figuras 3 e 4).

Posteriormente, a análise da viabilidade da metodologia de extração de DNA por Trizol $^{\circledR}$ foi realizada a partir da amplificação (PCR) de DNA extraídos com os iniciadores da cisteíno-peptidase (Figura 5). 
Figura 5 - Análise de Produto de PCR Extração de DNA por Trizol ${ }^{\circledR}$ em gel de agarose 1,5\%

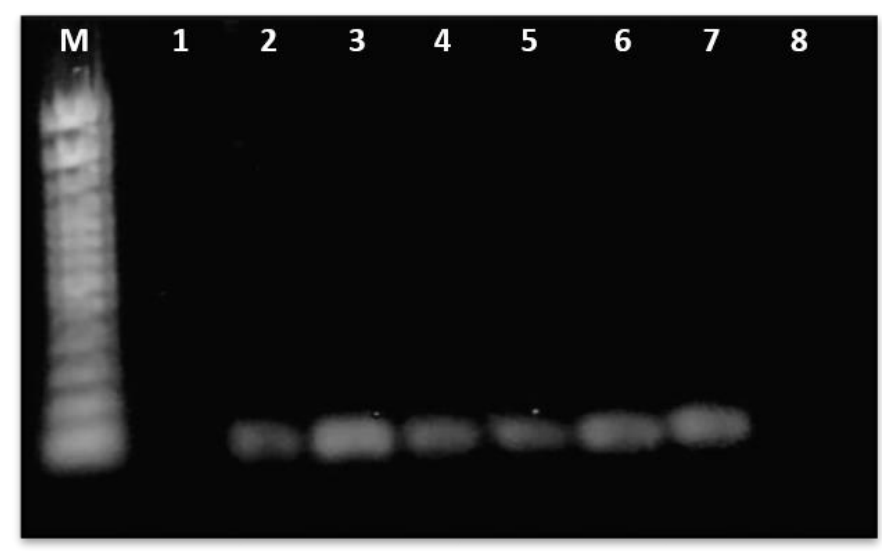

Legenda: Análise de Produto de PCR do gene cisteíno-peptidase por eletroforese em gel de agarose 1,5\% (p/v). DNA de Trypanosoma cruzi, cepa CL Brener, foram extraídos com a metodologia Trizol ${ }^{\bullet}$. Poço M marcador de peso molecular de 100pb (Thermo Fisher Scientific); Poço 1-3 DNA extraídos no laboratório de pesquisa; Poço 4-6 DNA extraídos na ESPJV; Poço 7: Controle positivo (não foi detectado); Poço 8: Controle negativo. A banda esperada possui $115 \mathrm{pb}$.

Ao passo que foi realizado o gel de poliacrilamida, observou-se que o fragmento de uma das triplicatas que foi extraída no laboratório de pesquisa não foi detectado no gel de agarose, porém no gel de poliacrilamida se mostrou amplificado. Além disso, pôde-se observar que todas as outras amostras foram corretamente amplificadas, incluindo o controle positivo, fato esse que comprova que as amostras estão viáveis para posteriores análises (Figuras 5 e 6 ).

Figura 6 - Análise de Produto de PCR Extração de DNA por Trizol ${ }^{\circledR}$ em Gel de poliacrilamida 10,5\%

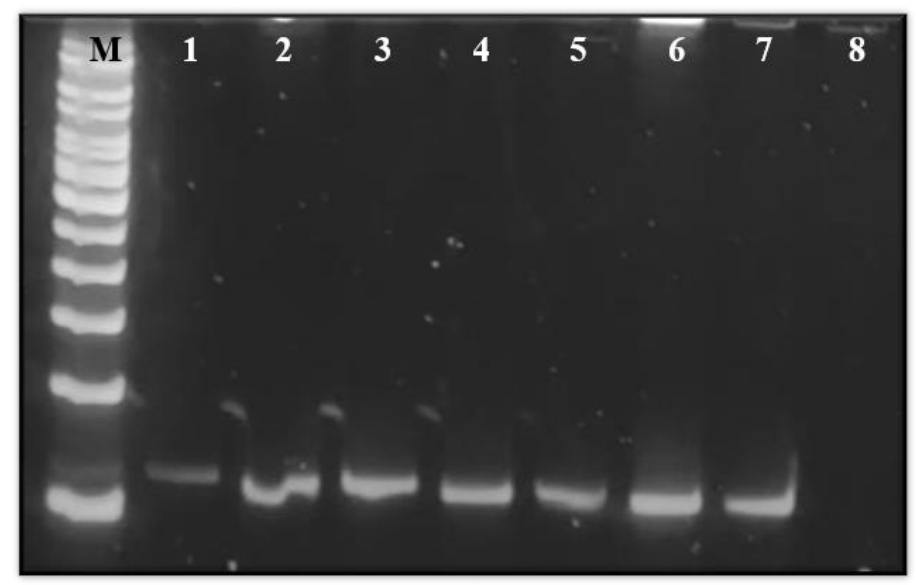

Legenda: Análise de Produto de PCR do gene cisteíno-peptidase por eletroforese em gel de poliacrilamida 10,5\% (p/v). DNA de Trypanosoma cruzi, cepa CL Brener, foram extraídos com a metodologia Trizol ${ }^{\circledR}$. Poço

WWW.AMPLLAEDITORA.COM.BR $(2)$

CONTATO@AMPLlaEditora.COM.BR M 
M - marcador de peso molecular de 100pb (Thermo Fisher Scientific); Poço 1-3 DNA extraídos no laboratório de pesquisa; Poço 4-6 DNA extraídos na ESPJV; Poço 7: Controle positivo; Poço 8: Controle negativo. A banda esperada possui 115 pb.

Por fim, foi feita a análise da viabilidade dos produtos obtidos por amplificação com iniciadores da cisteíno-peptidase das amostras extraídas pelo protocolo de extração de DNA por DNAzol ${ }^{\circledR}$ (Figura 7).

Figura 7 - Análise de Produto de PCR Extração de DNA por DNAzol ${ }^{\circledR}$ em gel de agarose 1,5\%

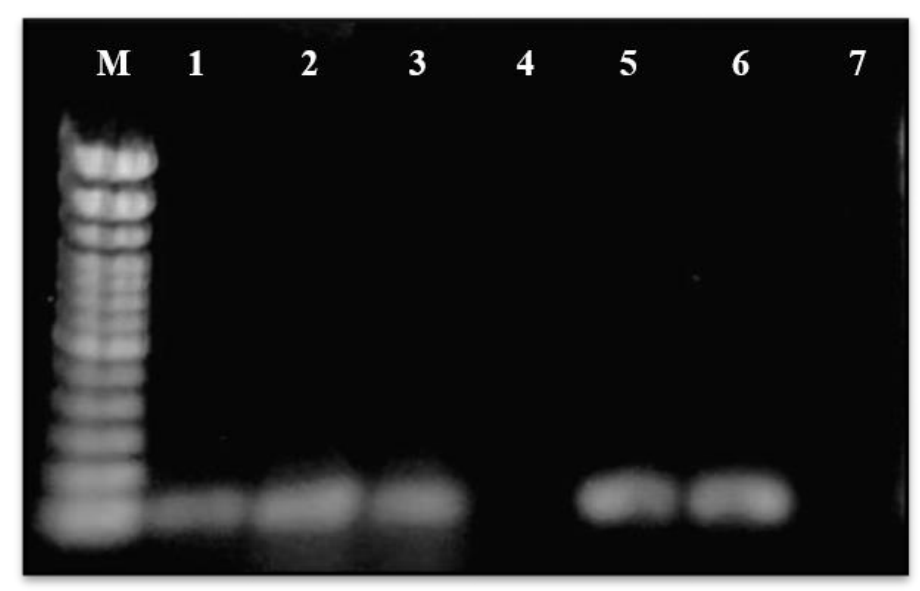

Legenda: Análise de Produto de PCR do gene cisteíno-peptidase por eletroforese em gel de agarose 1,5\% (p/v). DNA de Trypanosoma cruzi, cepa CL Brener, foram extraídos com a metodologia DNAzol ${ }^{\circledR}$. Poço Poço M - marcador de peso molecular de 100pb (Thermo Fisher Scientific); Poço 1-3 DNA extraídos no laboratório de pesquisa; Poço 4-5 amostra DNA extraídos no laboratório de ensino; Poço 6: Controle positivo; Poço 7: Controle negativo. A banda esperada possui 115 pb.

A mesma análise foi feita por meio do gel de poliacrilamida, no qual podemos observar que os produtos amplificados que foram detectados no gel de agarose, também foram detectados no de poliacrilamida, com exceção do DNA extraído no laboratório de ensino, na qual não foi aplicada por motivos de não possuir volume suficiente. Além disso a amostra do poço 4, não foi detectada no gel de agarose, porém no gel de poliacrilamida foi detectada de forma fraca, enquanto todas as outras amostras foram amplificadas, o que confirma a viabilidade das amostras em questão (Figuras 7 e 8). 
Figura 8 - Análise de Produto de PCR Extração de DNA por DNAzol ${ }^{\circ}$ em Gel de poliacrilamida 10,5\%

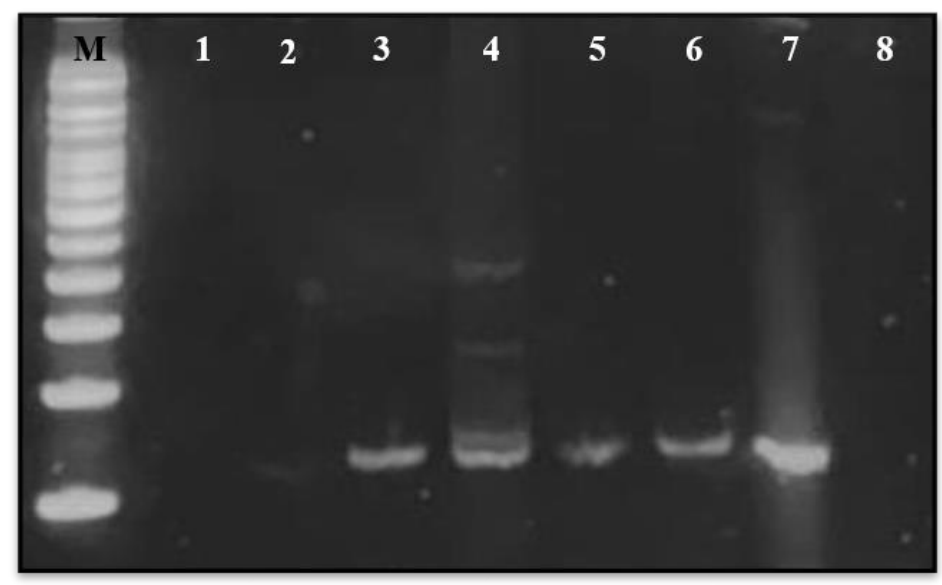

Legenda: de Produto de PCR do gene cisteíno-peptidase por eletroforese em gel de poliacrilamida 10,5\% (p/v). DNA de Trypanosoma cruzi, cepa CL Brener, foram extraídos com a metodologia DNAzol ${ }^{\circ}$. Poço M marcador de peso molecular de 100pb (Thermo Fisher Scientific); Poço 1-3 DNA extraídos no laboratório de ensino; Poço 4-6 DNA extraídos no laboratório de pesquisa; Poço 7: Controle positivo; Poço 8: Controle negativo. A banda esperada possui $115 \mathrm{pb}$.

Com o intuito de fazer uma comparação entre a viabilidade do DNA extraído pelas distintas técnicas em questão (Trizol ${ }^{\oplus}, \mathrm{DNAzol}^{\circledR} \mathrm{e}$ in house), foi realizado um gel de agarose para tal comprovação (Figura 9).

Figura 9 - Análise de Produto de PCR Extração de DNA por todas as metodologias (Trizol ${ }^{\bullet}$, DNAzol ${ }^{\circledR}$ e in house) em Gel de agarose 1,5\%

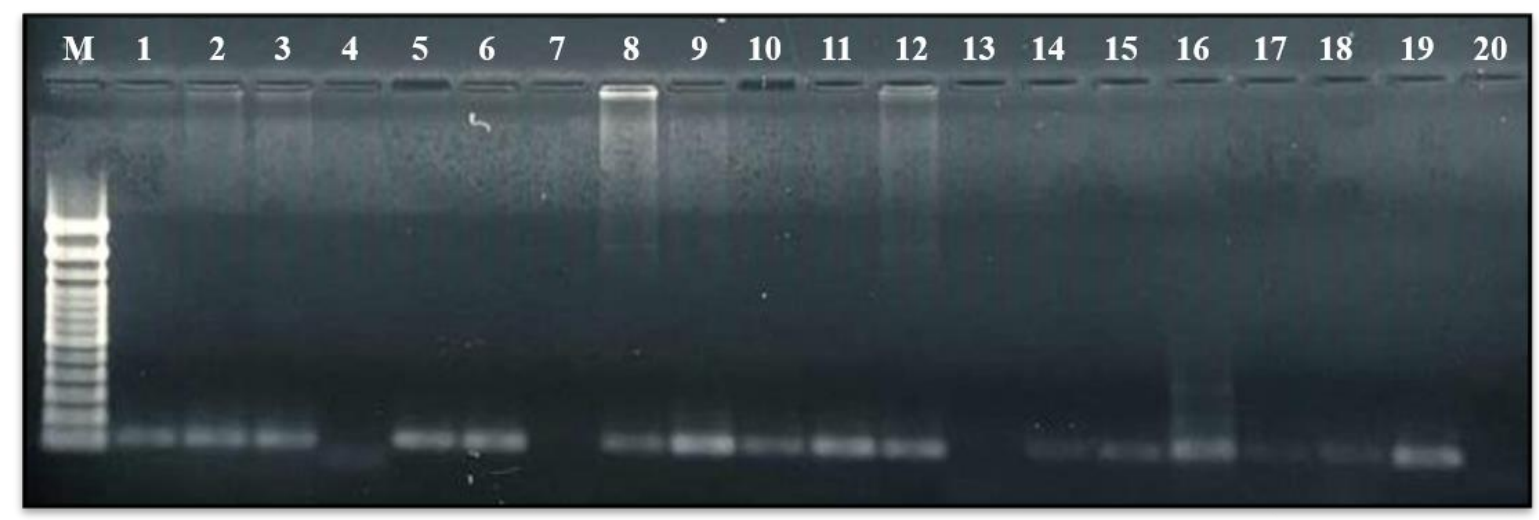

Legenda: Análise da Produto de PCR do gene cisteíno-peptidase por eletroforese em gel de poliacrilamida 10,5\% (p/v). DNA de Trypanosoma cruzi, cepa CL Brener, foram extraídos pelos métodos DNAzol ${ }^{\circ}$, Trizol ${ }^{\circ}$ e in house. Poço M - marcador de peso molecular de 100pb (Thermo Fisher Scientific); Poço 1-3 Extração de DNA DNAzol ${ }^{\oplus}$ realizada no laboratório de pesquisa; Poço 4-6 Extração de DNA DNAzol realizada no laboratório de ensino; Poço 7-9 Extração de DNA por Trizol ${ }^{\circledR}$ realizada no laboratório de ensino; Poço 10 -

WWW.AMPLLAEDITORA.COM.BR (2) 
12 Extração de DNA por Trizol realizada no laboratório de pesquisa; Poço 13-15 Extração de DNA in house realizada no laboratório de pesquisa; Poço 16-18 Extração de DNA in house realizada no laboratório de ensino. Poço 19- Controle positivo; Poço 20 - Controle negativo. A banda esperada possui 115 pb.

Feita a análise do gel, podemos observar que houve amplificação, de modo geral, em todas as extrações em algumas das triplicatas, com exceção do DNAzol e do Trizol, no laboratório de ensino, por falta de volume e por baixa concentração de DNA. O fragmento de DNA extraído pelo método in house, no laboratório de pesquisa, também não foi amplificado por erro de manipulação ou baixa sensibilidade no gel de agarose. Além disso, o fragmento do poço 13, apesar de não ter sido visualizado no gel de agarose, foi visualizado com sucesso no gel de poliacrilamida.

\section{CONSIDERAÇÕES FINAIS}

A partir dos resultados descritos, verificamos que todos os protocolos foram capazes de extrair o DNA do T. cruzi com qualidade, obedecendo aos parâmetros impostos para avaliação do grau de pureza (A260/A280) com concentração suficiente para a realização de técnicas posteriores (eletroforese em géis de agarose e poliacrilamida e PCR). Apesar do laboratório de ensino não haver área específica destinada à realização de técnicas de Biologia Molecular, o mesmo mostrou-se apto à realização de tais procedimentos voltados para a capacitação profissional, bem como para o estímulo à pesquisa ao aluno.

\section{REFERÊNCIAS}

Avila HA, Pereira JB, Thiemann O, De Paiva E, DeGrave W, Morel CM, Simpson L (1993) Detection of Trypanosoma cruzi in blood specimens of chronic chagasic patients by polymerase chain reaction amplification of kinetoplast minicircle DNA: comparison with serology and xenodiagnosis. J Clin Microbiol 31: 2421-2426

Chagas C (1909) Nova tripanosomiaze humana. Estudos sobre morfolojia e o ciclo evolutivo do Schizotrypanum cruzi n.g., n. sp., ajente etiolojico de nova entidade morbida do homen. Mem Inst Oswaldo Cruz 1: 159-218

González IJM, M.A.; Perkins, M.D. (2010) Chagas disease (American trypanosomiasis). Infectious Diseases (Third Edition) 2: 1205-1212 
FB, Dozza M, Peterka R, Chiari L, Wall C, 3rd (2009) Vibrotactile biofeedback improves tandem gait in patients with unilateral vestibular loss. Ann N Y Acad Sci 1164: 279-281

Jurberg JR, J.M.S.; Moreira, F. F. F. ; Dale, C.; , Cordeiro IRSL, V.D.J.; Galvão, C.; Rocha, D.S. (2014) Atlas Iconográfico dos triatomíneos do Brasil (vetores da doença de Chagas).

McGwire BS. (2015) Explainer: what is Chagas disease? The conversation. Disponivel em: https://theconversation.com/explainer-what-is-chagas-disease-40047 Acesso em: 05 de dez. de 2019.

Moser DR, Kirchhoff LV, Donelson JE (1989) Detection of Trypanosoma cruzi by DNA amplification using the polymerase chain reaction. J Clin Microbiol 27: 14771482

Mottram JC, Brooks DR, Coombs GH (1998) Roles of cysteine proteinases of trypanosomes and Leishmania in host-parasite interactions. Curr Opin Microbiol 1: $455-460$

Nagajyothi F, Machado FS, Burleigh BA, Jelicks LA, Scherer PE, Mukherjee S, Lisanti MP, Weiss LM, Garg NJ, Tanowitz HB (2012) Mechanisms of Trypanosoma cruzi persistence in Chagas disease. Cell Microbiol 14: 634-643

Nicklas JA, Buel E (2003) Quantification of DNA in forensic samples. Anal Bioanal Chem 376: 1160- 1167

Requena-Mendez A, Aldasoro E, de Lazzari E, Sicuri E, Brown M, Moore DA, Gascon J, Munoz J (2015) Prevalence of Chagas disease in Latin-American migrants living in Europe: a systematic review and meta-analysis. PLoS Negl Trop Dis 9: e0003540

Rotureau B, Gego A, Carme B (2005) Trypanosomatid protozoa: a simplified DNA isolation procedure. Exp Parasitol 111: 207-209

Toso MA, Vial UF, Galanti N (2011) [Oral transmission of Chagas' disease]. Rev Med Chil 139: 258- 266

WHO (2015) Chagas disease in Latin America: an epidemiological update based on 2010 estimates.Wkly Epidemiol Rec 90: 33-44

Yoshida N (2009) Molecular mechanisms of Trypanosoma cruzi infection by oral route. Mem Inst Oswaldo Cruz 104 Suppl 1: 101-107 


\title{
CAPÍTULO Y
}

\section{CORYNEBACTERIUM STRIATUM: PATÓGENO MULTIRRESITTENTE NEGLIGENCIADO PELA DIF́CLL E INCORRETA IDENTIFICAÇÃO}

\author{
Giorgio Silva de Santana ${ }^{1,2}$ \\ Bruna Ribeiro Sued Karam² \\ Laís Menegoi de Oliveira Fernandes² \\ Igor Ferreira da Silva ${ }^{2}$ \\ Cassius de Souza ${ }^{2}$ \\ Ana Luíza de Mattos Guaraldi ${ }^{1,2}$
}

${ }^{1}$ Instituto de Microbiologia Paulo de Góes, Universidade Federal do Rio de Janeiro, Brasil.

${ }^{2}$ Laboratório de Difteria e Corinebactérias de Importância Clínica, Universidade do Estado do Rio de Janeiro, Brasil.

\section{RESUMO}

Corynebacterium striatum faz parte da microbiota normal da pele humana e tem sido cada vez mais envolvido em várias doenças nosocomiais, incluindo infecções invasivas fatais em pacientes imunossuprimidos e imunocompetentes. Entretanto, os casos de infecções por $C$. striatum ainda são negligenciados, mesmo quando recuperados em cultura pura de locais que deveriam ser estéreis, como o sangue. $O$ isolamento de $C$. striatum em laboratórios clínicos é difícil, por seu crescimento relativamente lento e metodologia de identificação complexa, necessitando de uma grande quantidade de métodos fenotípicos. O aprimoramento de técnicas microbiológicas e o estudo da sobrevida de pacientes com doença de base e/ou imunossupressão, têm comprovado que $C$. striatum é um agente etiológico de infecções nosocomiais, em diferentes níveis de gravidade. A capacidade de alguns clones $C$. striatum de produzir biofilme, pode contribuir para a persistência do patógeno e a disseminação da resistência antimicrobiana no ambiente hospitalar. Além disso, a antibioticoterapia empírica pode selecionar cepas multirresistentes e transferir horizontalmente genes intra e interespécies. Esta revisão objetiva certificar o papel de $C$. striatum como patógeno hospitalar multirresistente, cada vez mais associado a infecções graves com tratamentos antimicrobianos recorrentes em pacientes hospitalizados, imunocompetentes e imunocomprometidos, com doenças subjacentes.

Palavras-chave: Corynebacterium striatum. infecção. patógeno negligenciado. resistência antimicrobiana.

\section{INTRODUÇÃO}

O gênero Corynebacterium, descrito por Lehmann e Neumann (1896), pertence

à classe Actinobacteria, ordem Actinomecetales e família Corynebacteriaceae

WWW.AMPLLAEDITORA.COM.BR (2)

CONTATO@AMPLLEDITORA.COM.BR M 
(LEHMANN e NEUMANN, 1896, p. 1907). Corynebacterium spp. são caracterizadas pela presença de arabinose, galactose, ácido meso-diaminopimélico e cadeias curtas de ácido micólico na parede celular, são aeróbicas, catalase-positivas, não esporuladas e imóveis, que podem ser observadas por microscopia de luz como bastonetes Grampositivos irregulares (com morfologia celular pleomórfica, apresentando as formas cocoides, bacilares ou filamentosas), individualizados ou agrupados em pares e/ou em forma de paliçadas. Algumas espécies podem apresentar ácidos corinomicólicos e grânulos metacromáticos como reserva de fosfato de alta energia (ex.: Corynebacterium diphtheriae) (BIBERSTEIN e ZEE, 1994, p. 157-161; FUNKE e BERNARD, 2011, p. 413-442).

Durante muitas décadas, o potencial patogênico das corinebactérias foi negligenciado, principalmente pela dificuldade na identificação e distinção entre colonização e infecção, esses motivos levaram a escassez de relatos de infecções por corinebactérias produtoras de toxina não-diftérica (difteróides - DT) (CAMELLO et al., 2003; MARTINS et al., 2009). Corinebactérias DT isoladas de cultura pura tem sido consideradas como patógenos oportunistas, que prevalecem em inúmeras condições orgânicas, produzindo infecções graves. Entretanto, microbiologistas clínicos erroneamente, ainda consideram DT como contaminantes de amostras clínicas, dando importância apenas a $C$. diphtheriae o agente etiológico da difteria clássica, como a única espécie patogênica do gênero. A atual valorização de corinobactérias como agentes etiológicos, está intimamente relacionada a crescente atuação como agente etiológico em doenças humanas, decorrente do uso de procedimentos invasivos, bem como condições de pacientes hospitalizados por períodos prolongados, como idade avançada, doenças neoplásicas, transplante de órgãos, síndrome de imunodeficiência adquirida (AIDS), diabetes, antibioticoterapia prologada, além de procedimentos como cateterismo, implantes protéticos e de válvulas cardíacas (MARTINS et al., 2009).

Até o presente momento, foram descritas 115-129 espécies do gênero Corynebacterium (PARTE, 2014; ZASADA e MOSIEJ, 2018), distribuídas em diferenciados ambientes, como solo, esgoto e superfícies de plantas (BAIO et al., 2013). Embora a maioria das espécies estejam disseminadas no ambiente e como parte da microbiota humana (anfibiôntica), pelo menos 50 espécies foram relatadas como agente etiológico de infecções humanas (BERNARD et al., 2013; ZASADA e MOSIEJ, 2018), e estão 
amplamente difundidas no ambiente hospitalar, possuindo grande importância médica (FUNKE e BERNARD, 2011, p. 413-442; BAIO et al., 2013).

As corinebactérias vêm adquirindo crescente importância epidemiológica, em países mais desenvolvidos e em desenvolvimento, pois as infecções causadas por esses micro-organismos podem levar a óbito, tanto pacientes imunocomprometidos quanto imunocompetentes. Além das corinebactérias produtoras de toxina, que são amplamente conhecidas como patógenos humanos e animais como $C$. diphtheriae (difteria humana) (JANDA, 1998; SCHRÖDER et al., 2012), C. pseudotuberculosis (linfadenite caseosa em ruminantes) e C. ulcerans (difteria humana e zoonótica) (BAIO et al., 2013), cepas DT tem demonstrado grande relevância clínica, por apresentarem clones multirresistentes (MDR, multidrug resistant profile) e causarem infecções hospitalares graves, entre elas, destacam-se C. afermentans, C. amycolatum, C. jeikeium, C. pseudodiphtheriticum, C. striatum e C. urealyticum (RENOM et al., 2007; MARTINS et al., 2009). Constantemente têm sido identificados clones apresentando resistência natural e/ou adquirida a antimicrobianos como $C$. macginleyi, $C$. minutissimum e $C$. xerosis, tanto em ambientes comunitários quanto em hospitalares (RENOM et al., 2007; REDDY et al., 2012). Estudos tem demonstrado que a prevalência desses clones MDR dependem da localização geográfica, além da constante aquisição de genes de outras espécies, que conferem os fenótipos de resistência a novos antimicrobianos (ZASADA e MOSIEJ, 2018).

Esta revisão objetiva certificar o papel de $C$. striatum como patógeno hospitalar multirresistente, cada vez mais associado a infecções graves com tratamentos antimicrobianos recorrentes em pacientes hospitalizados, imunocompetentes e imunocomprometidos, com doenças subjacentes.

\section{INFECÇÕES POR CORYNEBACTERIUM STRIATUM}

Corynebacterium striatum foi descrito inicialmente como partícipe da microbiota natural da pele e mucosa nasal em humanos, tendo sido, por muito tempo, reconhecido como contaminante e sistematicamente desconsiderado durante o diagnóstico clínicolaboratorial (LEE et al., 2005; BERNARD et al., 2013). Contudo, clones MDR têm sido isolados do trato respiratório em humanos com infecções comunitárias e em pacientes

WWW.AMPLLAEDITORA.COM.BR (2)

CONTATO@AMPLLAEDITORA.COM.BR 
hospitalizados, sua disseminação entre pacientes através das mãos contaminadas de profissionais de saúde tem sido um dado preocupante (MOORE et al., 2010; DíEZAGUILAR et al., 2013).

Um número crescente de casos de infecções invasivas por $C$. striatum são relatados em indivíduos imunocomprometidos e imunocompetentes, incluindo: bacteremia e sepse (RENOM et al., 2007; WONG et al., 2010), artrite séptica (CONE et al., 1998; SCHOLLE, 2007), endocardite, meningite (WEISS et al., 1996; OLIVA et al., 2010), osteomielite (FERNÁNDEZ-AYALA et al., 2001; SCHOLLE, 2007), sinusite (HEIDEMANN et al., 1991), infecção pulmonar (RENOM et al., 2007; WONG et al., 2010) e sinovite (CONE et al., 1998; SCHOLLE, 2007). Também tem sido identificado como agente etiológico de abscessos hepáticos (STONE et al., 1997) e em mama (BOLTIN; MARTINS et al., 2009), queratites/ceratite (HEIDEMANN et al., 1991), feridas em pele e cirúrgica (MOORE et al., 2010), infecções intrauterinas (BOLTIN; CAMPANILE et al., 2009), peritonites (BHANDARI et al., 1995), em pacientes acometidos por Síndrome da Imunodeficiência Adquirida (SIDA), câncer e transplantados (TARR et al., 2003; MARTINS et al., 2009), por esse motivo atualmente é considerado por muitos pesquisadores um patógeno muito virulento (OLIVA et al., 2010; DíEZ-AGUILAR et al., 2013).

A identificação de $C$. striatum pode ser realizada através de métodos bioquímicos convencionais (Anexo I), também disponíveis em sistemas semi-automatizados (CAMELLO et al., 2003; JORGENSEN et al., 2015). Métodos moleculares como o sequenciamento de genes $16 \mathrm{~S}$ rRNA e rpoB geralmente são utilizados em Laboratórios de Referência (BAIO et al., 2013). Atualmente, a identificação de espécies bacterianas por espectrometria de massa oferece protocolos mais práticos e rápidos como o MALDI (Matrix Assisted Lazer Desorption lonization), seguido pela detecção em um analisador do tipo tempo de vôo (TOF) e mass spectrometry (MS) (MALDI-TOF MS) (DíEZ-AGUILAR et al., 2013).

Avanços tecnológicos levaram a melhorias nas condições de sobrevivência de pacientes imunocomprometidos, assim como o desenvolvimento de tecnologias de identificação, possibilitaram o crescente número de relatos de casos na literatura sobre infecções causadas por corinebactérias (LEE et al., 2005; BERNARD et al., 2013).

Na primeira década do século XXI (entre 2001 a 2010), C. striatum foi associado a infecções nosocomiais, principalmente em pacientes imunodeprimidos, internados 
por longos períodos em unidades de terapia intensiva (UTIs) e pelo uso de dispositivos médicos invasivos como cateteres intravenosos (SUPERTI et al., 2009; WONG et al., 2010). A utilização de múltiplos dispositivos médicos propiciou a colonização do trato respiratório superior, com subsequente infecção invasiva. Portanto, esse microrganismo deve receber atenção especial, principalmente quando isolado em cultura pura de materiais clínicos, coletados de pacientes cronicamente debilitados e/ou fazendo uso de dispositivos invasivos (RENOM et al., 2007; WONG et al., 2010). Esta bactéria foi descrita como agente etiológico de infecções no trato respiratório inferior em pacientes hospitalizados com doença respiratória crônica e imunossupressão (DÍEZ-AGUILAR et al., 2013).

C. striatum é um patógeno capaz produzir surtos em ambiente hospitalar (BAIO et al., 2013), sendo constantemente isolado em pacientes e em diversos materiais hospitalares, como de assistência respiratória, urológicos, broncoscópios, cateteres, colonoscópios, laparoscópicos e nasofibroscópios (SCHOLLE, 2007; OLIVA et al., 2010). Infecções causadas por esse microrganismo já foram relatadas em pacientes do setor de oncologia pediátrica do St. Jude Children's Research Hospital (Tennessee, EUA), com progressão para bacteremia (ADDERSON et al., 2008). Estes pacientes tiveram complicações decorrentes dessas infecções, com recorrência e progressão para artrite séptica (ADDERSON et al., 2008). Sendo o primeiro caso de infecção no trato urinário por C. striatum em paciente ambulatorial, com ausência de fatores predisponentes foi relatado por López et al. (2009) (LÓPEZ et al., 2009).

\section{RESISTÊNCIA ANTIMICROBIANA NOS AMBIENTES NOSOCOMIAIS}

A incidência de bactérias resistentes aos antimicrobianos isoladas em infecções adquiridas na comunidade e nos hospitais, constitui um dos problemas mais graves em Saúde Pública mundial, que desperta a atenção de órgãos governamentais nacionais e internacionais como a Organização Mundial de Saúde (OMS), Centers for Disease Control and Prevention (CDC/USA), Agência Nacional de Vigilância Sanitária (ANVISA) além de Comissões de Controle e Prevenção a Infecções Hospitalares (CCIH) de diversas instituições de saúde (OLIVEIRA et al., 2009). O desenvolvimento de resistência aos antimicrobianos tem evoluído rapidamente, levando à falha terapêutica e, 
consequentemente, a limitações nas opções de tratamento, por esse motivo, a descoberta de novos fármacos com propriedades bactericidas torna-se cada vez mais necessária. Nos últimos 40 anos, apenas dois medicamentos foram introduzidos no mercado: a linezolida e daptomicina (CAUMO et al., 2010).

A disseminação de microrganismos multirresistentes no ambiente hospitalar tem sido motivo crescente de preocupação, devido ao aumento na taxa de resistência adquirida aos antimicrobianos $\beta$-lactâmicos, clindamicina, eritromicina, ciprofloxacino e gentamicina por espécies de Corynebacterium, tornando a utilização da vancomicina último recurso terapêutico. Até o momento, a vancomicina, teicoplanina e linezolida são as drogas mais ativas in vitro contra as corinebactérias (YOON et al., 2011; REDDY et al., 2012). Exceto pela eficaz atividade da vancomicina contra as corinebactérias, a variabilidade na aquisição da resistência a outras classes de antimicrobianos ressalta a necessidade de contínua vigilância dos perfis de resistência dessas espécies (WEISS et al., 1996).

Embora a maioria das cepas $C$. striatum descritas até o momento sejam suscetíveis a uma ampla variedade de antibióticos (WEISS et al., 1996), foi relatado que a pressão seletiva exercida pelos tratamentos prévios com antimicrobianos, induziu o crescimento de $C$. striatum como segundo microrganismo corineforme mais prevalente em pacientes imunocomprometidos. Neste sentido, a identificação de cepas MDR é motivo de grande preocupação (ADDERSON et al., 2008; CAMPANILE et al., 2009). Entretanto, os critérios de avaliação de susceptibilidade aos antimicrobianos para as corinebactérias ainda não são padronizados, alguns autores sugerem que sejam relatados os casos de resistência total aos antibióticos, ou seja, ausência de qualquer zona (halo) de inibição em teste de susceptibilidade a antimicrobianos (TSA), pelo método de disco-difusão em meio ágar Mueller-Hinton (MHA), a fim de entender o comportamento das diferentes espécies desse gênero sob exposição as drogas utilizadas no tratamento de infecções (DÍEZ-AGUILAR et al., 2013).

Um número crescente de relatos de infecções por clones de $C$. striatum multirresistentes tem sido documentado em pacientes hospitalizados (BOLTIN et al., 2009; WONG et al., 2010) em diversos países, como: Itália, Espanha, Holanda, Estados Unidos, China e Japão (ADDERSON et al., 2008; CAMPANILE et al., 2009). Entretanto, em países em desenvolvimento, incluindo os países da América Latina, as notificações de

WWW.AMPLLAEDITORA.COM.BR (2)

CONTATO@AMPLLAEDITORA.COM.BR M 
infecções por C. striatum permanecem ocasionais (CAMELLO et al., 2003; SUPERTI et al., 2009). Este fato pode estar relacionado com a dificuldade que a maioria dos laboratórios desses países enfrentam, para realizar a identificação precisa de bastonetes Grampositivos irregulares, devido à necessidade de profissionais capacitados para o isolamento e identificação de microrganismos de crescimento lento. Adicionalmente, a exigência da utilização de muitos testes fenotípicos e a necessidade de procedimentos sofisticados e onerosos de difícil acesso, dificultam e, por vezes, impossibilitam a identificação de espécies corineformes em laboratórios desprovidos de recursos (PIMENTA et al., 2008; TORRES et al., 2013).

No Japão, Otsuka et al. (2006) relatam taxas variáveis da susceptibilidade de $C$. striatum aos $\beta$-lactâmicos e aminoglicosídeos, além de elevados níveis de resistência à eritromicina, tetraciclina, rifampicina e ciprofloxacina, embora todas as cepas isoladas tenham sido suscetíveis à vancomicina. Através da análise por Pulsed-field Gel Electrophoresis (PFGE) foram identificados 14 pulsotipos de C. striatum, onde os pulsotipos descritos como A, D e E foram associados a surtos nosocomiais de origem respiratória, e os subtipos $A 1, A 2, D 2$ e $E$ foram associados a resistência a ampla variedade de antimicrobianos (OTSUKA et al., 2006).

Na Espanha, Renom et al. (2007) observaram que $100 \%$ das cepas de C. striatum isoladas de surtos nosocomiais eram multirresistentes, ou seja, apresentavam resistência a três ou mais antimicrobianos de diferentes classes, dos quais $65 \%$ eram resistentes a quatro ou cinco classes de antibióticos, sendo 6,9\% suscetíveis apenas a imipenem e vancomicina, $11 \%$ suscetíveis somente à vancomicina (RENOM et al., 2007).

Na América do Sul, o Brasil tem notificado o isolamento de C. striatum em materiais hospitalares utilizados por pacientes internados com sinais e sintomas de infecção (MARTINS et al., 2009). Em 2009 este agente deflagrou um surto no Hospital Universitário Pedro Ernesto, Rio de Janeiro, Brasil; onde cepas C. striatum foram isoladas em UTIs e enfermarias cirúrgicas, principalmente em aspirados traqueais de pacientes submetidos a procedimentos de intubação endotraqueal e, em sua maioria foi multirresistente. Cerca de $87 \%$ das cepas pertenciam aos pulsotipos I e II, e foram relacionadas com óbito de 5 pacientes infectados. Surpreendentemente, apenas os pacientes adultos encontravam-se colonizados por cepas multirresistentes e $50 \%$ tinham idade superior a 50 anos. As infecções por esses clones multirresistentes

WWW.AMPLLAEDITORA.COM.BR (2) 
assustadoramente foram correlacionadas com óbito dos pacientes (BAIO et al., 2013). Outra investigação no Brasil, revelou que cepas clínicas oriundas de pacientes com câncer sob tratamento, em um centro de referência no Rio de Janeiro, foram identificadas como C. striatum, isoladas de diferentes sítios de colonização, incluindo o trato respiratório superior e inferior, e feridas cirúrgicas, comprovando assim a eficiência desse microrganismo como um patógeno nosocomial (MARTINS et al., 2009).

Atualmente não há nenhum banco de dados disponível para $C$. striatum, tais como PulseNet (http://www.cdc.gov/pulsenet), que permita a comparação dos padrões de PFGE observados em diferentes surtos nosocomiais. Estudos realizados por Campanile et al. (2009), demonstraram perfis Swal-PFGE de C. striatum com bandas variando de tamanho entre 48.5 a 533.5 kb (CAMPANILE et al., 2009). Baio et al. (2013), demonstraram perfis Swal-PFGE de C. striatum com bandas variando de tamanho entre 97.0 a $533.5 \mathrm{~kb}$ (BAIO et al., 2013). Uma análise comparada entre os dois surtos, revela ausência de bandas variando de tamanho entre 48.5 a $97.0 \mathrm{~kb}$, sugerindo que as cepas MDR isoladas no surto brasileiro por Baio et al. (2013) diferem das cepas MDR isoladas no surto italiano por Campanile et al. (2009) (CAMPANILE et al., 2009; BAIO et al., 2013). Além disso, a análise dos perfis fenotípicos das cepas C. striatum brasileiras, demonstram diferenças ao serem comparadas com cepas isoladas em um surto na Holanda (biótipo: nitrato/pyz - positivos e sacarose - negativo) (BRANDENBURG et al., 1996).

Os mecanismos de tolerância e resistência de C. striatum ainda não estão completamente elucidados, entretanto, sabe-se que a baixa permeabilidade da parede externa, o grande conteúdo lipídico e a capacidade de formar biofilme podem contribuir para a tolerância a diversos agentes antimicrobianos (FONTANA, 2008; LORENA et al., 2009).

\section{CONTROLE DO CRESCIMENTO MICROBIANO NO AMBIENTE HOSPITALAR}

As infecções hospitalares têm grande relevância epidemiológica, tanto no contexto da Saúde Pública, quanto na assistência hospitalar. Elas elevam as taxas de morbimortalidade, ampliam o tempo de permanência dos pacientes nos hospitais e, 
consequentemente, elevam os custos no tratamento, com consequências irreparáveis do ponto de vista humano, econômico e social. Costumeiramente, nas UTIs os índices de infecções são mais elevados do que nos demais setores hospitalares, como resultado da interação entre microrganismos, superfícies infectadas que servem de reservatório de patógenos e deficiência imunológica dos pacientes (ANVISA, 2000).

O ambiente hospitalar destina-se a recuperação da saúde do paciente, entretanto há uma preocupação mundial com o controle desses ambientes em razão das recorrências de surtos de infecções, causadas por várias espécies microbianas multirresistentes. A eliminação de surtos epidêmicos, requer uma rigorosa descontaminação do ambiente hospitalar, dependente de procedimentos e rotinas específicos, empenho e treinamento técnico especializados para essa finalidade (ANVISA, 2014).

Para o combate das doenças infecciosas responsáveis por surtos epidêmicos, é necessário ter um ambiente controlado, devendo levar em consideração o controle de terapias antimicrobianas com uso racional de antibióticos, possuir gerenciamento ou gestão por uma Comissão de Controle de Infecções Hospitalar (CCIH) responsável por padronizar rotinas e protocolos com treinamento de funcionários, selecionando agentes químicos descontaminantes, aplicando técnicas atualizadas de limpeza, descontaminação e desinfecção, com a constante avaliação da eficácia desses agentes com testes padronizados pela ANVISA (ANVISA, 2004).

Dentre os fatores que contribuem para que $C$. striatum possa causar infecções hospitalares destacam-se: transferência de genes de resistência, uso inadequado e irracional de antimicrobianos promovendo a seleção de bactérias resistentes, ineficiência na limpeza e descontaminação das superfícies hospitalares e materiais utilizados nas áreas críticas (centro cirúrgico, de esterilização, hemodiálise, lactário, tratamento de queimados, necrotério, laboratório e expurgo) e semi-críticas (enfermarias, quartos, ambulâncias, ambulatórios) (RUTALA et al., 1996; VERMELHO et al., 2008). Procedimentos invasivos realizados em ambientes nosocomiais, especialmente em setores críticos, podem contribuir para infecções relacionadas à assistência à saúde (IRAS). Apesar dos procedimentos de esterilização e de técnicas de assepsia mais avançadas, as infecções associadas a dispositivos hospitalares ainda representam um grave problema, em parte, pelo desenvolvimento de resistência aos

WWW.AMPLLAEDITORA.COM.BR $(2)$ 
antimicrobianos pelas bactérias (RENOM et al., 2007). Relatos constantes de transmissão de agentes infecciosos em procedimentos invasivos, são decorrentes de ineficiência na limpeza e desinfecção do ambiente cirúrgico, mas principalmente da reutilização de materiais hospitalares sem a devida descontaminação (HOWIE et al., 2008).

Diversos agentes químicos podem ser utilizados para controlar o crescimento bacteriano nos ambientes hospitalares, tanto na presença quanto na ausência de matéria orgânica, contudo, nenhum deles isoladamente são capazes de eliminar $100 \%$ dos microrganismos e nem todos são apropriados para todas as circunstâncias, seja em superfícies bióticas ou abióticas (VERMELHO et al., 2008). A escolha dos agentes químicos apropriados para cada tipo diferente de desinfecção, bem como o modo de desinfecção utilizado para cada tipo de superfície é fundamental para obtenção de um ambiente hospitalar controlado com mínimo risco de infecções (RUTALA et al., 2008, p. 6).

Dentre os componentes que podem ser utilizados como desinfetantes no ambiente hospitalar, destaca-se o glutaraldeído (GA) pelo seu amplo espectro, atuando contra bactérias, Gram-positivas, Gram-negativas, micobactérias (especialmente, Mycobacterium tuberculosis), alguns vírus, fungos e seus esporos causadores de infecções hospitalares. A atividade microbicida desse agente advém da alquilação de grupos sulfidrila, hidroxila, carboxila e amino dos microrganismos, alterando seu DNA, RNA e síntese de proteínas, com consequente ação inibitória sobre o transporte e sistemas enzimáticos, onde o acesso do substrato à enzima é comprometido. Por outro lado, a atividade esporicida do glutaraldeído está relacionada a interação com a superfície do esporo, provocando o endurecimento das camadas externas. A solução a $2 \%$, em pH 8.0 (glutaraldeído ativado/alcalino) tem sido utilizada em muitos hospitais, para desinfecções de materiais com fins cirúrgicos nos ambientes críticos e semicríticos, que não podem ser submetidos ao calor (borracha e plásticos), principalmente por ser um produto químico não corrosivo, mas infelizmente, sua utilização é limitada a desinfecções de alto nível devido a sua toxicidade (LORENA et al., 2009).

Outro agente químico de destaque é o ácido peracético, que possui alto poder oxidante em componentes celulares, agindo sobre a membrana citoplasmática e desativando as funções fisiológicas, incluindo a barreira osmótica. O seu uso foi sugerido

WWW.AMPLLAEDITORA.COM.BR(2)

CONTATO@AMPLLAEDITORA.COM.BR 
como alternativa para substituir o gluteraldeído na desinfecção de materiais em ambientes críticos e semicríticos, pela eficácia contra diversos microrganismos, ação bactericida, tuberculocida, virocida, fungicida e esporocida, mesmo na presença de matéria orgânica (SATTAR e SPRINGTHORPE, 2001, p. 80-86; McDONNELL, 2007). Entretanto, possui como desvantagens, o tempo reduzido de ação pós-diluição (uma solução a $1 \%$ perde a atividade em seis dias por hidrólise ou oxidação na presença de ferro e cobre), baixa estabilidade em estoque e manuseio especializado, por possuir atividade corrosiva podendo provocar irritação na pele (BLOCK, 2001, p. 185-204).

O hipoclorito de sódio é um sal do ácido hipocloroso, em equilíbrio com o ânion hipoclorito possui alto poder oxidante devido à carga neutra, difunde-se facilmente pela parede celular das bactérias. Sua utilização se limita a superfícies abióticas e outros materiais que não entram em contato direto com o paciente. Devido ao seu alto poder corrosivo, não deve ser utilizado na desinfecção de materiais no ambiente crítico e semicrítico, uma vez que estes são constituídos de materiais sensíveis como plástico, borracha e metais leves (ANDRADE, 1988).

O monopersulfato de potássio é um agente químico novo, que atua oxidando os grupos sulfidrilas presente nas proteínas, eliminado os microrganismos, sua característica mais importante é a atividade na presença de matéria orgânica, além de não ser corrosivo para metais. Entretanto, tem sido mais utilizado em materiais no ambiente não crítico (consultório médico, farmácia, ou seja, onde não há risco de transmissão de infecção e não exista pacientes), devido a sua baixa eficácia em micobactérias, a perda de atividade após sete dias de ativação, a necessidade de profissionais tecnicamente capacitados para diluição mantendo sua coloração, pois a redução da intensidade na cor significa diminuição da eficácia (RUTALA et al., 1996; SILVA et al., 2013).

O ortoftalaldeído foi considerado desinfetante de alto nível pelo FDA (Food and Drug Administration) em outubro de 1999, por interagir com proteínas e aminoácidos dos microrganismos, possui vantagens quando comparado com glutaraldeído em relação à toxicidade, odor, boa estabilidade em pH 3.0-9.0, não é irritante aos olhos nem às vias aéreas, não é teratogênico nem mutagênico. Entretanto, possui as desvantagens de manchar a pele, mucosas e superfícies expostas ao meio ambiente, pode causar hipersensibilidade em pacientes com exposições repetidas e possui custo

WWW.AMPLLAEDITORA.COM.BR (2) 
mais elevado que o glutaraldeído, além de possuir baixa atividade esporocida (PSALTIKIDIS et al., 2014).

A glucoprotamina é oriunda de uma reação de conversão do aminoácido ácido L-Glutâmico com a cocosamina, uma substância extraída do coco. Seu mecanismo de ação ainda não é completamente elucidado, mas sua eficácia é comprovada, muitos acreditam que tem relação com a oxidação de substância vitais dos microrganismos, possui vantagens ecologicamente importantes, pois é biodegradável e seu descarte não agride o meio ambiente, não sendo necessária sua neutralização. Outro ponto positivo é seu alto espectro de ação contra microrganismos, não é corrosivo e tem afinidade com grande parte dos metais como aço inoxidável, latão, alumínio e outros (WIDMER et al., 2003).

São escassos os trabalhos relatando a resistência a agentes biocidas em corinebactérias. Corinebactérias estão listadas entre os microrganismos resistentes detectados em ensaios de análise de eficiência de protocolos de desinfecção utilizados em instrumentos e ambientes de assistência à saúde, especialmente as espécies $C$. striatum e C. amycolatum. Corinebactérias foram detectadas após o reprocessamento de endoscópios gastrointestinais submetidos à desinfecção com soluções de ácido peracético a $2 \%$ ou glutaraldeído a $2 \%$, por períodos de exposição de até 30 minutos. Ensaios comparativos entre diversos agentes biocidas, demonstraram a atividade microbicida in vitro da povidone iodine a $5 \%$, do digluconato de clorexidina a $4 \%$ e do ácido hipocloroso a $0.01 \%$ para C. striatum e C. amycolatum indicando seu uso na antissepsia pré-operatória (ANAGNOSTOPOULOS, 2018).

Nas superfícies bióticas (pele, conjuntiva ocular e mucosas) submetidas a procedimentos pré-operatórios tratadas com solução de clorexidina $0.05 \%$ a $0.5 \%$, foi observada redução significativa no isolamento de corinebactérias, contudo não houve efeito microbicida esperado para este agente in vivo (GILI et al., 2018). Recentemente, uma análise comparativa da eficiência de desinfecção entre duas associações de biocidas (clorexidina $0.5 \%$ e álcool etílico $70 \%$ versus iodine $1 \%$ e álcool etílico $70 \%$ ) utilizadas em cirurgias ortopédicas, foi possível identificar corinebactérias entre os microrganismos mais isolados da superfície da pele após o procedimento cirúrgico (SHADID et al., 2019). 
Os artigos compilados apenas relatam a ocorrência da resistência aos agentes e buscam sua correlação com falhas nos procedimentos durante da desinfecção, sem levar em consideração aspectos microbiológicos específicos.

\section{FATORES QUE INTERFEREM NO PROCESSO DE DESINFECÇÃO}

A matéria orgânica está diretamente relacionada com a ineficácia de agentes químicos, pois alguns agentes químicos têm a ação reduzida na presença de cadeias carbônicas. Avaliar a influência da matéria orgânica no processo de desinfecção é muito importante, uma vez que materiais dos ambientes crítico e semicrítico estão em contato direto com substâncias orgânicas com pus, sangue, soro e outras (LEWIS e ARENS, 1995).

A limpeza mecânica com água e sabão, realizada manualmente com auxílio de escova e com uso de equipamento de proteção individual (EPI), visa a remoção de todo material orgânico e a redução dos microrganismos presentes nos materiais cirúrgicos, para que não haja a interferência na atividade antimicrobiana dos desinfetantes, ou não constitua uma barreira física de proteção aos microrganismos durante os processos de desinfecção e esterilização por meios físicos e químicos. A limpeza meticulosa dos materiais cirúrgicos, antes de submetê-los à desinfecção ou esterilização é um procedimento unânime e universal (SOUZA et al., 1998).

A parede celular das bactérias Gram-positivas possui alta concentração de diversos compostos bioquímicos como lipopolissacarídeo (LPS), lipídios com perfil hidrofóbico muito intenso, conferindo propriedades favoráveis a tolerância aos agentes químicos hidrofílicos e de adesividade a superfícies hidrofóbicas. Adicionalmente, mecanismos de adesividade e persistência apresentados por microrganismos, especialmente sob condições de estresse, como a expressão de adesinas e invasinas, enzimas capazes de neutralizar a ação de agentes oxidantes e sequestrar micronutrientes e a habilidade de produzir biofilme colaboram para a resistência a ação de agentes biocidas (COSTERTON et al., 1999).

Outros fatores também podem alterar a ação dos agentes químicos nos processos de desinfecção, como a aquisição de genes de resistência através de transferência genética, mecanismos de bombeamento de substâncias químicas para fora do citoplasma bacteriano (bombas de efluxo), proteínas de grande peso molecular 
encontradas na membrana externa de bactérias (canais de porinas), que favorecem a entrada de substâncias hidrofílicas, entretanto, quando estes canais são irregulares há uma diminuição de substâncias e nutrientes hidrofílicos, a própria composição da membrana bacteriana, composta por lipídeos e pepitideoglicano que são bastante impermeáveis (COSTERTON et al., 2003). Deficiências nos canais de purinas (proteínas expostas nas superfícies da célula bacteriana, que geralmente transportam moléculas como antibióticos e desinfetantes para o interior da célula), também podem representa um mecanismo de tolerância a agentes químicos, sobretudo com agentes a base de aldeído, como glutaraldeído e ortoftaladeído (SVETLíkOVÁ et al., 2009).

Corynebacterium striatum é um microrganismo potencialmente patogênico que causa surtos nosocomiais. No entanto, pouco se sabe sobre seus fatores de virulência que podem contribuir para Infecções Relacionadas à Saúde (IRAS). Publicações recentes revelam a capacidade de $C$. striatum aderir a várias superfícies abióticas e formar biofilmes em modelos de cateter in vitro. Identificando uma associação entre o aumento na formação de biofilme, multirresistência antimicrobiana e clonalidade das cepas. Os isolados clínicos desses tipos de PFGE, expressaram uma alta capacidade de formar biofilmes em superfícies abióticas hidrofílicas (vidro; carga positiva) e hidrofóbicas (poliestireno; carga negativa), incluindo superfícies de cateter de poliuretano (carga positiva) (SOUZA et al., 2015; RAMOS et al., 2019).

\section{DISCUSSÃO}

Atualmente, mais da metade das doenças infecciosas que afetam pacientes imunocomprometidos, estão relacionadas a espécies bacterianas encontradas no meio ambiente e na microbiota normal do corpo humano. Patógenos como C. striatum, podem resistir aos agentes antimicrobianos empregados no tratamento das infecções. Seu isolamento a partir de amostras clínicas de pacientes com diferentes graus de imunocomprometimento e infecções graves, vem aumentando tanto em países mais desenvolvidos quanto em países em desenvolvimento. Esse fato se agrava pela ausência de vacinas eficazes contra a maioria desses patógenos (CAMPANILE et al., 2009). Portanto, profissionais da saúde e laboratoristas devem estar atentos para a coleta adequada do material biológico, procedimentos de cultivo e de identificação das 
espécies corinebactérias, particularmente devido ao fato desses microrganismos serem encontrados em associação com outros em culturas bacterianas (RIEGEL, 1998).

C. striatum está constantemente relacionado com quadros infecciosos, por vezes fatais em indivíduos imunocomprometidos e imunocompetentes, apesar de poderem ser encontrados na pele e trato respiratório superior de indivíduos sadios. É um patógeno que possui clones multirresistente, capazes de causar infecções nosocomiais e colonizar o trato respiratório de pacientes com doenças pulmonares avançadas e graves (CAMELLO et al., 2003; RENOM et al., 2007). Relatos descrevem C. striatum tem sido isolado de cultura pura de secreção traqueal em pacientes submetidos a procedimentos de intubação endotraqueal, devendo-se intensificar as medidas universais de higiene para evitar a sua propagação e surtos (CAMPANILE et al., 2009).

Cepas MDR, tem sido preocupação constante dos epidemiologistas e de toda a comunidade médica, por serem isoladas tanto no ambiente hospitalar, quanto na comunidade (SANTOS, 2004; ANVISA, 2007). A busca por estratégias para diminuir a disseminação das IRAS, hoje é uma preocupação mundial (SANTOS, 2004; ANVISA, 2007). Os mecanismos envolvidos na resistência a antimicrobianos são cada vez mais bem compreendidos. A resistência pode ser uma propriedade natural de um microorganismo (intrínseca), ou adquirida por mutação, aquisição de plasmídeos e transposons. Estudos relacionados ao desenvolvimento de multirresistência em $C$. striatum, tem foco na presença de genes de resistência, como erm(X), que codifica resistência à eritromicina e clindamicina, tet $A$ e tet $B$, que codifica resistência à tetraciclina, oxitetraciclina e oxacilina, $c m x$ e $a p h A 1$, que codifica a resistência à aminoglicosídeos e cloranfenicol (CAMPANILE et al., 2009). Muitas medidas estão sendo tomadas no Brasil para controlar o surgimento de cepas MDR de $C$. striatum (SANTOS, 2004; ANVISA, 2007).

Em laboratórios de bacteriologia clínica, cepas C. striatum ainda são descartadas como contaminantes, inclusive quando isoladas a partir de amostras de sangue (SAVINI et al., 2013). Considerar este microrganismo como contaminante é um erro grave, especialmente quando isolado de pacientes cronicamente debilitados que utilizam dispositivos invasivos (BRANDENBURG et al., 1996; RENOM et al., 2007). Nos casos de infecções respiratórias, tem crescido o número de isolamentos de $C$. striatum a partir de 
cultura pura, indicio de sua importância como patógeno (BAIO; DÍEZ-AGUILAR et al., 2013).

São muitas as promessas para o desenvolvimento de novos antimicrobianos e produtos de desinfecção para materiais médicos-cirúrgicos. Entretanto, muitas barreiras devem ser transpostas, os benefícios da implementação de uma nova droga devem sobrepor as desvantagens. Novos estudos têm procurado investigar alternativas terapêuticas para infecções causadas por bactérias multirresistentes, como as combinações sinérgicas de dois ou mais antibióticos, ampliar a eficácia e diminuir toxidade do medicamento (SOARES, 2001; MITSUGUI et al., 2008).

Desinfetantes e antissépticos são usados extensivamente em hospitais e outras instituições de saúde para uma variedade de aplicações tópicas em diversas superfícies. Em particular, eles são uma parte essencial das práticas de controle de infecção e ajuda na prevenção de infecções nosocomiais. O uso disseminado de produtos antissépticos e desinfetantes tem levado a algumas investigações sobre o desenvolvimento de resistência microbiana, em especial uma resistência cruzada aos antibióticos. A atividade antimicrobiana pode ser influenciada por muitos fatores, tais como formulação química, presença de resíduos orgânicos, temperatura, diluição e método de descontaminação (RUTALA et al., 2008, p. 6; VERMELHO et al., 2008). Os biocidas quando adequadamente utilizados e aliados a outros procedimentos no controle de infecções, são essenciais no combate as IRAS e na erradicação de microrganismos MDR. Dentro de uma gestão ineficiente, o uso inadequado dos biocidas durante os processos de limpeza no ambiente hospitalar pode contribuir para a persistência e disseminação de patógenos oportunistas, tanto em hospitais, quando na comunidade (McDONNELL e RUSSELL, 1999).

\section{CONCLUSÃO}

Diante deste panorama, vale ressaltar a importância de $C$. striatum e outros microrganismos corineformes, durante a elaboração de estratégias para o controle e prevenção da disseminação da resistência a antimicrobianos nos ambientes de assistência à saúde e no monitoramento de infecções por agentes multirresistentes tanto nos ambientes nosocomiais quanto comunitários. 


\section{AGRADECIMENTOS}

Gostaríamos de agradecer ao Instituto de Microbiologia Paulo de Góes, Universidade Federal do Rio de Janeiro (UFRJ), Brasil. Laboratório de Difteria e Corynebacteria de Relevância Clínica, Universidade do Estado do Rio de Janeiro (UERJ), Brasil. Este estudo foi financiado em parte pelo Conselho Nacional de Desenvolvimento Científico e Tecnológico (CNPq), Coordenação de Aperfeiçoamento de Pessoal de Nível Superior (CAPES) Código Financeiro 001 e Fundação de Amparo à Pesquisa do Estado do Rio de Janeiro (FAPERJ).

\section{REFERÊNCIAS}

ADDERSON E. E., BOUDREAUX J. W., HAYDEN R. T. Infections caused by coryneform bacteria in pediatric oncology patients. Pediatr Infect Dis J. v. 27, n. 2, p. 136$141,2008$.

Agência Nacional de Vigilância Sanitária (ANVISA), 2007. Disponível em: http://www.anvisa.gov.br/servicosaude/controle/reniss/manual\%20_controle_ bacterias.pdf. Acesso em: 15 de Fevereiro de 2013.

Agência Nacional de Vigilância Sanitária (ANVISA). Anvisa enhances infection control in health services. Rev Saúde Pública. v. 38, n. 3, p. 475-478, 2004.

Agência Nacional de Vigilância Sanitária (ANVISA). Controle de Infecção em Serviços da Saúde, $2014 . \quad$ Disponível em: http://www.anvisa.gov.br/servicosaude/controle/legis.htm. Acesso em: 04 de Janeiro de 2014.

Agência Nacional de Vigilância Sanitária (ANVISA). Curso Básico de Controle de Infecção Hospitalar. In: Caderno C - Métodos de proteção anti-infecciosa. Brasil, p. 84, 2000. Disponível em: http://www.cvs.saude.sp.gov.br/pdf/ClHCadernoC.pdf. Acesso em: 02 de Dezembro de 2013.

ANAGNOSTOPOUlOS A. G., RONG A., MILLER D., TRANQ A. Q., HEAD T., LEE M. C., LEE W. W. 0.01\% Hypochlorous Acid as an Alternative Skin Antiseptic: An In Vitro Comparison. Dermatol Surg. v. 44, p. 1489-1493, 2018.

ANDRADE N. J. O uso de compostos clorados na indústria de laticínios. Inf Agropec Belo Horizonte. v. 13, n. 155, p. 48-52, 1988.

BAIO P. V. P., MOTA H. F., FREITAS A. D., GOMES D. L. R., RAMOS J. N., SANT'ANNA L. O., SOUZA M. C., CAMELLO T. C. F., HIRATA JR R., VIEIRA V. V., MATTOS-GUARALDI 
A. L. Clonal multidrug-resistant Corynebacterium striatum within a nosocomial environment, Rio de Janeiro, Brazil. Mem Inst Oswaldo Cruz. v. 108, n. 1, p. 6398, 2013.

BERNARD K., PACHECO A. L., CUNNINGHAM I., GILL N., BURDZ T., WIEBE D. Emendation of the description of the species Corynebacterium propinquum to include strains which produce urease. Int J Syst Evol Microbiol. v. 63, n. Pt6, p. 2146-2154, 2013.

BHANDARI S., MEIGH J. A., SELLARS L. CAPD peritonitis due to Corynebacterium striatum. Perit Dial Int. v. 15, n. 1, p. 88-89, 1995.

BIBERSTEIN E. L., ZEE Y. C. Tratado de microbiologia veterinária. Zaragoza: Acribia, DL. p. 157-161, 1994.

BLOCK S. S. Peroxygen compounds. In: Block SS, Disinfection, sterilization, and preservation. Philadelphia: Lipp. Wil \& Wil. p. 185-204, 2001.

BOLTIN D., KATZIR M., BUGOSLAVSKY V., YALASHVILI I., BROSH-NISSIMOV T., FRIED M., ELKAYAM O. Corynebacterium striatum - a classic pathogen eluding diagnosis. Eur J Intern Med. v. 20, n. 3, p. e49-e52, 2009.

BRANDENBURG A. H., VAN BELKUM A., VAN PELT C., BRUINING H. A., MOUTON J. W., VERBRUGH H. A. Patient-to-patient spread of a single strain of Corynebacterium striatum causing infections in a surgical intensive care unit. J Clin Microb. v. 34, n. 9, p. 2089-2094, 1996.

CAMEllo T. C. F., MATtOS-GUARALDI A. L., FORMigA L. C. D., MARQUeS E. A. Nondiphtherial Corynebacterium species isolated from clinical specimens of patients in a university hospital, Rio de Janeiro, Brazil. Braz J Microbiol. v. 34, p. 39-44, 2003.

CAMPANILE F., CARRETTO E., BARBARINI D., GRIGIS A., FALCONE M., GOGLIO A., VENDITTI M., STEFANI S. Clonal multidrug-resistant Corynebacterium striatum strains, Italy. Emerg Infect Dis. v. 15, n. 1, p. 75-78, 2009.

CAUMO K., DUARTE M., CARGNIN S. T., RIBEIRO V. B., TASCA T., MACEDO A. J. Resistência bacteriana no meio ambiente e implicações na clínica hospitalar. Rev Liberato (Novo Hamburgo). v. 11, n. 16, p. 183-190, 2010.

CONE L. A., CURRY N., WUESTOFF M. A., O'CONNELL S. J., FELLER J. F. Septic synovitis and arthritis due to Corynebacterium striatum following an accidental scalpel injury. Clin Infect Dis. v. 27, n. 6, p. 1532-1533, 1998.

COSTERTON J. W., STEWART P. S., GREENBERG E. P. Bacterial biofilms: a common cause of persistent infections. Science. v. 284, n. 5418, p. 1318-1322, 1999. 
COSTERTON W., VEEH R., SHIRTLIFF M., PASMORE M., POST C., EHRLICH G. The application of biofilm science to the study of and control of chronic bacterial infections. J Clin Inv. v. 112, n. 10, p. 1466-1477, 2003.

DÍEZ-AGUILAR M., RUIZ-GARBAJOSA P., FERNÁNDEZ-OLMOS A., GUISADO P., DEL CAMPO R., QUEREDA C., CANTÓN R., MESEGUER M. A. Non-diphtheriae Corynebacterium species: an emerging respiratory pathogen. Eur J Clin Microbiol Infect Dis. v. 32, n. 6, p. 769-772, 2013.

FERNÁNDEZ-AYALA M., NAN D. N., FARIÑAS M. C. Vertebral osteomyelitis due to Corynebacterium striatum. Am J Med. v. 111, n. 2, p. 167, 2001.

FONTANA R. T. The Mycobacterias of rapid growth and the hospital infection: a public health problem. Rev Bras Enferm. v. 61, n. 3, p. 371-376, 2008.

FUNKE G., BERNARD K. A. Coryneform Gram-positive rods, p. 413-442. In: VERSALOVIC J. et al., (ed), Manual of clinical microbiology 10th ed, Volume 1. ASM Press, Washington, DC, 2011.

GILI N. J., NOREN T., TÖRNQUIST E., CRAFOORD S., BÄCKMAN A. Preoperative preparation of eye with chlorhexidine solution significantly reduces bacterial load prior to 23-gauge vitrectomy in Swedish health care. BMC Ophthalmology. v. 18, p. 167, 2018.

HEIDEMANN D. G., DUNN S. P., DISKIN J. A., AIKEN T. B. Corynebacterium striatum keratitis. Cornea. v. 10, p. 81-82, 1991.

HOWIE R., ALFA M. J., COOMBS K. Survival of enveloped and non-enveloped viruses on surfaces compared with other micro-organisms and impact of suboptimal disinfectant exposure. J Hosp Infec. v. 69, n. 4, p. 368-376, 2008.

JANDA W. M. Corynebacterium species and the coryneform bacteria: Part I: New and emerging species in the genus Corynebacterium. Clin Microb Newles USA. v. 20, p. 41-52, 1998.

JORGENSEN J. H., PFALLER M. A., CARROLL K. C., FUNKE G., LANDRY M. L., RICHTER S. S., WARNOCK D. W. Manual of clinical microbiology. 11th ed. ASM Press, 2015.

LEE P. P., FERGUSON JR D. A., SARUBBI F. A. Corynebacterium striatum: an underappreciated community and nosocomial pathogen. J Infect. v. 50, n. 4, p. 338-343, 2005.

LEHMANN K. B., NEUMANN R. O. Atlas und grundriss der bakteriologie und lehrbuch der speziellen bakteriologischen diagnostic. 1st ed. München: Lehmann JF. p. 1907, 1896. 
LEWIS D. L., ARENS M. Resistance of microorganisms to disinfection in dental and medical devices. Nat Med. v. 1, n. 9, p. 956-958, 1995.

LÓPEZ A. B., RUIZA M. T. G., PRADO L. V., OLIVARES M. F. Cistitis y hematuria por Corynebacterium striatum. A propósito de un caso y revisión de la literatura científica. Actas Urol Esp. v. 33, n. 8, p. 909-912, 2009.

LORENA N. O. S., DUARTE R. S., PITOMBO M. B., TCBC-RJ. Infecção por micobactérias de crescimento rápido após procedimentos videocirúrgicos - a hipótese do glutaraldeído. Rev Col Bras Cir. v. 36, n. 3, p. 266-267, 2009.

MARTINS C., FARIA L., SOUZA M., CAMELLO T., VELASCO E., HIRATA JR R., THULER L., MATTOS-GUARALDI A. L. Microbiological and host features associated with corynebacteriosis in cancer patients: a five-year study. Mem Inst Oswaldo Cruz. v. 104, n. 6, p. 905-913, 2009.

McDONNELL G., RUSSELL A. D. Antisepsis and disinfection: action, and resistance. Clin Microbiol Rev. v. 12, n. 1, p. 147-179, 1999.

McDONNELL G. E. Antisepsis, disinfection, and sterilization: types, action, and resistance. 2nd ed. ASM Press, 2007.

MITSUGUI C. S., TOGNIM M. C. B., CARRARA-MARRONE F. E., GARCIA L. B. The in vitro antimicrobial effect of polymyxin B associated with ceftazidime in Pseudomonas aeruginosa clinical isolates. Ciênc Cuid Saúde. v. 7, n. supl. 1, p. 76-81, 2008.

MOORE K., HALL V., PAULL A., MORRIS T., BROWN S., MCCULLOCH D., RICHARDSON M. C., HARDING K. G. Surface bacteriology of venous leg ulcers and healing outcome. J Clin Pathol. v. 63, n. 9, p. 830-834, 2010.

OLIVA A., BELVISI V., IANNETTA M., ANDREONI C., MASCELLINO M. T., LICHTNER M., VULLO V., MASTROIANNI C. M. Pacemaker lead endocarditis due to multidrugresistant Corynebacterium striatum detected with sonication of the device. J Clin Microbiol. v. 48, n. 12, p. 4669-4671, 2010.

OLIVEIRA A. C., DAMASCENO Q. S., RIBEIRO S. M. C. P. Healthcare-associated infection: challenges in its prevention and control. Rev Min Enf. v. 13, n. 3, p. 445-450, 2009.

OTSUKA Y., OHKUSU K., KAWAMURA Y., BABA S., EZAKI T., KIMURA S. Emergence of multidrug-resistant Corynebacterium striatum as a nosocomial pathogen in longterm hospitalized patients with underlying diseases. Diagn Microbiol Infect Dis. v. 54, n. 2, p. 109-114, 2006.

PARTE A. C. LPSN-list of prokaryotic names with standing in nomenclature. Nucleic Acids Res. v. 1, n. 42[Database issue], p. D613-D616, 2014. 
PiMentA F. P., SOUZA M. C., PEREIRA G. A., HIRATA JR R., CAMEllO T. C., MATTOSGUARALDI A. L. DNase test as a novel approach for the routine screening of Corynebacterium diphtheriae. Lett Appl Microbiol. v. 46, n. 3, p. 307-311, 2008.

PSALTIKIDIS E. M., LEICHSENRING M. L., NAKAMURA M. H. Y., BUSTORFF-SILVA J. M., PASSERI L. A., VENÂNCIO S. I. High-level disinfectants alternative to glutaraldehyde for processing flexible endoscopes. Cogitare Enferm. v. 19, n. 3, p. 423-432, 2014.

RAMOS J. N., SOUZA C., FARIA Y. V., SILVA E. C., VERAS J. F. C., BAIO P. V. P., SEABRA S. H., MOREIRA L. O., HIRATA JR R., MATTOS-GUARALDI A. L., VIEIRA V. V. Bloodstream and catheter-related infections due to different clones of multidrugresistant and biofilm producer Corynebacterium striatum. BMC Infectious Diseases. v. 19, p. 672, 2019.

REDDY B. S., CHAUDHURY A., KALAWAT U., JAYAPRADA R., REDDY G., RAMANA B. V. Isolation, speciation, and antibiogram of clinically relevant non-diphtherial corynebacteria (Diphtheroids). Indian J Med Microbiol. v. 30, n. 1, p. 52-57, 2012.

RENOM F., GARAU M., RUBÍ M., RAMIS F., GALMÉS A., SORIANO J. B. Nosocomial outbreak of Corynebacterium striatum infection in patients with chronic obstructive pulmonary disease. J Clin Microbiol. v. 45, n. 6, p. 2064-2067, 2007.

RIEGEL J. A., MADDRELL S. H., FARNDALE R. W., CALDWELL F. M. Stimulation of fluid secretion of malpighian tubules of Drosophila melanogaster meig. by cyclic nucleotides of inosine, cytidine, thymidine and uridine. J Exp Biol. v. 201, n. Pt 24, p. 3411-3418, 1998.

RUTALA W. A., MPH, CIC (1994, 1995, 1996 APIC Committee). APIC guideline for selection and use of disinfectants. Am J Infect Control. v. 24, p. 313-342, 1996.

RUTALA W. A., WEBER D. J., WOODS G. L. Healthcare infection control practices advisory committee (HICPAC), Guideline for disinfection and sterilization in healthcare facilities. Center for diseases control and prevention. S.D.; Diag Microb Texto e atlas colorido, Rio de Janeiro. p. 6, 2008.

SANTOS N. Q. Bacterial resistence in the context of hospital infection. Texto Contexto Enferm. v. 13, n. esp, p. 64-70, 2004.

SATTAR S. A., SPRINGTHORPE V. S. New methods for efficacy testing of disinfectants and antiseptics. In: Rutala WA, ed. Disinfection, sterilization and practices in healthcare facilities. Washington. D.C: Assoc. Infect Cont Epid. v.174, p. 80-86, 2001. 
SAVINI V., GHERARDI G., FAVARO M., FONTANA C., MARROLLO R., ARGENTIERI A. V., DICUONZO G., FAZII P., D'ANTONIO D. About a bloodstream Corynebacterium striatum isolate. Folia Microbiol. v. 58, n. 6, p. 451-453, 2013.

SCHOLLE D. A spontaneous joint infection with Corynebacterium striatum. J Clin Microbiol. v. 45, n. 2, p. 656-658, 2007.

SCHRÖDER J., MAUS I., MEYER K., WÖRDEMANN S., BLOM J., JAENICKE S., SCHNEIDER J., TROST E., TAUCH A. Complete genome sequence, lifestyle, and multi-drug resistance of the human pathogen Corynebacterium resistens DSM 45100 isolated from blood samples of a leukemia patient. BMC Genomics. v. 23, n. 13, p. 141, 2012.

SHADID M. B., SPETH M. J. G. M., VOORN G. P., WOLTERBEEK N. Chlorhexidine $0.5 \% / 70 \%$ Alcohol and lodine 1\%/70\% Alcohol Both Reduce Bacterial Load in Clean Foot Surgery: A Randomized, Controlled Trial. The Journal of Foot \& Ankle Surgery. v. 58, p. 278-281, 2019.

SILVA F., LIMA F., FERREIRA A. M., COLOMBO T. E., RUBIO F. G., ALMEIDA M. T. G. Fungal contamination of hospital mattresses before and following cleaning and disinfection. Acta Paul Enferm. v. 26, n. 5, p. 485-491, 2013.

SOARES M. A. Resistência antibiótica. Pharm Bras. p. 59-62, 2001.

SOUZA A. C. S., PEREIRA M. S., RODRIGUES M. A. V. Descontaminação prévia de materiais médico-cirúrgicos: estudo da eficácia de desinfetantes químicos e água e sabão. Rev Latino-Am Enf. v. 6, n. 3, p. 95-105, 1998.

SOUZA C., FARIA Y. V., SANT'ANNA L. O., VIANA V. G., SEABRA S. H., SOUZA M. C., VIEIRA V. V., HIRATA JR R., MOREIRA L. O., MATTOS-GUARALDI, A. L. Biofilm production by multiresistant Corynebacterium striatum associated with nosocomial outbreak. Mem Inst Oswaldo Cruz. v. 110, p. 242-248, 2015.

STONE N., GILLETT P., BURGE S. Breast abscess due to Corynebacterium striatum. Br J Dermatol. v. 137, n. 4, p. 623-625, 1997.

SUPERTI S. V., MARTINS D. S., CAIERÃO J., SOARES F., PROCHNOW T., CANTARELLI V. V., ZAVASCKI A. P. Corynebacterium striatum infecting a malignant cutaneous lesion: the emergence of an opportunistic pathogen. Rev Inst Med Trop S Paulo. v. 51, n. 2, p. 115-116, 2009.

SVETLÍKOVÁ Z., SKOVIEROVÁ H., NIEDERWEIS M., GAILLARD J. L., MCDONNELL G., JACKSON M. Role of porins in the susceptibility of Mycobacterium smegmatis and Mycobacterium chelonae to aldehyde-based disinfectants and drugs. Antimicrob Agents Chemother. v. 53, n. 9, p. 4015-4018, 2009. 
TARR P. E., STOCK F., COOKE R. H., FEDORKO D. P., LUCEY D. R. Multidrug-resistant Corynebacterium striatum pneumonia in a heart transplant recipient. Transpl Infect Dis. v. 5, n. 1, p. 53-58, 2003.

TORRES L. F., RIBEIRO D., HIRATA JR R., PACHECO L. G., SOUZA M. C., DOS SANTOS L. S., DOS SANTOS C. S., SALAH M., COSTA M. M., RIBEIRO M. G., SELIM S. A., AZEVEDO V. A., MATTOS-GUARALDI A. L. Multiplex polymerase chain reaction to identify and determine the toxigenicity of Corynebacterium spp. with zoonotic potential and an overview of human and animal infections. Mem Inst Oswaldo Cruz. v. 108, n. 3, p. pii:S0074-027620130003002722013.

VERMELHO A. B., BASTOS M. C. F., BRANQUINHA DE SÁ M. H. Bacteriologia Geral. 1st ed. Guanabara Koogan, Brasil, 2008.

WEISS K., LABBÉ A. C., LAVERDIÈRE M. Corynebacterium striatum meningitis: case report and review of an increasingly important Corynebacterium species. Clin Infect Dis. v. 23, n. 6, p. $1246-1248,1996$.

WIDMER A. E., FREI R. Antimicrobial activity of glucoprotamin: a clinical study of a new disinfectant for instruments. Infect Control Hosp Epidemiol. v. 24, n. 10, p. 762764, 2003.

WONG K. Y., CHAN Y. C., WONG C. Y. Corynebacterium striatum as an emerging pathogen. J Hosp Infect. v. 76, n. 4, p. 371-372, 2010.

YOON S., KIM H., LEE Y., KIM S. Bacteremia caused by Corynebacterium amycolatum with a novel mutation in gyrA gene that confers high-level quinolone resistance. Korean J Lab Med. v. 31, n. 1, p. 47-48, 2011.

ZASADA A. A., MOSIEJ E. Contemporary microbiology and identification of Corynebacteria spp. causing infections in human. Lett Appl Microbiol. v. 66, p. 472-483, 2018. 


\section{ANEXO I}

Tabela 1 - Características bioquímicas utilizadas na identificação das principais espécies do gênero Corynebacterium.

\begin{tabular}{|c|c|c|c|c|c|c|c|c|c|c|c|c|c|c|c|c|c|c|}
\hline \multirow[b]{2}{*}{ Espécies } & \multicolumn{18}{|c|}{ Parâmetros } \\
\hline & 安 & $\stackrel{\breve{\Sigma}}{\Sigma}$ & $气$ & 妾 & 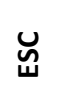 & 岀 & 岑 & $\frac{\partial}{a}$ & 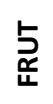 & 灾 & $\vec{J}$ & $\stackrel{u}{J}$ & $\bar{\Sigma}$ & w & $\sum_{\overleftarrow{S}}^{0}$ & $\sum_{\text {至 }}$ & $\begin{array}{l}\mathscr{y} \\
\sum_{0}^{0} \\
0\end{array}$ & $\stackrel{\varrho}{F}$ \\
\hline $\begin{array}{l}\text { C. } \\
\text { afermentans }\end{array}$ & + & 0 & v & - & - & - & - & V & - & + & - & - & - & - & v & v & - & $\begin{array}{l}N \\
D\end{array}$ \\
\hline $\begin{array}{l}\text { C. } \\
\text { amycolatum }\end{array}$ & + & $\mathrm{F}$ & - & + & - & - & v & v & + & - & + & - & v & v & - & - & - & - \\
\hline $\begin{array}{l}\text { C. } \\
\text { diphtheriae } \\
\text { sub. belfanti }\end{array}$ & + & $\mathrm{F}$ & v & v & - & v & - & - & $\begin{array}{l}N \\
D\end{array}$ & $\begin{array}{l}N \\
D\end{array}$ & + & v & + & v & - & - & + & $\begin{array}{l}N \\
D\end{array}$ \\
\hline $\begin{array}{l}\text { C. } \\
\text { diphtheriae } \\
\text { sub. gravis }\end{array}$ & + & $\mathrm{F}$ & - & + & - & v & - & - & $\begin{array}{l}\mathrm{N} \\
\mathrm{D}\end{array}$ & + & + & + & + & v & - & v & + & $\begin{array}{l}N \\
D\end{array}$ \\
\hline $\begin{array}{l}\text { C. } \\
\text { diphtheriae } \\
\text { sub. } \\
\text { intermedius }\end{array}$ & + & $\mathrm{F}$ & + & + & - & v & - & - & $\begin{array}{l}\mathrm{N} \\
\mathrm{D}\end{array}$ & $\begin{array}{l}N \\
D\end{array}$ & + & - & + & - & - & - & + & $\begin{array}{l}N \\
D\end{array}$ \\
\hline $\begin{array}{l}\text { C. } \\
\text { diphtheriae } \\
\text { sub. mitis }\end{array}$ & + & $\mathrm{F}$ & - & + & - & v & - & - & $\begin{array}{l}N \\
D\end{array}$ & $\begin{array}{l}N \\
D\end{array}$ & + & - & + & v & - & v & + & $\begin{array}{l}N \\
D\end{array}$ \\
\hline C. jeikeium & + & 0 & + & - & - & - & - & + & - & + & + & $\begin{array}{l}N \\
D\end{array}$ & v & - & - & - & $\begin{array}{l}\mathrm{N} \\
\mathrm{D}\end{array}$ & $\begin{array}{l}N \\
D\end{array}$ \\
\hline C. macginleyi & + & $\mathrm{F}$ & + & + & - & - & $\begin{array}{l}N \\
D\end{array}$ & - & $\begin{array}{l}N \\
D\end{array}$ & $\begin{array}{l}N \\
D\end{array}$ & + & $\begin{array}{l}N \\
D\end{array}$ & + & + & - & - & + & $\begin{array}{l}N \\
D\end{array}$ \\
\hline $\begin{array}{l}\text { C. } \\
\text { minutissimu } \\
m\end{array}$ & + & $\mathrm{F}$ & - & - & - & - & - & + & + & $\begin{array}{l}N \\
D\end{array}$ & + & $\begin{array}{l}N \\
D\end{array}$ & V & v & v & - & v & + \\
\hline $\begin{array}{l}\text { C. } \\
\text { pseudodipht } \\
\text { heriticum }\end{array}$ & + & 0 & - & + & - & - & + & + & $\begin{array}{l}\mathrm{N} \\
\mathrm{D}\end{array}$ & $\begin{array}{l}\mathrm{N} \\
\mathrm{D}\end{array}$ & - & $\begin{array}{l}\mathrm{N} \\
\mathrm{D}\end{array}$ & - & - & - & - & $\begin{array}{l}\mathrm{N} \\
\mathrm{D}\end{array}$ & - \\
\hline $\begin{array}{l}\text { C. } \\
\text { pseudotuber } \\
\text { culosis }\end{array}$ & + & $\mathrm{F}$ & - & v & - & v & + & - & - & $\begin{array}{l}N \\
D\end{array}$ & + & v & + & v & $\begin{array}{l}\text { RE } \\
\mathrm{V}\end{array}$ & + & - & $\begin{array}{l}N \\
D\end{array}$ \\
\hline C. striatum & + & $\mathrm{F}$ & - & v & - & - & - & + & v & v & + & $\begin{array}{l}\mathrm{N} \\
\mathrm{D}\end{array}$ & - & V & v & - & $\begin{array}{l}\mathrm{N} \\
\mathrm{D}\end{array}$ & + \\
\hline C. ulcerans & + & $\mathrm{F}$ & - & - & - & v & + & - & $\begin{array}{l}N \\
D\end{array}$ & + & + & v & + & - & $\begin{array}{l}\text { RE } \\
\mathrm{V}\end{array}$ & + & + & $\begin{array}{l}N \\
D\end{array}$ \\
\hline $\begin{array}{l}\text { C. } \\
\text { urealyticum }\end{array}$ & + & 0 & + & - & - & - & + & + & $\begin{array}{l}N \\
D\end{array}$ & $\begin{array}{l}\mathrm{N} \\
\mathrm{D}\end{array}$ & - & $\begin{array}{l}N \\
D\end{array}$ & - & - & - & - & $\begin{array}{l}N \\
D\end{array}$ & $\begin{array}{l}N \\
D\end{array}$ \\
\hline C. xerosis & + & $\mathrm{F}$ & - & v & - & $\begin{array}{l}\mathrm{N} \\
\mathrm{D}\end{array}$ & - & + & $\begin{array}{l}N \\
D\end{array}$ & v & + & $\begin{array}{l}\mathrm{N} \\
\mathrm{D}\end{array}$ & + & + & - & - & $\begin{array}{l}N \\
D\end{array}$ & $\begin{array}{l}N \\
D\end{array}$ \\
\hline
\end{tabular}

Legendas: positivo (+); negativo (-); positivo fraco ( \pm ); variável (V); reação reversa (RER); dados não declarados (ND); subespécie (sub); catalase $=\mathrm{CAT}$; metabolismo $=\mathrm{MET}$; oxidativo $=0$; fermentativo $=\mathrm{F}$; 
lipofilia = LIP (multiplicam-se bem em meio de cultura contendo 1\% de Tween 80); redução de nitrato $\left(\mathrm{NO}_{3-}\right)=\mathrm{NIT}$; hidrólise de esculina = ESC; hidrolise de gelatina = GEL; uréase = URE; atividade pirazinamidásica $=$ PYZ; produção de ácido a partir do metabolismo da frutose $=F R U T$; da galactose $=\mathrm{GAL}$; da glicose = GLI; do glicogênio/amido = GLIC; da maltose = MAL; da sacarose = SAC; hemólise sinérgica com $\beta$-hemolisina de $S$. aureus em sangue de ovelha = CAMP; hemólise em meio nutritivo contendo sangue de ovelha = HEM; produção de desoxirribonuclease = DNase; tirosina = TIR (FUNKE e BERNARD, 2011; ANVISA, 2014). 


\title{
CAPÍTULO XI
}

\section{BIOFILME FORMADO POR STAPHYLOCOCCUS AUREUS: CAUSA ALARMANTE DE INFECÇÕES NOSOCOMIAIS}

\author{
Giorgio Silva de Santana ${ }^{1,2}$ \\ Paula Marcele Afonso Pereira Ribeiro ${ }^{2}$ \\ Barbara Araújo Nogueira ${ }^{2}$ \\ Dryelle Rodrigues de Oliveira ${ }^{2}$ \\ Guilherme Goulart Cabral de Oliveira ${ }^{2}$ \\ Ana Luíza de Mattos Guaraldi ${ }^{1,2}$
}

${ }^{1}$ Instituto de Microbiologia Paulo de Góes, Universidade Federal do Rio de Janeiro, Brasil.

2 Laboratório de Difteria e Corinebactérias de Importância Clínica, Universidade do Estado do Rio de Janeiro, Brasil.

\section{RESUMO}

Estudos relacionados à formação de biofilmes bacterianos são de extrema relevância, pela associação constante com doenças humanas graves. A organização dessa comunidade microbiana séssil, proporciona aos microrganismos que a constitui proteção contra opsonização e a fagocitose, tornando o sistema imunológico do hospedeiro incapaz em combatê-las, assim como a ineficácia da terapia antimicrobiana. Staphylococcus aureus faz parte da microbiota da pele e cavidade nasal em indivíduos saudáveis, entretanto, muitas estirpes tornam-se patógenos oportunistas, principalmente pela capacidade de formar biofilme em diversos tipos de implantes e dispositivos médicos, utilizando-os como via de acesso à corrente sanguínea. Sua habilidade em formar biofilme é amplamente conhecida, tornando responsável por diversas infecções graves como endocardite, bacteremia e sepse. Vários são os fatores que contribuem para a formação de biofilme bacteriano, como a expressão de genes específicos e a interação entre proteínas envolvidas na adesão ao substrato. Este trabalho objetiva explorar os principais aspectos relacionados à formação de biofilme por S. aureus, utilizando os principais bancos de indexação da literatura científica Esta revisão fornecerá melhor compreensão sobre a formação de biofilme e seu impacto na saúde do hospedeiro.

Palavras-chave: Biofilme. Infecção sistêmica. MRSA. Staphylococcus aureus.

\section{INTRODUÇÃO}

Staphylococcus aureus faz parte da família Staphylococcaceae (GARRITY, 2006), do gênero Staphylococcus e do grupo dos cocos Gram-positivos, pode medir entre 0,5 a 1,5 $\mu \mathrm{m}$ de diâmetro e geralmente encontram-se agrupados semelhantes a "cachos de 
uvas" (BANNERMAN e PEACOCK, p. 390-410; JONGERIUS et al., 2007; KATEETE et al., 2010), são imóveis, não esporulados e anaeróbios facultativos. Nesse gênero foram diferenciadas 33 espécies até o momento, nas quais 17 podem ser isoladas de materiais biológicos humano (SANTOS et al., 2007; PAHARIK e HORSWILL, 2016). Entre as principais características bioquímicas estão à capacidade de produzir as enzimas catalase e coagulase, que podem ser utilizadas como método de identificação da espécie em laboratório (BANNERMAN e PEACOCK, 2007, p. 390-410; KATEETE et al., 2010). O seu cultivo em meio sólido contendo $5 \%$ de sangue, torna possível visualizar colônias com aspecto mucoide, de coloração esbranquiçada à levemente amarelada, decorrente de pigmentos carotenóides gerados durante seu metabolismo, e também a formação de um halo de hemólise total ao redor da colônia ( $\beta$-hemólise), gerado a partir da produção de hemolisina (CARROLL, 2014, p. 199-207). O meio de cultura seletivo comumente utilizado é denominado ágar manitol-salgado, possui em sua composição o açúcar D-manitol e cloreto de sódio ( $\mathrm{NaCl}$ ), sua hipertônicidade é capaz de selecionar espécies do gênero Staphylococcus e indicar outras espécies capazes de fermentar o Dmanitol (BANNERMAN e PEACOCK, 2007, p. 390-410).

Este microrganismo pode ser encontrado em 27 a $50 \%$ dos seres humanos (YOUNG et al., 2012) de forma assintomática na pele, superfície de mucosas, narina, axilas e períneo (GIAROLA et al., 2012; KIM et al., 2014; PAHARIK e HORSWILL, 2016). Aproximadamente 20 a $40 \%$ dos humanos adultos saudáveis são colonizados permanentemente, enquanto 75 a $80 \%$ são colonizados de forma intermitentemente (alternando períodos colonizados e períodos não colonizados) ou não fazem parte de sua microbiota (OTTO, 2010; AMALARADJOU e VENKITANARAYANAN; KIM et al., 2014). Esse percentual pode variar de acordo com a demografia do local onde é efetuado o estudo de identificação, qualidade das amostras e técnicas utilizadas para coleta dos microrganismos (WERTHEIM et al., 2005).

Nesta revisão abordaremos os principais aspectos estruturais, morfológicos e características bioquímicas de $S$. aureus que diferencia esse microrganismo dos outros Gram-positivos, e seus fatores de virulência, responsáveis por várias infecções nosocomiais e na comunidade. Enfocando a formação de biofilme, os métodos de prevenção e tratamento, com o objetivo de aumentar a compreensão sobre essa 
bactéria, para melhor orientar pesquisadores e profissionais da área de saúde sobre as patologias por ela provocada.

\section{PRINCIPAIS CARACTERÍSTICAS PATOGÊNICAS}

Staphylococcus aureus possui grande importância clínica, é um dos patógenos mais prevalentes em infecções graves, relacionadas à comunidade ou em ambiente hospitalar (OTTO, 2010; KIM et al., 2014; RAMSEY et al., 2016). A transmissão ocorre através de fômites, secreção nasal e principalmente pelo contato direto entre profissionais da área de saúde e lesões expostas de pacientes infectados (MICHELIM et al., 2005; ARCHER et al., 2011; Koch et al., 2014). Essa fácil transmissão torna a erradicação das infecções hospitalares estafilocócicas extremamente difíceis (MICHELIM et al., 2005).

Esse patógeno oportunista é capaz de se adaptar com grande facilidade a diversas temperaturas, níveis de $\mathrm{pH}$ e osmolaridade (STAPLETON et al., 2002; CARVALHO et al., 2010; MARTINS et al., 2012; RAMSEY et al., 2016). Entretanto, para estabelecer uma infecção, a bactéria precisa expressar várias moléculas que determinam sua patogenicidade (fatores de virulência) (KONG et al., 2006), alguns desses fatores fazem parte da estrutura da parede celular, como os polissacarídeos, proteínas antigênicas entre outras, com potencial para induzir uma resposta imunológica no hospedeiro (MAMIZUKA, 2005). Porém, nem todas as estirpes necessariamente possuem as mesmas propriedades antigênicas, possibilitando a descobertas de novas características patogênicas (MACHADO et al., 2005; KUEHL et al., 2009).

Sua grande versatilidade e seu extenso arsenal de fatores de virulência garantem o sucesso durante a infecção, que influenciam diretamente em sua capacidade de aderir e colonizar, infectar e evadir do sistema imune do hospedeiro (TAVARES, 2002; OTTO, 2012). Os fatores de virulência podem ser classificados em três categorias: (I) relacionados com adesão a células do hospedeiro, fibrinogênio, fibronectina e colágeno por meio de proteínas de superfície do microrganismo. Podemos destacar como principais as MSCRAMMs (microbial surface components recognizing adhesive matrix molecules), que são componentes de superfície microbiana capazes de reconhecerem 
moléculas adesivas da matriz celular do tecido, resultando em maior adesão do patógeno ao hospedeiro (WALSH et al., 2001); (II) relacionados com a evasão do sistema imunológico, como a cápsula (estrutura polissacarídica que envolve a parede celular bacteriana), mais precisamente os polissacarídeos do tipo 1, 5 e 8 , que protegem a bactéria contra fagocitose pelo sistema complemento e neutrófilos. A proteína $A$ associada ao peptideoglicano, além de atuar como uma adesina, pode também ligar-se a porção $\mathrm{Fc}$ da imunoglobulina $\mathrm{G}$ (IgG) impedindo sua ação como opsonina (LUTZ et al., 2003; OTTO, 2010). Também podemos ressaltar as enterotoxinas estafilocócicas (SEs) e a toxina da síndrome do choque tóxico (TSST-1). Um dos principais fatores de evasão é o biofilme, constituído por uma matriz extracelular (glicocálix) composta por proteínas, ácidos nucléicos, lipídeos e polissacarídeos, que confere aos microrganismos no seu interior proteção contra o sistema imune e antimicrobianos (OTTO, 2006; MADIGAN et al., 2016), prolongando o período de colonização no epitélio e em superfícies de dispositivos médicos, como sondas e cateteres (OTTO, 2012; XIA et al., 2013); (III) relacionados com a invasão na célula do hospedeiro e penetração nos tecidos, como as proteases, nucleases, hialuronidase, lipase, colagenase, toxinas alfa, beta, gama e delta hemolisinas, as leucocidinas, como por exemplo de Panton-Valentine (PVL) (WALSH et al., 2001; TAVARES, 2002; OTTO, 2012). A PVL tem como alvo principal os neutrófilos humanos, em altas concentrações formam poros na membrana dos neutrófilos, alterando a permeabilidade e causando lise celular, em baixa concentração promovem a apoptose por se ligarem a membrana mitocondrial resultando na liberação de espécies reativas do oxigênio (reactive oxygen species, ROS) (GENESTIER et al., 2005; BOYLEVAVRA et al., 2007; SILVA-SANTANA et al., 2016).

As doenças causadas por $S$. aureus podem estar relacionadas à invasão direta do microrganismo nos tecidos através da bacteremia. Entretanto, as toxinas secretadas são os fatores determinantes de sua virulência (BUKOWSKI; NOVICK et al., 2010; KIM et al., 2014). Este microrganismo é considerado o agente mais comum das infecções pirogênicas, as quais podem se localizar em um ou em múltiplos sítios tendo como origem primária a pele, mas também pode ser associado à pneumonia, endocardite, choque tóxico e sepse, incluindo aqueles associados a dispositivos intravasculares (ANDRIOLO, 2005; BOLES e HORSWILL, 2008; RUDKIN et al., 2012), que propicia o acesso do patógeno a tecidos subjacentes e a corrente sanguínea (LOWY, 1998). Tem sido

WWW.AMPLLAEDITORA.COM.BR (2) 
comum o isolamento de $S$. aureus em $80 \%$ das infecções relacionadas com bacteremia (RAMSEY et al., 2016), entretanto o microrganismo está comumente associado a infecções em tecidos moles (LOWY, 1998; KIM et al., 2014). As infecções possuem como características patológicas a formação de lesões purulentas e abcesso por infiltração de neutrófilos ao redor do local infectado (CHENG et al., 2009; KIM et al., 2014), não são capazes de produzir resposta imune específica, por esse motivo é comum infeç̧ões persistentes ou recorrentes (LESSA et al., 2010; KIM et al., 2014).

Em infecções sistêmicas, duas proteínas de superfície produzidas por $S$. aureus desempenham um papel chave na patogênese da sepse: adenosina sintetase $A$ (AdsA) e a proteína de ligação a fibrinogênio A (fator de aglutinação, ClfA). Ao invadir a corrente sanguínea, S. aureus produz AdsA, aumentando o nível extracelular de adenosina que se associa aos receptores de adenosina do tipo A2a, expresso perifericamente em células imunes/inflamatórias, mediando às cascatas de sinalização anti-inflamatórias e de resolução da inflamação. Isso resulta em inibição da agregação plaquetária, degranulação de neutrófilos e aumento da produção de interleucina 10 (IL-10), uma citocina anti-inflamatória, contribuindo como fator de evasão dos mecanismos de defesa inato e adaptativo. Também podem interagir com receptores $A 2 b$ resultando na potencialização da resposta inflamatória (KIM et al., 2014). A presença da proteína AdsA na bactéria é necessária para sua sobrevivência no interior dos neutrófilos, possibilitando o escape dos atributos bactericidas da célula imune, incluindo: ROS, enzimas hidrolíticas e defensinas peptídicas (GARZONI e KELLEY, 2009; KIM et al., 2014).

A ClfA na superfície bacteriana (McADOW et al., 2011; KIM et al., 2014) promove a junção com o domínio $D$ do fibrinogénio e fibrina, revestindo-as e impedindo 0 reconhecimento pelas opsoninas. Isso reduz a opsonofagocitose por neutrófilos e macrófagos (McDEVITT et al., 1997; GANESH et al., 2008; KIM et al., 2014), também promove oclusões vasculares por bactérias aglutinadas nos tecidos dos órgãos (McADOW et al., 2011; KIM et al., 2014). 


\section{RESISTÊNCIA ANTIMICROBIANA}

No início de 1940, o uso da penicilina na terapia antimicrobiana acreditou ser o fim das infecções bacterianas, entretanto, mas em 1942 a resistência foi detectada em vários hospitais (MOELLERING, 2012; KOCH et al., 2014). Seu mecanismo de ação consiste na desestabilização da síntese da parede celular bacteriana, pela associação às proteínas de ligação a penicilinas (penicillin-binding proteins, PBPs) (GEISEL et al., 2001; AGUAYO-REYES et al., 2018). Mas a aquisição de plasmídeos contendo os genes blaZ, blal e blaRI possibilitou que estirpes produzissem beta-lactamase, uma enzima extracelular responsável por causar danos ao anel beta-lactâmico da penicilina tornando-a inativa, gerando resistência ao antimicrobiano (RAMMELKAMP e MAXON, 1942; EAST e DYKE, 1989; OLIVEIRA et al., 2002; KOCH et al., 2014).

Diferentemente ocorreu com a meticilina, uma penicilina semi-sintética desenvolvida em 1959 inatingível às penicilinases (DEURENBERG e STOBBERINGH, 2009). Entretanto, a resistência foi conferida a S. aureus através da aquisição do gene $m e c A$ inserido em um elemento genético móvel denominado cassete estafilocócico cromossômico mec (staphylococcal cassette chromosome mec, SCCmec) (HIRAMATSU et al., 2014; STEFANI et al., 2015; BAIG et al., 2018), presente em todas as estirpes resistentes à meticilina (methicillin-resistant S. aureus, MRSA) (MEHNDIRATTA e BHALLA, 2012). Até o momento foram descritos treze SCCmec, classificados em diferentes tipos através de análises genéticas das regiões internas do cassete, com a capacidade de transportar genes de resistência a múltiplas drogas, incluindo sulfametoxazol-trimetoprim, doxiciclina e rifampicina (multiple-resistant S. aureus) (DERESINSKI, 2005; RUDKIN et al., 2012). Os SCCmec tipo III e IV são prevalentes em infecções humanas no Brasil (CABOCLO et al., 2012), os tipos I, II e III são grandes e estão associados a cepas multirresistentes, comumente encontradas no ambiente hospitalar, denominadas HA-MRSA (hospital-associated, MRSA), os tipos IV e V são menores, habitualmente encontrados em estirpes da comunidade, denominados CA-MRSA (community-associated, MRSA) e geralmente carreia poucos genes de resistência (IWGSCC, 2009; RUDKIN et al., 2012).

O gene mecA codifica a proteína de ligação a penicilina 2 (PBP2) com modificações em sua estrutura molecular (PBP2a) (ALEKSHUN e LEVY, 2007), conferindo 
resistência a meticilina pela baixa afinidade dos receptores proteicos em relação ao antimicrobiano. As PBPs são proteínas ligadas à membrana que catalisam a transpeptidação e transglicosilação do peptidoglicanos, o principal componente da parede bacteriana (RUDKIN et al., 2012).

As linhagens de MRSA se espalharam pelo mundo desde 1960, atualmente as estirpes deixaram de ser exclusivas do ambiente hospitalar e passaram a ser isoladas também em infeç̧ões comunitárias (HAGIHARA; RUDKIN et al., 2012). As infecções por MRSA causam aumento da mortalidade (HAGIHARA et al., 2012), maior tempo de internação e aumento dos custos em comparação com infeç̧ões causadas estirpes suscetíveis (methicillin-susceptible S. aureus, MSSA) (HAGIHARA; RUDKIN et al., 2012).

Os fatores de risco associados à bacteremia causada por MRSA incluem: idade (susceptibilidade de pacientes $\geq 60$ anos) (SOUZA e FIGUEIRED, 2008), hospitalização prolongada, tratamento prévio com antimicrobianos, cateterização e uso de sonda nasogástrica (BUTTERLY et al., 2010; DHAND e SAKOULAS; RUDKIN et al., 2012). A alta dificuldade em tratar as infecções por MRSA classifica-o como altamente patogênico (RUDKIN et al., 2012).

A vancomicina (glicopeptídeo) representa a melhor escolha no tratamento de infecções por MRSA. Entretanto, o uso de forma incorreta levou ao aparecimento de várias estirpes com suscetibilidade reduzida à vancomicina, o primeiro relatado foi no Japão em 1996 (KOCH et al., 2014). Estas estirpes são denominadas S. aureus intermédio para vancomicina (vancomycin-intermediate S. aureus, VISA), embora seu nível de resistência seja mais próximo de ser classificada como moderada por possuir concentração mínima inibitória (minimum inhibitory concentration, MIC) entre 4 a 8 $\mu \mathrm{g} / \mathrm{ml}$, em comparação com as estirpes resistentes à vancomicina (vancomycin resistant S. aureus, VRSA) com CIM $\geq 16 \mathrm{mg} / \mathrm{ml}$ (KOCH et al., 2014).

Nas estirpes VRSA a resistência é conferida plenamente pela expressão do gene vanA, após ser regulado por vanS e vanR (HONG et al., 2008, p. 200-213), culminando na produção de D-Ala-D-Lactato ou D-Ala-D-serina, que substituem o terminal D-Ala-DAla no peptidoglicano da parede celular bacteriana, propiciando menor afinidade à vancomicina (HOLMES; XIA et al., 2013; KUMAR, 2016). Atualmente, a resistência à vancomicina representa uma grande ameaça no tratamento de infecções nosocomiais 
causadas por S. aureus levando o paciente a óbito (HOWDEN et al., 2010; $\mathrm{KOCH}$ et al., 2014).

\section{BIOFILME E SUA FUNÇÃO NA PATOGENICIDADE}

O biofilme definido como uma comunidade microbiana, encapsulada em uma matriz polimérica formada por polissacarídeo aderido ao substrato (séssil) (WU et al., 2011; PAHARIK e HORSWILL; SILVA-SANTANA et al., 2016).

Inicialmente é formado por uma monocamada de bactérias que aderem e se acumulam em superfície biótica ou abiótica, produzindo uma matriz polimérica extracelular contendo bactérias, polissacarídeos e proteínas (ATSHAN; REVDIWALA et al., 2012). Quando um microrganismo infecta um dispositivo médico, inúmeras variáveis determinam a formação de biofilme: (I) o microrganismo deve permanecer em contato com a superfície do substrato tempo necessário para promover adesão irreversível (fixação). Características químicas e moleculares do substrato podem influenciar na formação de biofilme (REVDIWALA et al., 2012), (II) colonização, (III) adesão célulacélula, (IV) multiplicação mediada pós-regulação de alguns genes como ica, agr e proteínas adesinas, (V) destacamento/dispersão (DONELLI; O'GARA, 2007; PAHARIK e HORSWILL, 2016).

Este fator de virulência aumenta 1.000 vezes a resistência e sobrevivência dos microrganismos, quando comparados com bactérias planctônicas. Mais de 80\% das infecções bacterianas estão relacionadas à formação de biofilme (KARAOLIS et al., 2005; YEAGLEY et al., 2013; PAHARIK e HORSWILL, 2016) e 25\% levam a doença crônica e óbito (ARCHER; KIEDROWSKI e HORSWILL, 2011; PAHARIK e HORSWILL, 2016). Na maioria das vezes, o tratamento dessas infecções não é bem-sucedido, pela dificuldade da penetração do antimicrobiano e do sistema imune inato do hospedeiro na complexa matriz polimérica (ARCHER; KIEDROWSKI e HORSWILL, 2011; SILVA-SANTANA et al., 2015), prolongando o tempo de internação do paciente e aumentando consideravelmente os custos hospitalares (KARAOLIS et al., 2005; FALORD et al., 2011; YEAGLEY et al., 2013). 


\subsection{Adesão inicial ao substrato e colonização bacteriana}

Staphylococcus aureus é capaz de aderir em superfícies abióticas (dispositivos médicos) como também em bióticas (tecido cardíaco, cartilagem e feridas crônicas) para colonização inicial. O implante médico (cateter) em contato com o tecido humano rapidamente é recoberto por proteínas da matriz, como fibrinogênicas A e B (FnBPA e FnBPB), de aglutinação e aglomeração das proteínas fibrinogênicas A e B (ClfA e ClfB), proteína de ligação ao colágeno ( $\mathrm{Cna}$ ) e sialoproteína óssea (Bbp), possibilitando a adesão e colonização bacteriana através de adesinas que estão ligadas covalentemente ao peptidoglicanos da parede celular das bactérias como as MSCRAMMs, fator importante na produção de biofilme (BEENKEN et al., 2004; KIEDROWSKI et al., 2011; PAHARIK e HORSWILL, 2016).

\subsection{Adesão mediada por polissacarídeo}

O locus ica é essencial para a formação de biofilme, constituído pelos genes icaR (regulador/repressor) e icaADBC (biossintéticos) induzidos em anaerobiose pelo regulador da resposta respiratória estafilocócica (SrrAB), mas também podem ser regulados por outros fatores ambientais como glicose, etanol, osmolaridade, temperatura e alguns antimicrobianos como tetraciclina (GÖTZ, 2002; BEENKEN et al., 2004; ARCHER et al., 2011).

Esses genes são responsáveis pela expressão de adesina intercelular polissacarídica (PIA), também denominada Poli-N-Acetil Glucosamina (PNAG), essencial para a adesão célula-célula, que em conjunto com proteínas de superfície formam e fixam o biofilme (O'GARA, 2007; ATSHAN; POZZI et al., 2012).

Estudos demonstraram que biofilmes podem ser formados independentes de PIA, através de proteínas de adesão a fibronectina (FnBPs) que se ligam através de autolisinas (AtIA e AtIE) (ARCHER et al., 2011; PAHARIK e HORSWILL, 2016), pela agregação celular mediada pela proteína associada a biofilme (biofilm-associated protein, Bap) (ARCHER et al., 2011), pela proteína associada a acúmulo (Aap) após ser proteoliticamente clivada (ROHDE et al., 2005), ou pela regulação do gene sigB (ARCHER et al., 2011). Os processos pelos quais $S$. aureus pode formar biofilme independente de PIA ainda não estão bem elucidados, entretanto, relatos sugerem algumas proteínas podem desempenhar a mesma função na ausência de ica (ARCHER et al., 2011).

WWW.AMPLLAEDITORA.COM.BR (2) 


\subsection{Comunicação mediada por peptídeos auto-indutores (Quorum-Sensing)}

Bactérias gram-positivas e gram-negativas são capazes de sintetizar moléculas sinalizadoras de natureza química variável, denominadas peptídeos autoindutores (autoinducing peptides, AIP). Durante a divisão celular, os AIPs acumulam-se no meio extracelular atingindo uma determinada densidade ou "quorum", ativando uma cascata reguladora responsável por controlar tipos específicos de processos celulares, esse fenômeno chama-se quorum-sensing (QS), mecanismo pelo qual bactérias podem "perceber" a quantidade de microrganismos no meio, funcionando como sensor de densidade populacional no interior do biofilme, estabelecendo algo semelhante à “comunicação” entre células (KONG et al., 2006; O'GARA, 2007; THOENDEL et al., 2011).

Em S. aureus o locus gene regulador acessório (accessory gene regulator, agr) é formado por um sistema composto por quatro genes $\operatorname{agr} B, \operatorname{agrD}, \operatorname{agrC}$ e $\operatorname{agr} A(\operatorname{agrBDCA})$ e está localizado no cromossomo em uma ilha de patogenicidade. O locus agr é determinante na patogênese e no desenvolvimento do biofilme através de um quorum, codificado por dois operons divergentes controlados pelos promotores P2 e P3 relacionados aos QS1 e QS2 respectivamente (VUONG et al., 2000; THOENDEL et al., 2011; YOUNG et al., 2012; SILVA-SANTANA et al., 2016).

O promotor P2 induz o locus agr a produzir mRNAll responsável pela biossíntese do PIA em três passos: (I) o gene icaA expressa a proteína IcaA que atua como $\mathrm{N}$ acetilglicosaminil-transferase utilizando UDP-N-acetilglucosamina como substrato (semelhante a quinase NodC), IcaA se associa a proteína IcaD formando IcaAD e gerando oligômeros de $\mathrm{N}$-acetilglucosamina com 10 a 20 resíduos, aumentando 20 vezes sua ação transferase. A proteína IcaD orienta o desdobramento e inserção de IcaA na membrana, e também como elo de conexão entre IcaA e IcaC, (II) a proteína IcaC expressa pelo gene icaC, sintetiza cadeias longas de oligômeros que se associam com IcaAD forma oligômeros completos com 130 resíduos, prontos para serem exportados no meio extracelular formando PIA, (III) acredita-se que a proteína IcaB seja responsável pela desacetilação do PIA, predominante na fase de acumulo do biofilme e importante na virulência de muitas estirpes (FRANK; VUONG et al., 2004) 
O promotor P3 induz o locus agr a produzir o mRNAlll responsável pela biossíntese de $\delta$-hemolisina e $h d l$ (KONG et al., 2006; THOENDEL et al., 2011). As proteínas AgrB e AgrD formadas pelos genes agrB e agrD se unem produzindo um AIP, que se liga ao receptor de AgrC (proteína transmembrânica - histidina quinase) fosforilando e ativando AgrA. A ativação da proteína AgrA aumenta a transcrição de genes de virulência como exotoxinas, simultaneamente reduz a produção de proteínas de superfície (MSCRAMMs) (THOENDEL et al., 2011; LINDSEY; YOUNG et al., 2012). A produção da proteína IcaR formada pelo gene icaR regula negativamente a expressão de polissacarídeos de adesão, acredita-se que sua ausência pode aumentar consideravelmente a produção de PIA (CRAMTON et al., 1999; GÖTZ, 2002). Em associação com o sistema agr negativo, pode ocorre a expressão do gene luxS, também capaz de regular negativamente a produção de PIA, diminuído a adesão celular e contribuído para a fase de destacamento (KONG et al., 2006; KUEHL et al., 2009; TSUJI et al., 2011).

Ao longo do tempo a função do locus agr mostrou ser controversa, a expressão dos genes agrBDCA nem sempre se mostra favorável à formação de biofilme, isso dependerá de qual promotor (P2 ou P3) atuará como indutor (SHIRTLIFF et al., 2002; KONG et al., 2006). Portanto, o locus agr ao regular negativamente genes associados à produção de proteínas da parede celular bacteriana relacionadas à adesão, indiretamente reduz a formação de biofilme e fazendo com que as células voltem ao estado planctônico (SANTOS et al., 2007). Por esse motivo, propõe-se que estirpes expressando níveis elevados de agr teriam a capacidade reduzida em formar biofilme, e que quanto maior for a produção de $\delta$-hemolisina por uma estirpe, menor será produção de MSCRAMMs e menos aderente a bactéria será no substrato. Alguns pesquisadores consideram a $\delta$-hemolisina como um bom marcador para o fenótipo relacionado a pouca produção de biofilme (VUONG et al., 2000; NOVICK, 2003).

\section{TERAPIA ANTIMICROBIANA CONTRA INFECÇÕES ASSOCIADAS A BIOFILME}

O tratamento mais eficaz para doenças relacionadas a biofilme é a remoção cirúrgica do tecido, drenagem e limpeza do local infectado. Principalmente com a 
retirada do implante médico contendo o biofilme responsável pela doença (ARCHER et al., 2011). Entretanto, em pacientes debilitados incapazes de resistir ao processo cirúrgico, e em usuários de próteses articulares a remoção torna-se inviável (DONELLI et al., 2007).

Atualmente, a terapia antimicrobiana sozinha não é eficaz, devendo ser associada quando possível à cirurgia de remoção do implante. Os agentes $\beta$-lactâmicos (por exemplo, penicilina G, oxacilina) são frequentemente utilizados para o tratamento de estirpes sensíveis, mantendo a concentração plasmática em $4 \times$ a MIC. Nos casos de resistência aos $\beta$-lactâmicos a alternativa é a vancomicina (ARCHER; KIEDROWSKI e HORSWILL, 2011).

A vancomicina pertence à classe dos glicopeptídeos, sua utilização foi aprovada no ano 1.950 e por mais de 50 anos foi considerada a principal escolha no tratamento de infecções por MRSA (RODVOLD e McCONEGHY, 2014). Em infecção sistêmica e nos casos de sepse, recomenda-se que sua administração seja combinada com um $\beta$ lactâmico e um inibidor de $\beta$-lactamases, essa combinação é capaz de incluir patógenos gram-negativos como tratamento empírico (LEVINE, 2008; DILWORTH et al., 2014). Dentre as limitações intrínsecas desse antimicrobiano, está à baixa penetração nos tecidos com eliminação lenta do patógeno, alta toxicidade renal (nefrotoxicidade), ototoxicidade e a administração deve ser parenteral (BOUZA, 2009; GIULIANO et al., 2010; NEELY et al., 2014).

A daptomicina e a linezolida são alternativas para o tratamento de infecções associadas a biofilme por MRSA (ARCHER; KIEDROWSKI e HORSWILL, 2011). A daptomicina é considerada a principal opção no tratamento de infecção na corrente sanguínea (ICS) por MRSA em casos de susceptibilidade reduzida à vancomicina, heteroVISA (hVISA) e VISA (WERTH et al., 2013; GUDIOL et al., 2017). Entretanto, não é indicada no tratamento de pneumonia por interagir com o surfactante pulmonar, levando à inibição seletiva da atividade do antimicrobiano (CARPENTER e CHAMBERS, 2004). A linezolida é o primeiro antimicrobiano da classe das oxazolidinonas utilizado para o tratamento de infecções causadas microrganismos gram-positivos, incluindo amostras MRSA, hVISA, VISA e VRSA (KAISER et al., 2007), uma alternativa de substituição à vancomicina. No entanto, sua atividade bacteriostática faz com que ela não seja a 
primeira escolha para tratamento de ICS ou endocardite, apesar de apresentar eficácia em pneumonias por MRSA (TACCONELLI e CATALDO, 2007).

No tratamento da endocardite causada por biofilme formado por MRSA em cateter intravascular, os antimicrobianos indicados são a vancomicina e a daptomicina (RODVOLD e McCONEGHY, 2014). Nos casos de falha no tratamento pela utilização individual desses antimicrobianos, se faz necessário a utilização dos mesmos em conjunto formando sinergismo ou com um $\beta$-lactâmico cessando a bacteremia persistente (STEFANI et al., 2015; CHAMBERS et al., 2016).

A teicoplanina pertence à mesma classe da vancomicina, seu uso em maior escala se deu apenas em 1980 pela similaridade com a vancomicina em espectro de ação e eficácia (AHMED; HOLMES e HOWDEN, 2014; GUDIOL et al., 2017), tornando-se uma opção no tratamento de ICS, endocardite, osteomielite e outras infecções por MRSA (PACE e YANG, 2006).

Este patógeno ainda apresenta susceptibilidade à associação entre sulfametoxazol-trimetoprim (SXT) (KRIEGESKORTE et al., 2015; GUDIOL et al., 2017), por esse motivo tem sido usados com frequência no tratamento de ICS por MRSA com prognóstico de sucesso (GOLDBERG e BISHARA, 2011; RODVOLD e McCONEGHY, 2014), também em infecções de pele e partes moles por VISA e em outros tipos de infecções por VRSA (NURJADI et al., 2014).

Estudos demonstraram grande eficácia no pré-tratamento com tetraciclinas contra a formação de biofilme. Pacientes usuários de cateteres revestidos com minociclina ou rifampicina não desenvolveram ICS, quando comparados com pacientes sem o pré-tratamento (KIEDROWSKI e HORSWILL, 2011).

Pesquisas atuais demostraram o ressurgimento de estirpes $S$. aureus suscetível à penicilina, talvez pela redução do seu uso clínico, melhorando assim o prognóstico das infecções e favorecendo a utilização dos $\beta$-lactâmicos no tratamento das infecções estafilocócicas (CHENG; RESMAN et al., 2016). 


\section{NOVAS PROPOSTAS TERAPÊUTICAS CONTRA A FORMAÇÃO DE BIOFILME}

A grande dificuldade no desenvolvimento de medidas de tratamento para as infecções decorrentes da formação de biofilme, atualmente incentiva novos estudos na tentativa de gerar compostos com atividade antimicrobiana e antibiofilme, gerando modelos que ampliem as terapias existentes atualmente. Alguns desses estudos realizados com S. aureus estão representados na Tabela 1.

Tabela 1 - Estudos realizados com o propósito de desenvolver novas estratégias terapêuticas contra a formação de biofilme.

\begin{tabular}{|c|c|c|c|}
\hline \multicolumn{4}{|c|}{ Atividade Antimicrobiana e Antibiofilme } \\
\hline Composto/Derivados & Resultados Obtidos & $\begin{array}{c}\text { Perspectivas } \\
\text { futuras }\end{array}$ & Referências \\
\hline Cyclic di-GMP & $\begin{array}{l}\text { Inibição da agregação, diminuição } \\
\text { da interação célula-célula (perda } \\
\text { do aspecto em "cacho de uvas") e } \\
\text { redução em } 66 \% \text { da adesão em } \\
\text { células HeLa. Possivelmente, é } \\
\text { internalizado ocasionando } \\
\text { mudanças na expressão de } \\
\text { proteínas de superfície. }\end{array}$ & $\begin{array}{l}\text { Utilização como } \\
\text { bloqueador da } \\
\text { formação de } \\
\text { biofilme. Síntese } \\
\text { de análogos com } \\
\text { propriedades } \\
\text { semelhantes a } \\
\text { fármacos. }\end{array}$ & $\begin{array}{l}\text { KARAOLIS } \\
\text { et al., } 2005\end{array}$ \\
\hline Terapia Fotodinâmica & $\begin{array}{l}\text { Redução do biofilme em } 3,1 \log _{10} \\
\text { (99,9\%) após único tratamento } \\
\text { com fotossensibilizador } 1,25 \mathrm{mM} \\
\text { de EDTA + } 5 \% \text { de EtOH + 0,03\% MB } \\
\text { na presença de luz } 670 \mathrm{~nm} \text { com } \\
\text { taxa de fluência de } 150 \mathrm{~mW} / \mathrm{cm}^{2} \text {. }\end{array}$ & $\begin{array}{l}\text { Dados não } \\
\text { declarados. }\end{array}$ & $\begin{array}{l}\text { BIEL et al., } \\
2011 \\
\text { BIEL et al., } \\
2013\end{array}$ \\
\hline Timoquinona & $\begin{array}{l}\text { Inibição da formação de biofilme } \\
\text { em } 90 \% \text { utilizado puro, como } \\
\text { adjuvante em meio de cultura na } \\
\text { concentração } 75 \text { a } 51 \mu \mathrm{g} / \mathrm{ml} \text { inibi } \\
\text { em } 90 \% \text { e superior a } 90 \% \\
\text { respectivamente a formação de } \\
\text { biofilme. }\end{array}$ & $\begin{array}{l}\text { Inclusão no } \\
\text { arsenal de } \\
\text { substâncias } \\
\text { bioativas após } \\
\text { estudos in vivo. }\end{array}$ & $\begin{array}{l}\text { CHAIEB et } \\
\text { al., } 2011\end{array}$ \\
\hline $\begin{array}{c}\text { BisBAL e } \\
\text { BisBDT/PYR* }\end{array}$ & $\begin{array}{l}\text { Ambos superaram os resultados } \\
\text { obtidos em comparação com } \\
\text { antimicrobianos, BisBAL inibiu a } \\
\text { formação de biofilme 40-80 } \\
\mu \mathrm{g} / \mathrm{ml}^{-1}(>7,7) \text { e BisBDT/PYR } \sim 40- \\
200 \mu \mathrm{g} / \mathrm{ml}^{-1} \text { (log 4,9). }\end{array}$ & $\begin{array}{l}\text { Desenvolvimento } \\
\text { de produtos } \\
\text { antissépticos, } \\
\text { atividade } \\
\text { antimicrobiana } \\
\text { em feridas e } \\
\text { antibiofilme em } \\
\text { feridas crônicas. }\end{array}$ & $\begin{array}{l}\text { FOLSOM et } \\
\text { al., } 2011\end{array}$ \\
\hline
\end{tabular}




\begin{tabular}{|c|c|c|}
\hline Cinamaldeído & $\begin{array}{l}\text { Potencial agente } \\
\text { terapêutico ou } \\
\text { adjuvante em } \\
\text { concentrações } \\
\text { sub-MIC na } \\
\text { prevenção de } \\
\text { infecções } \\
\text { causadas por } \\
\text { biofilme. }\end{array}$ & $\begin{array}{c}\text { JIA et al., } \\
2011\end{array}$ \\
\hline Hamamelitannina & $\begin{array}{l}\text { Na concentração } 100 \mathrm{mg} / \mathrm{L} \text { inibiu } \\
\text { atividade metabólica em } 23,0 \% \text { ( } \pm \\
10,7 \% \text { ) e o sistema quorum- } \\
\text { sensing do biofilme. }\end{array}$ & $\begin{array}{l}\text { COBRADO } \\
\text { et al., } 2012\end{array}$ \\
\hline Nanoparticulas (NPs) & $\begin{array}{ll} & \text { Nova abordagem } \\
& \text { para } \\
& \text { revestimento de } \\
\text { Completa inibição da formação de } & \text { superfícies } \\
\text { biofilme quando associadas a } 0,1 & \text { estéreis de } \\
\mathrm{mg} / \mathrm{ml} \text { de fluoreto de ítrio III }\left(\mathrm{YF}_{3}\right) . & \text { aplicação médica, } \\
& \text { impedindo a } \\
& \text { adesão } \\
& \text { bacteriana. }\end{array}$ & $\begin{array}{l}\text { LELLOUCHE } \\
\text { et al., } 2012\end{array}$ \\
\hline 2-aminopirimidina & $\begin{array}{l}\text { Inibição da formação de biofilme } \\
\text { por MSSA } 64-89 \% \text { e por MRSA } \\
\sim 80,1-85,5 \% .\end{array}$ & $\begin{array}{l}\text { LINDSEY et } \\
\text { al., } 2012\end{array}$ \\
\hline Vacina & $\begin{array}{l}\text { Alvo principal as células bacterianas no interior do } \\
\text { biofilme ou a matriz polissacarídica (PIA). Utilizando } \\
\text { como método a identificação de antígenos putativos } \\
\text { em proteínas de superfície "vacinologia reversa", } \\
\text { análise transcriptômica de patógenos através de } \\
\text { Microarranjos ou tecnologias baseadas em } \\
\text { recombinação de expressão in vivo (RIVET), como } \\
\text { identificação de antígenos expressos in vivo durante } \\
\text { infeç̧ão. Entre as limitações está a seleção de } \\
\text { antígenos apropriados. }\end{array}$ & $\begin{array}{l}\text { ARCHER et } \\
\text { al., } 2011\end{array}$ \\
\hline & $\begin{array}{llll}\text { opropanol } & (2: 3) & \text { (BisBAL); } & \text { N-óxido }\end{array}$ & bisms \\
\hline
\end{tabular}

\section{CONSIDERAÇÕES FINAIS}

Staphylococcus aureus é um patógeno oportunista associado a infecções graves, clinicamente alarmante devido à resistência a múltiplos antimicrobianos em especial os $\beta$-lactâmicos. Os múltiplos fatores de virulência que possui são responsáveis pelo agravamento da doença e evasão do sistema imune, entre os mais importantes está a formação de biofilme, responsável por causar inúmeras infecções crônicas e recalcitrantes. As terapias atuais para tratar e prevenir as infecções são limitadas e 
insatisfatórias, levando a intervenção cirúrgica para retirada do implante contendo o biofilme e assim implementação da terapia antimicrobiana, até o momento esse é o melhor meio de cura.

A escassez de medidas terapêuticas, tem conduzido gradualmente a busca por novas abordagens no tratamento dessas infecções. Atualmente pesquisadores consideram hipóteses para o desenvolvimento de vacinas, tendo como alvo moléculas e antígenos específicos combinando técnicas genômicas e proteômicas. Entretanto, essas abordagens devem ser avaliadas cuidadosamente, necessitando investigação aprofundada.

\section{AGRADECIMENTOS}

Gostaríamos de agradecer ao Instituto de Microbiologia Paulo de Góes, Universidade Federal do Rio de Janeiro (UFRJ), Brasil. Laboratório de Difteria e Corynebacteria de Relevância Clínica, Universidade do Estado do Rio de Janeiro (UERJ), Brasil. Este estudo foi financiado em parte pelo Conselho Nacional de Desenvolvimento Científico e Tecnológico (CNPq), Coordenação de Aperfeiçoamento de Pessoal de Nível Superior (CAPES) Código Financeiro 001 e Fundação de Amparo à Pesquisa do Estado do Rio de Janeiro (FAPERJ).

\section{REFERÊNCIAS}

AGUAYO-REYES A., QUEZADA-AGUILUZ M., MELLA S., RIEDEL G., OPAZO-CAPURRO A., BELLO-TOLEDO H., DOMÍNGUEZ M., GONZÁLEZ-ROCHA G. Molecular basis of methicillin-resistance in Staphylococcus aureus. Rev Chilena Infectol. v. 35, n. 1, p. 7-14, 2018. doi: 10.4067/s0716-10182018000100007

AHMED A., HUSSAIN S., IJAZ T., HASHEMY I. Susceptibility of methicillin-resistant Staphylococcus aureus and enterococci to teicoplanin in Pakistan: the MRSET study. J Pak Med Assoc. v. 64, n. 3, p. 256-259, 2014.

ALEKSHUN M. N., LEVY S. B. Molecular mechanisms of antibacterial multidrug resistance. Cell. v. 128, p. 1037-1050, 2007. doi: 10.1016/j.cell.2007.03.004

AMALARADJOU M. A. R., VENKITANARAYANAN K. Antibiofilm effect of octenidine hydrochloride on Staphylococcus aureus, MRSA and VRSA. Pathogens. v. 3, p. 404-416, 2014. doi: 10.3390/pathogens3020404 
ANDRIOLO A. Guias de Medicina Ambulatorial e Hospitalar. UNIFESP/Escola Paulista de Medicina - Medicina Laboratorial. Coordenador Adagmar Andriolo. São Paulo: Manole, 2005.

ARCHER N. K., MAZAITIS M. J., COSTERTON J. W., LEID J. G., POWERS M. E., SHIRTLIFF M. E. Staphylococcus aureus biofilms: properties, regulation, and roles in human disease. Virulence. v. 2, n. 5, p. 445-459, 2011. doi: 10.4161/viru.2.5.17724

ATSHAN S. S. SHAMSUDIN M. N., LUNG L. T. T., SEKAWI Z., GHAZNAVI-RAD E., PEI PEI C. Comparative characterisation of genotypically different clones of MRSA in the production of biofilms. J Biomed Biotechnol. ID 417247, p. 1-7, 2012. doi: $10.1155 / 2012 / 417247$

BAIG S., JOHANNESEN T. B., OVERBALLE-PETERSEN S., LARSEN J., LARSEN A. R., STEGGER M. Novel SCCmec type XIII (9A) identified in an ST152 methicillin-resistant Staphylococcus aureus. Infect Genet Evol. v. 61, p. 74-76, 2018. doi: 10.1016/j.meegid.2018.03.013

BANNERMAN T. L., PEACOCK S. J. Staphylococcus, Micrococcus, and other catalasepositive cocci. In: Manual of Clinical Microbiology, 9th ed, p. 390-410. Edited by: MURRAY P. R., BARON E. J., JORGENSEN J. H., LANDRY M. J., PFALLER M. A. Washigton - DC, ASM Press, 2007.

BEENKEN K. E., DUNMAN P. M., McALEESE F., MACAPAGAL D., MURPHY E., PROJAN S. J., BLEVINS J. S., SMELTZER M. S. Global gene expression in Staphylococcus aureus biofilms. J. Bacteriol. v. 186, n. 14, p. 4665-4684, 2004 . doi: 10.1128/JB.186.14.4665-4684.2004

BIEL M. A., PEDIGO L., GIBBS A., LOEBEL N. Photodynamic therapy of antibiotic-resistant biofilms in a maxillary sinus model. Int Forum Allergy Rhinol. v. 3, n. 6, p. 46873, 2013. doi: 10.1002/alr.21134

BIEL M. A., SIEVERT C., USACHEVA M., TEICHERT M., BALCOM J. Antimicrobial photodynamic therapy treatment of chronic recurrent sinusitis biofilms. Int Forum Allergy Rhinol. v. 1, n. 5, p. 329-334, 2011. doi: 10.1002/alr.20089

BOLES B. R., HORSWILL A. R. agr-mediated dispersal of Staphylococcus aureus biofilms. PLoS Pathogens. v. 4, n. 4, p. e1000052, 2008 . doi: 10.1371/journal.ppat.1000052

BOUZA E., PÉREZ-MOLINA J., MUÑOZ P. on behalf of the Cooperative Group of the European Study Group on Nosocomial Infections (ESGNI). Report of ESGNI-001 and ESGNI-002 studies. Bloodstream infections in Europe. Clin Microbiol Infect. v. 5, p. 2S1-2S12, 1999. doi: 10.1111/j.1469-0691.1999.tb00536.x 
BOYLE-VAVRA S., DAUM R. S. Community-acquired methicillin-resistant Staphylococcus aureus: the role of Panton-Valentine leukocidin. Lab Invest. v. 87, n. 1, p. 3-9, 2007. doi: 10.1038/labinvest.3700501

BUKOWSKI M., WLADYKA B., DUBIN G. Exfoliative toxins of Staphylococcus aureus. Toxins. v. 2, n. 5, p. 1148-1165, 2010. doi: 10.3390/toxins 2051148

BUTTERLY A., SCHMIDT U., WIENER-KRONISH J. Methicillin-resistant Staphylococcus aureus colonization, its relationship to nosocomial infection, and efficacy of control methods. Anesthesiology. v. 113, n. 6, p. 1453-1459, 2010. doi: 10.1097/ALN.0b013e3181fcf671

CABOCLO R. M., CAVALCANTE F. S., PONTES I. N. L., SCHUENCK R. P., OLENDZKI A. N., FELIX M. J., CHAMON R. C., NETTO K. R. S. Methicillin-resistant Staphylococcus aureus in Rio de Janeiro hospitals: dissemination of the USA400/ST1 and USA800/ST5 SCCmec type IV and USA100/ST5 SCCmec type II lineages in a public institution and polyclonal presence in a private one. Am J Infect Control. v. 41, p. e21-e25, 2013. doi: 10.1016/j.ajic.2012.08.008

CARPENTER C. F., CHAMBERS H. F. Daptomycin: another novel agent for treating infections due to drug-resistant gram-positive pathogens. Clin Infect Dis. v. 38, n. 7 , p. $994-1000,2004$. doi: $10.1086 / 383472$

CARROLL K. C. Estafilococos. In: Microbiologia Médica, 26th ed, p. 199-207. Edited by: JAWETZ, MELNICK e ADELBERG. New York - NY, McGraw-Hill Global Education, 2014.

CARVALHO K. S., MAMIZUKA E. M., GONTIJO FILHO P. P. Methicillin/Oxacillin-resistant Staphylococcus aureus as a hospital and public health threat in Brazil. Braz J Infect Dis. v. 14, n. 1, p. 71-76, 2010. doi: 10.1016/s1413-8670(10)70014-3

CHAIEB K., KOUIDHI B., JRAH H., MAHDOUANI K., BAKHROUF A. Antibacterial activity of thymoquinone, an active principle of Nigella sativa and its potency to prevent bacterial biofilm formation. BMC Complement Altern Med. v. 11, p. 29, 2011. doi: 10.1186/1472-6882-11-29

CHAMBERS D. A., FEERO W. G., KHOURY M. J. Convergence of implementation science, precision medicine, and the learning health care system: a new model for biomedical research. JAMA. v. 315, n 18, p. 1941-1942, 2016 . doi: 10.1001/jama.2016.3867

CHENG A. G., KIM H. K., BURTS M. L., KRAUSZ T., SCHNEEWIND O., MISSIAKAS D. M. Genetic requirements for Staphylococcus aureus abscess formation and persistence in host tissues. FASEB J. v. 23, n. 10, p. 3393-3404, 2009. doi: 10.1096/fj.09-135467 
CHENG M. P., RENE P., CHENG A. P., LEE T. C. Back to the future: penicillin-susceptible Staphylococcus aureus. Am J Med. v. 129, n. 12, p. 1331-1333, 2016. doi: 10.1016/j.amjmed.2016.01.048

COBRADO L., AZEVEDO M. M., SILVA-DIAS A., PEDRO RAMOS J. P., PINA-VAZ C., RODRIGUES A. G. Cerium, chitosan and hamamelitannin as novel biofilm inhibitors? J Antimicrob Chemother. v. 67, n. 5, p. 1159-62, 2012. doi: 10.1093/jac/dks007

CRAMTON S. E., GERKE C., SCHNELL N. F., NICHOLS W. W., GÖTZ F. The intercellular adhesion (ica) locus is present in Staphylococcus aureus and is required for biofilm formation. Infect Immun. v. 67, n. 10, p. 5427-5433, 1999.

DERESINSKI S. Methicillin-resistant Staphylococcus aureus: an evolutionary, epidemiologic, and therapeutic odyssey. Clin Infect Dis. v. 40, n. 4, p. 562-573, 2005. doi: $10.1086 / 427701$

DEURENBERG R. H., STOBBERINGH E. E. The molecular evolution of hospital-and community-associated methicillin-resistant Staphylococcus aureus. Curr Mol Med. v. 9, n. 2, p. 100-115, 2009. doi: 10.2174/156652409787581637

DHAND A., SAKOULAS G. Reduced vancomycin susceptibility among clinical Staphylococcus aureus isolates ('the MIC Creep'): implications for therapy. F1000 Med Rep. v. 4, p. 4, 2012. doi: 10.3410/M4-4

DILWORTH T. J., LEONARD S. N., VILAY A. M., MERCIER R. C. Vancomycin and piperacillintazobactam against methicillin-resistant Staphylococcus aureus and vancomycinintermediate Staphylococcus aureus in an in vitro pharmacokinetic/pharmacodynamic model. Clin Ther. v. 36, n. 10, p. 1334-1344, 2014. doi: 10.1016/j.clinthera.2014.06.027

DONELLI G., FRANCOLINI I., ROMOLI D., GUAGLIANONE E., PIOZZI A., RAGUNATH C., KAPLAN J. B. Synergistic activity of dispersin B and cefamandole nafate in inhibition of Staphylococcal biofilm growth on polyurethanes. Antimicrob Agents Chemother. v. 51, n. 8, p. 2733-2740, 2007. doi: 10.1128/AAC.01249-06

EAST A. K., DYKE K. G. H. Cloning and sequence determination of six Staphylococcus aureus $\beta$-lactamases and their expression in Escherichia coli and Staphylococcus aureus. J Gen Microbiol. v. 135, n. 4, p. 1001-1015, 1989. doi: 10.1099/00221287-135-4-1001

FALORD M., MADER U., HIRON A., DEBARBOUILLE M., MSADEK T. Investigation of the Staphylococcus aureus GraSR regulon reveals novel links to virulence, stress response and cell wall signal transduction pathways. PLoS One. v. 6, n. 7, p. e21323, 2011. doi: 10.1371/journal.pone.0021323 
FOLSOM J. P., BAKER B., STEWART P. S. In vitro efficacy of bismuth thiols against biofilms formed by bacteria isolated from human chronic wounds. J Appl Microbiol. v. 111, p. 989-996, 2011. doi: 10.1111/j.1365-2672.2011.05110.x

FRANK K. L., HANSSEN A. D., PATEL R. icaA is not a useful diagnostic marker for prosthetic joint infection. J Clin Microbiol. v. 42, n. 10, p. 4846-4849, 2004. doi: 10.1128/jcm.42.10.4846-4849.2004

GANESH V. K., RIVERA J. J., SMEDS E., KO Y. P., BOWDEN M. G., WANN E. R., GURUSIDDAPPA S., FITZGERALD J. R., HÖÖ M. Structural model of the Staphylococcus aureus ClfA-fibrinogen interaction opens new avenues for the design of anti-staphylococcal therapeutics. PLoS Pathogens. v. 4, n. 11, p. e1000226, 2008. doi: 10.1371/journal.ppat.1000226

GARRITY G. M. Bergey's Manual of Sistematic Bacteriology. 2nd ed, v. 3: The low G + C gram positives. Spriger-Verlag, New York, 2006.

GARZONI C., KELLEY W. L. Staphylococcus aureus: new evidence for intracellular persistence. Trends Microbiol. v. 17, n. 2, p. 59-65, 2009. doi: 10.1016/j.tim.2008.11.005

GEISEL R., SCHMITZ F., FLUIT A., LABISCHINSKI H. Emergence, mechanism, and clinical implications of reduced glycopeptide susceptibility in Staphylococcus aureus. Eur J Clin Microbiol Infect Dis. v. 20, p. 685-697, 2001. doi: 10.1007/s100960100595

GENESTIER A. L., MiChAllet M. C., PRÉVOST G., BELlOT G., CHALABREYSSE L., PEYROL S., THIVOLET F., ETIENNE J., LINA G. VALLETTE F. M., VANDENESCH F., GENESTIER L. Staphylococcus aureus Panton-Valentine leukocidin directly targets mitochondria and induces Bax-independent apoptosis of human neutrophils. J Clin Invest. v. 115, n. 11, p. 3117-3127, 2005. doi: 10.1172/JCI22684

GIAROLA L. B., SANTOS R. R., BEDENDO J., JÚNIOR W. V. S., BORELLI S. D. HLA molecules and nasal carriage of Staphylococcus aureus isolated from dialysis and kidney transplant patients at a hospital in Southern Brazil. BMC Res Notes. v. 5, p. 90, 2012. doi: 10.1186/1756-0500-5-90

GIULIANO C., HAASE K. K., HALL R. Use of vancomycin pharmacokineticpharmacodynamic properties in the treatment of MRSA infections. Expert Rev Anti Infect Ther. v. 8, n. 1, p. 65-106, 2010. doi: 10.1586/eri.09.123

GOLDBERG E., BISHARA J., LEV S., SINGER P., COHEN J. Organ transplantation from a donor colonized with a multidrug-resistant organism: a case report. Transplant Infectious Disease. v. 1, p. 1-4, 2011. doi: 10.1111/j.1399-3062.2011.00697.x

GÖTZ F. Staphylococcus and biofilms. Mol Microbiol. v. 43, n. 6, p. 1367-1378, 2002. doi: 10.1046/j.1365-2958.2002.02827.x 
GUDIOL C., CUERVO G., SHAW E., PUJOL M., CARRATALÀ J. Pharmacotherapeutic options for treating Staphylococcus aureus bacteremia. Expert Opin Pharmacother. v. 18, n. 18 , p. 1947-1963, 2017. doi: 10.1080/14656566.2017.1403585

HAGIHARA M., UMEMURA T., MORI T., MIKAMO H. Daptomycin approved in Japan for the treatment of methicillin-resistant Staphylococcus aureus. Ther Clin Risk Manag. v. 8, p. 79-86, 2012. doi: 10.2147/TCRM.S23875

HIRAMATSU K., KATAYAMA Y., MATSUO M., SASAKI T., MORIMOTO Y., SEKIGUCHI A., BABA T. Multi-drug-resistant Staphylococcus aureus and future chemotherapy. J Infect Chemother. v. 20, p. 593-601, 2014. doi: 10.1016/j.jiac.2014.08.001

HOLMES N. E., HOWDEN B. P. What's new in the treatment of serious MRSA infection? Curr Opin Infect Dis. v. 27, n. 6, p. 471-478, 2014. doi: 10.1097/QCO.0000000000000101

HOLMES N. E., TURNIDGE J. D., MUNCKHOF W. J., ROBINSON J. O., KORMAN T. M., O'SULLIVAN M. V., ANDERSON T. L., ROBERTS S. A., WARREN S. J., GAO W., HOWDEN B. P., JOHNSON P. D. Vancomycin AUC/MIC and 30-day mortality in patients with Staphylococcus aureus bacteremia. Antimicrob Agents Chemother. v. 57, n. 4, p. 1654-1663, 2013. doi: 10.1128/AAC.01485-12

HONG H. J., HUTCHINGS M. I., BUTTNER M. J. Vancomycin resistance VanS/VanR twocomponent systems. In Bacterial Signal Transduction: Networks and Drug Targets. Springer, New York, NY. p. 200-213, 2008.

HOWDEN B. P., DAVIES J. K., JOHNSON P. D. R., STINEAR T. P., GRAYSON M. L. Reduced vancomycin susceptibility in Staphylococcus aureus, including vancomycinintermediate and heterogeneous vancomycin intermediate strains: resistance mechanisms, laboratory detection, and clinical implications. Clin Microbiol Rev. v. 23, n. 1, p. 99-139, 2010. doi: 10.1128/CMR.00042-09

International Working Group on the Classification of Staphylococcal Cassette Chromosome Elements (IWG-SCC). Classification of Staphylococcal Cassette Chromosome mec (SCCmec): Guidelines for Reporting Novel SCCmec Elements. Antimicrob Agents Chemother. v. 53, n. 12, p. 4961-4967, 2009.

JIA P., XUE Y. J., DUAN X. J., SHAO S. H. Effect of cinnamaldehyde on biofilm formation and sarA expression by methicillin-resistant Staphylococcus aureus. Lett Appl Microbiol. v. 53, n. 4, p. 409-416, 2011. doi: 10.1111/j.1472-765X.2011.03122.x

JONGERIUS I., KÖHL J., PANDEY M. K., RUYKEN M., VAN KESSEL K. P. M., VAN STRIJP J. A. G., ROOIJAKKERS S. H. M. Staphylococcal complement evasion by various convertase-blocking molecules. J Exp Med. v. 204, n. 10, p. 2461-2471, 2007. doi: 10.1084/jem.20070818 
KAISER C. R., CUNICO W., PINHEIRO A. C., DE OLIVEIRA A. G., PERALTA M. A., DE SOUZA M. V. Oxazolidinones: a new class of compounds against tuberculosis. Rev Bras Farm. v. 88, n. 2, p. 83-88, 2007. doi: 10.1016/S1069-417X(00)80031-X

KARAOLIS D. K. R., RASHID M. H., CHYTHANYA R., LUO W., HYODO M., HAYAKAWA Y. cdi-GMP (3'-5'-cyclic diguanylic acid) inhibits Staphylococcus aureus cell-cell interactions and biofilm formation. Antimicrob Agents Chemother. v. 49, n. 3, p. 1029-1038, 2005. doi: 10.1128/AAC.49.3.1029-1038.2005

KATEETE D. P., KIMANI C. N., KATABAZI F. A., OKENG A., OKEE M. S., NANTEZA A., JOLOBA M. L., NAJJUKA F. C. Identification of Staphylococcus aureus: DNase and mannitol salt agar improve the efficiency of the tube coagulase test. Ann Clin Microbiol Antimicrob. v. 9, p. 23, 2010. doi: 10.1186/1476-0711-9-23

KIEDROWSKI M. R., HORSWILL A. R. New approaches for treating staphylococcal biofilm infections. Ann N Y Acad Sci. v. 1241, p. 104-121, 2011. doi: 10.1111/j.17496632.2011.06281.x

KIEDROWSKI M. R., KAVANAUGH J. S., MALONE C. L., MOOTZ J. M., VOYICH J. M., SMELTZER M. S., BAYLES K. W., HORSWILL A. R. Nuclease modulates biofilm formation in community-associated methicillin-resistant Staphylococcus aureus. PLoS One. v. 6, n. 11, p. e26714, 2011. doi: 10.1371/journal.pone.0026714

KIM H. K., MISSIAKAS D., SCHNEEWIND O. Mouse models for infectious diseases caused by Staphylococcus aureus. J Immunol Methods. v. 410, p. 88-99, 2014. doi: 10.1016/j.jim.2014.04.007

KOCH G., YEPES A., FÖRSTNER K. U., WERMSER C., STENGEL S. T., MODAMIO J., OHLSEN K., FOSTER K. R., LOPEZ D. Evolution of resistance to a last-resort antibiotic in Staphylococcus aureus via bacterial competition. Cell. v. 158, n. 5, p. 1060-1071, 2014. doi: 10.1016/j.cell.2014.06.046

KONG K. F., VUONG C., OTTO M. Staphylococcus quorum sensing in biofilm formation and infection. Int J Med Microbiol. v. 296, p. 133-139, 2006. doi: 10.1016/j.ijmm.2006.01.042

KRIEGESKORTE A., LORÈ N. I., BRAGONZI A., RIVA C., KELKENBERG M., BECKER K., PROCTOR R. A., PETERS G., KAHL B. C. Thymidine-dependent Staphylococcus aureus small colony variants (SCVs) are induced by trimethoprimsulfamethoxazole (SXT) and have an increased fitness during SXT challenge. Antimicrob Agents Chemother. v. 59, n. 12, p. 7265-7272, 2015. doi: 10.1128/AAC.00742-15

KUEHL R., AL-BATAINEH S., GORDON O., LUGINBUEHL R., OTTO M., TEXTOR M., LANDMANN R. Furanone at subinhibitory concentrations enhances staphylococcal biofilm formation by luxS repression. Antimicrob Agents Chemother. v. 53, n. 10, p. 4159-4166, 2009. doi: 10.1128/AAC.01704-08 
KUMAR M. Multidrug-Resistant Staphylococcus aureus, India, 2013-2015. Emerg Infect Dis. v. 22, n. 9, p. 1666-1667, 2016. doi: 10.3201/eid2209.160044

LELLOUCHE J., FRIEDMAN A., GEDANKEN A., BANIN E. Antibacterial and antibiofilm properties of yttrium fluoride nanoparticles. Int J Nanomedicine. v. 7, p. 56115624, 2012. doi: 10.2147/IJN.S37075

LESSA F. C., MU Y., DAVIES J., MURRAY M., LILLIE M., PEARSON A., FRIDKIN S. K. Comparison of incidence of bloodstream infection with methicillin-resistant Staphylococcus aureus between England and United States, 2006-2007. Clin Infect Dis. v. 51, n. 8, p. 925-928, 2010. doi: 10.1086/656414

LEVINE D. P. Vancomycin: understanding its past and preserving its future. South Med J. v. 101, n. 3, p. 284-291, 2008. doi: 10.1097/SMJ.0b013e3181647037

LINDSEY E. A., WORTHINGTON R. J., ALCARAZ C. C., MELANDER C. 2-Aminopyrimidine as a novel scaffold for biofilm modulation. Org Biomol Chem. v. 10, p. 2552-2561, 2012. doi: 10.1039/c2ob06871k

LOWY, F. D. Staphylococcus aureus infections. N Engl J Med. v. 339, n. 8, p. 520-532, 1998. doi: 10.1056/NEJM199808203390806

LUTZ L., MACHADO A., KUPLICH N., BARTH A. L. Clinical failure of vancomycin treatment of Staphylococcus aureus infection in a tertiary care hospital in southern Brazil. BJID. v. 7, n. 3, p. 224-228, 2003.

MACHADO A. R. L., ARNS C. C., FOLLADOR W., GUERRA A. Cost-effectiveness of linezolid versus vancomycin in mechanical ventilation-associated nosocomial pneumonia caused by methicillin-resistant Staphylococcus aureus. Braz J Infect Dis. v. 9, n. 3, p. 191-200, 2005. doi: 10.1590/s1413-86702005000300001

MADIGAN M. T., MARTINKO J. M., BENDER K. S., BUCKLEY D. H., STAHL D. A. Microbiologia de Brock - 14th ed. Editora: Artmed, 2016.

MAMIZUKA E. Projeto de resistência microbiana em serviços de Saúde, Staphylococcus. Gerência-Geral de Tecnologia em Serviços e Saúde. Brasilia: Agência Nacional de Vigilância Sanitária, 2005. Disponível em: www.anvisa.gov.br. Acesso em: 18 de Novembro de 2019.

MARTINS A., CUNHA M. L. Epidemiological aspects of oxacillin-resistant Staphylococcus spp.: The use of molecular tools with emphasis on MLST. Epidemiology Insights. ISBN 978-953-51-0565-7, 2012. Disponível em: http://www.intechopen.com. Acesso em: 18 de Novembro de 2019.

McADOW M., KIM H. K., DeDENT A. C., HENDRICKX A. P. A., SCHNEEWIND O., MISSIAKAS D. M. Preventing Staphylococcus aureus sepsis through the inhibition of its 
agglutination in blood. PLoS Pathogens. v. 7, n. 10, p. e1002307, 2011. doi: 10.1371/journal.ppat.1002307

McDEVITT D., NANAVATY T., HOUSE-POMPEO K., BELL E., TURNER N., MCINTIRE L., FOSTER T., HOOK M. Characterization of the interaction between the Staphylococcus aureus clumping factor (ClfA) and fibrinogen. Eur J Biochem. v. 247, n. 1, p. 416-424, 1997. doi: 10.1111/j.1432-1033.1997.00416.x

MEHNDIRATTA P. L., BHALLA P. Typing of Methicillin resistant Staphylococcus aureus: a technical review. Indian J Med Microbiol. v. 30, n. 1, p. 16-23, 2012. doi: 10.4103/0255-0857.93015

MICHELIM L., LAHUDE M., ARAÚJO P. R., GIOVANAZ D. S. H., MÜLLER G., DELAMARE A. P. L., COSTA S. O. P., ECHEVERRIGARAY S. Pathogenic factors and antimicrobial resistance of Staphylococcus epidermidis associated with nosocomial infections occurring in intensive care units. Braz J Microbiol. v. 36, n. 1, p. 17-23, 2005. doi: $10.1590 / \mathrm{s} 1517-83822005000100004$

MOELLERING JR. R. C., FERRARO M. J. Introduction: solving the clinical problem of vancomycin resistance. Clin Infect Dis. v. 54, n. S3, p. S201-S202, 2012. doi: 10.1093/cid/cir1046

NEELY M. N., YOUN G., JONES B., JELLIFFE R. W., DRUSANO G. L., RODVOLD K. A., LODISE T. P. Are vancomycin troughs adequate for optimal dosing? Antimicrob Agents Chemother. v. 58, n. 1, p. 309-316, 2014. doi: 10.1128/AAC.01653-13

NOVICK R. P. Autoinduction and signal transduction in the regulation of staphylococcal. Mol Microbiol. v. 48, n. 6, p. 1429-1449, 2003. doi: 10.1046/j.13652958.2003.03526.x

NOVICK R. P., CHRISTIE G. E., PENADÉS J. R. The phage-related chromosomal islands of Gram-positive bacteria. Nat Rev Microbiol. v. 8, n. 8, p. 541-551, 2010. doi: 10.1038/nrmicro2393

NURJADI D., OLALEKAN A. O., LAYER F., SHITTU A. O., ALABI A., GHEBREMEDHIN B., SCHAUMBURG F., HOFMANN-EIFLER J., VAN-GENDEREN P. J. J., CAUMES E., FLECK R., MOCKENHAUPT F. P., HERRMANN M., KERN W. N., ABDULLA S., GROBUSH M. P., KREMSNER P. G., WOLZ C., ZANGER P. Emergence of thrimetoprin resistance gene $d f r G$ in Staphylococcus aureus causing human infection and colonization in sub-saharian Africa and its important to Europe. J Antimicrob Chemother. v. 69, p. 2361-2368, 2014. doi: 10.1093/jac/dku174

O'GARA J. P. ica and beyond: biofilm mechanisms and regulation in Staphylococcus epidermidis and Staphylococcus aureus. FEMS Microbiol Lett. v. 270, n. 2, p. 179188, 2007. doi: 10.1111/j.1574-6968.2007.00688.x 
OLIVEIRA D. C., LENCASTRE H. Multiplex PCR strategy for rapid identification of structural types and variants of the mec element in methicillin-resistant Staphylococcus aureus. Antimicrob Agents Chemother. v. 46, n. 7, p. 2155-2161, 2002. doi: 10.1128/aac.46.7.2155-2161.2002

OTTO M. Bacterial evasion of antimicrobial peptides by biofilm formation. Curr Top Microbiol Immunol. v. 306, p. 251-258, 2006. doi: 10.1007/3-540-29916-5_10

OTTO M. Looking toward basic science for potential drug discovery targets against community-associated MRSA. Med Res Rev. v. 30, n. 1, p. 1-22, 2010. doi: 10.1002/med.20160

OTTO M. MRSA virulence and spread. Cell Microbiol. v. 14, n. 10, p. 1513-1521, 2012. doi: 10.1111/j.1462-5822.2012.01832.x

PACE J. L., YANG G. Glycopeptides: update on an old successful antibiotic class. Biochem Pharmacol. v. 71, p. 968-980, 2006. doi: 10.1016/j.bcp.2005.12.005

PAHARIK A. E., HORSWILL A. R. The staphylococcal biofilm: adhesins, regulation, and host response. Microbiol Spectr. v. 4, n. 2, p. 529-566, 2016 . doi: 10.1128/microbiolspec.VMBF-0022-2015

POZZI C., WATERS E., RUDKIN J. K., SCHAEFFER C. R., LOHAN A. J., TONG P., LOFTUS B. J., PIER G. B., FEY P. D., MASSEY R. C., O'GARA J. P. Methicillin resistance alters the biofilm phenotype and attenuates virulence in Staphylococcus aureus deviceassociated infections. PLoS Pathog. v. 8, n. 4, p. e1002626, 2012. doi: 10.1371/journal.ppat.1002626

RAMMELKAMP C. H., MAXON T. Resistance of Staphylococcus aureus to the action of Penicillin. Exp Biol Med (Maywood). v. 51, p. 386-389, 1942. doi: 10.3181/00379727-51-13986

RAMSEY M. M., FREIRE M. O., GABRILSKA R. A., RUMBAUGH K. P., LEMON K. P. Staphylococcus aureus shifts toward commensalism in response to Corynebacterium species. Front Microbiol. v. 7, p. 1-15, 2016. doi: 10.3389/fmicb.2016.01230

RESMAN F., THEGERSTRÖM J., MÅNSSON F., AHL J., THAM J., RIESBECK K. The prevalence, population structure and screening test specificity of penicillinsusceptible Staphylococcus aureus bacteremia isolates in Malmö, Sweden. J Infect. v. 73, n. 2, p. 129-135, 2016. doi: 10.1016/j.jinf.2016.05.011

REVDIWALA S., RAJDEV B. M., MULLA S. Characterization of bacterial etiologic agents of biofilm formation in Medical Devices in Critical Care Setup. Critical Care Research and Practice. ID 945805, p. 1-6, 2012. doi: 10.1155/2012/945805 
RODVOLD K. A., McCONEGHY K. W. Methicillin-resistant Staphylococcus aureus therapy: past, present, and future. Clin Infect Dis. v. 58, n. S1, p. S20-S27, 2014. doi: 10.1093/cid/cit614

ROHDE H., BURDELSKI C., BARTSCHT K., HUSSAIN M., BUCK F., HORSTKOTTE M. A., KNOBLOCH, J. K. M., HEILMANN C., HERRMANN M., MACK D. Induction of Staphylococcus epidermidis biofilm formation via proteolytic processing of the accumulation-associated protein by staphylococcal and host proteases. Mol Microbiol. v. 55, n. 6, p. 1883-1895, 2005 . doi: 10.1111/j.13652958.2005.04515.x

RUDKIN J. K., EDWARDS A. M., BOWDEN M. G., BROWN E. L., POZZI C., WATERS E. M., CHAN W. C., WILLIAMS P., O'GARA J. P., MASSEY R. C. Methicillin resistance reduces the virulence of healthcare-associated methicillin-resistant Staphylococcus aureus by interfering with the agr quorum sensing system. J Infect Dis. v. 205, n. 5, p. 798-806, 2012. doi: 10.1093/infdis/jir845

SANTOS A. L., SANTOS D. O., FREITAS C. C., FERREIRA B. L. A., AFONSO I. F., RODRIGUES C. R., CASTRO H. C. Staphylococcus aureus: visiting a strain of clinical importance. J Bras Patol Med Lab. v. 43, n. 6, p. 413-423, 2007. doi: 10.1590/S167624442007000600005

SHIRTLIFF M. E., MADER J. T., CAMPER A. K. Molecular interactions in biofilms. Chem Biol. v. 9, n. 8, p. 859-871, 2002. doi: 10.1016/S1074-5521(02)00198-9

SILVA-SANTANA G., CASTRO H. C., FERREIRA B. L. A., AGUIAR-ALVES F. Staphylococcus aureus biofilm development: the urgent need for treatment alternatives. Journal of Global Biosciences. v. 4, n. 5, p. 2092-2107, 2015.

SILVA-SANTANA G., LENZI-ALMEIDA K. C., LOPES V. G. S., AGUIAR-ALVES F. Biofilm formation in catheter-related infections by Panton-Valentine leukocidinproducing Staphylococcus aureus. Int Microbiol. v. 19, n. 4, p. 199-207, 2016. doi: 10.2436/20.1501.01.278

SOUZA L. B. G. D., FIGUEIRED B. D. B. Prevalência de infecções nosocomiais provocadas por Staphylococcus aureus resistente à meticilina (MRSA), no Hospital Universitário Regional de Maringá. Rev Bras Anal Clin. v. 40, n. 1, p. 31-34, 2008.

STAPLETON P. D., TAYLOR P. W. Methicillin resistance in Staphylococcus aureus: mechanisms and modulation. Sci Prog. v. 85, n. Pt1, p. 57-72, 2002. doi: $10.3184 / 003685002783238870$

STEFANI S., CAMPANILE F., SANTAGATI M., MEZZATESTA M. L., CAFISO V., PACINI G. Insights and clinical perspectives of daptomycin resistance in Staphylococcus aureus: a review of the available evidence. Int J Antimicrob Agents. v. 46, n. 3, p. 278-289, 2015. doi: 10.1016/j.ijantimicag.2015.05.008 
TACCONELLI E., CATALDO M. A. Antimicrobial therapy of Staphylococcus aureus bloodstream infection. Expert Opin Pharmacother. v. 8, n. 15, p. 2505-2518, 2007. doi: 10.1517/14656566.8.15.2505

TAVARES W. Manual de antibióticos e quimioterápicos antiinfecciosos. 3th ed. São Paulo: Atheneu, 2002. Cap 1: Classificação dos antimicrobianos. Cap 5: Resistência bacteriana.

THOENDEL M., KAVANAUGH J. S., FLACK C. E., HORSWILL A. R. Peptide signaling in the staphylococci. Chem Rev. v. 111, n. 1, p. 117-151, 2011. doi: 10.1021/cr100370n

TSUJI B. T., MACLEAN R. D., DRESSER L. D., MCGAVIN M. J., SIMOR A. E. Impact of accessory gene regulator (agr) dysfunction on vancomycin pharmacodynamics among Canadian community and health-care associated methicillin-resistant Staphylococcus aureus. Ann Clin Microbiol Antimicrob. v. 10, p. 1-7, 2011. doi: 10.1186/1476-0711-10-20

VUONG C., KOCIANOVA S., VOYICH J. M., YAO Y., FISCHER E. R., DELEO F. R., OTTO M. A crucial role for exopolysaccharide modification in bacterial biofilm formation, immune evasion, and virulence. J Bio Chem. v. 279, n. 52, p. 54881-54886, 2004. doi: $10.1074 / j b c . m 411374200$

VUONG C., SAENZ H. L., GÖTZ F., OTTO M. Impact of the agr quorum-sensing system on adherence to polystyrene in Staphylococcus aureus. J Infect Dis. v. 182, n. 6, p. 1688-1693, 2000. doi: 10.1086/317606

WALSH T. R., BOLMSTRÖM A., QWÄRNSTRÖM A., HO P. WOOTTON M., HOWE R. A., MACGOWAN A. P., DIEKEMA D. Evaluation of current methods for detection of staphylococci with reduced susceptibility to glycopeptides. J Clin Microbiol. v. 39, n. 7, p. 2439-2444, 2001. doi: 10.1128/JCM.39.7.2439-2444.2001

WERTH B., STEED M., KAATZ G. W., RYBAK M. J. Evaluation of ceftaroline (CPT) activity against heteroresistant vancomycin intermediate Staphylococcus aureus (hVISA) and VISA methicillin-resistant $S$. aureus (MRSA) strains in an in vitro pharmacokinetic/pharmacodynamic model: exploring the "seesaw effect". Antimicrob Agents Chemother. v. 57, n. 6, p. 2664-2668, 2013. doi: 10.1128/AAC.02308-12

WERTHEIM H. F., MELLES D. C., VOS M. C., VAN LEEUWEN W., VAN BELKUM A., VERBRUGH H. A., NOUWEN J. L. The role of nasal carriage in Staphylococcus aureus infections. Lancet Infect Dis. v. 5, p. 751-62, 2005. doi: 10.1016/S14733099(05)70295-4

WU X., WANG Y., TAO L. Sulfhydryl compounds reduce Staphylococcus aureus biofilm formation by inhibiting PIA biosynthesis. FEMS Microbiol Lett. v. 316, n. 1, p. 4450, 2011. doi: 10.1111/j.1574-6968.2010.02190.x 
XIA J., GAO J., KOKUDO N., HASEGAWA K., TANG W. Methicillin-resistant Staphylococcus aureus antibiotic resistance and virulence. BioSci Trends. v. 7, n. 3, p. 113-121, 2013. doi: 10.5582/bst.2013.v7.3.113

YEAGLEY A. A., SU Z., MCCULLOUGH K. D., WORTHINGTON R. J., MELANDER C. Nsubstituted 2-aminoimidazole inhibitors of MRSA biofilm formation accessed through direct 1,3-bis(tert-butoxycarbonyl) guanidine cyclization. Org Biomol Chem. v. 11, p. 130-137, 2013. doi: 10.1039/c2ob26469b

YOUNG B. C., GOLUBCHIK T., BATTY E. M., FUNG R., LARNER-SVENSSOND H., VOTINTSEVAA A. A., MILLERA R. R., GODWINE H., KNOXF K., EVERITTA R. G., IQBALD Z., RIMMERD A. J., CULEB M., IPB C. L. C., DIDELOTB X., HARDINGG R. M., DONNELLY P., PETO T. E., CROOKA D. W., BOWDENB R., WILSON D. J. Evolutionary dynamics of Staphylococcus aureus during progression from carriage to disease. Proc Natl Acad Sci USA. v. 109, n. 12, p. 4550-4555, 2012. doi: 10.1073/pnas.1113219109 


\title{
CAPÍTULO YII
}

\section{INFECÇÕES DO TRATO URINÁRIO CAUSADAS POR CORYNEBACTERIUM SPP.}

\author{
Igor Ferreira da Silva ${ }^{1}$ \\ Lincoln de Oliveira Sant'Anna ${ }^{2}$ \\ Giorgio Silva de Santana ${ }^{3}$ \\ Fellipe de Oliveira Cabral ${ }^{4}$ \\ Louisy Sanches dos Santos Sant'Anna ${ }^{5}$ \\ Ana Luíza Mattos-Guaraldi ${ }^{6}$
}

\footnotetext{
${ }^{1}$ Graduando do curso de Ciências Biológicas pela Universidade do Estado do Rio de Janeiro - UERJ

2 Doutorando em Microbiologia pela Universidade do Estado do Rio de Janeiro - UERJ

3 Doutorando em Ciências (Microbiologia) pela Universidade Federal do Rio de Janeiro - UFRJ

${ }^{4}$ Mestrando em Microbiologia Médica Humana pela Universidade do Estado do Rio de Janeiro - UERJ

${ }^{5}$ Pós-doutoranda da Faculdade de Ciências Médicas, Universidade do Estado do Rio de Janeiro - FCM/UERJ

${ }^{6}$ Professora Doutora da Faculdade de Ciências Médicas, Universidade do Estado do Rio de Janeiro - FCM/UERJ
}

\section{RESUMO}

As infecções do trato urinário (ITU) acometem homens e mulheres de todas as faixas etárias, afetando cerca de 150 milhões de pessoas por ano no mundo. Dentre as espécies bacterianas mais frequentemente associadas às ITU está a Escherichia coli. Por muitas décadas, o potencial patogênico da maioria das espécies do gênero Corynebacterium foi subestimado. Atualmente, diversas espécies de Corynebacterium têm sido descritas como agentes causadores de infecções humanas, sobretudo em ambiente hospitalar. $\mathrm{O}$ objetivo do presente trabalho foi realizar um levantamento das infecções no trato urinário por Corynebacterium spp. nos últimos cinco anos. A estratégia de consulta utilizou o PubMed e a partir disso foram avaliados os artigos que reportavam relatos de casos ou informações de ITU por Corynebacterium spp. Após o levantamento bibliográfico, se iniciou a análise de dados direcionada para as variáveis: espécie causadora, classificação da ITU e perfil de susceptibilidade aos antimicrobianos. A partir das 80 referências fornecidas, 16 foram selecionadas após análise do abstract. As espécies Corynebacterium coyleae e Corynebacterium urealyticum foram as mais reportadas em ITU. Todas as espécies foram susceptíveis à vancomicina. Com base nestes dados, torna-se imprescindível o aprofundamento no conhecimento das espécies de Corynebacterium como agente etiológico de ITU, uma vez que estas estão entre as infecções mais frequentes no ambiente hospitalar e na comunidade.

Palavras-chave: Bactérias. Corynebacterium spp. Infecção. ITU. Trato urinário.

\section{INTRODUÇÃO}

O gênero Corynebacterium caracteriza-se por bacilos Gram-positivos irregulares, imóveis, não álcool-ácido resistente, aeróbios ou anaeróbios facultativos, não 
formadores de esporos, catalase positiva e com elevado conteúdo $G+C$ em seu DNA (CRESCI, 2016; FUNKE et al, 1997; GHERARDI, 2015). Além destas características, a presença de uma camada lipídica na parede celular constituída de ácido micólico está presente na maioria das espécies desse gênero. Curiosamente, essa característica se assemelha funcionalmente à membrana externa das bactérias Gram-negativas (BURKOVSKI, 2013).

Por muitas décadas, o potencial patogênico das corinebactérias foi subestimado e negligenciado. Atribui-se a isso o fato de muitas espécies pertencerem a microbiota residente de pele e mucosas. Contudo, nas últimas décadas têm sido crescente o relato de casos de infecções em humanos causadas por Corynebacterium spp. em diversos sítios, além de surtos nosocomiais em países industrializados e em desenvolvimento (BAIO, 2013; IARIA et al, 2007; SANT'ANNA, 2016). Dentre os quadros infecciosos associados a corinebactérias, destacam-se: infecções respiratórias, endocardite, infecções ortopédicas e infecções do trato urinário (ITU) (COSTALES et al, 2019; KALT et al, 2018; LEE et al, 2018; SHARIFF et al, 2018). É preciso ressaltar que ainda são poucos os estudos acerca do potencial patogênico e perfis de multirresistência aos agentes antimicrobianos (MDR) destas espécies.

As ITU podem ocorrer em indivíduos do sexo masculino e feminino, independente da faixa etária (DUBBS; SOMMERKAMP, 2019; MILLNER; BECKNELL, 2019). As ITU consistem na invasão do trato urinário por microrganismos, podendo apresentar sinais e sintomas variados que, em casos mais graves, podem evoluir para infecção sistêmica (COLLINS, 2019; KAUFFMAN, 2014; NICOLLE, 2013). As ITU podem ser classificadas de acordo com a posição anatômica do órgão acometido: ITU inferior uretrite, cistite e prostatite; ITU superior - pielonefrite, nefrite intersticial e ureterite (ANVISA, 2004; SMELTZER; BARE, 2005). A principal via de infeç̧ão utilizada pelos uropatógenos é a via ascendente ou transuretral, em que o acesso à bexiga acontece através da uretra. Adicionalmente, este pode ser dar pela via hematogênica ou por extensão direta, em que o patógeno consegue acesso à bexiga através de uma fístula formada pelo intestino (FLORES-MEIRELES, 2015; SMELTZER; BARE, 2005).

As ITU também podem ser classificadas como complicadas e não complicadas, para as quais são recomendadas terapias diferenciadas. As ITU complicadas geralmente ocorrem em indivíduos portadores de: anormalidades anátomo-funcionais no trato

WWW.AMPLLAEDITORA.COM.BR (2) 
urinário; diabetes mellitus; anemia falciforme; e cálculos renais. Podem ainda ocorrer em pacientes submetidos a transplante renal, procedimentos cirúrgicos e/ou instrumentação no trato urinário, e em mulheres grávidas. Na Alemanha, cerca de $21,6 \%$ de todas as infecções nosocomiais ocorrem no trato urinário e em mais de $60 \%$ dos casos desse tipo de infecção estão associadas com cateteres urinários. O número de pacientes com bacteriúria, aumenta de 3 a $8 \%$ por cada dia que um paciente utiliza o cateter, sendo que após 30 dias utilizando o cateter, praticamente todos os pacientes apresentam bacteriúria (KRANZ et al, 2020; FENELEY et al, 2015).

As ITU não complicadas geralmente acometem indivíduos hígidos, incluindo mulheres não grávidas. Observa-se que as ITU complicadas estão relacionadas ao ambiente hospitalar, enquanto as ITU não complicadas são comumente observadas na comunidade (ANVISA, 2004; GEERLINGS, 2016). Cerca de 20 a 30\% das mulheres que apresentam cistite aguda possuem casos recorrentes e apresentam esse quadro, em média, de duas a três vezes por ano (MCLELLAN; HUNSTAD, 2016). A uretra é o canal de eliminação da urina e ao redor do introito uretral externo, além da microbiota residente, é possível que uropatógenos colonizem e consigam desencadear uma ITU. Esse cenário é comumente observado em indivíduos imunocomprometidos. Há uma diferença anatômica em relação ao tamanho da uretra de homens e mulheres favorecendo esse tipo de infecção em indivíduos do sexo feminino. A uretra feminina por ser mais curta, facilita os microrganismos patogênicos em alcançarem a bexiga e estabelecer a infecção. Além disso, a entrada da uretra nas mulheres está mais próxima ao reto, o que possibilita a contaminação e infecção por enterobactérias (FOXMAN, 2010; GEERLINGS, 2016).

Nos Estados Unidos da América, casos de ITU são frequentemente reportados, afetando aproximadamente 7,5 milhões de mulheres por ano (COLLINS, 2019). No mundo, o número de pessoas infectadas por ano ultrapassa 150 milhões. As infecções podem ser causadas por diversos patógenos e muitos apresentam perfis MDR, sendo considerados um grande problema para o sistema de saúde mundial, pois estão associados à letalidade, hospitalização prolongada e, consequentemente, ao aumento de custos (MCLELLAN; HUNSTAD, 2016; STAPLETON, 2016; TRENTIN et al, 2013).

As ITU podem ser causadas por diversos patógenos, estando a Escherichia coli relacionada com 65 e $75 \%$ dos casos complicados e não complicados, respectivamente.

WWW.AMPLLAEDITORA.COM.BR (2) 
Enterococcus spp. e Candida spp. também têm sido capazes de causar ITU em pacientes que utilizam dispositivos invasivos urinários. Ainda que em menor frequência, outros patógenos Gram-negativos e Gram-positivos também podem causar ITU tanto no ambiente nosocomial quanto na comunidade. Dentre esses patógenos, destacam-se bactérias pertencentes a família Enterobacteriaceae, Pseudomonas aeruginosa, Acinetobacter spp., Stenotrophomonas spp., além de Staphylococcus aureus, Streptococcus do grupo B, Enterococcus spp. e Corynebacterium spp. (CHIN et al, 2011; FLORES-MIRELES et al, 2015; MARTINS et al, 2009; CAMELLO et al, 2003; NICOLLE, 2013).

O presente trabalho teve como objetivo analisar os dados clínicos e microbiológicos de casos de ITU causadas por Corynebacterium spp. reportados na literatura internacional nos últimos cinco anos (2015-2019).

\section{METODOLOGIA}

A estratégia de consulta utilizou o PubMed como banco de indexação de resumos da literatura científica de nível acadêmico, entre janeiro e agosto de 2020. Os descritores utilizados foram: "Corynebacterium", "urinary tract infection", "Corynebacterium and cystitis", "Corynebacterium and pyelonephritis", "Corynebacterium and urethritis" e "Corynebacterium and prostatitis". Como critérios de inclusão foram avaliados os artigos que reportavam relatos de casos ou informações de ITU por Corynebacterium spp. Após o levantamento bibliográfico, a análise de dados foi direcionada para as variáveis: espécie causadora, classificação da ITU e perfil de susceptibilidade aos antimicrobianos.

\section{RESULTADOS E DISCUSSÃO}

Diversas espécies de Corynebacterium têm sido descritas como agentes causadores de infecções humanas, sobretudo em ambiente hospitalar. No presente estudo, a partir das 80 referências fornecidas seguindo a metodologia descrita, foram selecionados 16 artigos contendo relato de casos de ITU por Corynebacterium spp. Os artigos selecionados, bem como os dados das variáveis investigadas, podem ser visualizados na Tabela 1. 
Tabela 1. Casos de infecções do trato urinário por Corynebacterium spp. relatados na literatura internacional entre 2015 e 2019

\begin{tabular}{|c|c|c|c|c|c|}
\hline $\begin{array}{l}\mathrm{N}^{\circ} \text { do } \\
\text { artigo }\end{array}$ & Artigos & Espécie isolada & Topografia & Multirresistência & $\begin{array}{c}\text { Casos } \\
\text { reportados }\end{array}$ \\
\hline 1 & $\begin{array}{l}\text { ACOSTA et al. } \\
\qquad(2017)\end{array}$ & $\begin{array}{c}\text { Corynebacterium } \\
\text { riegelii }\end{array}$ & $\mathrm{NI} *$ & $\mathrm{NI}$ & 1 \\
\hline 2 & $\begin{array}{l}\text { BARBERIS et al. } \\
\text { (2018) }\end{array}$ & $\begin{array}{c}\text { Corynebacterium } \\
\text { coyleae }\end{array}$ & $\mathrm{NI} *$ & MDR & 1 \\
\hline 3 & $\begin{array}{l}\text { COSTALES et } \\
\text { al. (2019) }\end{array}$ & $\begin{array}{c}\text { Corynebacterium } \\
\text { urealyticum }\end{array}$ & $\mathrm{NI}$ & $\mathrm{NI}$ & 1 \\
\hline 4 & $\begin{array}{c}\text { GHERARDI et } \\
\text { al. (2015) }\end{array}$ & $\begin{array}{l}\text { Corynebacterium } \\
\text { glucuronolyticum }\end{array}$ & Uretrite & MDR & 1 \\
\hline 5 & $\begin{array}{l}\text { GILA et al. } \\
\text { (2018) }\end{array}$ & $\begin{array}{c}\text { Corynebacterium } \\
\text { jeikeium }\end{array}$ & $\mathrm{NI} *$ & MDR & 1 \\
\hline 6 & $\begin{array}{l}\text { LANSALOT- } \\
\text { MATRAS et al. } \\
\text { (2016) }\end{array}$ & $\begin{array}{c}\text { Corynebacterium } \\
\text { urealyticum }\end{array}$ & Cistite* & $\mathrm{NI}$ & 4 \\
\hline 7 & LO et al. (2015) & $\begin{array}{c}\text { Corynebacterium } \\
\text { aurimucosum }\end{array}$ & $\mathrm{NI}$ & MDS & 1 \\
\hline 8 & $\begin{array}{l}\text { MARTÍNEZ et } \\
\text { al. (2018) }\end{array}$ & $\begin{array}{c}\text { Corynebacterium } \\
\text { urealyticum }\end{array}$ & Prostatite* & $\mathrm{NI}$ & 1 \\
\hline 9 & $\begin{array}{l}\text { MARTíN- } \\
\text { NAVARRO et } \\
\text { al. (2015) }\end{array}$ & $\begin{array}{c}\text { Corynebacterium } \\
\text { urealyticum }\end{array}$ & $\mathrm{NI} *$ & $\mathrm{NI}$ & 1 \\
\hline 10 & $\begin{array}{c}\text { MEŠTROVIĆ } \\
\text { (2019) }\end{array}$ & $\begin{array}{l}\text { Corynebacterium } \\
\text { glucuronolyticum }\end{array}$ & Uretrite & $\mathrm{NI}$ & 3 \\
\hline 11 & $\begin{array}{l}\text { OZKAN et al. } \\
\text { (2018) }\end{array}$ & $\begin{array}{c}\text { Corynebacterium } \\
\text { urealyticum }\end{array}$ & Cistite* & $\mathrm{NI}$ & 1 \\
\hline 12 & $\begin{array}{l}\text { PERRUCCI et } \\
\text { al. (2016) }\end{array}$ & $\begin{array}{c}\text { Corynebacterium } \\
\text { simulans }\end{array}$ & Cistite* & $\mathrm{NI}$ & 1 \\
\hline
\end{tabular}




\begin{tabular}{|c|c|c|c|c|c|}
\hline 13 & $\begin{array}{l}\text { PICHON et al. } \\
\text { (2019) }\end{array}$ & $\begin{array}{c}\text { Corynebacterium } \\
\text { riegelii }\end{array}$ & $\mathrm{NI} *$ & $\mathrm{NI}$ & 1 \\
\hline 14 & $\begin{array}{l}\text { SAKHI et al. } \\
\text { (2018) }\end{array}$ & $\begin{array}{c}\text { Corynebacterium } \\
\text { urealyticum }\end{array}$ & $\mathrm{NI} *$ & $\mathrm{NI}$ & 1 \\
\hline 15 & $\begin{array}{l}\text { SALJOGHI et al. } \\
\qquad(2016)\end{array}$ & $\begin{array}{c}\text { Corynebacterium } \\
\text { urealyticum }\end{array}$ & $\mathrm{NI} *$ & $\mathrm{NI}$ & 1 \\
\hline 16 & $\begin{array}{c}\text { SOKOL- } \\
\text { LESZCZYNSKA } \\
\text { et al. (2019) }\end{array}$ & $\begin{array}{c}\text { Corynebacterium } \\
\text { coyleae }\end{array}$ & $\mathrm{NI}$ & $\mathrm{NI}$ & 39 \\
\hline
\end{tabular}

Legenda: NI, não informado; MDR, multidroga resistente; MDS, multidroga sensível; *, ITU complicada. Fonte: Autoria própria.

Como observado na Tabela 1, nos últimos 5 anos, 59 cepas, pertencentes a 7 espécies de Corynebacterium spp., foram isoladas de ITU e reportadas na literatura. Dentre estas espécies, Corynebacterium coyleae foi a predominante ( $n=40,67,80 \%)$, seguida de Corynebacterium urealyticum $(n=10,16,95 \%)$. É preciso ressaltar que três trabalhos (LANSALOT-MATRAS et al, 2016; MEŠTROVIĆ, 2019; SOKOL-LESZCZYNSKA et al, 2019) relataram mais de um caso de ITU causada por Corynebacterium spp. Quanto à topografia das ITU, foi possível observar que a maioria dos trabalhos ( $n=10,62,50 \%$ ) não especifica a região acometida. Contudo, dentre os 11 casos em que a topografia é especificada, a cistite foi a mais frequente $(n=6,54,54 \%)$, seguida da uretrite $(n=4,36,36$ $\%)$ e prostatite $(n=1,9,10 \%)$. Este dado corrobora a literatura, segundo a qual a cistite é considerada um dos tipos mais comuns de ITU (KOLMAN, 2019). Dentre os artigos analisados, o de SOKOL-LESZCZYNSKA et al. (2019) não permitiu a classificação das ITU em complicada e não complicada, pois não descreve os casos individualmente. As ITU complicadas corresponderam a 11 dos 20 casos restantes (55\%).

Na Tabela 1 é ainda possível observar que dos 16 trabalhos selecionados, apenas 4 investigaram o perfil de susceptibilidade dos isolados aos antimicrobianos (25\%). Os perfis de susceptibilidade dos isolados estão apresentados na Tabela 2. 
Tabela 2. Perfis de susceptibilidade aos antimicrobianos das cepas de Corynebacterium spp. isoladas de casos de infecção urinária relatados na literatura internacional entre 2015 e 2019

\begin{tabular}{|c|c|c|c|c|c|c|c|c|c|c|c|c|c|c|c|c|c|c|}
\hline \multirow{2}{*}{$\begin{array}{c}N^{\circ} \text { do } \\
\text { artig } \\
0\end{array}$} & \multicolumn{18}{|c|}{ Antimicrobianos } \\
\hline & $\begin{array}{c}P e \\
n\end{array}$ & $\begin{array}{c}\text { Te } \\
\mathbf{t}\end{array}$ & Amp & Rif & Gen & Lzd & Ceft & Cefo & Imi & Cip & Eri & Cli & Van & Sxt & Nit & Fos & Lev & Mem \\
\hline $2 *$ & $R$ & NT & NT & NT & NT & NT & $R$ & NT & NT & 1 & NT & NT & $S$ & $\mathrm{R}$ & NT & NT & NT & NT \\
\hline $4^{*}$ & $S$ & NT & NT & S & $\mathrm{R}$ & $S$ & NT & $S$ & NT & S & $R$ & $\mathrm{R}$ & S & NT & NT & NT & NT & NT \\
\hline $5 *$ & $R$ & $\mathrm{~S}$ & NT & NT & $S$ & NT & NT & $R$ & NT & NT & NT & NT & $S$ & NT & NT & $R$ & $R$ & $\mathrm{R}$ \\
\hline 7 & $R$ & $S$ & NT & NT & NT & NT & NT & $S$ & $S$ & NT & $S$ & NT & $S$ & $R$ & NT & NT & NT & NT \\
\hline
\end{tabular}

Legenda: Pen, penicilina; Tet, tetraciclina; Amp, ampicilina; Rif, rifampicina; Gen, gentamicina; Lzd, linezolida; Ceft, ceftriaxona; Cefo, cefotaxima; Imi, imipenem; Cip, ciprofloxacina; Eri, eritromicina, Cli, Clindamicina; Van, vancomicina; Sxt, sulfametoxazol com trimetoprima; Nit, nitrofurantoína; Fos, fosfomicina; Lev, levofloxacino; Mem, meropenem; S, sensível; R, resistente; I, intermediário; NT, não testado, *, Multirresistência.

Fonte: Autoria própria.

Na Tabela 2, é possível observar que, embora os isolados clínicos tenham sido isolados de ITU, para as quais os principais antimicrobianos preconizados são as sulfonamidas, fluoroquinolonas e beta-lactâmicos (MCLELLAN; HUNSTAD, 2016), apenas penicilina e vancomicina foram testadas por todos os autores. Este fato pode ser explicado pelas divergências entre os comitês utilizados para as análises. Além disto, em nenhum dos trabalhos, a susceptibilidade à ampicilina, principal beta-lactâmico indicado em casos de ITU, foi investigada.

O aparecimento de cepas resistentes de Corynebacterium spp. vem sendo descrita há alguns anos por diversos pesquisadores (BAIO et al, 2013; CAMPANILE et al, 2009; DRAGOMIRESCU et al, 2020; RAMOS et al, 2020; ZOU et al, 2020.). Dentre os antimicrobianos para os quais tem sido observada elevada resistência, está a penicilina. Conforme observado na Tabela 2, apenas um dos isolados apresentou sensibilidade a este antimicrobiano.

O fenótipo MDR também já foi descrito na literatura para algumas espécies deste gênero, como: Corynebacterium striatum, C. urealyticum e Corynebacterium jeikeium. É 
preciso destacar que alguns isolados desta última espécie foram encontrados apresentando sensibilidade apenas à vancomicina (MARTINS et al, 2009). Dentre as cepas testadas nos trabalhos investigados no presente estudo, 3 apresentaram perfil MDR (75\%) e pertenciam às espécies: C. coyleae, Corynebacterium glucuronolyticum e C. jeikeium. Ressalta-se a preservação da susceptibilidade à vancomicina entre as cepas testadas, incluindo naquelas com perfil MDR.

\section{CONSIDERAÇÕES FINAIS}

As ITU são consideradas um grave problema de saúde pública em todo mundo. Embora os principais uropatógenos sejam bactérias Gram-negativas, espécies Grampositivas, como do gênero Corynebacterium, vêm emergindo como agentes causadores destas infecções. Contudo, dificuldades no isolamento e identificação laboratorial, em parte devido à carência de testes e procedimentos padronizados para caracterização destes isolados em laboratórios microbiológicos de rotina, levam à perda dos isolados e, assim, à subnotificação dos casos. Além disto, estas espécies têm seu potencial como uropatógenos subestimado devido à descrição como componentes da microbiota residente humana e à carência de dados acerca dos seus mecanismos de virulência. Como observado neste levantamento, diferentes espécies do gênero Corynebacterium apresentam a capacidade de causar ITU, inclusive do tipo complicada. Ressalta-se o isolamento de cepas com fenótipo MDR. Estudos adicionais com enfoque na investigação do potencial de virulência, bem como na aquisição e evolução da resistência aos antimicrobianos, permanecem necessário para o melhor manejo clínico destas infecções.

\section{REFERÊNCIAS}

ACOSTA, P. et al. Encefalopatía hiperamoniémica secundaria a infección urinaria por germen productor de ureasa. Caso clínico pediátrico. Arch Argent Pediatr, v. 115, n. 6, p. e454-e457, 2017. DOI: https://doi.org/10.5546/aap.2017.e454.

AGÊNCIA NACIONAL DE VIGILÂNCIA SANITÁRIA - ANVISA (Brasil). Principais síndromes infecciosas. In: Manual de Microbiologia Clínica para o Controle de Infecção em Serviços de Saúde. 1a ed. Brasília: Ed. Agência Nacional de Vigilância Sanitária, 2004. p. 1-8. 
BAILIFF, N. L. Corynebacterium urealyticum urinary tract infection in dogs and cats: 7 cases (1996-2003). J Am Vet Med Assoc, v. 226, n. 10, p. 1676-80v, 2005. DOI: https://doi.org/10.2460/javma.2005.226.1676.

BAIO, P. V. P. et al. Clonal multidrug-resistant Corynebacterium striatum within a nosocomial environment. Rio de Janeiro, Brazil. Mem Inst Oswaldo Cruz, v. 108, n. 1, p. 23-29, 2013. DOI: https://doi.org/10.1590/S0074-02762013000100004.

BARBERIS, C. M. et al. Total nephrectomy following Corynebacterium coyleae urinary tract infection. JMM Case Reports, v. 5, n. 9, p. e005149, 2018. DOI: https://doi.org/10.1099/jmmcr.0.005149.

BURKOVSKI, A. Cell Envelope of Corynebacteria: Structure and Influence on Pathogenicity. ISRN Microbiology, v. 2013, p. 1-11, 2013. DOI: http://dx.doi.org/10.1155/2013/935736.

CAMELLO, T. C. F. et al. Nondiphtherial Corynebacterium species isolated from clinical specimens of patients in a university hospital, Rio de Janeiro, Brazil. Brazilian Journal of Microbiology, v. 34, p. 39-44, 2003.

CAMPANILE, F. et al. Clonal Multidrug-Resistant Corynebacterium striatum Strains, Italy. Emerging Infectious Diseases, v. 15, n. 1, p. 75-78, 2009.

CHIN, B. S. et al. Risk factors of all-cause in-hospital mortality among Korean elderly bacteremic urinary tract infection (UTI) patients. Archives of Gerontology and Geriatrics, v. 52, n. 1, p. e50-e55, 2011. DOI:10.1016/j.archger.2010.05.011.

COLLINS, L. Diagnosis and management of a urinary tract infection. British Journal of Nursing, v. $28, \quad$ n. 2, p. $84-88,2019$. DOI: https://doi.org/10.12968/bjon.2019.28.2.84.

COSTALES, J. et al. Corynebacterium urealyticum: rare urinary tract infection with serious complications. Can. J. Urol., v. 26, n. 1, p. 9680-9682, 2019.

$\mathrm{CRESCl}, \mathrm{M}$. et al. Corynebacterium phoceense sp. nov., strain $\mathrm{MC1}^{\top}$ a new bacterial species isolated from human urine. New Microbes and New Infections, v. 14, n. C, p. 73-82, 2016. DOI: http://dx.doi.org/10.1016/j.nmni.2016.09.001.

DRAGOMIRESCU, C. C. et al. Antimicrobial Susceptibility Testing for Corynebacterium Species Isolated from Clinical Samples in Romania. Antibiotics (Basel), v. 9, n. 1, 2020. DOI: 10.3390/antibiotics9010031.

DUBBS, S. B. \& SOMMERKAMP, S. K. Evaluation and Management of Urinary Tract Infection in the Emergency Department. Emergency Medicine Clinics of North America, p. 1-17, 2019. DOI:10.1016/j.emc.2019.07.007. 
FENELEY, R. C. L. et al. Urinary catheters: history, current status, adverse events and research agenda.J Med Eng Technol, v. 39, n. 8, p. 459-470, 2015. DOI: https://doi.org/10.3109/03091902.2015.1085600.

FISHER, J. F. et al. Candida urinary tract infection: pathogenesis. Clin Infect Dis, v. 52, p. 437-451, 2011. DOI: https://doi.org/10.1093/cid/cir110.

FLORES-MIRELES, A. L. et al. Urinary tract infections: epidemiology, mechanisms of infection and treatment options. Nat Rev Microbiol, v. 13, n. 5, p. 269-284, 2015. DOI: https://doi.org/10.1038/nrmicro3432.

FOXMAN, B. The epidemiology of urinary tract infection. Nat Rev Urol, v. 7, n. 12, p. 653-660, 2010. DOI: https://doi.org/10.1038/nrurol.2010.190.

FUNKE, G. et al. Clinical microbiology of coryneform bacteria. Clinical Microbiology, Zurich, v. 10, n. 1, p. 125-159, 1997.

GEERLINGS, S. E. Clinical presentations and epidemiology of urinary tract infections. Microbiology Spectrum, v. 4, n. 5, p. 1-11, 2016. DOI: https://doi.org/10.1128/microbiolspec.UTI-0002-2012.

GHERARDI, G. et al. Corynebacterium glucuronolyticum causing genitourinary tract infection: Case report and review of the literature. IDCases, v. 2, n. 2, p. 56-8, 2015. DOI: https://doi.org/10.1016/j.idcr.2015.03.001.

GILA, Juan de Dios López-González et al. Infección urinaria por Corynebacterium jeikeium y buena respuesta clínica al tratamiento con nitrofurantoína. Rev Esp Quimioter, v. 31, n. 1, p. 89-90, 2018

IACOVELLI, Valerio et al. Nosocomial urinary tract infections: a review. Urologia Journal, v. 81 , n. 4, p. 222-227, 2014. DOI: https://doi.org/10.5301/uro.5000092.

IARIA, C. et al. Outbreak of multi-resistant Corynebacterium striatum infection in an Italian general intensive care unit. J Hosp Infect, v. 67, n. 1, p. 102-104, 2007. DOI: 10.1016/j.jhin.2007.07.002

KALT, F. et al. Corynebacterium Species Rarely Cause Orthopedic Infections. Journal of Clinical Microbiology, v. 56, n. 12, 2018. DOI: https://doi.org/10.1128/JCM .01200-18.

KAUFFMAN, C. A. Diagnosis and management of fungal urinary tract infection. Infect Dis Clin North Am, v. 28, n. 1, p. 61-74, 2014. DOI: https://doi.org/10.1016/j.idc.2013.09.004.

KLINE, K. A.; LEWIS, A. L. Gram-positive uropathogens, polymicrobial urinary tract infection, and the emerging microbiota of the urinary tract. Microbiol Spectr, $v$. 
4, n. 2, p. 1-54, 2016. DOI: https://doi.org/10.1128/microbiolspec.UTI-00122012.

KOLMAN, K. B. (2019). Cystitis and Pyelonephritis: Diagnosis, Treatment, and Prevention. Primary Care: Clinics in Office Practice, v. 46, n. 2, p. 191-202, 2019. DOI:10.1016/j.pop.2019.01.001.

KRANZ, J. et al. Catheter-associated urinary tract infections in adult patients. Dtsch Ärztebl Int, v. 117, n. 6, p. 83-88, 2020. DOI: https://doi.org/10.3238/arztebl.2020.0083.

LANSALOT-MATRAS, P. et al. Cystite incrustante à Corynebacterium urealyticum. Médecine et Maladies Infectieuses, v. 29, n. 4, p. 328-330, 2016. DOI: https://doi.org/10.1016/j.medmal.2016.11.004.

LEE, J. Y. et al. Three-valve Endocarditis Caused by Corynebacterium striatum. Korean Circ J, v. 48, n. 9, p. 861-862, 2018. DOI: https://doi.org/10.4070/kcj.2018.0126.

LO, S. et al. Urinary tract infection with Corynebacterium aurimucosum after urethroplasty stricture of the urethra: a case report. J Med Case Rep, v. 14, n. 9, p.156, 2015. DOI: https://doi.org/10.1186/s13256-015-0638-0.

MARTÍNEZ, A. P. et al. Encrusted prostatitis by Corynebacterium urealyticum: The importance of clinical suspicion. Actas. Urol. Esp., 2018 DOI: 10.1016/j.acuro.2018.01.006.

MARTINS, C et al. Microbiological and host features associated with corynebacteriosis in cancer patients: a five-year study. Mem. Inst. Oswaldo Cruz, v. 104, n. 6. 2009. DOI: http://dx.doi.org/10.1590/S0074-02762009000600015.

MARTÍN-NAVARRO, J. A. et al. Struvite urolithiasis with Corynebacterium urealyticum infection: A case report. Nefrología, v. 35, n. 4, p. 410-411, 2015. DOI: https://doi.org/10.1016/j.nefro.2015.06.009.

MAUREY, C. et al. Clinical description of Corynebacterium urealyticum urinary tract infections in 11 dogs and 10 cats. Journal of Small Animal Practice, p. 1-8, 2019. DOI: https://doi.org/10.1111/jsap.12973.

MCLELLAN, L. K.; HUNSTAD, D. A. Urinary Tract Infection: Pathogenesis and Outlook. Trends in Molecular Medicine, v. 22, n. 11, p. 946-957, 2016. DOI: https://doi.org/10.1016/j.molmed.2016.09.003.

MEŠTROVIĆ, T. A microbial game of whack-a-mole: clinical case series of the urethral uncloaking phenomenon caused by Corynebacterium glucuronolyticum in men treated for Chlamydia trachomatis urethritis. Infection, v. 47, n. 1, p. 121-124, 2018. DOI: https://doi.org/10.1007/s15010-018-1211-8. 
MILLNER, R.; BECKNELI, B. Urinary Tract Infections. Pediatric Clinics of North America, v. 66, n. 1, p. 1-13. 2019. DOI:10.1016/j.pcl.2018.08.002.

NICOLLE, L. E. Urinary tract infection. Critical Care Clinics, v. 29, p. 699-715, 2013. DOI: https://doi.org/10.1016/j.ccc.2013.03.014.

OLIVEIRA, A. C.; DAMASCENO, Q. S.; RIBEIRO, S. M. C. P. Infecções relacionadas à assistência em saúde: desafios para a prevenção e controle. Rev Min Enferm, v. 13, n. 3, p. 445-450, 2009.

OZKAN, T. A. et al. Encrusted cystitis caused by Corynebacterium urealyticum: a case report with novel treatment strategy of intravesical dimethyl sulfoxide. Int Braz J Urol, v. 44, p. 1252-1255, 2018. DOI: https://doi.org/10.1590/S16775538.IBJU.2017.0588.

PADOVEZE, M. C.; FORTALEZA, C. M. C. B. Infecções relacionadas à assistência à saúde: desafios para a saúde pública no Brasil. Rev Saúde Pública, v. 48, n. 6, p. 9951001, 2014. DOI: https://doi.org/10.1590/S0034-8910.2014048004825.

PARDO, M. A. et al. Celdoprostatitis incrustante por Corynebacterium urealyticum: la importancia de la sospecha clínica. Actas Urol Esp, v. 42, n. 6, p. 420-421, 2018. DOI: https://doi.org/10.1016/j.acuro.2018.01.006.

PERRUCCI, E. Encrusted cystitis after definitive radiotherapy for cervical cancer: a case report. J Contemp Brachytherapy, v. 8, n. 6, p. 541-543, 2016. DOI: https://doi.org/10.5114/jcb.2016.62958.

PICHON, M. et al. A rare case of Corynebacterium riegelii urosepsis: Role of the MALDITOF mass spectrometry in the identification of emerging pathogens. Med Mal Infect, v. 49, n. 6, p. 474-477, 2019. DOI: https://doi.org/10.1016/j.medmal.2019.06.005.

RAMOS, J. N. et al. Novel mutations in the QRDR region gyrA gene in multidrugresistance Corynebacterium spp. isolates from intravenous sites. Antonie Van Leeuwenhoek, v. 113, n. 4, p. 589-592, 2020. DOI: 10.1007/s10482-019-01353w.

RIEGEL, P. et al. Isolation of Corynebacterium tuscaniae sp. nov. from blood cultures of a patient with endocarditis. J Clin Microbiol, v. 44, n. 2, p. 307-312, 2006. DOI: https://doi.org/10.1128/JCM.44.2.307-312.2006.

SAKHI, H. et al. Acute kidney injury, flank pain, and kidney calcifications in an 80-yearold woman. Kidney Int, v. 93, n. 2, p. 527-528, 2018. DOI: https://doi.org/10.1016/j.kint.2017.08.017.

SALOGHI, R. et al. Encrusted uretero-pyelitis: Case report. Urol Case Rep, v. 7, p. 58-60, 2016. DOI: https://doi.org/10.1016/j.eucr.2016.04.014. 
SANT'ANNA, L. O. Caracterização de corinebactérias isoladas de infecções urinárias e investigação de mecanismos de virulência de Corynebacterium mycetoides. Dissertação (Mestrado em Ciências Médicas) - Faculdade de Ciências Médicas, Universidade do Estado do Rio de Janeiro. Rio de Janeiro, p. 108. 2016.

SENGUPTA, M. et al. Corynebacterium amycolatum: An unexpected pathogen in the ear.J Clin Diagn Res, v. 9, n. 12, p. DD01-DD03, 2015. DOI: https://doi.org/10.7860/JCDR/2015/15134.7002.

SHARIFF, M.; ADITI; BERI, K. Corynebacterium striatum: an emerging respiratory pathogen. J. Infect Dev Ctries, v. 12, n. 7, p. 581-586. 2018. DOI: 10.3855/jidc.10406. Acesso em 30 abr. 2020.

SMELTZER, S. C.; BARE, B. G. Tratado de enfermagem médico-cirúrgica. 10. ed. Rio de Janeiro: Ed. Guanabara Koogan, v. 4, n. 3, p. 1386-1443, 2005.

SOKOL-LESZCZYNSKA, B. et al. Corynebacterium coyleae as potential urinary tract pathogen. Eur J Clin Microbiol Infec Dis, v. 38, n. 7, p. 1339-1342, 2019. DOI: https://doi.org/10.1007/s10096-019-03565-4.

STAPLETON, A. E. The Vaginal Microbiota and Urinary Tract Infection. Microbiology $\begin{array}{lllllll}\text { Spectrum, } & \text { v. } 4, \quad \text { n. } & \text { 6, p. } & \text { 1-9. }\end{array}$ https://doi.org/10.1128/microbiolspec.UTI-0025-2016.

TRENTIN, D. S. et al. Biofilmes bacterianos patogênicos: aspectos gerais, importância clínica e estratégias de combate. Revista Liberato, v. 14, n. 22, 2013. DOI: https://doi.org/10.31514/rliberato.2013v14n22.p213.

ZOU, J. et al. Phenotypic and Genotypic Correlates of Penicillin Susceptibility in Nontoxigenic Corynebacterium diphtheriae, British Columbia, Canada, 20152018. Emerg Infect Dis., v. 26, n. 1, p. 97-103, 2020. DOI:10.3201/eid2601.191241. 


\title{
CAPÍTULO YIIII
}

\section{IDENTIFICAÇÃO DE BACTÉRIAS NOCIVAS DECORRENTES DO MANUSEIO INCORRETO DO KEFIR}

\author{
Inaam Al Hafi ${ }^{1}$ \\ Camila Valéria Da Silva ${ }^{2}$ \\ Monica Chen ${ }^{3}$
}

\footnotetext{
${ }^{1}$ Graduanda do curso de Farmácia. Centro Universitário Dinâmica Das Cataratas - UDC

${ }^{2}$ Graduanda do curso de Farmácia. Centro Universitário União Das Américas - UniAmérica

${ }^{3}$ Graduanda do curso de Farmácia. Centro Universitário União Das Américas - UniAmérica
}

\section{RESUMO}

O presente artigo apresenta um estudo feito a partir de amostras de grãos de Kefir, produto esse, originário das montanhas do Cáucaso, localizado na Rússia. Este alimento possui valores nutricionais significativos ao que diz respeito à qualidade de vida e saúde. Desta forma, nos últimos anos a procura por esse produto aumentou, porém não há normas que regem padrões de higiene em sua manipulação por ser um produto de cultivo domiciliar sem nenhum órgão fiscalizador. Diante disso, a presente pesquisa evidenciou a presença e a identificação de bactérias patogênicas nas amostras analisadas e a elaboração de um manual de boas práticas para um correto cultivo dos grãos.

Palavras-chave: Kefir. Bactérias. Identificação. Manipulação. Contaminação.

\section{INTRODUÇÃO}

O Kefir é uma associação simbiótica de leveduras, bactérias e ácidos láticos, envoltos por uma matriz de polissacarídeos, apresentando forma irregular e cor amarelada ou esbranquiçada. Rico em bactérias dos gêneros 41 lactobacilos, lactococos e leuconostoc, seu consumo melhora a digestão de proteínas, absorção de vitaminas e minerais, reduzindo significativamente os níveis de colesterol total com diminuição do LDL colesterol. Decorrente de seus benefícios nutricionais significativos, consequentemente houve aumento de seu consumo, desencadeando um progressivo cultivo domiciliar, carente de normas que regem padrões de higiene em sua manipulação. Tal fato adjunto à escassa de informação da população culmina em um elevado número de indivíduos que desconhecem a maneira correta de manipulá-lo, 
ocasionando contaminação por bactérias patogênicas. O presente artigo, por meio da realização de provas bioquímicas e análises microbiológicas buscou a identificação de bactérias presentes em três amostras de Kefir, bem como a legitimação da necessidade de seguir corretamente um manual de boas práticas na manipulação desse probiótico.

\section{METODOLOGIA}

Para a elaboração desse manual de boas práticas no manuseio de Kefir, foram feitas análises de materiais coletados na cidade de Foz do Iguaçu-PR, voluntariamente cedidos por cultivadores, entre os meses de agosto e setembro de 2018.

Posterior à coleta do material, foi feito o cultivo das amostras por sete dias pelo método tradicional (www.kefir.com.br) antes de sua semeadura em meios sólidos de ágar em placas de Petri para verificação da presença de microrganismos patogênicos.

A partir dessa semeadura foram realizadas análises microbiológicas e bioquímicas, com o objetivo de identificar cepas bacterianas patogênicas presentes nas amostras.

A coleta foi realizada do material congelado e transportado em recipiente esterilizado.

Seu preparo e armazenamento ocorreram da seguinte forma:

- Iniciou-se o descongelamento da amostra em temperatura ambiente;

- Após completo descongelamento, os grãos passaram por peneiramento e posterior enxague com leite.

- Houve esterilização de recipiente de vidro com água fervente, e após resfriamento, foram depositados os grãos em seu interior, seguido de $500 \mathrm{ml}$ de leite integral UHT em temperatura ambiente.

- Os recipientes foram tampados com uma folha de papel toalha, preso com borracha, evitando que adentre algum inseto ou poeira na amostra, e permitindo também a respiração do Kefir.

- As amostras foram deixadas em local arejado, com temperatura em torno de $25^{\circ} \mathrm{C}$, por um prazo de 24 horas;

- Após o prazo estabelecido, o leite foi coado, separando dos grãos, e a partir desse leite fermentado foram realizadas as análises. 
Para visualizar a presença de microrganismos, foram realizadas semeaduras nos seguintes meios: Ágar Sangue, Ágar MacConkey e Ágar Nutritivo. Posteriormente, feito - Teste de Coloração de Gram para visualizar a sua morfologia e Prova da Catalase para diferenciar estreptococos e estafilococos. Foram realizadas também Provas Bioquímicas em meios: Citrato Simmons, SIM (Sulfato Indol Motilidade) e TSI (Triplo Açúcar Ferro). E como testes confirmatórios, utilizaram-se caldo BHI e Ágar Manitol.

Após a identificação das bactérias prejudiciais presentes, elaborou-se um manual contendo o passo a passo no manuseio do Kefir, bem como de seu armazenamento, doação e descarte, a fim de reduzir riscos decorrentes de contaminação, para que seus benefícios sejam amplamente aproveitados.

\section{RESULTADOS}

A partir dos testes feitos na amostra de número 1 foram encontradas bactérias do tipo cocos gram-positivo (figura 1), não apresentando crescimento no ágar sangue, TSI, SIM e Citrato Simmons (figura 2). Catalase negativa, com crescimento apenas no Caldo $\mathrm{BHI}$, confirmando a presença de bactérias da espécie Enterococos faecalis. $\mathrm{Na}$ amostra de número 2 foram encontradas bactérias do tipo cocos gram-positivo (figura 3), prova de catalase e TSI positivos. Sendo os resultados dos testes SIM e Citrato Simmons negativos (figura 4). No entanto, houve crescimento no ágar Manitol, confirmando resultado positivo para a presença de Staphylococcus aureus. No que tange a amostra de número 3 foram encontrados bacilos gram-negativo (figura 5), além da prova da catalase, TSI, SIM e Citrato Simmons também com resultados positivos (figura 6), assim evidenciando bactérias do gênero da Salmonella spp, e demais bactérias como Enterobacter aerogenes, Enterobacter cloacae e Klebsiella oxytoca.

Figura 1 - Microscopia com Cocos Gram positivos

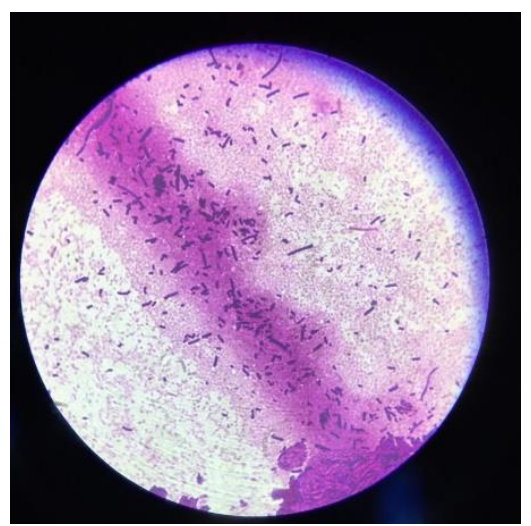


Figura 2 - Na ordem: TSI, SIM e Citrato Simmons

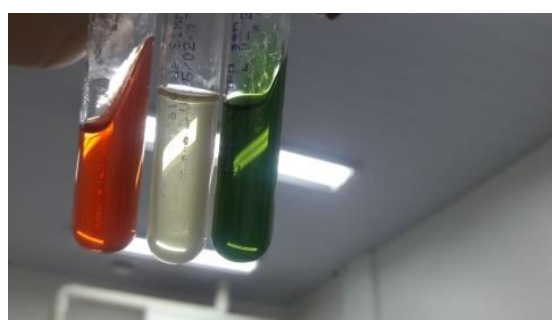

Figura 3 - Cocos Gram Positivo

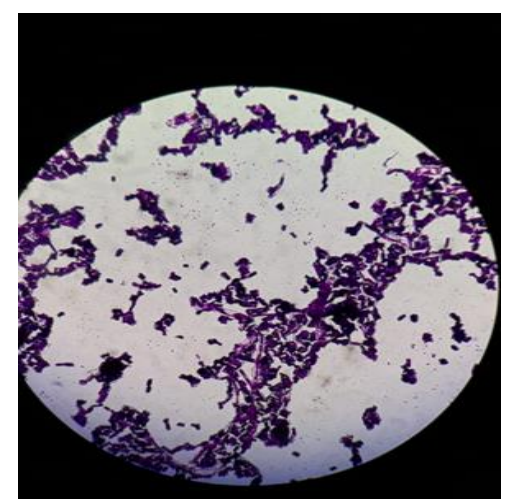

Figura 4 - Na ordem: TSI, SIM e Citrato Simmons

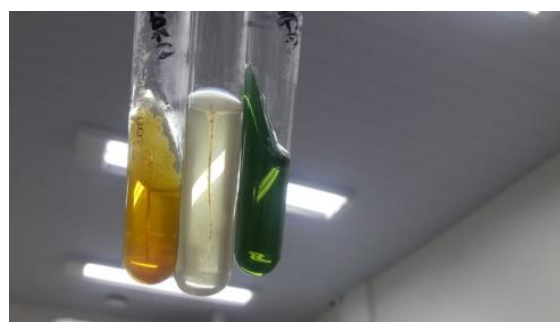

Figura 5 - Bacilos Gram negativos

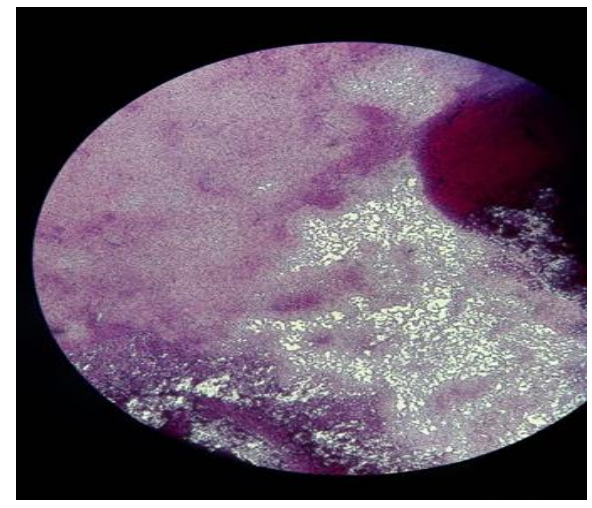

Figura 6 - Na ordem: TSI, SIM e Citrato Simmons

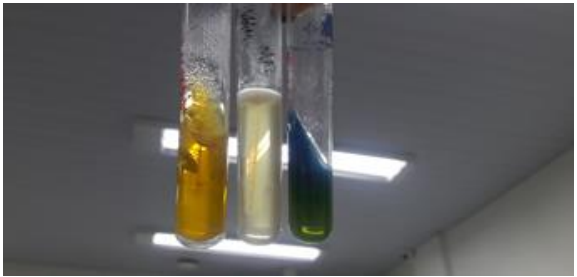

WWW.AMPLLAEDITORA.COM.BR (2) 


\section{CONCLUSÃO}

Os resultados obtidos demonstraram que todas as amostras analisadas apresentavam algum grau de contaminação decorrente da falta de boas práticas no manuseio dos grãos de Kefir. Contaminações essas, que comprometem o bom funcionamento do organismo de quem o consome, acarretando no desenvolvimento de patologias.

Pois de nada adianta consumir um probiótico de alto poder nutricional, que dentre vários benefícios, conta com capacidade de equilíbrio da flora intestinal, porém paralela a toda essa benesse ocorrer a ingestão associada de bactérias prejudiciais a saúde.

De acordo com os resultados, fica claro também a falta de conhecimento da população quanto à manipulação correta desse alimento. Evidenciando a necessidade da implantação do manual elaborado a partir do presente artigo onde o mesmo apresenta um padrão de normas a serem seguidas, a fim de evitar o comprometimento nutricional do Kefir.

\section{REFERÊNCIAS BIBLIOGRÁFICAS}

ANVISA (Agência Nacional de Vigilância Sanitária). Microbiologia Clínica para o controle de infecção relacionada à assistência à saúde. Modulo 5: Tecnologias em Serviços de Saúde: Descrição dos Meios de Cultura Empregados nos Exames Microbiológicos. Agência Nacional de Vigilância Sanitária. - Brasília: Anvisa, 2013.

CAETANO, D. R.; MONTANHINI, M. T. M.; Análise Microbiológica de Leite Fermentado Kefir Produzido com Leite Contaminado por Escherichia Coli. 2014 6f. Revista Brasileira de Pesquisa em Alimentos v. 5, n. 1, p. 33-38, 2014.

ERTEKIN, B.; GUZEL-SEYDIM, Z.B. Effect of fat replacer on kefir quality. Journal of the Science of food and Agriculture. V.90, p. 543-548, 2009.

HERTZLER, S.R., CLANCY, S.M. Kefir improves lactose digestion and tolerance in adults with lactose mal digestion. Journal so American Dietetic Association. V. n. 5, p. 582-587, 2003.

MARTINS, F.L. J; MARINHO, E., FIRMINO, H.H., RAFAEL, C.V.; FERREIRA, L.F.C.L. Avaliação da adição do Kefir em dieta hospitalar. Revista do Instituto de Laticínios Cândido Tostes. v 67, n.386, 2012. 
VARAVALLO, A.M.; THOME, N.J.; TESHIMA, E. Aplicação de bactérias probióticas para profilaxia e tratamento de doenças gastrointestinais. Semina: Ciências Biológicas e da Saúde, v. 29 n. 1, p.83-104, 2008.

WITTHUHN, R.C. et al. Characterisation of the microbial population at different stages of Kefir production and Kefir grain mass cultivation. International Dairy Journal, v.15, p. 383-389, 2005. 


\title{
CAPÍTULO XIV
}

\section{INFECÇÃO POR TREPONEMA PALLIDUM E DANOS NO DESENVOLVIMENTO EMBRIONÁRIO E FETAL}

\author{
Neusa Loíse Nunes Albuquerque ${ }^{1}$ \\ Maria Nicolle Pereira da Silva ${ }^{2}$ \\ Maria Lusia de Morais Belo Bezerra ${ }^{3}$ \\ ${ }^{1}$ Graduanda do curso de Ciências Biológicas. Universidade Federal de Alagoas - UFAL \\ ${ }^{2}$ Graduanda do curso de Ciências Biológicas. Universidade Federal de Alagoas - UFAL \\ ${ }^{3}$ Professora da Universidade Federal de Alagoas - UFAL
}

\section{RESUMO}

A sífilis é causada pelo Treponema pallidum e transmitida, principalmente, por via sexual desprotegida e por via materno-fetal, culminando com a Sífilis Congênita (SC). Nessa forma de infecção ocorrem danos no embrião/feto, ocasionando aborto, natimorto, prematuridade ou um amplo espectro de manifestações clínicas. Diante deste contexto, este trabalho teve por objetivo realizar uma revisão integrativa acerca dos principais fatores que promovem a infecção e danos causados por T. pallidum durante o desenvolvimento embrionário e fetal. Trata-se de uma revisão integrativa, realizada nas bases de dados LILACS e Scielo, considerando o intervalo de 2010 a 2019. Foi conduzida em consonância com a questão norteadora, utilizando os descritores: "sífilis congênita" e "Treponema pallidum" com o operador booleano "AND". Os estudos foram pré-selecionados obedecendo aos critérios de inclusão e exclusão, no qual totalizaram 13 estudos, destes, 08 artigos foram selecionados. Observou-se que as gestantes realizam o pré-natal inadequado desencadeando danos que podem ser irreversíveis ao filho, quando infectado durante a gestação. O T. pallidum pode atingir a placenta e o cordão umbilical e, ainda, alcançar órgãos importantes para o desenvolvimento, principalmente, pósnascimento. E ainda, causar anomalias, como a hepatoesplenomegalia e hidrocefalia comunicante, no sistema nervoso, entre outros sintomas, podendo inviabilizar ou prejudicar a qualidade de vida e bem-estar do indivíduo.

Palavras-chave: Espiroquetas. Microrganismo. Neurologia. Sífilis

\section{INTRODUÇÃO}

As Infecções Sexualmente Transmissíveis (IST) atingem um grande número de indivíduos de várias faixas etárias anualmente em todo o mundo, onde, se diagnosticada tardiamente, pode ocasionar, no mínimo, ineficácia de medicamentos que atenuam as manifestações e, no máximo, morte. Indivíduos de regiões em desenvolvimento são os mais vulneráveis, principalmente, pela falta de informação disseminada entre a 
população e isenção de assistência médica (CESAR et al., 2020; SVIDLER LÓPEZ et al., 2019). De acordo com informações contidas na Pesquisa Assistência Médico-Sanitário (BRASIL, 2002), dentre as capitais brasileiras, o Rio de Janeiro é a capital onde existem mais indivíduos que não procuram atendimento médico pelo SUS (Sistema Único de Saúde) em nenhum momento do ano.

Uma das IST mais destacável por sua prevalência é a sífilis que possui como agente etiológico a bactéria gram-negativa e espiralada, Treponema pallidum. Na maioria dos casos, a sífilis é transmitida por via sexual desprotegida, entretanto, outras vias podem participar no processo de contágio, bem como contato direto com feridas principalmente localizadas na boca e mãos de indivíduos hospedeiros do $T$. pallidum (SÁNCHEZ et al., 2019).

Ademais, a sífilis apresenta quatro fases ou estágios distintos característicos, denominadas: primária, secundária, latente e terciária. A sífilis primária é a primeira forma de manifestação da presença da bactéria no organismo, onde é demonstrada com feridas ricas em bactérias dispostas em algumas regiões do corpo, porém, são comumente encontradas nos lábios (AVELLEIRA; BOTTINO, 2006).

Quando não tratada, a sífilis pode evoluir para sua fase secundária que, além das feridas típicas, notam-se outros sintomas, por exemplo, a dor muscular e febre (SÁNCHEZ et al., 2019). Anterior à fase terciária, o indivíduo pode entrar em um quadro de latência, entretanto, ainda é soropositivo para sífilis mesmo sendo assintomático e, ainda, pode permanecer nessa fase durante meses ou até 30 anos sequenciais (KALININ et al., 2016).

A fase terciária é o último estágio de evolução da infecção que, além dos sintomas já citados, a infecção atinge outros órgãos importantes, o que causa desestabilização das funções vitais exercidas pelo corpo, bem como o fígado com o desenvolvimento de hepatomegalia, ou seja, ocasiona o aumento anormal das proporções do tamanho desse órgão (TORTORA et al., 2016; AVELLEIRA; BOTTINO, 2006).

Outrossim, a sífilis não é exclusivamente partilhada entre indivíduos já nascidos, ela também pode ser transmitida por via vertical entre a portadora, a genitora, e o feto em desenvolvimento nos primeiros três meses da fase gestacional. E, dependendo da fase da infecção em que se encontra a gestante, pode alterar o estado normal de

WWW.AMPLLAEDITORA.COM.BR (2)

CONTATO@AMPLLAEDITORA.COM.BR 
crescimento e, consequentemente, resultar em mudanças importantes durante a formação dos órgãos do feto em questão (BOLDRINI et al.,2020; SILVA et al., 2019).

Na última década, a sífilis congênita (SC) teve um aumento significativo no Brasil, que ultrapassou o número de 9 casos de SC a cada 1.000 indivíduos nascidos vivos (BRASIL, 2019). Entre os anos de 2010-2015, as cinco regiões do Brasil tiveram o aumento contínuo das taxas de SC, para cada ano, o Nordeste e o Sudeste foram as regiões que mais apresentaram aumento dos casos de SC, de 2,7 a 6,9 / 1.000 nascidos vivos. Já as taxas na região Sul em 2015 eram consistentes com as do Nordeste e Sudeste, com a estimativa de 6,9/ 1.000 nascidos vivos (BEZERRA et al., 2019). Esse resultado mostra uma estatística cada vez mais crescente em casos diagnosticados de SC e relembra os principais riscos para os nascidos que, logo, se tornarão adultos com problemas, já que pode desencadear imediatamente ou futuramente um amplo espectro de manifestações clínicas importantes e possivelmente crônicas (OPAS, 2019).

De acordo com Rocha e colaboradores (2020), quando não há a manifestação prévia, o indivíduo pode desencadear esses sintomas e outros ao longo da vida refletindo nos estágios da sífilis, entretanto, o indivíduo pode nascer com um quadro de morte prematura ou, em muitos casos, em abortos.

Portanto, para conduzir o presente estudo, desenvolveu-se a seguinte questão norteadora: $\mathrm{O}$ que mostram as pesquisas científicas sobre as causas e consequências da infecção por T. pallidum no desenvolvimento embrionário e fetal? Nesse sentido, o objetivo deste trabalho foi realizar uma revisão integrativa acerca dos fatores que promovem a infecção e danos causados por T. pallidum durante o desenvolvimento embrionário e fetal.

\section{REVISÃO BIBLIOGRÁFICA}

A SC é uma condição na qual o indivíduo do sexo feminino, com um quadro de gravidez confirmado e com a presença do T. pallidum no organismo, contamina o embrião/feto por meio da placenta principalmente na fase latente da sífilis, entretanto, também é possível a infecção nas fases primárias e secundárias, normalmente, resulta em natimorte (TORTORA et al., 2016). 
Por conta das manifestações visíveis da sífilis adquirida, pode haver a desconfiança da genitora e sua confirmação por meio de exames laboratoriais realizados durante o pré-natal, porém, quando não há o tratamento adequado da gestante, haverá uma grande chance do feto nascer com SC e, dessa forma, a prevalência da SC em gestantes tornou-se um indicador de qualidade da assistência e acessibilidade à saúde (MARASCHIN et al., 2019).

Segundo o Sistema de Informações de Agravos de Notificação (SINAN) em conjunto com o Departamento de Doenças de Condições Crônicas e Infecções Sexualmente Transmissíveis - DCCI, nos anos de 2005 a 2020, os casos totais de sífilis em gestantes no Brasil foi quantificado em 384.411 casos, sendo que a maioria ocorreu em 2019, 25,1\% dos casos foram classificados clinicamente como pertencentes à sífilis primária. Com relação à SC, os números também são elevados sendo registrados 236.355 casos no mesmo intervalo de tempo já citado.

\subsection{Características da sífilis em recém nascidos}

Cerca de $90 \%$ dos casos de sífilis gestacional desenvolve-se em congênita em todo o globo e os principais sintomas podem manter-se em um período de latência ou manifestar-se logo após os três primeiros meses de vida (ECHAVEZ SÁNCHEZ; BULA ROMERO, 2019). No recém-nascido, a sífilis pode manifestar-se visualmente em feridas cutâneas que geralmente estão localizadas nas mãos e, além disso, no desenvolvimento também em complicações bem como, anemia e baixo peso corporal (TREVISAN et al., 2018).

Segundo Ocampo-Chaparro e colaboradores (2019), a sífilis sem diagnóstico e tardia pode causar sérios danos neurais, bem como o AVC (Acidente Vascular Cerebral), problemas auditivos, deficiências motoras, disfunção cognitiva e entre outros, já que o T. pallidum possui a capacidade de adentrar as barreiras protetivas existentes na entrada do cérebro, onde uma das funções, teoricamente, é inviabilizar a entrada de invasores nocivos, dessa forma, a invasão da bactéria ocasiona danos ao Sistema Nervoso Central e condições subjacentes.

Segundo Barros et al. (2005), essa invasão pode ocorrer durante a sífilis em seu estágio precoce, entretanto, o sistema imunológico presente no indivíduo pode agir contra a infecção e quando isso não acontece, a neurossífilis (Infecção por T. pallidum 
ao SNC, meninges e medula espinhal) pode desencadear, entre os 5 e 12 anos, em complicações na regulação e controle das células imunológicas, já na neurossífilis em sua versão tardia, entre os 18 e 25 anos, o quadro pode evoluir para atrofia cerebral e outras complicações ao indivíduo.

As lesões ósseas, geralmente, são diagnosticadas após o quinto mês de desenvolvimento da gestação e são uma das primeiras formas de manifestação da SC antes do nascimento, ainda, as lesões podem varias de acordo com a fase da SC, precoce e tardia, uma vez que são, respectivamente, periostite e a osteólise, onde a segunda pode evoluir para necrose do osso na vida adulta (MOREIRA-SILVA et al., 2009).

Ademais, ainda por ser um desenvolvimento ósseo considerado doloroso, uma vez que a criança está com alterações radiológicas importantes e possivelmente um deslocamento, faz com que os movimentos das extremidades do corpo seja bastante reduzida, o que leva ao desenvolvimento de pseudoparalisia de Parrot e, por fim, na maioria dos casos de SC, os ossos humanos mais atingidos são aqueles que possuem estaturas longas, bem como a tíbia (GAMEIRO et al., 2017).

\section{PROCEDIMENTOS METODOLÓGICOS}

Trata-se de uma revisão integrativa de literatura, compreendendo o período de 2010 a 2019, acerca da infecção por T. pallidum e os danos que esta bactéria pode ocasionar durante o desenvolvimento embrionário e fetal no. A revisão integrativa é um método de pesquisa que permite a síntese de múltiplos estudos publicados, no qual inclui a análise de pesquisas relevantes que dão suporte para a tomada de decisão e a melhoria da prática clínica do estado de conhecimento de determinado assunto (MENDES; SILVEIRA; GALVÃO, 2008).

A revisão integrativa seguiu passos para a construção, do qual iniciou-se pela questão norteadora, em sequência pela escolha dos descritores, que foram: "sífilis congênita" e "Treponema pallidum" utilizando o operador booleano "AND" nas estratégias de busca. A coleta de dados foi realizada nas bases de dados LILACS (Literatura Latino-Americana e do Caribe em Ciências da Saúde) e SCIELO (Scientific Electronic Library Online). Os critérios de inclusão foram: publicações disponíveis on-line e gratuitas, com idioma em português, com texto completo, com intervalo de tempo 
compreendido entre 2010 a 2019 e documentos do tipo artigos originais e de revisão. Os critérios de exclusão foram: publicações fora do foco da temática após a leitura de título e resumo, com idioma inglês, espanhol, alemão e francês, estudos incompletos, indisponíveis e duplicados.

A partir das buscas padronizadas nas bases de dados realizadas em julho de 2020, foram encontrados 103 estudos, os quais após aplicação dos critérios pré-definidos foram excluídas 90 publicações. Após a leitura de título e resumo das 13 publicações pré-selecionadas, conservaram-se 08 para análise detalhada.

Para a análise dos estudos selecionados, todos foram lidos com atenção voltada para o foco da temática e atendendo as exigências, procurando responder a questão norteadora. Desta forma, foram organizadas duas categorias temáticas: a) Fatores relacionados à transmissão vertical do T. pallidum; e, b) Danos causados pelo T. pallidum durante o desenvolvimento embrionário e fetal.

\section{RESULTADOS E DISCUSSÃO}

A maioria das publicações (07 artigos) foi localizada na base Lilacs, representando $87,5 \%$ dos estudos coletados, enquanto $12,2 \%$ (01 artigo) foi encontrado na base Scielo. Dentre os artigos incluídos, foram identificados alguns tipos de estudos, caracterizados pelos autores como: ecológico (2), exploratório-descritivo (1), revisão de literatura (1), descritivo e retrospectivo (2), epidemiológico descritivo (1) e estudo de caso (1). Quanto ao ano de publicação se obteve a seguinte distribuição: 2018 (2), 2017 (2), 2016 (1), 2014 (1), 2012 (2). Essas informações podem ser visualizadas no quadro 1. 
Quadro 1- Caracterização dos trabalhos selecionados para análise crítica.

\begin{tabular}{|c|c|c|c|c|}
\hline $\mathbf{N}^{\circ}$ & $\begin{array}{c}\text { AUTOR (ES) / } \\
\text { ANO }\end{array}$ & TíTULO & TIPO DE ESTUDO & $\begin{array}{c}\text { BASES DE } \\
\text { DADOS }\end{array}$ \\
\hline 01 & $\begin{array}{c}\text { Galatoire; } \\
\text { Rosso; Sakae } \\
\text { (2012) }\end{array}$ & $\begin{array}{l}\text { Incidência de sífilis } \\
\text { congênita nos estados do } \\
\text { Brasil no período de } 2007 \text { a } \\
2009\end{array}$ & Ecológico & LILACS \\
\hline 02 & $\begin{array}{l}\text { Mesquita et al } \\
\text { (2012) }\end{array}$ & $\begin{array}{l}\text { Análise dos casos de sífilis } \\
\text { congênita em Sobral, Ceará: } \\
\text { contribuições para } \\
\text { assistência pré-natal }\end{array}$ & $\begin{array}{c}\text { Exploratório- } \\
\text { descritivo }\end{array}$ & LILACS \\
\hline 03 & $\begin{array}{l}\text { Romanelli et } \\
\text { al (2014) }\end{array}$ & $\begin{array}{l}\text { Abordagem neonatal nas } \\
\text { infecções congênitas - } \\
\text { toxoplasmose e sífilis }\end{array}$ & $\begin{array}{l}\text { Revisão de } \\
\text { literatura }\end{array}$ & LILACS \\
\hline 04 & $\begin{array}{l}\text { Lafetá et al } \\
\text { (2016) }\end{array}$ & $\begin{array}{l}\text { Sífilis materna e congênita, } \\
\text { subnotificação e difícil } \\
\text { controle }\end{array}$ & $\begin{array}{c}\text { Descritivo e } \\
\text { retrospectivo }\end{array}$ & SciELO \\
\hline 05 & $\begin{array}{l}\text { Silva; Sousa; } \\
\text { Sakae (2017) }\end{array}$ & $\begin{array}{c}\text { Incidência da sífilis } \\
\text { congênita no estado de } \\
\text { Santa Catarina no ano de } \\
2012\end{array}$ & Ecológico & LILACS \\
\hline 06 & $\begin{array}{l}\text { Lima et al } \\
\text { (2017) }\end{array}$ & $\begin{array}{l}\text { Perfil epidemiológico dos } \\
\text { casos de sífilis congênita em } \\
\text { um município de médio } \\
\text { porte no nordeste brasileiro }\end{array}$ & $\begin{array}{l}\text { Epidemiológico, } \\
\text { descritivo }\end{array}$ & LILACS \\
\hline 07 & $\begin{array}{l}\text { Ramos; Boni } \\
\text { (2018) }\end{array}$ & $\begin{array}{l}\text { Prevalência da sífilis } \\
\text { gestacional e congênita na } \\
\text { população do município de } \\
\text { Maringá -PR }\end{array}$ & $\begin{array}{l}\text { Descritivo } \\
\text { retrospectivo }\end{array}$ & LILACS \\
\hline 08 & $\begin{array}{l}\text { Andrade et al } \\
\text { (2018) }\end{array}$ & $\begin{array}{l}\text { Diagnóstico tardio de sífilis } \\
\text { congênita: uma realidade na } \\
\text { atenção à saúde da mulher } \\
\text { e da criança no Brasil }\end{array}$ & Estudo de caso & LILACS \\
\hline
\end{tabular}

Fonte: Dados da pesquisa. 


\subsection{Fatores relacionados à transmissão vertical do T. pallidum}

Ocorrências dos casos de SC estão intrinsecamente ligadas às falhas do tratamento das gestantes infectadas, focando na detecção precoce da gestante, no diagnóstico, e tratamento da sífilis adquirida, assim como na captação dos parceiros (LIMA et al., 2017). Há falhas no acompanhamento dos parceiros sexuais com sífilis adquirida recente, que atuam como casos-fontes de disseminação da doença, da transmissão vertical da bactéria (MESQUITA et al., 2012). Para intervir com a doença durante a gestação com a finalidade de evitar a infecção do concepto, a forma mais simples de possibilitar o diagnóstico precoce é com o pré-natal (RAMOS; BONI, 2018).

Elementos fundamentais no enfrentamento da sífilis por transmissão vertical são ações de diagnóstico e prevenção, que precisam ser reforçados especialmente no prénatal e no parto (GALATOIRE; ROSSO; SAKAE, 2012). Vale ressaltar, a excelência da realização do exame não-treponêmico VDRL (Venereal Disease Research Laboratory) para a detecção da infecção da bactéria, no que resulta no diagnóstico, podendo iniciar o tratamento contra a doença. Os reagentes dos exames de VDRL pode dar resultados 1:1, e outro 1:4, a titulação em recém-nascido é maior que a da mãe, que indica que foi infectado, diagnosticado com SC (ANDRADE et al., 2018; MESQUITA et al., 2012; SILVA; SOUSA; SAKAE, 2017). A detecção do DNA do $T$. pallidum pela reação da cadeia da polimerase (PCR) destaca-se também como técnica promissora para o diagnóstico prénatal e pós-natal (ROMANELLI et al., 2014). Adicionalmente, para o teste confirmatório de SC consiste na pesquisa de espiroquetas em anexos embrionários, em amostras da placenta e cordão umbilical dos recém-nascidos (RAMOS; BONI, 2018).

\subsection{Danos causados pelo $T$. pallidum durante 0 desenvolvimento embrionário e fetal}

A transmissão ao concepto é bem maior nas etapas iniciais da doença, quando há mais espiroquetas na circulação. Com isso, a infecção por T. pallidum desencadeia danos que podem ser irreversíveis à portadora e, principalmente, ao filho. A bactéria atinge os anexos embrionários, como a placenta e o cordão umbilical (MESQUITA et al., 2012). 
De acordo com os estudos de Lafetá et al. (2016) as gestantes entre 20 e 30 anos estão mais propensas a desenvolver fetos com SC e as suas consequências. No estudo de Silva, Sousa e Sakae (2017) foi possível observar que cerca de $80 \%$ dos casos apresentavam-se assintomáticos, porém os casos que apresentavam sintomas, manifestam na forma, principalmente, icterícia, anemia, esplenomegalia, hepatomegalia e lesões cutâneas nos recém-nascidos.

A sífilis adquirida durante a gravidez pode resultar na reabsorção do embrião, aborto, natimorto, malformação dentre outras sequelas pós-natais variáveis de apresentação precoce ou tardia. Considera-se SC quando é diagnosticado no período durante a gestação, parto ou puerpério. E apesar da existência da sífilis recente (até dois anos de vida) que apresenta diversas anomalias que o bebê desenvolve ao nascer, como lesões bolhosas, condiloma latum etc, a tardia (após dois anos de vida), por ter sintomas como ceratite intersticial, surdez dentre outros sintomas, mostra-se agressiva e mais prejudicial (ROMANELLI et al., 2014).

Alguns sintomas como alterações ósseas importantes, icterícia, lesões cutâneas, função hepática alterada e alterações musculares, relacionados à SC são destacados por Ramos e Boni (2018). Além disso, a SC também pode afetar o sistema nervoso central, onde há a possibilidade do indivíduo nascer com diversas anomalias, bem como a hidrocefalia comunicante, dentre outros (ROMANELLI et al., 2014; SILVA; SOUSA; SAKAE, 2017).

Segundo Andrade et al. (2018) o exame da placenta na hora do parto é importante para a investigação de diagnóstico da sífilis, uma vez que a placentite causada pelo T. pallidum apresenta-se clinicamente por placenta pálida, grosseira e de grande dimensão.

\section{CONSIDERAÇÕES FINAIS}

Os estudo analisados corroboram que a infecção por T. pallidum durante a gestação está relacionado aos fatores associados, principalmente, o manejo inadequado do pré-natal, que provoca o aumento de casos de SC por não viabilizar o diagnóstico precoce, com isso, ocasiona em diversos danos, desde o aborto a natimorto e, quando há a possibilidade de nascimento, o indivíduo pode desenvolver complicações sérias que 
comprometem alguns órgãos, bem como o fígado e o baço, e ocasionam condições relacionadas ao sistema nervoso central.

No entanto, o estudo ora apresentado possui limitações, tais como: não ter sido realizada a buscar de artigos em outros idiomas, ficando restrito à língua portuguesa, bem como a utilização de apenas duas bases de dados para busca das publicações. Mas, a literatura incluída neste estudo ressalta a SC como uma grande problemática na saúde pública, especialmente no Brasil.

\section{REFERÊNCIAS}

ANDRADE, A. L. M. B. et al. Diagnóstico tardio de sífilis congênita: uma realidade na atenção à saúde da mulher e da criança no Brasil. Revista Paulista de Pediatria, v. 36, n. 3, p. 376-381, 2018.

AVELLEIRA, J. C. R.; BOTTINO, G. Sífilis: diagnóstico, tratamento e controle Syphilis: diagnosis, treatment and control. Anais Brasileiros de Dermatologia, v. 81, n. 2, p. 111-26, 2006.

BARROS, A. M. et al. Neurossífilis: revisão clínica e laboratorial. Arquivos de Medicina, v. 19, n. 3, p. 121-129, 2005.

BEZERRA, M. L.M.B. et al. Congenital Syphilis as a Measure of Maternal and Child Healthcare, Brazil. Emerging infectious diseases, v. 25, n. 8, p. 1469, 2019.

BOLDRINI, N. A. T. et al. Syphilis among HIV serodiscordant partners associated with Human Papillomavirus Infection in a bisexual man. DST jornal brasileiro de doenças sexualmente transmissíveis, v. 32, p. 1-4, 2020.

BRASIL. Ministério da Saúde. Indicadores e Dados Básicos da Sífilis nos Municípios Brasileiros. Sinan - Sistema de Informação de Agravos de Notificação. Departamento de Doenças de Condições Crônicas e Infecções Sexualmente Transmissíveis - DCCl, 2020. Disponível em: indicadoressifilis.aids.gov.br. Acesso em: 30 de nov. de 2020.

BRASIL. Ministério da Saúde. Produção de Serviços por Unidade Assistencial. Pesquisa Assistência Médica Sanitária, 2002. Disponível em: tabnet.datasus.gov.br/cgi/tabcgi.exe

?ams/cnv/uamsmbr.def/. Acesso em: 30 de nov. de 2020.

BRASIL. Ministério da Saúde. Boletim Epidemiológico Sífilis 2019. Secretaria de Vigilância em Saúde, Departamento de Doenças de Condições Crônicas e Infecções Sexualmente Transmissíveis. - Brasília: Ministério da Saúde, 2019. 
CESAR, J. A. et al. Não realização de teste sorológico para sífilis durante o pré-natal: prevalência e fatores associados. Revista Brasileira de Epidemiologia, v. 23, p. e200012, 2020.

ECHAVEZ SÁNCHEZ, M. A.; BULA ROMERO, J. A. Vigilancia Epidemiológica de la sífilis gestacional y congénita en el departamento de Córdoba, Colombia, 20122016. Revista de salud pública (Córdoba), p. 7-22, 2019.

GALATOIRE, P. S. A; ROSSO, J. A.; SAKAE, T. M. Incidência da sífilis congênita nos estados do Brasil no período de 2007 a 2009. Arquivo Catarinenses de Medicina, v. 41, n. 2, p. 26-32, 2012.

GAMEIRO, V. S. et al. Congenital syphilis with bone lesion: case report. Revista Brasileira de Ortopedia (English Edition), v. 52, n. 6, p. 740-742, 2017.

LAFETÁ, K. R. G. et al. Sífilis materna e congênita, subnotificação e difícil controle. Revista Brasileira de Epidemiologia, v.19, n. 1, 2016.

LIMA, V. C. et al. Perfil epidemiológico dos casos de sífilis congênita em um município de médio porte no nordeste brasileiro. Journal of Health \& Biological Sciences, v. 5, n. 1, p. 56-61, 2017.

MARASCHIN, M. S. et al. Sífilis materna e sífilis congênita notificadas em um hospital de ensino. Nursing (Säo Paulo), p. 3209-3213, 2019.

MENDES, K. D. S.; SILVEIRA, R. C. C. P.; GALVÃO, C. M.; Revisão integrativa: método de pesquisa para a incorporação de evidências na saúde e na enfermagem. Texto e Contexto Enfermagem, v. 17, n. 4, p. 758-64, 2008.

MESQUITA, K. O. et al. Análise dos casos de sífilis congênita em Sobral, Ceará: contribuições para assistência pré-natal. DST- Jornal Brasileiro de Doenças Sexualmente Transmissíveis, v. 24, n. 1, p. 20-27, 2012.

MOREIRA-SILVA, S. F. et al. Alterações ósseas em lactentes com sífilis congênita. Jornal Brasileiro de Doenças Sexualmente Transmissíveis, v. 21, n. 4, p. 175-178, 2009.

OCAMPO-CHAPARRO, J. M. et al. Neurosífilis meningovascular como causa de accidente cerebrovascular en paciente joven: reporte de caso. Revista Médicas UIS, v. 32, n. 2, p. 53-58, 2019.

OPAS. Organização Mundial da Saúde publica novas estimativas sobre sífilis congênita. Fev. $2019 . \quad$ Disponível em: <https://www.paho.org/bra/index.php?option=com_content\&view=article\&id= 5879:organizacao-mundial-da-saude-publica-novas-estimativas-sobre-sifiliscongenita\&/temid=812>. Acesso em: 23 Nov. 2020. 
RAMOS, M. G.; BONI, S. M. Prevalência da sífilis gestacional e congênita na população do município de Maringá-PR. Saúde e Pesquisa, v. 11, n. 3, p. 517-526, 2018.

ROCHA, C. C. et al. Abordagens sobre sífilis congênita. Research, Society and Development, v. 9, n. 8, 2020.

ROMANELLI, R. M. C. et al. Abordagem neonatal nas infecções congênitas toxoplasmose e sífilis. Revista Médica de Minas Gerais, v. 24, n. 2, 2014.

SÁNCHEZ BERARDO, M. et al. El rol del odontólogo en el diagnóstico del secundarismo sifilítico. Revista de la Sociedad Odontológica de La Plata, p. 7-9, 2019.

SILVA, H. C. C.; SOUSA, T. O.; SAKAE, T. M. Incidência da sífilis congênita no estado de Santa Catarina no ano de 2012. Revista Arquivos Catarinenses de Medicina, v. 46, n. 2, p. 15-25, 2017.

SILVA, P. S. et al. Gestational and congenital syphilis in a municipality in Brazil between 2014 and 2018. DST jornal brasileiras de doenças sexualmente transmissíveis, p. 112-117, 2019.

SVIDLER LÓPEZ, L. Manifestaciones coloproctológicas de las infecciones de transmisión sexual ocasionadas por Chlamydia Trachomatis, Neisseria Gonorrhoeae y Treponema Pallidum. Presentación casuística. Revista argentina coloproctología, p. 80-87, 2019.

SOUZA, M. H. T.; BECK, E. Q. Compreendendo a sífilis congênita a partir do olhar materno. Revista de Enfermagem da UFSM, v. 9, p. 56, 2019.

TORTORA, G. J.; CASE, C. L.; FUNKE, B. R. Microbiologia-12a Edição. Artmed Editora, 2016.

TREVISAN, M. G. et al. Prevalência da sífilis gestacional e congênita no município de Francisco Beltrão. Revista Espaço para a Saúde, v. 19, n. 2, p. 84-96, 2018.

KALININ, Y.; PASSARELI NETO, A.; PASSARELLI, D. H. C. Sífilis: aspectos clínicos, transmissão, manifestações orais, diagnóstico e tratamento. Odonto, v. 23, n. 45-46, p. 65-76, 2016. 


\title{
CAPÍTULO YV
}

\section{PERCEPÇÕES DOCENTES E DISCENTES SOBRE FEEDBACK EM ESTÁGIOS PRÁTICOS NO CURSO DE MEDICINA}

\begin{abstract}
Simone Stagini ${ }^{1}$
Lena Vânia Carneiro Peres ${ }^{2}$

${ }^{1}$ Mestranda. Programa de Pós Graduação Inovação do Ensino Superior em Saúde - USCS

2 Professora do Programa de Mestrado Profissional Inovação no Ensino Superior em Saúde. Universidade Municipal de São Caetano do Sul - USCS
\end{abstract}

\section{RESUMO}

Introdução: No ensino médico, o feedback é um dos componentes principais da avaliação formativa. Feedback é definido como transmissão de uma informação ao observar os alunos em ação a fim de propiciar melhorias para aquisição de competências médicas. O objetivo desse estudo foi avaliar se há dificuldades de transmissão e recepção de feedback pelos preceptores e alunos durante os estágios práticos do curso de medicina. Método: Este estudo teve delineamento qualitativo quantitativo, sendo o feedback avaliado utilizando questões categóricas e abertas. Foi utilizada análises descritivas nos dados quantitativos e técnica de conteúdo nos dados qualitativos. Resultados: Objetivos do feedback são: apontar melhorias, promover reflexão crítica, oportunizar adequações, esclarecer dúvidas e detectar pontos positivos. Preceptores afirmaram fornecer feedback muito frequente, porém os alunos gostariam de receber feedback mais frequentemente. Metade dos preceptores tem dificuldade em dar feedback negativo, porém, $60 \%$ dos alunos relataram lidar bem com críticas. Conclusão: Os preceptores afirmaram ter conhecimento e saberem dos objetivos do feedback, porém eles têm dificuldades em como transmiti-los, principalmente quando envolve críticas para correções de comportamentos ou atitudes. Os alunos aceitam críticas e requerem que o feedback seja transmitido com mais frequência. Há necessidade de melhorar o processo de fornecer e receber feedback.

Palavras-chave: Ensino médico. Feedback. Estágios práticos. Medicina.

\section{INTRODUÇÃO}

Desde a instalação da corte portuguesa no Brasil diversas modificações ocorreram no ensino médico brasileiro, dentre elas destacam-se a reforma flexeneriana implementada durante o regime militar, a qual propunha uma escola médica embasada em universidades, que apresentasse um programa pedagógico com bases científicas e o curso com duração de quatro anos, sendo dois destinados às áreas básicas e dois às

WWW.AMPLLAEDITORA.COM.BR (2)

CONTATO@AMPLLAEDITORA.COM.BR M 
atividades práticas. Nesse período, o ensino médico era baseado nas doenças e na medicalização para a cura das mesmas, não considerando os aspectos psicossociais do indivíduo (PAGLIOSA; DA ROS, 2008).

Em 1988 com a criação do Sistema Único de Saúde, o modelo de saúde implantado passou a abranger toda população, valorizando as necessidade de saúde individuais e o caráter psicossocial do indivíduo (BRASIL, 1990), com isso houve a necessidade de formar médicos que atendessem essas necessidades, o que se concretizou com as Diretrizes Curriculares Nacionais (DCN) de graduação médica de 2001 e de 2014. Estas DCNs propunham a formação do médico generalista, para atuar na prevenção, promoção, recuperação e reabilitação do paciente (BRASIL, 2001; BRASIL 2014). Devido as DCNs, as quais passaram a vigorar a partir de 31 de Dezembro de 2018 (BRASIL, 2014), o aluno tornou-se o principal ator do seu aprendizado, sendo o professor um coadjuvante, facilitador do processo de ensino e aprendizagem, através das quais o aluno passa a ser avaliado pelas competências adquiridas no aprendizado, além de utilizar as metodologias ativas de ensino (BRASIL, 2001; PAGLIOSA; DA ROS, 2008; PANÚNCIO-PINTO; TRONCON, 2020).

Para determinar se o aluno atingiu ou não as competências desejadas à formação médica há necessidade de uma avaliação. Com a implantação das DCNs, as avaliações deixaram de visar apenas uma graduação através de notas para saber se o aluno está apto ou não a passar para outra etapa do curso, passando a ser uma avaliação formativa com a preocupação em averiguar falhas no decorrer das atividades práticas, para que sejam refletidas pelos alunos através de assimilação de conceitos e de cenários já vivenciados e promovam mudança de comportamento para que sejam obtidas as competências desejadas (HARDAVELLA et al, 2017). A principal característica desse tipo de avaliação é o uso do instrumento de aprendizado chamado feedback ou devolutiva, o qual é realizado imediatamente após uma atividade ( TRONCON, 2020).

Devolutivas ou Feedback na prática médica pode ser definido como a transferência de dados observados pelos preceptores durante a prática médica, contextualizando o saber cognitivo, a habilidade prática, a tomada de decisão e se os objetivos do aprendizado foram atingidos, visando uma reflexão do estudante para que ele reconstrua seus conhecimentos e altere seu modo de agir, melhorando sua performance para que atinja as competências necessárias à profissão em prol do

WWW.AMPLLAEDITORA.COM.BR (2) 
paciente (ALBANO et al, 2019). As devolutivas são importantes para os alunos refletirem sobre como está sendo sua performance, qual é o desempenho desejado e buscarem suporte para melhorarem suas desenvolturas em ambientes de prática. De forma secundária, as devolutivas são importantes para os alunos atuarem de forma autônoma, através da autorreflexão e da aprendizagem contínua (HARDAVELLA et al, 2017). Seu objetivo consiste em enfatizar as boas práticas médicas, valorizando o que os alunos desempenharam bem e promovendo uma reflexão crítica sobre os aspectos que necessitam de melhorias, além de como podem melhorá-los (CANTILLON; SARGEANT, 2008; HARDAVELLA et al, 2017) .

Para as devolutivas serem efetivas é necessário que haja um entrosamento entre professor e o aluno, clareza na transmissão, entendimento do aluno e identificação de quais os objetivos do aprendizado desejados tanto pelo aluno quanto pelo preceptor (ALBANO et al, 2019). Além disso, também influencia na efetividade da devolutiva o tempo destinado à observação, o local que a devolutiva foi realizada, o conteúdo e a forma de transmissão da devolutiva (JAMSHIDIAN et al, 2019). Sendo assim, há vários obstáculos para o fornecimento e recebimento de uma evolutiva efetiva. Há relatos de que muitos preceptores desconhecem ou não estão acostumados a transmitir devolutivas aos alunos ( BERNARD; KMAN; KANDELWAL, 2011; DENT; HARDEN, 2009). Além disso, muitos alunos não entendem que estão recebendo devolutivas ${ }^{8}$. Portanto, visando construir propostas de melhorias para o fornecimento e recebimento das devolutivas o principal objeto do estudo foi avaliar a percepção dos preceptores e alunos da USCS - Bela Vista, sobre as devolutivas nos estágios em Diadema.

\section{MÉTODOS}

\subsection{Tipo de estudo}

Foi conduzido um estudo transversal qualitativo-quantitativo com o intuito de analisar a percepção de um grupo de discentes e docentes de medicina sobre feedback. Este estudo foi aprovado pelo Comitê de Ética em Pesquisa da Universidade Municipal de São Caetano do Sul (USCS). Número do Parecer: 3.551.101 e protocolo do CEP: 17717019.8.0000.5510. 


\subsection{Local}

Os dados dessa amostra foram coletados a partir de quatro locais públicos de saúde, sendo o Hospital Municipal de Diadema (HMD), o Pronto Socorro Municipal de Diadema (PS Central), o Sistema de Atendimento Móvel de Urgência (SAMU) da prefeitura de Diadema e o Centro de Atenção Psicossocial (CAPS), ambos localizados na cidade de Diadema, município de São Paulo, região sudeste do Brasil.

\subsection{Critérios de elegibilidade}

Foram incluídos estudantes graduandos de medicina da USCS da sétima etapa e oitava etapa (Campus Bela Vista) e que havia passado pelos seguintes estágios práticos em Diadema: Clínica Médica - HMD, Pediatria - PS Central, SAMU e CAPS, no período de 05 de março de 2018 a 21 de agosto de 2019, que aceitaram participar da pesquisa e assinaram o termo de consentimento. Também foram incluídos nesse estudo os preceptores contratados e/ou concursados pela USCS que são responsáveis pelos estágios práticos nos mesmos locais e períodos citados acima e que aceitaram participar da pesquisa.

Não foram incluídos nesse estudo os alunos da sétima etapa que não tinham passado por todos estágios (Clínica Médica, Pediatria, SAMU e CAPS), no período da avaliação do estudo. Foram excluídos do estudo os alunos e/ou preceptores que não assinaram o termo de consentimento livre e esclarecido ou que não aceitaram participar da pesquisa.

\subsection{Procedimentos}

Os potenciais sujeitos selecionados para esse estudo foram convidados por Whatsapp. Os questionários para avaliação foram fornecidos aos alunos na secretaria da USCS e fornecido aos preceptores nos respectivos locais de trabalho. No período de 05 de março à 21 de agosto, cinco grupos de alunos passaram pelos quatro estágios práticos, totalizando cinquenta alunos. Destes, trinta alunos aceitaram participar do estudo e responderam ao questionário. Dentre os nove preceptores responsáveis pelos estágios práticos, oito aceitaram e foram incluídos. 
Os questionários foram baseados nas perguntas de Maia e colaboradores (2018). As perguntas foram adaptadas para questões categóricas e qualitativas em dois questionários, um para os preceptores e outro para os alunos. O questionário adaptado para a avaliação dos alunos continha 11 itens que avaliaram o feedback. Já para a avaliação dos preceptores foi aplicado um questionário sócio demográfico e em seguida a versão do questionário modificado e adaptado, contendo nove questões (MAIA, 2018).

As variáveis primárias do estudo foram perguntas referentes as dificuldades encontradas pelos alunos e preceptores em receberem e fornecerem devolutivas, respectivamente. Como varáveis secundárias estavam a frequência do recebimento e da oferta das devolutivas, experiência dos preceptores com as devolutivas, mudança de comportamento dos alunos e quais características devem ter o preceptor e o aluno.

\subsection{Análise estatística}

Os dados quantitativos desse estudo foram analisados utilizando análise de frequência para dados categóricos que calcula os números absolutos e percentuais para cada questão avaliada; e por análise descritiva para dados contínuos, que a média e desvio padrão de cada variável.

A análise estatística qualitativa foi realizada utilizando a técnica de conteúdo. Essa técnica analisa os dados através do método de dedução frequencial e também por análise por categorias temáticas (CAREGNATO; MUTTI, 2006). Para auxiliar na análise de conteúdo e identificar termos chaves foi utilizado o método Natural Language Tookit (NLTK, disponível em https:// 3. www.nltk.org/).

\section{RESULTADOS}

Um total de 58 sujeitos foram convidados a participar desse estudo, sendo nove preceptores e 50 alunos. Destes, 38 sujeitos aceitaram participar e foram incluídos para a análise dos dados deste estudo, sendo oito preceptores e 30 discentes. Os principais motivos que alguns sujeitos convidados não participaram do estudo foram: não foi possível o contato via e-mail ou WhatsApp porque o sujeito não respondeu. Os preceptores eram 4 homens e 4 mulheres com média de idade de 39 anos (DP =5,4). A maioria eram médicos (75\%), o nível de escolaridade variava entre pós-graduação e residência, ambos atingindo $75 \%$ dos docentes, a mestrado (37,5\%) e doutorado (25\%).

WWW.AMPLLAEDITORA.COM.BR (2) 
Um total de $75 \%$ dos preceptores apresentou ter experiência com educação na saúde e destes, o tempo de experiência era em média de 23 meses ( $D P=39,9$ ).

\subsection{Resultados preceptores}

O autorrelato dos docentes sobre o conhecimento por feedback variou de nenhum conhecimento (13\%) a muito conhecimento (25\%). Nenhum docente se classificou com extremo conhecimento, sendo que a maioria dos docentes se classificou como pouco conhecimento sobre feedback (38\%).

Sobre a clareza dos docentes em relação aos objetivos de fornecer feedback, $25 \%$ dos docentes nem concordaram e nem discordaram de a terem, o maior percentual (75\%) concordou. De forma qualitativa, os objetivos que os docentes relataram sobre fornecer um feedback, foram agrupados entre motivação ao aluno, clareza de informações e reflexão do aluno.

Os resultados sobre a frequência com que os docentes forneceram o feedback variou muito de acordo com cada docente, por exemplo, enquanto $13 \%$ dos docentes nunca forneceram devolutivas, $25 \%$ deles forneceram em todas as aulas práticas.

Metade dos docentes relataram conhecer os diferentes modos de fornecer feedback aos alunos, apenas $25 \%$ dos docentes relataram não conhecer. Qualitativamente, os docentes responderam que os tipos de feedback que mais costumam oferecer são feedbacks orais (o qual predominou), feedbacks breves e construtivos.

Enquanto $35 \%$ dos docentes relataram não terem dificuldade em oferecer feedback, $25 \%$ e $13 \%$ concordaram e concordaram completamente sobre terem dificuldades em oferecer feedback aos alunos. As situações que deixaram os docentes com mais dificuldade foram à respeito de devolutivas sobre aspectos subjetivos do aluno, ou quando houve necessidade de correção do aluno e de serem dependentes da interpretação do mesmo.

Apenas $25 \%$ dos docentes concordaram de conseguirem avaliar se o feedback foi efetivo para os alunos. Enquanto 50\% deles nem concordaram e nem discordaram com a afirmação e os outros $25 \%$ discordaram, relatando que não conseguiram avaliar se o feedback foi efetivo ou não. Quando perguntados como eles fazem esta avaliação, os 
docentes responderam que perguntam ao aluno, ou que observam as atitudes do aluno durante as próximas aulas práticas.

Um total de $63 \%$ dos docentes relatou que os alunos precisam ter características específicas para se beneficiar de um feedback, sendo que apenas $12,5 \%$ dos docentes discordaram dessa afirmação. As características citadas pelos docentes de forma qualitativa foram ter interesse, saber escutar, ter resiliência, respeito e empatia.

Quando os docentes foram questionados sobre a frequência que solicitavam feedback sobre a sua conduta como professor, $13 \%$ responderam que nunca solicitaram, $25 \%$ solicitaram raramente, $38 \%$ e $25 \%$ solicitaram feedback ocasionalmente e muito frequentemente, respectivamente. Adicionalmente, $50 \%$ e $25 \%$ dos docentes concordaram e concordaram completamente em modificar a sua conduta como professor os alunos após receber um feedback.

\subsection{Resultados alunos}

Os alunos reportaram ter moderado conhecimento (40\%), muito conhecimento (53\%) ou extremo conhecimento (7\%) sobre feedback. Além disso, os alunos também relataram ter clareza sobre os objetivos de receberem um feedback, sendo que $63 \%$ dos alunos concordaram com essa afirmação e $33 \%$ concordaram completamente. Na visão deles os objetivos do feedback estão relacionados a identificar pontos fortes e fracos para melhorar a prática clínica e crescimento pessoal.

Nenhum aluno relatou ter recebido feedback em todas as aulas práticas, sendo que $3 \%$ dos alunos relatou que não receberam nenhum feedback durante os estágios práticos. A maioria dos alunos relatou que a frequência que receberam feedback variou entre $33 \%$ que receberam raramente, $37 \%$ ocasionalmente e $27 \%$ dos alunos que receberam feedback muito frequentemente.

De acordo com os alunos o feedback trouxe impacto positivo para o aprendizado deles, sendo que 53\% dos alunos concordaram com a afirmação e $40 \%$ concordaram completamente. Os impactos positivos mais relatados pelos alunos foram conseguir identificar os erros que eles não percebiam antes, mudanças de comportamento durante $o$ atendimento e o aprimoramento da prática clínica.

Quando questionados sobre o impacto negativo do feedback no aprendizado, $30 \%$ e $43 \%$ dos alunos discordaram completamente ou discordaram dessa afirmação. 
$\mathrm{Na}$ avaliação qualitativa muitos alunos deixaram de responder essa questão, provavelmente, devido a não repararem em aspectos negativos do feedback, aqueles que responderam relataram se sentirem desmotivados após um feedback, dependendo da forma como ele foi realizado, outros se sentiram agredidos com um feedback rude ou então relatam que o impacto negativo foi que eles não mudaram de atitude na prática clínica porque não receberam um feedback eficaz.

Sobre a dificuldade do aluno em receber o feedback $37 \%$ e $47 \%$ discordaram completamente e discordaram, respectivamente, em sentir desconforto de receber feedback após performance na prática. Apenas $3 \%$ dos alunos relataram sentir desconforto em receber feedback. As únicas situações que deixaram os alunos desconfortáveis foram a exposição, quando o feedback é dado frente ao paciente ou dos colegas, ou então quando receberam apenas feedback negativo sem apontar pontos de melhorias. Um total de $60 \%$ e $13 \%$ dos alunos concordou, ou concordou completamente que lidam bem com críticas negativas durante um feedback. Nenhum aluno relatou que não lida bem com críticas negativas.

A maioria dos alunos concordaram (57\%) ou concordaram completamente (37\%) que observaram mudanças na prática clínica após receber feedback dos preceptores. Foram diversas as mudanças relatadas pelos alunos tanto sobre mudança de conduta clínica como mudança de relacionamento pessoal, com colegas, equipe de trabalho e até mesmo os pacientes.

Metade dos alunos 53,33\% concordaram que há necessidade de o preceptor ter características específicas para oferecer um bom feedback. De forma qualitativa os alunos relataram que um bom feedback é aquele fornecido pelo preceptor com clareza em sua fala, sem julgar, ser um bom observador e coerente com as competências pretendidas, individualizar o grau de conhecimento de cada aluno, ser respeitoso e ser qualificado para usar técnicas de feedback e propor correções e melhorias nas competências pretendidas e ter empatia.

A maioria dos alunos concordaram (53\%) e concordaram completamente (37\%) que o feedback deveria ser uma prática constante em seu curso. As preferências dos alunos sobre a forma em que o feedback seja fornecido é oral e que seja realizado com mais frequência, adicionalmente, a preferência sobre local é individualizada em local 
privado e como preferência sobre os tipos de feedback foram eleitos os feedbacks construtivos que apontam críticas construtivas.

Os alunos foram questionados se conseguiam fazer um feedback ao preceptor e as respostas foram variadas, alguns conseguiram e até viram mudança na prática do professor, porém a maioria não conseguiu ou não conseguiu espaço e se sentem inseguros para oferecer um feedback ao professor.

\section{DISCUSSÃO}

Sendo o feedback o componente de avaliação formativa, com caráter contínuo e com o intuito de detectar aspectos que necessitam de melhorias, esse método se torna um importante instrumento para o treinamento da prática médica. O presente estudo teve como objetivo principal avaliar a percepção e dificuldades dos preceptores e dos alunos sobre a transmissão e recebimento de feedback durante os estágios práticos do ensino no curso de medicina. Para isso, foram realizadas perguntas sobre o conhecimento do que é feedback, quais são seus objetivos, tipos, modelos de transmissão, frequência com que é dada para alunos e preceptores. Para os alunos além das perguntas acima, também foram perguntados o grau de aceitação de críticas, a efetividade, sobre como gostariam de receber o feedback e quais mudanças foram percebidas.

Sobre os objetivos do feedback, os preceptores e os alunos estavam de acordo e relataram, por exemplo, que o esclarecimento de dúvidas é um dos objetivos, assim como reforçar os aspectos positivos da atividade prática, além de motivar reflexão crítica das ações realizadas. Esses conceitos vão de acordo a literatura, as devolutivas devem enfocar o desenvolvimento do aluno na prática, informando-o sobre modificações necessárias que contribuam para melhorar o desempenho, além de motivar estudantes a refletirem para solucionarem os problemas detectados (BURGESS; MELLIS, 2015). Os objetivos das devolutivas também são de conscientizar os alunos sobre as suas boas práticas durante o estágio e quais domínios de conhecimento, seja, cognitivo, psicomotor e comportamentais precisam de melhorias para auxiliar o aluno a obter as competências desejadas durante o estágio (HARDAVELLA et al, 2017). Além 
disso, o feedback deve conter informações com orientações para que os alunos desempenhem melhores performances em atividades futuras (CARR et al, 2019).

A frequência do feedback é muito importante para garantir efetividade na avaliação, enquanto na visão dos preceptores as devolutivas foram ofertadas com alta frequência ou em todas aulas práticas, porém, nenhum estudante relatou ter recebido devolutiva em todas aulas práticas e poucos alunos disseram as terem recebido com frequência. Este achado se assemelha ao que ocorreu no estudo de Liberman e colaboradores (2005), no qual os autores relataram que $86,2 \%$ dos cirurgiões deram feedback imediatamente após a atividade prática e apenas 12,5\% dos residentes perceberam esta frequência (LIBERMAN et al,2005). Os professores não têm compreensão sobre a prática do feedback e de como transmiti-lo, por isso a frequência de transmissão pode ser menor do que os preceptores relataram (BURGESS; MELLIS, 2015). Isso reforça o fato de que ser especialista no assunto a ser transmitido, bem como o tempo de atuação no campo da educação médica não significa, necessariamente, ser um bom preceptor, ou seja, aquele que estimula a reflexão do aluno e promove informações a respeito das necessidades de melhorias. Existem médicos preceptores que não se atualizam, nestes casos, eles transmitem o conteúdo de acordo como aprenderam, por acreditarem que seu tempo de experiência seja capaz de suprir suas necessidades pedagógicas, não havendo o engajamento necessário para modificações em seu comportamento perante a realização das devolutivas. Essa dificuldade de transmissão das devolutivas pode repercutir na percepção do estudante, o fato das devolutivas não apresentarem uma informação específica de qual comportamento deve ser modificado e não conter sugestões de como melhorá-las fazendo com que os alunos não percebam as devolutivas (CARR et al, 2019). Assim, há necessidade de melhorar a interação entre professor e aluno, necessidade de feedback claros e direcionados para que haja a efetividade.

Há dados que mostram que sozinho, o aluno tem dificuldade de perceber onde e como pode melhorar suas competências clínicas, sendo assim a habilidade de dar devolutivas específicas, oportunas e claras são habilidades fundamentais ao preceptor (CARR et al, 2019). Para Nottingham e colaboradores (2014), os preceptores com menos experiências promoveram menor número de feedback aos estudantes, enquanto os mais experientes promovem mais, o que também é notado nesse estudo onde 
preceptores com maior tempo de experiência na área de educação em saúde (dois anos e 10 anos) ofereceram devolutivas em todas aulas práticas.

No presente estudo, os tipos de devolutivas utilizadas pelos preceptores foram a oral, breve e construtiva. Apesar de existirem diversas maneiras de realizar o feedback, os alunos preferiram os feedbacks orais, provavelmente, devido a facilidade de serem ofertados e recebidos imediatamente (BRANCH; PARANJAPE, 2002). Outras formas de feedback que poderiam ser incorporadas são: (1) o Brief feedback (Breve) que visa fornecer a informação da necessidade de mudança de alguma ação no momento em que é observada; (2) formal, no qual a informação é dada ao final da atividade, focando em uma ou duas habilidades específicas com duração de 5 a 20 minutos; (3) maior (Major) que é a orientação dada no meio do estágio ou no final a respeito de performances e comportamentos mais complexos, culminando com um plano de ação para se obter melhorias antes do término do ciclo do estágio com duração de 15 à 30 minutos (BRANCH; PARANJAPE, 2002).

Sobre a avaliação da efetividade de um feedback, apenas um quarto dos preceptores relataram saber como avaliar. Esse resultado se difere de um estudo prévio, no qual $90,9 \%$ dos preceptores cirurgiões relataram avaliar efetividade no feedback oferecido aos residentes (LIBERMAN, 2005). A efetividade da devolutiva pode ser avaliada através da observação das tarefas e ações para as quais foram propostas melhorias e se essas foram realizadas, além do grau de motivação do aluno para reconstruir seu conhecimento em desempenhar as alterações necessárias. Nem sempre o feedback é aceito pelos alunos, levando à autorreflexão e mudanças comportamentais, principalmente quando as informações dadas pelos preceptores entram em conflito com os pensamentos dos alunos. Quando isto acontece, pode haver prejuízo na aquisição de competências clínicas e portanto, não atingir a efetividade que o feedback se propõe (TELIO; AJJWAI; REGEHR, 2015). No presente estudo, metade dos preceptores sentiram dificuldades em fornecer devolutivas negativas para os alunos. Os professores têm a percepção de que ao fornecer devolutivas negativas ocasionem um rompimento do relacionamento professor/aluno, além de terem sua popularidade afetada. Para amenizar esses efeitos os preceptores abordam críticas de forma mais amena, transmitindo mensagens de maneira indireta. A falta de um feedback 
direcionado de forma clara para o aluno pode não ser um feedback eficaz (TELIO; AJJWAI; REGEHR, 2015).

Por outro lado, o percentual de impactos negativos com as devolutivas ofertadas nesse estudo foi pequeno. Para que esse impacto negativo seja reduzido, a transmissão do feedback precisa ser clara, de maneira respeitosa, sem julgamentos, basear-se no que foi observado no momento e o que é passível de alteração para que se promova a reflexão e a motivação e, assim, favorecer as na mudanças na prática clínica (RAMANI; KRACHOV, 2012). O local em que essa devolutiva é dada parece ser a principal razão para o desconforto. Em local privado as devolutivas podem ser dadas de maneira clara, oportuna e específica, propiciando um incremento na aprendizagem do aluno, pois facilita a comunicação entre o aluno e o preceptor sem receio de ser ridicularizado pelos colegas (NTULI; SEPTEMBER; SITHOLE, 2018). Além disso, as mudanças comportamentais ocorrem mais quando há concordância do que foi falado pelo professor com o modo de pensar do estudante, adicionalmente, o grau de aceitação das devolutivas está associado ao poder de auto-avaliação do estudante (SCHARTEL, 2012).

Com relação aos impactos positivos do feedback, os resultados observados nesse estudo foram positivos e assemelham-se a outro estudo na literatura em que $95 \%$ dos estudantes tentaram mudar o comportamento com as devolutivas recebidas (BERNARD; KMAN; KHANDELWAL, 2011).

Outro ponto importante a destacar foi que maioria dos estudantes relataram desejo de que as devolutivas sejam práticas rotineiras nos estágios práticos. Os alunos reportam que embora os preceptores tenham conhecimento e clareza sobre os objetivos do instrumento de avaliação, ele não é usado nos estágios de forma constante. Concordando com os nossos resultados, entre 60 a $75 \%$ dos estudantes do estudo de Al-Mously e colaboradores (2014) consideraram a frequência de recebimento do feedback baixa à adequada, atribuindo a falta de uma base estrutural para que a transmissão do feedback fosse realizada (AL-MOUSLY et al, 2014).

As devolutivas dos alunos ao preceptor não parecem ser frequentes na prática dos estágios. Estudantes podem promover aos preceptores devolutivas sobre sua percepção à respeito dessa transmissibilidade, propiciando uma troca de informações para serem refletidas e propiciarem as mudanças necessárias, constituindo uma aprendizagem bidirecional (CARR et al, 2018). Notou-se que preceptores preferem

WWW.AMPLLAEDITORA.COM.BR $(2)$ 
receber devolutivas de pessoas que tenham competências para avaliarem sua desenvoltura na prática profissional, o que também é percebido com os alunos, os quais preferem receber feedback de professores que consideram como modelos profissionais (JAMSHIDIAN et al, 2019).

Preceptores que recebem devolutivas e as utilizam para melhorarem seu desempenho profissional, seja como médico ou professor, estão mais engajados a fornecerem devolutivas para o aluno (MENACHERY et al, 2006).

\section{CONCLUSÃO}

Conclui-se que há necessidade de aprimoramento dos preceptores para a realização de uma avaliação efetiva por feedback. Apenas um quarto dos preceptores relataram ter muito conhecimento sobre o feedback, enquanto mais da metade dos alunos afirmaram ter de muito a extremo conhecimento sobre essa estratégia de aprendizado. Os alunos têm maior clareza sobre os objetivos do feedback, demonstrando que estão habituados com esse instrumento de aprendizado por receberem feedback não só nos estágios práticos, mas também, em outras atividades de aprendizagem. Isso também explica o fato dos estudantes não sentirem desconforto ao receberem devolutivas as quais constituem práticas deliberativas em outras atividades. Outro ponto a destacar é que embora a maioria dos preceptores relatem que transmitem as devolutivas com frequência, mais da metade dos alunos afirmam as terem recebido raramente e ocasionalmente, podendo configurar falta de comunicação efetiva entre o preceptor e o aluno. Além disso, a pouca solicitação dos preceptores por devolutivas pode caracterizar o medo de que têm a respeito de receberem devolutivas criticando sua atuação pedagógica, podendo haver resquícios da superioridade atribuída aos professores durante o uso das metodologias tradicionais. Este fato deve ser banido, pois para haver melhor aceitação das devolutivas deve haver uma aliança educacional, o que significa maior proximidade entre preceptor e aluno. Os alunos lidam bem com críticas e aceitam as devolutivas gerando impactos positivos em seu aprendizado, percebendo maior confiança em si no que se refere a atuação médica, raciocínio clínico, percepção de erros e requerem que as devolutivas sejam uma prática constante nos estágios práticos. Uma pequena porcentagem de alunos relatou impactos

WWW.AMPLLAEDITORA.COM.BR (2) 
negativos e desconforto devido problemas na transmissão das devolutivas e foram relacionados ao local, exposição frente a outras pessoas ou forma de falar. Para que as devolutivas sejam efetivas, os alunos relatam que o professor precisa ser claro em sua fala, não fazer julgamentos, ser respeitoso, propor correções, melhorias, ter didática para o ensino médico e qualificação para sua transmissão. Isso pode ser obtido por meio de informações de como estruturar um feedback através da criação de um guia sobre devolutiva, treinos para habilitação da transmissão das devolutivas, bem como uma verificação de como estão sendo realizadas e interpretadas na prática. Já no ponto de vista dos preceptores, os alunos devem ter habilidades de fala e escuta, empatia, respeito, interesse e com essas qualidades se tornarem pró-ativos no processo para o aperfeiçoamento das competências designadas, tornando o feedback uma estratégia efetiva de aprendizado.

\section{REFERÊNCIAS}

ALBANO, S., et al. "Resident Perspective on Feedback and Barriers for Use as an Educational Tool." Cureus, v. 11, n. 5, p. e4633, 2019.

BERNARD, A. W.; KMAN, N. E.; KHANDELWAL, S. Feedback in the emergency medicine clerkship. West J Emerg Med., v.12, n. 4, p. 537-542, 2011.

BRASIL. Lei no 8.080, de 19 de setembro de 1990. Organização do Sistema Único de Saúde - SUS, Disponível em: http://prattein.com.br/home/images/stories/Saude/Lei-orgsaude.pdf

CÂMARA DE EDUCAÇÃO SUPERIOR. Conselho Nacional de Educação. Resolução no 4, de 7 de novembro de 2001. Institui Diretrizes Curriculares Nacionais do Curso de Graduação em $2001 . \quad$ Disponível em: http://portal.mec.gov.br/cne/arquivos/pdf/CES04.pdf. Acesso em: 5 mar. 2019.

CÂMARA DE EDUCAÇÃO SUPERIOR. Conselho Nacional de Educação. Resolução no 3, de 20 de junho de 2014. Institui Diretrizes Curriculares Nacionais do Curso de Graduação em Medicina e dá outras providências, 2014. Disponível em: http://portal.mec.gov.br/cne/arquivos/pdf/CES04.pdf. Acesso em: 5 mar. 2019.

BURGESS, A.; MELLIS C. Feedback and assessment for clinical placements: achieving the right balance. Adv Med Educ Pract. v.6, p.373-81. 2015.

BRANCH, W. T; PARANJAPE, A. Feedback and Reflection: Teaching Methods for Clinical Settings, Academic Medicine, v.77, n.12, p.1185-1188, 2002. BRANCO, M. L.; FRAZÃO, R. A educação progressiva na atualidade: o legado de John Dewey. Educ.Pesqui., v.40, n.3, p. 783-798, 2014. 
CANTILLON, P.; SARGEANT, J. Giving feedback in clinical settings. BMJ (Clin Res Ed), Galway, v. 337, p. a1961, 2008.

CAREgNATO, R. C. A.; MUTTI, R. Pesquisa qualitativa: análise de discurso versus análise de conteúdo. Texto contexto - enferm., v. 15, n. 4, p. 679-684, 2006.

CARR, B. M. et al. Bridging the gap to effective feedback in residency training: perceptions of trainees and teachers. BMC medical education, v. 18, n. 1, p. 1-6, 2018.

DENT, J. A.; HARDEN, R. M. A Practical Guide for Medical Teacher, 3 ed. Churchill Lvingstone: Elsevier, p. 357-364, 2009.

HARDAVELLA, G., et al. How to give and receive feedback effectively. Breathe (Sheffield, England), v. 13, n. 4, p. 327-333, 2017.

JAMSHIDIAN, S., et al. Provision of feedback to medical teachers on their educational performance: perspectives of internal medicine teachers. Adv Med Educ Pract, v. 10, p. $85-94,2019$

LIBERMAN, S., et al. Surgery residents and attending surgeons have different perceptions of feedback. Medical teacher, v. 27, n. 5, p. 470-472, 2005.

MAIA, I. L. Avaliação e percepção dos estudantes de medicina sobre mudança de atitude e desenvolvimento de competências a partir da utilização de feedback estruturado. Dissertação (Mestrado de Educação em Saúde) - Centro Universitário Unichristus, Fortaleza, 2018.

MENACHERY, E. P., et al. Physician characteristics associated with proficiency in feedback skills. J Gen Intern Med., v. 21, n. 5, p. 440-446, 2006

AL-MOUSLY, N. et al. Undergraduate medical students' perceptions on the quality of feedback received during clinical rotations. Med Teach., v. 36, p. S17-S23, 2014.

NOTTINGHAM, S.; HENNING, J. Feedback in clinical education, part II: approved clinical instructor and student perceptions of and influences on feedback. Journal of athletic training, v. 49, n. 1, p. 58-67, 2014

NTULI, S.; SEPTEMBER, N. N.; SITHOLE, N. South African podiatry students' perceptions of feedback given as part of clinical training. J Foot Ankle Res., v. 11, n. 36, 2018. OLIVEIRA, C. A.; SENGER, M. H. Avaliação formativa: estamos preparados para

PAGLIOSA, F. L.; Da ROS, M. A. O relatório Flexner: para o bem e para o mal. Rev. bras. educ. med., v. 32, n. 4, p. 492-499, 2008.

PANÚNCIO-PINTO, M. P.; TRONCON, L. E. Avaliação do estudante - aspectos gerais. Medicina (Ribeirão Preto. Online), v. 47, n. 3, p. 314-323, 2014.

RAMANI, S.; KRACKOV, S. N. Twelve tips for giving feedback effectively in the clinical environment, Med Teach., v. 34, n. 10, p. 787- 791, 2012. 
SCHARTEL, S. A. Giving feedback-An integral part of education. Best practice \& research Clinical anesthesiology, v. 26, n. 1, p. 77-87, 2012.

TELIO, S.; AJJAWI, R.; REGEHR, G. The "educational alliance" as a framework for reconceptualizing feedback in medical education. Academic Medicine, v. 90, $\mathrm{n}$. 5, p. 609-614, 2015.

TRONCON, L. E. Avaliação do Estudante de Medicina. Medicina (Ribeirão Preto.

Online), v. 29, n. 4, p. 429-439, 1996. 


\title{
CAPÍTULO XVI
}

\section{CAFÉ E SUAS PROPRIEDADES FUNCIONAIS: UMA BREVE REVISÃO DE LITERATURA SOBRE $O$ USO DA CAFEINA E SEUS BENEFICIOS}

\author{
Anna Luiza Santana Neves ${ }^{1}$ \\ Anna Carolinne Santana Neves ${ }^{2}$ \\ ${ }^{1}$ Graduando do curso de História. Universidade Federal do Rio Grande do Norte - UFRN \\ ${ }^{2}$ Mestrando em Recursos Hídricos. Programa de Pós-Graduação em Engenharia - UFBA \\ ${ }^{3}$ Professor Adjunto do Departamento de Artes. Universidade Federal do Amazonas - UFAM
}

\section{RESUMO}

$\mathrm{O}$ alto índice de consumo de café, em nível mundial, tem despertado o interesse de muitos pesquisadores no que tange a relação entre a qualidade da bebida e compostos bioativos, ligados ao café verde, e, mas principalmente ao torrado, que é a forma mais comumente consumida. Entre os compostos do café, destaca-se a cafeína, classificada como metilxantina, sem valor nutricional, e lipossolúvel. Ultimamente, devido a mudança no estilo de vida da população, a busca por estimulantes fez a cafeína ser uma das substâncias mais consumidas do mundo possivelmente devido a seus recursos recurso farmacológicos. Diversos estudos investigaram os efeitos positivos da cafeína sobre a saúde humana, e o objetivo dessa revisão é reunir os últimos trabalhos que englobem os estudos sobre cafeína tanto na forma manipulada como in natura e suas propriedades funcionais. Para a realização da revisão de literatura, foram utilizados artigos contidos no "PubMed"e Portal de "Periódico da CAPES", praticada uma busca sistemática com os seguintes descritores: "caffeine" "coffee", "benefits", "functional properties" "effects". Foram encontrados mais de 1000 artigos, após leitura dos títulos e resumos foram selecionados 15 registros. Os artigos demonstraram diferentes aplicações da cafeína, a maioria dos artigos encontrados associando seu uso principalmente a melhora da função cognitiva e melhora da performance física, mas muito se fala também sobre tratamento de doenças, inclusive do câncer.

Palavras-chave: Benefícios. Efeitos. Metilxantina. Propriedades funcionais.

\section{INTRODUÇÃO}

Sem dúvidas, o café é uma paixão por grande parte da população brasileira. Conforme apresenta a Associação Brasileira da Industria de Café - ABIC, o Brasil é o maior produtor de café do mundo com 58,5 milhões de sacas produzidas em 2018, tendo Minas Gerais como o maior produtor de café entre os estados (ABIC, 2019). 
O café é uma mistura complexa de milhares de componentes químicos, incluindo hidratos de carbono, lipídios, componentes nitrogenados, vitaminas, minerais e alcaloides. Os grãos de café verde contêm o complexo de antioxidantes, principalmente ácidos clorogênicos (ácidos cafeoilquinóicos), e mostram propriedades antioxidantes in vitro (JESZKA-SKOWRON et al., 2016)

A fermentação do café, incluindo a de grãos torrados, também contém ácidos clorogênicos e cafeína e outros compostos bioativos com capacidade antioxidante, como teofilina e teobromina, tocoferóis, cafestol, kahweol e trigonelina, além de produtos da reação de Maillard (JESZKA-SKOWRON et al., 2015)

Mas é a cafeína e os seus efeitos no organismo que deram popularidade ao café (ALMEIDA, 2015). Indubitavelmente o café serve como fonte primária de cafeína para o adulto, sendo consumido em diferentes níveis e segmentos pela maioria da população.

A cafeína é uma droga classificada como metilxantina, sem valor nutricional, e lipossolúvel. Essa substância pode ser encontrada em diversos produtos de alto consumo mundial como o guaraná, o chocolate, o mate, entre outros, sendo uma das drogas mais consumidas do mundo (VAZ, 2016)

O café possui de 1 a 2,5 \% de cafeína, que é o componente mais conhecido por seus efeitos estimulantes sobre o sistema nervoso central, e geralmente é associada a uma melhora no estado de alerta, na capacidade de aprendizado e resistência ao esforço físico. Após ser transformada pelo organismo humano, ela pode contribuir para a atividade antioxidante da bebida (ABIC, 2019)

Do ponto de vista alimentício, todos esses componentes fazem do café uma bebida natural e saudável e se ingerido em doses moderadas, pode fazer muito bem para a saúde, além de outros benefícios. Com esse foco em mente, o objetivo do trabalho é buscar na literatura artigos que confirmem os benefícios do café e principalmente da cafeína do ponto de vista funcional e de saúde.

\section{REVISÃO BIBLIOGRÁFICA}

O fruto do café origina-se de um arbusto da família Rubiaceae, ordem Gentianales, que se desenvolve em regiões tropicais ou subtropicais e está presente na natureza em mais de sessenta espécies. É nativo da Etiópia, país do continente africano 
e apresenta distribuição nas Américas Central e do Sul, na África e leste da Ásia, sendo cultivado principalmente no Brasil (DE CARVALHO OLIVEIRA et al., 2018; (BAGYARAJ et al., 2015)

O cultivo do café evoluiu de maneira significativa ao longo do desenvolvimento histórico e econômico do Brasil, especialmente em termos de localização da produção. Entre as espécies mais cultivadas está o café arábica (Coffea arábica L.), que responde por cerca de $60 \%$ a $70 \%$ da produção mundial, sua expansão geográfica está concentrada na América Latina, na América Central, na África Oriental, na Índia e, até certo ponto, na Indonésia (CARVALHO et al., 2017).

Desde os primórdios das transações mercantis simples, o café tem sido um produto de extrema relevância nas economias mundiais se destacando como o segundo produto mais comercializado no mundo depois do petróleo (DE CARVALHO OLIVEIRA et al., 2018) Os grãos de café arabica são tidos como sendo mais caros e valiosos pelas suas características organoléticas únicas (BAGYARAJ et al.,2015) O segmento do café representa, atualmente, aproximadamente $12 \%$ do mercado internacional da bebida (SEBRAE, 2019)

Sua popularidade pode estar associada a complexidade da bebida, resultado do grande número de compostos químicos contidos nos grãos de café verde. A composição química dos grãos crus é determinada por aspectos genéticos, ambientais, adubação, trato fitossanitários, ligados à maturação dos frutos, cuidados durante a colheita, secagem e por fim no beneficiamento, armazenagem e modo de preparo. (SILVA, 2005; SIMOES et al., 2008).

As transformações sofridas por essa composição química em todas as fases do processamento do grão e da extração do café, originam uma grande diversidade de estruturas complexas que se podem encontrar numa xícara de café (ROTHFOS, 1980).

Uma alimentação rica em produtos vegetais sempre esteve associada a uma vida mais saudável, com isso, diversos estudos sobre as funcionalidades dos vegetais no organismo estão abrangendo o conhecimento sobre os compostos bioativos que também recebem diversos nomes como fitoquímicos, nutracêutico e compostos bioprotetores (TORTORA; DERRICKSON, 2012) Nos últimos anos houve um aumento no interesse por alimentos com atividades biológicas, principalmente com propriedades antioxidantes (NEWMAN; CRAGG, 2012).

WWW.AMPLLAEDITORA.COM.BR (2) 
As bebidas de café são reconhecidas pelas características sensoriais de aroma, acidez, corpo, amargor e adstringência, e os atributos aroma doce, de café e sabor ácido se apresentaram como diferencial durante safras e processamentos (SCHOLZ et al., 2019).

Uma particularidade da bebida do café é o facto de apresentar um valor nutricional irrelevante, sendo consumida pelos efeitos fisiológicos, nomeadamente a sua atividade estimulante, psicológicos e pelas propriedades sensoriais resultantes do aroma e sabor que a cafeína proporciona. O efeito estimulante da cafeína tem levado a que os consumidores reduzam a frequência do seu consumo, devido a possíveis efeitos colaterais sobre o sistema nervoso central, endócrino e cardiovascular (GAWLIK-DZIKI et al., 2014).

\subsection{Café e seus componentes}

As estatísticas mostram que o consumo moderado de café ( 3 a 5 xícaras / dia) reduz o risco de doença cardiovascular. Há evidências crescentes de que o café pode prevenir algumas doenças crônicas, como câncer, doenças cardiovasculares, doenças metabólicas e cirrose (WANG et al., 2016; SHANG et al., 2016 ; BRAVI et al., 2017)

O café apresenta mais de 800 compostos de várias classes já identificados, Os principais compostos ativos no café que desempenham esses papéis incluem cafeína, ácido clorogênico, cafestol e kahweol (SILVA et al., 2018)

As pessoas acreditam que o café possui apenas cafeína em sua composição. No entanto, o mesmo contém apenas 1 a 2,5 \% de cafeína, que faz parte dos grupos das xantinas, além de diversas outras substâncias em maior quantidade com funções nutricionais, com destaque não apenas para a cafeína em sua composição, mas por sua alta concentração de polifenóis que são ricos em vitaminas do complexo $B$, nutrientes esses tão importantes comparados a cafeína (EMBRAPA, 2011)

Podemos encontrar em um grão de café minerais como: potássio (K), magnésio $(\mathrm{Mg})$, cálcio $(\mathrm{Ca})$, sódio $(\mathrm{Na})$, ferro (Fe), manganês $(\mathrm{Mn})$, rubídio $(\mathrm{Rb})$, zinco $(\mathrm{Zn})$, Cobre $(\mathrm{Cu})$, estrôncio $(\mathrm{Sr})$, cromo $(\mathrm{Cr})$, vanádio $(\mathrm{V})$, bário (Ba), níquel (Ni), cobalto (Co), chumbo $(\mathrm{Pb})$, molibdênio (Mo), titânio (Ti) e cádmio ( $\mathrm{Cd})$; aminoácidos como alanina, arginina, asparagina, cisteína, ácido glutâmico, glicina, histidina, isoleucina, lisina, metionina, fenilalanina, prolina, serina, treonina, tirosina, valina; lipídeos como triglicerídeos e 
ácidos graxos livres, açúcares como sucrose, glicose, frutose, arabinose, galactose, maltose e polissacarídeos

\subsubsection{Kahweol}

Furstenau et al (2019) relatam que o kahweol (1,2 didesidrocafestol) é o diterpeno presente em maior quantidade em cafés não filtrados, como o café turco e seus efeitos protetores são descritos como antioxidantes, anti- inflamatórios, antitumorais e quimioprotetores em diferentes modelos experimentais ( LEE, 2007 ; CÁRDENAS et al., 2011 ; CÁRDENAS et al., 2014 ; CHOl et al., 2019 ; IWAMOTO et al., 2019)

\subsubsection{Cafestol}

A única diferença entre o cafestol e kahweol em termos estruturais é que o kahweol possui uma ligação dupla extra (HALVORSEN et al., 1998)

Cafestol e kahweol podem regular uma variedade de mediadores inflamatórios para reduzir a inflamação. Além disso, os dois diterpenos do café podem impedir a ocorrência de câncer, bloqueando a ativação de agentes cancerígenos e melhorando a função de desintoxicação do fígado. Eles também podem inibir a proliferação e a angiogênese das células tumorais e fornecer uma nova abordagem para a prevenção e tratamento do câncer (REN et al., 2019).

Figura I. Estrutura e características químicas de cafestol e kaweol. São diterpenos naturais extraídos de grãos de café.

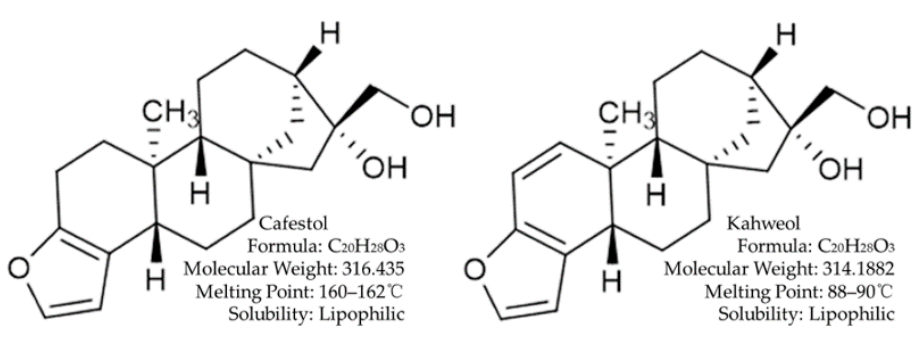

Fonte: ALVES (2009)

\subsection{2. Ácidos clorogênicos}

Os ácidos clorogênicos são polifenóis de ação antioxidante, que na torração formam quinídeos, os quais causam efeito antagonista ao opióide, que bloqueiam no sistema límbico, levando o indivíduo insatisfeito à depressão. O consumo diário de 4 
xícaras de café pode evitar à depressão. (Fonseca et al., 2011) Outro importante constituinte do café são os ácidos clorogênicos que quando hidrolisados dão origem aos ácidos cafeico e quínico. O ácido cafeico representa cerca de 50\% dos ácidos clorogênicos presentes no café. Ou seja, em uma xícara de $200 \mathrm{~mL}$ de café é possível encontrar entre 70 a 350mg de ácidos clorogênicos e de 35 a 175mg de ácido cafeico (FOOD-INFO, 2014).

Figura II: Principais compostos bioativos do café: ácidos clorogênicos.

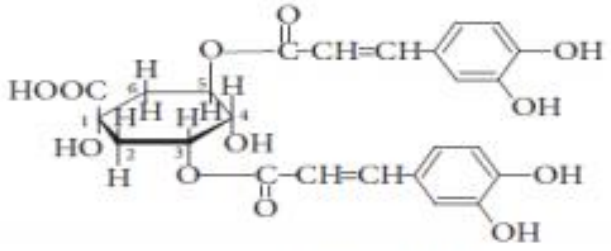

Acido 3,5-dicafeoilquínico (3,5-AdiCQ)

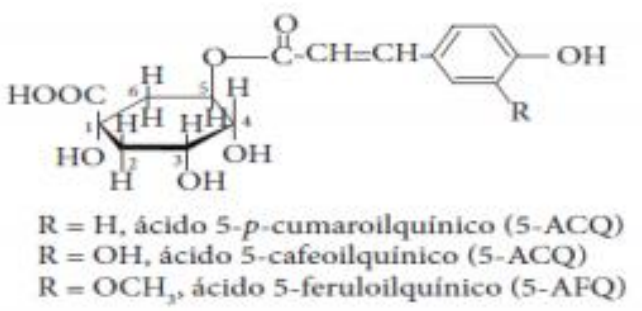

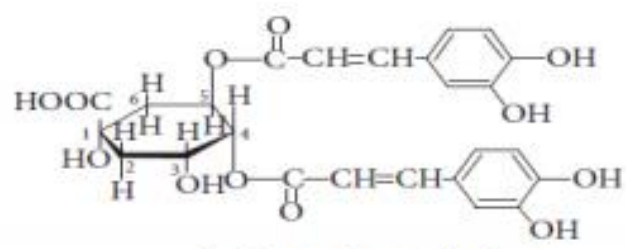

Ácido 4,5-dicafeoilquínico (4,5-AdiCQ)

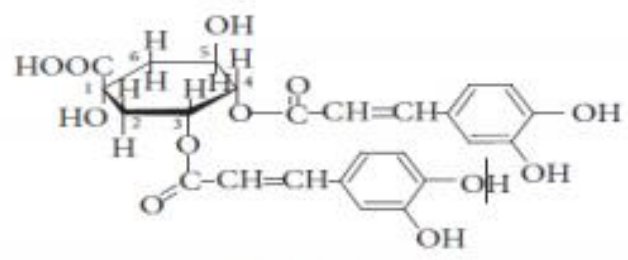

Âcido 3,4-dicafeoilquínico (3,4-AdiCQ)

Fonte: ALVES (2009)

\subsubsection{Cafeína}

A cafeína é um alcaloide natural (1,3,7-trimetilxantina) dos grãos de café, que está presente também em chá e em outras bebidas cafeínadas amplamente consumidas, assim como no chocolate e em alguns medicamentos (REIS et al., 2014).

Tem ação principalmente como inibidor no sistema nervoso central, sistema cardiovascular e na homeostase do cálcio, resultando na elevação da pressão sanguínea, aumento do metabolismo e na produção de suco gástrico. É absorvida pelo trato gastrointestinal e principalmente metabolizado pelo fígado. Esse alcaloide exerce certa influência sobre as funções cognitivas e físicas, uma vez que a maioria das atividades do mundo real exige complexas tomadas de decisão, processamento e movimento motor. A cafeína exerce seus efeitos bloqueando os receptores de adenosina. (ROSA et al., 2018) 
Após a ingestão de baixa ( $\sim 40 \mathrm{mg}$ ou $\sim 0,5 \mathrm{mg} \mathrm{kg}^{-1}$ ) a moderada ( 300 mg ou $4 \mathrm{mg} \mathrm{kg}^{-1}$ ) doses de cafeína, a vigilância, atenção e tempo de reação melhoram, mas efeitos menos consistentes são observados na memória e na função executiva de ordem superior, como julgamento e tomada de decisão. Efeitos sobre o desempenho físico em uma vasta gama de métricas de desempenho físico, como força e resistência muscular e sprints de alta intensidade típicos de esportes coletivos, são evidentes após doses que excedem cerca de $200 \mathrm{mg}\left(\sim 3 \mathrm{mg} \mathrm{kg}^{-1}\right)$ Muitas ocupações, incluindo militares, socorristas, trabalhadores de transporte e trabalhadores em turnos noturnos, exigem funções físicas e cognitivas ideais para garantir o sucesso, a segurança e a produtividade no local de trabalho. Nessas circunstâncias, que podem incluir sono restrito, a administração repetida de cafeína é uma estratégia eficaz para manter as capacidades físicas e cognitivas (MCLELLAN et al., 2016)

Figura III: Estruturas química da cafeína (1,3,7-trimetilxantina)<smiles>Cn1c(=O)c2c(ncn2C)n(C)c1=O</smiles>

Fonte: ALVES (2009)

A empregabilidade ativa da cafeína é amplamente utilizada pela população em geral nas mais diversas formas, seja pelo efeito estimulante do sistema nervoso central quando ingerida, ou mesmo de utilizações cosméticas com objetivo de promover lipólise local (ALTERMANN et al., 2008). Estimulantes são substâncias psicoativas eficientes em modificar a fisiologia do organismo e são usados principalmente por esportistas e indivíduos que desejam aumentar a resistência física, ter uma maior concentração, evitar o sono e aumentar a sensação de bem estar (MARIA ; GOMIDE, 2019)

No entanto novas ações terapêuticas, além das usuais, estão sendo rotineiramente estudadas e atribuídas ao consumo da cafeína, assim mostrando-se necessário o aprofundamento literário neste assunto (TROMBINI ; OLIVEIRA, 2013) 


\subsubsection{Mecanismos de ação da cafeína}

Podemos encontrar aproximadamente 47 a 134 mg de cafeína em uma xicara de café. A cafeína é uma substância absorvida de modo rápido e eficiente, via administração oral, através do trato gastrointestinal com aproximadamente $100 \%$ de biodisponibilidade, alcançando um pico de concentração máxima na corrente sanguínea após 15 a 120 minutos de sua ingestão (SINCLAIR; GEIGER, 2000)

O pico plasmático da cafeína ocorre de 30 minutos a 2 horas após seu consumo, potencializando seu efeito através da ingestão de alimentos. Sua absorção ocorre no trato intestinal, de forma completa, com grande biodisponibilidade e elevada solubilidade em água. Sua principal ligação com proteínas plasmáticas acontece com a albumina, de 10 a 35 \% com um volume de distribuição de aproximadamente 0,6 a 0,07 L.kg-11. Seus efeitos biológicos são resultantes da sua ação em variados sítios de ligação: Receptores de adenosina, fosfodiesterases, canais de cálcio, receptores de GABAA entre outros (TAVARES; SAKATA, 2012).

\section{METODOLOGIA}

\subsection{Delineamento do estudo}

Trata-se de uma revisão descritiva da literatura. Neste estudo, foram descritas informações contidas em estudos originais e de revisão sobre os estudos realizados com cafeína e suas propriedades funcionais.

\subsection{Fontes de dados}

A busca foi realizada eletronicamente, utilizando as bases de dados PubMed e Portal de Periódico da CAPES.

\subsection{Descritores}

Os descritores utilizados nas fontes de dados selecionadas foram: "caffeine", "coffee", "benefits", "functional properties" "effects"

\subsection{Critérios de inclusão e exclusão}

Foram incluídos os artigos disponíveis gratuitamente na íntegra (open acess), com data de publicação entre novembro de 2015 e novembro de 2019, e escritos nos 
idiomas português, espanhol ou inglês. Foram excluídos os artigos com apenas o resumo disponível, estudos que não se referissem ao tema de interesse, ou que não descrevessem bem como com data de publicação anterior a novembro de 2015, ou escritos em outros idiomas que não o português, inglês ou espanhol. Foram encontrados mais de 1000 artigos, após leitura dos títulos e resumos foram selecionados 15 registros.

\subsection{Pesquisa bibliográfica}

Foi então realizada a pesquisa de dados e a leitura cuidadosa dos títulos e resumos dos artigos recuperados pela estratégia de busca, respeitados os devidos critérios de inclusão e exclusão. Esta foi a pré-seleção de artigos. Então, os trabalhos pré-selecionados passaram por avaliação mais rigorosa, na qual não só os títulos e resumos foram lidos e examinados, mas todo o artigo. Após esta análise, mais artigos foram considerados inadequados, de forma que apenas os artigos restantes foram incluídos no estudo. Os dados obtidos dos artigos selecionados foram utilizados para a construção dos resultados e discussões.

\section{RESULTADOS E DISCUSSÕES}

Há alguns benefícios estudados que aproximam a atividade da cafeína como adjuvante no controle glicêmico em indivíduos portadores do diabetes tipo 2. Apesar de essa xantina promover, indiretamente, a ativação do sistema adrenérgico no organismo, o que a princípio promoveria o aumento do glucagon e, consequentemente, a glicogenólise, disponibilizando glicose no sangue. Existem estudos que identificam tal substância como capaz de reduzir a resistência periférica no tecido muscular esquelético de maneira a auxiliar, mesmo que em taxas discretas, o controle glicêmico. (CAZARIM; UETA, 2015)

As atuais evidências de Silvestre et al (2018) mostram que a utilização da cafeína como recurso ergogênico nutricional promove melhora do desempenho físico, principalmente em modalidades de endurance, e essa melhora no desempenho é devido aos mecanismos de ação da cafeína no sistema nervoso central.

Um estudo realizado no ano de 2015 por Nirmala e colaboradores sobre a ingestão de cafés e a sua relação com câncer de mama na pós menopausa sugeriu que 
a ingestão de cafeína pode estar associada a menor risco de desenvolvimento de câncer de mama na pós-menopausa.

Em um trabalho publicado no ano de 2018 por Estevam et al., foi possível concluir que houve uma tendência no aumento de força máxima proporcionado pela cafeína em homens adultos ativos, comprovado pelo teste de 1RM, o mesmo resultado foi apresentado para o retardo da fadiga, comprovado pelo teste de Repetições máximas. Em outro estudo que estudava a percepção de dor durante um treinamento de força, foi concluído que os efeitos da suplementação de cafeína demonstraram-se com uma menor percepção de dor durante o treinamento de força (OLIVEIRA et al., 2017)

A ingestão de $5 \mathrm{mg} \cdot \mathrm{kg}-1$ de CAF por atletas juniores de futebol após uma semana de abstinência, segundo Lima et al., (2017) exerce efeito ergogênico durante o teste de prioridade aeróbia de alta intensidade, principalmente quanto a parâmetros de melhora no consumo máximo de $\mathrm{O} 2$ e redução no tempo individual de execução de teste.

Há indícios científicos de que a cafeína, através da interação com os sistemas dopaminérgico, glutaminérgico e GABA-érgico, altera o curso clínico do Parkinson e do Alzheimer. Devido à sua ação central, através da diminuição da atividade da adenosina e do GABA, a cafeína apresenta alguns efeitos neuroprotetores em injúrias cerebrais associadas ao sistema glutaminérgico, como os efeitos observados nos modelos experimentais da doença de Alzheimer e do Parkinson (CAZARIM; UETA, 2015)

Carvalho (2019) evidenciou em seus estudos que o café possui potencial neuroprotetor por ser antagonista do receptor $\mathrm{A} 2 \mathrm{~A}$, de caráter excitatório, promovendo redução no risco de desenvolver a Doença de Parkinson (DP). Além disso, a cafeína também foi associada com a diminuição de tremores concatenados ao comprometimento motor e não motor ao longo da evolução dessa patologia. Entretanto, o estudo em questão também mostrou controvérsias na correlação entre o uso da cafeína e o desenvolvimento da DP, visto que em alguns pacientes o efeito se mostrou inexistente, enquanto em outros o consumo do café apareceu como um fator de risco, denunciando a interferência da interação entre a cafeína com o genótipo do indivíduo.

Hauschild \& Adami (2018) relataram em seu estudo que a cafeína contribi para um menor consumo de carboidratos como também na perda de \% gordura corporal e

WWW.AMPLLAEDITORA.COM.BR (2)

CONTATO@AMPLLAEDITORA.COM.BR 
consumo de carboidratos, cafeína, proteína e calorias totais, associaram se com o aumento do peso magro.

Além das aplicações nas áreas de saúde, cafeína provou em um trabalho de MIRANDA (2019) ter potencial para utilização como larvicida natural, uma vez que os efeitos dela foram semelhantes a de inseticidas conhecidos. Os tratamentos também afetaram o intestino médio das larvas de A. aegypti, causando estresse oxidativo, ativando a apoptose, inibindo a proliferação de células-tronco e reduzindo o número de células enteroendócrinas FMRFamida. Além do mais, a borra de café usada no estudo apresenta menor toxicidade ao meio ambiente e a organismos não-alvos, em relação aos inseticidas químicos, e é um produto livre de custos, por ser de uso cotidiano e de descarte, transformado em ferramenta de controle alternativo de vetores.

Um estudo prospectivo realizado na Finlândia demonstrou que o consumo de quatro ou mais xícaras de café por dia poderia ser um fator de risco para artrite reumatóide com fator reumatóide positivo (OLIVEIRA, 2011).

Em uma revisão sistemática desenvolvida por Silva et al (2015) acerca da associação entre consumo de cafeína na gestação e ocorrência de TDAH nos filhos, foram identificados apenas cinco estudos que avaliaram os efeitos do consumo materno de cafeína durante a gestação e a ocorrência de TDAH na infância, sendo seus achados controversos. Dentre os quatro estudos mais bem delineados e analisados apenas um encontrou associação entre consumo de cafeína e hiperatividade aos 18 meses de idade. Assim, a evidência atualmente disponível é insuficiente para que se possa afirmar ou refutar a associação entre o prevalente hábito de consumir alimentos ricos em cafeína na gestação e a ocorrência de TDAH entre os filhos.

Em um estudo no ano de 2015 com 539.577 participantes sobre consumo de café e risco de câncer de próstata, Liu et al. concluíram que o risco relativo apontava para uma associação inversa. O risco de câncer de próstata diminuiu 2,5\% para cada 2 xícaras de café consumidas por dia Liu et al. ( 2015 ) acreditavam que são necessários mais estudos para confirmar ainda mais os achados.

Em uma outra metanálise, Liu et al. ( 2016 ), agora sobre melanoma maligno que incluíram estudos de caso e estudos de coorte. Um total de 844.246 participantes foram incluídos no estudo. Foi estabelecido que participantes com mais ingestão de cafeína podem ter um risco reduzido de melanoma. Os resultados do estudo indicaram que as

WWW.AMPLLAEDITORA.COM.BR (2)

CONTATO@AMPLLAEDITORA.COM.BR M 
bebidas com cafeína podem ter alguns efeitos quimio-preventivos em relação ao melanoma, e concluiu-se que mesmo uma xícara de café com cafeína por dia diminui o risco de melanoma.

Xie et al. ( 2016 ) em um estudo com mais de 1.000.000 de participantes. descobriram forte associação entre beber café e uma redução no risco de câncer gástrico. Um aumento no consumo de café mostrou que houve uma diminuição no risco de câncer gástrico

Em um estudo em 2017, cujo objetivo era investigar os efeitos modificadores da cafeína na lesão hepática induzida pela administração de tioacetamida (TAA) em ratos machos, no grupo de co-tratamento os animais receberam uma dose de TAA de $200 \mathrm{mg}$ / kg b.w e 37,5 mg / kg de cafeína. Após oito semanas de tratamento, foi observado que o TAA induziu toxicidade hepática, e aumentou consideravelmente os níveis de citocinas pró-inflamatórias (TNF-a, IL-1 $\beta$ e IL-6) no soro. O co-tratamento com cafeína e TAA restaurou a estrutura e função normal do fígado. Deste modo, a cafeína forneceu um efeito anti-fibrogênico, antiinflamatório e antioxidante que foi associado à recuperação de alterações hepáticas histológicas e funcionais da hepatotoxicidade induzida por TAA (AMER et al., 2017)

\section{CONSIDERAÇÕES FINAIS}

Por meio da pesquisa, pode-se concluir que a cafeína apresenta uma grande variedade de efeitos benéficos, como melhora da atenção; melhora no rendimento físico; quebra de gorduras; menor consumo de carboidratos, entre outros, em outras palavras, a cafeína apresenta um leque de aplicabilidades. Embora esta substância apresente efeitos benéficos, seu uso deve ser feito de maneira cautelosa, pois como toda droga, a cafeína, também apresenta efeitos colaterais de dependência e toxicidade. Por ser uma substância muito consumida necessita de mais estudos para caracterizar esses efeitos adversos. O aprofundamento literário em alguns aspectos pode contribuir para a elucidação de mecanismos ainda desconhecidos ou controversos, pelo qual a cafeína interage com os diversos sistemas fisiológicos. 


\section{REFERÊNCIAS}

ABIC. Sabor do café: história do café. Associação Brasileira Da Indústria De Café. Disponível em: <http://abic.com.br/cafe-com/historia/>. Acesso em: nov. de 2019.

ABIC. Café e Saúde. Composição Química. Associação Brasileira Da Indústria De Café. Disponível em: < http://abic.com.br/o-cafe/cafe-e-saude/composicaoquimica/> Acesso em: nov. de 2019.

ALMEIDA, S. A. M. Consumo de café pelos estudantes de Medicina da Universidade da Beira Interior. 2015. 48f. Dissertação para obtenção do Grau de Mestre em Medicina. Universidade da Beira Interior, Covilhã, 2015.

ALTERMANN, A. M. et al. A influência da cafeína como recurso ergogênico no exercício físico: sua ação e efeitos colaterais. Revista Brasileira de Nutrição Esportiva, São Paulo, v. 2, n. 10, p. 225-239, 2008.

ALVES, R. C.; CASAL, S.; OLIVEIRA, B. Benefícios do café na saúde: mito ou realidade? Quim. Nova, v. 32, n. 8, p.2169-2180, 2009

AMER, M. G.; MAZEN, N. F.; MOHAMED, A. M. Caffeine intake decreases oxidative stress and inflammatory biomarkers in experimental liver diseases induced by thioacetamide: Biochemical and histological study. International Journal of Immunopathology and Pharmacology. v. 30 (1), p. 13-24, 2017.

BAGYARAJ, D. J., ET AL. (2015). Below ground microbial diversity as influenced by coffee agroforestry systems in the Western Ghats, India. Agriculture, Ecosystems \& Environment, 202, pp. 198-202.

BRAVI, F .; TAVANI, A .; BOSETTI, C .; BOfFETTA, P .; LA VECCHIA, C. Café e o risco de carcinoma hepatocelular e doença hepática crônica: uma revisão sistemática e metanálise de estudos prospectivos. EUR. J. Câncer Prev.v.26, p.368-377. 2017

CÁRDENAS, C. QUESADA, A.R; MEDINA, M.A. Propriedades anti-angiogênicas e antiinflamatórias do kahweol, um diterpeno do café. PLoS One v.6.2011.

CÁRDENAS, C.; QUESADA, A. R.; MEDINA, M. A Insights sobre os efeitos antitumorais do kahweol no câncer de mama humano: diminuição da sobrevida e aumento da produção de espécies reativas de oxigênio e citotoxicidade. Biochem. Biophys. Res. Comum. v. 447. p. 452 - 458. 2014.

CARVALHO A.C.; CARVALHO D.F; FILGUEIRAS G.C.; ARAÚJO A.C.S.; CARVALHO A.V.; Panorama e importância econômica do café no mercado internacional de commodities agrícolas: uma análise espectral. Agroecossistemas. v. 9, n.2, p. 223-222. 2017. 
CARVALHO, L.O.R.; VALÉRIO, D. G. B.; NÓBREGA, H. M.G.; DANTAS, I. C. M.; LEITE, N. S. B.; SOUSA, M. N. A. Influence of coffee in Parkinson's Disease. Rev. Bra. Edu. Saúde, v. 9, n. 2, p. 41-47, abr-jun, 2019.

CAZERIM, M. S.; UETA, J. Café: uma bebida rica em substâncias com efeitos clínicos importantes, em especial a cafeína. Rev Ciênc Farm Básica Apl. v.35(3) p.363370. 2015 ISSN 1808-4532

CHOI, J.H.; HWANG, Y. P.;IIN, S. W.; LEE, G. H.; KIM, G. H.; HAN, E. H.; KIM, S. K.;KANG , K. W.; CHUNG, Y. C.;JEONG, H. G. Supressão de fibrossarcoma humano induzido por PMA invasão e metástase de HT-1080 por kahweol através da inibição de Akt / JNK1 / Via de sinal MAPK 2 / p38 e atividades transcricionais dependentes de NF-Kb. Food Chem. Toxicol.v.125,p.1- 9. 2019

DE CARVALHO OLIVEIRA, F.; SRINIVAS K.; HELMS G.L.; ISERN N.G.; CORT J.R .; GONÇALVES A.R.; AHRING B.K. Characterization of coffee (Coffea arabica) husk lignin and degradation products obtained after oxygen and alkali addition. Bioresource Technology n. 257, p. 172-180. 2018

DÓREA J.G., COSTA T.H.M. Is coffee a functional food? BJN. v. 93(6):p. 773-782. 2005

EMBRAPA. Café e saúde humana (2011). Disponível em:< https://ainfo.cnptia.embrapa.br/digital/bitstream/item/92424/1/cafe-doc01.pdf>. Acesso: 14 de nov. 2019.

ESTEVAM, M. S. ; MOTA, R. I. C. ; AGUILLAR, I. N. ; AMÂNCIO, L. C. C. ; SILVA, A. G. ; ROCCO, D. D. F. M . Efeito da ingestão de cafeína no teste de 1 RM e repetições máximas em homens adultos ativos. Anais do Encontro Nacional de PósGraduação - VII ENPG Vol.2 (2018)

FERNANDES C, MONTEIRO, S. Viagem gastronômica através do Brasil. 7ạ ed. São Paulo: Editora Senac; 2005.

FÜRSTENAU, C. R. ; DE SOUZA, I. C. C. ; DE OLIVEIRA, M. R. The effects of kahweol, a diterpene present in coffee, on the mitochondria of the human neuroblastoma SH-SY5Y cells exposed to hydrogen peroxide. Toxicology in Vitro. v.61, p.104601. December 2019.

FONSECA, A. F. A. ; SALVA T. J. G. ; FERRÃO, M. A. G. ; FERRÃO, R. G. ; VOLPI, P. S. ; FILHO, A. C. V. ; GUARÇONI, R. COMPOSIÇÃO QUÍMICA DE CAFÉ CONILON (COFFEA CANEPHORA). VII Simpósio de Pesquisa dos Cafés do Brasil 22 a 25 de Agosto de 2011, Araxá - MG

FOOD-INFO. Coffe: Acids compounds. 2014. Disponível em: <http://www.foodinfo.net/uk/products/coffee/acids.htm>. Acesso em: 6 de nov. 2019.

GAWLIK-DZIKI, U., et al. Lipoxygenase inhibitors and antioxidants from green coffeemechanism of action in the light of potential bioaccessibility. Food Research International. v. 61, p. 48-55. 2014. 
HALVORSEN, B .; RANHEIM, T.; NENSETER, MS; HUGGETT, AC; DREVON, CA Efeito de um lipídio do café (cafestol) no metabolismo do colesterol em fibroblastos da pele humana. J. Lipid Res. v. 39 , p.901-912. 1998.

HAUSCHILD, S. D. ; ADAMI, F. S. Relação entre consumo de macronutrientes e cafeína com o estado nutricional e composição corporal. Revista Brasileira de Obesidade, Nutrição e Emagrecimento. São Paulo. v.12. p.851-858. Jan./Dez. 2018. ISSN 1981-9919

ICO. INTERNATIONAL COFFEE ORGANIZATION. World coffee consumption. 2019 [online]. Disponível: <http://www.ico.org/prices/newconsumptiontable.pdf> Acessado em 29 Out. 2019.

IWAMOTO,H.; IZUMI,K.;NATSAGDORJ,A.; NAITO,R.; MAKINO,T.;KADOMO O,S.; HIRATSUKA, K. SHIGEHARA,K.;KADONO,Y.; K. NARIMOTO,Y.; SAITO , K.; NA KAGAWA-GOTO , A. O café inibe sinergicamente a proliferação e migração de células de câncer de próstata. Toxicol. Lett. v.79 p. 468 - 479. 2019

JESZKA-SKOWRON, M.; ZGOŁA-GRZEŚKOWIAK, A.; GRZEŚKOWIAK ,T. Analytical methods applied for the characterization and determination of bioactive compounds in coffee. Eur Food Res Technol. v.240. p. 19-31. 2015.

JESZKA-SKOWRON M.; SENTKOWSKA A.; PYRZYŃSKA K.; DE PEÑA M.P. Chlorogenic acids, caffeine content and antioxidant properties of green coffee extracts: influence of green coffee bean preparation.Eur Food Res Technol v.242. p. $1403-1409.2016$

LEEJEONG, H.G. Efeitos protetores de kahweol e cafestol contra o estresse oxidativo induzido por peróxido de hidrogênio e danos ao DNA. Toxicol. Lett., v. 173,p. $80-87.2007$.

LIMA, C. A.; SANTOS, J. L.;SANTOS, R. M. ;ARAÚJO, S. S. ;MACHIORO, M.;ESTEVAM, C. S.;FREIRE, J. M. M. Efeito da cafeína sobre o desempenho em teste de capacidade aeróbica. Revista Brasileira de Nutrição Esportiva, São Paulo. v. 11. n. 67. Suplementar 1. p.884-890. Jan./Dez. 2017. ISSN 1981-9927.

LIU, H.;HU, G.;WANG, X.;HUANG, T.;XU, L; LAI, P.;XU, Y. Coffee consumption and prostate cancer risk: a meta-analysis of cohort studies. Nutrition and Cancer. v. 67 (3), p. $392-400.2015$

LIU, J.; SHEN, B.; SHI, M. ;CAI, J. Higher caffeine intake is associated with lower risk of malignant melanoma: a meta-analysis study.PLoS One . v.11 (1), p.1-14. 2016.

MARIA, Y. Y. M.; GOMIDE, L. M. M.Caffeine and coffee: the duality between its toxic and antioxidant effects. Revista Intersaúde. v. 1 p 73-85.2019

MCLELLAN, T. M. ; CALDWELL, J. A. ; LIEBERMAN, H. R. A review of caffeine's effects on cognitive, physical and occupational performance. Neuroscience and Biobehavioral Reviews. v.71, p.294-312. December, 2016 
MIRANDA, Franciane Rosa. Desenvolvimento pós-embrionário do intestino médio e efeito da cafeína e da borra de café em Aedes aegypti (diptera: culicidae). Dissertação de Mestrado em Biologia Celular e Estrutural. Universidade Federal de Viçosa. Minas Gerais. Brasil. 2019.

NEWMAN, D. J.; CRAGG, G. M. Natural products as sources of new drugs over the 30 years from 1981 to 2010. Journal of natural products. v. 75, n. 3, p. 311- 335, 2012

NIRMALA B.P,; PETRA H.M.P.; CUNO S.P.M.U;, BUENO M.H.B.; AWANG M.B.; BODIL H.B. Coffee and tea consumption and risk of pre- and postmenopausal breast cancer in the European Prospective Investigation into Cancer and Nutrition (EPIC) cohort study. Breast Cancer Res. v.17 p. 1-15. 2015.

OLIVEIRA, C. S.; ALVES, R. C.; ZANDONÁ, B. A; BUENO, J. C. A; JUNIOR, T. P. S. Efeitos da suplementação de cafeína no desempenho, percepção subjetiva do esforço e percepção de dor durante o treinamento de força: Uma revisão. Revista Brasileira de Prescrição e Fisiologia do Exercício, São Paulo. v.11. n.71. Suplementar 2. p.967-972. Jan./Dez. 2017.ISSN 1981-9900.

OLIVEIRA, N. C. Estilo de vida e doenças reumáticas: uma revisão. Lifestyle Journal, v. 1, n. 2, p.11-8, 2011.

POSSANI, L. M. M.; FRANCESCHI, D. I.; CARMO, M. G.; MOTT, M. P.; MEZZOMO, N.J.; ZAGO, A.M.; RECH, V.C. Caffeine prevents the inhibition caused by phenylalanine on pyruvate kinase in the cerebral cortex of rats. Ciências da Saúde, Santa Maria, v. 14, n. 2 , p. 145-151. 2013.

REN, Y. ; WANG, C. ; XU, J. ; WANG, S. Cafestol and Kahweol: A Review on Their Bioactivities and Pharmacological Properties. International journal of molecular sciences. v. 20. 30 August 2019

ROSA, A. L.; SANTOS, P. R. K. F.; AKEL, S. M. Hepatotoxic Evaluation Of Caffeine In Relation To Paracetamol- A Literature Review. Revista Saúde e Desenvolvimento. v.12, p. 192-1991 n.13. 2018.

ROTHFOS, B. Coffee production. Hamburgo: Salish Sea Books, 1980.

SALAZAR-MARTINEZ, E.; WILLET, W. C.; ASCHERIO, A.; MANSON, J. E.; LEITZMAN, M . F.; STAMPFER, M. J.; HU, F. B. Coffee consumption and risk for type 2 diabetes mellitus. Annals of Internal Medicine, v. 140, n.1, p. 1-8, 2004.

SCHOLZ, M. B. S.; PRUDENCIO, S.H.; KITZBERGER, C. S. G.; SILVA, R.S.S.F. Physicochemical characteristics and sensory attributes of coffee beans submitted to two post-harvest processes. Journal of Food Measurement and Characterization. v. 13, p. 831-839. 2019.

SHANG, F .; LI, X .; JIANG, X. Consumo de café e risco da síndrome metabólica: uma metaanálise. Diabetes Metab. v.42 , p.80-87. 2016. 
SILVA, V. A. Influência dos grãos defeituosos na qualidade do café orgânico. Dissertação de mestrado em Ciências dos alimentos. Universidade Federal de Lavras - UFLA, 2005. 120p.

SILVA, B. D. P.; ANSELMI, L.; SHMIDT, V.; SANTOS, I. Caffeine consumption during pregnancy and attention deficit hyperactivity disorder (ADHD): a systematic literature review. Cad. Saúde Pública. Rio de Janeiro v.31(4) p.682-690. abr, 2015.

SILVESTRE, J. C.; GIANONI, R.; PEREIRA, P.E.; Caffeine and exercise: metabolism and action mechanisms. Revista Brasileira de Fisiologia do Exercício. v. 17 p.130-7. 2018.

SIMÕES, R. O.; FARONI, L. R. D.; QUEIROZ, D. M. Qualidade dos grãos de café (Coffea arabica L.) em coco processados por via seca. Revista Caatinga. v. 21, n. 2, 2008.

SINCLAIR, C. J. D.; GEIGER, J. D. Caffeine use in sport: a pharmacological review. The Journal of Sports Medicine and Physical Fitness, v. 40, n. 1, p. 71-79, 2000.

TAVARES, C.; SAKATA R. K. Cafeína para o Tratamento de Dor. Revista Brasileira de Anestesiologia, v. 62, $\mathrm{n}^{\circ} .3,2012$.

TORTORA, G. J.; DERRICKSON, B. Corpo Humano fundamentos de anatoia e fidiologia. Artmed, v. 80, 2012.

TROMBINI, B. C.; OLIVEIRA, G. G. Therapeutic update on caffeine: beneficial effects and side. Revista Terra e Cultura. v.57. p 11-21. 2013

WANG, A .; WANG, $\mathrm{S}$.; ZHU, C .; HUANG, $\mathrm{H}$.; WU, L .; WAN, $\mathrm{X}$.; YANG, $\mathrm{X}$.; ZHANG, H .; MIAO, R .; ELE, L .; Café e risco de câncer: Uma metanálise de estudos observacionais prospectivos. Sci. Rep. v. 6, 33711. 2016.

VAZ, Lucyana Galindo Arcoverde; DE SANTO ANTÃO, Vitória. Efeito do consumo agudo de cafeína na capacidade anaeróbia quantificada pelos principais métodos de estimativa.

XIE, Y.; HUANG, S.;HE, T.;E SU, Y.Coffee consumption and gastric cancer risk: an updated meta-analysis. Asia Pacific Journal of Clinical Nutrition. v.25 (3), p. $578-588$. 2016 


\title{
CAPÍTULO YVII
}

\section{CONTROLE DE QUALIDADE EM MEDICAMENTOS CONTENDO 0 PRINCÍPIO ATIVO MELOXICAM}

\author{
Kezia R. Bassi Zacarkim ${ }^{1}$ \\ Natalia Irala Chun ${ }^{2}$ \\ Fernando Augusto Freitas ${ }^{3}$
}

${ }^{1}$ Acadêmica do Curso de Farmácia do Centro de Ensino Superior de Foz do Iguaçu (Cesufoz), Foz do Iguaçu, PR.
${ }^{2}$ Acadêmica do Curso de Farmácia do Centro de Ensino Superior de Foz do Iguaçu (Cesufoz), Foz do Iguaçu, PR.
${ }^{3}$ Professor do curso de Farmácia do Centro de Ensino Superior de Foz do Iguaçu (Cesufoz), Foz do Iguaçu, PR.

\section{RESUMO}

O Meloxicam é um anti-inflamatório não esteroidal que possui atividades antiinflamatórias, antipiréticas e analgésicas, sendo que para a obtenção dos respectivos registros na ANVISA, é necessário estabelecer a intercambialidade entre os medicamentos genéricos e similares, com aqueles de referência. Este trabalho teve como objetivo efetuar o controle de qualidade e equivalência farmacêutica em medicamentos na forma de comprimidos que contêm o meloxicam como princípio ativo. O medicamento de referência $(R)$ foi utilizado em comparação com dois similares ( $M X$ e $\mathrm{ML}$ ) e dois genéricos (MM e $\mathrm{MT}$ ), todos com $15 \mathrm{mg}$. As análises parciais realizadas foram peso médio, dureza e friabilidade, seguindo as normas da Farmacopeia Brasileira 5a Ed. $A$ avaliação de peso-médio mostrou boa uniformidade nos resultados obtidos, onde o medicamento $R$ apresentou o coeficiente de variação (CV) e desvio-padrão (DP) iguais a $1,4 \%$ e $\pm 0,0025$, respectivamente. Ainda, os valores de CV e DP para os medicamentos similares e genéricos foram: $M X(1,61 \%$ e $\pm 0,0027), M L(1,43 \%$ e $\pm 0,0029), M M(0,72 \%$ e $\pm 0,0022)$ e $M T(1,07 \%$ e $\pm 0,0018)$. No teste de friabilidade todos os medicamentos foram aprovados, já que as perdas verificadas foram iguais a $\mathrm{R}(0,0028 \%), \mathrm{MX}(0,2185 \%)$, ML $(0,1477 \%), \operatorname{MM}(0,1170 \%)$ e $M T(0,2989 \%)$. Os testes parciais mostrados até o presente momento, mostraram que os medicamentos genéricos e similares examinados apresentaram-se equivalentes ao medicamento de referência correspondente.

Palavras-chave: Controle de qualidade. Equivalência Farmacêutica. Meloxicam.

\section{INTRODUÇÃO}

Os anti-inflamatórios não esteroidais (AINEs) estão entre as classes medicamentosas mais difundidas no mundo, para tratar inflamação, dor e edema, osteoartrites e artrite reumatoide. Dentre as principais causas para esse crescimento, destacam-se a grande facilidade de acesso ao fármaco e uma população mais idosa com 
doenças reumatológicas. Os anti-inflamatórios não esteroidais são inibidores da enzima cicloxigenase (COX), seletivos ou não, o que impede a formação de prostaglandinas (PGs). Existem duas isoformas da enzima cicloxigenase, designadas COX-1 e COX-2, com estruturas químicas similares. A isoforma COX-1 é expressa de forma constitutiva na maioria dos tecidos, enquanto a COX-2 é induzida nas inflamações. A COX-1 é essencial para a manutenção do estado fisiológico normal de muitos tecidos, incluindo a proteção da mucosa gastrointestinal, controle do fluxo sanguíneo renal, homeostasia, respostas autoimunes, funções pulmonares e do sistema nervoso central, cardiovasculares e reprodutivas, enquanto a COX-2, induz a inflamação por vários estímulos, como citocinas, endotoxinas e fatores de crescimento (BATLOUNI, 2010).

As prostaglandinas são produzidas a partir de fosfolipídios da membrana celular por uma cascata enzimática. Em uma primeira etapa ocorre a conversão de fosfolipídios da membrana em ácido araquidônico pela enzima fosfolipase A2, o qual é liberado no citoplasma. $\mathrm{O}$ ácido araquidônico, por sua vez, pode servir de substrato para duas vias diferentes, uma baseada na ação das cicloxigenases e a outra relacionada com a enzima lipoxigenase, conforme mostrado na Figura 1.

Figura 1 - Cascata do Ácido araquidônico.

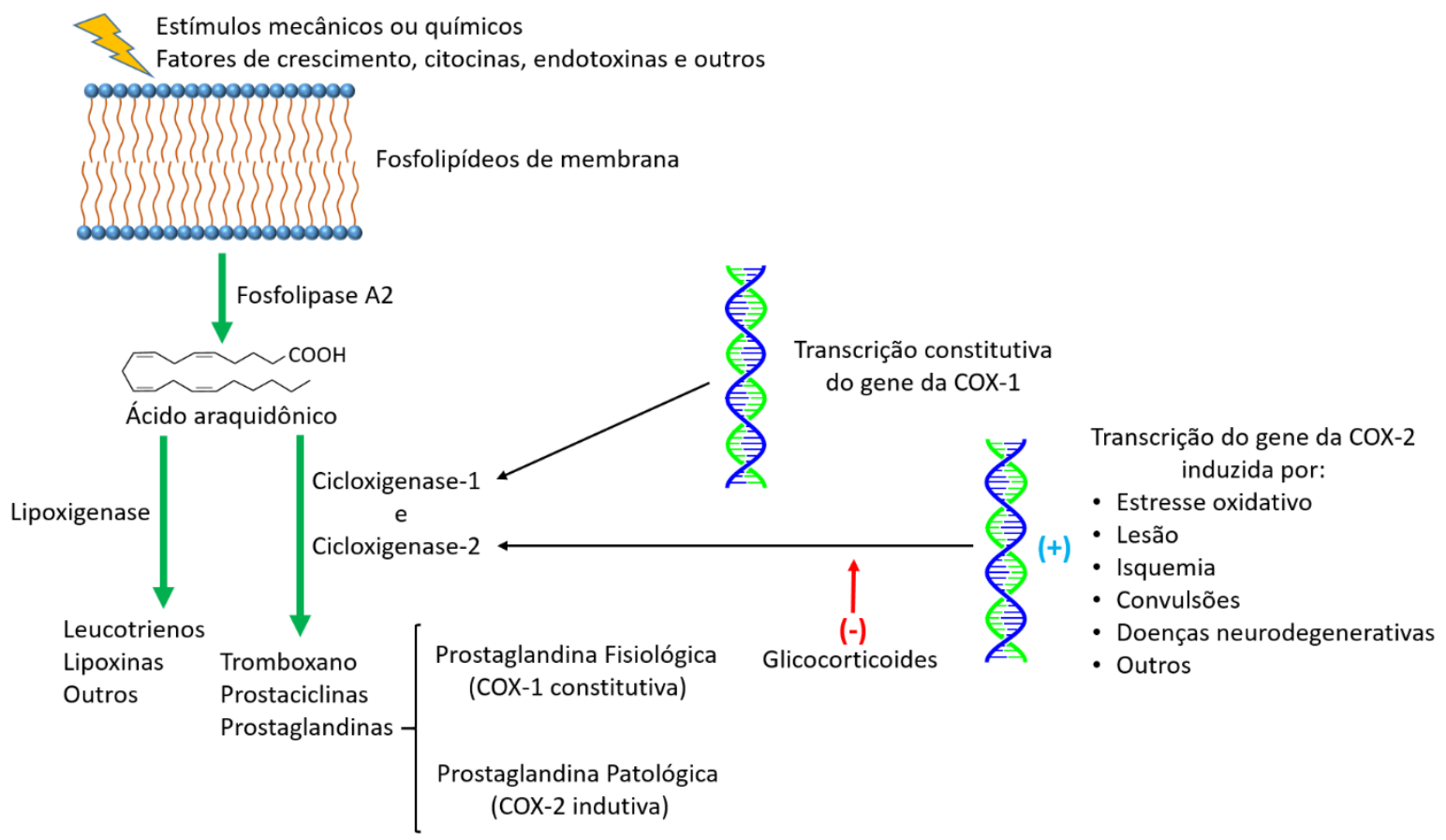

Fonte: Baseado em HILÁRIO; TERRERI; LEN (2006) e DIETRICH; CARRIS; PANAVELIL (2016), com modificações. 
O Meloxicam é um anti-inflamatório não esteroidal que possui comercialmente três formas farmacêuticas, injetável, suspensão oral e comprimido. Pertence à classe do ácido Enólico, que tem como finalidade atividades anti-inflamatórias, antipiréticas e analgésicas. Este fármaco é indicado para tratamento dos sintomas da artrite reumatoide e osteoartrite, amenizando a dor e a inflamação. Sua fórmula estrutural está mostrada na Figura 2.

Figura 2 - Fórmula estrutural do Meloxicam.

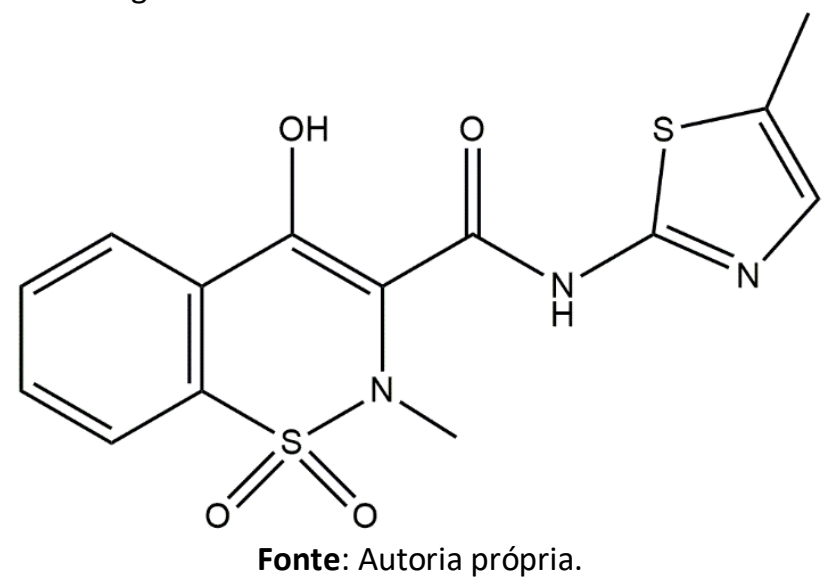

O mecanismo de ação do Meloxicam consiste em inibir a biossíntese de prostaglandinas, mediadores da inflamação, como consequência da inibição da COX-1 em menor extensão e COX-2, embora recentes estudos informem na bula do Meloxicam que este ativo seja seletivo para COX-2, agindo diretamente na inflamação e resultando em maior segurança na sua utilização.

A Política Nacional de Medicamentos (PNM) teve como objetivo garantir a segurança, eficácia e qualidade dos medicamentos, racionalizar seu uso e garantir o acesso da população aos considerados essenciais. Nela está inclusa a promoção do uso dos medicamentos genéricos, envolvendo a produção, comercialização, prescrição e uso, para consolidá-los no Brasil e permitir maior inclusão dos medicamentos para a população (ARAÚJO et al., 2010). Sendo assim, com a Lei no 9.787 de 10 de fevereiro de 1999, foi implantada no Brasil a política de medicamentos genéricos, para a melhoria da qualidade dos medicamentos e a facilitação ao acesso do público ao tratamento medicamentoso. Esse produto deve ser intercambiável com os medicamentos de referência ou também conhecidos como éticos. Os genéricos são produzidos após a 
expiração ou renúncia da proteção da patente ou de outros direitos de exclusividade, cuja proteção é determinada pela Lei no 9.279, de 14 de maio de 1996.

A Resolução da Diretoria Colegiada (RDC) № 47, de 28 de março de 2001, determina que os medicamentos genéricos devem ser identificados com uma faixa amarela contendo a letra G em azul em suas embalagens externas. Já o medicamento similar é aquele que contém a mesma forma farmacêutica, concentração, princípio ativo, via de administração, posologia e indicação terapêutica, preventiva ou diagnóstica do medicamento inovador, mas diferem nas características relativas ao tamanho e forma do produto, prazo de validade, embalagem, rotulagem, excipientes e veículos. A identificação deve ocorrer por meio do nome comercial ou marca (ANVISA, 2009).

O conceito de equivalência farmacêutica, de acordo com a RDC № 31, de 11 de agosto de 2010, refere-se aos equivalentes farmacêuticos como medicamentos que contém a mesma forma farmacêutica, a mesma via de administração e mesma quantidade de substancia ativa. Devem seguir os requisitos da monografia da Farmacopeia Brasileira 5a Ed. (2010), ou seguir as especificações de outros códigos oficiais, normas ou regulamentos aprovados pela ANVISA. Na ausência desses, devem cumprir os requisitos com outros padrões de qualidade. Os testes realizados para a comprovação dos equivalentes farmacêuticos são avaliados por meio dos testes in vitro (ANVISA, 2010).

Após a implantação da PNM, o perfil de consumo de medicamentos genéricos pela população tem mudado consideravelmente com o passar dos anos, conforme relatado por Araújo (2010). A autora relata que houve um crescimento de aproximadamente 249,42\% entre junho de 2000 e agosto de 2001 e em abril de 2004 havia um total de 1.124 medicamentos genéricos registrados, o que torna evidente a necessidade de garantir a bioequivalência com os medicamentos de referência. Desta forma, este trabalho teve como objetivo efetuar o controle de qualidade e equivalência farmacêutica em medicamentos na forma de comprimidos não revestidos que contêm o meloxicam como princípio ativo. 


\section{MATERIAIS E MÉTODOS}

Os testes efetuados de peso médio, dureza e friabilidade seguiram as orientações determinadas pela Farmacopeia Brasileira 5a Ed. Para a realização dos testes, foi utilizado um total de 50 comprimidos de cada medicamento, incluindo os medicamentos de referência $(R)$, dois similares $(M X$ e $M L)$ e dois genéricos (MM e $M T)$, todos com $15 \mathrm{mg}$ do princípio ativo, sendo que tais medicamentos foram adquiridos em uma farmácia comercial na cidade de Foz do Iguaçu, PR. Todos os testes foram efetuados com comprimidos pertencentes a um mesmo lote para cada medicamento.

\subsection{Peso Médio}

Para a avaliação do peso médio, utilizou-se uma balança analítica da marca SHIMADZU, modelo AUY220 (precisão de 0,0001 g), sendo que a média foi obtida pela razão entre o peso total obtido e a quantidade de 20 comprimidos utilizados.

\subsection{Dureza}

O teste de dureza foi efetuado utilizando-se o aparelho durômetro da marca Ethik, modelo 298/DGP (precisão de 0,1 N), sendo a força calculada em newtons (N). Foram utilizados 10 comprimidos para cada medicamento e, conforme orientação da Farmacopeia Brasileira 5 ad., todos os comprimidos foram posicionados com a mesma orientação no equipamento durante a realização do experimento.

\subsection{Friabilidade}

Conforme as especificações da Farmacopeia Brasileira 5a Ed., o teste de friabilidade deve ser efetuado somente nos comprimidos não revestidos. 0 equipamento utilizado trata-se de um friabilômetro da marca Ethik Technology, modelo 300-2 (versão II), o qual foi regulado para uma velocidade de 25 rotações por minuto (rpm) e um tempo de 4 minutos. Os 20 comprimidos de cada medicamento foram inicialmente pesados e posteriormente submetidos às condições descritas. Após o período de 4 minutos no friabilômetro, os comprimidos foram pesados novamente depois da remoção de qualquer resíduo de pó da superfície. Os cálculos da friabilidade foram efetuados observando-se as diferenças dos pesos iniciais e finais para cada medicamento, sendo que os resultados foram expressos em porcentagem de perda. 


\section{RESULTADOS E DISCUSSÃO}

A avaliação do peso médio permite avaliar a homogeneidade relacionada à quantidade do princípio ativo para um mesmo lote de um determinado medicamento (BUZZI et al., 2006). Conforme as orientações da Farmacopeia Brasileira 5a Ed., a variação máxima permitida para o Coeficiente de Variação (CV) em comprimidos não revestidos com peso médio entre 80 e $250 \mathrm{mg}$ (medicamentos $\mathrm{R}, \mathrm{MX}, \mathrm{ML}$ e $\mathrm{MT}$ ) é de \pm 7,5\%. De maneira similar, o limite para os comprimidos não revestidos com peso médio superior a $250 \mathrm{mg}$ (medicamento $\mathrm{MM}$ ) é de $\pm 5 \%$. Além dessa primeira limitação, também não podem ser toleradas mais do que duas unidades fora dos limites de $\pm 1 \mathrm{CV}$, bem como também não pode haver nenhuma unidade fora dos limites de $\pm 2 \mathrm{CV}$.

Os resultados obtidos para a avaliação de peso-médio mostraram boa uniformidade e foram aprovados nos critérios estabelecidos, conforme mostrado na Tabela 1. Observa-se que o medicamento similar MX apresentou os maiores valores para o CV $(1,61 \%)$ e DP $( \pm 0,0027)$, mas ainda assim, verifica-se que estes valores se encontram bem abaixo dos limites permitidos.

Tabela 1 - Resultados obtidos no teste de peso médio nos comprimidos de meloxicam.

\begin{tabular}{ccccccc}
\hline Medicamento & $\begin{array}{c}\text { Peso médio } \\
(\mathbf{m g})\end{array}$ & DP & $\begin{array}{c}\text { CV } \\
\mathbf{( \% )}\end{array}$ & \multicolumn{2}{c}{$\begin{array}{c}\text { No de comprimidos } \\
\text { fora dos limites }\end{array}$} & Avaliação \\
& & & & $\pm 1 \mathrm{CV}$ & $\pm 2 \mathrm{CV}$ & \\
\hline $\mathrm{R}$ & 180,35 & 0,0025 & 1,40 & 0 & 0 & Aprovado \\
MX & 168,22 & 0,0027 & 1,61 & 0 & 0 & Aprovado \\
ML & 200,71 & 0,0029 & 1,43 & 0 & 0 & Aprovado \\
MM & 303,91 & 0,0022 & 0,72 & 0 & 0 & Aprovado \\
MT & 165,00 & 0,0018 & 1,07 & 0 & 0 & Aprovado \\
\hline
\end{tabular}

Fonte: Autoria própria.

O teste de dureza consiste em observar a resistência do comprimido ao esmagamento e, conforme consta na Farmacopeia Brasileira 5a Ed., os resultados obtidos nestes testes são apenas informativos. No entanto, o teste de dureza permite constatar se o medicamento examinado possui a resistência adequada, tendo em vista que as diversas etapas relacionadas à produção, transporte e manuseio posterior, podem causar desgaste por fricção em função de choques mecânicos (MEDEIROS; 
MOTA; ALVIM, 2019). Os valores médios observados em 10 comprimidos utilizados para cada medicamento, em Newtons $(N)$, foram R (44,0 N), MX (41,9 N), ML (79,0 N), MM $(62,8 \mathrm{~N})$ e MT $(31,8 \mathrm{~N})$.

No teste de friabilidade o limite tolerado de perdas é de 1,5\% no máximo, sendo que os resultados de perdas obtidos para os 20 comprimidos de cada medicamento foram iguais a $\mathrm{R}(0,0028 \%), \mathrm{MX}(0,2185 \%), \mathrm{ML}(0,1477 \%), \mathrm{MM}(0,1170 \%)$ e $M T$ (0,2989\%). Observa-se que o medicamento genérico MT apresentou a maior variação de peso, mas mesmo assim está bem abaixo do limite máximo permitido, de modo que os resultados demonstraram que todos os medicamentos foram aprovados.

\section{CONSIDERAÇÕES FINAIS}

Este trabalho descreve os resultados parciais do conjunto de testes determinados pelas normas da Farmacopeia Brasileira 5a Ed. para comprovar a equivalência farmacêutica. No entanto, os resultados obtidos até este momento mostraram que os medicamentos genéricos e similares examinados apresentaram-se equivalentes ao medicamento de referência correspondente. Nas próximas etapas serão realizados os ensaios complementares, cujos resultados poderão garantir a equivalência farmacêutica e intercambialidade dos medicamentos avaliados.

\section{AGRADECIMENTOS}

Os autores agradecem ao Centro de Ensino Superior de Foz do Iguaçu (Cesufoz) pelo apoio logístico institucional.

\section{REFERÊNCIAS}

ANVISA. Resolução da Diretoria Colegiada-RDC no 47, de 8 de setembro de 2009. Disponível em: <http://portal.anvisa.gov.br/documents/33836/2814380/RDC+47+09.pdf>. Acesso em: 12 mar. 2020.

ANVISA. Resolução da Diretoria Colegiada-RDC no 31, de 11 de agosto de 2010. Disponível em: <http://portal.anvisa.gov.br/legislacao\#/visualizar/28572>. Acesso em: 18 mar. 2020. 
ARAÚJO, L. U. et al. Medicamentos genéricos no Brasil: panorama histórico e legislação.

Rev Panam Salud Publica, v. 28, n. 6, p. 480-492, 2010.

BATLOUNI, M. Anti-Inflamatórios Não Esteroides: Efeitos Cardiovasculares, CérebroVasculares e Renais. Arq Bras Cardiol, v. 94, n. 4, p. 556-563, 2010.

BRASIL. Ministério da Saúde. Farmacopeia Brasileira. 5a ed. Brasília, 2010.

BUZZI, V. et al. Avaliação da qualidade de comprimidos de Atenolol: Estudo comparativo entre medicamentos de referência, genérico e similar. Arq. Ciênc. Saúde Unipar, Umuarama, v. 10, n. 3, p. 119-122, 2006.

DIETRICH E.; CARRIS, N.; PANAVELIL, T. A. Anti-inflamatórios, antipiréticos e analgésicos. In: WHALEN, K.; FINKE, R.; PANAVELIL, T. A. (Eds.). Farmacologia Ilustrada. 6. ed. Porto Alegre: Artmed, 2016. p. 449.

HILÁRIO, M. O. E.; TERRERI, M. T.; LEN, C. A. Nonsteroidal anti-inflammatory drugs: Cyclooxygenase 2 inhibitors. Jornal de Pediatria, v. 82, n. SUPPL. 2, p. 206-212, 2006.

MEDEIROS, E. F. C.; MOTA, L. V.; ALVIM, H. G. O. Medicamentos de referência, genérico e similar: avaliação da qualidade dos comprimidos de captopril e enalapril. Rev. Cient. Sena Aires, v. 8, n. 1, p. 49-61, 2019. 


\title{
CAPÍTULO XVIII
}

\section{POTENCIAL ANTIOBESOGÊNICO DO EXTRATO DE FEIÃOA-BRANCO (PHASEOLUS VULGARIS L)}

\author{
Jardel Alves da Costa ${ }^{1}$ \\ Clécia Maria da Silva ${ }^{2}$ \\ Sâmia Karine de Moura Martins ${ }^{3}$ \\ Amanda de Andrade Alencar Ramalho ${ }^{4}$ \\ Bruna Virgínia da Silva Santos ${ }^{5}$ \\ Nara Vanessa dos Anjos Barros ${ }^{6}$ \\ 1, 2, 4,5 Graduando do curso de Nutrição. Universidade Federal do Piauí - UFPI. \\ 3 Pós-graduando em Nutrição Oncológica (Especialização). Programa de Pós-Graduação do Hospital São Marcos- \\ HSM. \\ 6 Professor Adjunto da Coordenação do Curso de Nutrição. Universidade Federal do Piauí- UFPI.
}

\section{RESUMO}

A ocorrência de obesidade é atualmente considerada uma pandemia global e é amplamente fundamentado que, além dos seus distúrbios metabólicos associados, por exemplo, doença hepática gordurosa não alcoólica, essa patologia também aumenta o risco de uma série de doenças crônicas não transmissíveis, incluindo diabetes tipo 2 , doenças cardiovasculares e câncer. Atualmente, os remédios para o tratamento da obesidade baseados em suplementos dietéticos são populares, sugerindo que a etnofarmacologia e a fitoterapia podem servir como estratégias no tratamento e prevenção da patologia. A faseolamina é uma proteína constituinte do feijão branco comum (Phaseolus vulgaris L.) e tem sido destacada como um importante inibidor de alfas- amilases, usada para reduzir a glicemia e a absorção de calorias por meio da prevenção ou retardo da digestão de carboidratos complexos, agindo como antihiperglicêmico e anti-obesogênico. Diante do exposto, este estudo objetivou revisar a literatura acerca de estudos relevantes e atuais que relataram o uso do extrato de feijãobranco como composto com ação antiobesidade. O extrato de feijão-branco apresentou elevado potencial antiobesidade, pois é capaz de promover a redução da digestão de amidos da dieta e desta maneira a energia derivada dos carboidratos e a taxa de absorção corporal da energia na forma de glicose pode ser amenizada, reduzindo a formação de tecido adiposo, além de diminuir colesterol e triglicérides prevenindo a obesogênese.

Palavras-chave: Phaseolus Vulgaris. Obesidade. Alfa-amilase. 


\section{INTRODUÇÃO}

Atualmente a obesidade é considerada uma pandemia global e é amplamente fundamentado que, além dos seus distúrbios metabólicos associados, por exemplo, doença hepática gordurosa não alcoólica, essa patologia também aumenta o risco de uma série de doenças crônicas não transmissíveis, incluindo diabetes tipo 2, doenças cardiovasculares e câncer (HEYMSFIELD e WADDEN, 2017).

O controle da dieta e dos exercícios são os pilares do controle do excesso de peso. Alimentos com baixo índice glicêmico podem reduzir o risco de diabetes e doenças cardíacas, bem como suas complicações. Como alternativa a uma dieta de baixo índice glicêmico, há um crescente corpo de pesquisas em produtos que retardam a absorção de carboidratos por meio da inibição de enzimas responsáveis por sua digestão (BARRETT e UDANI, 2011).

Existem inúmeras práticas integrativas e complementares para a prevenção e tratamento da obesidade, incluindo terapias medicinais e o uso de plantas e derivados. Atualmente, os remédios para obesidade baseados em suplementos dietéticos são populares, sugerindo que a etnofarmacologia e a fitoterapia podem servir como estratégias no tratamento e prevenção da patologia (CASTILLO, GONZÁLEZ e MOORECARRASCO, 2019).

O inibidor da alfa-amilase pancreática isoforma 1 (alfa-Al 1), também conhecido como faseolamina, é uma proteína constituinte do feijão branco comum e do feijão vermelho (Phaseolus vulgaris L.). Ao lado dela, existem duas outras isoformas e um inibidor da alfa-amilase (alfa-Al 2, alfa-Al 3 e alfa-AlL, respectivamente). O mais amplamente distribuído na planta é o alfa-Al 1, que representa cerca de um décimo do conteúdo total de proteína da semente (OBIRO, ZHANG e JIANG, 2008).

O gênero Phaseolus vulgaris (Figura 1) inclui todas as espécies de sementes de leguminosas normalmente chamadas de feijão comum. Atualmente, $P$. vulgaris é considerado um importante alimento funcional: extratos de $P$. vulgaris têm sido repetidamente relatados para reduzir a ingestão de alimentos, peso corporal, depósito de lipídios e glicemia em uma série de modelos animais com obesidade, diabetes e síndrome metabólica (LOI et al., 2013). 
Figura 1: Feijão branco (Phaseolus vulgaris $L$ )

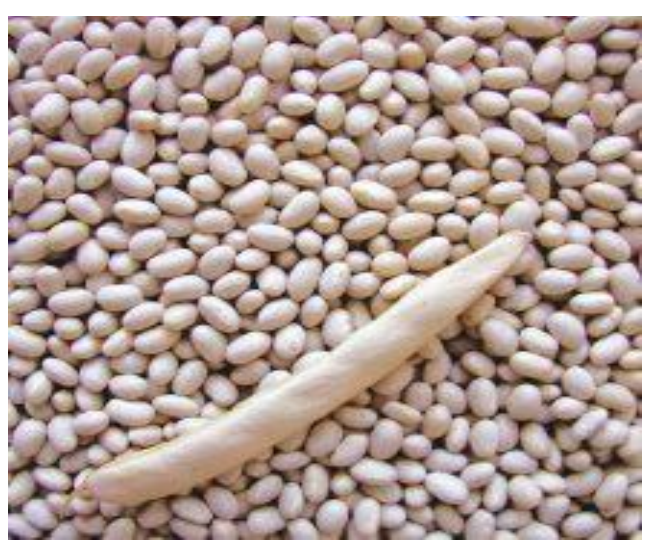

Fonte: https://www.semo.cz/en/nazev-latinsky/phaseolus-vulgaris-l/

Diante do exposto, este estudo objetivou revisar a literatura acerca de estudos relevantes e atuais que relataram o uso do extrato de feijão-branco como composto com ação antiobesidade.

\section{MÉTODOS}

Trata-se de um estudo de revisão narrativa da literatura, com a seguinte pergunta de pesquisa: o extrato do feijão-branco tem ação antiobesidade? A busca de artigos incluiu a pesquisa em bases eletrônicas indexadas e busca manual de citações nas publicações selecionadas. As bases eletrônicas pesquisadas foram LILACS (Literatura Latino Americana e do Caribe em Ciências de Saúde), e literatura internacional em Ciências da Saúde (MEDLINE). Foram utilizados os seguintes descritores: Phaseolus Vulgaris, Obesidade, Alfa-amilase, ambos nos idiomas português e inglês. O período de abrangência da busca foi entre janeiro de 2015 a dezembro/2020.

\section{REVISÃO BIBLIOGRÁFICA}

\subsection{Obesidade}

Desde a década de 1970, a prevalência global da obesidade quase triplicou em adultos e aumentou ainda mais dramaticamente em crianças e adolescentes. A obesidade contribui para uma expectativa de vida reduzida de até 20 anos devido ao aumento da mortalidade por doenças não transmissíveis, incluindo doenças cardiovasculares ateroscleróticas, diabetes tipo 2 e certos tipos de câncer. Além das 
consequências da patologia no nível individual, a pandemia da obesidade pode criar um enorme fardo para a saúde pública da sociedade (SWINBURN et al., 2011).

Segundo a Organização Mundial da Saúde (OMS), obesidade é definida como "acúmulo anormal ou excessivo de gordura que apresenta risco à saúde". Em contraste com a visão de que esta representa apenas um fator de risco para doenças, a World Obesity Federation declarou a própria obesidade como uma doença crônica, recorrente e progressiva (BRAY et al., 2017).

Isso tem sido justificado por uma abordagem de modelo epidemiológico que considera a fisiopatologia da obesidade como uma interação de fatores ambientais (disponibilidade e acessibilidade de alimentos ricos em energia, baixa necessidade de atividade física), com susceptibilidade genética, resultando em um balanço energético positivo e maior peso corporal. Os fortes mecanismos que promovem o ganho de peso e defendem um peso corporal mais elevado, mesmo contra intervenções direcionadas para a perda de peso, argumentam ainda mais a visão de que a obesidade é uma doença crônica e não uma decisão (MÜLLER e GEISLER, 2017).

\subsubsection{Obesidade como fator de risco para outras}

\section{patologias}

A obesidade foi bem identificada como uma condição pró-inflamatória em que o excesso de adiposidade visceral resulta em efluxo de citocinas pró-inflamatórias que afetam os processos celulares sistêmicos, sendo bem fundamentado que adultos obesos têm aumento das citocinas pró-inflamatórias circulantes com aumento da leptina e diminuição da produção de adiponectina, causando resistência sistêmica à leptina e potencial impacto no perfil imunológico padrão dos indivíduos obesos, abrindo uma janela de ampla gama para instalação de diversas comorbidades metabólicas associadas (RICHARD et al., 2017).

A obesidade é correlacionada a diversas comorbidades que não são menos prejudiciais à saúde do que a própria obesidade, como diabetes mellitus tipo 2, hipertensão arterial sistêmica, doenças da artéria coronária, aterosclerose, osteoartrite e acidente vascular cerebral (AFOLABI et al., 2020).

Sattar, Mcinnes e Mcmurray (2020) relataram que a obesidade aumentou vários fatores de risco cardiovasculares, como o desenvolvimento prematuro de doença 
cardiovascular e efeitos adversos cardiorrenais. Em pessoas com diabetes ou com alto risco de diabetes, a obesidade e a gordura ectópica acumulada frequentemente resultaram em diminuição da resistência à insulina e da função das células beta do pâncreas. Ambos limitaram a capacidade de alguns pacientes com diabetes de produzir uma resposta metabólica adequada aos problemas imunológicos, levando a uma enorme necessidade de insulina em infecções graves.

\subsubsection{Inibidores de alfa-amilases na terapêutica da obesidade}

Atualmente, há uma variedade de alvos terapêuticos disponíveis para redução de peso, como lipase pancreática, alfa-amilase, receptor de peptídeo-1 semelhante ao glucagon (GLP-1) e receptor de serotonina. Junto com a redução geral do uso de supressores de apetite que atuam no sistema nervoso central (SNC), por exemplo, fenfluramina, d-fenfluramina e

rimonabanto (TUCCI, BOYLAND e HALFORD, 2010).

Em humanos, várias formas de carboidratos são responsáveis por entre $40 \%$ a $80 \%$ da ingestão calórica total. Alimentos com baixo índice glicêmico (IG) (valor IG <55), a forma polimérica de carboidratos que são absorvidos lentamente, têm sido associados ao controle glicêmico e perda de peso. Uma alternativa aos alimentos de baixo IG são os produtos que podem diminuir a absorção de carboidratos por meio da supressão de enzimas relacionadas, como a $\alpha$-amilase pancreática (MARRELLI et al., 2013).

Com o aumento do número de pacientes com obesidade e diabetes, as pesquisas sobre a inibição da digestão do amido e absorção de carboidratos têm chamado muita atenção. Os inibidores da amilase podem bloquear a digestão de certos amidos, o que pode ser útil no controle dos níveis de açúcar no sangue. Portanto, a inibição da digestão do amido catalisada por amilase em ambiente gastrointestinal complexo é uma estratégia eficaz para a digestão controlada (LIU, 2020).

\subsection{Extrato do feijão branco (Phaseolus vulgaris L.) como composto antiobesidade}

Os estudos dispostos no quadro 1 demonstram as evidências do efeito antiobesidade desempenhado pelo extrato de feijão branco. 
Quadro 1: Descrição dos estudos que evidenciaram o efeito antiobesidade do extrato de feijão branco (Phaseolus vulgaris L.).

\begin{tabular}{|c|c|c|}
\hline Estudo & Objetivo & Resultados \\
\hline SONG et al. (2016) & $\begin{array}{l}\text { Avaliar a influência do extrato de feijão } \\
\text { branco na obesidade e na resistência à } \\
\text { insulina associada à obesidade e na } \\
\text { esteatose hepática em camundongos } \\
\text { alimentados com dieta rica em } \\
\text { gordura. }\end{array}$ & $\begin{array}{l}\text { A suplementação de extrato de } \\
\text { feijão branco reduziu } \\
\text { significativamente o ganho de peso } \\
\text { corporal induzido por dieta rica em } \\
\text { gordura, bem como o peso relativo } \\
\text { do tecido adiposo branco visceral e } \\
\text { resultou em um peso corporal final } \\
\text { mais baixo nos camundongos } \\
\text { tratados com extrato de feijão } \\
\text { branco. } \\
\text { Foi relatado retardo da digestão de } \\
\text { amidos da dieta por meio da inibição } \\
\text { da alfa amilase pancreática. }\end{array}$ \\
\hline MICHELI et al. (2019) & $\begin{array}{l}\text { Avaliar a eficácia de um tratamento } \\
\text { crônico com um extrato de semente } \\
\text { padronizado de feijão branco, } \\
\text { contendo } 6 \% \text { do composto bioativo } \\
\text { não nutritivo faseolamina. }\end{array}$ & $\begin{array}{l}\text { A suplementação de extrato de } \\
\text { feijão branco reduziu o peso } \\
\text { corporal ao longo do tempo, bem } \\
\text { como reduziu efetivamente a } \\
\text { glicemia, os triglicerídeos e o } \\
\text { colesterol em camundongos obesos. } \\
\text { Foi relatado retardo da digestão de } \\
\text { amidos da dieta por meio da inibição } \\
\text { da alfa amilase pancreática. }\end{array}$ \\
\hline WANG et al. (2020) & $\begin{array}{l}\text { Avaliar a influência do extrato de feijão } \\
\text { branco administrado em forma de } \\
\text { cápsula antes das refeições diárias } \\
\text { sobre a perda de peso de indivíduos } \\
\text { obesos. }\end{array}$ & $\begin{array}{l}\text { A administração de extrato de feijão } \\
\text { branco promoveu redução do índice } \\
\text { de massa corporal (IMC) em média } \\
0,79 \text { e redução da gordura corporal } \\
\text { em } 1,53 \% \text { em humanos obesos. } \\
\text { Foi relatado retardo da digestão de } \\
\text { amidos da dieta por meio da inibição } \\
\text { da alfa amilase pancreática. }\end{array}$ \\
\hline $\begin{array}{l}\text { CASTILLO, GONZÁLEZ e } \\
\text { MOORE-CARRASCO } \\
\text { (2019) }\end{array}$ & $\begin{array}{l}\text { Investigar a atividade antiobesidade } \\
\text { do extrato de feijão branco por meio } \\
\text { da quantificação da lipólise em }\end{array}$ & $\begin{array}{l}\text { A administração de extrato de feijão } \\
\text { branco promoveu aumento da } \\
\text { libertação de glicerol de forma } \\
\text { significativa e redução do acúmulo }\end{array}$ \\
\hline
\end{tabular}




\begin{tabular}{|l|l|l|}
\hline & $\begin{array}{l}\text { adipócitos maduros e em tecido } \\
\text { adiposo branco de ratos. }\end{array}$ & $\begin{array}{l}\text { de triglicerídeos no meio } \\
\text { intracelular. } \\
\text { Foi relatado retardo da digestão de } \\
\text { amidos da dieta por meio da inibição } \\
\text { da alfa amilase pancreática. }\end{array}$ \\
\hline
\end{tabular}

Fonte: Autoria própria

\section{CONSIDERAÇÕES FINAIS}

O extrato de feijão-branco ( $P$. vulgaris L.) apresentou elevado potencial antiobesidade pois é capaz de promover a redução da digestão de amidos da dieta, e desta maneira a energia derivada dos carboidratos e a taxa de absorção corporal da energia na forma de glicose pode ser amenizada, reduzindo a formação de tecido adiposo, além de diminuir colesterol e triglicérides prevenindo a obesogênese.

\section{REFERÊNCIAS}

AFOLABI, Hafeez Abiola et al. The relationship between obesity and other medical comorbidities. Obesity Medicine, v. 17, p. 100164, 2020.

BARRETT, Marilyn L.; UDANI, Jay K. A proprietary alpha-amylase inhibitor from white bean (Phaseolus vulgaris): a review of clinical studies on weight loss and glycemic control. Nutrition Journal, v. 10, n. 1, p. 24, 2011.

BRAY, G. A. et al. Obesity: a chronic relapsing progressive disease process. A position statement of the World Obesity Federation. Obesity Reviews, v. 18, n. 7, p. 715723, 2017.

CASTILLO, Felipe; GONZÁLEZ, Daniel R.; MOORE-CARRASCO, Rodrigo. Effects of phaseolus vulgaris extract on lipolytic activity and differentiation of 3T3-L1 preadipocytes into mature adipocytes: a strategy to prevent obesity. Journal of nutrition and metabolism, v. 2019, 2019.

HEYMSFIELD, Steven B.; WADDEN, Thomas A. Mechanisms, pathophysiology, and management of obesity. New England Journal of Medicine, v. 376, n. 3, p. 254266, 2017.

LIU, Qi-Zheng et al. Inhibition of starch digestion: The role of hydrophobic domain of both $\alpha$-amylase and substrates. Food Chemistry, v. 341, p. 128211, 2020.

LOI, Barbara et al. Reducing effect of an extract of Phaseolus vulgaris on food intake in mice-Focus on highly palatable foods. Fitoterapia, v. 85, p. 14-19, 2013. 
MARRELLI, Mariangela et al. Inhibition of key enzymes linked to obesity by preparations from Mediterranean dietary plants: effects on $\alpha$-amylase and pancreatic lipase activities. Plant foods for human nutrition, v. 68, n. 4, p. 340-346, 2013.

MICHELI, Laura et al. Phaseolus vulgaris L. Extract: alpha-amylase inhibition against metabolic syndrome in mice. Nutrients, v. 11, n. 8, p. 1778, 2019.

MICHELI, Laura et al. Phaseolus vulgaris L. Extract: alpha-amylase inhibition against metabolic syndrome in mice. Nutrients, v. 11, n. 8, p. 1778, 2019.

MÜLLER, M. J.; GEISLER, C. Defining obesity as a disease. European Journal of Clinical Nutrition, v. 71, n. 11, p. 1256-1258, 2017.

OBIRO, Wokadala Cuthbert; ZHANG, Tao; JIANG, Bo. The nutraceutical role of the Phaseolus vulgaris $\alpha$-amylase inhibitor. British journal of nutrition, v. 100, n. 1, p. 1-12, 2008.

RICHARD, Caroline et al. Individuals with obesity and type 2 diabetes have additional immune dysfunction compared with obese individuals who are metabolically healthy. BMJ Open Diabetes Research and Care, v. 5, n. 1, 2017.

SATTAR, Naveed; MCINNES, lain B.; MCMURRAY, John JV. Obesity a risk factor for severe COVID-19 infection: multiple potential mechanisms. Circulation, 2020.

SONG, Haizhao et al. Dietary Phaseolus vulgaris extract alleviated diet-induced obesity, insulin resistance and hepatic steatosis and alters gut microbiota composition in mice. Journal of Functional Foods, v. 20, p. 236-244, 2016.

SWINBURN, Boyd A. et al. The global obesity pandemic: shaped by global drivers and local environments. The Lancet, v. 378, n. 9793, p. 804-814, 2011.

TUCCI, Sonia A.; BOYLAND, Emma J.; HALFORD, Jason CG. The role of lipid and carbohydrate digestive enzyme inhibitors in the management of obesity: a review of current and emerging therapeutic agents. Diabetes, metabolic syndrome and obesity: targets and therapy, v. 3, p. 125, 2010.

WANG, Shenli et al. Regular intake of white kidney beans extract (Phaseolus vulgaris L.) induces weight loss compared to placebo in obese human subjects. Food Science \& Nutrition, v. 8, n. 3, p. 1315-1324, 2020. 


\title{
CAPÍTULO YIX
}

\section{AVALLAÇÃO DO CONHECIMENTO DOS ALUNOS INGRESSOS DE UMA INSTITUIÇÃO DE ENSINO TÉCNICO PRIIADO DA ÁREA DA SAÚDE SOBRE ISTS NO MUNIĆPIO DE SÃO GONÇALO/R]}

\author{
Agatha Chrystie dos Santos Ribeiro ${ }^{1}$ \\ Mariana Fernandes da Rocha ${ }^{2}$ \\ Paula Monnerat Floriano ${ }^{2}$ \\ Yasmin da Silva Santos ${ }^{3}$
}

Aluna do curso técnico em Análises Clínicas. Senes/UNETEC-São Gonçalo/RJ

2 Bióloga docente do curso técnico de Análises Clínicas. Senes/UNETEC-São Gonçalo/RJ.

${ }^{3}$ Mestre em ciências, biomédica docente do curso técnico de Análises Clínicas. Senes/UNETEC-São Gonçalo/RJ.

\section{RESUMO}

As infecções sexualmente transmissíveis (IST) podem ser transmitidas por diversos microrganismos patogênicos, com maior conhecimento público sendo o HIV/AIDS. O objetivo deste trabalho é avaliar o conhecimento de alunos da área da saúde sobre ISTs em uma instituição de ensino através de uma pesquisa descritiva de natureza qualitativa, com questionário fechado sobre o perfil do candidato e conhecimento sobre ISTs dos alunos de uma instituição de ensino privado do município de São Gonçalo/RJ. Os dados foram analisados pela técnica de análise de Conteúdo de Bardin. Foram coletados 46 questionários onde, $87 \%$ são do sexo feminino, com média de idade de 28 anos, $49 \%$ moram com parceiros. $80,4 \%$ possuem o ensino médio completo e, $50 \%$ dos participantes afirmaram ter aula e palestra de educação sexual na escola. 58,7\% nunca realizaram algum teste diagnóstico para detecção de IST, mas somente $45,7 \%$ utilizam o preservativo em todas as relações sexuais. $8 \%$ dos participantes afirmam não ter medo de se infectar e, 13\% acreditam que todas as ISTs apresentam sintomas clínicos. Podemos observar que os candidatos afirmam ter algum tipo de conhecimento sobre IST, contudo, os resultados confrontam uma realidade diferente, podendo ser explicada pela presença de um parceiro fixo. A confiança em não adquirir doença descarta o uso do preservativo, mas, muitos candidatos nunca realizaram nenhum teste diagnóstico o que pode ser preocupante para a saúde do indivíduo e de terceiros.

Palavras-chave: Conhecimentos, Infecção sexualmente transmissível, Orientação sexual, Sexualidade. 


\section{INTRODUÇÃO}

O município de São Gonçalo pertence à Região Metropolitana do Rio de Janeiro e possui uma população estimada de 1.084.839 habitantes (IBGE, 2019), sendo o segundo mais populoso do estado. A maioria da população encontra-se na faixa etária de 25 a 34 anos, são majoritariamente católicos apostólicos romanos seguidos da população evangélica com salário médio mínimo, $81,4 \%$ da população tem acesso ao saneamento básico adequado e 96,7\% das crianças de 6 a 15 anos estão na escola (IBGE, 2019). O município possui promoção à atenção primária de saúde reconhecida no estado (ALVES, 2019), principalmente voltada para a população idosa que apresenta comorbidades crônicas relevantes (FIOCRUZ, 2017). As infecções sexualmente transmissíveis (ISTs) são tratadas com a devida atenção pelo Centro de testagem e acolhimento do município (CTA/SAE), realizando testes laboratoriais para Sífilis, HIV, e teste rápido para HIV (BRASIL, 2020).

Reconhecemos que Infecções sexualmente transmissíveis (IST) são patologias transmitidas por microrganismos (bactérias, vírus, fungos e protozoários), principalmente, pelo contato sexual desprotegido com um indivíduo infectado. Também podem ser transmitidos em poucos casos por transfusão de sangue, compartilhamento ou acidentes com perfuro cortantes e de forma congênita. As ISTs mais conhecidas pela população são o HIV e a sífilis graças às campanhas de prevenção constantemente vinculadas e pelos exemplos em indivíduos conhecidos na mídia. Contudo, não são as únicas que promovem riscos à saúde do indivíduo (MINISTÉRIO DA SAÚDE, 2019).

As ISTs podem se apresentar com diferentes manifestações clínicas. A avaliação clínica realizada por um profissional médico é de extrema relevância para o diagnóstico. A identificação das diferentes vulnerabilidades, histórico do paciente, o exame físico e coleta de material biológico para a realização de testes laboratoriais ou rápidos mantém a acurácia diagnóstica aplicada às ISTs, esta abordagem se baseia nos aspectos clínicos para classificar os principais agentes etiológicos e definir o tratamento sem o apoio de testes laboratoriais ou rápidos. (BRASIL, 2020). Sempre que possível nos serviços especializados em ISTs e/ou doenças infecciosas devem ser realizadas exames para triagem de gonorreia, clamídia, sífilis, HIV e hepatites B e C (MINISTÉRIO DA SAÚDE, 2018). 
O controle das infecções assintomáticas está atrelado às novas tecnologias diagnósticas como os testes rápidos para sífilis e para o HIV, além de outras mais elaboradas aplicadas ao diagnóstico molecular, mas que contam com a possibilidade de implantação, como os testes para gonorreia e clamídia. Vale ressaltar que ISTs são de notificação compulsória, e devem ser sinalizadas através do SINAN (MINISTÉRIO DA SAÚDE, 2018).

A Síndrome da Imunodeficiência Adquirida (AIDS) é uma doença crônica causada pelo Vírus da Imunodeficiência Humana (HIV), ocasionando perda progressiva da imunidade celular e, consequentemente, o aparecimento de infecções oportunistas. Estima-se que 38 milhões de pessoas em todo mundo possuam o vírus, contudo o acesso a medidas profiláticas tem representado uma ótima medida controle a incidência. (MINISTÉRIO DA SAÚDE, 2018; UNAIDS, 2020).

Atualmente o indivíduo portador do vírus possui vida normal graças ao controle e manejo da doença ao usar os medicamentos indicados e acessíveis através do Sistema único de saúde (SUS), o que possibilita indivíduos de baixa renda a não comprometerem seu orçamento, e manter o tratamento sem interrupções além dos frequentes acompanhamentos clínicos. (BRASIL,2020).

Existem atualmente duas estratégias de tratamento preventivo que favorecem novas campanhas de combate a transmissão do HIV, diminuindo de forma relativa a transmissão do vírus, a profilaxia Pré-exposição (PrEP) e a Profilaxia Pós-Exposição (PEP). A PrEP é uma estratégia de prevenção que utiliza medicamentos antirretrovirais de forma contínua por pessoas não infectadas a fim de reduzir o risco de aquisição do HIV através de relações sexuais. O PrEP também é utilizado por casais para prevenção de um indivíduo que não possui positividade a doença. Já a PEP, é uma estratégia de prevenção que utiliza medicamentos antirretrovirais durante 28 dias em pessoas que tiveram risco de contato com o HIV através de relações sexuais desprotegidas ou acidentes de trabalho com exposição a material biológico, com a finalidade de impedir que o HIV se instale no organismo de forma definitiva. Este tratamento deve ser iniciado logo após a situação de risco dentro do prazo máximo de 72 horas. (MINISTÉRIO DA SAÚDE, 2018; PREP BRASIL, 2020)

O uso de preservativos em todas as relações sexuais (orais, anais e vaginais) é o método mais eficaz para evitar a transmissão das ISTs além de ser um importante 
método contraceptivo. O indivíduo que realiza sexo desprotegido pode contrair uma IST, sem predileção por idade, classe social, orientação sexual ou religião. Um indivíduo aparentemente saudável pode estar infectado por uma IST (DIVE, 2020)

No município de São Gonçalo o atendimento realizado a pessoas portadoras de alguma ISTs é realizado em três locais diferentes: pelo Centro de testagem e acolhimento, na parada 40, atuando na testagem laboratorial para HIV e sífilis, além do teste rápido para HIV, com ferramenta de triagem; na Clínica Municipal Gonçalense, no barro vermelho fornecendo a PrEP; e o Centro de Referência, Polo Sanitário Hélio Cruz com equipe de infectologistas e enfermagem para atendimento da população (O SÃO GONÇALO, 2020).

\section{MÉTODOS}

A pesquisa é descritiva de natureza qualitativa, utilizando questionário on-line (SURVIO) com questões fechadas e semiabertas sobre o perfil do candidato (Idade, Sexo, Local de moradia e Escolaridade) e perfil de conhecimento sobre ISTs (Educação sexual, Meios de transmissão, Métodos contraceptivos e Métodos profiláticos) dos alunos de uma instituição de ensino privado do município de São Gonçalo/RJ (OKOMOTO ET AL, 2016; LINHARES ET AL, 2018). Todos os participantes assinaram um termo de consentimento livre e esclarecido para serem incluídos no trabalho. O projeto foi apresentado ao Comitê de ética em pesquisa (CEP), aprovado com o número CAAE: 32503520.6 .0000 .5237$.

Os dados recolhidos do trabalho estão dispostos em uma planilha do software Excel onde as variáveis foram analisadas pela técnica de Conteúdo de Bardin (SANTOS 2012; BARDIN, 2016). A instituição de ensino particular onde foi analisada a pesquisa está situada no município de São Gonçalo, mas recebe alunos de regiões vizinhas como, por exemplo, Niterói e Itaboraí, portanto foram elegíveis os participantes da pesquisa devidamente matriculados na instituição. Como critério de exclusão adotou-se participantes que já concluíram o curso, que estavam realizando somente a disciplina de estágio ou menores de idade. Devido à situação de pandemia de Sars-CoV-2 que acontece no momento, a equipe concluiu que o andamento dos questionários poderia 
ser realizada on-line através da plataforma Survio. O presente trabalho é o produto de um Trabalho de conclusão de curso.

O benefício oferecido por este estudo está na resposta à comunidade sobre a qualidade da informação dos participantes para o mercado de trabalho.

Esperávamos que neste trabalho fosse possível avaliar a qualidade do conhecimento dos alunos de uma instituição privada e divulgar estes resultados através de um trabalho científico para a comunidade.

\section{RESULTADOS E DISCUSSÃO}

Foram coletados quarenta e seis questionários onde, $87 \%$ são do sexo feminino, com média de idade de 28 anos, 49\% moram com parceiros e são residentes do município de São Gonçalo (87\%) e Niterói (13\%).

Possuem o ensino médio completo e, 50\% dos participantes afirmaram ter aula e palestra de educação sexual na escola (ensino fundamental ou médio). 58,7 \% nunca realizaram algum teste diagnóstico para detecção de IST, mas somente 45,7\% utilizam o preservativo em todas as relações sexuais. Aproximadamente $8 \%$ dos participantes afirmam não ter medo de se infectar e, 13\% acreditam que todas as IST's apresentam sintomas clínicos.

Podemos observar que o perfil dos candidatos é de jovens que afirmam ter algum tipo de conhecimento sobre ISTs. Contudo, os resultados confrontam uma realidade diferente, podendo ser explicada pela presença de um parceiro fixo. A confiança em não adquirir doença também pode ser explicada por este fato que descartaria o uso do preservativo. No entanto muitos candidatos nunca realizaram nenhum teste diagnóstico o que pode ser preocupante para a saúde do indivíduo e de terceiros.

Apesar da metade dos participantes afirmarem ter tido aula ou palestras de educação sexual, os mesmos não se protegem através do sexo seguro. Como propósito original deste trabalho era compreender o conhecimento dos alunos em torno das ISTs, foi possível constatar que os participantes necessitam de uma reciclagem sobre o assunto em sala de aula e em projetos pedagógicos aplicados à carreira dos mesmos. 
Como alunos da área da saúde, devem se conscientizar sobre o assunto a fim de preservar os mesmos na rotina de trabalho com amostras e pacientes, além do papel como possível disseminador de informação para a população.

\section{AGRADECIMENTOS}

As autoras do trabalho agradecem a todos os participantes que responderam o questionário on-line voluntariamente, possibilitando o desenvolvimento deste trabalho.

\section{REFERÊNCIAS}

ALVES, T. Atenção Básica de São Gonçalo foi destaque na efetivação de políticas públicas em 2019. Portal São Gonçalo, disponível em: https://www.saogoncalo.rj.gov.br/noticiaCompleta.php?cod=10250\&tipoNotici $\mathrm{a}=\mathrm{Sa} \%$ FAde

Bardin, L. (2006). Análise de conteúdo (L. de A. Rego \& A. Pinheiro, Trads.). Lisboa: Edições 70. (Obra original publicada em 1977)

Você sabe o que é HIV e o que é AIDS?- disponível em: https://unaids.org.br/2017/03/voce-sabe-o-que-e-hiv-e-o-que-e-aids/

Departamento de Doenças de Condições Crônicas e Infecções Sexualmente Transmissíveis MINISTÉRIO DA SAÚDE disponível em: http://www.aids.gov.br/pt-br/profissionais-de-saude/ist/diagnostico-das-ist

Protocolo Clínico e Diretrizes Terapêuticas para Atenção Integral às Pessoas com Infecções Sexualmente Transmissíveis (IST) disponível em: http://www.dive.sc.gov.br/index.php/d-a/item/infeccoes-sexualmentetransmissiveis

Protocolo Clínico e Diretrizes Terapêuticas para Profilaxia Pré-Exposição (PrEP) de Risco à Infecção pelo HIV disponível em: http://www.aids.gov.br/pt$\mathrm{br} /$ pub/2017/protocolo-clinico-e-diretrizes-terapeuticas-para-profilaxia-preexposicao-prep-de-risco

BRASIL. Protocolo Clínico e Diretrizes Terapêuticas para Atenção Integral às Pessoas com Infecções Sexualmente Transmissíveis (IST)/Ministério da Saúde, Secretaria de Vigilância em Saúde, Departamento de Doenças de Condições Crônicas e Infecções Sexualmente Transmissíveis. - Brasília: Ministério da Saúde, 2020.

CARVALHO, O; PINTO, R.G.S., SANTOS, M.S. Conhecimento sobre as infeç̧ões sexualmente transmissíveis por estudantes adolescentes de escolas públicas. 
Revista oficial do núcleo de estudos da saúde do adolescente/UERJ. Vol. 15 no 1 - Jan/Mar - 2018

FIOCRUZ. Atenção básica à saúde construção da linha de cuidado à pessoa idosa do município de São Gonçalo, 2017 Disponível em: https://saudedapessoaidosa.fiocruz.br/pratica/aten\%C3\%A7\%C3\%A3ob\%C3\%A1sica-\%C3\%A0-sa\%C3\%BAde-constru\%C3\%A7\%C3\%A3o-da-linha-decuidado-\%C3\%A0-pessoa-idosa-do-munic\%C3\%ADpio-de-s\%C3\%A3o Acesso em $01 / 05 / 2020$

LINHARES, E.S.; ASSIS, H.P.; MANGIAVACCHI, B.M. Infeccções sexualmente transmissíveis: Conhecimento, atitudes e vulnerabilidades de adolescentes escolares no município de Bom Jesus do Itabapoana/RJ. Revista científica interdisciplinar, $n^{\circ} 3$, volume 1 , artigo $n^{\circ} 4$, Janeiro/Junho 2018.

MINISTÉRIO DA SAÚDE. Departamento de doenças de condições crônicas e infecções sexualmente transmissíveis. Disponível em http://www.aids.gov.br/ptbr/ctasae-sao-goncalo-posto-de-atendimento-medico-pam-neves Acesso em $01 / 05 / 2020$

OKAMOTO, C.T; FARIA, A. A. B; SATER, A. C.; DISSENHA, B. V.; STASIEVSKI, B. S. Perfil do Conhecimento de Estudantes de uma Universidade Particular de Curitiba em relação ao HPV e Sua Prevenção. Revista Brasileira de Educação Médica Dez 2016, Volume 40 № 4 Páginas $611-620$.

Santos, F. M. Análise de conteúdo: a visão de Laurence Bardin. Revista Eletrônica de Educação, v. 6, n. 1, mai. 2012.

Secretaria de Vigilância em Saúde, Ministério da Saúde Número Especial , Boletim Epidemiológico de HIV e Aids Dez. 2019

UNAIDS, disponível em https://unaids.org.br/estatisticas/?gclid=CjOKCQiAtqLBRCOARIsAF4K3WGFvmEPC6rWpFC9nbxJUbEQHfxIMC5K5XnDlviuuFupXFGmiG gSs-8aAvnXEALw_wcB Acessado em 03/12/2020

PrEP BRASIL, disponível em http://prepbrasil.com.br/entendendo-a-prep/ Acessado em $03 / 12 / 2020$

DIVE- DIRETORIA DE VIGILÂNCIA EPIDEMIOLÓGICA, 2020. Disponível em http://www.dive.sc.gov.br/index.php/d-a/item/infeccoes-sexualmentetransmissiveis Acessado em 03/12/2020.

O

São

Gonçalo

,2020.

Disponível

em https://www.osaogoncalo.com.br/servicos/79873/sao-goncalo-inaugura-novocentro-de-referencia-e-testagem-goncalense Acessado em 03/12/2020. 


\section{CAPÍTULO XY}

\section{USO RACIONAL DAS PANCS: UM RESGATE NA REGIÃO NA REGIÃO DE AMERICANA/SP}

Osmar Azol Fernandes ${ }^{1}$

${ }^{1}$ Especialista em Biologia. Universidade de São Paulo - USP

\section{RESUMO}

A educação ambiental deve ser implementada no currículo da educação básica e desenvolvida de modo que promova a interação entre as disciplinas, contextualizando as características da comunidade. Trabalho estabelecido com a finalidade de propiciar uma atividade de educação ambiental com foco na questão da sustentabilidade, possibilitando que os envolvidos desenvolvessem seu protagonismo num tema que abrange diversas áreas de conhecimento, favorecendo uma interação que desperte a formação de alunos críticos e conscientes com os problemas ambientais. O projeto foi desenvolvido na Escola Estadual Professora Clarice Costa Conti em Americana, Estado de São Paulo, destacando que possibilitou uma aprendizagem prática, um laboratório a céu aberto. Os resultados e ações colaboraram para que a educação ambiental possibilitasse condições em que os envolvidos entendessem o contexto em que estão inseridos, focando na melhora do processo de ensino e aprendizagem. O Projeto Uso Racional das PANCs: Um Resgate na Região de Americana possibilitou o envolvimento de todos favorecendo um processo de aprendizagem mais interessante e prático, com a parte teórica trabalhada em sala de aula e a prática contribuindo como um recurso fundamental para a compreensão dos temas que referem ao seu desenvolvimento.

Palavras-chave: Educação ambiental. PANCs. Sustentabilidade.

\section{INTRODUÇÃO}

Ao deparar com atividades de Educação Ambiental, o individuo passa a ser sensibilizado sobre a importância das ações que preservam o ambiente em que está inserido e percebe a inter-relação entre os seres vivos.

O desenvolvimento de atividades de Educação Ambiental deverá sempre abordar a importância de promover o entusiasmo de analisar e enxergar o meio ambiente de maneira diferente, sentindo-se como parte integrante do mesmo.

O Projeto Uso Racional das PANCs: Um Resgate na Região de Americana, elaborado com a finalidade de integrar várias fontes e recursos de aprendizagem, 
visando estabelecer possibilidades para o desenvolvimento de ações pedagógicas por associar práticas em equipe abordando diferentes formas de aprender, desenvolvida no ano letivo de $2020 \mathrm{com}$ a finalidade de recuperar um terreno ocioso com entulhos e vegetação alta no entorno da Escola Clarice, município de Americana-SP, para evitar a proliferação de animais peçonhentos, principalmente o escorpião amarelo, devido á alta incidência no bairro onde a escola está inserida.

Diante dessa situação, o Projeto elaborado e proposto visou despertar o interesse dos envolvidos no contato com o ambiente, atuando com comprometimento e responsabilidade, em diversas etapas de desenvolvimento, tais como: limpeza do local, construção dos canteiros, escolha das PANCs (plantas alimentícias não convencionais) a serem cultivadas, processo de plantio, rega e manutenção, entre outras, com a orientação e supervisão do professor.

Com o desafio lançado, buscou-se desenvolver nos envolvidos habilidades de investigação e espírito cientifico com atividades direcionadas ao uso do solo, envolvendo-os na implementação, com técnicas articuladas promovendo um aprendizado significativo com o contato direto na terra, priorizando a importância do trabalho em equipe.

A execução do Projeto originou da necessidade de despertar um novo olhar e respeito com o meio ambiente, a elaboração, manejos, cuidados, dedicação e comprometimento, elementos fundamentais para a eficiência que resultaram no sucesso.

O projeto foi estabelecido para que os envolvidos tivessem conhecimento de todas as etapas, participando de cada uma delas, contribuindo para sua execução, desde o preparado do terreno até a colheita das PANCs.

\section{REVISÃO BIBLIOGRÁFICA}

\subsection{Elaboração e configuração do projeto}

Com o cronograma elaborado e metas planejadas, acreditando que os envolvidos são capazes de entenderem a importância da educação ambiental e 
acreditando em fazer uma educação de qualidade, partimos para o desenvolvimento do projeto com a finalidade de um aprendizado significativo.

Considerando a ideia que por meio do conhecimento da educação ambiental é possível promover alterações na comunidade no que se refere ao cultivo de PANCs, à saúde e melhor qualidade de vida, participando coletivamente numa atividade que gere interesse e ao mesmo tempo tendo a possibilidade de ser o agente de tais mudanças.

Considerando que os Parâmetros Curriculares Nacionais estabelecem que os conteúdos de Meio Ambiente inter-relacione aos demais, num envolvimento de transversalidade dentro de uma situação motivadora dentro do tema, proporcionando uma abrangência geral do problema ambiental.

Concordando que o mundo contemporâneo proporciona novas perspectivas e tendências e que a escola aporta o papel de nicho apropriado por desenvolver as habilidades e competências que colaborem para a formação dos alunos como cidadãos conscientes para enfrentarem o novo século, com suas escolhas.

Tais ações são importantes para alcançar a principal finalidade da educação, que é o pleno desenvolvimento do indivíduo, preparando o aluno para o exercício da cidadania, conforme estabelece a LDB.

Nessa perspectiva de mudanças e transformações, o professor possui papel fundamental de agente colaborador, e nesse contexto a sustentabilidade surge como parâmetro para uma interação presente e futuro.

O projeto tem por finalidade implementar o cultivo de PANCs na unidade escolar, relacionando sua execução como alavanca de proposta de ensino para Educação ambiental, além de promover uma reflexão sobre a melhor qualidade dos alimentos servidos na merenda escolar e ao mesmo tempo propiciar aos envolvidos uma atividade prática.

Após a escolha do local para implementação, o ponto de partida foi limpeza com remoção de entulhos e corte da vegetação. Com o terreno limpo, capinado, iniciamos a preparação do local para os primeiros plantios. 


\subsection{Planejamento}

Discutimos com os envolvidos a importância de se estabelecer o planejamento, analisando os tipos de cultivo, medidas dos canteiros, modo de regar e manutenção, essa etapa foi debatida em sala de aula.

"A horta inserida no ambiente escolar pode ser um laboratório vivo que possibilita o desenvolvimento de diversas atividades pedagógicas em educação ambiental e alimentar unindo teoria e prática de forma contextualizada, auxiliando no processo de ensino-aprendizagem e estreitando relações através da promoção do trabalho coletivo e cooperado entre os agentes sociais envolvidos". (MORGADO, 2006. p.1).

De acordo com Silvia Lucilia Fonseca de Souza Tavares - 2014, a alimentação é essencial para o bom desenvolvimento dos alunos, dessa maneira o estímulo da alimentação saudável propiciará um desenvolvimento.

"O plantio, os cuidados e a colheita serão realizados com os demais alunos, podendo perceber o interesse e empolgação dos alunos na confecção da horta, que tem como objetivo enriquecer a merenda escolar com diferentes nutrientes. A horta inserida no ambiente escolar torna-se um laboratório vivo que possibilita o desenvolvimento de diversas atividades pedagógicas em educação ambiental e alimentar, unindo teoria e prática de forma contextualizada, auxiliando no processo de ensino-aprendizagem e estreitando relações através da promoção do trabalho coletivo".

Uma das etapas do projeto constituía-se de uma pesquisa contendo algumas questões visando obter informações relativas cultivo de horta em casa, consumo e interesse em ter conhecimento sobre as técnicas de iniciar um cultivo.

De acordo com a cartilha Horta Solidária, Cultivo de Hortaliças, organizada pela Embrapa - 2010, na página 05, destaca que:

"Ter uma horta em casa não é somente uma forma de economizar. É ter facilidades para preparar as refeições com diversos produtos, enriquecendo a mesa e variando os sabores. É aprender a cuidar de plantas. É fazer exercícios físicos. É ter alegria, prazer e saúde. Pensando em saúde, as hortaliças são importantes fontes de vitaminas e sais minerais que, aliadas às propriedades medicinais que muitas possuem, ajudam a regular e a manter o bom funcionamento do organismo". 


\subsection{Levantamento de dados}

Visando a obtenção de informações, no prosseguimento das atividades, efetuamos uma pesquisa envolvendo 305 pessoas da comunidade escolar, que possibilitando mapear os dados em gráficos.

Figura 01: Fonte autoria própria - Cultivo de hortaliças em casa.

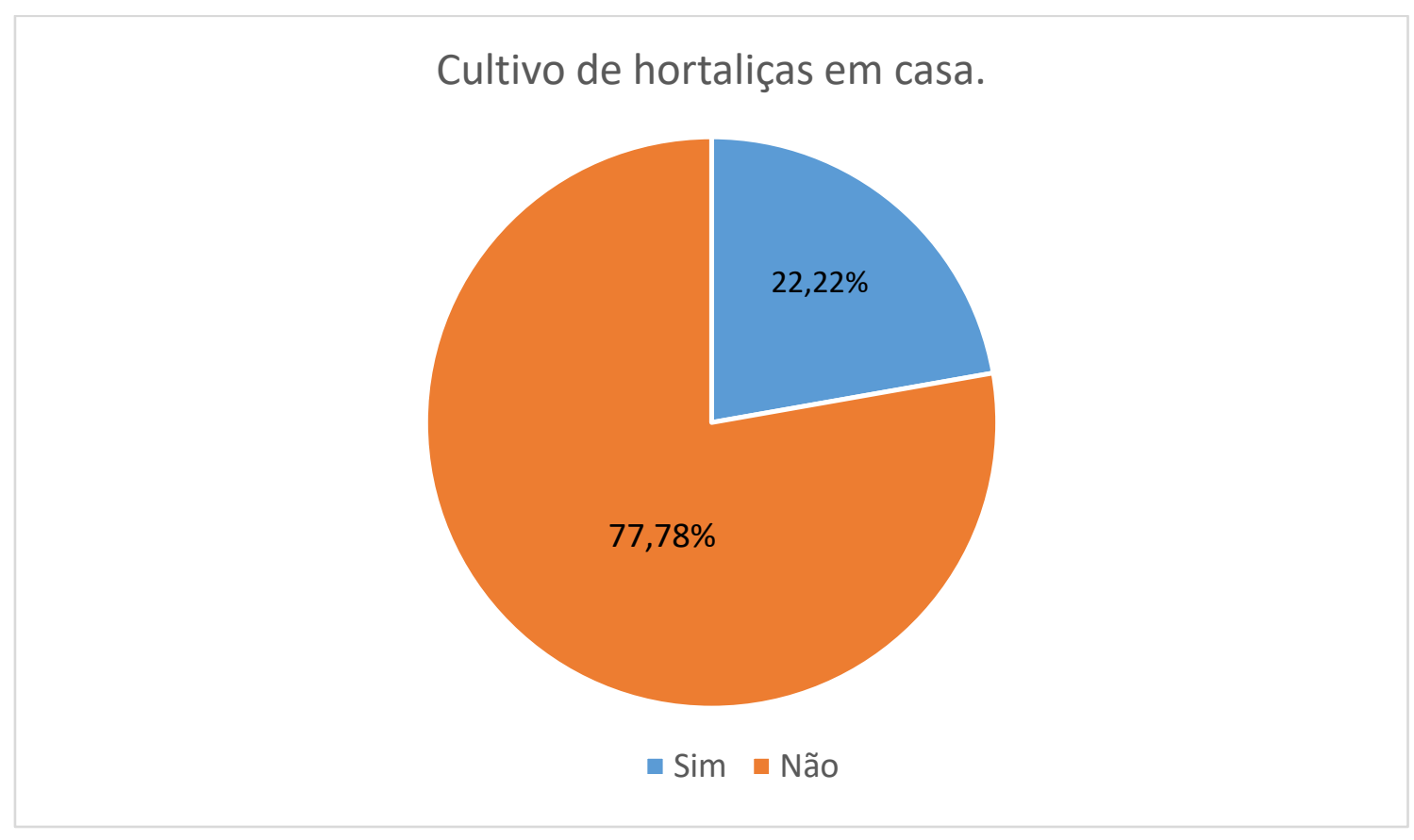

Notamos que um número elevado de pessoas não cultivam hortaliças em casa, figura 01, principalmente se tratando de uma região carente do município. Em relação ao consumo de hortaliças, figura 02 , chamou atenção índice alto de pessoas que não possuem o hábito de consumir hortaliças. No quesito sobre a obtenção de informações sobre o cultivo de hortaliças, figura 03, apontou um grande interesse. 
Figura 02: fonte autoria própria - Consumo de hortaliças

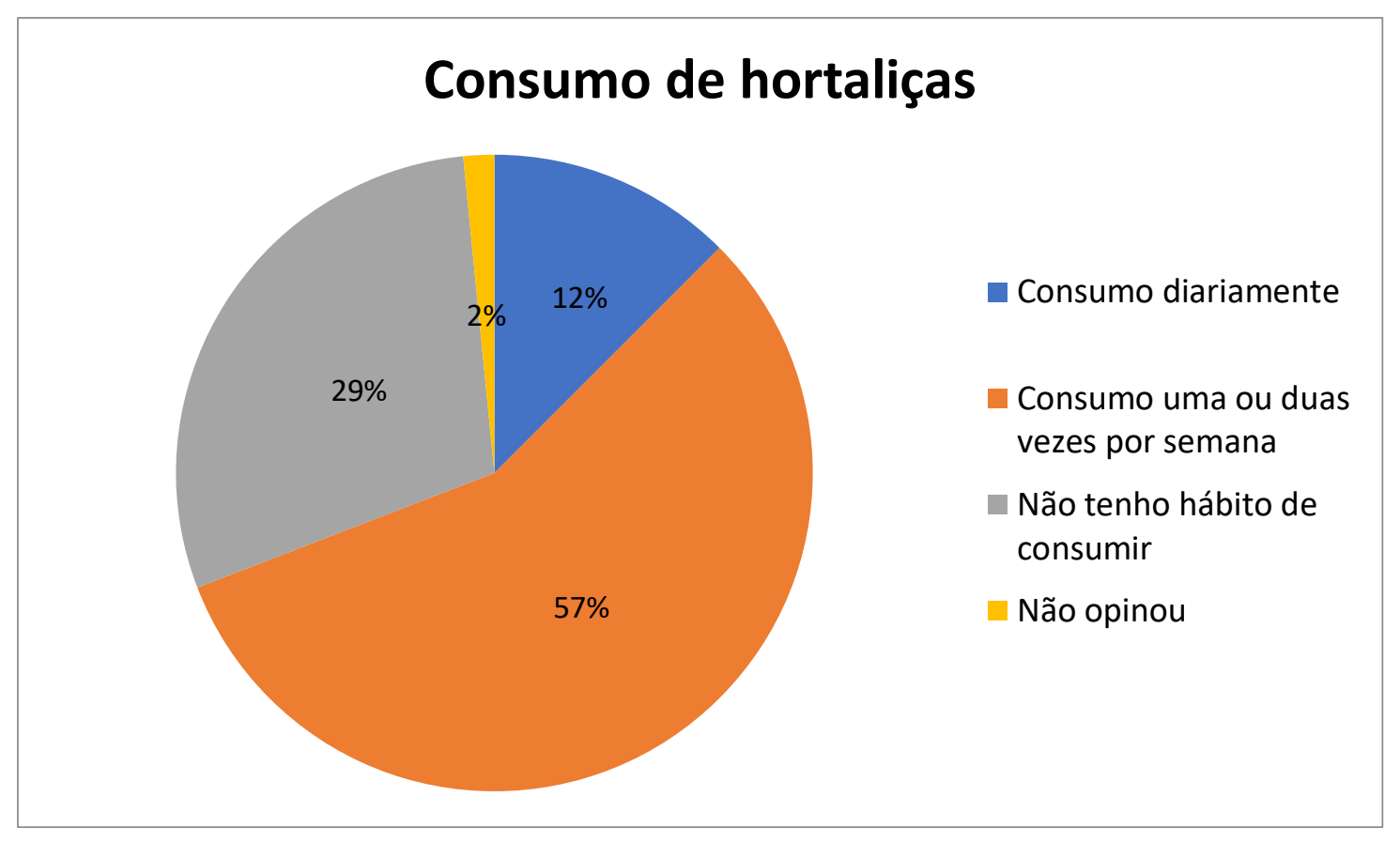

Figura 03: fonte autoria própria - Obtenção de informações sobre cultivo de hortaliças

Gostaria de ter informações sobre cultivo de hortaliças

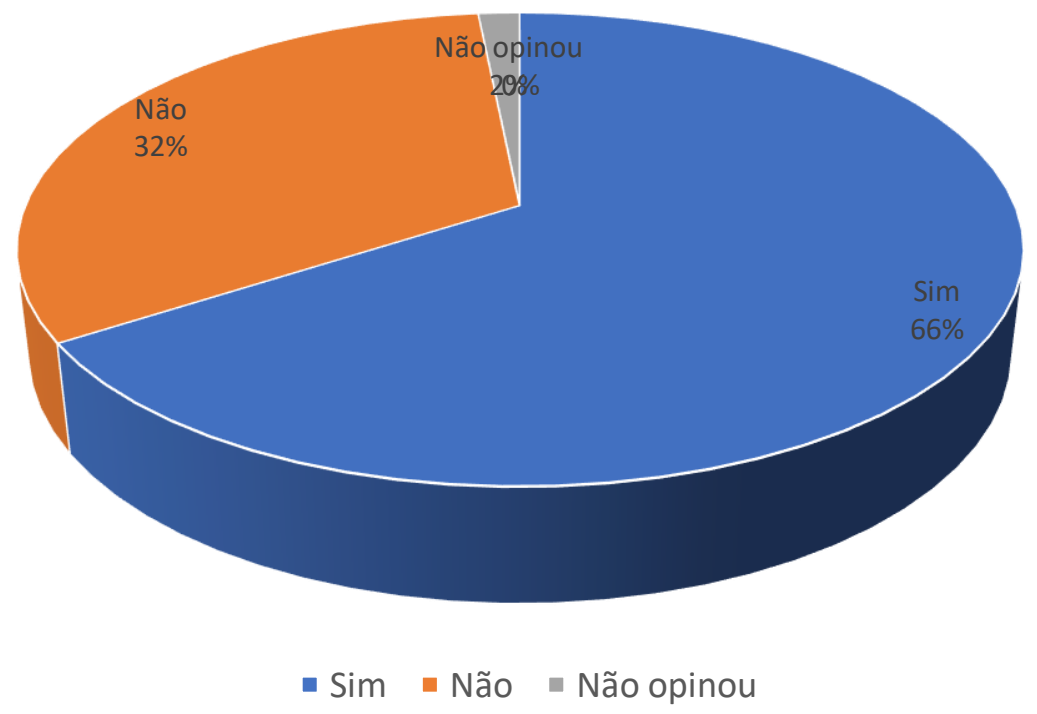

Figura 03: fonte autoria própria - Obtenção de informações sobre cultivo de hortaliças

No questionamento sobre o porque não cultiva hortaliças em casa? (figura 04), a maioria apontou falta de conhecimento, sabemos que muitas hortaliças exigem poucas técnicas e são cultivadas em pequenos espaços ou até mesmo em vasos. 
Figura 04: fonte autoria própria - Porque não cultiva hortaliças em casa?

\section{Porque não cultiva hortaliças em casa?}

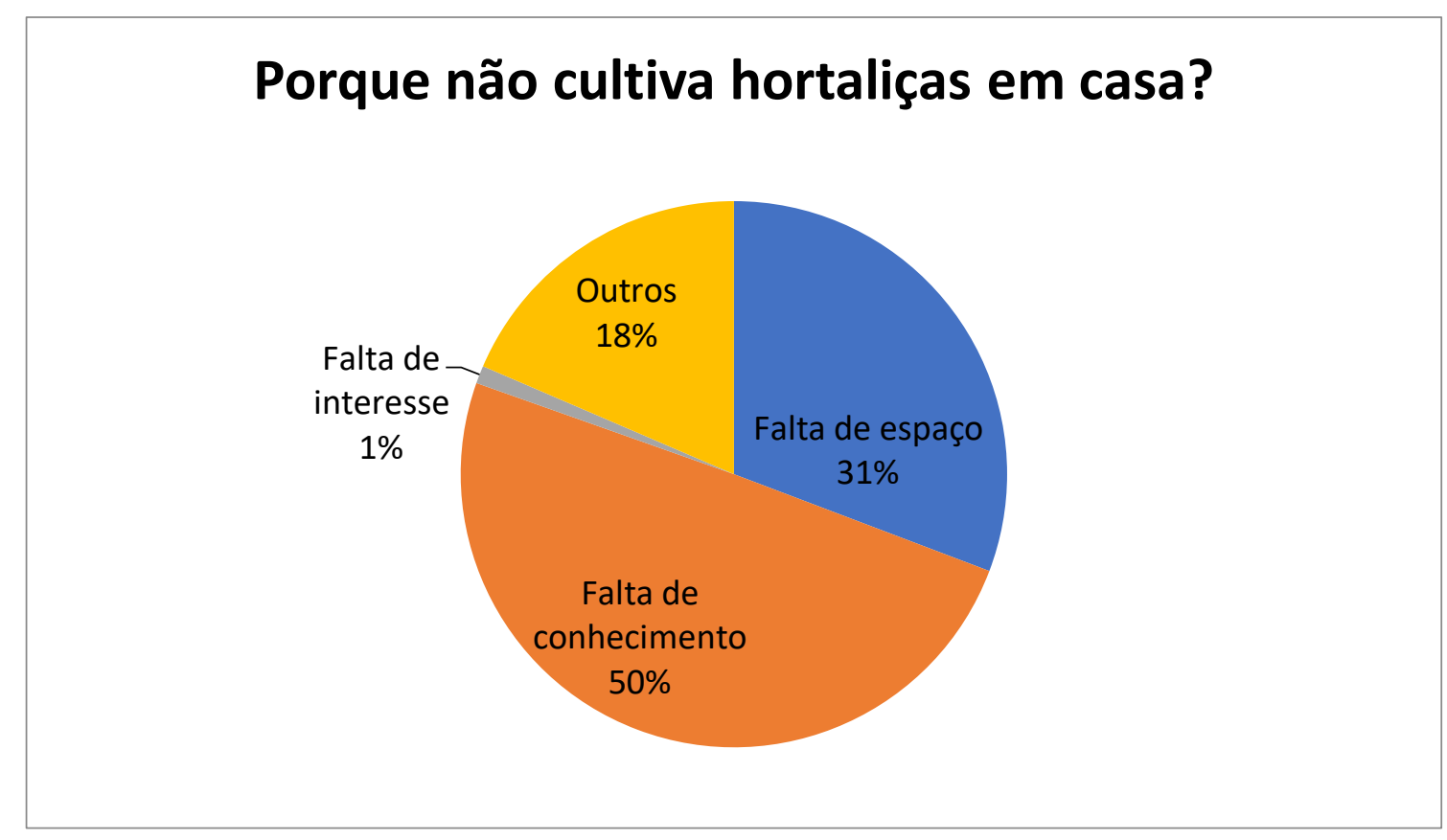

Figura 05: fonte autoria própria - Você conhece o que são PANCs!

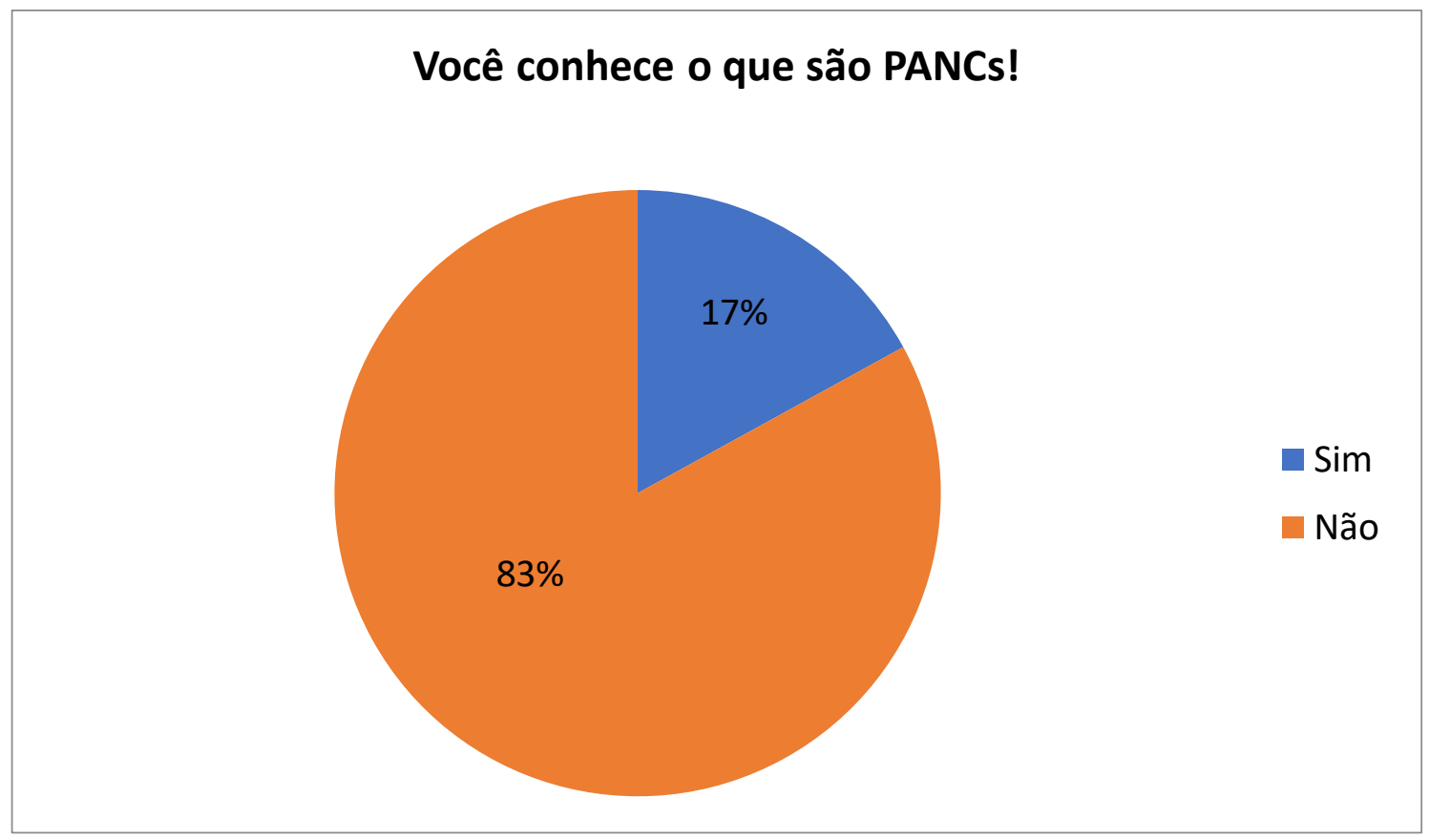

Referente ao conhecimento sobre o que são as PANCs? Figura 05, indicou um alto desconhecimento, após essa analise e verificando a necessidade da discussão sobre a importância de debatemos sobre o tema, com respeito ao meio ambiente, momento que o aluno perceberá seu papel como cidadão responsável pela manutenção do meio em que está inserido. 
Esse campo de informações com certeza possibilitará ao aluno a escolha correta, no que refere a respeito dos alimentos a serem escolhidos para consumo e desse modo, colaborar para a adoção de uma alimentação saudável.

Segundo Campos, 2017, a escola tem o papel da discussão sobre o cuidado com o meio ambiente.

"A escola deve abordar os princípios da educação ambiental de forma sistemática e transversal em todos os níveis de ensino. Abordando o tema horta na escola dará oportunidade não só de oferecer alimentos que satisfaçam as necessidades nutricionais dos educandos no período em que estão na escola, mas também de contribuir para a melhoria do processo de ensino aprendizagem e a formação de hábitos e práticas alimentares".

Após o preparo da área, prosseguimos nas discussões dos materiais, ferramentas e utensílios necessários para realização, além de técnicas de regas e adubação.

Num levantamento nas proximidades da Escola encontramos algumas espécies de plantas alimentícias não convencionais, cultivadas como ornamentais, cerca viva, outras tidas como mato, nascidas em calçadas ou terrenos baldios, entres elas, ora-pronóbis, peixinho da horta (figura 06), almeirão roxo, serralha, caruru, beldroega, taioba, vinagreira, bertalha, trapoeraba, azedinha e capuchina. 
Figura 06: Fonte autoria própria - peixinho da horta

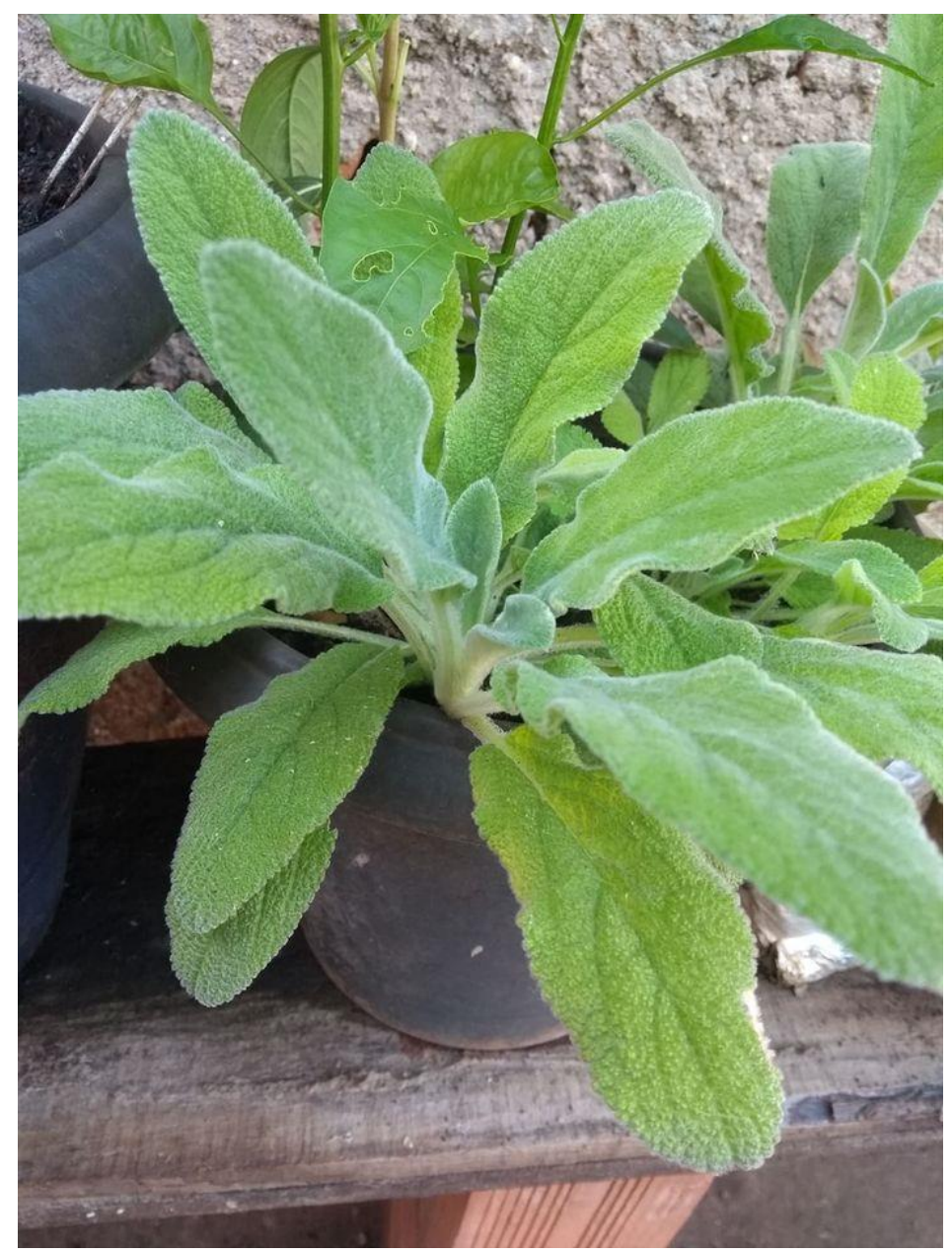

\subsection{CONCRETIZAÇÃO DO PROJETO}

Debatemos sobre diversos vídeos sobre cultivo de PANCs disponibilizados no site da Embrapa com a finalidade obtermos informações sobre os cuidados e técnicas de manuseio para aplicarem na prática os conhecimentos adquiridos.

Reconhecida área de efetivação, iniciou a elaboração do primeiro canteiro para cultivo, cavando o local para afofar solo.

Promovendo a participação e a interação entre os alunos na dinâmica do trabalho de construção da horta, considerando a fundamentação da educação ambiental, a Embrapa destaca que:

"Um dos principais objetivos da Educação Ambiental consiste em contribuir para a compreensão da complexidade do ambiente em suas dimensões ecológicas, econômicas, sociais, culturais, políticas, éticas e tecnológicas, de maneira a sensibilizar a coletividade quanto à importância de sua organização e participação na defesa de todas as formas de vida. Pretende-se, assim, incentivar a mobilização dos cidadãos a partir do reconhecimento das causas e das consequências 
dos impactos socioambientais que afligem o planeta, buscando satisfazer as necessidades fundamentais da humanidade ao mesmo tempo em que são respeitados os direitos das gerações futuras terem acesso a um ambiente saudável" (EMBRAPA, 2011).

Antes de qualquer procedimento prático, foi discutido as normas e técnicas para serem aplicadas com segurança em todas as etapas das atividades, para seu desenvolvimento.

Debatemos que o cultivo de uma PANC é uma maneira natural de produzir alimento, aplicando métodos adequados, utilizando adubos orgânicos, sem aplicação de agrotóxicos ou qualquer outro produto que possa provocar danos à saúde de quem irá consumi-la e ao meio ambiente, criando um cultivo sem defensivos químicos possibilita interagir com a natureza, contribuindo na preservação dos recursos naturais, protegendo a biodiversidade e mantendo o equilíbrio da diversidade biológica.

O desenvolvimento da horta escolar possibilita ao educando um melhor e mais proveitoso aprendizado, onde á a necessidade do toque na terra, contato com as plantas, diferenciação de formas, texturas, cheiro e da cor. Estimulando a inteligência, os sentidos e a interação com o meio ambiente, desenvolvendo também a consciência ambiental (OLIVEIRA, 2005).

Considerando que o ensino com atividade prática, demanda mudanças e acreditando que essas mudanças só terão real significado se entre os envolvidos a interação e o diálogo forem estreitados.

É certo que o saber cientifico e suas ações alteram nossa realidade, principalmente com atividades práticas, promovem uma nova maneira de analisar sobre tudo o que está ao nosso entorno.

O estudo com a PANCs possibilitou compreender fenômenos naturais, a diversidade, os processos de manutenção com ferramentas especificas e por outro lado como o ser humano pode transformar o mundo, começando por ele mesmo e por sua comunidade, explorando recursos e solucionando problemas.

As ações são fundamentais para atingir os principais objetivos do projeto, que é a interação do aluno, preparando para o desenvolvimento do seu protagonismo e para o exercício da cidadania. Nesse sentido cabe á escola promover e planejar atividades que privilegie a interação dos conhecimentos para uma aprendizagem significativa. 
O projeto foi uma possibilidade e um processo para o desenvolvimento de metas pedagógicas, por conceder o comprometimento dos participantes, permitindo novas maneiras de ensinar e aprender.

A horta inserida no ambiente escolar pode ser um laboratório vivo que possibilita o desenvolvimento de diversas atividades pedagógicas em educação ambiental e alimentar unindo teoria e prática de forma contextualizada, auxiliando no processo de ensino-aprendizagem e estreitando relações através da promoção do trabalho coletivo e cooperado entre os agentes sociais envolvidos. (MORGADO, 2006. p.1).

Satisfação de dever cumprido, sensação observada nos alunos, quando perceberam que as hortaliças estavam prontas para o consumo, resultado obtido com a formação de valores, com ensino e aprendizagem de habilidades e metodologia aplicada utilizando saberes adquiridos durante o desenvolvimento das atividades e que puderam ser socializados.

Buscou com o cultivo a complementação da alimentação com a inserção de plantas sem adição de agrotóxicos, produzidas apenas com insumos orgânicos e acompanhadas do plantio a colheita, pelos alunos.

\section{CONSIDERAÇÕES FINAIS}

O presente projeto possibilitou aos alunos a partir do processo de construção da horta, manutenção, cuidados, organização do espaço, preparo do solo, adubação, plantio e interesse com o desenvolvimento das hortaliças, entendessem de modo dinâmico os conteúdos e a metodologia envolvida despertou o interesse pela educação ambiental, gerando aprendizagem significativa.

O projeto foi elaborado com a finalidade de integrar várias fontes e recursos de aprendizagem, visando estabelecer possibilidades para o desenvolvimento de ações pedagógicas por associar práticas em equipe abordou diferentes formas de aprender.

Recuperou um terreno ocioso com entulhos e mato alto no entorno da escola, evitando a proliferação de animais peçonhentos, principalmente o escorpião amarelo, devido á alta incidência no bairro onde a escola está inserida.

Diante do problema construiu a horta e as plantas produzidas foram utilizadas para enriquecer a alimentação. Na implantação, o local passou por uma limpeza com a remoção de entulhos, corte do mato alto, construção dos canteiros e plantio.

WWW.AMPLLAEDITORA.COM.BR (2) 
O desafio foi atingido, pois os alunos puderam gradativamente desenvolver habilidades de desenvolver e ter um olhar crítico, elaborando opiniões esclarecedoras, propondo soluções para determinadas questões levantadas, com fundamento nos conteúdos abordados durante o decorrer das atividades, destacando a importância do trabalho em equipe.

\section{REFERÊNCIAS}

Manual para Escolas A Escola promovendo hábitos alimentares saudáveis. Artigo disponível em: <http://bvsms.saude.gov.br/bvs/publicacoes/horta.pdf. Acesso em: 12 fev. 2020.

Entrevista especial sobre Projeto Horta nas Escolas. Artigo disponível em: < www.coocafe.com.br/noticia/entrevista-especial-sobre-projeto-horta-nasescolas/415.html. Acesso em: 03 mar. 2020.

Projeto Horta Solidária - Cultivo de Hortaliças. Artigo disponível em: <https://www.cnpma.embrapa.br/down_site/horta/cartilha_horta_final2010.p df. Acesso em: 10 mar. 2020.

Documentário Plantar Saber- Horta Didática na Escola. Disponível em: <https://www.youtube.com/watch?v=tw5_zpXiuL4. Acesso em: 10 mar. 2020.

Educando com a Horta Escolar. Disponível em: <https://www.youtube.com/watch?v=bmzNPFUiyn4. Acesso em: 15 mar. 2020.

- https://www.youtube.com/watch?v=VGaYEPrMWFs. Acesso em: 20 mar. 2020.

Projeto Educando com a Horta Escolar I Terra Sul. Disponível em: <https://projetohortaescolardasmegoiania.blogspot.com/2017/05/aimportancia-da-horta-na-escola.html. Acesso em: 22 mar. 2020.

MORGADO, F.S. A horta Escolar na Educação Ambiental e Alimentar: experiencia do Projeto Horta Viva nas Escolas Municipais de Florianópolis. Florianópolis (SC). 2006 (Monografia). 


\title{
CAPÍTULO YYXI
}

\section{PREVALÊNCIA DOS TRANSTORNOS MENTAIS COMUNS ENTRE OS ESTUDANTES DO CURSO TÉCNICO EM ADMINISTRAÇÃO}

\author{
Danilo Lucena Chagas ${ }^{1}$ \\ Carla Caroliny de Almeida Santana ${ }^{2}$ \\ Aurenice Pontes Loio $\mathrm{Vaz}^{3}$ \\ Reginete Cavalcanti Pereira ${ }^{4}$ \\ ${ }^{1}$ Graduando do curso de Letras. Universidade Federal Rural de Pernambuco - UFRPE \\ 2 Professora do Colégio Dom Agostinho Ikas da UFRPE. Universidade Federal Rural de Pernambuco - UFRPE \\ ${ }^{3}$ Professora do Colégio Dom Agostinho Ikas da UFRPE. Universidade Federal Rural de Pernambuco - UFRPE \\ 4 Professora Titular do Colégio Dom Agostinho Ikas da UFRPE. Universidade Federal Rural de Pernambuco - UFRPE
}

\section{RESUMO}

INTRODUÇÃO: Transtornos Mentais Comuns (TMC) caracterizam-se pela presença de sintomas de irritabilidade, fadiga, insônia, dificuldade de concentração, esquecimento, ansiedade e queixas somáticas, porém não implica em um diagnóstico psiquiátrico formal. OBJETIVO: Investigar a prevalência dos TMC nos estudantes do Curso Técnico de Administração em uma Instituição Pública. MÉTODO: Pesquisa de abordagem quantitativa. Dos 322 alunos matriculados em 2019 no curso, apenas 96 alunos, maiores de 18 anos, participaram do estudo. Para isso utilizou-se um questionário sociodemográfico e o Self Report Questionnaire (SRQ - 20). RESULTADOS: 37,5\% dos alunos apresentaram sintomas dos TMC, predominando mulheres (72,9\%), 54\% se autodeclararam pardos, a idade variou entre 18 e 55 anos, 66,6\% evangélicos, $78 \%$ solteiros, $65,6 \%$ tem pais não separados. Apenas $32,2 \%$ compreenderam o estudo como uma forma de crescimento pessoal. Foi encontrada associação significativa nas variáveis status marital dos pais dos alunos e a etnia dos participantes. Quando se autodeclaram de cor preta, a prevalência de TMC foi menor e ter pais não separados diminui a probabilidade do estudante apresentar sintomas dos TMC. CONCLUSÃO: Os resultados encontrados demonstram uma elevada prevalência de TMC na população estudada. Espera-se que os resultados desta pesquisa venham subsidiar ações para prevenção e cuidado com a saúde mental dos estudantes.

Palavras-chave: Epidemiologia. Estudantes. Saúde mental.

\section{INTRODUÇÃO}

Transtornos Mentais Comuns (TMC) termo criado por Goldberg e Huxley em 1992 para caracterizar um conjunto de sintomas não psicóticos como: insônia, 
irritabilidade, ansiedade, fadiga, dificuldade de concentração, esquecimento, e queixas somáticas levando a situações de sofrimento emocional.

Os Transtornos Mentais Comuns (TMC) não preenchem os critérios para um diagnóstico psiquiátrico formal de acordo com os dois manuais de diagnósticos: Manual Diagnóstico e Estatístico de Transtornos Mentais - $5^{\text {a }}$ edição (DSM- 5) organizado pela Associação Americana de Psiquiatria em 2014, e a 10a revisão da Classificação Internacional de Doenças (CID-10) da Organização Mundial de Saúde, no entanto, ter os sintomas dos Transtornos Mentais Comuns pode levar a sofrimentos e a prejuízos.

Não sendo na maioria das vezes notificados, os transtornos mentais comuns trazem um grande impacto na qualidade de vida das pessoas. A identificação precoce e um diagnóstico correto dos transtornos mentais comuns têm grande relevância para evitar prejuízos físicos e psicológicos à pessoa acometida (PARREIRA et al., 2017).

Para Skapinakis et al., (2013) as expectativas é que em 2030 a depressão esteja entre as perturbações mentais mais incapacitantes. Diante das projeções de aumento do transtorno mental na população geral percebe-se que é necessário estudar mais sobre a incidência e prevalência dos TMC em diversas populações. Uma investigação realizada com 3.597 pessoas em uma população urbana de um município localizado no nordeste do Brasil revelou uma prevalência para o TMC de 29,9\%. (ROCHA et al., 2010).

Considerando o impacto que os TMC possam ocasionar na população de estudantes e em especial nos alunos dos cursos técnicos que têm expectativas de entrar no mercado de trabalho e ter autonomia financeira assim que terminar o curso, essas variáveis podem levar esses discentes a desenvolver sintomas de TMC.

Este estudo tem como objetivo investigar a prevalência dos sintomas dos transtornos mentais comuns nos estudantes do curso técnico de administração em uma instituição pública, neste sentido a realização do presente estudo se justifica pela importância da identificação dos sintomas dos transtornos mentais comuns entre estudantes, porque mesmo não sendo tão grave como os transtornos psicóticos, a alta prevalência dos sintomas dos transtornos mentais comuns podem trazer graves efeitos na população estudantil. 


\section{MÉTODO}

Trata-se de uma pesquisa de corte transversal de natureza descritiva e de abordagem quantitativa. Em uma população de 322 discentes matriculados no Curso Técnico em Administração do Colégio Agrícola da Universidade Federal Rural de Pernambuco, aceitaram participar do estudo 96 alunos maiores de 18 anos e que assinaram o Termo de Consentimento Livre e Esclarecido (TCLE). Foi utilizado um questionário com dados sociodemográficos e o Self Report Questionnaire (SRQ - 20) validado para o contexto brasileiro com apenas 20 questões para rastreamento de Transtornos Mentais não-psicóticos (MARI e WILLIAMS, 1986), com questões de respostas "sim"/"não". No presente estudo foi considerado como escore SRQ-20 positivo para TMC, a soma de sete ou mais respostas afirmativas. A coleta dos dados foi realizada, durante as atividades acadêmicas, antes ou logo após as aulas. Estudo aprovado pelo Comitê de Ética em Pesquisa do Centro de Ciências da Saúde da UFPE e registrado sob CAAE № 09206019.1.0000.5208. Os dados foram analisados usando o pacote estatístico IBM SPSS versão 24.0.

\section{RESULTADOS E DISCUSSÃO}

A amostra foi representada por 96 alunos do curso técnico de administração, como pode ser observado na Tabela 1, a grande maioria dos participantes foram mulheres (72,9\%), 54,2\% se autodeclararam pardos, a idade variou entre 18 e 55 anos ( $M=23,64 ; D P=6,81), 50,5 \%$ evangélicos, $78,1 \%$ solteiros, $64,6 \%$ com pais que viviam juntos e $8,3 \%$ faziam uso de bebidas alcoólicas.

No que se refere à idade dos alunos que frequentam o curso técnico observa-se na Tabela 1 que o maior percentual ficou na faixa dos 21 a 30 anos de idade (42,7\%), considerados adultos jovens, esse aspecto pode representar uma população que ainda não entrou no mercado de trabalho e o curso técnico terá relevância para a construção da sua vida profissional e financeira. Por outro lado, este cenário mostrou-se diferente da pesquisa de Musse e Machado (2013): a maioria dos alunos que cursavam educação profissional no Brasil estavam na faixa etária de 19 a 24 anos (31,13\%).

No tocante a etnia conforme a tabela abaixo em maior percentual se autodeclararam pardos $(54,2 \%)$ e pretos $(27,1 \%)$, também em desacordo com o estudo 
de Musse e Machado, 2013 que apresentou um número maior de brancos e amarelos que frequentam educação profissional. Proporcionalmente, $4,46 \%$ dos brancos e amarelos, contra $3,64 \%$ dos pretos e pardos.

A Tabela 1 apresenta as características sociodemográficas da amostra.

Tabela 1 - Características sociodemográficas dos participantes $(\mathrm{N}=96)$

\begin{tabular}{|c|c|c|}
\hline Variável & $\mathbf{N}$ & $\%$ \\
\hline \multicolumn{3}{|l|}{ Sexo } \\
\hline Masculino & 26 & 27,1 \\
\hline Feminino & 70 & 72,9 \\
\hline \multicolumn{3}{|l|}{ Idade (anos) } \\
\hline$<20$ & 40 & 41,7 \\
\hline $21-30$ & 41 & 42,7 \\
\hline $31-40$ & 13 & 13,5 \\
\hline $41-50$ & 1 & 1,0 \\
\hline $51-60$ & 1 & 1,0 \\
\hline \multicolumn{3}{|l|}{ Qual religião? } \\
\hline Não possui religião & 21 & 22,1 \\
\hline Católica & 19 & 20,0 \\
\hline Evangélica & 48 & 50,5 \\
\hline Espírita & 2 & 2,1 \\
\hline Outra & 5 & 5,3 \\
\hline \multicolumn{3}{|l|}{ Etnia } \\
\hline Branco & 14 & 14,6 \\
\hline Preto & 26 & 27,1 \\
\hline Pardo & 52 & 54,2 \\
\hline Amarelo & 3 & 3,1 \\
\hline Indígena & 1 & 1,0 \\
\hline \multicolumn{3}{|l|}{ Estado civil } \\
\hline Solteiro(a) & 75 & 78,1 \\
\hline Casado(a) & 16 & 16,7 \\
\hline União estável (juntos) & 2 & 2,1 \\
\hline Divorciado(a) & 2 & 2,1 \\
\hline Viúvo(a) & 1 & 1,0 \\
\hline \multicolumn{3}{|l|}{ Separação dos pais } \\
\hline Sim & 34 & 35,4 \\
\hline Não & 62 & 64,6 \\
\hline \multicolumn{3}{|l|}{ Uso de álcool e outras drogas* } \\
\hline Sim & 8 & 8,3 \\
\hline Não & 88 & 91,7 \\
\hline \multicolumn{3}{|l|}{ Significado de estudar } \\
\hline Adquirir conhecimento & 64 & 66,7 \\
\hline Uma forma de crescimento pessoal & 31 & 32,3 \\
\hline Uma obrigação & 1 & 1,0 \\
\hline Total & 96 & 100 \\
\hline
\end{tabular}


A Tabela 2 mostra as respostas dos participantes com relação às dimensões avaliadas pelo SRQ-20. Observa-se os sintomas mais prevalentes apresentados pelos estudantes com relação aos Transtornos Mentais Comuns foram: nervosismo, estado de tensão ou preocupação (61,5\%), dificuldade na tomada de decisões $(47,9 \%)$, e tristeza $(42,7 \%)$.

Chama atenção o percentual de 61,5\% dos alunos apresentarem preocupação, pressupõe que a opção por uma qualificação profissional técnica possibilite à inserção no mercado de trabalho, que em 2019 o IBGE revelou um contingente de 12,6 milhões de pessoas desocupadas, de certo que esse percentual de sintomas de preocupação pode está relacionado a diversas variáveis, entretanto o desemprego juvenil é uma característica de preocupação em muitos países.

Tabela 2 - Respostas dos participantes em relação às dimensões do SRQ-20

\begin{tabular}{lll}
\hline \multirow{2}{*}{ Dimensões (SRQ-20) } & \multicolumn{2}{l}{ Respostas } \\
\cline { 2 - 3 } & Sim & Não \\
\hline Humor depressivo-ansioso & $\%$ & $\%$ \\
Sente-se nervoso(a), tenso(a) ou preocupado(a)? & 61,5 & 38,5 \\
Assusta-se com facilidade? & 35,4 & 64,4 \\
Tem se sentido triste ultimamente? & 42,7 & 57,3 \\
Tem chorado mais do que de costume? & 16,7 & 83,3 \\
Sintomas somáticos & & \\
Você tem dores de cabeça frequente? & 35,4 & 64,6 \\
Dorme mal? & 30,2 & 69,8 \\
Tem sensações desagradáveis no estômago? & 36,5 & 63,5 \\
Tem má digestão? & 15,6 & 84,4 \\
Tem falta de apetite? & 22,9 & 77,1 \\
Tem tremores nas mãos? & 21,9 & 78,1 \\
Decréscimo de energia vital & & \\
Você se cansa com facilidade? & 33,3 & 66,7 \\
Tem dificuldades para tomar decisões? & 47,9 & 52,1 \\
Encontra dificuldades para realizar com satisfação suas atividades diárias? & 34,4 & 65,4 \\
Tem dificuldades no serviço (seu trabalho é penoso, causa-lhe sofrimento)? & 6,3 & 93,8 \\
Sente-se cansado(a) o tempo todo? & 34,4 & 65,4 \\
Tem dificuldade de pensar claramente? & 37,5 & 62,5 \\
Pensamentos depressivos & & \\
É incapaz de desempenhar um papel útil em sua vida? & 5,2 & 94,8 \\
Tem perdido o interesse pelas coisas? & 28,1 & 71,9 \\
Tem tido ideia de acabar com a vida? & 8,3 & 91,7 \\
Sente-se inútil em sua vida? & 9,4 & 90,6 \\
\hline Nota. \% = porcentagem válida. &
\end{tabular}

Nota. \% = porcentagem válida. 
De acordo com o Gráfico 1 dentre o universo amostral de 96 participantes do curso técnico de administração, 37,5\% dos sujeitos apresentaram Prevalência de Transtornos Mentais Comuns (TMC). Por outro lado, uma investigação publicada no início de 2020 com estudantes universitários 39,9\% apresentaram TMC (GOMES, 2020). Mesmo se tratando de população diferente o percentual encontrado de TMC nesses estudantes mostram similitude. Em uma avaliação realizada por Silva e Costa em 2012 com estudantes universitários da área de saúde $41 \%$ dos discentes no início do curso e $28 \%$ ao final do curso apresentaram sintomas do TMC. Esses percentuais de sintomas de TMC entre estudantes, sendo do curso técnico ou curso superior apontam para uma preocupação importante nesta população.

O Gráfico 1 apresenta a prevalência de TMC entre os sujeitos.

Gráfico 1 - Prevalência de Transtornos Mentais Comuns entre os participantes.

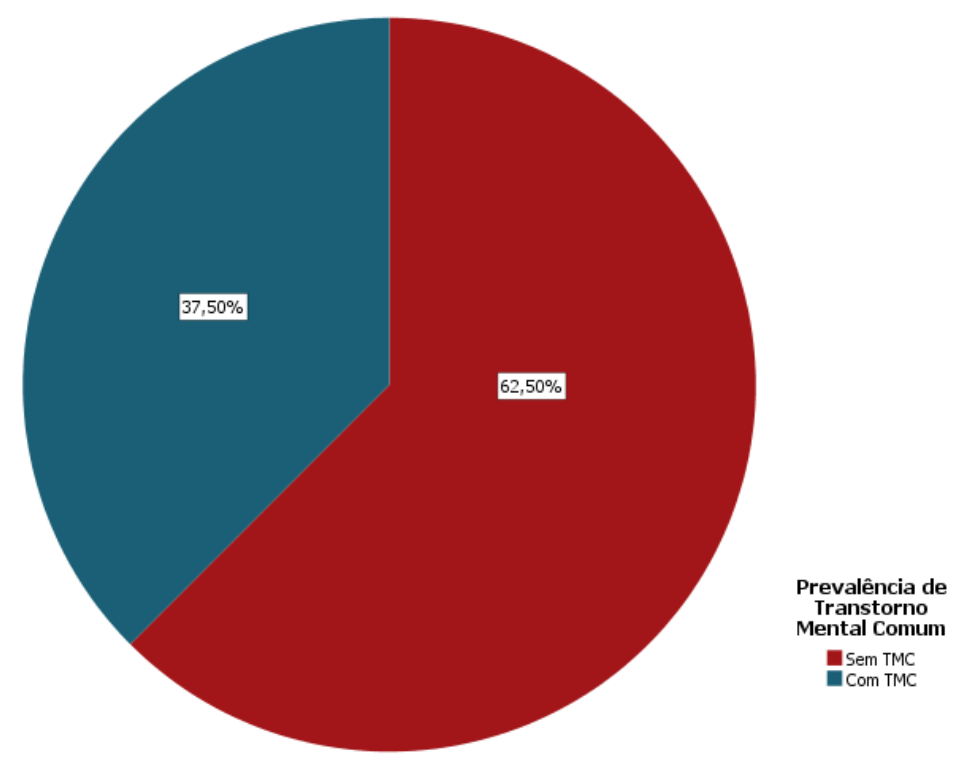

Fonte: autores (2020).

Na tabela 3 apresenta a prevalência de TMC com base nas características da amostra, Foi encontrada associação significativa nas variáveis status marital dos pais dos alunos e a etnia dos participantes. Quando se autodeclaram de cor preta, a prevalência de TMC foi menor e ter pais não separados diminui a probabilidade do estudante apresentar sintomas dos TMC. 
Tabela 3 - Prevalência de Transtornos Mentais Comuns (TMC) em estudantes do curso de Administração de acordo com a caracterização sociodemográfica

\begin{tabular}{|c|c|c|c|}
\hline \multirow{2}{*}{ Variável } & \multicolumn{3}{|c|}{ Prevalência de TMC } \\
\hline & $\mathbf{N}$ & $\%$ & $\mathbf{p}$ \\
\hline Sexo & & & 0,72 \\
\hline Masculino & 9 & 34,6 & \\
\hline Feminino & 27 & 38,6 & \\
\hline Idade (anos) & & & 0,32 \\
\hline$<20$ & 40 & 41,7 & \\
\hline $21-30$ & 41 & 42,7 & \\
\hline $31-40$ & 13 & 13,5 & \\
\hline $41-50$ & 1 & 1,0 & \\
\hline $51-60$ & 1 & 1,0 & \\
\hline Qual religião? & & & 0,81 \\
\hline Não possui religião & 7 & 33,3 & \\
\hline Católica & 7 & 36,8 & \\
\hline Evangélica & 20 & 41,7 & \\
\hline Espírita & 0 & 0,0 & \\
\hline Outra & 1 & 20,0 & \\
\hline Etnia & & & $0,02 *$ \\
\hline Branco & 6 & 42,9 & \\
\hline Preto & 4 & 15,4 & \\
\hline Pardo & 24 & 46,2 & \\
\hline Amarelo & 2 & 66,7 & \\
\hline Indígena & 0 & 0,0 & \\
\hline Estado civil & & & 0,11 \\
\hline Solteiro(a) & 28 & 37,3 & \\
\hline Casado(a) & 4 & 25,0 & \\
\hline União estável (juntos) & 2 & 100,0 & \\
\hline Divorciado(a) & 1 & 50,0 & \\
\hline Viúvo(a) & 1 & 100,0 & \\
\hline Separação dos pais & & & $0,02^{*}$ \\
\hline Sim & 18 & 52,9 & \\
\hline Não & 18 & 29,0 & \\
\hline Uso de álcool e outras drogas & & & 0,70 \\
\hline Sim & 2 & 25 & \\
\hline Não & 34 & 38,6 & \\
\hline Significado de estudar & & & 0,78 \\
\hline Adquirir conhecimento & 23 & 35,9 & \\
\hline Uma forma de crescimento pessoal & 13 & 41,9 & \\
\hline Uma obrigação & 0 & 0,0 & \\
\hline Total & 96 & 100 & \\
\hline
\end{tabular}

Nota. $\mathrm{f}=$ frequência relativa à prevalência do TMC em cada variável; $\%=$ porcentagem relativa; $p=p$-valor associação entre as variáveis e a prevalência de TMC na amostra. $* p<0,05$. 
Como apresentado na Tabela 3, o cálculo do teste exato de Fisher demonstrou haver associação significativa entre a etnia dos participantes e a prevalência de TMC na amostra $\left[\chi^{2}(4)=9,32 ; p<0,05\right]$. Ao se observar os contrastes, verifica-se que a principal diferença ocorreu entre os participantes autodeclarados pretos, de modo que a probabilidade de prevalência de TMC foi menor entre esse grupo de sujeitos na amostra, como demonstra o Gráfico 2. Dito de outra forma, os estudantes autodeclarados como pretos exibiram uma probabilidade menor de apresentar TMC do que os participantes brancos, pardos, amarelos e indígenas. Em discordância com o estudo de GOMES et al. (2020) que revelou que a cor da pele dos estudantes que se declaram preta (42,9\%), branca $(41,2 \%)$ e parda $(36,2 \%)$ compõem os maiores índices de casos suspeitos de TMC.

Um dos fatores que podem justificar a emergência desse resultado é a atual corrente de empoderamento étnico-racial da população negra, cuja importância tem sido muito debatida e difundida entre a juventude. Diante de uma sociedade extremamente desigual, cujas disparidades sociais e econômicas são demarcadas por questões de raça e etnia, como ocorre no Brasil, é provável que a autoidentificação dos estudantes como sendo parte de uma minoria social esteja funcionando como um fator de manutenção de sua identidade. Mais especificamente, levanta-se a hipótese de o fato de se reconhecerem como negros, em um contexto socialmente racista, esteja levando os estudantes a avaliarem positivamente a sua autoimagem e, consequentemente, esse processo psicológico venha acarretando uma estratégia de proteção à organização psíquica. 
Gráfico 2 - Associação entre etnia e prevalência de transtornos mentais comuns.

Fonte: autores (2020).

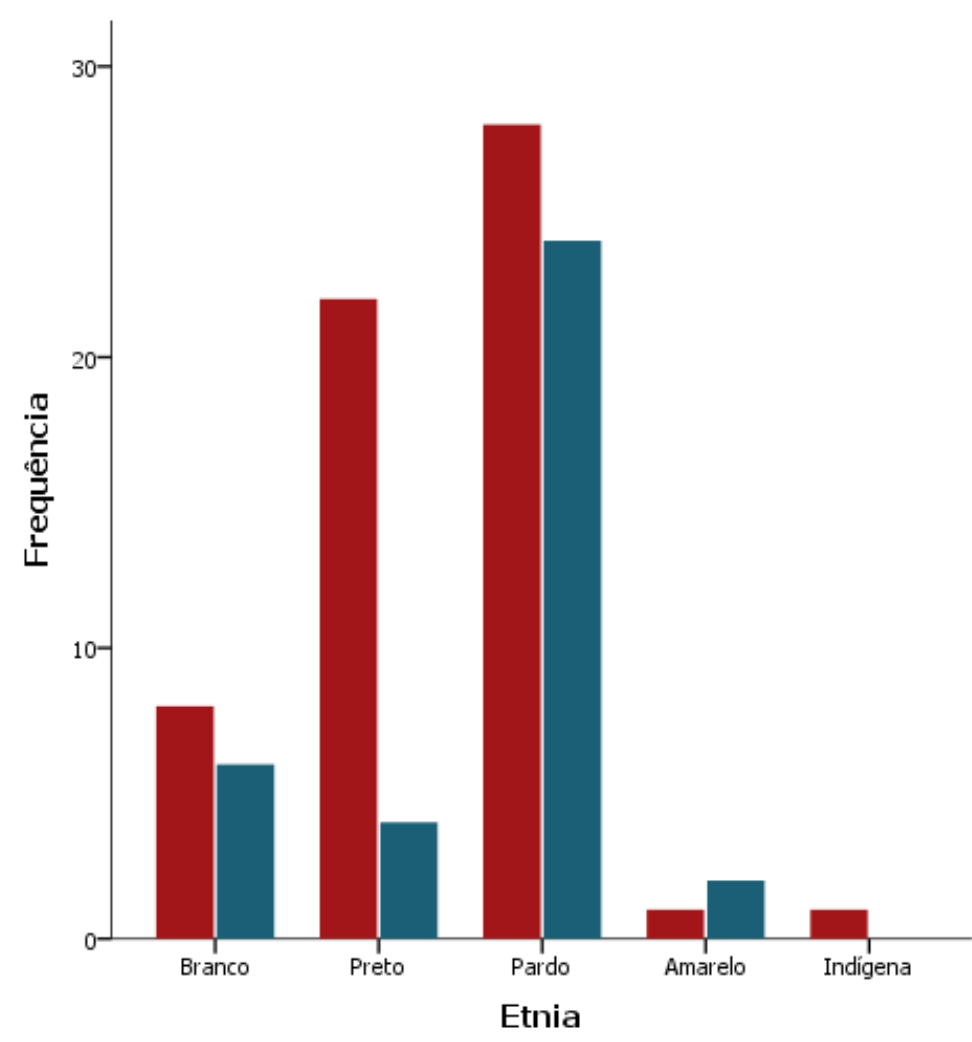

Prevalência de TMC

Dem TMC

Com TMC

O teste de qui-quadrado também demonstrou a associação estatística entre a variável separação dos pais e a prevalência de TMC $\left[\chi^{2}(1)=5,35 ; p<0,05\right]$. Esse resultado demonstra que a probabilidade de um estudante não apresentar TMC é maior quando os seus pais não são separados (Gráfico 3). Ou seja, os participantes que declararam conviver com os pais na mesma casa apresentaram uma prevalência de TMC estatisticamente menor que aqueles cujos pais são separados.

Estudos têm demonstrado que o convívio com os pais pode ser um fator protetivo para a saúde mental de crianças e adolescentes. Nesse sentido, os resultados encontrados nesse estudo corroboram com a literatura ao demonstrar que estudantes cujos pais estão juntos apresentaram menor probabilidade de apresentar TMC do que aqueles cujos pais são separados. 
Gráfico 3 - Associação entre a separação dos pais e a prevalência de transtornos mentais comuns. Fonte: autores (2020).

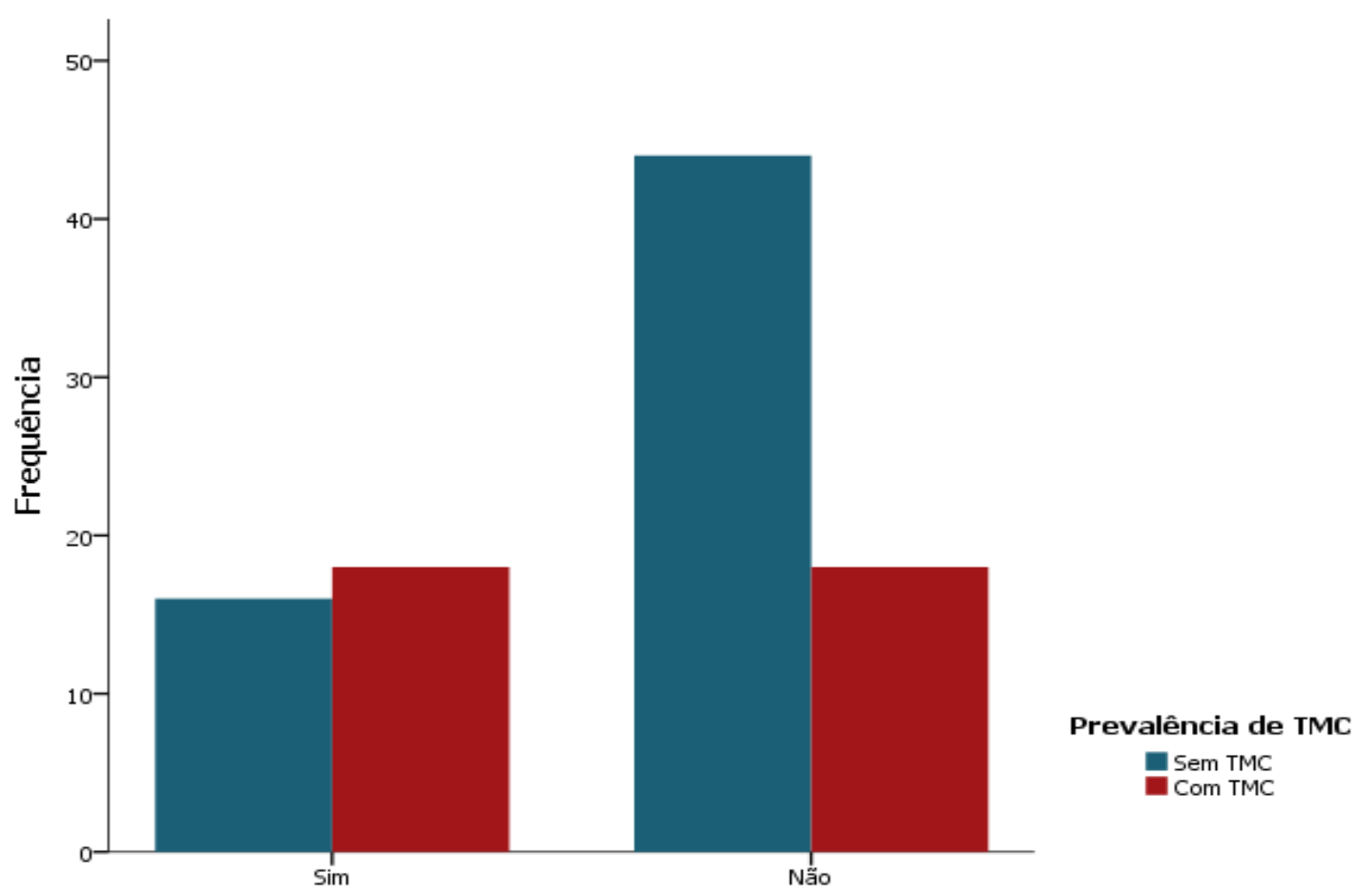

Separção dos pais

Após a análise de associação entre variáveis, foi verificada as diferenças individuais dos participantes com relação ao nível de sintomatologias relacionadas à prevalência de TMC (escore total). Para isso, foram realizados cálculos de diferenças entre médias por meio dos testes t de Student para amostras independentes e da análise de variância (ANOVA). Os resultados demonstraram que não houve diferenças significativas em relação à pontuação total no SRQ-20 quanto ao sexo [t $(94)=-0,52 ; p$ $=0,60]$, à faixa etária $[F(4,91)=0,53 ; p=0,71]$, à religião $[F(4,90)=0,59 ; p=0,67]$, à etnia $[F(4,91)=1,97 ; p=0,10]$, ao estado civil $[F(4,91)=2,02 ; p=0,09]$, à separação dos pais $[t(94)=1,61 ; p=0,10]$, ao uso de álcool e outras drogas [t $(94)=0,18 ; p=0,85$ ] e ao significado de estudar dos estudantes $[F(2,93)=0,01 ; p=0,98]$. Além disso, através do cálculo de correlação r de Pearson, verificou-se que não houve relação entre a idade e a pontuação dos participantes no instrumento $(r=-0,01 ; p=0,91)$.

É provável que esses resultados estejam refletindo uma limitação amostral. Dado que o número reduzido de participantes, as diferenças entre médias não foram grandes os suficientes para serem consideradas estatisticamente significativas. Nesse sentido, 
recomenda-se que em estudos posteriores sejam priorizadas amostras mais robustas, e de preferência com cálculo amostral realizado a priori.

\section{CONSIDERAÇÕES FINAIS}

Os resultados desta investigação permitem traçar o perfil dos estudantes do curso técnicos de administração do Colégio Agrícola Dom Agostinho lkas da Universidade Federal Rural de Pernambuco - CODAI/UFRPE em relação aos Transtornos Mentais Comuns (TMC). Os resultados revelaram um percentual elevado de TMC, entre os 20 sintomas apresentados no questionário da pesquisa, receberam destaque: nervosismo, estado de tensão, preocupação; dificuldade na tomada de decisões e tristeza. Foi encontrada associação significativa nas variáveis status marital dos pais dos alunos e a etnia dos participantes. Quando se autodeclaram de cor preta, a prevalência de TMC foi menor e ter pais não separados diminui a probabilidade do estudante apresentar sintomas dos TMC. As informações desta pesquisa vêm suprir uma lacuna quanto à investigação relacionada à saúde emocional dos discentes do ensino técnico profissionalizante e aponta para a necessidade de subsidiar ações de prevenção à saúde mental nesta população.

\section{REFERÊNCIAS}

IBM CORP. IBM SPSS: Statistics for Windows, Version 24.0. Armonk, NY: IBM Corp, 2016. GOLDBERG David \& HUXLEY Peter. Common mental disorders: a bio-social model. London: Tavistock. 1992.

INSTITUTO BRASILEIRO DE GEOGRAFIA E ESTATÍSTICA (IBGE). Disponível em https://biblioteca.ibge.gov.br/index.php/biblioteca-

catalogo?view=detalhes\&id=2101743. Acesso em 22 de novembro de 2020.

GOMES, Carlos Fabiano Munir et al. Transtornos mentais comuns em estudantes universitários: abordagem epidemiológica sobre vulnerabilidades. SMAD, Rev. Eletrônica Saúde Mental Álcool Drogas. (Ed. port.), Ribeirão Preto, v. 16, n. 1, p. 1-8, mar. 2020.

MANUAL DIAGNÓSTICO E ESTATÍSTICO DE TRANSTORNOS MENTAIS: DSM-5. 5. ed. Porto Alegre: Artmed, 2014.

MARI JJ, WILLIAMS P. A validity study of a psychiatric screening questionnaire (SRQ-20) in primary care in the city of São Paulo. Br. J. Psychiatry. 148:23-6 1986. 
MUSSE, Isabel; MACHADO, Ana Flavia. Perfil dos indivíduos que cursam educação profissional no Brasil. Econ. soc. Campinas, v. 22, n. 1, pág. 237-262, 2013.

PARREIRA, Bibiane Dias Miranda et al. Transtorno mental comum e fatores associados: estudo com mulheres de uma área rural. Rev. esc. enferm. USP, São Paulo, v. 51, e03225, 2017.

ROCHA, Saulo Vasconcelos et al. Prevalência de transtornos mentais comuns entre residentes em áreas urbanas de Feira de Santana, Bahia. Rev. bras. epidemiol., São Paulo, v. 13, n. 4, p. 630-640, dez. 2010.

SILVA, Rodrigo Sinnotti; COSTA, Letícia Almeida. Prevalência de Transtornos Mentais Comuns entre estudantes universitários da área de saúde. Encontro Revista de Psicologia. Volume 15, № 23, ano, 2012.

SKAPINAKIS, Petros et al. Prevalence and sociodemographic associations of common mental disorders in a nationally representative sample of the general population of Greece. BMC Psychiatry, 4(13), 163, 2013. 


\title{
CAPÍTULO YYXII
}

\section{COMPREENSÃO EXISTENCIAL-FENOMENOLÓGICA DO SUICIDIO DURANTE A} PANDEMIA

\author{
Bruna Rafaela da Silva Miguel ${ }^{1}$ \\ Evellyn Cássia Barbosa de Santana ${ }^{2}$ \\ Jakelyne Ribeiro de Souza Raposo ${ }^{3}$ \\ Zirlana Menezes Teixeira ${ }^{4}$ \\ ${ }^{1}$ Graduanda em Enfermagem. Centro Universitário Mauricio de Nassau - UNINASSAU \\ ${ }^{2}$ Graduanda em Psicologia. Faculdade de Ciências Humanas de Olinda - FACHO \\ ${ }^{3}$ Graduanda em Psicologia. Faculdade de Ciências Humanas de Olinda - FACHO \\ ${ }^{4}$ Docente orientadora. Faculdade de Ciências Humanas de Olinda - FACHO
}

\section{RESUMO}

Em março de 2020, a sociedade brasileira foi pega de sobressalto com o isolamento social estabelecido pela pandemia do Covid-19. Diante disso, o homem como um Dasein, isto é, Ser-no-mundo, Ser-aí lançado às possibilidades, mas, também, Ser-para-morte, finito e temporário se encontrou diante de algumas situações que requerem reflexão. A partir disso, questões existenciais como a solidão, investimento interior e sentido de vida, antes delegadas tiveram espaço para eclodirem. Nesse sentido, este trabalho tem como objetivo investigar como o contexto atual no Brasil de Pandemia do Covid-19 influencia no número de suicídios. Com isso, ficou evidente que o fato de o mundo estar diante de um vírus desconhecido é um agravamento para desdobramentos existenciais, ao considerar que as incertezas e o medo aumentam diariamente. Consequentemente, as pessoas podem acabar por encontrar na morte voluntária a solução para todos os seus problemas. Ressalta-se que alguns fatores no contexto brasileiro para o suicídio são: o uso abusivo de álcool e outras drogas, sofrimento psíquico e vulnerabilidade financeira, pois houve um aumento no número de desempregados e aumento da violência doméstica. Assim, ao considerar as desigualdades antes já vistas no Brasil e que ficaram mais evidentes na pandemia, percebe-se que o medo da contaminação e morte dos entes queridos tendem a gerar angústia, dificultando que as pessoas encontrem e cumpra um sentido de vida ou superem este "absurdo" existencial.

Palavras-chave: Pandemia. Covid-19. Fenomenologia-existencial. Sentido. Absurdo.

\section{INTRODUÇÃO}

A pandemia causada pelo Covid-19 pegou o mundo de surpresa e mudou o modo de todos viverem e se relacionarem consigo e com os outros. Salienta-se que o suicídio é um problema de saúde pública no Brasil e que segundo dados da Organização Mundial

WWW.AMPLLAEDITORA.COM.BR $(2)$

CONTATO@AMPLLAEDITORA.COM.BR M 
de Saúde (OMS) 800 mil pessoas se suicidam, além disso, nesse dado não está incluso o número de tentativas mal sucedidas e dos casos que não são computados.

O homem para Heidegger (1977) é um Dasein, isto é, Ser-no-mundo, Ser-aí lançado às possibilidades. Este homem também é um Ser-para-morte, isto é, finito e temporário, entretanto, contudo muitos têm medo desse momento por gerar angústia e tendem a tentar fugir.

Em março, a sociedade brasileira foi pega de sobressalto com o Covid-19 tendo como origem Wuhan- China. Por conseguinte, um grande número de pessoas passou a morrer com esse vírus. A OMS decretou estado de pandemia e a principal recomendação foi ficar em casa, isolados, distantes do contato pessoal com os outros.

A partir disso, questões existenciais como a perda de sentido na vida, antes negligenciadas tiveram espaço para eclodirem. Sobre esta questão, sociólogo Durkheim (2000) o suicídio é um ato realizado pela própria vítima, toda morte que resulta mediata ou imediatamente de ato positivo ou negativo. Segundo a Fundação Oswaldo Cruz (FIOCRUZ), 51\% dos casos de autoextermínio acontecem dentro de casa e, com o isolamento social, A Organização Pan-Americana da Saúde (OPAS) alertou para o fato de que o número de casos e de tentativas de suicídios poderiam aumentar.

Além disso, Heidegger (1977) também considera que o Dasein é constituído em um tempo, pois ele é um ser temporal e que se mostra como possibilidade frente ao mundo. Desse modo, é possível observar como os tempos hodiernos influenciaram e mudaram a vida das pessoas.

Assim, este estudo tem como objetivo investigar como o contexto atual no Brasil de Pandemia pelo Covid-19 influencia o suicídio. Para tal, se utilizará da psicologia fenomenológica-existencial, que, por sua vez, considera o homem em sua totalidade, suspende os seus pré-conceitos e conhecimentos para compreendê-lo em movimento. Além disso, tem a proposta de "voltar às coisas mesmas", ou seja, deixar o fenômeno se apresentar como é, e às vezes, compreender que ele permanecerá velado, de forma a não ser possível uma compreensão completa, mas apenas aquilo que ele permite mostrar (HEIDEGGER, 1977). 


\section{REVISÃO BIBLIOGRÁFICA}

\subsection{Impactos da pandemia na saúde mental}

Na compreensão do filósofo coreano Byung-chul Han (2015), a população contemporânea é marcada como a "sociedade do desempenho" ou do cansaço, ou seja, empresários de si mesmos. Nela impera o poder ilimitado e a permissividade, além da alta produção, por outro lado, gera sujeitos depressivos e insatisfeitos. Diante disso, Han (2015, p. 24) enfatiza: “Nada promete duração e subsistência. Frente a essa falta do Ser surgem nervosismos e inquietações", como são tempos de instabilidade, na pandemia isso se intensificou mais ainda trazendo prejuízos a saúde mental das pessoas.

Ao se considerar que esta sociedade não se permite sofrer, pensar suas angústias e buscar sentido para sua existência, os tempos atuais se instalaram como um desafio diário. Além do mais, Heidegger (1977) entende que o Dasein também é ser-com-osoutros, ou seja, se constitui a partir e com o relacionamento com as demais pessoas. Porém, foi imprescindível para a segurança de todos que houvesse um distanciamento social.

Nesse sentido, pesquisas já apontam para o seguinte fato:

[...] algumas formas de mal-estar são comuns, como a sensação de impotência, tédio, solidão, irritabilidade, tristeza e medos diversos (de adoecer, morrer, perder os meios de subsistência, transmitir o vírus), podendo levar a alterações de apetite e sono, a conflitos familiares e a excessos no consumo de álcool ou drogas ilícitas (LIMA, 2020, p. 10).

Em outras palavras, o estar sozinho, inquieta o homem que na maioria das vezes não sabe como lidar com a solidão, com o estar consigo mesmo e cuidar de si, além do medo trazido pela própria pandemia. Sem contar com o fato de que o homem é social e necessita do contato com os outros até para elaborar suas angústias. Em virtude disso, May (1991) defende que os homens usam uns aos outros como espelhos, com os quais podem afirmar sua própria existência. Diante disso, o sentimento de temor em ficar distantes dos demais revela o fato de a solidão se manifestar como uma ameaça que pode aniquilar o próprio eu.

Naturalmente, a solidão em si é ontológica do ser, ajuda-o em seu desenvolvimento pessoal e não seria capaz de causar tamanho impacto, contudo levando em consideração o isolamento estabelecido repentinamente como uma medida 
de segurança pública é possível notar o porquê de tanta resistência de alguns em se manter distantes do contato social físico. Antes desse fenômeno mundial, as pessoas tinham uma rotina e maneiras específicas de se relacionar com os outros, agora distante deles a solidão encontra espaço para se inserir e se torna a via possível para refletir sobre questões elementares que há muito foram delegadas (MAY, 1991).

Ainda segundo May (1991, p. 28):

Todo ser humano adquire grande parte do senso de sua própria realidade pelo que os outros dizem e pensam a seu respeito. Mas quem foi longe demais nessa dependência alheia acabou temendo que se ela faltasse perderia o senso de sua própria existência, ficaria "disperso", como água escorrendo na areia. Muita gente vive assim, tateando como cego, tocando uma sucessão de pessoas.

Em outras palavras, algumas pessoas experimentaram a possibilidade de isolamento pela primeira vez com a pandemia, sem que tivesse a liberdade de escolher por tal. Com isso, sem poder contar com a orientação que os outros ofereciam no cotidiano precisaram enfrentar a situação com recursos próprios, cujo desenvolvimento anterior não foi plenamente iniciado. Assim, ficam temerosas quanto à própria capacidade de enfrentar a situação sem se perder, principalmente em um contexto no qual a morte do outro e a sua própria se revela como um acontecimento possível.

A partir disso, a solidão se revela como ameaçadora, uma vez que aponta para um vazio e coloca a pessoa diante de seu ser mais próprio, logo de uma parte de si que foi há muito esquecida em troca de uma convivência coletiva. Quanto a isso, May (1991, p. 20) afirma:

\footnotetext{
Quando a pessoa está cercada de cordialidade, imersa no grupo, é reabsorvida, como se voltasse ao ventre materno, em simbologia analítica. Temporariamente esquece a solidão, embora ao preço da renúncia à sua existência como personalidade independente. Perde assim a única coisa que a ajudaria positivamente a vencer a solidão a longo prazo, isto é, o desenvolvimento de seus recursos interiores, da força e do senso de direção, para usá-los como base de um relacionamento significativo com os outros seres humanos.
}

Em consequência, ao se notar pela primeira vez sozinha, a pessoa tende a se encontrar perdida, de modo que sua saúde mental pode ser negativamente afetada durante esse período. Destarte, o fato de que somente aqueles que investiram em si próprios de antemão são capazes de se isolar torna compreensível à ocorrência do sofrimento psíquico em decorrência do distanciamento, ainda que provisório, dos outros. 
Nesse seguimento, o tempo integral em casa também ocasionou em um aumento da violência doméstica, seja física ou psicológica e do consumo de álcool/drogas (ORSINI, 2020). Além do mais, o filósofo Kierkegaard ao ser citado por Da Silva; Alves; Do Couto (2016) já salientava que por vezes o ser humano pode se encontrar desesperado frente às escolhas e acontecimentos que permeiam a vida. Estando em isolamento aconteceu o que os existencialistas já discutiam:

\footnotetext{
O tédio existencial, ao ser percebido como uma forma de desespero, pode ser compreendido como a situação em que a pessoa sofre a dor de ver o tempo passar e não estar colocando em prática o desenvolvimentos de suas possibilidades existenciais (DA SILVA; ALVES; DO COUTO, 2016, p.186).
}

Consequentemente, o não desenvolvimento das possibilidades tem suas consequências e com a consciência atingida pelo não "poder-ser", as pessoas podem acabar por encontrar na morte a solução para todos os seus problemas. Destarte, o isolamento tem posto a prova à capacidade da população de encontrar no sofrimento um sentido para continuar e cuidar da vida mental (Lima, 2010). Sob esta ótica, também acontece de distúrbios psiquiátricos se intensificarem, como a depressão, ansiedade e o estresse pós-traumático (ORSINI, 2020).

Atrelado a isso tem um cenário político e econômico incerto, no qual a desigualdade antes já existente foi escancarada, gerando muito sofrimento a população menos favorecida.

Esses fatores podem ser entendidos como riscos para uma pessoa que já tenha ideações suicidas, mas não devem ser levados como definidores, uma vez que o ser pode escolher em pôr fim a sua vida independente de ter um transtorno, pois é livre.

Além disso, o ser da presença está originariamente familiarizada com o contexto em que ela foi posta e por isso é fundamentada em uma interpretação ontológicaexistencial, conforme afirma Heidegger (1977, p. 131): “Tal possibilidade pode ser apreendida expressamente quando a própria pre-sença assume a tarefa de interpretar originariamente o seu ser e suas possibilidades ou até o sentido do ser em geral". Isso significa que as circunstâncias impostas pela pandemia oferecem uma abertura para o ser, sua angústia e relação com esse novo mundo que se revela. 


\subsection{Compreensão existencial do suicídio}

Segundo a analítica existencial heiddegeriana, é inerente ao ser pensar a sua existência e questioná-la, porém, este não pode ser simplesmente dado, isto é, lançado no mundo (HEIDEGGER, 1977). É importante que ele se posicione e escolha se deseja ou não questionar o ser, e para isso pode recorrer às relações, tendo em vista que elas o constitui também. Mas, posto a pandemia sem aviso e matando muitas pessoas rapidamente, a angústia precisou ter um novo significado, tendo em vista que sua fuga pode ocasionar um estreitamento das possibilidades do ser.

Por conseguinte, o Ser-aí pode optar por não mais lidar com o sofrimento, a morte surge como saída e solução para todos os problemas. Nesse sentido, é possível compreender que embora a morte seja a única certeza do ser humano e possibilidade de abertura para uma vida autêntica. As questões existenciais como transitoriedade e angústia, inerentes ao processo da morte e da perda são afastados pelo ser. Porém, assim como ele está lançado a facticidade, em um mundo que não escolheu, a pandemia surgiu como uma situação de privações, trazendo o luto para o mundo inteiro.

A partir desse momento, as questões antes tidas como tabu foram evidenciadas. O homem passou a precisar lidar com o luto: de seus entes queridos, da sua rotina, situação financeira e afim. Ao passo que a possibilidade de ressignificação do Dasein no contato com-o-outro e com-o-mundo Ihe foi negado, Heidegger $(1977$, p. 170) infere que esse ser-no-mundo: "[...] é determinado pelo com, o mundo é sempre o mundo compartilhado com os outros".

Mas esse novo horizonte permeado pela falta pode ter levado o homem a sua angústia de ser-para-morte e a incapacidade de lidar com ela intensifica sua falta de sentido em existir e a exigência de novas formas de ser-no-mundo (HEIDEGGER, 1977). Além disso, por ele estar vivendo de maneira impessoal, pode recorrer ao suicídio, decorrente de uma intensa angústia com sua finitude e a culpa por não ter aproveitado como deveria. Como aponta a analítica heideggeriana, a angústia é originária do ser e se desvela a procura de um sentido.

No entanto, o Ser-aí pode optar por continuar imerso em sua cotidianidade e absorvido na impessoalidade em vez de se apropriar de uma existência autêntica (HEIDEGGER, 1977). Isso porque a divisa entre os dois modos de existir, isto é, próprio e 
autêntico ou impessoal e inautêntico, é a própria angústia. Logo, ao optar por fugir dela, o homem acaba por fugir de si mesmo, caindo em um modo de existir distante de si próprio.

Em outro sentido, se o Ser-aí escolher o caminho da consciência, ele poderá está aberto à angústia e assim se libertar do impessoal, podendo ser mais autêntico, o que pode ser compreendido como resolução. Com ela, aceita seu destino, ou seja, assume que também é um ser-para-morte e desempenha seu papel no mundo como autônomo (HEIDEGGER, 1977). O poder-ser e o se apropriar da existência dependem das escolhas que se fazem na vida e por vezes o ser pode se defrontar com a frustração de não se está vivendo de modo próprio. No qual a imposição dos outros põe o ser no que pode ser a sua última escolha: o suicídio

Nesse sentido, Sartre (1970) entende que o homem a princípio não é passível de definição por não ser nada para depois ser o que ele fizer, escolher de si. Além do mais, o filósofo difere liberdade do senso comum e do sonho: conseguir o que quiser sem barreiras. E a liberdade baseada na realidade: está fundamentada na autonomia de escolha. Essa liberdade é atuante mesmo que haja oposições, independente do local e posição que ocupe na sociedade, o homem é livre ou não, a partir das posições que se coloca e como se projeta, ele é o único responsável por isso.

Só será possível agir se ele tiver essa compreensão de que ele próprio precisa planejar como será sua vida na terra. Mesmo que esteja imerso na cotidianidade, "O homem é tão-somente, não apenas como ele se concebe, mas também como ele se quer; como ele se concebe após a existência, como ele se quer após esse impulso para a existência" (SARTRE, 1970, p. 10). Embora nem sempre o Ser-aí se der conta disso e do fato de que suas escolhas afetam além de si mesmo: a esfera social, deixando marcas.

O suicida, por sua vez, deixa uma mensagem para sociedade que ele não suportava mais esse sistema que adoece e é conhecida como sociedade do cansaço, conforme Byung-chul Han (2015). Infere-se que na inexistência de um lugar próprio, o suicídio se mostra como a escolha assertiva, faz o ser se apropriar de si nem que seja a última coisa que faça.

Por sua parte, Frankl (1987; 2015), assim como Heidegger e Sartre, defende que o homem é um ser livre, porém essa liberdade é na realidade circunstanciada por sua situação concreta, isto é, contexto no qual se insere, e relação com o mundo e os outros.

WWW.AMPLLAEDITORA.COM.BR (2) 
Esse fato fica nítido, ao notar que durante o curso existencial as pessoas passam por uma série de situações nas quais muitas vezes não escolheram, mas que ainda sim precisam se posicionar diante da vida.

Nesses casos, porém, "o que realmente conta é a firmeza e a atitude com que ele vai ao encontro de um destino inevitável e irrevogável" (FRANKL, 2015, p. 26). Em outras palavras, mesmo diante de adversidades que acabam por causar sofrimento, como se apresenta o fenômeno da pandemia do Covid-19, o distanciamento social e a mudança na rotina, o homem ainda tem liberdade para se interrogar e se posicionar diante da situação.

Diante disso, Frankl $(1987 ; 2015)$ defende o fenômeno da transcendência, que revela o fato de o homem sempre apontar para algo além de si mesmo, algo que não é ele próprio, mas um sentido que precisa cumprir seja no serviço a uma causa ou no amor a outra pessoa. Logo, a autotranscendência é a possibilidade de a pessoa realizar-se a si própria enquanto se volta para fora de si. Com isso, a vontade de sentido acompanha o todo o percurso existencial do homem e expressa a possibilidade dele poder se realizar ao entregar algum trabalho ao mundo, experimentar algo ou se posicionar diante do sofrimento.

Quanto ao sentido, é expresso como o algo que emerge a partir do posicionamento do homem diante da vida, por isso sempre há diferentes sentidos para diferentes pessoas em todos os momentos e contextos da vida (Frankl, 1987).

Em complemento, Frankl (2015, p. 15) defende:

[...] Não há nenhuma situação na qual a vida cesse de oferecer uma possibilidade de sentido, e não há nenhuma pessoa para quem a vida não coloque à disposição um dever. A possibilidade de realização de um sentido é, em cada caso, única, e a personalidade que pode realizar-se é igualmente singular em cada caso.

Em outras palavras, é sugerida uma mudança de postura diante das situações, com a qual em vez de se questionar sobre o que se espera da vida se deve indagar quanto ao quê ela espera de você, isto é, o que ainda é necessário realizar. Com isso, a pessoa tem a possibilidade de encontrar e cumprir o sentido daquela situação específica, aprender e autotranscender. Visto que em todas as situações é possível encontrar e cumprir um sentido, com a pandemia do Covid-19 não seria diferente, 
embora o isolamento social, a mudança de rotina e maior contato com os outros virtualmente impostos por ela não tenha sido uma escolha pessoal.

Assim, é preciso encontrar e cumprir o sentido mesmo diante do sofrimento advindo desse fenômeno mundial, pois na impossibilidade de fazê-lo a pessoa pode cair no vazio existencial e o suicídio se apresenta como uma possibilidade. Quanto a isso, Frankl (2015) declara que o surgimento desse vazio vem do fato de que, diferentemente dos animais, o homem não tem quem dizer o que deve fazer ou ser, de modo que não possui orientações do que fazer com a própria vida. Em consequência, tem dificuldade em projetar um projeto de vida e esse sentimento de vazio existencial pode se manifestar através do tédio, agressividade, criminalidade, uso de drogas e, principalmente em jovens universitários, suicídio.

Diferentemente do que se pode pensar, "o suicida também crê num sentido, ainda que não de vida, de continuação da vida, mas ao menos no sentido da morte. Se não acreditasse realmente em nenhum sentido, não teria forças sequer para mover um dedo e, portanto, cometer o suicídio" (FRANKL, 2015, p. 80). Com isso em mente, é possível notar que até mesmo ao arquitetar a própria morte a pessoa acredita que exista um sentido, embora não o tenha conseguido de fato encontrá-lo, e utiliza essa lógica para sustentar sua última ação diante da vida.

No decorrer de seus casos clínicos e vivências nos campos de concentração, Frankl $(1987 ; 2015)$ notou que não eram poucos os causos de tentativas de suicídio em decorrência do sentimento de vazio existencial. Nesse seguimento, ao se deparar com aqueles que expressavam a ideação costumava questionar "por que você não opta pelo suicídio?". A partir da resposta apresentada, seu trabalho seguia no intuito de possibilitar que a pessoa compreendesse que existia algo para além dela, que se desse conta de que a vida sempre espera algo dela que estava para além daquela situação.

Fica nítido com Frankl (1987; 2015), seja por experiência própria ou suas atuações clínicas, que é possível que o homem supere qualquer adversidade contanto que consiga encontrar e cumprir um sentido, que se interrogue sobre o que a vida espera dele e aprenda com aquela vivência, superando a si e a situação. Isto posto, o mais defendido é que, embora nem todo ato de suicídio advenha especificamente do sentimento devastador de falta de sentido, sempre existe uma possibilidade dele ser 
evitado caso a pessoa tome consciência de algum sentido e propósito para além dela pelo qual valha a pena manter sua vida.

Por sua vez, a perspectiva de Albert Camus (1979) se propõe a investigar o fenômeno do suicídio não em um panorama social, mas em um quadro de pensamento individual, no qual alerta que há inúmeras situações no qual a pessoa pode optar por arquitetar a própria morte. À vista disso, diferentemente de Frankl, sua reflexão permeia a questão "A vida vale a pena ou não ser vivida?".

Nesse seguimento, o homem contemporâneo é cada vez mais absorvido por um contexto em que precisa dar conta muitas atividades ao longo da semana e a vida cotidiana se apresenta cada vez mais corrida e automática, no qual a reflexão surge desproporcional ao cansaço diário. Diante disso, Camus (1979) defende que é o cansaço que constrói a base necessária para a consciência começar a se manifestar e que apresenta a pessoa duas opções: "a continuação é o retorno inconsciente à mesma trama ou o despertar definitivo. No extremo do despertar vem, com o tempo, a consequência: suicídio ou restabelecimento" (p.13).

Ante o exposto, o homem compreende que a existência não tem sentido, que não há esperança para si, tampouco uma lógica que governe os acontecimentos do mundo, que a vida é fantasiosa e absurda. A partir de então, surge o intenso conflito humano: sua luta diária em relação ao mundo, essa permeada através do absurdo. Todavia, é necessário salientar que essa descoberta do absurdo não convoca a pessoa a assumir uma visão negativista e outorgada em relação à existência. Muito pelo contrário, ao surgir em um mundo absurdo e se dar conta disso, resta ao homem ter consciência de sua existência, revoltar-se e libertar-se (CAMUS, 1979).

É a partir disso que surge a verdadeira reviravolta, tão bem apresentada no mito de Sísifo. No mito, Sísifo foi condenado pelos deuses a rolar um rochedo incessante e inutilmente até o alto de uma montanha, onde a pedra caía de novo por seu próprio peso e ele precisava fazer tudo novamente por toda a eternidade. Por isso, Sísifo é o chamado Herói do absurdo, uma vez que é consciente de sua tragédia e revolta-se diariamente, mesmo sem esperanças para si enfrenta o rochedo como seu desafio pessoal e consegue levá-lo sempre ao alto, fazendo-o dono do próprio destino (CAMUS, 1979). 
Em outras palavras, ao enfrentar o seu destino, o homem se dirige para o mundo com uma atitude completamente nova, não mais irrefletida, automática e voltada sempre para o amanhã, mas aceita o desafio diário de se rebelar contra o absurdo. Destarte, essa insatisfação em relação ao mundo é o que o mantém não somente senhor do próprio destino como também dá valor à vida e responde ao porquê de mantê-la.

É ilógico, pois, pensar que há uma forma mais efetiva de lidar com o absurdo senão com a revolta, como se apresenta o fenômeno do suicídio. É preciso destacar, assim, que mesmo diante de situações adversas, como crises, morte de um ente querido, isolamento em decorrência da pandemia do Covid-19, o homem ainda tem apego à própria vida e tende a tentar mantê-la (CAMUS, 1979).

Isso evidencia que o que está em jogo na verdade é o que fazer com o reconhecimento de que essa não possui esperança ou significado: tentar evitar ou superar? Nesse seguimento, Camus (1979, p. 35) declara que "ele escapa ao suicídio à medida que é, ao mesmo tempo, consciência e recusa da morte", de modo que não há como o homem resolver o absurdo e a única forma de vencê-lo é dizer sim diariamente à vida, à insatisfação em relação ao mundo e ao seu confronto. Assim, fica nítido que apesar de o suicídio se apresentar como a tentativa de escape desse absurdo, na realidade em vez de exprimir a mais pura forma de libertação acaba por aprisionar o Ser, evidenciando o fato de que o mundo ganhou no jogo da vida.

\section{CONSIDERAÇÕES FINAIS}

Foi possível constatar que a facticidade do mundo traz angústia para o Ser e embora ela seja originária dele próprio busca formas na cotidianidade de terceirizar a responsabilidade de suas escolhas se diluindo no impessoal. Porém, a pandemia causada pelo Covid-19 obrigou o homem a isolar-se e defrontar-se consigo mesmo, necessitando de muito esforço para continuar encontrando sentido na sua existência. Posto que o Dasein, como ser-no-mundo e ser-com-os-outros, também tem a oportunidade de ressignificar seus sofrimentos e inquietações. Contudo, a partir de março de 2020 ele precisou responder a outras questões, inclusive se tinha um sentido pelo qual viver e se sua vida valia a pena ser vivida. 
Por outro lado, percebe-se que os sujeitos também se diferenciam ao entrar em contato com os outros, como entende Rollo May (1991) que os homens são como um espelho. E nessa falta do outro, transtornos como ansiedade, depressão e estresse póstraumático se intensificaram. Além da violência contra mulheres e crianças, além do abuso de álcool e outras drogas. Muitos se viram desesperados frente ao tédio, tendo em vista que a sociedade do século XXI se caracteriza pela alta produção e grande número de estímulos que acelera suas atividades.

A inconstância também foi exacerbada, o medo da contaminação, de não saber como seria o dia seguinte, se ainda teria um emprego ou não. O ser-para-morte que antes conseguia ignorar essa possibilidade foi obrigado a encará-la numa escala mundial e o sentimento de impotência despertou sua angústia. Diante disso, o sujeito pôde se colocar numa posição de abertura, poderia optar por assumir sua existência autêntica e oferecer um sentido a esse sofrimento ou continuar perdido no impessoal.

Mesmo que o homem não tenha tido a possibilidade de escolher onde e quando nasceria ou se iria vivenciar uma pandemia, isto se deu e ele precisa realizar escolhas frente a isso. Porém, primeiro é necessário que tenha consciência e responsabilidade por suas escolhas, além de considerar as implicações que podem acarretar na sociedade. Muitos ao se depararem com a finitude como uma possibilidade concreta, antes negligenciada, pode ter se angustiado ao ter consciência das consequências de suas escolhas.

Além de perceber que em sua existência não há sentido ou propósito a ser cumprido, o Ser, por sua vez, não consegue entender que, como salientou Frankl (2015), embora ele não tenha controle sobre as circunstâncias da pandemia, é imprescindível que se posicione e busque o algo para além de si mesmo e desse momento. Caso contrário, ao se deparar diariamente com o luto das famílias ou da sua própria, desigualdades e crises de caráter social, econômico e na saúde, talvez ele não consiga encontrar um lugar em que se apoie. Consequentemente, pôr fim a própria vida surge como uma clara solução e possibilidade de escolher, mesmo que esta seja a sua última e irrevogável.

Foi possível, também, constatar que mesmo diante de situações adversas, como crises, morte de um ente querido, isolamento em decorrência da pandemia do Covid19, o homem ainda tem apego à própria vida e tende a tentar mantê-la. Diante disso,

WWW.AMPLLAEDITORA.COM.BR (2)

CONTATO@AMPLLAEDITORA.COM.BR 
resta a escolha do que fazer diante do reconhecimento de que a vida não possui esperança ou significado. Se a pessoa opta por confrontar o absurdo, dizendo sim à vida e à insatisfação perante o mundo, ou ceder a ele ao escolher a morte voluntária, é uma escolha que cada um precisa se responsabilizar.

Salienta-se que é importante que a sociedade seja influenciada a pensar as questões da sua existência e que sentido tem atribuído a ela, como tem se posicionado. O ser autêntico escolhe baseado nas suas necessidades e anseios, ou seja, não atribui a outrem a sua responsabilidade e não seria diferente no caso do suicídio. Por fim, esse fenômeno não deve ser negligenciado, mas debatido a fim de que haja uma abertura do Ser para suas possibilidades e sentidos de existência.

\section{REFERÊNCIAS}

BRAGA, Tatiana Benevides Magalhães; FARINHA, Marciana Gonçalves. Heidegger: em busca de sentido para a existência humana. Revista da Abordagem Gestáltica: Phenomenological Studies, v. 23, n. 1, p. 65-73, 2017.

CAMUS, Albert. O MITO DE SísIFO: ensaio sobre o absurdo. Lisboa: Livros do Brasil, 1979.

DA SILVA, Karina de Fátima Aparecida; ALVES, Mariany Aparecida; DO COUTO, Daniela Paula. Suicídio: Uma escolha existencial frente ao desespero humano. PretextosRevista da Graduação em Psicologia da PUC Minas, v. 1, n. 2, p. 184-203, 2016.

DURKHEIM, Émile. O suicídio. São Paulo: Martins Fontes, 2000.

FRANKL. Viktor E. Em busca de sentido: um psicólogo no campo de concentração. Trad. de Walter O. Schlupp e Carlos C. Aveline. Porto Alegre: Sulina; São Leopoldo, Sinodal, 1987.

FRANKL, Viktor E. O sofrimento de uma vida sem sentido: caminhos para encontrar a razão de viver. Trad. Karleno Bocarro. 1ํe ed. São Paulo: É Realizações, 2015.

GREFF, Aramita Prates et al. Saúde mental e atenção psicossocial na pandemia COVID19: suicídio na pandemia COVID-19. 2020.

HAN, Byung-Chul. Sociedade do cansaço. Editora Vozes Limitada, 2015.

HEIDEGGER, Martin. Ser e tempo. Tradução Márcia de Sá Cavalcante. Petrópolis: Editora Vozes, 1977. 
LIMA, ROSSANO CABRAL. Distanciamento e isolamento sociais pela Covid-19 no Brasil: impactos na saúde mental. Physis: Revista de Saúde Coletiva, v. 30, p. e300214, 2020.

MAY, Rollo. O homem à procura de si mesmo. 18a ed. Petrópolis: Vozes, 1991.

ORSINI, Marco et al. Danos psíquicos durante pandemia por COVID-19 no Brasil. Enfermagem Brasil, v. 19, n. 3, p. 196-201, 2020.

Pandemia de COVID-19 aumenta fatores de risco para suicídio. Organização PanAmericana de Saúde, 10 de set. de 2020. Disponível em: <https://www.paho.org/pt/noticias/10-9-2020-pandemia-covid-19-aumentafatores-risco-para-suicidio>. Acesso em 19 de nov. de 2020.

SARTRE, Jean-Paul. O Existencialismo é um Humanismo. Tradução de Rita Correia Gudes. Paris, 1970.

SUICÍDIO: principais fatos. Organização Pan-Americana de Saúde. Disponível em: https://www.paho.org/pt/topicos/suicidio. Acesso em 19 de nov. de 2020 


\title{
CAPÍTULO XXIII
}

\section{ASSITÊNCIA DE ENFERMAGEM NO DIAGNÓSTICO E TRATAMENTO FOTOTERÁPICO DA ICTERÍCIA FISIOLÓGICA EM NEONATOS PRÉ-TERMO}

\author{
Jhônata Santos Brito ${ }^{1}$ \\ João Nilton Barreto Andrade ${ }^{2}$ \\ ${ }^{1}$ Graduando do curso de Enfermagem. Faculdade de Ciências e Empreendedorismo - FACEMP \\ 2 Professor Adjunto do curso de Saúde. Faculdade de Ciências e Empreendedorismo - FACEMP
}

\section{RESUMO}

Introdução: A icterícia neonatal fisiológica, é definida pela coloração amarelada da pele em consequência o aumento da bilirrubina indireta (não conjugada), presente na corrente sanguínea. Em média $80 \%$ dos prematuros (pré-termo) desenvolvem algum grau de icterícia. Na maior parte das vezes a mesma representa um fenômeno fisiológico transitório. É resultante da presença anormal de pigmentos biliares, podendo ser fisiológica ou patológica, influenciando diretamente no seu tratamento que dependerá do tipo e intensidade da mesma. A bilirrubina é um composto resultante da degradação da hemoglobina proveniente da destruição das hemácias. Na fase fetal a bilirrubina é filtrada pela placenta e excretada pelo fígado da mãe. Após o nascimento, é imprescindível que o fígado do recém-nascido seja capaz de fazer o processo da metabolização e excreção. Os neonatos que desenvolvem icterícia na primeira semana de vida extrauterina (fora do útero) passam por uma série de situações, dentre as quais a prematuridade, pode fazer com que os níveis de bilirrubina cresçam exageradamente, alastrar para vários tecidos, inclusive o sistema nervoso central. A presença de grande quantidade de bilirrubina por tempo prolongado pode lesar permanentemente estruturas como globo pálido, núcleos subtalâmicos, hipocampo e núcleo óculor-motor, dando origem ao chamado Kernicterus ou encefalopatia bilirrunínica, evidenciando a importância do diagnóstico precoce e tratamento imediato. Contudo, é importante que o tratamento seja realizado imediatamente após sua descoberta, para tanto, faz-se necessário maior qualificação dos profissionais de enfermagem, e nessa conjuntura, é observado o papel dos enfermeiros junto a equipe de enfermagem, pois, os mesmos estão ligados diretamente ao cuidado do binômio mãe-bebê, prestando os cuidados nas primeiras horas de vida do RN, sendo tais profissionais primordiais na detecção e tratamento de RN ictéricos. Desta maneira, o objetivo do trabalho é analisar a importância do profissional de enfermagem no diagnóstico e tratamento fototerápico da icterícia fisiológica em neonatos pré-termo. Revisão Bibliográfica: Icterícia neonatal fisiológica, é definida pela coloração amarelada da pele em consequência o aumento da bilirrubina indireta (não conjugada), presente na corrente sanguínea. Na fase intrauterina, o desenvolvimento fetal requer altas concentrações de hemoglobina para extrair efetivamente o oxigênio da circulação materna e entrega-la para os tecidos fetais. De imediato após o nascimento, com o provimento de oxigênio pelo próprio pulmão do $\mathrm{RN}$, esta necessidade de hemoglobina declina consideravelmente. 
Considerando que a vida média das hemácias fetais é menor do que a dos adultos, logo após o nascimento os RN têm uma alta carga de hemoglobina para ser convertida em bilirrubina e excretada no período pós-natal imediato. A assistência de enfermagem proporciona o surgimento dos métodos e instrumentos do trabalho da enfermagem. Uma das metodologias utilizadas pelo enfermeiro para implantação e operacionalização do cuidado é a Sistematização da Assistência de Enfermagem (SAE), que contempla a coleta de dados (histórico de enfermagem), diagnóstico de enfermagem, planejamento de enfermagem, implementação de enfermagem e avaliação de enfermagem, o qual oferta um cuidado organizado, sistematizado, contínuo e seguro ao recém-nascido. $O$ cuidado de enfermagem em neonatologia é o meio pelo qual se conduz a recuperação, adaptação e o bem estar, sendo que, este cuidado encontra-se fundamentado em conhecimentos científicos e na autonomia do profissional de enfermagem. Sendo seus principais objetivos na neonatologia: identificar as situações de saúde-doença; as necessidades de cuidados de enfermagem; subsidiar as intervenções de promoção, prevenção, recuperação e reabilitação da saúde do recém-nascido. No exame físico, a detecção depende principalmente da análise da pigmentação da pele e dos olhos do recém-nascido, sendo que icterícia por hiperbilirrubinemia indireta apresenta progressão céfalo-caudal, denominada zona de Kramer. O tratamento fototerápico é a terapêutica mais utilizada, no mundo, para tratar a icterícia neonatal, devido à sua elevada eficácia e falta de efeitos colaterais que expliquem o não usa da mesma. É uma terapêutica que usa a energia luminosa para modificar a bilirrubina acumulada no sangue, em produtos mais hidrossolúveis, expelido ligeiramente pela bile e pela urina. No tratamento fototerapia o(a) enfermeiro(a) desenvolve cuidados na proteção ocular, distância e posicionamento da fonte luminosa da fototerapia, prevenção de queimaduras, controle de perda hídrica, observação de eliminação, pesagem, mudança de decúbito a cada duas horas e cuidados com higiene. A atuação do enfermeiro junto ao recém-nascido pré-termo, portador da icterícia fisiológica deve iniciar-se na detecção precoce da mesma, durante o exame físico do recém-nascido e estendendo-se durante a terapêutica proposta. Conclusão: Nesta perspectiva, nos cuidados envolvidos a saúde do recém-nascido, percebe-se a importância das ações de enfermagem na atenção e sistematização do cuidado aos neonatos pré-termo com icterícia fisiológica. Pois, a assistência de enfermagem, possui atribuições importantes desde o exame físico, contribuindo para o diagnostico, até no tratamento da icterícia neonatal. Fazendo-se, necessário a qualificação do atendimento, para proporcionar um diagnóstico precoce e dar início ao tratamento escolhido.

Palavras-chave: Ictéricia nenatal. Ictéricia fisiológica. Fototerapia. Assistência de Enfermagem.

\section{INTRODUÇÃO}

A icterícia é frequente no período neonatal, em média de $60 \%$ a $70 \%$ dos recémnascidos a termo e $80 \%$ dos prematuros (pré-termo) desenvolvem algum grau de 
icterícia. Na maior parte das vezes a mesma representa um fenômeno fisiológico transitório (PAGANINI, 2009).

Em torno de 1,5 milhão de recém nascidos (RNs) apresentam icterícia nos primeiros dias de vida por ano, cerca de 250 mil encontra-se em estado crítico e com maior risco de neurotoxicidade, kernicterus ou óbito (FONTES, 2019).

É resultante da presença anormal de pigmentos biliares, podendo ser fisiológica ou patológica, influenciando diretamente no seu tratamento que dependerá do tipo e intensidade da mesma. A bilirrubina é um composto resultante da degradação da hemoglobina proveniente da destruição das hemácias. Na fase fetal a bilirrubina é filtrada pela placenta e excretada pelo fígado da mãe. Após o nascimento, é imprescindível que o fígado do recém-nascido seja capaz de fazer o processo da metabolização e excreção (SACRAMENTO, 2017).

O recém-nascido tem várias limitações no metabolismo da bilirrubina que evidencia a icterícia em pacientes saudáveis, tais como sobrecarga de bilirrubina ao hepatócito e a menor capacidade de captação, conjugação e excreção hepática de bilirrubina (POVALUK, 2017).

Os neonatos que desenvolvem icterícia na primeira semana de vida extrauterina (fora do útero) passam por uma série de situações, dentre as quais a prematuridade, pode fazer com que os níveis de bilirrubina cresçam exageradamente, alastrar para vários tecidos, inclusive o sistema nervoso central. A presença de grande quantidade de bilirrubina por tempo prolongado pode lesar permanentemente estruturas como globo pálido, núcleos subtalâmicos, hipocampo e núcleo óculor-motor, dando origem ao chamado Kernicterus ou encefalopatia bilirrunínica, evidenciando a importância do diagnóstico precoce e tratamento imediato (SACRAMENTO, 2017).

A icterícia fisiológica manifesta-se após as 24 horas de vida. No récem-nascido a termo, que nasceram entre 37 a 41 semanas e 06 dias de gestação, há aumento de bilirrubina sanguínea nos primeiros 3 dias de vida de até $6-8 \mathrm{mg} / \mathrm{dl}$, sendo que níveis inferiores a $12 \mathrm{mg} / \mathrm{dl}$ são considerados dentro dos limites fisiológicos. No recém-nascido pré-termo, nascido antes de completar 37 semanas de gestação, o valor máximo de bilirrubina pode ser de cerca de $10-12 \mathrm{mg} / \mathrm{dl}$ no $5^{\circ}$ dia, podendo atingir $15 \mathrm{mg} / \mathrm{dl} \mathrm{sem}$ anomalia no metabolismo ${ }^{(1)}$. 
É necessário que os enfermeiros sejam qualificados e capazes de realizar o diagnóstico clínico de icterícia bem como proporcionar adequada assistência de enfermagem durante o tratamento (SENA, 2015)

Contudo, é importante que o tratamento seja realizado imediatamente após sua descoberta, para tanto, faz-se necessário maior qualificação dos profissionais de enfermagem, e nessa conjuntura, é observado o papel dos enfermeiros junto a equipe de enfermagem, pois, os mesmos estão ligados diretamente ao cuidado do binômio mãe-bebê, prestando os cuidados nas primeiras horas de vida do RN, sendo tais profissionais primordiais na detecção e tratamento de RN ictéricos (POVALUK, 2017). Desta maneira, o objetivo do trabalho é analisar a importância do profissional de enfermagem no diagnóstico e tratamento fototerápico da icterícia fisiológica em neonatos pré-termo.

\section{REVISÃO BIBLIOGRÁFICA}

Icterícia neonatal fisiológica, é definida pela coloração amarelada da pele em consequência o aumento da bilirrubina indireta (não conjugada), presente na corrente sanguínea (REGINATTO, 2016).

$\mathrm{Na}$ fase intrauterina, o desenvolvimento fetal requer altas concentrações de hemoglobina para extrair efetivamente o oxigênio da circulação materna e entrega-la para os tecidos fetais. De imediato após o nascimento, com o provimento de oxigênio pelo próprio pulmão do $\mathrm{RN}$, esta necessidade de hemoglobina declina consideravelmente. Considerando que a vida média das hemácias fetais é menor do que a dos adultos, logo após o nascimento os RN têm uma alta carga de hemoglobina para ser convertida em bilirrubina e excretada no período pós-natal imediato (POVALUK, 2017)

A bilirrubina é um dos produtos da quebra da hemoglobina que resulta na destruição das hemácias. Quando há uma quebra das hemácias, seu produto é liberado na circulação, onde a hemoglobina se divide em heme e globina. A porção da globina é usada pelo corpo, e a porção heme é convertida a bilirrubina não conjugada (substância insolúvel que se liga a albumina) (HOCKENBERRY, 2018) 
Desde o fígado, a bilirrubina separa da albumina, e através da enzima glicuronil transferase, é conjugada com ácido glicurônico para produzir a bilirrubina conjugada (solúvel) sendo excretada pela bile. No intestino sofre uma ação bacteriana, reduzindo a bilirrubina conjugada a urobilinôgenio. Dessa maneira grande parte da bilirrubina reduzida (urobilinogenio) é excretada pelas fezes e uma quantidade pequena é eliminada na urina, como mostra o esquema de como é feita a metabolização no organismo do recém-nascido, na figura 1 (HOCKENBERRY, 2018).

Figura 1: Metabolização da Bilirrubina

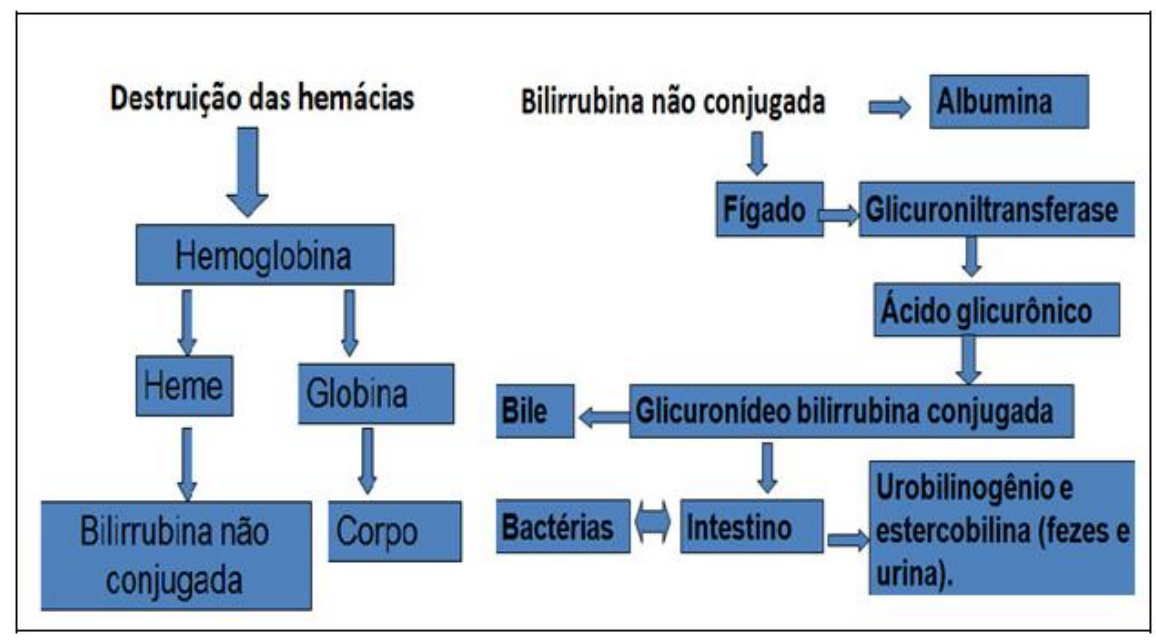

Fonte: CALVACANE, 2013.

A assistência de enfermagem proporciona o surgimento dos métodos e instrumentos do trabalho da enfermagem. Uma das metodologias utilizadas pelo enfermeiro para implantação e operacionalização do cuidado é a Sistematização da Assistência de Enfermagem (SAE), que contempla a coleta de dados (histórico de enfermagem), diagnóstico de enfermagem, planejamento de enfermagem, implementação de enfermagem e avaliação de enfermagem, o qual oferta um cuidado organizado, sistematizado, contínuo e seguro ao recém-nascido. O cuidado de enfermagem em neonatologia é o meio pelo qual se conduz a recuperação, adaptação e o bem estar, sendo que, este cuidado encontra-se fundamentado em conhecimentos científicos e na autonomia do profissional de enfermagem (SARLI, 2018).

No diagnóstico da icterícia neonatal por meio da história clínica, é de fundamental importância colher dados sobre o histórico e fatores epidemiológicos, pois permitem detectar a possibilidade de desenvolvimento de hiperbilirrubinemia significante na primeira semana de vida. Dessa maneira, evidencia a importância do processo de 
enfermagem no atendimento ao recém-nascido de uma maneira fundamental na construção do desfecho clínico (WILLIAMSON, 2017).

No exame físico, a detecção depende principalmente da análise da pigmentação da pele do recém-nascido sendo que icterícia por hiperbilirrubinemia indireta apresenta progressão céfalo-caudal. Kramer no final de 1960 descreveu a progressão céfalo-caudal da icterícia, dividindo o corpo do $\mathrm{RN}$ de termo em cinco zonas, como descreve na figura 2, associando estas zonas com a concentração de bilirrubina sérica (SACRAMENTO, 2017).

Figura 2: Zonas Dérmicas de Kramer

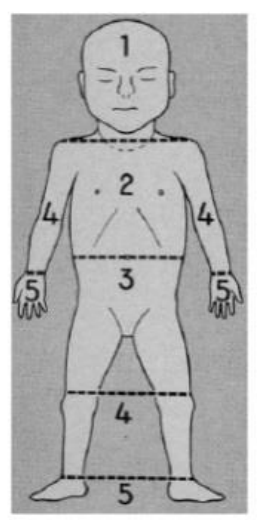

Zona 1: cabeça e pescoço

Zona 2: até cicatriz umbilical

Zona 3: até o joelhos e cotovelos

Zona 4: até tornozelos e punhos

Zona 5: até região plantar e palmar

Fonte: CALVACANTE, 2013.

Os neonatos ictéricos devem ter uma dosagem de bilirrubina sérica (que pode ser feita através do hemograma) e/ou uma aferição transcutânea (BTC), já que a estimativa visual como parâmetro diagnóstico depende da experiência profissional, do tipo e da pigmentação da pele do RN, da luminosidade, podendo ser submetida em peles pigmentadas em ambientes claros e prejudicada em locais escuros. A dosagem sérica de bilirrubinas é o exame mais recomendado, quando na BTC os níveis forem superiores a $12-14 \mathrm{mg} / \mathrm{dl}$ (SARLI, 2018).

Para definição do tipo de tratamento adequado deve-se observar diversos fatores que corroboram para o diagnóstico, a fim de garantir que seja instituída a terapêutica mais eficaz. Preconiza-se que, primeiramente, observe-se o histórico materno e o histórico neonatal, analisar o aparecimento e a evolução da icterícia por meio do exame físico minucioso no recém-nascido e em seguida realizar a coleta de 
sangue do recém-nascido para análises. Deve-se, por fim, determinar se a hiperbilirrubinemia enquadra-se no tipo fisiológico ou patológico (CALVACANTE, 2013).

O tratamento fototerápico é a terapêutica mais utilizada, no mundo, para tratar a icterícia neonatal, devido à sua elevada eficácia e falta de efeitos colaterais que expliquem o não usa da mesma. É uma terapêutica que usa a energia luminosa para modificar a bilirrubina acumulada no sangue, em produtos mais hidrossolúveis, expelido ligeiramente pela bile e pela urina (FONTES, 2019).

A realização dos cuidados ao neonato pelo(a) enfermeiro(a) tem como principais objetivos a identificação de situações de saúde-doença; as necessidades de cuidados de enfermagem; ajudar nas intervenções de promoção, prevenção, recuperação e reabilitação da saúde do recém-nascido. Possibilitando o desenvolvimento de ações neonatais que modificam o estado do processo de vida e de saúde-doença e promove a saúde do recém-nascido (FONTES, 2019).

Nesta perspectiva, os recursos tecnológicos, a capacitação profissional, os avanços na profissão de Enfermagem e o uso de instrumento de controle, proporcionam uma assistência à saúde do recém-nascido de qualidade, reduzindo a mortalidade infantil, promovendo a qualidade de vida declinando as desigualdades em saúde (PAGANINI, 2009).

O enfermeiro (a) é responsável pelo recebimento e preparação do recémnascido na unidade de saúde para a realização da terapêutica, que muita das vezes o diagnóstico é feito dentro da maternidade após horas do parto, bem como, preparam os aparelhos que serão usados para a fototerapia, como os focos de luz, as incubadoras, entre outros. Além disso, é de fundamental importância a humanização da assistência nesse processo por meio do profissional para com o neonato e a família (CALVACANTE, 2013).

A atuação do enfermeiro é essencial e indispensável, diante da assistência integral e individualizada prestada por esses profissionais sendo estes o responsável por receber e programar ações voltadas ao neonato, tendo como cuidados a proteção ocular, distância e posicionamento da fonte luminosa da fototerapia, prevenção de queimaduras, controle de perda hídrica, observação de eliminação, pesagem, mudança de decúbito a cada duas horas e cuidados com higiene (CALVACANTE, 2013). 
Ainda assim, vem a existir uma fragilidade entre os enfermeiros quando se trata da implementação aos cuidados com o recém-nascido portador da icterícia, possuindo dificuldades no manuseio da fototerapia, na realização do balanço hídrico, mudança de decúbito e pesagem, na qual as dificuldades vem a ser relacionada com a fragmentação da assistência dos profissionais de enfermagem e a falta de elaboração das rotinas de assistência criada pelas instituições (PAGANINI, 2009).

O trabalho do enfermeiro em neonatologia é um desafio constante, um caso de icterícia neonatal, exige vigilância, capacidade, respeito e sensibilidade, porque o paciente assistido é muito vulnerável e altamente depende da equipe de enfermagem, que lhe proporciona assistência direta. $A$ atuação do enfermeiro junto ao recém-nascido portador da icterícia fisiológica deve iniciar-se na detecção precoce da mesma, durante o exame físico do RN e estendendo-se durante a terapia proposta (SENA, 2015).

A equipe de enfermagem necessita conhecer e estar atenta para todos os sinais e sintomas exibidos pelo recém-nascido, com vista a prevenir complicações e aumentar a eficácia da terapêutica (WILLIAMSON, 2017)

\section{CONSIDERAÇÕES FINAIS}

Nesta perspectiva, nos cuidados envolvidos a saúde do recém-nascido, percebese a importância das ações de enfermagem na atenção e sistematização do cuidado aos neonatos pré-termo com icterícia fisiológica. Pois, a assistência de enfermagem, possui atribuições importantes desde o exame físico, contribuindo para o diagnostico, até no tratamento da icterícia neonatal. Fazendo-se, necessário a qualificação do atendimento, para proporcionar um diagnóstico precoce e dar início ao tratamento escolhido.

Portanto, é perceptível a importância do diagnóstico da icterícia fisiológica logo nas primeiras horas de vida do RN, pois evita terapias clínicas desnecessárias, separação de pais-recém-nascido e diminui risco de um diagnostico tardio, que compromete ainda mais a saúde do recém-nascido podendo leva-lo a óbito.

\section{REFERÊNCIAS}

CAVALCANTE, Francisca Farias. Tratamento Alternativo Associado com Fototerapia em Recém-Nascidos Ictéricos. 2013. Dissertação (Mestrado em Bioengenharia) Universidade Camilo Castelo Branco, [S. I.], 2013. 
FONTES, Michelle Barros; BATISTA, Thayse C. Oliveira. Assitencia do Enfermeiro na Atenção a Saúde do Recém-nascido com Icterícia Neonatal: Uma Revisão Integrativa. Universidade Tiradentes - UNIT, [s. I.], 9 maio 2019.

HOCKENBERRY, Marilyn J. et al. Problemas de Saúde dos Recém-Nascidos: Hiperbilirrubinema. In: Fundamentos de Enfermagem Pediátrica. 10. ed. [S. I.: s. n.], cap. 8 , p. $255-263,2018$

PAGANINI, Camila Bianca Lecciolle; FERREIRA, Aleksandro Belo; GLACCI, Clery Bernadi. Icterícia Neonatal: Fatores de Riscos para Reinternação em uma População de Recém-nascidos Vivos na Cidade de São Paulo. Arq Med Hosp Fac Cienc Med Santa Casa São Paulo, [s. I.], 2009.

POVALUK, Patrícia. Acurácia do Biliufpr - Um Analisador de Bilirrubina Transcutânea na Avaliação da Icterícia Neonatal. 2017. Dissertação (Mestrado em Saúde da Criança e do Adolescente) - Universidade Federal do Paraná, [S. I.], 2017.

REGINATTO, Flávia Pereira et al. Prevalência e caracterização das afecções cutâneas neonatais nas primeiras $\mathbf{7 2}$ horas de vida. Jornal de Pediatria (Rio J). , [s. I.], 16 jun. 2016.

SARLI, Yone de Oliveira Di. Associação entre Tempo de Clampeamento do Cordão Umbilical e Icterícia Neonatal Precoce em Récem-Nascidos a Termo. 2018. Dissertação (Mestrado em Ciências da Saúde) - Universidade Santo Amaro, [S. I.], 2018.

SENA, Divina T. Carvalho de; REIS, Rosane Pereira dos. A Importância da Atuação do Enfermeiro no Tratamento da Icterícia Neonatal. Revista Eletrônica Estácio Saúde, [s. I.], 2015.

SACRAMENTO, Larrissa C. Araújo; LEAL, Gabriele de Andrade; RIBEIRO , Joathan Borges; SANTOS, Josefa Jadiane dos.. Icterícia Neonatal: O Enfermeiro Frente ao Diagnóstico e a Fototerapia como Tratamento. INTERNATIONAL NURSING CONGRESS, [s. I.], 9 maio 2017.

WILLIAMSON, Mary A. et al. Doenças do Sistema Digestório: Ictéricia. In: Interpretação de Exames Laboratoriais. 10. ed. [S. I.: s. n.]. cap. 10, p. 438-441, 2017. 


\title{
CAPITULO XYIV
}

\section{PRÉ-NATAL HUMANIZADO E EDUCAÇÃO EM SAÚdE PARA 0 PARTO ATIVO: PERCEPÇÃO DOS MÉDICOS E ENFERMEIROS DE UMA UNIDADE BÁSICA DE SAÚDE}

\author{
D0I: I0.5I859/amplla.cse238.II2I-24
}

\author{
Regina Dias Pereira ${ }^{1}$ \\ Neudson Johnson Martinho ${ }^{2}$
}

\footnotetext{
${ }^{1}$ Enfermeira na área de saúde da mulher. (UFMT). Pesquisador na área de Educação em Saúde.
}

2 Doutor em Educação. Professor Associado da Faculdade de Medicina da Universidade Federal de Mato Grosso

\section{RESUMO}

O parto ativo trata-se de uma forma adequada em se descrever o trabalho de parto, como a parturiente reage aos seus próprios instintos e a lógica fisiológica do seu corpo. É uma maneira de dizer que a gestante realmente está no controle do seu corpo durante o processo de parir e que não é o objeto de uma "conduta ativa" do parto pela equipe obstétrica (BALASKAS, 1993). Mas, para que a gestante possa ter esse tipo de parto, se faz necessário que esta tenha um pré-natal humanizado que a eduque quanto a importância deste tipo de parto para sua saúde e do filho, assim como, que se trata de um direito seu optar por ser a protagonista do ato de parir. Frente a este fenômeno, desenvolvemos esse estudo objetivando desvelar saberes / fazeres de profissionais da saúde quanto ao significado e significância sobre pré-natal humanizado e promover processos educativos quanto a educação em saúde durante o pré-natal visando educar a gestante, companheiro e família para o parto ativo. O mesmo foi desenvolvido em uma Unidade de Saúde da Família do Município de Cuiabá-MT, com base no método qualitativo. Consideramos a partir dos fenômenos identificados neste estudo, que se faz necessário repensar a formação acadêmica nos curso nos cursos de medicina e enfermagem, os quais devem introduzir em seus respectivos currículos teoria e prática sobre pré-natal humanizado e parto ativo, assim como, educação em saúde para o parto ativo durante as consultas de pré-natal, visando a diminuição da elevada incidência de partos iatrogênicos, violências obstétricas e realização de procedimentos cirúrgicos de cesáreas desnecessárias, consequentemente baixando a morbimortalidade materna no Brasil.

Palavras-chave: Pré-natal Humanizado; Parto Ativo; Educação em Saúde.

\section{INTRODUÇÃO}

O movimento de mulheres, enfermeiras obstetrizes e obstetras para a promoção do parto ativo, liderado por uma educadora perinatal sul-africana, chamada Janet

WWW.AMPLLAEDITORA.COM.BR (2)

CONTATO@AMPLLAEDITORA.COM.BR M 
Balaskas, hoje ressignificado como parto natural ou humanizado, teve início na década de 70 em Londres, gerando grandes conflitos nas salas de partos, o que resultou em sua proibição. Entretanto, a luta continuou e o movimento foi resgatado através de uma manifestação realizada por seus simpatizantes em um dia de domingo, mais precisamente 11 de abril de 1982, denominada de "Comício pelos direitos de parir". Em seguida, esse movimento se expandiu por outros países. (BALASKAS, 1993).

No Brasil, esse movimento ressurge com mais força na década de 90, através da Associação Brasileira de Obstetrizes e Enfermeiros Obstetras (ABENFO), a qual incentiva a criação dos centros de parto natural e/ou casas de parto, tendo apoio da fundação Japonesa JICA.

Mas, até a presente data, a luta e aceitação do parto ativo ainda é uma realidade distante e até certo ponto utópico para muitos profissionais da saúde e para muitas gestantes, tendo em vista a visão distorcida que se disseminam quanto ao mesmo com a finalidade em atender demandas mercadológicas e corporativas de profissões hegemônicas da saúde, de modo específico em hospitais e maternidades do mundo ocidental (MARTINHO, 2005).

Ainda se pode observar empiricamente nas unidades básicas de saúde e em hospitais / maternidades que a maioria dos profissionais pré - natalistas concentram as ações executadas durante a consulta pré-natal no foco biologicista, sem uma abordagem efetivamente holística que considere e prepare a gestante como sujeito ativo do processo de gestar e parir (MARTINHO, 2005).

Nessa perspectiva, o Grupo de Pesquisas Multiprofissionais em Educação e Tecnologias em Saúde - PEMEDUTS/UFMT sentiu a necessidade em desenvolver um Projeto de Pesquisa com interface na extensão intitulado: "Pré-natal humanizado: Educação em saúde para o parto ativo", do qual emergiu este estudo como recorte deste processo construtivo de conhecimentos na área da saúde da mulher.

Objetivamos com esse estudo desvelar saberes / fazeres de profissionais da saúde quanto ao significado e significância sobre pré-natal humanizado, visando promover processos educativos quanto a educação em saúde durante o pré-natal para a gestante, o companheiro e a família quanto ao parto ativo.

Enfatizamos que fenômenos observados empiricamente durante práticas acadêmicas curriculares em unidades básicas de saúde (UBS) do município de Cuiabá -

WWW.AMPLLAEDITORA.COM.BR (2) 
MT e em um hospital público universitário, analogizados à leituras flutuantes em literaturas pertinentes sobre parto ativo/humanizado, nos despertou a necessidade em desenvolver este estudo visando desmistificar paradigmas que impedem profissionais da saúde pré-natalistas, assim como usuárias gestantes, em compreenderem o verdadeiro significado e significância do parto ativo para saúde e vida das mulheres, filhos e consequentemente da família.

\section{REVISÃO BIBLIOGRÁFICA}

\subsection{Pré- natal humanizado}

A humanização do pré-natal se caracteriza por um atendimento à gestante de forma holística, dando atenção aos aspectos biopsicossociais da mesma, ouvindo-a atentamente e possibilitando que ela tome decisões conscientes a partir de saberes adquiridos na consulta, os quais culminarão na decisão desta em optar por parto natural, vaginal, erradicando os pré-conceitos e tabus inerentes aos mesmo (CARVALHO, 2007).

O sucesso do pré-natal humanizado dependerá bastante da atuação do pré natalista, o qual deve ser competente para orientar convenientemente a gestante reconhecendo a tempo os problemas ocorridos durante a gravidez e conduzindo-os corretamente. Deve ser humano para entender e viver com a mulher as emoções da gravidez orientando-a e esclarecendo as dúvidas para diminuir suas tensões e dedicado ao ponto de dispensar todo tempo necessário para um atendimento adequado (MARTINHO, 2005).

\subsection{Parto ativo}

Uma mulher dá a luz ativamente quando ela é capaz de secretar seus próprios hormônios ou, em outras palavras não precise de hormônios sintéticos e/ou outras intervenções médicas. Nesse contexto, o conceito de parto ativo foi introduzido para mulheres que querem ter de volta o controle e a responsabilidade sobre o parto (BALASKAS, 1993).

O parto ativo trata-se de uma forma de parturição no qual a parturiente reage aos seus próprios instintos e a lógica fisiológica do seu corpo. Nesse tipo de parto a 
gestante realmente fica no controle do seu corpo durante o processo de parir, não sendo objeto de uma "conduta ativa" do parto pela equipe obstétrica (BALASKAS, 1993).

Balaskas (1993) enfatiza que as ações do Parto Ativo contribuirão para diminuir a probabilidade de complicações na gravidez, assegurando que a gestante chegue ao processo de parturição em ótimas condições de saúde, além de melhorar e apressar sua recuperação, independente do que tenha acontecido.

No início da gravidez a mulher terá que se adaptar as transformações hormonais, físicas e psicológicas que são normais nesse período inicial da concepção, sendo que ela poderá em alguns momentos precisar conviver com cansaço ou náuseas incomodas. Porém, depois de passado algum tempo, a gestante começará a sentir-se mais disposta, confiante e desfrutará de uma sensação de vitalidade, saúde e bem-estar onde poderá exercer as condutas preconizadas para o parto ativo para auxiliar a gestante no período da gestação, pode-se utilizar exercícios de yoga. Tais exercícios são originários da Índia e atualmente é praticado em todo o mundo (BALASKAS, 1993).

O conceito e os propósitos inerentes ao parto ativo se adaptaram conforme as mudanças paradigmáticas que ocorreram no setor saúde e foram influenciadas pelas transformações ocorridas nos processos pedagógicos da formação profissional e educação escolar de maneira geral. Portanto, podemos dizer que se trata de um sistema conceitual aberto (MACIEL, 2009).

\subsection{Educação em saúde no pré-natal}

Educar em saúde não se legitima pela realização de uma palestra, porque o processo educativo não deve ser um monólogo, mas, um diálogo. Educação em saúde é sobretudo mobilizar saberes existentes para transformações positivas à partir das vivências e visão de mundo do educando (MARTINHO, 2014).

$\mathrm{Na}$ arte de educar em saúde saberes, fazeres e vivências são imbricados numa construção de conhecimento para a práxis, ou seja, uma prática transformadora (MARTINHO, 2014).

Educação em saúde no pré-natal é sobretudo uma ação dialógica entre as mulheres e profissionais pré-natalistas (enfermeiros e médicos), visando o despertar da consciência crítica à partir de saberes intercambiados quanto a importância dos cuidados à saúde no período da gestação e do parto (MARTINHO, 2005).

WWW.AMPLLAEDITORA.COM.BR (2) 
A saúde é uma construção social, um conceito amplo e subjetivo, está imbricada na educação, não havendo a existência de uma sem a presença da outra. Portanto, ações para a manutenção e resgate da saúde devem ser precedidas por processos dialógicos educativos (MARTINHO, 2014).

\section{MATERIAL E MÉTODO}

Este é um estudo descritivo, exploratório, com abordagem qualitativa.

Sampieri, Collado e Lucio (2006), descrevem que o enfoque qualitativo da pesquisa em geral é utilizado para descobrir e refinar as questões da mesma. Esse enfoque baseia-se em métodos de coleta de dados com descrições e observações, nesses processos surgem questões flexíveis que se alternam entre os eventos e a forma de interpretação, também entre as respostas e o desenvolver da teoria, tendo como propósito a reconstrução de uma realidade tal qual observada pelos atores de um sistema social predefinido.

Para Gil (2010) o estudo exploratório tem como objetivo tornar mais explicito o problema, na tentativa de aprofundar as ideias sobre o objeto de estudo, enquanto a o processo descritivo busca delinear as características da população ou de um fenômeno. O planejamento deste tipo de estudo é flexível, pois deve considerar os mais variados aspectos relativos ao fato ou fenômeno estudado.

O lócus desta pesquisa foi uma Unidade Básica de Saúde (UBS) da cidade de Cuiabá - MT, cujo desenvolvimento da mesma se deu no período compreendido entre dezembro de 2016 a junho de 2017, cujos participantes foram médicos e enfermeiros que atavam na referida unidade, selecionados aleatoriamente com base nos critérios descriminados abaixo:

Critérios de inclusão:

- Profissionais da saúde que estejam ativos e realizem consultas pré-natal na UBS lócus do estudo;

Critérios de inclusão:

- Profissionais que não atuem na unidade lócus desta pesquisa ou que estejam afastados do serviços por motivos diversos. 
A coleta de dados ocorreu nos meses de abril e maio de 2017, logo após a aprovação do referido projeto pelo Conselho de Ética em Pesquisas com seres Humanos (CEP) do HUJM, tendo parecer aprovado com o no 2.046.110/2017, conforme Resolução 466/2012 da CONEP/CNS/MS.

Esta etapa foi feita com base em um roteiro com temas geradores sobre pré-natal humanizado e parto ativo (Apêndice A). Os referidos temas foram dialogados durante rodas de conversa, perfazendo um total de três (03) rodas de conversa.

Ressaltamos que esta pesquisa foi desenvolvida obedecendo as recomendações éticas inerentes à pesquisas em seres humanos preconizadas pela CONEP/CNS/MS. Nesse contexto, antes do início da mesma, foi solicitado a assinatura do termo de anuência pela representante da Secretaria Municipal de Saúde de Cuiabá (Apêndice B) e do Termo de Consentimento Livre e Esclarecido (TCLE) pelos profissionais da saúde da UBSF lócus do estudo, sendo entregue uma via aos mesmos (Apêndice C).

Para compreensão dos resultados foi utilizada a técnica de análise temática e processo de categorização segundo Bardin (2011), além, da triangulação com a literatura e observações realizadas durante as rodas de conversa.

Esse processo sistemático de sistematização e análise dos dados seguiu as seguintes etapas de execução:

1‥ Realização das rodas de conversa para coleta e transcrição dos dados apreendidos nos discursos dos participantes;

2a. Pré-análise: Esta etapa consistiu na leitura flutuante dos discursos transcritos. A partir desta leitura emergiram os fenômenos significantes, possibilitando identificar potenciais categorias discursivas a partir dos relatos dos profissionais;

3ạ. Realização de leituras exaustivas dos conteúdos das falas agrupadas por homogeneidade de semelhanças de sentidos, para a organização e sistematização dos conteúdos, permitindo o agrupamento em grandes categorias;

4a. Análises dos conteúdos das falas que foram reunidas por categorias, identificando unidades de significados, procedendo-se aos agrupamentos finais;

5ạ. Análise e compreensão dos dados, descrevendo as significâncias (sentidos) dos conteúdos.

Franco (2007) ressalta que esses são pontos de partida para a análise, sejam elas verbais, figurativas, gestuais ou diretamente provocadas, para que assim se identifique 
o significado e sentido que os fenômenos expressos nas falas tiveram para os participantes do estudo.

\section{RESULTADOS E DISCUSSÕES}

O processo de organização e classificação dos dados permitiu a elaboração das unidades temáticas: "Percebendo a humanização no pré-natal”, "(in)viabilidade do prénatal humanizado para o parto ativo", "percepção dos profissionais sobre parto ativo" e "Educar para o parto ativo", as quais emergiram da análise das falas do profissionais médicos, enfermeira e residentes de medicina nas três (03) oficinas supracitadas na coleta de dados.

\subsection{Categoria 1 - Percebendo a humanização no pré-natal}

Nessa categoria os profissionais ressaltaram a importância de se estabelecer um vínculo com as gestantes e familiares destas. Sendo a escuta ativa nas consultas uma forma de legitimar esse elo de confiança e vínculo.

“(...) o pré-natal humanizado se dá através de uma parceria com a gestante (...)"

- Med. 01;

“(...) durante o pré-natal o profissional precisa preocupar-se com o contexto familiar (...)" - Enfa. 02;

“(...) o pré-natal começa com o acolhimento na condução das consultas (...)" Enfa. 01;

“(...) o pré-natal é humanizado quando a gestante é protagonista do cuidado (...)" - Prof. 02;

“(...) esclarecendo as dúvidas e respeitando as escolhas das gestantes, gera vínculo e humaniza o pré-natal(...)" - Med. 02;

“(...) desenvolvendo o diálogo de forma horizontal e dando espaço para a fala da gestante, escutando-a atentamente, cria vínculo e humaniza o pré-natal (...)" Enfa. 01.

Zampieri \& Erdmann (2010) corroboram as falas supracitadas, afirmando que é importante devolver à mulher o protagonismo na gestação, no parto e pós-parto, considerando-os como situações normais da vida e não como doenças, eventos femininos que apresentam significados diferentes para as mulheres dos atribuídos pelos 
profissionais. Nestes processos, o profissional deveria fazer parte da rede de apoio à gestante, sem substituí-la, os autores fundamentam a percepção dos profissionais quanto a importância da autonomia da mulher desde a pré concepção até o pós-parto.

Os atendimentos oferecidos as gestantes durante a consulta pré-natal precisam contemplar a dimensão biopsicossocial das mulheres. Além da realização das manobras de Leopold, solicitação dos exames laboratoriais e suplementação de sulfato ferroso recomendada nas cartilhas do Ministério da Saúde.

\subsection{Categoria 2 - Pré-natal humanizado para o parto ativo:}

\section{para que?}

Os profissionais relataram certa frustração ao realizarem consultas de pré-natal humanizadas. Apresentam séria críticas ao atendimento hospitalar e nas maternidades, cujo modelo de atendimento destas instituições desconstrói o processo humanizado proporcionado durante o pré-natal, tendo em vista que nestes cenários os profissionais médicos não aceitam e nem aderiram ao parto ativo, desrespeitando os direitos das gestantes no momento destas parirem.

“(...)é possível realizar o pré-natal humanizado apenas nas unidades de atenção primaria, porém nos hospitais não vemos a humanização no atendimento(...)" Enfa. 01;

“(...) é possível fazer um pré-natal humanizado, porém tem sido muito fragmentada a assistência, acredito que deveria haver uma conexão entre a assistência primaria, secundária e terciaria." - Med. 02;

“(...)a gente até orienta as gestantes sobre os seus direitos e sobre as vias do parto, mas, quando elas chegam nos hospitais e maternidades são "obrigadas" a parir conforme determina a rotina médica hospitalar(...)" - Enfa. 02;

“(...)O pré-natal humanizado ocorre na unidade básica de saúde, mas quando as gestantes chegam na atenção hospitalar elas se deparam com uma assistência impositiva (...)" - Med. 02.

As narrativas dos profissionais demonstram a inexistência de integralidade entre a atenção primária, secundária e terciária. Sendo este fenômeno apontado como um fator limitador para o empoderamento feminino e suas possíveis escolhas relacionadas ao seu corpo, conviç̧ões e/ou cultura quanto ao momento de parir. 
Segundo Pinheiro \& Mattos (2001), a integralidade das ações de saúde em nível micro deve ser fruto do esforço e da confluência dos vários saberes de uma equipe multiprofissional para traduzir e atender as necessidades de saúde. Sendo plena quando há articulação entre os serviços de saúde e destes com outras instituições sociais, portanto, a integralidade ampliada é a relação articulada, complexa, complementar e dialética entre o cuidado dado pelo profissional, pela equipe e rede de serviços de saúde.

Os sentimentos de descontentamento e desmotivação implícitos nas narrativas dos profissionais que realizam o pré-natal na UBS lócus desta pesquisa, nos fez compreender a urgente necessidade de mobilização social para que se criem políticas públicas estruturantes nos sistemas de saúde municipais, estaduais, tendo em vista que mesmo tendo sido instituído pelo Ministério da Saúde através da Portaria/GM no 569, desde o ano de 2000 o Programa de Humanização no Pré-natal e nascimento, fato é que na maioria dos hospitais e maternidades do país ainda prevalecem práticas desumanas e violências obstétricas, além da prevalência da alta taxa de realização de cesáreas desnecessárias. O que demonstra a inexistência de políticas estruturantes que garantam um atendimento obstétrico humanizado e o direito das gestante em optarem por qual tipo de parto querem parir seu filho e que esta seja respeitada e cumprida pelas maternidades e hospitais.

Nesse contexto, consideramos também que é factual a necessidade dos cursos de graduação em medicina repensem seus currículos, de modo a possibilitar aos futuros médicos uma formação mais humanizada no contexto da ginecologia-obstetrícia, respeito ao trabalho em equipe considerando os saberes e fazeres dos enfermeiros obstetras nas salas de partos, considerando o protagonismo das mulheres no ato de pariri e direito destas em optarem quanto a que profissional querem neste momento singular de suas vidas, se querem um médico ou enfermeiro obstetra.

\subsection{Categoria 3 - Parto ativo: realidade ou utopia?}

Esta categoria corroborou a anterior, considerando que os relatos dos profissionais reforçam o que afirmaram anteriormente quanto a não ser viável um pré-natal humanizado. Entretanto, apresentaram dúvidas sobre o parto ativo e expressaram seus descontentamentos com o sistema de saúde no nível atenção secundária.

WWW.AMPLLAEDITORA.COM.BR (2) 
“(...) O parto ativo está mais relacionado ao sentido obstétrico ou em relação à gestante?" (Dúvida!) - Med. 02;

“(...)O parto ativo não é quando a mulher escolhe a via do parto que ela irá querer? (Dúvida!)" - Enfa. 01;

“(...) na minha opinião o vínculo entre a atenção primária, secundária e terciária é fraco no Brasil, impossibilitando o parto ativo. Não existe a tal integralidade." - Med. 01;

“(...) na unidade básica tem sido uma realidade o atendimento onde a gestante é protagonista da sua concepção, mas, em centros hospitalares não é possível, é mais difícil" - Enfa. 02;

“(...) há uma complexidade entre o que a gestante quer e o sistema de saúde oferece no Brasil, principalmente aqui no Estado de Mato Grosso" - Med. 01; “(...) durante o pré-natal fazemos um trabalho humanizado, porém, quando chega a hora do parto a gestante não tem na maioria das vezes um bom atendimento nas maternidades e hospitais" - Enfa. 02.

É evidente nesta categoria que os profissionais demonstram certa desmotivação quanto a educar as gestante quanto ao parto ativo, por considerarem que a rede hospitalar e maternidades não aderem ao mesmo. Sendo frustrante para eles saberem que a mulher não terá o seu direito garantido quanto ao parto ativo ao chegar nestas unidades de saúde para parir. Outra evidência é que existem lacunas quanto a conhecimentos sólidos sobre parto ativo, assim como, em relação a sua viabilidade. Fato que nos leva a inferir a latente necessidade de se repensar a formação dos profissionais da saúde (médicos e enfermeiros) que poderão futuramente ser pré - natalistas, quanto ao pré-natal humanizado com enfoque no parto ativo.

Segundo Silva, Strapasson \& Fischer (2011), as práticas e os serviços de atenção ao parto são influenciados pelos papéis desempenhados pela parturiente, pelos profissionais que a assistem e pelo ambiente onde ocorre o evento. Sendo que, locais com atendimento voltado a fisiologia do nascimento, onde a atuação de enfermeiros obstetras e obstetrizes é garantida e respeitada, o parto ativo é mais preconizado, ocorrendo práticas menos intervencionistas.

Em instituições nas quais somente médicos obstetras podem realizar o parto, a parturiente na maioria das vezes é tratada apenas como mero objeto de manipulação e

WWW.AMPLLAEDITORA.COM.BR $(2)$

CONTATO@AMPLLAEDITORA.COM.BR M 
intervenção médica, sem direito a ser protagonista do ato de parir. Portanto, o comportamento das gestantes (ativa ou passiva frente a equipe), dos profissionais e o ambiente físico, influenciam diretamente no ato de parir (MARTINHO, 2005).

Mudanças comportamentais só ocorrem a partir de um processo educativo eficaz, daí a necessidade de mudanças na formação acadêmica dos profissionais da saúde quanto a humanização do parto, este é o caminho para que políticas públicas sejam efetivadas e transformações organizacionais ocorram nas instituições de saúde no que tange ao respeito ao direito das mulheres e maior atuação dos enfermeiros obstetras nas maternidades e hospitais.

\subsection{Categoria 4 - Estratégias para educação em saúde de gestantes no pré-natal}

Os pré - natalistas (médicos e enfermeiras) participantes das rodas de conversas, mencionaram algumas estratégias viabilizadoras para que se possa educar em saúde para o parto ativo, sendo unânime entre eles a implantação de grupos de gestantes nas unidades básicas de saúde e mais escuta qualificada e diálogos.

“(...)montar um grupo de gestantes e usar de tecnologias disponíveis na unidade seria importante para troca de experiências entre elas, mais diálogo e escuta. Até porque, devido à alta demanda de atendimento, muitas vezes não dá tempo de falar nas consultas de pré-natal" - Enfa 1;

“A válvula de escape para as gestantes é a orientação fornecida nas consultas de pré-natal (...)" - Med. 02;

“Orientar as pacientes, compreendendo que cada uma tem suas particularidades e que cada parto se dá conforme o fisiológico da mulher" - Enfa. 02;

“Perguntar para a gestante no início do pré-natal, quem será o seu ou sua acompanhante durante o parto e recomendar que esta pessoa participe de algumas consultas, para que saiba como agir quando iniciar o trabalho de parto. Isso, acho que é importante e humaniza o pré-natal" - Enfa. 01.

Nesta categoria é perceptível que na concepção dos profissionais participaram deste estudo, que a formação de grupos de gestantes é uma estratégia para educá-las quanto ao pré-natal e parto, considerando a escassez de tempo para um diálogo mais 
profícuo com as mulheres durante as consultas de pré-natal, em consequência da alta demanda de atendimentos.

As participantes enfermeiras em suas falas demonstraram uma visão mais humanizada quanto ao pré-natal, as quais trouxeram elementos importante do processo de humanização do cuidado a saúde, como: o diálogo e a participação de alguém que seja do afeto da gestante (familiar ou não) durante o pré-natal, para poder saber agir e dar suporte a gestante durante o processo de trabalho de parto.

Maldonado et al (1997), corrobora as enfermeiras afirmando que considerar a participação e envolvimento da família ou outra pessoa do afeto da gestante no processo gestacional é necessário e importante. A família passa a vivenciar e sentir a gravidez de forma indireta junto com a mulher grávida, tornando-se "grávida" também, além da segurança que a gestante sente ao ter ao seu lado alguém de sua confiança e afeto.

Zampieri \& Erdmann (2010), enfatizam que o cuidado humanizado no pré-natal consiste em encontros terapêuticos, educativos e interdisciplinares para maior compreensão das vivências, expressão de sentimentos e dúvidas. Além da avaliação do bem-estar materno fetal, deve haver preparação para o parto, a maternidade e paternidade, envolvendo as relações familiares, conjugais, os diálogos entre gestantes e com os profissionais.

O sucesso do pré-natal dependerá bastante da atuação do pré - natalista, o qual deve ser: Competente para orientar convenientemente a gestante reconhecendo em tempo hábil os problemas ocorridos durante a gravidez e conduzindo-os corretamente; ser humano para entender e viver com a mulher as emoções da gravidez, orientando-a e esclarecendo as dúvidas para diminuir as tensões e dedicado ao ponto de dispensar todo tempo necessário para um atendimento adequado (MARTINHO, 2005).

\section{CONSIDERAÇÕES FINAIS}

Este estudo nos possibilitou desvelar como os profissionais da atenção primária em saúde, mais especificamente, de uma unidade de saúde da família, percebem e desenvolvem as consultas de pré-natal sob o ponto de vista da humanização do cuidado. 
Ficou evidenciado que existe um certo nível de desconhecimento entre os profissionais em relação ao que seja um parto ativo na sua essência e que mesmo sem esta compreensão os mesmos referem ser difícil as mulheres conseguirem nas maternidades e hospitais este tipo de parto, consequência da formação e prática principalmente dos médicos obstetras e das políticas organizacionais das instituições de saúde.

As consultas de pré-natal nas unidades básicas de saúde ainda estão centralizadas em procedimentos técnicos que contemplam pouco ou não consideram a educação em saúde para o parto ativo como parte da conduta do pré-natalista. A maioria das consultas tem enfoque apenas biologicista e buscam atender somente o que preconiza as normas e rotinas dos manuais disponibilizados pela rede de atenção à saúde.

Os fenômenos desvelados apontam que ainda existem lacunas na formação dos profissionais pré-natalistas (médicos e enfermeiros), no que tange a realização de um pré-natal essencialmente humanizado que prepare a gestante e família para um possível parto ativo.

Consideramos a partir dos fenômenos identificados neste estudo, que se faz necessário repensar a formação acadêmica nos curso nos cursos de medicina e enfermagem, os quais devem introduzir em seus respectivos currículos teoria e prática sobre pré-natal humanizado e parto ativo, assim como, educação em saúde para o parto ativo durante as consultas de pré-natal, visando a diminuição da elevada incidência de partos iatrogênicos, violências obstétricas e realização de procedimentos cirúrgicos de cesáreas desnecessárias, consequentemente baixando a morbimortalidade materna no Brasil.

\section{AGRADECIMENTOS}

Aos colegas do Grupo de Pesquisas Multiprofissionais em Educação e Tecnologias em Saúde (PEMEDUTS) da Faculdade de Medicina da Universidade Federal de Mato Grosso (UFMT), pelas discussões e aprendizagem coletiva;

Aos profissionais de Saúde que aceitaram colaborar com esta pesquisa, participando deste estudo e socializando seus saberes e fazeres; 


\section{REFERÊNCIAS}

BALASKAS, Janet. Parto Ativo - Guia prático para o parto natural. 2a edição, São Paulo: Ground, 1993.

BARDIN, L. Análise de conteúdo. Tradução de Luís Antero Reto, Augusto Pinheiro. São Paulo: Edições 70,157.

CARVALHO, Bruno Ramalho. Humanização do atendimento à gestante. 2007. Disponível em: Acesso em: 10 dez 2017.

FRANCO, M. L. P. B. Análise do Conteúdo. 2. ed. Brasília: Liber Livro, 2007.

GIL, A. C. Como elaborar projetos de pesquisa. 5. ed. São Paulo: Atlas, 2010.

MACIEL, Marjorie Ester Dias. Educação em Saúde: Conceitos e Propósitos. Rev. Cogitare Enfermagem, 2009. Out/Dez; 14(4):773-6.

MALDONADO, M. T. Psicologia da gravidez: parto e puerpério. São Paulo: Saraiva, 1997.

MARTINHO, Neudson Johnson. Guia de conduta em Pré-natal: Desenvolvimento de tecnologia em Enfermagem à luz da CIPE - versão alfa. Fortaleza: UFC, 2005. 112 f. Dissertação (Mestrado em Enfermagem) - Programa de Pós-Graduação em Enfermagem, Faculdade de Farmácia, Odontologia e Enfermagem (FFOE), Universidade Federal do Ceará, 2005.

Sentidos e significados de educação em saúde a partir da homeopatia popular: Uma compreensão fenomenológica, 2014 165f. Tese (Doutorado) - Programa de Pós- Graduação em Educação, Universidade Federal de Mato Grosso, Cuiabá, 2014.

PINHEIRO R.; MATTOS, R. A. de (org.). Os Sentidos da Integralidade: na atenção e no cuidado à saúde. 1. Ed. Rio de Janeiro: UERJ, IMS: ABRASCO, 2001.

SAMPIERI, R. H.; COLLADO, C. F.; LUCIO, P. B. Definição da Pesquisa a ser realizada: exploratória, descritiva, co-relacional ou explicativa. In: SAMPIERI, R. H.; COLLADO, C. F.; LUCIO, P. B. Metodologia de pesquisa. $3^{\circ}$ ed. São Paulo: McGraw-Hill, 2006.

Silva, E. F., STRAPASSON, M. R, FISCHER, A. C. S. Métodos não farmacológicos de alívio da dor durante trabalho de parto e parto. Rev. Enferm. UFSM, 2011 Mai/Ago;1(2):261-271

ZAMPIERI, M. F. M., ERDMANN, A. L. Cuidado humanizado no pré-natal: um olhar para além das divergências e convergências. Rev. Bras. Saúde Matern. Infant., Recife, 10 (3): 359-367 jul. / set., 2010 


\title{
CAPÍTULO XYV
}

\section{AVALACG̈ÃO HIGIÊNICO-SANITÁRIA DE ALFACE (LACTUCA SATIIA L) COMERCIALIZADA IN NATURA EM RESTAURANTES SELF-SERVICE NO MUNICIPIO DE MARINGÁ-PR}

\author{
Polyana de Souza Costa ${ }^{1}$ \\ Augusto Curione ${ }^{2}$ \\ Sara Macente Boni ${ }^{3}$

\footnotetext{
1 Mestranda em Ciências da Saúde. Programa de Pós-Graduação em Ciências da Saúde - UEM

2 Especialista em Diagnóstico por Imagem. Hospital Israelita Albert Einstein

${ }^{3}$ Docente do Departamento de Biomedicina. Unicesumar
}

\section{RESUMO}

Atualmente, a preocupação com a saúde e a rotina acelerada vem obrigando o consumidor a optar por alimentos mais saudáveis e variados. Assim, os restaurantes se tornaram ótima opção para as principais refeições do dia. As frutas, verduras e legumes vêm ganhando muito espaço no prato da população. A alface é uma hortaliça rica em diversos tipos de vitaminas e em fibras, além de ter um baixo teor calórico. Servida in natura, necessita de grandes cuidados em sua manipulação e higienização. Este estudo objetivou fazer avaliação higiênico-sanitária de folhas de alface servidas em restaurantes self-service do município de Maringá- PR. Para isso, foram coletas 20 amostras da hortaliça em restaurantes distintos e analisadas quanto a presença de coliformes totais e termotolerantes, Staphylococcus aureus e Salmonella spp. Dezenove amostras apresentaram-se positivas para coliformes totais e termotolerantes, apresentando colônias características de E.coli, 10 para Staphylococcus aureus e uma amostra apresentou resultado positivo para Salmonella spp. Os resultados indicam que os estabelecimentos analisados necessitam de medidas higiênico-sanitária mais rigorosas para o manuseio e higienização destes alimentos.

Palavras-chave: Doenças Transmitidas por Alimentos. Inspeção de Alimentos. Alface. Restaurante. Contaminação de Alimentos. 


\section{INTRODUÇÃO}

A rotina acelerada e cansativa da atualidade, a grande concentração de pessoas nos centros urbanos, a crescente participação da mulher no mercado de trabalho e a distância existente entre a moradia e o trabalho, acabam interferindo muito na alimentação da população, levando ao aumento de refeições feitas fora de casa. Associado a este cenário, a busca ativa de melhores hábitos de saúde faz com que as pessoas optem por restaurantes que propiciam uma alimentação mais saudável e balanceada (AKUTSU et al., 2005; BALTAZAR et al., 2006).

Como os alimentos servidos em restaurantes já se encontram prontos para o consumo, acredita-se em sua qualidade higiênico-sanitária e que não oferecerão riscos à saúde de seus consumidores. Entretanto, alguns estabelecimentos acabam por não seguir rigorosamente as boas práticas de fabricação estabelecidas pela legislação brasileira, seja pela grande demanda ou pela falta de treinamento do manipulador dos alimentos. Além das contaminações poderem ocorrer na hora do preparo e manuseio dos alimentos, esta também pode advir da exposição em que os alimentos sofrem, podendo ser a causa de Doenças Transmitidas por Alimentos (DTA's) (BALTAZAR et al., 2006; SILVA JR., 2014).

Os alimentos têm várias funções no organismo, dentre elas a manutenção, prevenção e recuperação da saúde. Por isso, a escolha da dieta deve ser cuidadosa, optando por alimentos saudáveis, variados, agradáveis ao paladar e, principalmente, seguros de acordo com as características higiênico-sanitárias regulamentadas (AMSON, G. V.; HARACEMIV, S. M. C.; MASSON, M. L, 2006; MARTINS, 2011).

A inclusão de frutas, verduras e legumes no cardápio diário da população está cada vez maior (CALIL et al., 2013). A alface (Lactuca sativa L.), é uma das hortaliças mais consumidas em todo o território brasileiro. Originária da Europa e Ásia, é fonte de diversas vitaminas, fibras e sais minerais, além de ter baixíssimo teor calórico. Porém, sua ingestão na forma in natura pode favorecer a transmissão das DTA's (BRASIL, 2011; CALIL et al., 2013). Entre 2000 e 2011, estas hortaliças foram responsáveis por 12,5\% dos surtos alimentares ocorridos no Brasil (BRASIL, 2011).

As DTA's constituem um dos maiores problemas de saúde pública da contemporaneidade, causando grandes perdas econômico e sociais, acarretando em 
incapacidade laboral, gastos com tratamento e estudos epidemiológicos, prejuízos na área de turismo e no comercio de alimentos. Esta enfermidade abrange sintomas como náuseas, vômitos, dores de cabeça, prostrações, diarreias, cólicas abdominais, variando de incômodos leves e passageiros até consequências graves e letais dependendo da reação do organismo, da bactéria causadora e vários outros fatores (NYACHUBA, 2010; WELKER et al., 2010; FLORES \& MELO, 2015).

A incidência destas doenças está em constante aumento (MARINHO, 2015). Dentre os principais patógenos relacionados a estas enfermidades estão Salmonella spp, Escherichia coli e Staphylococcus aureus (SANTOS et al., 2015). Staphylococus aureus pertence ao grupo das bactérias Gram positivas, que possuem disposição em cachos. Sua parede celular possui cápsulas que a protegem inibindo a quimiotaxia e fagocitose, além de ser rica em peptídeoglicano proporcionando maior rigidez a parede desse micro-organismo (ALMEIDA et al., 2016). Esta espécie bacteriana é produtora de enterotoxinas, encontrado na microbiota dos seres humanos em locais como a pele, boca e orofaringe e sua presença em alimentos indica contaminação advinda de seus manipuladores ou até dos próprios consumidores ao irem se servir (SANTOS et al., 2015; FLORES \& MELO, 2015).

Salmonella é um bacilo Gram negativo, anaeróbio facultativo, capaz de produzir ácido e gás utilizando carboidratos, além de ser catalase positiva e oxidase negativa e poder crescer utilizando citrato como única fonte energética. (HENTZ \& SANTIN; 2010). Esta destaca-se com grande importância clínica, pois apresenta alta endemia e mortalidade relevante, além de ser de difícil controle por existir em uma grande variedade de alimentos. Escherichia coli, da família das Enterobactérias, apresenta caráter Gram negativo na forma de bastonete, encontrado principalmente no intestino de animais de sangue quente. O seu encontro em alimentos está diretamente relacionado com a falta dos processos higiênico-sanitárias, principalmente em seu processamento (LIMA \& SANTOS; 2016).

A contaminação da alface por bactérias pode ocorrer desde o início de sua produção, onde, por muitas vezes, é utilizado adubo orgânico e água sem tratamento para o cultivo, contribuindo para a contaminação com bactérias e parasitos. 0 transporte demonstra ser outro fator de contaminação dessas hortaliças por ser feito em engradados abertos. Há, ainda, as condições higiênico-sanitárias errôneas às quais

WWW.AMPLLAEDITORA.COM.BR(2) 
essas hortaliças são expostas em seu manuseio no estabelecimento onde será comercializada para o consumo (QUEIROZ et al 2016). Diante disso, o presente estudo buscou avaliar a qualidade microbiológica da alface (Lactuca sativa L.) servida nos restaurantes self-service no município de Maringá - PR.

As ilustrações deverão estar assinaladas no texto, com identificação na parte superior, precedida da palavra Figura, centralizada, seguida de seu número de ordem de ocorrência no texto, em algarismos arábicos, do respectivo título. Na parte inferior, deve ser indicada a fonte, legenda, notas e outras informações necessárias.

\section{METODOLOGIA}

Foram coletadas amostras de alface de 20 restaurantes do tipo self-service do município de Maringá-PR. A coleta se deu no balcão de exposição do alimento, como consumidores que optaram por levar o alimento para consumir em casa. Os restaurantes foram escolhidos por estarem inseridos em regiões universitárias, onde há grande fluxo de consumidores. As amostras foram acondicionadas em embalagens de isopor, sem contato manual, e transportadas em caixa térmica contendo gelo ao Laboratório de Microbiologia da Unicesumar, para pesquisa de coliformes totais, coliformes termotolerantes, Salmonella ssp. e Straphylococcus aureus. As análises ocorreram em até 2 horas após a coleta.

No laboratório, as amostras foram homogeneizadas assepticamente e uma unidade analítica de $25 \mathrm{~g}$ da amostra transferida para $225 \mathrm{ml}$ de água peptonada esterilizada (0,1\%) e homogeneizadas por 2 minutos. A partir desta solução mãe, foram preparadas diluições até $10^{-3}$ e posteriormente incubadas por 24 horas para enriquecimento (PINHEIRO et al., 2005).

As análises microbiológicas foram realizadas segundo metodologias descritas em American Public Health Association (APHA, 2001). Para a pesquisa de coliformes totais e termotolerantes foi utilizado à técnica do Número Mais Provável (NMP), usando Caldo Lauril Sulfato de Triptose (LST), Caldo Lactosado Verde Brilhante (VB) e Caldo Escherichia coli (EC). A prova presuntiva para análise de coliformes totais e termotolerantes baseouse na inoculação das amostras em LST. Os tubos foram incubados a 35-37ํㅡ por 24 a 48

WWW.AMPLLAEDITORA.COM.BR (2) 
horas para verificar o crescimento e produção de gás. Para a confirmação de coliformes totais, as amostras nos tubos com caldo Lauril positivos foram transferidas para tubos com Caldo VB sendo incubado a $35-37^{\circ} \mathrm{C}$ por 24 horas para verificação do crescimento e produção de gás. Para a deteç̧ão de coliformes termotolerantes, uma alíquota de cada tubo de LST positivo foi transferida para os tubos de Caldo EC e incubadas a 4545,5C por 24 horas para análise de crescimento microbiano e produção de gás.

A contagem de Staphylococcus aureus (UFC/g) foi realizada por espalhamento em superfície em meio de ágar Manitol e incubado a $35-37^{\circ} \mathrm{C}$, por $24-48$ horas. A confirmação das colônias foi efetuada pelos seguintes ensaios: coloração de Gram, teste de catalase e teste de coagulase.

A pesquisa de Salmonella spp em $25 \mathrm{~g}$ de amostras foi realizada com préenriquecimento, em Água Peptonada Tamponada (APT), com incubação a $35^{\circ} \mathrm{C}$, por $24 \mathrm{~h}$, seguida de enriquecimento seletivo, em caldo Selenito Cistina, Caldo Tetrationado e caldo Rappaport incubados, respectivamente, a $35^{\circ} \mathrm{C}$ e $42^{\circ} \mathrm{C}$, por $24 \mathrm{~h}$. O isolamento de Salmonella $s p$ foi realizado em ágar Xilose Lisina Desoxicolato (XLD) e ágar Hektoen incubados a $35^{\circ} \mathrm{C}$, por $24-48 \mathrm{~h}$. A partir das colônias suspeitas que cresceram nos meios seletivos, foi realizada a identificação de Salmonella spp, através da metodologia do kit de enterobactérias (Newprov ${ }^{\circledR}$ ) conforme orientações do fabricante.

\section{RESULTADOS E DISCUSSÃO}

Das 20 amostras de alface analisadas, 1 (5\%) estava contaminada com Salmonella spp. e 5 (25\%) apresentavam coliformes termotolerantes em valores superiores a $10^{3} \mathrm{NMP} / \mathrm{g}$, com características de colônia de $E$. coli. Estas contaminações indicam que $30 \%(6 / 20)$ do total das amostras estavam impróprias para o consumo humano, segundo a RDC N¹2 de 02 janeiro de 2001 (Brasil, 2001). Esta resolução estabelece que hortaliças, legumes e similares in natura prontos para o consumo devem conter no máximo $10^{2} \mathrm{NMP} / g$ de coliformes termotolerantes e ausência de Salmonella spp. em 25 gramas do alimento analisado (BRASIL, 2001).

Os resultados aqui encontrados são inferiores aos dados apresentados por Pereira \& Hoffmann (2011), que demonstraram positividade para coliformes termotolerantes em $80 \%$ das amostras de verduras minimamente processadas 
comercializadas na cidade de São José do Rio Preto - SP. Essa diferença de valores pode ser atribuída ao baixo número de amostras avaliadas em nosso estudo, ou devido ao fato do desrespeito às normas de manipulação de alimentos serem bem mais severas na cidade de São José do Rio Preto - SP. Estudos apresentam resultados próximos aos obtidos pela presente pesquisa, no qual parte das amostras também encontravam-se inaptas para o consumo humano, com $30 \%$ e 15,3\% respectivamente, de positividade para coliformes termotolerantes (ARAÚJO et. al., 2014; MENDES, COELHO E AZEREDO, 2011).

As amostras da hortaliça analisada apresentaram a alta incidência de coliformes totais (70\%), sendo que $60 \%(12 / 20)$ apresentaram concentração superior a $1,1 \times 10^{3}$ NMP/g. Foi observada a presença de Staphylococcus aureus em 10 (50\%) amostras analisadas. Embora não exista legislação específica para estas bactérias na alface, demostra-se uma considerável contaminação microbiana que pode ser justificada pela manipulação e/ou acondicionamento inadequados destes alimentos, indicando deficiência na qualidade higiênico-sanitária das folhas servidas nesses restaurantes.

Considerando os resultados obtidos, os estabelecimentos que comercializam a alface para ser consumido de imediato e in natura em Maringá - PR apresentam déficit de padrões higiênico-sanitário. Deve-se ter cuidado maior durante a preparação e manuseio do alimento, que pode estar passando por procedimento de lavagem incorreta das folhas, condições inadequadas dos utensílios utilizados em sua higienização, ou, ainda, sendo contaminados através do manipulador de alimentos e pelos clientes que ali frequentam.

Dos surtos relacionados com a alimentação, $88 \%$ tem comprovada origem em restaurantes (MARMENTINI, R. P.; RONQUI, L.; ALVARENGA, V. A, 2015). Portanto, fazse necessário a tomada de medidas para a efetiva redução de contaminação dos alimentos servidos fora do domicílio. Estas ações devem envolver o consumidor, com adoção de práticas seguras na alimentação (MAGNONI et al., 2016) e o estabelecimento comercial, com os devidos cuidados no manuseio das folhas de alface. Além disso, a ação de fiscalização dos locais de produção, transporte e comercialização dos alimentos, objetivando a promoção das boas práticas de fabricação, deve ser efetiva por parte do governo (SAÚDE, 2017). 
A falta de coerência na utilização dos Equipamentos de Proteção individual (EPI's), principalmente por reutilização de material descartável ou falta de treinamento para sua correta utilização, e a incorreta higienização das mãos dos manipuladores de alimentos, são considerados fatores de risco para um possível surto alimentar (MEDEIROS et al., 2015). Para minimizar estas falhas, a Agência Nacional de Vigilância Sanitária (ANVISA) lançou, em 2004, a Cartilha sobre Boas Práticas para Serviços de Alimentação que devem ser seguidas por todos os estabelecimentos alimentícios. Treinamentos contínuos, a fim de manter o funcionário atento aos riscos de contaminação dos insumos e a constante tentativa de evitá-la, tem se mostrado bastante eficaz no controle microbiológico dos alimentos (FORTES et al., 2018).

\section{CONSIDERAÇÕES FINAIS}

Conclui-se que a alface servida em parte dos restaurantes do tipo self-service de Maringá-PR encontra-se em desacordo com o que preconiza a legislação brasileira sobre contaminação mínima permitida em alimentos, o que os torna impróprios para consumo. As altas taxas de coliformes totais e termotolerantes encontradas, além da presença de Salmonella spp e S. aureus em algumas amostras, tornam este alimento um risco à saúde de seus consumidores. Desta forma, se torna necessário que estes estabelecimentos adotem medidas para redução dessa contaminação, bem como realizar treinamentos aos manipuladores dos alimentos a fim de evitar ao máximo a contaminação das hortaliças e dos demais alimentos.

\section{REFERÊNCIAS}

AKUTSU, R. C.; BOtelHo, R. A.; CAMARGO, E. B.; SÁVIO, K. E. O.; ARAÚJO, W. C. Adequação das boas práticas de fabricação em serviços de alimentação. Revista Nutrição, Campinas, v.18, n.3, p.419-427, 2005. Disponível em: $\quad$ http://www.scielo.br/scielo.php?script=sci_arttext\&pid=S141552732005000300013\&Ing=en\&nrm=iso. Acesso em: 14 de outubro de 2018

ALMEIDA, M.; MENDONÇA, R.; FREITAS, M.; VANDESMET, L. Staphylococcus aureus. Mostra Científica em Biomedicina, v. 1, n. 01, 2016.

AMSON, G. V.; HARACEMIV, S. M. C.; MASSON, M. L.; Levantamentos de dados epidemiológicos relativos à ocorrências/ Surtos de doenças transmitidas por alimentos (DTAs) no estado do Paraná-Brasil, no período de 1978 a 2000. 
Ciência e Agrotecnologia, Lavras, v.30, n.6, p.1139-1145, nov/dez, 2006. Disponível em: http://www.scielo.br/pdf/\%0D/cagro/v30n6/a16v30n6.pdf Acesso em: 11 de outubro de 2018.

ANVISA. Cartilha de Boas Práticas para serviços de alimentação, 2004. Disponível em: http://portal.anvisa.gov.br/documents/33916/389979/Cartilha+Boas+Pr\%C3\% A1ticas+para+Servi\%C3\%A7os+de+Alimenta\%C3\%A7\%C3\%A3o/d8671f20-2dfc4071-b516-d59598701afo Acesso em: 13 de outubro de 2018.

APHA. Compendium of methods for microbiological examinaton of foods. 4. ed. Washingyton, 2001. p.515-516.

ARAÚJO, K. S. S.; CARVALHO, K. A.; AZEVEDO, L. S.; SANTOS, R. M.; NASCIMENTO, I. O.; ARAÚJO, M. M. Avaliação do Armazenamento de Produtos Lácteos Comercializados em Supermercados de Imperatriz - MA. Revista Agroecossistemas, $\quad$ v. 6, n. 1, p. 97-102, 2014. DOI: https://doi.org/10.18542/ragros.v6i1.1848

BALTAZAR, C.; SHIMOZAKO, H. J.; AMAKU, M.; PINHEIRO, S. R.; PERONDI, A. M. T. Avaliação higiênico sanitária de estabelecimentos da rede fast food no município de São Paulo. Revista Higiene Alimentos. v.20, p.46- 51, 2006.

BRASIL, Resolução RDC n.12, de 02 de janeiro de 2001 da Agência Nacional de Vigilância sanitária. Aprova o regulamento técnico sobre padrões microbiológicos para alimentos. Poder Executivo, 10 de janeiro de 2001. Seção 1, pg. 45-53.

BRASIL. Ministério da Saúde. Portaria n².914, de 12 de dezembro 2011. Dispõe sobre os procedimentos de controle e de vigilância da qualidade da água para consumo humano e seu padrão de potabilidade. 2011. Disponível em: http://site.sabesp.com.br/site/uploads/file/asabesp_doctos/PortariaMS291412 122011.pdf Acesso em: 10 de outubro de 2018.

CALIL, E. M. B.; FERREIRA, F. L. A.; BRAZÃO, C. S.; SOVENHI, C. C. Qualidade microbiológica de saladas oferecidas em restaurantes tipo self-service. Atas de Saúde Ambiental - ASA, São Paulo, v.1, n.1, p.36-42, Set/Dez. 2013.

FLORES, A. M. P. C.; MELO, C. B. Principais bactérias causadoras de doenças de origem alimentar. Revista Brasileira de Medicina Veterinária, v.37, n.1, p.65-72, 2015.

FORTES, M. S.; FRIGO, M.; BELLÉ, T. H.; STARIKOFF, K. R.; FATEL, E. C. S. Boas práticas de manipulação de alimentos em municípios paranaenses. Revista Ciência em Extensão. v.14, n.1, p.166-176, 2018.

GENTA, T.; MAURÍCIO, A.; MATIOLI, G. Avaliação das boas práticas através de check-list aplicado em restaurantes self-service da região central de Maringá, Estado do Paraná. Acta Science Health, v. 27, n. 2, p. 151-156, 2005. 
HENTZ, S.; SANTIN, N. Avaliação da atividade antimicrobiana do óleo essencial de alecrim (Rosmarinus officinalis I.) contra Salmonella sp. Evidência, v. 7, n. 2, p. 93-100, 2007.

LIMA, S.; SANTOS, C. Educação e saúde pública: Determinação de cloro e Escherichia coli, na água utilizada para consumo no IFPE, Campus Afogados da Ingazeira. Revista Ouricuri, v.6, n.2, p.029-041, 2016.

MAGNONI, D.; TARDIOLI, M.; ZAGATO, M.; MIYAGI, M.; TAKAYAMA, P.; MOURA, S.; KOVACS, C.; CAMELO, V.; BARBOSA, M.; CUKIER, C. Segurança alimentar e informação nutricional podem reduzir a intoxicação alimentar na alimentação fora do lar. Revista Brasileira de Nutrição Clínica. v.31, n.2, p.91, 2016.

MARINHO, G. A. Perfil Epidemiológico das Doenças Transmitidas por Alimentos e Seus Fatores Causais na Região da Zona da Mata Sul de Pernambuco. UNOPAR Científica: Ciências biológicas e da saúde. v.17, n.4, pg. 238, 2015.

MARMENTINI, R. P.; RONQUI, L.; ALVARENGA, V. A. A importância das boas práticas de manipulação para os estabelecimentos que manipulam alimentos. Revista Facimed, v.40, n.8, p. 263, 2015.

MARTINS, L. A. Formação profissional de cozinheiros e percepção de risco em segurança nos alimentos: um estudo exploratório em serviços de alimentação localizada no estado do Rio de Janeiro. Dissertação (Mestrado de educação profissional em saúde) Escola Politécnica de saúde Joaquim Venâncio, Fundação Oswaldo Cruz, Rio de Janeiro, 2011.

MEDEIROS, M. G.; CARVAHO, L., R.; FRANCO, R., M. Percepção sobre a higiene dos manipuladores de alimentos e perfil microbiológico em restaurante universitário. Revista Ciência \& Saúde Coletiva, v.22, n.2, pg.383-392, 2017. DOI: 10.1590/1413-81232017222.17282015

MENDES, R. A.; COELHO, A. I. M.; AZEREDO, R. M. C. Contaminação por Bacillus cereus em superfícies de equipamentos e utensílios em unidade de alimentação e nutrição. Ciência \& Saúde Coletiva, v.16, n.9, p.3933-3938, 2011.

NYACHUBA, D. G. Foodborne illness: is it on the rise? Nutrition Reviews. v.68, n.5, p.257-269. 2010. DOI:10.1111/j.1753-4887.2010.00286.x

PEREIRA, A. P. M.; HOFFMANN F. L. Qualidade microbiológica de vegetais minimamente processados comercializados na cidade de São José do Rio Preto - SP. Revista Higiene Alimentar. v.25, n.196, p.60- 63, 2011.

PINHEIRO, NMS; FIGUEIREDO, EAT; FIGUEIREDO, RW; MAIA, GA; SOUZA, PHM. Avaliação da qualidade microbiológica de frutos minimamente processados 
comercializados em supermercados de Fortaleza. Revista Brasileira Fruticultura, v. 27, n. 1, p. 153-156, 2005.

QUEIROZ, J. J. F.; SANTANA, R. F.; SILVA, A. F. V. P. Realidade bacteriológica de hortaliças: um risco à saúde, 2016. Disponível em: http://repositorio.asces.edu.br/bitstream/123456789/511/1/TCC\%20Biomedici na\%20Jeyvson\%20e\%20Ruanna\%20Biomedicina\%202016.2.pdf Acesso em: 09 de outubro de 2018.

SANTOS, T. B. A.; SILVA, N.; JUNQUEIRA, V. C. A.; PEREIRA, J. L. Microrganismos indicadores em frutas e hortaliças minimamente processadas. Braz J. Food Technol. v.13, n.2, p.141. 2015. DOI: 10.4260/BJFT2010130200019

SAÚDE. Atribuições da vigilância sanitária de alimentos, 2017. Disponível em: http://www.saude.curitiba.pr.gov.br/vigilancia/sanitaria/separadoralimentos/a tribuicoes-da-vigilancia-sanitaria-de-alimentos.html. Acesso em: 08 de outubro de 2018.

SILVA JÚNIOR, E. A. Manual de controle higiênico sanitário em serviços de alimentação. ed.7. São Paulo: Varela, 2014.

WELKER C. A. D.; BOTH, J. M. C.; LONGARAY, S. M.; HAAS, S.; SOEIRO, M. L. T.; RAMOS, R. C. Análise microbiológica dos alimentos envolvidos em surtos de doenças transmitidas por alimentos (DTA) ocorridos no estado do Rio Grande do Sul, Brasil. Revista Brasileira de Biociência., v.8, n.1, p.44-48, 2010. 


\title{
CAPÍTULO YYKVI
}

\section{ATUAÇÃO DO ENFERMEIRO FRENTE AO CÂNCER DA MAMA MASCULINA NA ATENÇÃO BÁSICA}

\author{
Loraine Silva Ferroni ${ }^{1}$ \\ Fabíola Vieira Cunha ${ }^{2}$ \\ Rosana Maria Faria Vador ${ }^{3}$ \\ Maria Cristina Martins Alvarenga 4 \\ Andreara de Almeida e Silva ${ }^{5}$ \\ ${ }^{1}$ Graduanda do curso de Enfermagem. Instituto Taubaté de Ensino Superior - ITES \\ ${ }^{2}$ Coordenadora e Professora Titular do Departamento de Enfermagem. Instituto Taubaté de Ensino Superior - ITES \\ ${ }^{3}$ Professora Adjunta do Departamento de Enfermagem. Instituto Taubaté de Ensino Superior - ITES \\ ${ }^{4}$ Enfermeira Mestre e Coordenadora do Programa de Imunização do Município de São José dos Campos - SP \\ ${ }^{5}$ Professora Adjunta do Departamento de Enfermagem. Instituto Taubaté de Ensino Superior - ITES
}

\section{RESUMO}

Introdução: O câncer de mama é uma neoplasia predominante no sexo feminino, porém pouco é abordado pelos serviços preventivos de saúde e escasso nas literaturas quanto ao aparecimento deste tipo de câncer na população masculina. Logo, reforça-se a importância de realizar investigações acerca dessa temática, sobretudo com enfoque no nível primário, por se constituir porta de entrada para os serviços de saúde. Neste contexto o enfermeiro, tem papel fundamental no desenvolvimento de ações de promoção e prevenção de agravos quanto ao câncer da mama masculina. Objetivo: Identificar as ações à serem realizadas pelos enfermeiros frente ao câncer da mama masculina na atenção básica. Metodologia: Revisão integrativa da literatura. Realizouse uma busca e foram selecionados 20 artigos publicados em português e espanhol, no período de 2015 a 2020, nas bases de dados LILACS, SciELO, CAPES. Resultados: As principais dificuldades identificadas quanto à atuação do enfermeiro na atenção básica foram o desconhecimento do câncer da mama masculina pelo homem, falta de recursos (políticas públicas, protocolos), resistência do homem em frequentar serviços de saúde, desconhecimento do autoexame das mamas pelo homem, déficit de estudos e literaturas científicas, construções socioculturais masculinas, falta de reconhecimento da mama como parte do corpo masculino e desconhecimento do câncer da mama masculina pelos enfermeiros. Portanto, foi proposto um fluxograma que busca auxiliar o atendimento do homem pelo enfermeiro da atenção básica quanto à prevenção e diagnóstico precoce do câncer da mama masculina. Conclusão: No que se refere ao enfermeiro, verificou-se que o papel desse profissional na atenção básica à saúde precisa ser ampliado. A definição de suas ações na atenção primária deve ser regida pela política vigente. Para tal foi proposto um modelo fluxograma visando apoiar o enfermeiro no plano de assistência aos usuários com câncer da mama masculina.

Palavras-chave: Enfermeiro. Neoplasias da Mama Masculina. Atenção Primária à Saúde. 


\section{INTRODUÇÃO}

Câncer é o resultado da multiplicação descontrolada de células de um tecido ou órgão, que podem vir a invadir locais vizinhos, por meio da circulação sanguínea ou do sistema linfático. O câncer de mama (CM) é uma neoplasia predominante no sexo feminino, porém pouco é abordado pelos serviços de saúde e escasso nas literaturas quanto ao aparecimento deste tipo de câncer na população masculina. (Costa, Adorno, Araújo, Saback, Gomes, 2019; Guimarães, 2015).

Apesar de raro, o câncer da mama masculina (CMM) tem aumentado em todo mundo, correspondendo a 0,5 - 1\% de todos os canceres de mama. No ano de 2017, causou 203 mortes na população masculina, além de que quando comparados com outras neoplasias no sexo masculino, o de mama não tem valores tão expressivos, entretanto, com o crescimento do número de casos pela má qualidade de vida e pela dificuldade de se efetuar diagnóstico precoce, há necessidade de ações voltadas para seu controle. (Azevedo, Monteiro, 2018; Guimarães N, 2015; INCA, 2020).

Através de sua prevenção, seja pelo autoexame, prática de hábitos saudáveis, comparecimento aos serviços de saúde para detecção precoce é possibilitado ao portador desta neoplasia, um tratamento efetivo e com menor chance de mortalidade. Para isto, o homem deve aprender a reconhecer a mama como parte de si e ser implementadas diversas ações na atenção primária à saúde quanto à sua prevenção, para que o identifique nos estágios iniciais e dê início ao tratamento o mais precocemente possível. (Sousa, 2020).

Entretanto, a inserção do homem na atenção básica $(A B)$ que é a porta de entrada preferencial do Sistema Único de Saúde (SUS) é árdua e associada a impasses, que variam nos âmbitos sociais, culturais, ocupacionais, institucionais, o que leva a mantê-los distante das medidas preventivas e acostumados a buscar serviços de saúde somente quando adoecem, além de impossibilitar atingir os objetivos da Política Nacional de Atenção Integral à Saúde do Homem que visam o aumento da expectativa de vida e a redução dos índices de morbimortalidade por causas preveníveis e evitáveis na população em questão. (Azevedo, Monteiro, 2018).

Tendo em vista diversos empecilhos, a atuação do enfermeiro acerca da prevenção e diagnóstico precoce do câncer da mama masculina fica dificultada e 
custosa, visto que neste contexto, este profissional tem papel fundamental no desenvolvimento das ações de promoção e prevenção de agravos do câncer da mama masculina. (Dantas, Pereira, Alencar, Sousa, Farias, 2015).

Pela falta de atenção desta neoplasia no homem, foi levantado o seguinte questionamento: Por que o câncer da mama masculina na atenção básica é tão pouco abordado pelos enfermeiros? Assim, o presente estudo trata-se de uma revisão integrativa da literatura com o objetivo de identificar as ações à serem realizadas pelos enfermeiros frente ao câncer da mama masculina na atenção básica. Realizou-se uma busca nas bases de dados LILACS, SciELO e Portal CAPES de artigos publicados no período de 2015 a 2020 e foram selecionados 20 artigos em português e espanhol.

Portanto, através deste estudo objetivou-se levantar as principais dificuldades da atuação do enfermeiro da atenção básica frente à prevenção e diagnóstico precoce do câncer da mama masculina e propor estratégias direcionadas aos mesmos para correta e efetiva abordagem do homem, visando promoção e a educação a respeito desta neoplasia, minimizando a falta de informação e conscientização por parte dos homens, além de estimular o seu autocuidado.

\section{REVISÃO BIBLIOGRÁFICA}

\subsection{Câncer da mama masculina}

Quanto ao câncer, podemos defini-lo como um conjunto patologias que apresentam como principal característica o crescimento desordenado das células do corpo humano. Estas células acabam multiplicando-se de uma maneira muito veloz, agressiva e incontrolável, acarretando o desenvolvimento de tumores, que muitas vezes, acabam se espalhando do seu ponto inicial de formação para outras regiões do corpo. Logo, quando este processo de multiplicação desordenado ocorre nas mamas, gera-se o câncer de mama. Sendo apontado pelo INSTITUTO NACIONAL DE CÂNCER (INCA), a neoplasia que mais causou morte em mulheres no ano de 2017 , totalizando 16.724 óbitos. (INSTITUTO NACIONAL DE CÂNCER- INCA, 2019).

Entretanto, o câncer de mama também pode acometer o sexo masculino, mesmo que raramente e representando apenas $1 \%$ do total de casos desta neoplasia e $0,17 \%$ de todos os carcinomas no sexo masculino, visto que a mama é encontrada em

WWW.AMPLLAEDITORA.COM.BR (2) 
ambos os sexos, sendo semelhantes, mas somente nas mulheres que elas se desenvolvem e apresentam funcionalidade. No homem, a mama se apresenta muito rudimentar, em menores dimensões, constituída de tecido subcutâneo, tecido gorduroso, ductos mamários, mamilo e aréola. Sendo que atrás do mamilo, podemos encontrar uma pequena porção de tecido glandular. (INCA, 2019; Rodrigues, Bezerra, Passos, 2018; Ramos, Rodrigues, Silva, Balbino, Souza, Silvino, 2017).

$\mathrm{O} \mathrm{CM}$, revela-se por meio de uma massa indolor e firme, tendo como sinal primário, na maioria dos casos, o nódulo mamário, além da retração ou inversão mamilar, o espessamente da pele, a formação de crostas e a ulceração, já a secreção mamilar pode ser encontrada nos aspectos serosa e/ou serosanguinolenta. (Sousa, Martins, Freitas, Guimarães, 2017).

A causa do CMM ainda não foi definida, porém uma série de fatores como os extrínsecos, comportamentais e genéticos elevam o risco de desenvolvimento. No que tange aos fatores de riscos desta patologia, podemos citar a idade, pois a incidência de CMM está intimamente ligada ao avanço da idade, tendo a maior incidência na década dos 60 anos, a etnia, visto que os negros são os mais afetados. Além do histórico familiar que contribui consideravelmente para o desenvolvimento da doença, pois os indivíduos que apresentam casos na família possuem um risco de aquisição de 2 a 3 vezes mais do que os que não possuem histórico. Os distúrbios hormonais, como o aumento do estrogênio, propiciam a proliferação de células malignas no tecido mamário. (Salomon, Mendonça, Pasqualette, Pereira, Sondermman, 2015; Araujo, Julião, Leite, Jabbar, Neto, Freitas, 2019).

Para os aspectos epidemiológicos voltados ao CMM de uma forma geral, a relação de incidência da neoplasia entre os ambos os sexos, permite estimar que a cada 1000 novos casos de CM apenas 1 ocorrerá em homens. A Organização Mundial Da Saúde (OMS), por meio da Agência Internacional para Pesquisa do Câncer (International Agency for Research on Cancer - IARC) estimou para o CMM em 2012, uma incidência global estimada em cerca de 8 mil casos por ano. (Barros, 2016).

No continente africano, nos deparamos com uma alta incidência de CMM, sendo fundamentada pelos africanos manifestarem um elevado número de doenças hepáticas endêmicas, que na maioria da vezes, acarretam à insuficiência hepática, elevando o nível de estrogênio na corrente sanguínea devido à alteração na metabolização hormonal,

WWW.AMPLLAEDITORA.COM.BR (2) 
com números de casos que variam de 5 a 15 por 100 mil habitantes. Na Europa e EUA a quantidade de casos é considerada baixa, tendo em média, um caso para cada 100 mil habitantes, enquanto no Japão, os números de casos se apresentam ainda mais baixo, 0,5 para cada 100 mil habitantes. (Barros, 2016).

No Brasil, enquanto aos aspectos epidemiológicos do CMM, os estudos mostram-se escassos, associado com a inexistência de estimativas pelo INCA, pois o máximo de informação que obtemos ao consulta-lo sobre CMM é que trata-se de um câncer raro, representando apenas $1 \%$ do total de casos da doença. Entretanto, o Sistema De Informação De Câncer (SISCAN) permite visualizar o número de casos de CMM em algumas cidades das 5 regiões do nosso país. (Barros, 2016).

Tabela 2- Número de casos de câncer da mama masculina de 2014 a 2018 em São Paulo/Sudeste consultados em 16/03/2020

\begin{tabular}{|c|c|}
\hline \multicolumn{2}{|c|}{ SÃO PAULO/SUDESTE } \\
\hline ANO & NÚMERO DE CASOS \\
\hline 2014 & 14 \\
\hline 2015 & 14 \\
\hline 2016 & 12 \\
\hline 2017 & 15 \\
\hline 2018 & \\
\hline
\end{tabular}

Fonte: SISCAN (2020)

Tabela 3- Número de casos de câncer da mama masculina de 2014 a 2018 em Rio Grande Do Sul/Sul consultados em 16/03/2020

\begin{tabular}{|c|c|}
\hline \multicolumn{2}{|c|}{ RIO GRANDE DO SUL/SUL } \\
\hline ANO & NÚMERO DE CASOS \\
\hline 2014 & 5 \\
\hline 2015 & 1 \\
\hline 2016 & 1 \\
\hline 2017 & 0 \\
\hline 2018 & \\
\hline
\end{tabular}

Fonte: SISCAN (2020) 
Tabela 4- Número de casos de câncer da mama masculina de 2014 a 2018 em Mato Grosso/Centro-

Oeste consultados em 16/03/2020

\begin{tabular}{|c|c|}
\hline \multicolumn{2}{|c|}{ MATO GROSSO/CENTRO-OESTE } \\
\hline ANO & NÚMERO DE CASOS \\
\hline 2014 & 1 \\
\hline 2015 & 2 \\
\hline 2016 & 1 \\
\hline 2017 & 1 \\
\hline 2018 & \\
\hline
\end{tabular}

Fonte: SISCAN (2020)

Tabela 4- Número de casos de câncer da mama masculina de 2014 a 2018 em Bahia/Nordeste consultados em 16/03/2020

\begin{tabular}{|c|c|}
\hline \multicolumn{2}{|c|}{ BAHIA/NORDESTE } \\
\hline ANO & NÚMERO DE CASOS \\
\hline 2014 & 5 \\
\hline 2015 & 0 \\
\hline 2016 & 10 \\
\hline 2017 & 16 \\
\hline 2018 & \\
\hline
\end{tabular}

Fonte: SISCAN (2020)

Tabela 5- Número de casos de câncer da mama masculina de 2014 a 2018 em Amazonas/Norte consultados em 16/03/2020

\begin{tabular}{|c|c|}
\hline \multicolumn{2}{|c|}{ AMAZONAS/NORTE } \\
\hline ANO & NÚMERO DE CASOS \\
\hline 2014 & 0 \\
\hline 2015 & 0 \\
\hline 2016 & 0 \\
\hline 2017 & 1 \\
\hline 2018 & 0 \\
\hline
\end{tabular}

Fonte: SISCAN (2020)

Enquanto ao diagnóstico do CMM, ele ocorre da mesma maneira que o câncer da mama feminina (CMF). Consistindo em um conjunto de análise da história clínica, exames de imagem e estudo anatomopatológico. A mamografia é um exame muito 
utilizado para diagnosticar o $\mathrm{CM}$ em mulheres, visto que quando aplicada ao CMM, apresenta sensibilidade e especificidade de, respectivamente, 92\% e 90\%, porém, para os homens é escusável, uma vez que há existência de indícios que apontam a eficiência apenas da suspeita clínica a partir do exame físico aliado a confirmação histológica por meio de biópsia, além de que devido ao tamanho da mama masculina apresentar-se muito menor que a das mulheres, dificulta sua manipulação durante o exame, sendo preferencialmente realizada apenas em homens obesos, por possuírem um maior volume de mama. Podemos também contar com a ultrassonografia, como um instrumento de auxilio no diagnóstico, pois permite a avaliação do comprometimento linfonodal. (Cypriano, 2017; Guimarães C, 2019; Lima, 2015).

O tratamento para CMM é estabelecido por intervenções cirúrgicas que engloba a ressecção completa do tecido mamário, dos mamilos e o esvaziamento axilar, seguidas ou não de radioterapia e quimioterapia, além de hormonioterapia, seguindo a mesma vertente do tratamento para CMF. Tendo em vista, que a eficiência dos tratamentos para CM e sua recuperação total anda ao lado da descoberta precoce. (Araújo, Leite, Amorin, Silva, Fernandes, Carmo 2018; Guimarães C, 2019).

\subsection{Política Nacional De Atenção Básica}

Política Nacional de Atenção Básica (PNAB) através da Portaria no 2.436 de 21 de setembro de 2017, estabelece a revisão de diretrizes para organização da $A B$, no âmbito do SUS.

A PNAB é definida por um conjunto de ações de saúde, considerando o sujeito em sua singularidade, na complexidade, na integralidade e na inserção sócio-cultural, desde o âmbito individual até o coletivo, visando a busca da promoção de sua saúde, a prevenção e tratamento de doenças até a redução de danos ou de sofrimentos que possam comprometer suas possibilidades de viver de modo saudável. (Zapponi, Tocantins, Vargens, 2015).

Essas ações de saúde são baseadas em alguns princípios como a universalidade que visa garantir o acesso universal do usuário aos serviços de saúde, a equidade que consiste na oferta de cuidado de acordo com as carências dos indivíduos, reconhecendo suas diferenças e a integralidade que disponibiliza um conjunto de serviços executados 
pela equipe de saúde que visa atender as necessidades do indivíduo ou comunidade de forma integral. (Ministério da Saúde, 2017).

Segundo a Política Nacional Atenção Básica de 2017 referente a atribuições específicas do Enfermeiro:

I- Realizar atenção à saúde aos indivíduos e famílias vinculadas às equipes e, quando indicado ou necessário, no domicílio e/ou nos demais espaços comunitários (escolas, associações entre outras), em todos os ciclos de vida;

II- Realizar consulta de enfermagem, procedimentos, solicitar exames complementares, prescrever medicações conforme protocolos, diretrizes clínicas e terapêuticas, ou outras normativas técnicas estabelecidas pelo gestor federal, estadual, municipal ou do Distrito Federal, observadas as disposições legais da profissão;

III- Realizar e/ou supervisionar acolhimento com escuta qualificada e classificação de risco, de acordo com protocolos estabelecidos;

IV- $\quad$ Realizar estratificação de risco e elaborar plano de cuidados para as pessoas que possuem condições crônicas no território, junto aos demais membros da equipe;

V- Realizar atividades em grupo e encaminhar, quando necessário, usuários a outros serviços, conforme fluxo estabelecido pela rede local;

VI- Planejar, gerenciar e avaliar as ações desenvolvidas pelos técnicos/auxiliares de enfermagem, ACS e ACE em conjunto com os outros membros da equipe;

VII- Supervisionar as ações do técnico/auxiliar de enfermagem e ACS;

VIII- Implementar e manter atualizados rotinas, protocolos e fluxos relacionados a sua área de competência na UBS; e

IX- $\quad$ Exercer outras atribuições conforme legislação profissional, e que sejam de responsabilidade na sua área de atuação. (Ministério da Saúde, 2017).

\subsection{Política Nacional De Atenção Integral à Saúde do Homem}

\section{(PNAISH)}

Tradicionalmente, considera-se o sexo masculino mais forte quando comparado ao feminino. Desde o nascimento, é estipulado ao homem, o desenvolvimento de um perfil competitivo, corajoso, destemido, poderoso, violento, invulnerável, provedor e protetor, além de obrigatoriamente, suportarem, sem chorar, suas dores físicas e emocionais. (Coelho, Schwar, Bolsoni, Conceição, 2018).

Pelos motivos citados acima atrelados a outras condições, como o pensamento mágico dos homens que rejeita a possibilidade de adoecer, constata-se que a população masculina frequenta menos os serviços de Atenção Primária à Saúde quando comparada a feminina. Podemos confirmar este fato por meio de um estudo transversal, realizado em serviços de saúde do município de Ribeirão Preto/SP, com 320 participantes, onde 
concluiu-se que as mulheres buscam os serviços de saúde quase duas vezes a mais do que os homens. E também pela porcentagem de consultas em que os homens comparecerem por ano, sendo que em 2010, o número total de consultas médicas para homens entre 20 e 59 anos de idade registrado no SUS foi de 3.217.197, resultou uma média de 0,06 consulta/homem/ano. (Carneiro, Santos, Macena, Vasconcelos, 2016; Coelho, Schwar, Bolsoni, Conceição, 2018).

Comportamento no qual é influenciado por diversos fatores como o estereótipo de gênero, julgar-se invulnerável, posição de papel provedor e responsabilidade pelo sustento da família. Além disso, os serviços e as estratégias de comunicação nitidamente privilegiam as ações de saúde voltadas para as crianças e adolescentes, as mulheres e os idosos, além de que o horário de funcionamento dos serviços de saúde coincide, na maioria das vezes, com o horário de trabalho dos homens. Portanto, essas barreiras socioculturais e institucionais acabam contribuindo com a elevação da morbimortalidade do homem. (Ministério da Saúde, 2009).

No ano de 2009, passou-se a reconhecer as condições de saúde do sexo masculino no Brasil como um problema de saúde pública. Implementando então, a Política Nacional de Atenção Integral à Saúde do Homem (PNAISH), pela Portaria GM/MS nำ1944, de 27 de agosto de 2009 voltada prioritariamente para a população masculina na faixa 20 a 59. (Carneiro, Santos, Macena, Vasconcelos, 2016).

A PNAISH implantada em 2009 busca viabilizar a melhora das condições de saúde e vida do homem no Brasil, contribuindo com a diminuição dos índices da morbidade e mortalidade dessa população. Por meio do enfrentamento dos fatores de risco e mediante a facilitação ao acesso, às ações e aos serviços de assistência integral à saúde garantindo a universalidade e equidade nas ações e serviços de saúde voltados para a população masculina. (Ministério da Saúde, 2009).

2.4. Dificuldades da atuação do enfermeiro quanto à prevenção e diagnóstico precoce do câncer da mama masculina na Atenção Básica

A atenção básica é responsável por promover ações de promoção e prevenção de saúde através de programas destinados a toda população. O sexo masculino é caracterizado por ser o público que menos frequenta os serviços de saúde dificultando

WWW.AMPLLAEDITORA.COM.BR (2)

CONTATO@AMPLLAEDITORA.COM.BR M 
a assistência pelos profissionais enfermeiros no âmbito da $A B$, além de elevar o índice de morbimortalidade desse grupo por diversas doenças, inclusive as neoplasias mamárias. Situação na qual, sendo realizado exames e consultas periódicas pode ser evitada ou minimizada e através de um diagnóstico precoce as chances de um tratamento eficaz aumenta consideravelmente. (Macêdo, Ribeiro, Oliveira, Bezerra, Lima, Sousa, 2016; Vaz, Souza, Filho, Santos, Cavalcante, 2018).

As atribuições dos enfermeiros na $A B$ são previstas através da Portaria № 2.436, de 21 de setembro de 2017 que aprova a Política Nacional de Atenção Básica, e visam desde a promoção, prevenção, proteção, o diagnóstico, tratamento, reabilitação, redução de danos, até os cuidados paliativos e vigilância em saúde a todas as populações. (Ministério da Saúde, 2017)

Logo, os enfermeiros para cumprirem suas reais delegações determinadas pela PNAB, necessitam ser treinados, capacitados e ter sua abordagem direcionada pelo setor governamental responsável pela administração e manutenção da saúde pública do país, no caso, o Ministério da Saúde (MS) para correta condução da prevenção e diagnóstico precoce do CMM desde a realização de orientações sobre a existência da neoplasia e importância do autoexame até a suspeita clínica propriamente dita, após o exame físico na consulta de enfermagem. (Ministério da Saúde, 2017).

Entretanto ao consultar o Consenso para Controle do Câncer de Mama publicado publicada pelo MS em 2004 e as Diretrizes para Detecção Precoce do Câncer de Mama no Brasil publicada pelo INCA em 2015 não é possível encontrar diretrizes e ações específicas para o $\mathrm{CMM}$, mostrando a falta de material teórico para conduzir as condutas dos enfermeiros voltadas a prevenção de CM em homens, os deixando despreparados. (Cypriano, 2017).

O fato do CMM ser relativamente raro quando comparado ao câncer da mama feminina associado ao baixo índice de suspeita clínica acarretam ao atraso do diagnóstico e, consequentemente, o mesmo ocorre geralmente em estágios mais avançados, levando a um prognóstico não tão positivo quando descoberto precocemente. (Azevedo, Monteiro, 2018).

Sabe-se que a suspeita clínica ocorre após o exame físico por um profissional de saúde ou após o autoexame das mamas, porém a atenção a mama masculina se dá somente quando o homem relata sinais e sintomas intensificados, graves e tardios como

WWW.AMPLLAEDITORA.COM.BR (2) 
a presença de nódulo doloroso, retração ou ulceração do mamilo, sinais inflamatórios como o edema mamário devido a sua ausência nas instituições de promoção e prevenção de saúde e visto que, por tratar-se de uma neoplasia com baixa expressão epidemiológica, não há, atualmente, programas de rastreio a nível populacional. (Azevedo, Monteiro; 2018; Oiticica, 2016).

Outra fator que leva a dificuldade da abordagem do homem na $A B$ quanto a prevenção e diagnóstico precoce do câncer da mama masculina é que desde antigamente, as instituições privilegiam as ações de saúde voltadas a criança, o adolescente, a mulher e o idoso por serem classificados como os indivíduos mais frágeis de toda a população, o que acabou gerando o hábito dos homens a evitar o contato com os espaços da saúde, aversão à prevenção e ao autocuidado, além de levar os enfermeiros e os demais profissionais de saúde ao costume de desenvolverem ações de saúde com foco nas populações mais vulneráveis. (Ministério da Saúde, 2009; Oiticica, 2016).

Assim, o despreparo dos profissionais de saúde para lidar com essa problemática específica atrelado a inexistência de atenção ao CMM pelos órgãos governamentais e raridade de sua ocorrência evidenciam que esta patologia não vem recebendo a atenção que deveria, além de que sua ascensão aos logos dos anos está acontecendo gradativamente, e que a propagação de informações sobre o $\mathrm{CM}$ ao homem não está ocorrendo, dificultando o processo de identificação precoce de casos e como consequência, diminuição das chances de cura, além da sobrecarrega dos demais níveis de saúde. (Trajano, Menezes, Caldas, Souza, Lima, Alves; 2018).

\subsection{Atuação do enfermeiro quanto à prevenção e diagnóstico precoce do câncer da mama masculina na atenção básica}

Por intermédio da prevenção, o profissional enfermeiro se adentra no âmbito da saúde como aliado poderoso à redução dos índices de acometidos pelo CMM. Denominada como a arte do cuidar, a assistência de enfermagem fornece um cuidado pleno, científico e com caráter preventivo, pois são importantes multiplicadores das ações de prevenção, além de nenhum profissional de saúde ter um contato tão prolongado e próximo com o cliente como o enfermeiro. (Pereira, Oliveira, Andrade, 2018). 
A atuação do enfermeiro quanto à prevenção e detecção precoce do CMM na atenção primária à saúde (APS) é fundamental para estimular à adesão do homem a realizar ações preventivas contra esta neoplasia. Levando em consideração a PNAB e a PNAISH, o enfermeiro possuí um papel fundamental na $A B$, pois à ele é encarregado o atendimento integral ao homem, a consulta de enfermagem, o exame clínico e a realização de visita domiciliar. (Braga, Silva, Paiva, Targino, Gomes, Pinto et al., 2017; Teixeira, Goldnan, Gonçalves, Guitiérrez, Figueiredo, 2017).

Destacam-se como atribuições do enfermeiro no controle do CM: realizar consulta de enfermagem onde o profissional fará o levantamento do histórico do paciente, incluindo fatores de risco; o exame clínico das mamas, além de solucionar empecilhos no ato exame, como por exemplo, a vergonha, devido à exposição das mamas, levando-o ao desconforto do homem; examinar e avaliar sinais e sintomas relacionados à neoplasia; solicitar e avaliar exames de acordo com os protocolos locais; encaminhar e acompanhar nos serviços de referência para diagnóstico e/ou tratamento; realizar e participar das atividades de educação permanente como palestras educativas, orientação com relação aos fatores de riscos, incentivando a prática de alimentação saudável e de exercícios físicos, o distanciamento de vícios e o autoexame das mamas. (Fonseca, Rodrigues, Nóbrega, Nobre, França, 2016; Teixeira, Goldnan, Gonçalves, Guitiérrez, Figueiredo, 2017).

Quanto ao desenvolvimento de ações educativas para o autoexame das mamas (AEM) é oportuno para o enfermeiro realizá-la durante a consulta de enfermagem, cujo momento é fundamental, pois o profissional de enfermagem possui autonomia em acentuar as orientações, abordando aspectos mamários normais e aspectos característicos do CMM. (Cunha, Almeida, Fontinele, Junior, Oliveira, 2018).

Portanto, a participação efetiva do profissional enfermeiro na $A B$ referente ao CMM está diretamente ligada ao desenvolvimento de ações de autocuidado, tornando o homem participativo, consciente de seu potencial quanto a prevenção do CMM, logo, promovendo saúde. (Fonseca, Rodrigues, Nóbrega, Nobre, França, 2016).

Diante do exposto, foi proposto um modelo de fluxograma visando apoiar o enfermeiro no plano de assistência aos usuários com câncer da mama masculina na rede básica de saúde, conforme Figura 1: 
Figura 1 - Proposta de fluxograma quanto à abordagem do homem acerca da prevenção e diagnóstico precoce do câncer da mama masculina na consulta de enfermagem na atenção básica.

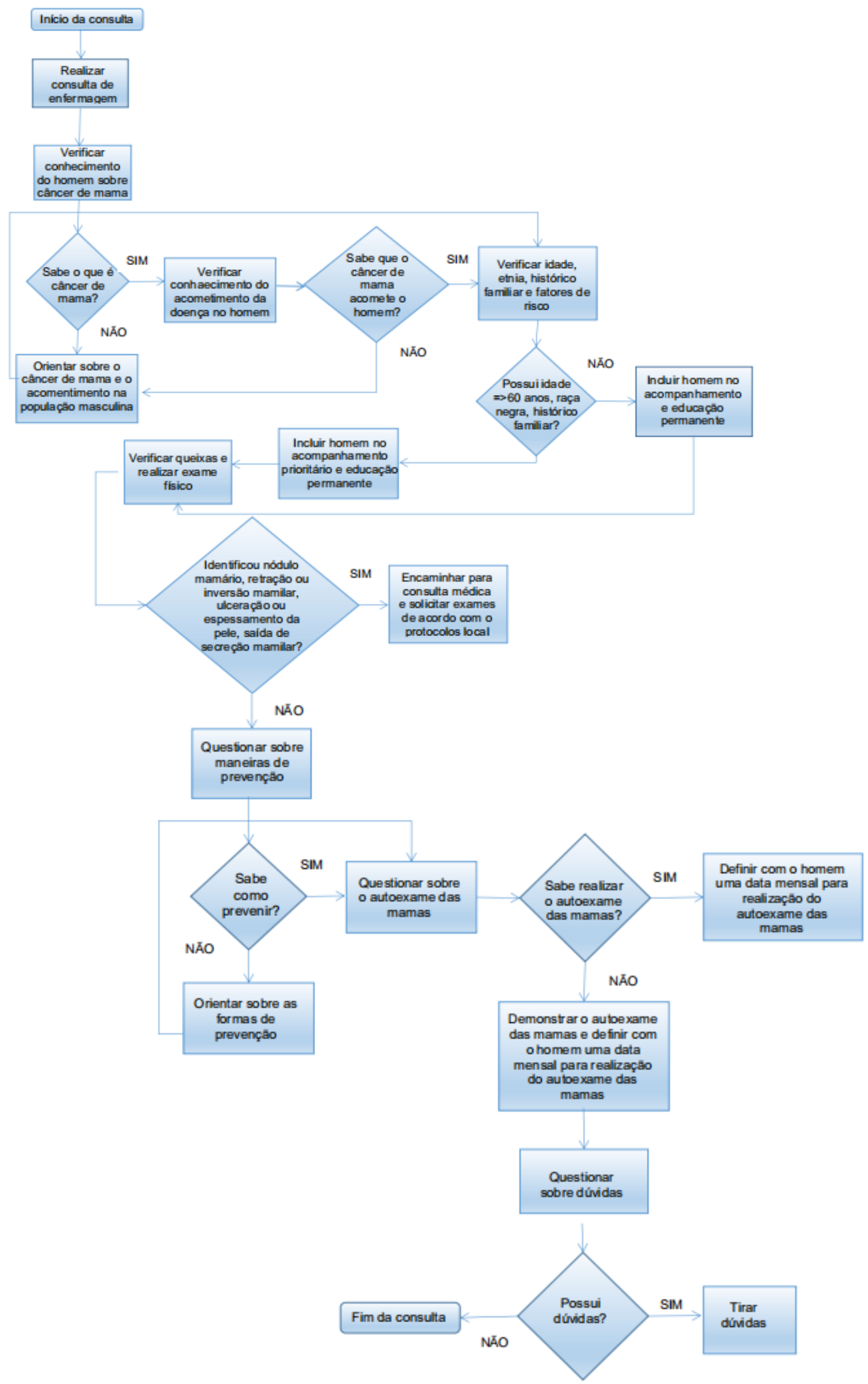

WWW.AMPLLAEDITORA.COM.BR (2) 


\section{CONSIDERAÇÕES FINAIS}

Por meio desta pesquisa, pode-se observar que a ocorrência do câncer da mama masculina vem aumentando gradativamente ao longo dos anos e em consequência demandando mais atenção, não obstante, diversas dificuldades impedem a atuação do enfermeiro do primeiro nível de atenção à saúde contra esta neoplasia no homem.

A neoplasia mamária no homem acarreta em consequências fatais na maioria dos casos, mostrando-se a necessidade de mais pesquisas para disseminação do tema e desenvolvimento de programas de rastreio precoce de câncer na mama masculina, visando o diagnóstico precoce.

No que se refere ao enfermeiro, verificou-se que o papel desse profissional na atenção básica precisa ser ampliado. A definição de suas ações na atenção primária deve ser regida pela política vigente. Para tal, foi proposto um modelo fluxograma visando apoiar o enfermeiro no plano de assistência aos usuários com câncer da mama masculina.

\section{REFERÊNCIAS}

COSTA, Mário Clodoaldo Batista da, ADORNO, Stefano dos Santos, ARAÚJO, Sebastião Marden Barbosa, SABACK, Moisés Castro, GOMES, Kleberson Adriano Silva. Câncer de mama masculino: uma revisão de literatura dos último dez anos. Revista Eletrônica Acervo Saúde. v. 11, n. 2, p. e220, 15 jan. 2019.

GUIMARÃES, N. A. Avaliação dosimétrica em teleterapia para o tratamento de câncer de mama masculina. 2015. 110 f. Tese (Doutorado em Engenharia Nuclear) Universidade Federal do Rio de Janeiro, Rio de Janeiro, 2015.

SOUSA, Citrya Jakellinne Alves. Câncer de mama em paciente do sexo masculino: A importância da atenção primária no diagnóstico e tratamento - um relato de caso. Revista Artigos. Com, v. 14, p. e2962, 24 jan. 2020.

Dantas, Rosimery Cruz de Oliveira; Pereira, Jéssica Barreto; Alencar, Layz Dantas de; Sousa, Andréia Karla Anacleto; Farias Maria do Carmo Andrade Duarte de. Câncer de mama em homem: uma realidade brasileira. Revista Brasileira De Educação E Saúde, Pombal, v. 5, n. 3, p. 29-34, jul-set, 2015.

Azevedo, Fernando Santos; Monteiro,, Aline Bessa Parmigiani. ABORDAGEM DO CÂNCER DE MAMA MASCULINO NA ATENÇÃO PRIMÁRIA: REVISÃO DA LITERATURA SOBRE ASPECTOS EPIDEMIOLÓGICOS, FATORES DE RISCO, MANIFESTAÇÕES CLÍNICAS E ENCAMINHAMENTO PRECOCE AO ESPECIALISTA. 
Rev. Cient. Esc. Estadual Saúde Pública Goiás "Cândido Santiago", v. 4, ed. 2, p. 129-138, 2018.

INSTITUTO NACIONAL DE CÂNCER. O que é câncer? [Internet]. Rio de Janeiro: INCA; 2019 [revisão 2019 abr 4; citado 2020 mar 29].

INSTITUTO NACIONAL DE CÂNCER. CÂNCER DE MAMA [Internet]. Rio de Janeiro: INCA; 2020 [revisão 2020 fev 4; citado 2020 mar 29].

INSTITUTO NACIONAL DE CÂNCER. Estatísticas de câncer [Internet]. Rio de Janeiro: INCA; 2020 [revisão 2020 fev 5; citado 2020 mar 20].

Rodrigues, Élida Sabrina Batista do Nascimento; Bezerra Juliana de Sousa; Passos Anderson Gonçalves. MAMOGRAFIA PARA DIAGNÓSTICO DO CÂNCER DE MAMA EM HOMENS. Anais do 14 Simpósio de TCC e 7 Seminário de IC da Faculdade ICESP, v. 14, p. 1815-1824, 2018.

Ramos, Stephanie Silva; Rodrigues, Lilia Marques Simões; Silva, Thiago Augusto Soares Monteiro da; Balbino, Carlos Marcelo; Souza, Marilei Melo Tavares e; Silvino, Zenith Rosa. Conhecimentos, mitos e implicações para o cuidado de enfermagem no câncer de mama masculino. REV ENF ATUAL, p. 83, 2017.

Sousa AF, Martins RP, Freitas RS, Guimarães ALC. Conhecimento de homens sobre a existência e prevenção do câncer de mama masculino. Rev Ciên Saúde. 2017 fev;(2):1-8.

Salomon MFB, Mendonça JV, Pasqualette HAP, Pereira PMS, Sondermman VRM. Câncer de mama no homem. Rev Bras Mastologia, v, 25, ed. 4, p. 141-145, 2015.

Araujo GA, Juliao KM, Leite ME, Jobbar R, Neto RLA, Freitas AA. Epidemiologia e fatores de risco do câncer de mama masculino. Rev Educ em Saúde: Anais XVI Mostra de Saúde, v. 7.

Barros HCS. Aspectos Epidemiológicos da Mortalidade Por Câncer De Mama Masculina No Brasil, No Período De 1996 A 2013 [Dissertação]. Maceió: Universidade Federal De Alagoas; 2016. 71 P. Mestrado Em Ciência da Saúde.

Cypriano AS. Ações promotoras de saúde frente ao câncer da mama masculina: subsídios ao gerenciamento do cuidado de Enfermagem na Atenção Básica [Dissertação]. Rio de Janeiro: Escola De Enfermagem Anna Nery: Universidade Federal do Rio de Janeiro; 2017. 114 p. Pós-graduação em Enfermagem. 
Ciências da Saúde Ensino, Formação e Pesquisa 
Ciências da Saúde

Ensino, Formação e Pesquisa 